\title{
MODELO COMPUTACIONAL PARA ANÁLISE DE TRANSIENTE HIDRÁULICO EM CANAIS
}

Stênio de Sousa Venâncio

Dissertação apresentada à Escola de Engenharia de São Carlos da Universidade de São Paulo, como parte dos requisitos para obtenção do título de Mestre em Hidráulica e Saneamento

ORIENTADOR: Prof. Dr. Swami Marcondes Villela 
Ficha catalográfica preparada pela Seçăo de Tratamento da Informaçăo do Serviço de Biblioteca - EESC/USP

Venâncio, Stênio de Sousa

V448m Modelo computacional para análise de transiente hidrálilico em canais / Stenio de Sousa Venancio. -Săo Carlos, 2003.

Dissertação (Mestrado) -- Escola de Engenharia de Săo Carlos-Universidade de Säo Paulo, 2003.

Area: Hidráulica e Saneamento.

Orientador: Prof. Dr. Swami Marcondes Villela.

1. Escoamento transiente. 2. Modelo computacional. 3. Condutos livres. I. Título. 
FOLHA DE JULGAMENTO

Candidato: Engenheiro STÊNIO DE SOUSA VENÂNCIO

Dissertação defendida e julgada em 03-07-2003 perante a Comissão Julgadora:
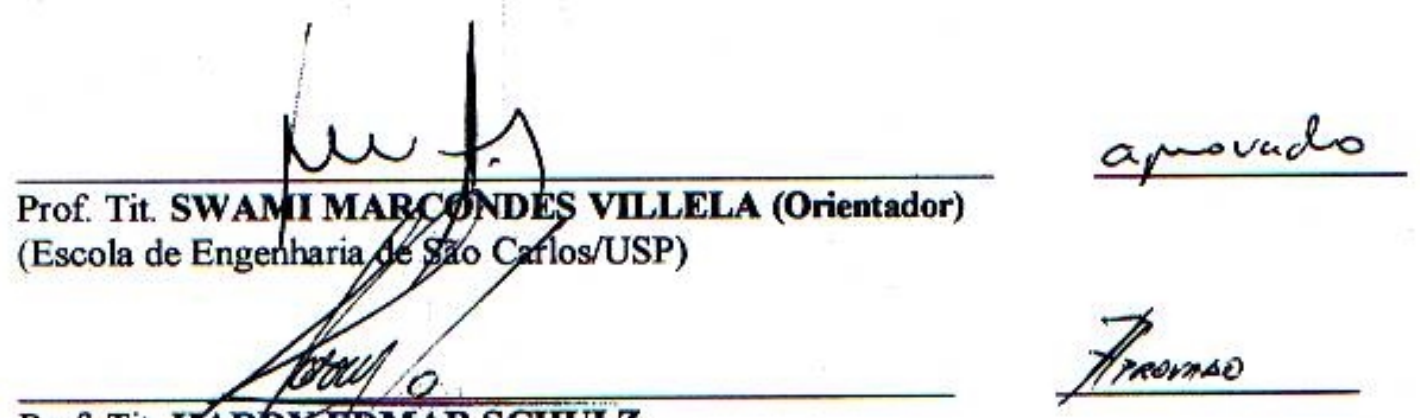

Prof. Tit. HARRY CDMAR SCHULZ

(Escola de Engehbaria de São Carlos/USP)
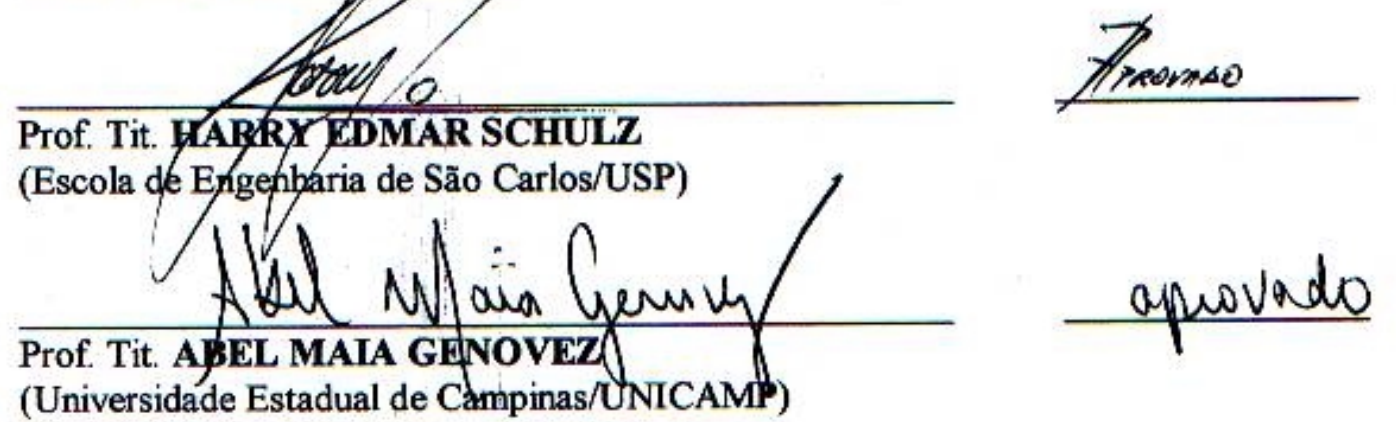

(Universidade Estadual de Campinas/UNICAMP)

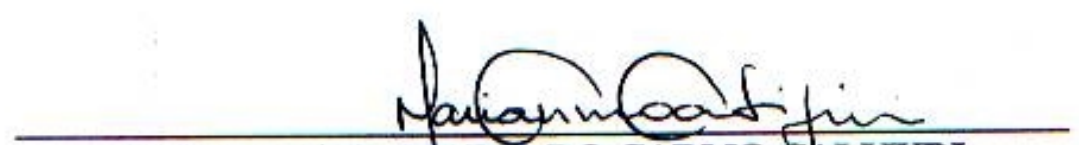

Profa. Associada MARIA DO CARMO QALIJURI

Coordenadora do Programa de Pós-Graduação em

Engenharia (Hidráulica e Saneamento) e

Presidente da Comissão de Pós-Graduação 
À minha esposa, Soraia, pelo seu amor repleto de companheirismo, dedicação e paciência. 


\section{AGRADECIMENTOS}

Ao Conselho Nacional de Desenvolvimento Científico e Tecnológico - CNPq, mantenedora da bolsa de estudos.

Ao professor Swami Marcondes Villela, por sua orientação, imbuída de dedicação plena, motivação e confiança. Tenho certeza de que aprendi ciência tão quanto a ser humano.

A COGERH, Companhia de Gestão dos Recursos Hídricos do Estado do Ceará, pela disponibilidade em viabilizar os dados referentes ao Canal do Trabalhador.

A CPFL, Companhia Paulista de Força e Luz, pelo subsídio dado através das visitas, discussões, informações e disponibilização dos dados referentes ao canal de alimentação da Usina Hidrelétrica Monjolinho.

Ao professor Harry Edmar Schulz, pela participação e relevante contribuição nas duas etapas do exame de qualificação.

Ao professor Marcius Giorgetti, pela disponibilidade e incentivo.

Ao colega Peter Cheung, pelo auxílio na idealização do algorítimo.

Ao amigo Leonardo, por sua colaboração nas várias etapas deste trabalho.

À Coordenação, aos professores, funcionários e colegas do Programa de Pós Graduação em Hidráulica e Saneamento da EESC, pelos ensinamentos, pelo incentivo e, principalmente pela amizade.

Aos meus pais, Iêzo e Anísia, pelo exemplo de caráter, e por tudo aquilo que me proporcionaram nos diversos momentos da vida.

À Deus, pelo dom da vida. Sem a Sua graça, nada seria possível. 


\section{SUMÁRIO}

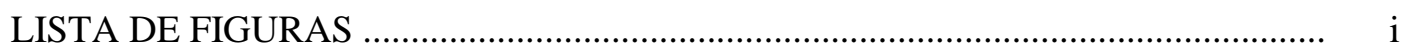

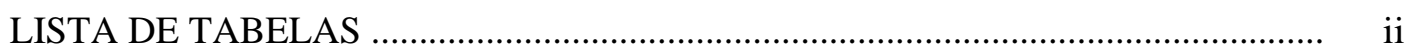

LISTA DE SÍMBOLOS …............................................................................... iii

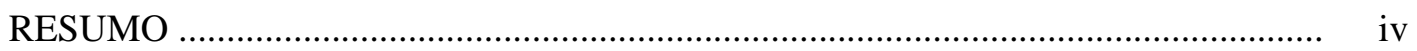

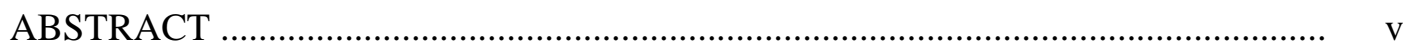

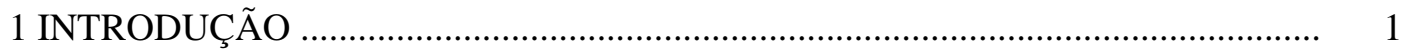

2 REVISÃO DA LITERATURA ……............................................................... 3

2.1 Um Breve Panorama da Situação da Água ............................................................ 3

2.2 Escoamento Não Permanente ................................................................................. 6

2.2.1 Conceituação do Fenômeno ............................................................................ 6

2.2.2 As Equações do Movimento ............................................................................ 9

2.2.2.1 Equação da Continuidade ..................................................................................... 9

2.2.2.2 Equação Dinâmica ............................................................................................ 12

2.2.2.3 Simplificação das Equações de Saint-Venant .................................................... 16

2.2.2.4 Modelo Onda Cinemática .............................................................................. 18

2.2.2.5 Modelo Onda de Difusão .................................................................................... 22

2.2.2.6 Modelos de Armazenamento .............................................................................. 22

2.2.3 Métodos Numéricos para a Resolução das Equações de Saint-Venant ................ 23

2.2.3.1 Esquemas Diretos .............................................................................. 25

2.2.3.1.1 Esquemas Diretos Explícitos ................................................................... 29

2.2.3.1.2 Esquemas Diretos Implícitos ..................................................................... 31

3 MATERIAIS E MÉTODOS _............................................................................... 34

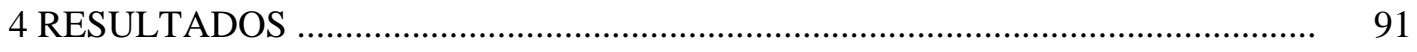

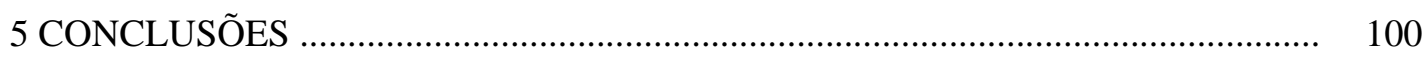

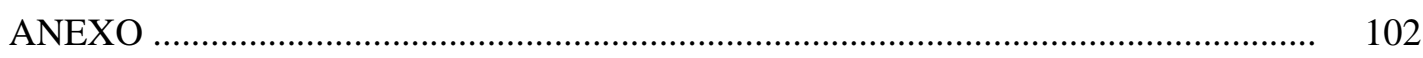

REFERÊNCIAS BIBLIOGRÁFICAS .......................................................... 158

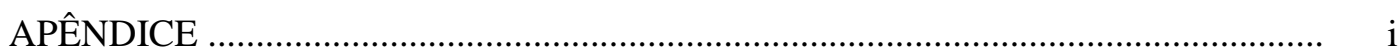




\section{LISTA DE FIGURAS}

FIGURA 01 - Bacias Hidrográficas no Brasil ........................................................... 04

FIGURA 02 - Alterações no Escoamento de Pequena Magnitude ................................ 07

FIGURA 03 - Tipos de Ondas de Translação em Perturbações de Pequena Magnitude 08

FIGURA 04 - Volume de Controle Elementar ............................................................... $\quad 10$

FIGURA 05 - Esboço de Referência para as Equações do Movimento ......................... 13

FIGURA 06 - Representação de uma Curva de Descarga em Laço ............................... 19

FIGURA 07 - Propagação da Onda Cinemática .......................................................... 20

FIGURA 08 - Etapas da Modelação ......................................................................... 24

FIGURA 09 - Pontos Utilizados para o Cálculo da Primeira Derivada de f .................. 26

FIGURA 10 - Grade Computacional ……………................................................... 28

FIGURA 11 - Grade Computacional para Esquema Explícito .................................... 29

FIGURA 12 - Esquema de Diferenças Finitas ......................................................... 32

FIGURA 13 - Esquema do Caso Estudado para Teste do Modelo ............................... 40

FIGURA 14 - Sistema da Solução Computacional .......................................................... 43

FIGURA 15 - Diagrama de Blocos ...................................................................... 44

FIGURA 16 - Esquema do Canal de Alimentação da UHE-Monjolinho ...................... 59

FIGURA 17 - Esquema do Sistema de Abastecimento de Água de Fortaleza .............. 73

FIGURA 18 - Esquema do Canal do Trabalhador ....................................................... 75

FIGURA 19 - Gráfico dos Perfis D'água (Teste do Modelo) ...................................... 91

FIGURA 20 - Gráfico das Velocidades (Teste do Modelo) ....................................... 92

FIGURA 21 - Gráfico das Alturas D'água - abertura da turbina ................................ 93

FIGURA 22 - Gráfico das Mínimas Alturas Ocorridas ................................................... 93

FIGURA 23 - Gráfico das Velocidades - abertura da turbina ..................................... 94

FIGURA 24 - Gráfico das Alturas D'água - fechamento da turbina ........................... 95

FIGURA 25 - Gráfico das Alturas Máximas Ocorridas .................................................. 95

FIGURA 26 - Gráfico das Velocidades - fechamento da turbina ................................ 96

FIGURA 27 - Enchimento do Canal do Trabalhador ao longo do tempo ..................... 98

FIGURA 28 - Esvaziamento do Canal do Trabalhador ao longo do tempo ................. 99 
LISTA DE TABELAS

TABELA 01 - Distribuição dos Recursos Hídricos, da Superfície e da População

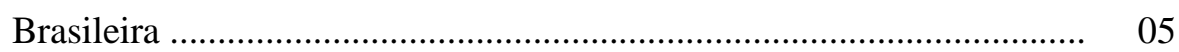

TABELA 02 - Evolução do Uso da Água no Mundo ................................................... 05

TABELA 03 - Resumo das Características dos Modelos de Escoamento ...................... 23 


\section{LISTA DE SÍMBOLOS}
A
área de seção transversal, $\mathrm{m}^{2}$
a
- $\quad$ aceleração, $\mathrm{m} / \mathrm{s}^{2}$
B
- largura da superfície livre, m
b
- largura, m
$\mathrm{Ch}$
- coeficiente de rugosidade de Chezy
$\mathrm{c}$
- celeridade relativa da onda, $\mathrm{m} / \mathrm{s}$
Fr $\quad-\quad$ número de Froude
g
- aceleração da gravidade, $\mathrm{m} / \mathrm{s}^{2}$
$\mathrm{H}$ - energia total do escoamento, $\mathrm{m}$
$\mathrm{h}$
- altura ou tirante d'água em relação ao plano de referência, m
1
- comprimento, $\mathrm{m}$
$\mathrm{m}$
- $\quad$ massa, $\mathrm{Kg}$
n
- coeficiente de rugosidade de Manning
$\mathrm{P} \quad$ - perímetro molhado, $\mathrm{m}$
Q - vazão, $\mathrm{m}^{3} / \mathrm{s}$
qLAT - vazão suplementar por unidade de comprimento das margens, $\mathrm{m}^{3} / \mathrm{s} . \mathrm{m}$
Rey - número de Reynolds
$\mathrm{Rh} \quad$ - raio hidráulico da seção, $\mathrm{m}$
$\mathrm{Sa} \quad$ - declividade da linha d'água, $\mathrm{m} / \mathrm{m}$
Sf - declividade da linha de energia, $\mathrm{m} / \mathrm{m}$
So - declividade de fundo do canal, $\mathrm{m} / \mathrm{m}$
$\mathrm{T} \quad$ - período da onda, $\mathrm{s}$
t $\quad-$ instante de tempo, $\mathrm{s}$
$\mathrm{V}$ - velocidade média do escoamento na seção, $\mathrm{m} / \mathrm{s}$
$\mathrm{V} \omega$ - velocidade absoluta ou celeridade absoluta, $\mathrm{m} / \mathrm{s}$
$\mathrm{x} \quad$ - abscissa medida ao longo do canal, $\mathrm{m}$
y - - altura ou tirante d'água medida em relação ao fundo, $m$
$\rho \quad-\quad$ massa específica da água, $\mathrm{Kg} / \mathrm{m}^{3}$
$\gamma$ - peso específico da água, $\mathrm{N} / \mathrm{m}^{3}$ 


\section{RESUMO}

Este trabalho representa a continuidade de estudos envolvendo a problemática dos escoamentos com superfície livre, contemplando a análise do fenômeno transiente em canais, a partir do modelo matemático unidimensional de Saint-Venant. Para tanto, é desenvolvido um modelo computacional em linguagem FORTRAN, capaz de avaliar o comportamento do escoamento não permanente. As equações hidrodinâmicas completas são discretizadas por um esquema completamente implícito de diferenças finitas e aplicadas no modelo computacional para a avaliação de dois casos. O modelo é previamente testado para um caso simples, cujos resultados são analisados viabilizando o modelo. No primeiro caso, o modelo é aplicado ao canal de alimentação da Usina Hidrelétrica Monjolinho em São Carlos-SP, para avaliar a necessidade de vertedouro quando se dá o fechamento brusco da turbina, e a ocorrência da entrada de ar na mesma quando da sua abertura repentina. No segundo caso, procurou-se avaliar o desenvolvimento do escoamento no Canal do Trabalhador, responsável pelo abastecimento da cidade de Fortaleza-CE. Com manobras de enchimento e esvaziamento do sistema, é possível determinar o tempo de antecedência de liga-desliga do sistema de recalque a partir das alturas d'água e velocidades de ocorrência, permitindo também a automação para as operações de controle. Em ambos os casos o modelo reproduziu resultados que ilustram com coerência os conceitos pré-estabelecidos, constituindo numa ferramenta útil para análise do fenômeno transiente nos escoamentos em condutos livres.

Palavras-chave: escoamento transiente; modelo computacional; condutos livres 


\section{ABSTRACT}

This work presents a computational model developed in FORTRAN language for the study of unsteady open-channel flows with the use of Saint-Venant one-dimensional equation. The discretization of hydrodynamic equations are presented in a completely implicit method of finite differences and applied in the model for the investigation of two cases, besides the one used previously to test the model. In the first case, the model is applied for a channel that supplies the Monjolinho hydroelectric plant in Sao Carlos - SP, aiming to evaluate the need of a spillway when the turbine is closed and the flow abruptly stopped, as well as the occurrence of air entering the turbine when it is opened instantaneously. In the second case, the model simulates the development of the flow in the Trabalhador channel, responsible for the water supply in the city of Fortaleza - CE, in order to make possible the automation of operational control, based on data of flow velocity and water level. In both cases the model is presented as a useful tool for the analysis of unsteady open-channel flows, showing results and coherency with theory.

Keywords: unsteady flow; computational model; open-channel 


\section{INTRODUÇÃO}

A análise de escoamentos de fluidos de um modo geral, requer a observação de determinadas condições gerais, princípios e leis da Dinâmica, teoria da turbulência, além dos muitos parâmetros externos que envolvem a questão. Entretanto, visto a necessidade de apresentar soluções práticas para os vários problemas reais que envolvem obras de engenharia, é praxe aplicar os conceitos pré-estabelecidos à particularidade de cada estudo, o que simplifica bastante o tratamento matemático, facilitando a implementação de modelos computacionais.

Um modelo computacional unidimensional para simulação do movimento transiente em canais é constituído basicamente pelas equações gerais do movimento e da continuidade (1D / Saint-Venant), discretizadas e aproximadas convenientemente, e utilizadas com condições de controle de vazões e/ou velocidades fixadas em função do tempo à montante, e níveis fixados em função do tempo à jusante, ou vice versa.

Atendendo ao objetivo proposto, o modelo computacional ora desenvolvido utiliza linguagem Fortran, e deve atuar como ferramenta útil na determinação dos níveis e velocidades ( $y(x, t)$ e $v(x, t))$ nos escoamentos em condutos livres, dados necessários e indispensáveis no planejamento da operação de canais longos, principalmente quando se deseja automatizar o funcionamento dos seus sistemas de controle.

A escolha da linguagem de programação, FORTRAN 6.1 na versão visual, deve-se ao fato de ser uma linguagem compilada, a exemplo das linguagens $\mathrm{C}, \mathrm{C}^{++}$,dentre outras, e por isso mais veloz, além de possuir várias rotinas desenvolvidas, pela aplicação em vários estudos ao longos dos anos. A versão visual do FORTRAN suprime uma deficiência que caracterizava a linguagem, face a impossibilidade de se realizar gráficos. Além disso, ela permite realizar interface com outras linguagens, permitindo a aplicação de sub-rotinas prontas desenvolvidas nas mesmas.

Como a resolução das equações de Saint-Venant analiticamente é restrita a casos especiais, devido a dificuldade de integração, são utilizados métodos que garantem sua aplicação à casos práticos. Dentre estes estão aqueles que contemplam simplificações das equações, reduzindo-as aos termos predominantes do problema particular, como é o caso do Modelo Onda Cinemática e Modelo Onda de Difusão. Outro método bastante utilizado é o 
das características, que utiliza transformações no equacionamento original onde o comportamento físico passa a ser descrito por equações características. Um dos mais utilizados, inclusive por este estudo, é a aplicação de esquemas diretos implícitos, devido a vantagem de serem linearmente estáveis e as equações de Saint-Venant serem utilizadas diretamente sem simplificações ou transformações.

Os casos abordados nesta pesquisa são caracterizados por canais com funções específicas. Estes casos são inseridos com o propósito de demonstrar a viabilidade de aplicação do modelo computacional implementado.

Como atualmente a escassez de água demanda captações cada vez mais distantes, a implementação de sistemas longos de transporte torna-se necessário e sua operação cada vez mais difícil, fato este que constitui a base de motivação para este estudo. Para tanto vale salientar que a automação dos sistemas de controle, não se restringe meramente a abastecimento urbano, visto que, obras contra inundações, canais de irrigação, de alimentação de usinas hidrelétricas, dentre outros, são passíveis a sistemas de controle automatizados. 


\section{REVISÃO DA LITERATURA}

Com o propósito de caracterizar o modelo de análise do escoamento transiente em canais como suporte para a automação de sistemas de controle, a revisão bibliográfica, apresentada nesta etapa, é calcada nos fundamentos científicos que contemplam os conceitos da hidráulica dos canais. A partir destes, descreve dentro do objetivo supracitado, os métodos matemáticos e numéricos disponíveis, necessários e indispensáveis para a modelagem e tratamento do escoamento não permanente.

Antepondo ao objetivo específico de abordagem do problema, é esboçado também um breve panorama das questões que envolvem a situação da água sobre as diversas necessidades. Retrata, para tanto, a situação geral do recurso, onde se possa justificar a implementação de pesquisas e estudos como o aqui proposto, que venham atuar como alternativas para a manipulação eficiente e eficaz do uso múltiplo da água.

\subsection{Um Breve Panorama da Situação da Água}

Há tempos é sabido e inquestionável a importância que a água exerce no meio ambiente, dado ao fator condicionante e crucial que ela representa para a sustentabilidade da vida e do seu desenvolvimento.

Boa parte do aproveitamento da água se dá por meio de escoamento superficial (aproximadamente 90\%) (CHAUDHRY, 2001*). De acordo com a mesma referência, águas subterrâneas são ocasionalmente utilizadas para abastecimento urbano e industrial e, portanto, é de interesse estudar o escoamento de superfície não só do ponto de vista de abastecimento, uma vez que o uso múltiplo deste recurso tem marcado presença relevante no cenário mundial. Podem-se citar como mais expressivos usos de recursos hídricos:

- Irrigação: promovendo, através do crescimento agrícola, o abastecimento e o desenvolvimento econômico;

*CHAUDHRY, Fazal Hussain (2001). Recursos Hídricos - Aspectos Quantitativos. / Curso ministrado na EESC/USP - São Carlos, no período de março-julho/2001 
- Navegação: atuando como meio de transporte de baixo custo;

- Abastecimento Público: garantindo, além da necessidade vital, a saúde pública;

- Geração de Energia: como condicionante direta pelo desenvolvimento do país, além da promoção de conforto;

Em se tratando de recursos hídricos brasileiros, o volume de água doce superficial representa um total de $11,6 \%$ da totalidade do planeta (UNIAGUA, 2002*). Entretanto, com todo o privilégio caracterizado a princípio, $70 \%$ da água disponível para o uso estão localizadas na Região Amazônica, onde o contingente populacional é baixo, restando $30 \%$ para um atendimento desigual ao longo do país, atendendo $93 \%$ de sua população (UNIAGUA, 2002*). Desta forma, conflitos pelo uso da água são inevitáveis. A FIGURA 01, apresentada a seguir, demonstra o gráfico com a distribuição das Bacias Hidrográficas no Brasil.

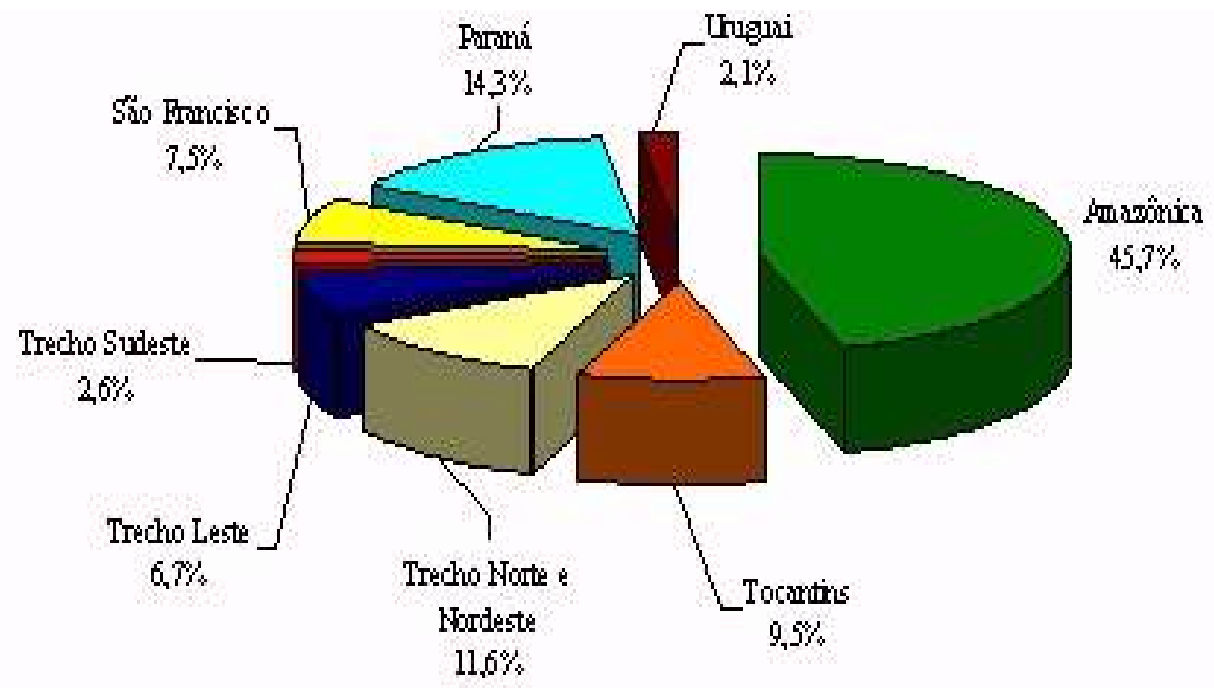

FIGURA 01 - Bacias Hidrográficas no Brasil (em \%) fonte:UNIÁGUA

*UNIÁGUA (2002). Site: www.uniagua.com.br- Universidade da Água, Água no Planeta 19/08/2002 às 10:15hs 
A conjuntura espacial tem um papel importante no confronto da disponibilidade e demandas. Quando se analisa a variabilidade ao longo do país, observa-se que nas regiões onde existe maior demanda, a água não está disponível (TABELA 01), seja na quantidade ou qualidade requerida. Enquanto só o rio Amazonas é responsável por cerca de $20 \%$ da vazão total de todos os rios do mundo, extensas regiões continentais e brasileiras apresentam deficiências consideráveis em termos de recursos hídricos superficiais e subterrâneos (UNIAGUA, 2002*). A demanda cresce paulatinamente, em função do contingente populacional, ao longo dos anos (TABELA 02), e a necessidade de se captar e transportar água a distâncias cada vez mais consideráveis é inevitável.

\begin{tabular}{cccc} 
RECIAO & $\begin{array}{c}\text { RECURSOS } \\
\text { HIDRCOS }\end{array}$ & SUPERACIE & FOFULACAO \\
Norte & 68,50 & 45,30 & 6,98 \\
Centro-Oeste & 15,70 & 18,80 & 6,41 \\
Sul & 6,50 & 6,80 & 15,05 \\
Sudeste & 6,00 & 10,80 & 42,65 \\
Nordeste & 3,30 & 18,30 & 28,91 \\
\hline Soma & 100,00 & 100,00 & 100,00
\end{tabular}

\section{TABELA 01 - Distribuição dos Recursos Hídricos, da Superfície e da População brasileira (em \% total do país) fonte:UNIÁGUA}

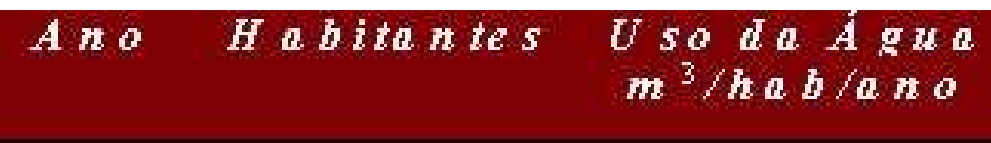

$\begin{array}{lll}1940 & 2,3 \times 10^{9} & 400 \\ 1990 & 5,3 \times 10^{9} & 800\end{array}$

\section{TABELA 02 - Evolução do Uso da Água no Mundo fonte:UNIÁGUA}

Do ponto de vista de abastecimento, a cidade de São Paulo, por exemplo, transporta água atualmente a distâncias em torno de $90 \mathrm{Km}$ e, de acordo com estudos realizados, a demanda crescente exigirá o alongamento do transporte como alternativa (POVINELLI, $2001 *)$.

*UNIÁGUA (2002). Site: www.uniagua.com.br- Universidade da Água, Água no Planeta $19 / 08 / 2002$ às $10: 15 \mathrm{hs}$

*POVINELLI, Jurandyr (2001). Conceitos Básicos em Recursos Hídricos. / Curso ministrado na EESC/USP - São Carlos, no período de março-julho/2001 
A cidade de Fortaleza, no Ceará, pode fazer hoje o seu transporte de água em uma extensão de aproximadamente 100km a partir do Rio Jaguaribe através do Canal do Trabalhador (VILLELA, 2002*). Considerando o uso múltiplo, surge o importantíssimo projeto de transposição das águas do Rio São Francisco para o desenvolvimento do semiárido nordestino, com integração entre abastecimento, irrigação e geração de energia (VILLELA, 2002*) .

Os exemplos citados evidenciam, de fato, a situação de balanço negativo entre oferta e demanda. A questão dos usos múltiplos geram situações de conflito que devem ser administradas com seriedade por um poder de decisão competente.

Apesar das caracterizações espaciais desfavoráveis entre a ocupação e os recursos hídricos, sem considerar nesta avaliação a questão da poluição do recurso, pesquisas e estudos têm atuado efetivamente como instrumentos de respaldo no processo de tomada de decisões na alçada política. O desenvolvimento de técnicas que respondam às necessidades impostas, são elementos fundamentais para o manejo responsável da água como garantia da utilização eficiente e eficaz.

\subsection{Escoamento não Permanente}

\subsubsection{Conceituação do Fenômeno}

Transcreve-se a seguir, por muito oportuno, um texto de PORTO, 1999, p3: "De um modo geral, os escoamentos de fluidos estão sujeitos a determinadas condições gerais, princípios e leis da dinâmica e à teoria da turbulência. No caso de líquidos, em particular a água, a metodologia de abordagem consiste em agrupar os escoamentos em determinados tipos, cada um dos quais com suas características comuns, e estudá-los por métodos próprios".

Muitos fenômenos de escoamentos em canais, de grande importância para a engenharia hidráulica, ocorrem em regime transiente (HENDERSON, 1966), ou seja, o tipo de escoamento onde as condições hidráulicas passam a variar ao longo do tempo.

*VILLELA, Swami Marcondes (2002). Tópicos de Obras Hidráulicas. / Curso ministrado na EESC/USP - São Carlos, no período de agosto-novembro/2002 
Seja a Figura 02-A, na qual uma pequena perturbação de amplitude $\delta$ y $\ll$ y se propaga com velocidade absoluta $\mathrm{V} \omega$ no sentido do escoamento para jusante. Como resultado da propagação, a velocidade média do escoamento muda de $\mathrm{V}$ para $\mathrm{V}+\delta \mathrm{V}$, portanto o escoamento é não permanente. Entretanto, como a alteração sofrida é de pequena magnitude e ocorre em intervalos curtos de tempo, sobrepõe-se ao campo de velocidade real um campo de velocidade dado por - $\mathrm{V} \omega$, isto é, no sentido de montante, onde o volume de controle definido, permite a análise do fenômeno em regime permanente (FIGURA 02-B). Neste caso a alteração sofrida pelo escoamento, é determinada pela perturbação na velocidade e é medida pela propagação em relação ao meio, isto é, medida em relação à corrente e não às margens. (PORTO, 1999)
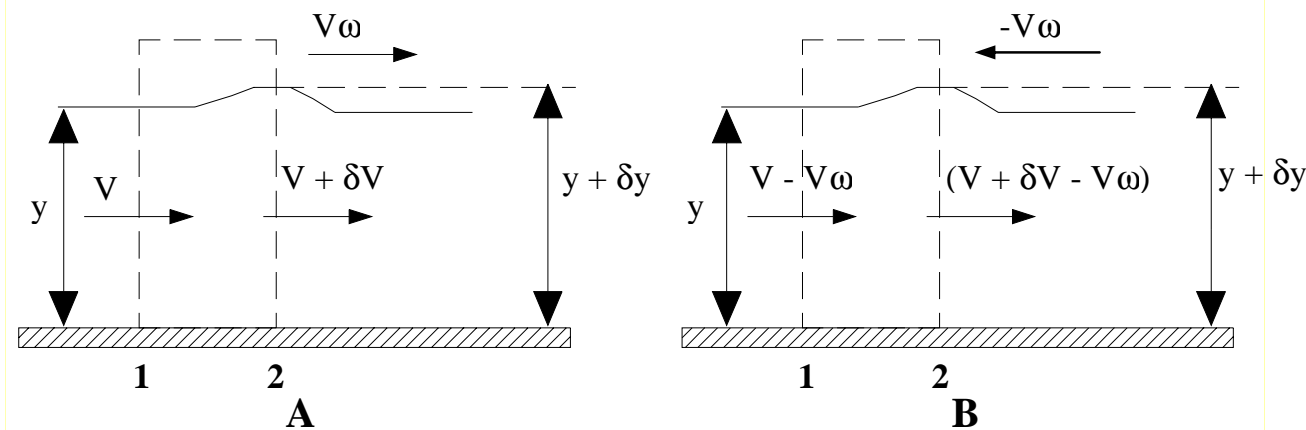

FIGURA 02 - Alterações no Escoamento de Pequena Magnitude

Pela combinação das equações básicas da continuidade e do teorema da quantidade de movimento, para o regime permanente, entre as seções 1 e 2 , por unidade de largura da seção, pode-se escrever:

$V \omega=V \pm \sqrt{g y}=V \pm c$

onde:

$\mathrm{V} \omega=$ velocidade absoluta ou celeridade absoluta (medida em relação às margens)

$\mathrm{V}=$ velocidade da água

$\mathrm{c}=(\mathrm{gy})^{1 / 2}=$ celeridade relativa da onda (medida em relação ao meio água)

O escoamento não permanente está associado ao movimento de ondas. Uma onda, por sua vez, pode ser definida como a variação temporal do nível da superfície da água e que se propaga através do fluido (RAJU, 1981).

As ondas, propriamente ditas, podem ser classificadas de várias maneiras. No contexto de escoamento instável, que é o problema comumente encontrado nos canais, o processo se 
dá através de ondas de translação (FIGURA 03), que é uma onda de gravidade (predomínio da atração gravitacional sobre a tensão superficial), resultando em um deslocamento apreciável das partículas de água em uma direção paralela ao escoamento (CHOW, 1973).
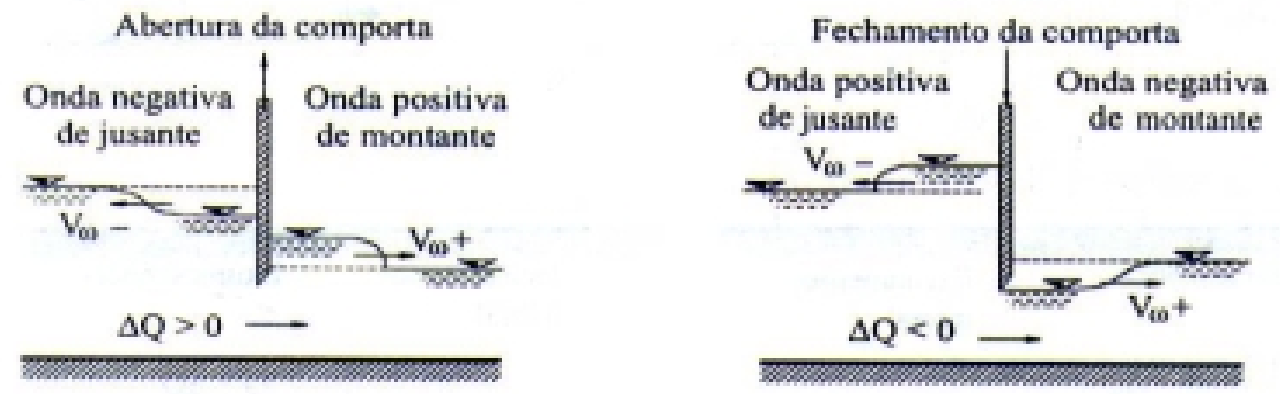

FIGURA 03 - Tipos de Ondas de Translação em Perturbações de Pequena Magnitude

Uma onda em um canal se constitui em variações bruscas ou graduais do escoamento. Essas variações serão bruscas em situações como operações rápidas em comportas, por exemplo, ou graduais, em casos como operações lentas de manobra, precipitações, dentre outras.(RAJU, 1981)

No caso de variação gradual, a curvatura do perfil de onda é moderada, e as mudanças das características do movimento são graduais. A componente vertical da aceleração das partículas de água é desprezível em comparação com a aceleração total, considerando que o efeito de cisalhamento do canal é normalmente apreciável e deveria ser levado em conta em uma análise precisa. Na variação rápida, a curvatura do perfil de onda é muito grande. Neste caso, a componente de aceleração vertical tem um papel importante no fenômeno, considerando que o efeito de cisalhamento do canal é praticamente desprezível em comparação ao efeito dinâmico do escoamento (CHOW, 1973).

Dentro das considerações apresentadas, é valido ressaltar que muitas situações físicas não suportam a hipótese de análise do escoamento transiente pela utilização do conceito de celeridade relativa de onda (c). Como exemplo, pode-se citar as ondas de cheia em canais, rios ou sistemas de drenagem, alterações de nível e vazões produzidas pelas partidas ou paradas de bombas ou turbinas hidráulicas, ondas originadas por manobras de comportas em canais de irrigação, dentre outras (PORTO, 1999). 
Neste contexto, o tratamento matemático das ondas de translação é feito por equações deduzidas a partir da continuidade e quantidade de movimento, com características complexas.

Em suma, o escoamento em um canal é dito não permanente ou variável, se a profundidade da água, assim como os outros parâmetros hidráulicos, variam com o tempo. $\mathrm{O}$ escoamento não permanente é em geral não uniforme ou variado, sendo que a não uniformidade se caracteriza pelo não paralelismo das linhas de corrente ao longo do escoamento (PORTO, 1999).

\subsubsection{As Equações do Movimento}

Os escoamentos em rios e canais são descritos por equações diferenciais parciais não lineares. As leis básicas da Mecânica, as quais servem de base para os estudos relativos aos transientes hidráulicos em escoamentos livres, são a equação da continuidade (conservação de massa) e a equação dinâmica (quantidade de movimento) (HENDERSON, 1966).

"As relações obtidas, são decorrentes da consideração de um conjunto de hipóteses simplificadoras como: escoamento unidimensional, distribuição de pressão hidrostática, canal de baixa declividade, canal prismático (seção reta e declividade de fundo constantes em toda a extensão), fluido incompressível com vazão dada por $\mathrm{Q}=\mathrm{V}(\mathrm{x}, \mathrm{t}) \cdot \mathrm{A}(\mathrm{x}, \mathrm{t})$, e perda de carga no regime variável computada por uma equação de resistência do regime permanente e uniforme".(PORTO, 1999, p.469)

\subsubsection{Equação da Continuidade}

De acordo com PORTO (1999, p. 469-471), a equação da continuidade pode ser obtida através da seguinte análise:

A partir do volume de controle elementar de comprimento dx, no qual o escoamento se processa da seção 1 para a seção 2, como mostra a FIGURA 04, sendo x uma abscissa medida ao longo do canal, A, a área da seção reta, y, altura ou tirante d'água, B, largura do canal na superfície livre, $\rho$, a massa específica da água e $\mathrm{V}$, a velocidade média na seção 1 , a equação da continuidade pode ser escrita, de uma maneira geral, na forma: 


$$
\int_{\text {S.C }} \rho \cdot \vec{V} \cdot d \vec{A}=-\frac{\partial}{\partial t} \int_{V \cdot C} \rho \cdot d V_{0}
$$

isto é, a vazão em massa através da superfície de controle (S.C) é igual à variação, por unidade de tempo, da massa ( $\rho . d V o l)$ no interior do volume de controle (V.C).

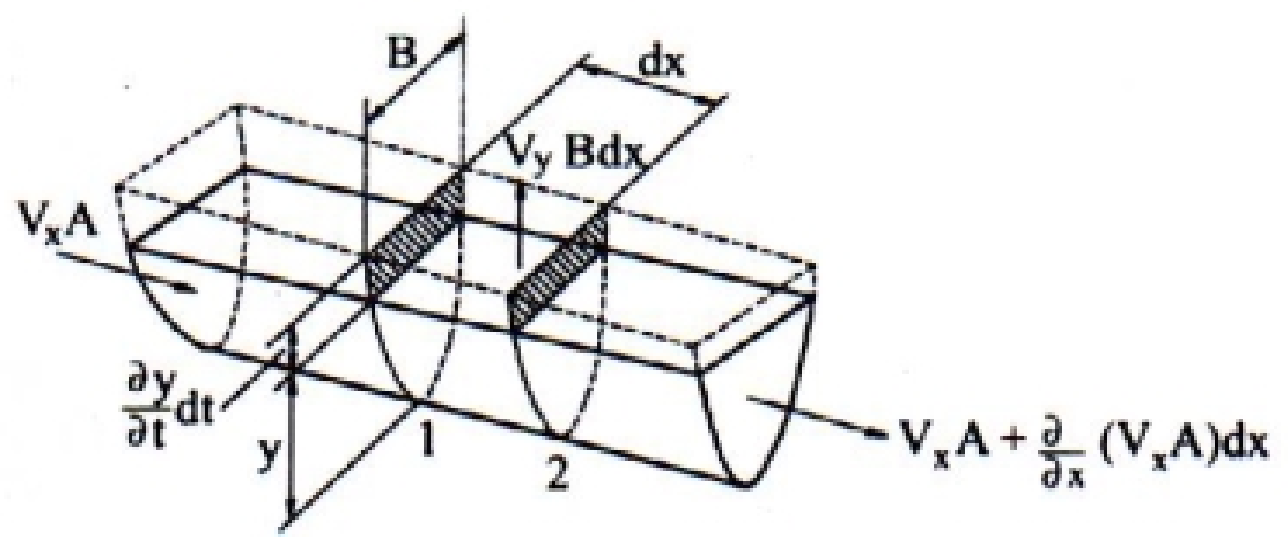

\section{FIGURA 04 - Volume de Controle Elementar}

Na hipótese do fluido incompressível, $\rho=$ cte., a equação da conservação da massa fica reduzida à conservação do volume, na forma:

$$
\int_{\text {S.C }} \vec{V} \cdot d \vec{A}=-\frac{\partial}{\partial t} \int_{V . C} d V_{0}
$$

Aplicando a equação (2.2) ao volume de controle da FIGURA 4, observando que o produto escalar, na parte da superfície de controle correspondente a seção 1 é negativo, e que não há aporte lateral de vazão, resulta:

$$
\begin{aligned}
& -V_{x} A+\left[V_{x} A+\frac{\partial}{\partial x}\left(V_{x} A\right) d x\right]=-\frac{\partial}{\partial t}\left[V_{0 l}\right]_{V . C .} \\
& \frac{\partial}{\partial x}\left(V_{x} A\right) d x=-\frac{\partial}{\partial t}[V o l]_{V . C}
\end{aligned}
$$

A variação de volume por unidade de tempo é o resultado de uma modificação na superfície livre $\partial \mathrm{y} / \partial \mathrm{t}$, entre as duas seções distanciadas de $\mathrm{dx}$ durante o intervalo de tempo $\mathrm{dt}$, e que corresponde a $(\mathrm{Bdx}) \partial \mathrm{y} / \partial \mathrm{t}$, onde $\mathrm{B}$ é a largura na superfície livre e $\partial \mathrm{y} / \partial \mathrm{t}=\mathrm{V}_{\mathrm{y}}$ 
representa a velocidade com que está se movimentando verticalmente a superfície livre da água. Portanto, a variação do volume por unidade de tempo fica sendo:

$\frac{\partial y}{\partial t} B d x=\frac{\partial A}{\partial t} d x=\frac{\partial V o l}{\partial t}$

Substituindo este resultado na equação (2.4), a equação da continuidade torna-se:

$\frac{\partial}{\partial \mathrm{x}}\left(\mathrm{V}_{\mathrm{x}} \mathrm{A}\right)+\frac{\partial \mathrm{A}}{\partial \mathrm{t}}=0 \therefore \mathrm{A} \frac{\partial \mathrm{V}_{\mathrm{x}}}{\partial \mathrm{x}}+\mathrm{V}_{\mathrm{x}} \frac{\partial \mathrm{A}}{\partial \mathrm{x}}+\frac{\partial \mathrm{A}}{\partial \mathrm{t}}=0$

Como para canais de fraca declividade a componente $\mathrm{V}_{\mathrm{x}}$ pode ser considerada igual a velocidade média na seção $\mathrm{V}=\mathrm{Q} / \mathrm{A}$, devido a baixa influência da ação gravitacional, resulta:

$\mathrm{A} \frac{\partial \mathrm{V}}{\partial \mathrm{x}}+\mathrm{V} \frac{\partial \mathrm{A}}{\partial \mathrm{x}}+\frac{\partial \mathrm{A}}{\partial \mathrm{t}}=0$

Na equação anterior, A e V são variáveis dependentes e x e t, variáveis independentes. A equação (2.7) também pode ser escrita:

$\frac{\partial \mathrm{Q}}{\partial \mathrm{x}}+\frac{\partial \mathrm{A}}{\partial \mathrm{t}}=0$

e como, $\partial \mathrm{A}=\mathrm{B} \partial \mathrm{y}$ a equação da continuidade assume também a forma:

$\mathrm{A} \frac{\partial \mathrm{V}}{\partial \mathrm{x}}+\mathrm{V} \frac{\partial \mathrm{A}}{\partial \mathrm{x}}+\mathrm{B} \frac{\partial \mathrm{y}}{\partial \mathrm{t}}=0$

Se uma vazão lateral suplementar sai ou entra no canal, entre as duas seções 1 e 2 , a equação anterior é modificada como:

$A \frac{\partial V}{\partial x}+V \frac{\partial A}{\partial x}+B \frac{\partial y}{\partial t} \pm q_{L A T}=0$

ou da forma: 
$\frac{\partial Q}{\partial x}+\frac{\partial A}{\partial t} \pm q_{L A T}=0$

onde:

$\mathrm{Q}=\operatorname{vazão}\left(\mathrm{m}^{3} / \mathrm{s}\right)$;

$\mathrm{A}=$ área da seção transversal $\left(\mathrm{m}^{2}\right)$;

$\mathrm{x}=$ distância longitudinal $(\mathrm{m})$;

$\mathrm{t}=$ tempo $(\mathrm{s})$;

$\mathrm{q}_{\mathrm{LAT}}=$ vazão suplementar por unidade de comprimento das margens do canal $\left(\mathrm{m}^{3} / \mathrm{s} . \mathrm{m}\right)$, tendo o sinal negativo se for influxo (entrada) e positivo se for efluxo (saída).

\subsubsection{Equação Dinâmica}

Segundo HENDERSON (1966, p. 90-91, 285-287), a equação dinâmica (quantidade de movimento) pode ser obtida como descrito na seqüência.

Para a definição do equacionamento, as condições usadas são expressas pela FIGURA 05.

Quando o escoamento é permanente, o gradiente da linha de energia total $(\mathrm{dH} / \mathrm{dx})$, é igual em magnitude e oposto em sinal a declividade da linha de energia $\left(S_{\mathrm{f}}\right)$.

A estimativa de $S_{\mathrm{f}}$ pode ser feita das seguintes formas:

a) por equilíbrio de forças:

$$
S_{f}=\frac{\tau_{0}}{भ R_{H}}
$$

b) utilizando a Fórmula de Chezy:

$$
S_{f}=\frac{V^{2}}{C h^{2} R_{H}}
$$

onde:

$\tau_{0}=$ tensão média de cisalhamento sobre o perímetro molhado $\left(\mathrm{N} / \mathrm{m}^{2}\right)$ 
$\gamma=$ peso específico da água $\left(\mathrm{N} / \mathrm{m}^{3}\right)$

$\mathrm{R}_{\mathrm{H}}=$ raio hidráulico da seção $(\mathrm{m})$

$\mathrm{V}=$ velocidade média do escoamento na seção $(\mathrm{m} / \mathrm{s})$

$\mathrm{Ch}=$ coeficiente de rugosidade de Chezy

mas

$\frac{\partial \mathrm{H}}{\partial \mathrm{x}}=\frac{\partial}{\partial \mathrm{x}}\left(\mathrm{h}+\frac{\mathrm{V}^{2}}{2 \mathrm{~g}}\right)$

onde:

$\mathrm{H}=$ energia total do escoamento $(\mathrm{m})$

$\mathrm{x}=$ distância na direção longitudinal (m)

$\mathrm{h}=$ altura d'água medida em relação ao plano de referência (m)

$\mathrm{V}=$ velocidade média do escoamento na seção $(\mathrm{m} / \mathrm{s})$

$\mathrm{g}=$ aceleração da gravidade $\left(\mathrm{m} / \mathrm{s}^{2}\right)$

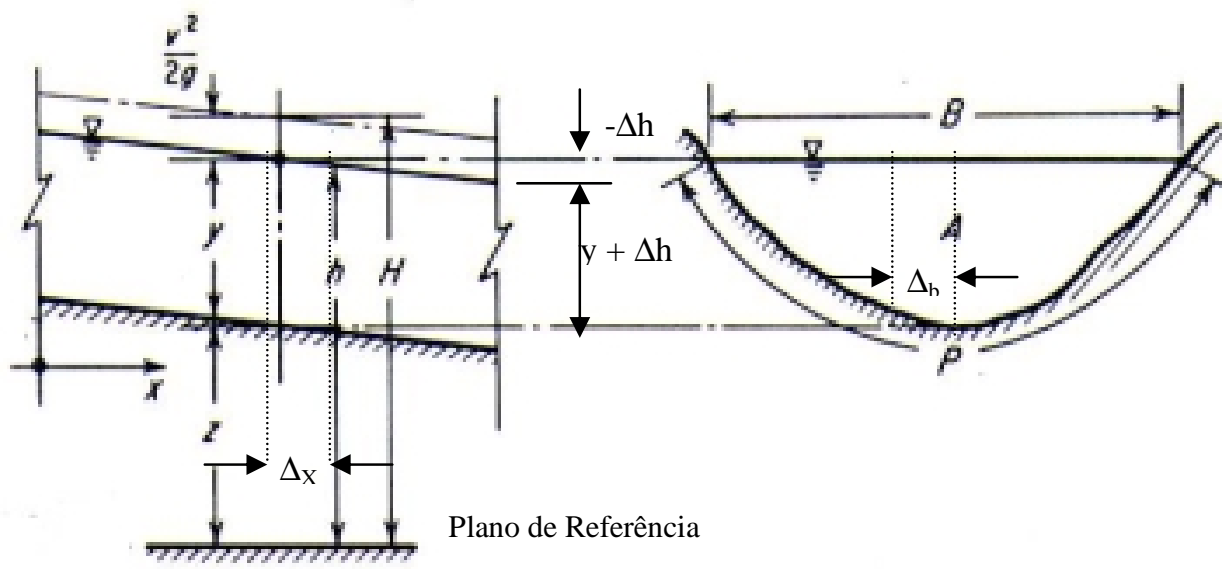

$\begin{array}{ll}\text { (a) Seção Longitudinal } & \text { (b) Seção Transversal }\end{array}$

FIGURA 05 - Esboço de Referência para as Equações do Movimento

No movimento não permanente a aceleração é expressa por:

$a_{x}=\frac{d V}{d t}=V \frac{\partial V}{\partial x}+\frac{\partial V}{\partial t}$

onde: 
$\mathrm{V} \frac{\partial \mathrm{V}}{\partial \mathrm{x}}=$ a parcela da aceleração convectiva (escoamento permanente)

$\frac{\partial \mathrm{V}}{\partial \mathrm{t}}=$ a parcela da aceleração local (escoamento não permanente)

Sabendo-se que a resultante das forças externas, atuantes num volume de controle limitado por $\Delta \mathrm{x}$ de um dado escoamento, é dada por $\sum \vec{F}=m \vec{a}$, onde "m" é a massa e "a" a aceleração, a equação do movimento se torna

$-\gamma \mathrm{A} \Delta \mathrm{h}-\tau_{0} \mathrm{P} \Delta \mathrm{x}=\rho \mathrm{A} \Delta \mathrm{x}\left(\mathrm{V} \frac{\partial \mathrm{V}}{\partial \mathrm{x}}+\frac{\partial \mathrm{V}}{\partial \mathrm{t}}\right)$

onde:

$-\gamma \mathrm{A} \Delta \mathrm{h}=$ a parcela correspondente à força de pressão no sentido contrário a $\mathrm{x}$

$-\tau_{0} \mathrm{P} \Delta \mathrm{x}=\mathrm{a}$ parcela correspondente à força de atrito no sentido contrário a $\mathrm{x}$, sendo $\mathrm{P} \mathrm{o}$ perímetro molhado da seção

$\rho \mathrm{A} \Delta \mathrm{x}$ = a massa de água em movimento

$\left(\mathrm{V} \frac{\partial \mathrm{V}}{\partial \mathrm{x}}+\frac{\partial \mathrm{V}}{\partial \mathrm{t}}\right)=\mathrm{a}$ aceleração desenvolvida no escoamento

Desenvolvendo a equação (2.16) fica

$\tau_{0}=-\gamma R_{H}\left(\frac{\partial h}{\partial x}+\frac{V}{g} \frac{\partial V}{\partial x}+\frac{1}{g} \frac{\partial V}{\partial t}\right)=-\gamma R_{H}\left(\frac{\partial H}{\partial x}+\frac{1}{g} \frac{\partial V}{\partial t}\right)$

Substituindo a equação (2.17) em $\tau_{0}$ das igualdades das equações (2.12) e (2.13) tem-se

$\frac{\partial H}{\partial x}+\frac{1}{g} \frac{\partial V}{\partial t}+\frac{V^{2}}{C h^{2} R_{H}}=0$

onde a equação (2.18) pode ser reformulada usando a equação (2.14), recordando que a declividade de fundo So é igual a $-\partial z / \partial x$. Visto que $h=z+y$, tem-se:

$\frac{\partial H}{\partial x}=\frac{\partial z}{\partial x}+\frac{\partial y}{\partial x}+\frac{V}{g} \frac{\partial V}{\partial x}$ 
$\frac{\partial \mathrm{H}}{\partial \mathrm{x}}=-\mathrm{S}_{0}+\frac{\partial \mathrm{y}}{\partial \mathrm{x}}+\frac{\mathrm{V}}{\mathrm{g}} \frac{\partial \mathrm{V}}{\partial \mathrm{x}}=-\frac{1}{\mathrm{~g}} \frac{\partial \mathrm{V}}{\partial \mathrm{t}}-\mathrm{S}_{\mathrm{f}}$

Consequentemente, a equação (2.18) pode ser escrita como segue:

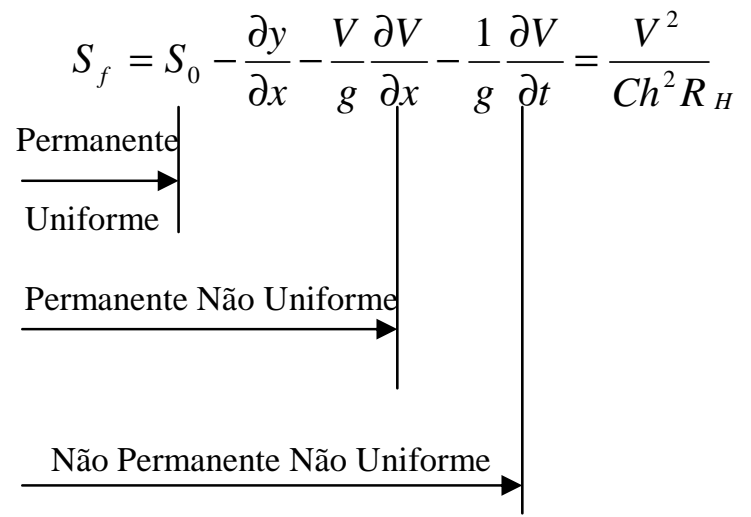

Este arranjo pode mostrar como a não uniformidade e a variabilidade do escoamento introduzem termos extras na equação dinâmica.

Semelhante às equações de escoamento permanente, das quais elas são uma extensão, as equações (2.18) e (2.21) só são verdadeiras quando a distribuição de pressão for hidrostática e quando os componentes verticais de aceleração são desprezíveis. (HENDERSON, 1966).

RIGHETTO (1998), utilizando a equação da continuidade, modificou a equação da quantidade de movimento, já considerando a contribuição lateral e multiplicando toda a equação por g, chegando a:

$$
\frac{\partial V}{\partial t}+V \frac{\partial V}{\partial x}+g \frac{\partial y}{\partial x}=g\left(S_{0}-S_{f}\right)-q_{L A T} \frac{\left(V-V_{L, X}\right)}{y}
$$

onde $\mathrm{V}_{\mathrm{L}, \mathrm{x}}$ é a componente de velocidade da contribuição lateral na seção $\mathrm{x}$ e, segundo o mesmo autor, pode ser desprezado se o ângulo de entrada da contribuição lateral em relação ao escoamento for próximo de $90^{\circ}$. 
As equações (2.9) e (2.21), estabelecidas pela primeira vez por Saint-Venant* em 1870, constituem um sistema de duas equações a derivadas parciais, em x e t, que descrevem, sob as hipóteses fixadas, os escoamentos não permanentes em canais, constituindo o modelo de propagação de cheia denominado modelo hidrodinâmico (PORTO, 1999). A integração exata das equações de Saint-Venant é muito complicada e sua solução analítica só é possível em casos muito especiais, como por exemplo, no estudo publicado por MORAMARCO et al (1999)*.

Segundo CHAUDHRY (2001)* as alternativas para se resolver tais equações para variação de vazão e altura d'água ao longo do escoamento e do tempo, são:

- Simplificação das Equações

- Fazer Transformações (Ex.: Método das Características)

- Utilizar Métodos Numéricos

Segundo LIGGETT \& CUNGE (1975), para propósitos de engenharia, a maioria das soluções das equações desenvolvidas para o escoamento não permanente, ocorrem com a utilização de métodos numéricos usando computadores digitais.

Esses métodos (WROBEL, 1989), reduzem um problema físico, contínuo, a um problema discreto que pode ser resolvido por computador.

\subsubsection{Simplificação das Equações de Saint-Venant}

Segundo PORTO (1999), as equações completas do escoamento não permanente, equações (2.9) e (2.21), requerem, para sua resolução, elaboradas técnicas numéricas bem como uma grande quantidade de dados hidráulicos do canal, principalmente se forem aplicadas aos cursos d'água naturais.

Para a dedução das equações algumas hipóteses simplificadoras são adotadas:

*SAINT-VENANT, (1870) conde, Adémas Jean-Claude Barré./ engenheiro francês , 1797-1886/

*MORAMARCO.T et al (1999).Analytical Solution for Channel Routing With Uniform Lateral Inflow./ Journal of Hydraulic Engineering, july./1999

*CHAUDHRY, Fazal Hussain (2001). Recursos Hídricos - Aspectos Quantitativos. / Curso ministrado na EESC/USP - São Carlos, no período de março-julho/2001 
fluido incompressível; escoamento unidimensional, no qual a velocidade média é representativa da variação espacial na seção e o sentido predominante do escoamento é longitudinal; distribuição hidrostática de pressão na vertical, desprezando-se eventuais efeitos de componentes de aceleração vertical; variação gradual das seções transversais e ausência de singularidades como contrações, pilares de ponte, soleiras de fundo etc; e, finalmente, assumindo que a declividade da linha de energia possa ser calculada por uma equação estabelecida para o regime permanente e uniforme, como a fórmula de Manning ou Chezy.

Observando-se cada um dos termos da equação (2.21), estes podem ser considerados como a representação de um gradiente ou declividade. O primeiro termo é a declividade energética que leva em conta o atrito. $\mathrm{O}$ segundo e terceiro termos representam a declividade da linha d'água, e são termos de gravidade e pressão. O quarto e quinto termos representam a declividade devido à variação da velocidade no espaço e no tempo e são termos de inércia.

A situação hidráulica do curso d'água, como declividade, largura da seção, existência de várzeas etc., impõe uma importância relativa a cada um dos termos da equação dinâmica geral, equação (2.21).

Segundo HENDERSON (1966), para rios com declividade de fundo So > 0,002 m/m, os dois termos de inércia na equação são, em geral muito pequenos, podendo ser desprezados com o objetivo de diminuir a dificuldade matemática da resolução do problema.

CUNGE et al (1980), baseados na observação de uma onda de cheia no rio Reno, mostram que a ordem de grandeza dos termos de inércia é $10^{-5}$, enquanto que a dos termos de atrito e gravidade é $10^{-3}$. Assim desprezando-se os termos devido às acelerações local e convectiva, termos de inércia, a equação (2.21) é simplificada como:

$$
\frac{\partial y}{\partial x}=S_{0}-S_{f}
$$

Esta equação, associada à equação da continuidade, equação (2.8), forma a base do modelo hidráulico de propagação de ondas de cheias denominado modelo de difusão ou não inercial. Tais modelos são aplicados nos casos em que não há grande variação espacial e 
temporal da velocidade no processo de propagação. Se além dos termos de inércia for também desprezado o termo de pressão, $\partial \mathrm{y} / \partial \mathrm{x}=0$, a equação assume a sua forma mais simplificada possível como:

$\mathrm{S}_{0}=\mathrm{S}_{\mathrm{f}}$

com a declividade da linha de energia $S_{\mathrm{f}}$ sendo calculada pela fórmula de Manning. Esta equação, associada à equação da continuidade, equação (2.8), forma a base do modelo hidráulico de propagação de ondas de cheias denominado modelo onda cinemática.

Segundo PORTO (1999), a utilização da equação (2.8), juntamente com a equação (2.21) em sua forma completa, sem desprezar nenhum termo, constitui o modelo de propagação de cheia denominado modelo hidrodinâmico. Tal metodologia propicia uma maior precisão na descrição do escoamento, à custa de uma maior dificuldade numérica de resolução das equações diferenciais e mais necessidade de dados que os modelos de difusão e onda cinemática.

\subsubsection{Modelo Onda Cinemática}

PONCE (1978) comenta que, embora sendo simplificado, o modelo Onda Cinemática tem sido satisfatório para descrever fenômenos físicos em uma variedade de casos, como escoamento superficial ou deslocamento de ondas de cheias variando lentamente. Entretanto, acrescenta que, devido às simplificações assumidas, o modelo não permite a atenuação física da onda.

O conceito de onda cinemática foi introduzido por LIGHTHILL \& WHITHAM (1955) como sendo uma onda na qual a vazão Q é somente função da profundidade y, o que implica que os outros termos da equação(2.21) sejam desprezíveis. Para tanto, é utilizado o seguinte equacionamento:

$\frac{\partial Q}{\partial x}+\frac{\partial A}{\partial t}=q_{L A T}$ 
$\mathrm{S}_{\mathrm{f}}=\mathrm{S}_{0}$

Partindo-se da expressão de Chezy, a equação dinâmica, equação (2.21), pode ser escrita como:

$$
V=C h \sqrt{R_{H} S_{f}}=C h \sqrt{R_{H}\left(S_{0}-\frac{\partial y}{\partial x}-\frac{V}{g} \frac{\partial V}{\partial x}-\frac{1}{g} \frac{\partial V}{\partial t}\right)}
$$

Para o escoamento permanente e uniforme a equação (2.26) simplifica-se na forma:

$$
V=C h \sqrt{R_{H} S_{0}}
$$

e portanto, a relação entre a velocidade média $\mathrm{V}$, ou a vazão $\mathrm{Q}$, e a profundidade $\mathrm{y}$, ou o raio hidráulico $\mathrm{R}_{\mathrm{H}}$ é dada pela FIGURA 06.

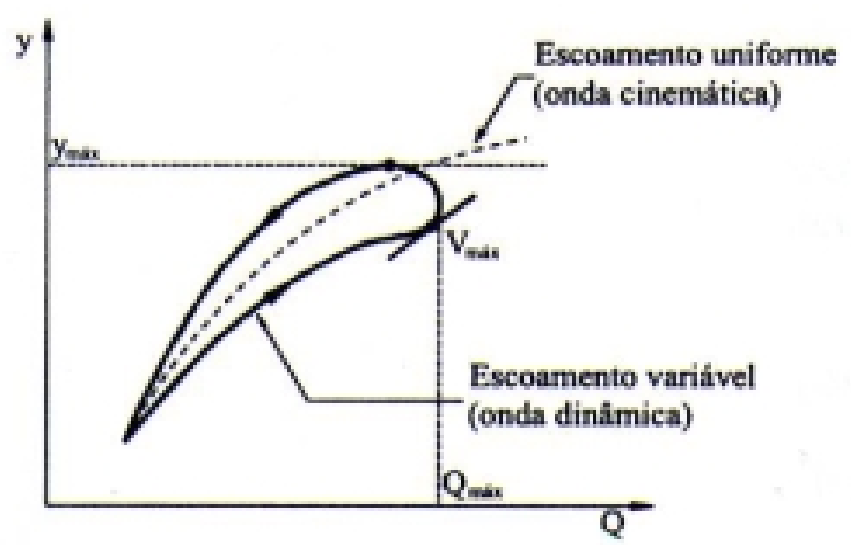

FIGURA 06 - Representação de uma Curva de Descarga em Laço

onde a largura do laço indica a importância relativa dos termos de inércia e de pressão na equação (2.24). A relação apresentada pela figura acima, $Q=f$ (y), é chamada usualmente de curva chave.

Considerando uma onda com estas características e utilizando a equação da continuidade, equação (2.8), vem: 
$\frac{\partial \mathrm{Q}}{\partial \mathrm{x}}+\frac{\partial \mathrm{A}}{\partial \mathrm{t}}=0 \therefore \frac{\partial \mathrm{Q}}{\partial \mathrm{x}}+\mathrm{B} \frac{\partial \mathrm{y}}{\partial \mathrm{t}}=0$

Sendo B a largura na superfície, a equação anterior pode ser reescrita como:

$\frac{\partial Q}{\partial y} \frac{\partial y}{\partial x}+B \frac{\partial y}{\partial t}=0$

Com o uso da diferenciação parcial, e imaginando um observador que se desloca no sentido da onda com uma velocidade igual à celeridade da onda, do seu ponto de vista, tanto a vazão Q quanto a profundidade y permanecem constantes. Assim a equação anterior fica:

$\frac{d y}{d t}=\frac{\partial y}{\partial x} \frac{d x}{d t}+\frac{\partial y}{\partial t}=0$

Da comparação entre as equações (2.29) e (2.30) conclui-se que:

$\frac{\mathrm{dx}}{\mathrm{dt}}=\mathrm{C}_{\mathrm{K}}=\frac{1}{\mathrm{~B}} \frac{\mathrm{dQ}}{\mathrm{dy}}=\frac{\mathrm{dQ}}{\mathrm{dA}}$

onde o termo $\mathrm{C}_{\mathrm{K}}$ é denominado celeridade da onda cinemática (FIGURA 07), que de acordo com a equação (2.29) só admite valores positivos, diferentemente da celeridade das ondas de gravidade, $\mathrm{V} \omega=\mathrm{V} \pm \mathrm{c}$, que pode assumir valores positivos (no sentido da corrente) e negativos (sentido contrário a corrente).

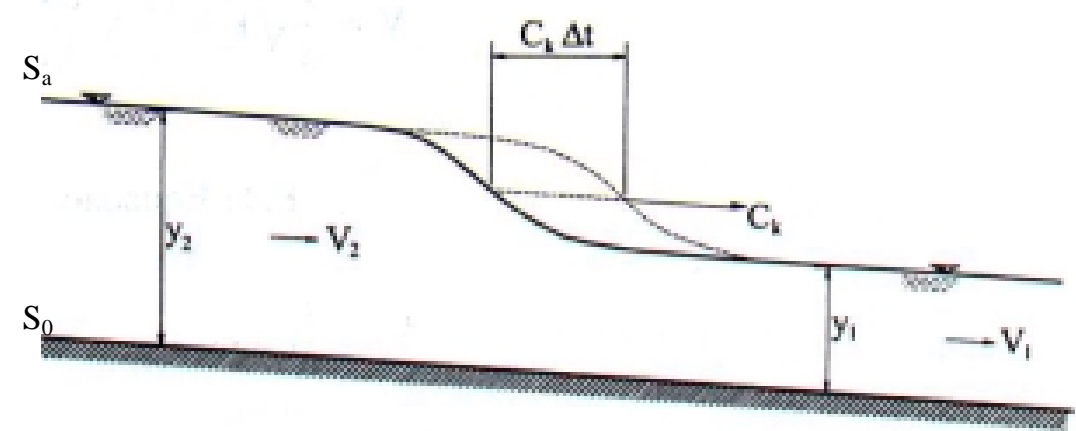

FIGURA 07 - Propagação da Onda Cinemática

A condição de aplicabilidade do modelo da onda cinemática, como uma aproximação válida para a equação dinâmica completa, é dada por WOOLHISER e LIGGETT (1967), na forma: 
$\mathrm{K}_{\mathrm{f}}=\frac{\mathrm{gLS}_{0}}{\mathrm{~V}^{2}}>20$

na qual $\mathrm{V}(\mathrm{m} / \mathrm{s})$ é a velocidade média no regime uniforme, $\mathrm{S}_{0}(\mathrm{~m} / \mathrm{m})$ é a declividade de fundo do canal e L (m), o comprimento do trecho do canal em estudo.

PONCE et al. (1978) baseados em análises das equações de Saint Venant linearizadas, concluiram que, com 95\% (noventa e cinco por cento) de precisão, o modelo da onda cinemática é aplicável quando se verificar a seguinte desigualdade:

$\frac{\mathrm{TS}_{0} \mathrm{~V}_{0}}{\mathrm{y}_{0}} \geq 171$

onde :

$\mathrm{T}=$ período da onda $(\mathrm{s})$

$\mathrm{S}_{0}=$ declividade do fundo do canal $(\mathrm{m} / \mathrm{m})$

$\mathrm{V}_{0}=$ velocidade média do escoamento uniforme $(\mathrm{m} / \mathrm{s})$

$\mathrm{y}_{0}=$ profundidade do estado uniforme

TUCCI (1987) afirma que, para que o modelo onda cinemática possa ser aplicado, é necessário comparar as celeridades de ondas cinemática e dinâmica. Para tanto, embora não seja suficiente, a seguinte condição deve ser satisfeita:

$\frac{5}{3} \mathrm{~V}<\mathrm{V}+\sqrt{\mathrm{gh}}$ ou $\mathrm{F}_{\mathrm{R}}<\frac{3}{2}$

onde:

$\mathrm{V}=$ velocidade média do escoamento $(\mathrm{m} / \mathrm{s})$

$\mathrm{F}_{\mathrm{R}}=$ número de Froude

Quando existem efeitos de jusante, o modelo não pode ser aplicado, pois, os termos da equação dinâmica (atrito e gravidade) não consideram estes efeitos. Esses casos ocorrem em rios e canais próximos a lagos, oceanos, estuários e nos afluentes de rios de grande porte. 


\subsubsection{Modelo Onda de Difusão}

O modelo da onda de difusão (PONCE, 1978) assume que os termos de inércia, na equação da quantidade de movimento, são desprezíveis quando comparados com os termos de pressão, atrito e gravidade. É utilizado o seguinte equacionamento:

$$
\frac{\partial Q}{\partial x}+\frac{\partial A}{\partial t}=q_{L A T}
$$

$\mathrm{e}$

$$
\frac{\partial y}{\partial x}=S_{0}-S_{f}
$$

Este modelo é mais abrangente do que o modelo da onda cinemática, pois considera o termo de pressão, o que permite levar em conta os efeitos de jusante e atenuação física da onda. Entretanto, a sua vantagem em diminuir o volume de cálculo com relação ao modelo dinâmico (que utiliza as equações completas de Saint Venant), perdeu importância com a disponibilidade do uso de computadores na realização dos cálculos. A aplicabilidade deste modelo foi estudada por PONCE et al.(1978), que vincula o seu uso a satisfação da seguinte condição de desigualdade:

T.S $S_{0}\left(\frac{g}{y_{0}}\right)^{1 / 2} \geq 30$

e, portanto, limitando a ordem de grandeza do período de onda $\mathrm{T}$, aos valores de $\mathrm{S}_{0}$ e $\mathrm{y}_{0}$. Se o período de onda à ser utilizado é menor que o limite imposto pela inequação, cabe ao modelo dinâmico a descrição e quantificação da atenuação da onda.

\subsubsection{Modelos de Armazenamento}

"Estes tipos de modelo tem sido utilizado em hidrologia devido principalmente à simplicidade de formulação e ao pequeno volume de dados usados. Relaciona o armazenamento com a vazões de entrada e saída: S = f( I, Q, I', Q') onde 
$\mathrm{S}=$ armazenamento $\left(\mathrm{m}^{3}\right)$

$\mathrm{I}=$ hidrograma de entrada $\left(\mathrm{m}^{3} / \mathrm{h}\right)$

$\mathrm{Q}=$ hidrograma de saída $\left(\mathrm{m}^{3} / \mathrm{h}\right)$

I' e Q' = derivadas de I e Q com relação ao tempo.

Alguns destes modelos são:

$\mathrm{S}=\mathrm{K} \mathrm{Q} \quad$ Reservatório linear simples

$\mathrm{S}=\mathrm{K}[\mathrm{x} \mathrm{I}+(1-\mathrm{x}) \mathrm{Q}] \quad$ Muskingun

$\mathrm{S}=\alpha / \mathrm{Q}^{\beta} \quad$ SSARR (Streamflow Synthesis and Reservoir Regulation)

Para utilizar este modelo são necessários, na fase de ajuste, somente os hidrogramas de montante e jusante. Esta é a vantagem principal, já que na prática é necessário obter resposta rápida além da carência de dados. Este tipo de modelo pode ser usado quando o efeito preponderante é o amortecimento devido ao armazenamento e não existem efeitos de jusante sobre o escoamento, como os devido à maré na foz de certos rios". TUCCI (1980, p.94-95)

Segundo o mesmo autor, os modelos de escoamento se resumem com as características apresentadas pela TABELA 03.

\begin{tabular}{l|cc|ccc} 
Modelos & Distribuído & $\begin{array}{l}\text { Efeito de } \\
\text { jusante }\end{array}$ & $\begin{array}{c}\text { Termos de } \\
\text { pressão }\end{array}$ & $\begin{array}{c}\text { Termo de } \\
\text { inércia }\end{array}$ & $\begin{array}{l}\text { Dados } \\
\text { físicos }\end{array}$ \\
\hline Armazenamento & Não & Não & Não & Não & Não \\
Onda cinemática & Sim & Não & Não & Não & Opcional \\
Difusão & Sim & Sim & Sim & Não & Opcional \\
Hidrodinâmico & Sim & Sim & Sim & Sim & Sim
\end{tabular}

TABELA 03 - Resumo das Características dos Modelos de Escoamento fonte:Modelos Hidrológicos (TUCCI, 1998)

\subsubsection{Métodos Numéricos para a Resolução das Equações de Saint Venant}

MASSAU (1889), foi o primeiro a propor uma solução gráfica para as equações do escoamento não permanente. THOMAS (1937), propôs uma solução numérica. Entretanto, nenhuma dessas aproximações teve aceitação, na época, devido ao tempo e esforço requeridos para os seus usos. (RAGAN, 1966) 
No mesmo artigo, RAGAN comenta também que o advento do computador digital, com grande velocidade de cálculo e grande capacidade de armazenamento de dados, fez renascer o interesse pelo uso das equações completas de Saint Venant.

Segundo FREAD (1973), a técnica de simulação de escoamento não permanente, com base nas equações completas de Saint Venant, teve como pioneiros ISACSON et al (1956), em estudos de cheias do rio Ohio. Desde então a técnica tem sido modificada e aplicada por muitos pesquisadores. De acordo com o mesmo autor e literatura atual disponível, alguns fizeram uso de técnicas diretas explícitas para a resolução das equações, tais como ISACSON et al (1958), LIGGETT \& WOOLHISER (1967), GARRISON et al (1969); outros, usaram técnicas diretas implícitas, como é o caso de ABBOTT \& IONESCU (1966), BALTZER \& LAI (1968), AMEIN \& FANG (1970), FREAD (1973); ou ainda utilizando o esquema das características, caso de AMEIN (1966), FLETCHERET \& HAMILTON (1967), LIGGETT (1968), HARRIS (1970), LAI (1988).

WENDLAND \& RÜBER (1998), com a complementação de JORGENSEN (1986), propõem (FIGURA 08) as etapas com os respectivos elementos importantes na modelação.

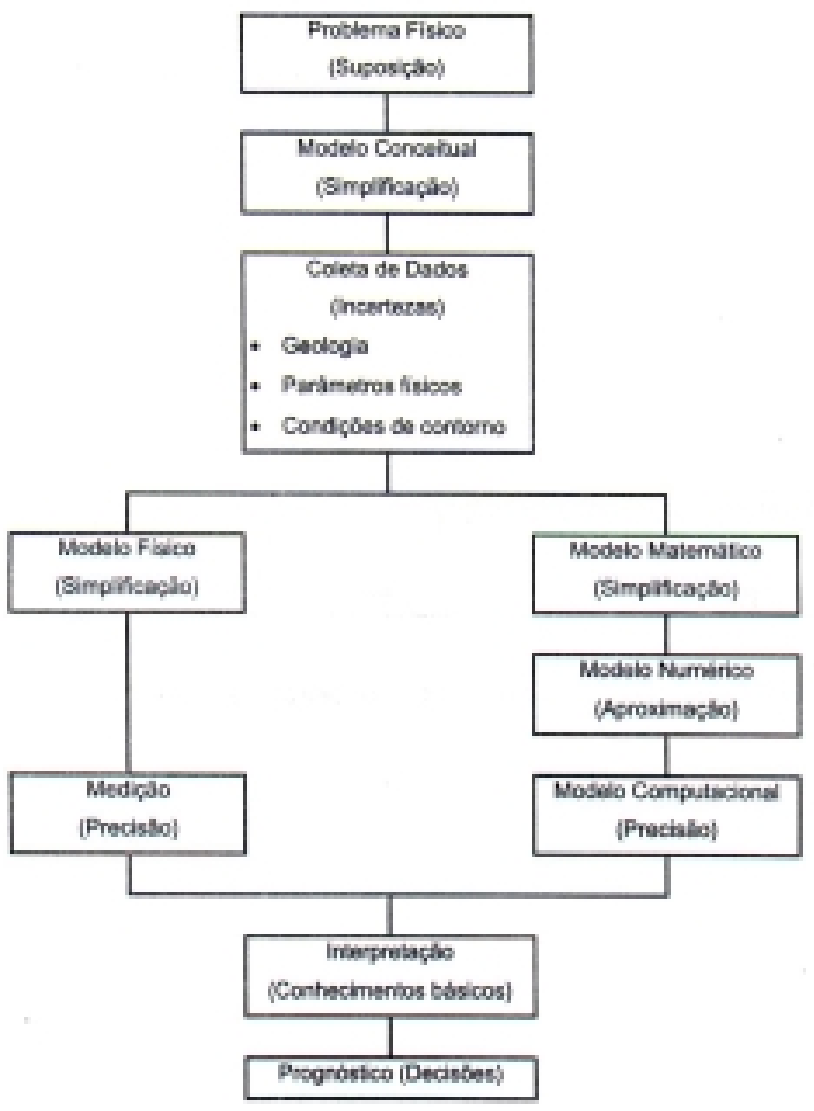

FIGURA 08 - Etapas da Modelação 
Como já mencionado, as equações diferenciais representativas do comportamento físico, dificilmente têm soluções analíticas na prática. Para resolvê-las utilizam-se métodos numéricos, tais como, método das diferenças finitas, método dos elementos finitos, método dos volumes finitos, dentre outros.

Segundo LIGGET \& CUNGE (1975), não há uma única resposta que define o melhor método para a solução do problema em questão. Esta resposta depende da aplicação particular, onde cabe ao usuário ter um mínimo de conhecimento de técnicas numéricas para uma melhor abordagem e solução da problemática envolvida.

De acordo com QUEIROZ (1991), por exemplo, quando o escoamento em um canal puder ser considerado unidimensional, o método das diferenças finitas pode ser utilizado com vantagem. Por ser relativamente simples de ser equacionado e tratado numericamente, ele se torna mais acessível aos usuários e produz, em geral, bons resultados. Já no caso de problemas de caráter tridimensional, por exemplo, o método dos volumes finitos produz um tratamento mais elaborado.

No caso do método de diferenças finitas, existem vários esquemas para sua aplicação à escoamento em canais (QUEIROZ, 1991) que podem ser agrupados nas seguintes categorias:

- Esquema das Características: em que as equações características são utilizadas para descrever o comportamento físico do escoamento;

- Esquemas Diretos Explícitos, que podem apresentar problemas de estabilidade; e Esquemas Diretos Implícitos, que são linearmente estáveis. São chamados de esquemas diretos devido às equações de Saint Venant serem utilizadas diretamente.

\subsubsection{Esquemas Diretos}

Como dito anteriormente, a solução das equações do escoamento não permanente pode ser obtida também através dos esquemas diretos de diferenças finitas.

Estes esquemas, segundo (GRIJSEN, 1986), se diferenciam entre si pela técnica utilizada na discretização dos termos contínuos das equações, podendo ser, por exemplo, centrados, progressivos ou regressivos no espaço. 
Segundo FORTUNA (2000), as técnicas de aproximação podem ser expressas pelas equações seguintes, obtidas a partir de aproximações por série de Taylor truncada:

Esquema centrado:

$\left(\frac{\partial f}{\partial x}\right)_{i} \cong \frac{f_{i+1}-f_{i-1}}{2 \Delta x}+O(\Delta x)^{2}$

Note-se que a aproximação dada pela equação (2.38) utiliza os pontos $x_{i-1}$ e $x_{i+1}$ para o cálculo da primeira derivada de $\mathrm{f}$ no ponto central, intermediário, $\mathrm{x}_{\mathrm{i}}$. Por essa razão, ela é denominada aproximação por diferenças centrais. A inclinação de $\mathrm{f}$ em $\mathrm{x}_{\mathrm{i}}$ é aproximada pela inclinação da reta N. (FIGURA 09)

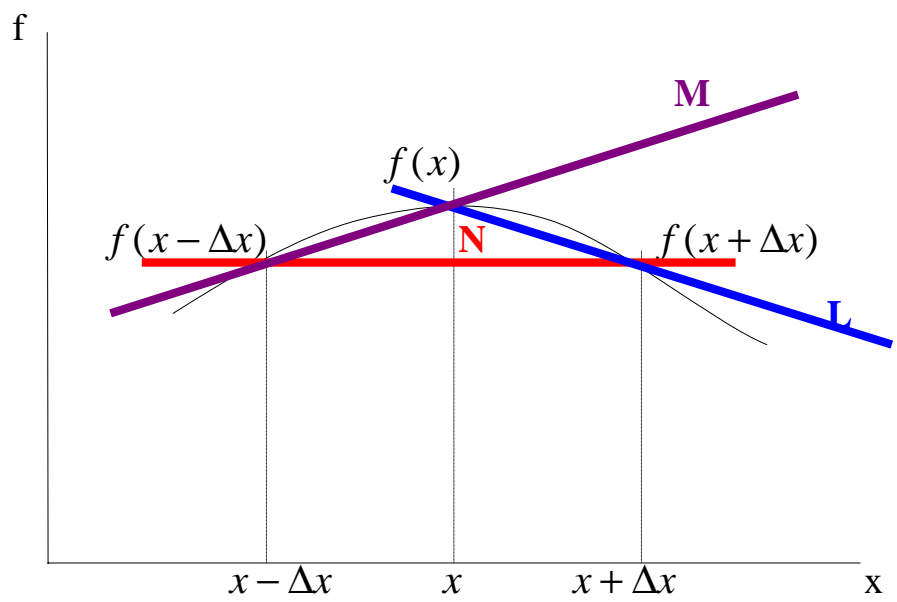

FIGURA 09 - Pontos utilizados para o cálculo da primeira derivada de f

Esquema progressivo:

$\left(\frac{\partial \mathrm{f}}{\partial \mathrm{x}}\right)_{\mathrm{i}} \cong \frac{\mathrm{f}_{\mathrm{i}+1}-\mathrm{f}_{\mathrm{i}}}{\Delta \mathrm{x}}+\mathrm{O}(\Delta \mathrm{x})$

A equação (2.39) representa uma aproximação de primeira ordem para a primeira derivada de $\mathrm{f}$, utilizando diferenças progressivas, ou seja:

- É de primeira ordem porque, no termo dominante do erro local de truncamento $(\mathrm{ELT}), \Delta \mathrm{x}$ aparece elevado à primeira potência. 
- É de diferenças progressivas porque, no cálculo da derivada no ponto $\mathrm{x}_{\mathrm{i}}$, foi utilizado um ponto adiante de $\mathrm{x}_{\mathrm{i}}$, no caso, $\mathrm{x}_{\mathrm{i}+1}$. A inclinação (primeira derivada) de $\mathrm{f}$ em $\mathrm{x}_{\mathrm{i}}$ é aproximada pela inclinação da reta L, conforme mostra a FIGURA 09.

Esquema regressivo

$\left(\frac{\partial \mathrm{f}}{\partial \mathrm{x}}\right)_{\mathrm{i}} \cong \frac{\mathrm{f}_{\mathrm{i}}-\mathrm{f}_{\mathrm{i}-1}}{\Delta \mathrm{x}}+\mathrm{O}(\Delta \mathrm{x})$

que é outra aproximação de primeira ordem para a primeira derivada de f. Diferente da equação (2.39), na qual utiliza-se um ponto adiante de $x_{i}$, a equação (2.40) utiliza o ponto $\mathrm{X}_{\mathrm{i}-1}$, ponto este que fica atrás de $\mathrm{x}_{\mathrm{i}}$. Por essa razão, a equação (2.40) é considerada uma aproximação por diferenças finitas atrasadas. A FIGURA 09 mostra os pontos utilizados nesta aproximação. A inclinação da função $f$ em $\mathrm{x}_{\mathrm{i}}$ é aproximada pela reta $\mathrm{M}$.

De acordo com QUEIROZ (1991), para as derivadas com relação ao tempo, responsáveis pela distinção dos esquemas em explícitos e implícitos, existem possibilidades similares.

$\mathrm{Na}$ aplicação da técnica de diferenças finitas a um problema físico qualquer, o domínio do problema (região dos valores assumidos pela variável independente geométrica) é discretizado por uma grade de pontos ou grade computacional. Por exemplo, na modelação unidimensional do transitório em um canal, por meio de diferenças finitas, o comprimento do canal é dividido em tramos, normalmente de comprimento uniforme $\Delta \mathrm{x}$, e as extremidades de cada tramo representam nós da grade ou nós computacionais. Se o trecho do canal é dividido em N-1 tramos, o primeiro nó (extremidade de montante) tem índice 1 e o último nó (extremidade de jusante) tem índice N. O primeiro e o último nó são chamados de nós de fronteira e os restantes de nós interiores. O processo computacional é feito em intervalos discretos de tempo e a diferença entre dois valores de tempo consecutivos é chamado de intervalo de tempo computacional. A FIGURA 10 mostra o exemplo de uma grade de pontos cujo objetivo consiste em determinar os valores de $\mathrm{y}(\mathrm{xi}, \mathrm{tk})$ e $\mathrm{V}(\mathrm{xi}, \mathrm{tk})$ nos pontos do domínio unidimensional $0 \leq \mathrm{x} \leq \mathrm{L}$, caracterizados por $\mathrm{xi}=1,2, \ldots, \mathrm{N}$ e nos tempos $\mathrm{tk}=$ $1,2, \ldots$, M. Neste caso, o domínio foi discretizado em intervalos de comprimento $\Delta \mathrm{x}$ e o tempo, t, em intervalos $\Delta \mathrm{t}$, de modo que xi $=(\mathrm{i}-1) \Delta \mathrm{x}$ e tk $=(\mathrm{k}-1) \Delta \mathrm{t} .(\mathrm{PORTO}, 1999)$ 


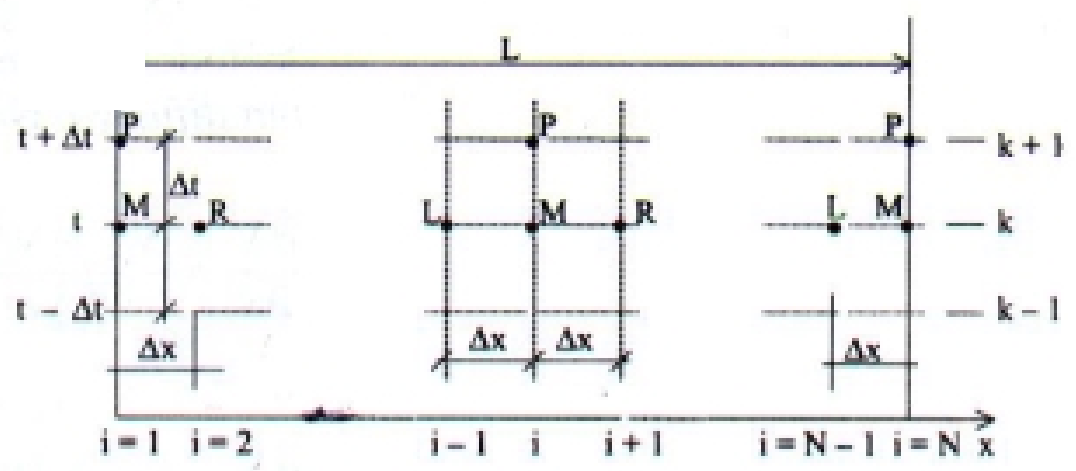

FIGURA 10 - Grade Computacional

Se em um tempo t qualquer são conhecidos a velocidade $V$ e a altura d'água $y$, em todos os pontos da grade (horizontal), pode-se determinar seus valores no tempo $t+\Delta t$. Quando $t=0$, corresponde às condições iniciais do problema que devem ser conhecidas.

Também segundo PORTO (1999), com a finalidade de simplificar a notação das equações discretizadas, o seguinte critério é adotado na representação das variáveis dependentes:

- subscrito denota os pontos da grade na direção de x e o sobrescrito denota os pontos da grade na direção de $t$, assim $V_{i}^{k}$ refere-se à velocidade média do escoamento na i.ésima seção do canal no k.ésimo nível de tempo.

- O sobrescrito k corresponde ao nível de tempo no qual as condições do escoamento são conhecidas e o sobrescrito $\mathrm{k}+1$, ao nível de tempo no qual as condições do escoamento são desconhecidas.

Se a aproximação por diferença finita da derivada espacial, em relação a $\mathrm{x}$, for expressa em termos de valores das variáveis no nível de tempo conhecido, as equações resultantes podem ser resolvidas diretamente, para cada nó computacional, caracterizando o esquema explícito. Se por outro lado, a derivada parcial for obtida no nível de tempo desconhecido, as equações algébricas do sistema inteiro são resolvidas simultaneamente e o esquema é dito implícito. Neste último, o sistema é resolvido por métodos como de eliminação de Gauss, de Gauss-Seidel, Newton-Raphson, etc.. (PORTO, 1999)

Para a computação do perfil d'água inicial, ou seja, no regime permanente, como dado de entrada para utilização dos esquemas diretos, utiliza-se a equação de energia descrita por HENDERSON (1966). Para tanto, lança-se mão de métodos de integração numérica para resolução da equação como por exemplo o "step method", descrito pelo referido autor para 
canais uniformes e irregulares, e apresentado neste estudo na análise específica de um dos casos abordados.

\subsection{Esquemas Diretos Explícitos}

Os esquemas diretos explícitos utilizam a informação da variável no tempo atual (k) em diferentes seções, para o cálculo da variável na seção (i), no tempo seguinte $(k+1)$, conforme ilustrado na FIGURA 11. Portanto a solução é dada por uma equação explícita da variável desconhecida, em função dos valores conhecidos. Estes esquemas avaliam a derivada com relação ao espaço, no tempo (k). (QUEIROZ,1991)

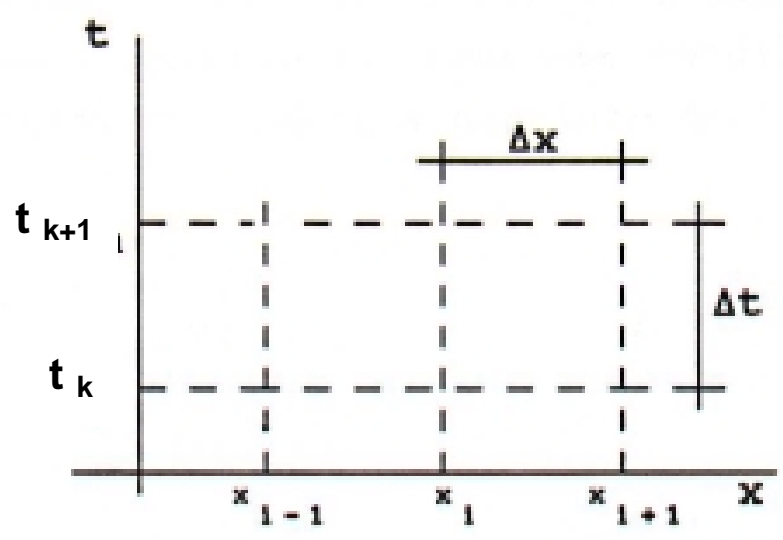

FIGURA 11 - Grade Computacional para Esquema Explícito

Vários esquemas explícitos têm sido desenvolvidos, apropriados às condições do escoamento a ser modelado, diferenciando-se basicamente, pela técnica de discretização adotada. (GUANARATNAM, 1970).

Entre os vários métodos que seguem esquemas explícitos (PORTO, 1999), utilizados na solução de problemas transitórios em escoamentos livres, está o esquema difusivo, em que as aproximações são descritas na forma:

$$
\frac{\partial \mathrm{V}}{\partial \mathrm{x}} \approx \frac{\mathrm{V}_{\mathrm{i}+1}^{\mathrm{k}}-\mathrm{V}_{\mathrm{i}-1}^{\mathrm{k}}}{2 \Delta \mathrm{x}}
$$




$$
\frac{\partial \mathrm{V}}{\partial \mathrm{t}} \approx \frac{\mathrm{V}_{\mathrm{i}}^{\mathrm{k}+1}-\left\lfloor\alpha \mathrm{V}_{\mathrm{i}}^{\mathrm{k}}+(1-\alpha)\left(\mathrm{V}_{\mathrm{i}+1}^{\mathrm{k}}+\mathrm{V}_{\mathrm{i}-1}^{\mathrm{k}}\right) / 2\right\rfloor}{\Delta \mathrm{t}}
$$

em que $0 \leq \alpha \leq 1$ é um parâmetro de ponderação chamado fator de relaxação. Substituindo estas aproximações na equação da continuidade, equação(2.9), e na equação da quantidade de movimento, equação(2.21), tem-se:

$$
\begin{aligned}
& y_{i}^{k+1}=\alpha y_{i}^{k}+\frac{(1-\alpha)\left(y_{i+1}^{k}+y_{i-1}^{k}\right)}{2}-\frac{\Delta t}{2 \Delta x}\left[V_{i}^{k}\left(y_{i+1}^{k}-y_{i-1}^{k}\right)+\left(\frac{A}{B}\right)_{i}^{k}\left(V_{i+1}^{k}-V_{i-1}^{k}\right)\right] \\
& V_{i}^{k+1}=\alpha V_{i}^{k}+\frac{(1-\alpha)\left(V_{i+1}^{k}+V_{i-1}^{k}\right)}{2}-\frac{\Delta t}{2 \Delta x}\left[V_{i}^{k}\left(V_{i+1}^{k}-V_{i-1}^{k}\right)+g\left(y_{i+1}^{k}-y_{i-1}^{k}\right)\right]+g\left(S o-S f_{i}^{k}\right) \Delta t
\end{aligned}
$$

Estas duas equações, são aplicadas para produzir os valores das variáveis dependentes somente nos nós interiores, sendo que os nós de fronteira são dependentes das condições de contorno de extremidades do canal.

Para que haja estabilidade numérica de um esquema explícito, o intervalo de tempo $\Delta \mathrm{t}$ deve ser limitado pelo critério de Courant [ DOOGE (1986); GRIJSEN (1986); GUANARATNAM (1970); e outros]. Portanto a seguinte desigualdade deve ser verificada:

$$
\Delta \mathrm{t} \leq \frac{\Delta \mathrm{x}}{(|\mathrm{V} \pm \mathrm{c}|) \max }
$$

onde:

$\mathrm{V}=\mathrm{V}(\mathrm{x}, \mathrm{t})$ é a velocidade média do escoamento

$\mathrm{c}=\mathrm{c}(\mathrm{x}, \mathrm{t})$ é a celeridade da onda de pequena amplitude, definida como $\sqrt{\mathrm{gh}}$, sendo $\mathrm{h}=\mathrm{h}(\mathrm{x}, \mathrm{t})$ a profundidade média

$(|\mathrm{V} \pm \mathrm{c}|)$ max é o maior valor absoluto previsto para a velocidade absoluta da onda

GUANARATNAM (1970), demonstrou que o critério de Courant não é uma condição suficiente para garantir a estabilidade de um esquema explícito. Apresentou como uma condição suficiente, em adição ao critério citado, a seguinte desigualdade 
$\Delta \mathrm{t} \leq \frac{\sqrt{\left(1+2\left|\frac{\mathrm{V}}{\mathrm{c}}\right|\right)}-1}{\left|\frac{\mathrm{V}}{\mathrm{c}}\right| \frac{\mathrm{gSo}}{\mathrm{V}}}$

Em relação à convergência dos esquemas explícitos, um fator limitante é o número de seções por comprimento de onda simulada L / $\Delta x$ (TUCCI, 1980). O referido autor afirma que esta relação deve ser pelo menos igual a 10, para que se obtenha uma precisão razoável.

A vantagem dos esquemas explícitos é a facilidade de formulação e programação computacional. Entretanto uma grande desvantagem do método é a limitação do intervalo de tempo $\Delta \mathrm{t}$, em decorrência da condição de estabilidade ou condição de Courant.

\subsection{Esquemas Diretos Implícitos}

Dada a limitação em $\Delta t$ imposta aos esquemas explícitos, e considerando o avanço da tecnologia computacional, surge como solução os esquemas implícitos de diferenças finitas.

Os esquemas implícitos (QUEIROZ, 1991), utilizam informações no tempo atual (k) e no tempo seguinte $(k+1)$, em diferentes seções, para o cálculo da variável na seção (i) no tempo seguinte, o que também pode ser visualizado através da FIGURA 11. Estes esquemas avaliam a derivada com relação ao espaço, no tempo $(k+1)$. Diferenciam-se entre si, pela formulação das equações algébricas resultantes (linear ou não linear), assim como pelo número de pontos de uma malha retangular.

AMEIN \& CHU (1975) comentam que o desenvolvimento dos esquemas implícitos tem sido estimulado pela necessidade prática de uso de grandes intervalos de tempo.

Existem diversos esquemas implícitos de comprovada eficácia. Um destes esquemas mais utilizados, segundo (PORTO, 1999), para a análise do escoamento não permanente com superfície livre é o esquema de Preissmann, apresentado por LIGGET \& CUNGE (1975).

Este esquema parte de uma função $\mathrm{f}(\mathrm{x}, \mathrm{t})$ contínua e derivável, como a velocidade média V ou a altura d'água y. Esta função e suas derivadas são aproximadas, incorrendo-se 
em um erro de truncamento, segundo o esquema mostrado pela FIGURA 12, por diferenças finitas, na forma:

$$
\begin{aligned}
& \mathrm{f}(\mathrm{x}, \mathrm{t}) \approx \theta\left[\phi \mathrm{f}_{\mathrm{i}+1}^{\mathrm{k}+1}+(1-\phi) \mathrm{f}_{\mathrm{i}}^{\mathrm{k}+1}\right]+(1-\theta)\left[\phi \mathrm{f}_{\mathrm{i}+1}^{\mathrm{k}}+(1-\phi) \mathrm{f}_{\mathrm{i}}^{\mathrm{k}}\right] \\
& \frac{\partial \mathrm{f}}{\partial \mathrm{x}} \approx \frac{1}{\Delta \mathrm{x}}\left[\theta\left(\mathrm{f}_{\mathrm{i}+1}^{\mathrm{k}+1}-\mathrm{f}_{\mathrm{i}}^{\mathrm{k}+1}\right)+(1-\theta)\left(\mathrm{f}_{\mathrm{i}+1}^{\mathrm{k}}-\mathrm{f}_{\mathrm{i}}^{\mathrm{k}}\right)\right] \\
& \frac{\partial \mathrm{f}}{\partial \mathrm{t}} \approx \frac{1}{\Delta \mathrm{t}}\left[\phi\left(\mathrm{f}_{\mathrm{i}+1}^{\mathrm{k}+1}-\mathrm{f}_{\mathrm{i}+1}^{\mathrm{k}}\right)+(1-\phi)\left(\mathrm{f}_{\mathrm{i}}^{\mathrm{k}+1}-\mathrm{f}_{\mathrm{i}}^{\mathrm{k}}\right)\right]
\end{aligned}
$$

em que $\theta$ e $\phi$ são fatores de ponderação no tempo e no espaço, respectivamente, assumindo valores entre 0 e 1 .

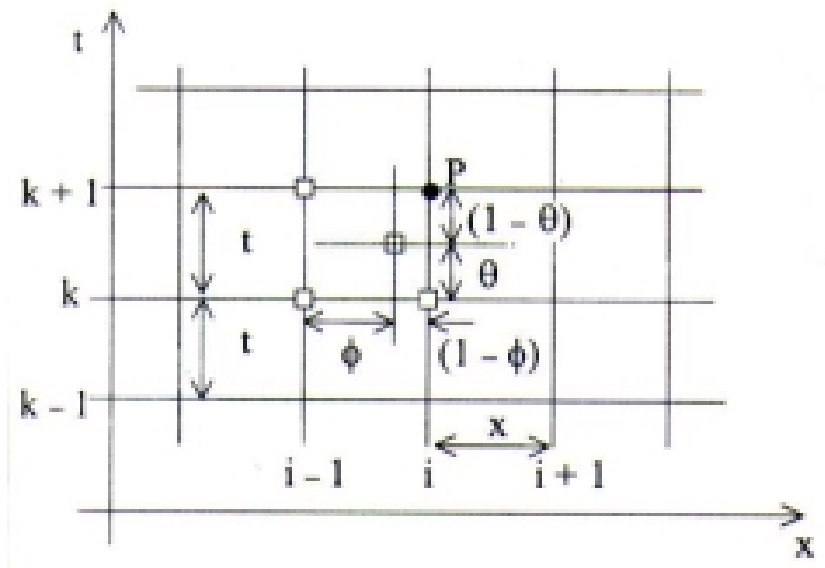

FIGURA 12 - Esquema de Diferenças Finitas

para $\phi=0,5$, as equações (2.47) constituem o esquema clássico de Preissmann, o que resulta em:

- $\operatorname{se} \theta=0$, o esquema é completamente explícito;

- se $\theta=1$, o esquema é completamente implícito;

- se $\theta=0,5$, o esquema é implícito centrado a quatro pontos.

Para assegurar que o esquema seja numericamente preciso e estável, recomenda-se usar um valor do coeficiente de ponderação $0,55 \leq \theta \leq 1$. 
A substituição das aproximações dadas pelas equações (2.47) nas equações completas de Saint-Venant, é contemplada no objeto desta pesquisa e, para tanto, deverá ser demonstrada posteriormente e oportunamente na abordagem específica dos casos estudados.

HROMADKA II et al (1985) propôs um esquema implícito de quatro pontos, progressivo, aplicado ao modelo dinâmico, onde as equações completas de Saint-Venant são discretizadas, resultando em equações algébricas lineares que são resolvidas pelo método de dupla varredura.

Em suma, os esquemas implícitos, aplicados convenientemente a casos específicos, permitem avaliar com precisão e rapidez os dados obtidos, como solução de inúmeros problemas práticos e, por hora, complexos. 


\section{MATERIAIS E MÉTODOS}

Para a aplicação do modelo computacional nos casos abordados por esta pesquisa, lançou-se mão de um caso simples para testar o modelo. Trata-se de uma simplificação realizada a partir de um caso real (estuário do Rio Cocó, situado em Fortaleza-CE) estudado em paralelo. Consiste de um canal com geometria retangular, simplificando a geometria característica do estuário, onde o escoamento é influenciado pelas condições de maré à jusante e o seu hidrograma de cheia à montante, que são as condições de contorno do problema.

$\mathrm{Na}$ seqüência portanto, é apresentado primeiramente os procedimentos realizados para teste do modelo computacional e, posteriormente, a aplicação deste, com as devidas adequações, aos dois casos previstos: Canal da Usina Monjolinho e Canal do Trabalhador.

\section{- Teste do Modelo Computacional}

Para a implementação do modelo computacional foi utilizado linguagem FORTRAN 6.1 na versão VISUAL, com dados de entrada e saída em arquivos texto. A escolha da linguagem deve-se ao amplo conhecimento da mesma no meio acadêmico, possuindo várias sub-rotinas prontas para aplicação, somando-se ainda o aspecto da velocidade de processamento, por se tratar de uma linguagem compilada. Além disso, permite trabalhar em interface com outras linguagens, como $\mathrm{C}^{++}$por exemplo. A versão VISUAL proporciona ainda a opção de elaborar gráficos a partir dos comandos de programação, o que representava uma desvantagem do FORTRAN em relação à outras linguagens

Analisando a eficiência do modelo para a resolução do sistema de equações lineares, através da coerência dos dados de saída produzidos na simulação de teste, passou-se à sua aplicação aos dois casos reais previstos por esta pesquisa, com adequações convenientes nas rotinas implementadas. Cabe ressaltar que neste caso não há validação do modelo, uma vez que não houve comparação com dados reais ou experimentais.

A seguir são apresentados o desenvolvimento do modelo matemático, o esquema de aproximação numérica utilizado, a discretização geral das equações e as simplificações cabíveis para caso particular, além da descrição do modelo computacional para este teste. 


\section{Desenvolvimento do Modelo Matemático}

\section{- $\quad$ equações governantes}

(1) Continuidade:

$A \frac{\partial V}{\partial x}+V \frac{\partial A}{\partial x}+B \frac{\partial y}{\partial t} \pm q_{L A T}=0$

ou

$A \frac{\partial V}{\partial x}+V B \frac{\partial y}{\partial x}+B \frac{\partial y}{\partial t} \pm q_{L A T}=0$

onde

$\mathrm{A}=$ área da seção transversal $-\left(\mathrm{m}^{2}\right)$

$\mathrm{B}=$ largura da superfície livre na seção $-(\mathrm{m})$

$\frac{\partial V}{\partial x}=$ variação da velocidade média do escoamento na direção $\mathrm{x}-(\mathrm{m} / \mathrm{s})$

$\frac{\partial y}{\partial x}=$ variação da altura d'água do escoamento ao longo do canal - (m)

$\frac{\partial y}{\partial t}=$ evolução da altura d'água no tempo $-(\mathrm{m})$

$\mathrm{q}_{\mathrm{LAT}}=$ contribuição de vazão lateral $\left(\mathrm{m}^{3} / \mathrm{s} . \mathrm{m}\right)$

que dividida por B fica

$\frac{A}{B} \frac{\partial V}{\partial x}+V \frac{\partial y}{\partial x}+\frac{\partial y}{\partial t} \pm \frac{q_{L A T}}{B}=0$

reescrevendo

$\frac{\partial y}{\partial t}+V \frac{\partial y}{\partial x}+\frac{A}{B} \frac{\partial V}{\partial x} \pm \frac{q_{L A T}}{B}=0$

como

$\frac{\partial y}{\partial x}=\frac{\partial h}{\partial x}-\frac{\partial z}{\partial x} \quad$ e $\quad \frac{\partial y}{\partial t}=\frac{\partial h}{\partial t}-\frac{\partial z}{\partial t} \quad$ (ver FIGURA 5)

sendo

$\pm \frac{\partial z}{\partial x}=S_{0} \quad$ e $\quad \frac{\partial z}{\partial t}=0$

a equação geral fica 
$\frac{\partial h}{\partial t}+V \frac{\partial h}{\partial x} \pm V S_{0}+\frac{A}{B} \frac{\partial V}{\partial x} \pm \frac{q_{L A T}}{B}=0$

onde $\mathrm{S}_{0}(\mathrm{~m} / \mathrm{m})$ é a declividade de fundo do canal.

(2) Quantidade de Movimento:

$S_{f}-S_{0}+\frac{\partial y}{\partial x}+\frac{V}{g} \frac{\partial V}{\partial x}+\frac{1}{g} \frac{\partial V}{\partial t}=0$

onde

$\mathrm{S}_{\mathrm{f}}=$ declividade da linha de energia $-(\mathrm{m} / \mathrm{m})$

$\frac{\partial V}{\partial x}=$ variação da velocidade média do escoamento na direção $\mathrm{x}-(\mathrm{m} / \mathrm{s})$

$\frac{\partial V}{\partial t}=$ variação da velocidade média do escoamento ao longo do tempo $\mathrm{t}-(\mathrm{m} / \mathrm{s})$

$\mathrm{g}=$ aceleração da gravidade $-\left(\mathrm{m} / \mathrm{s}^{2}\right)$

mas

$S_{0}= \pm \frac{\partial z}{\partial x} \quad, \quad S_{f}=\frac{V^{2}}{C h^{2} R_{H}} \quad$ e $\quad \pm \frac{\partial z}{\partial x}=\frac{\partial h}{\partial x}-\frac{\partial y}{\partial x} \quad$ (ver FIGURA 5)

onde, introduzindo essas definições na equação principal, resulta

$\frac{V^{2}}{C h^{2} R_{H}}+\frac{\partial h}{\partial x}+\frac{V}{g} \frac{\partial V}{\partial x}+\frac{1}{g} \frac{\partial V}{\partial t}=0$

multiplicando toda a equação por $\mathrm{g}$

$\frac{\partial V}{\partial t}+V \frac{\partial V}{\partial x}+\frac{g}{C h^{2} R_{H}} V|V|+g \frac{\partial h}{\partial x}=0$

onde

$\mathrm{R}_{\mathrm{H}}=$ raio hidráulico médio entre seções $\left(\mathrm{R}_{\mathrm{H}}=\frac{\mathrm{Am}}{\mathrm{Pm}}\right)$

$\mathrm{Ch}=$ coeficiente de Chezzy, que depende do raio hidráulico e do coeficiente de Manning $\mathrm{n}$

( $C h=\frac{R_{H}^{1 / 6}}{n}$ ), sendo que $\mathrm{C}$ e $\mathrm{R}_{\mathrm{H}}$ são determinados para cada intervalo de tempo discreto.

- $\quad$ aproximação das equações

Um dos esquemas mais utilizados para a análise do escoamento variável em canais é o esquema implícito de diferenças finitas de Preissmann (LIGGET e CUNGE 1975), dado por 


$$
\begin{aligned}
& \frac{\partial f}{\partial t}=\frac{1}{\Delta t}\left[\phi\left(f_{i+1}^{k+1}-f_{i+1}^{k}\right)+(1-\phi)\left(f_{i}^{k+1}-f_{i}^{k}\right)\right] \\
& \frac{\partial f}{\partial x}=\frac{1}{\Delta x}\left[\theta\left(f_{i+1}^{k+1}-f_{i}^{k+1}\right)+(1-\theta)\left(f_{i+1}^{k}-f_{i}^{k}\right)\right]
\end{aligned}
$$

sendo $\phi$ e $\theta$ fatores de ponderação onde, para $\phi=0,5$ e $\theta=1$ tem-se o esquema completamente implícito de Preissmann apresentado como segue

$$
\frac{\partial f}{\partial t}=\frac{1}{2}\left[\frac{\left(f_{i+1}^{k+1}-f_{i+1}^{k}\right)}{\Delta t}+\frac{\left(f_{i}^{k+1}-f_{i}^{k}\right)}{\Delta t}\right] \quad \text { e } \quad \frac{\partial f}{\partial x}=\frac{f_{i+1}^{k+1}-f_{i}^{k+1}}{\Delta x}
$$

onde o valor médio da variável f é calculado por

$$
\bar{f}=\frac{f_{i+1}^{k}+f_{i}^{k}}{2}
$$

sendo i a representação das seções, $\mathrm{k}$ o tempo de cálculo e $\mathrm{f}$ o valor representativo de qualquer variável do problema que, para o caso em questão, é dado por $\mathrm{V}(\mathrm{m} / \mathrm{s})$ e h $(\mathrm{m})$.

\section{- $\quad$ discretização das equações}

(1) Continuidade:

Substituindo o esquema de aproximação na equação (3.6) tem-se

$$
\frac{1}{2}\left[\frac{h_{i+1}^{k+1}-h_{i+1}^{k}}{\Delta t}+\frac{h_{i}^{k+1}-h_{i}^{k}}{\Delta t}\right]+\bar{V}\left[\frac{h_{i+1}^{k+1}-h_{i}^{k+1}}{\Delta x}\right] \pm \bar{V} S_{0}+\frac{\bar{A}}{\bar{B}}\left[\frac{V_{i+1}^{k+1}-V_{i}^{k+1}}{\Delta x}\right] \pm \frac{q_{L A T}}{B}=0
$$

sendo as variáveis que caracterizam a média linearizadas no tempo k, em que as condições do escoamento são supostamente conhecidas. Multiplicando toda equação por $2 \Delta t$

$$
\begin{aligned}
& h_{i+1}^{k+1}-h_{i+1}^{k}+h_{i}^{k+1}-h_{i}^{k}+\frac{2 \Delta t}{\Delta x} \bar{V}\left(h_{i+1}^{k+1}-h_{i}^{k+1}\right) \pm 2 \Delta t \bar{V} S_{0}+\frac{2 \Delta t}{\Delta x} \frac{\bar{A}}{B}\left(V_{i+1}^{k+1}-V_{i}^{k+1}\right) \pm \frac{2 \Delta t q_{L A T}}{B}=0 \\
& \text { fazendo } \frac{2 \Delta t}{\Delta x}=\alpha \\
& h_{i+1}^{k+1}-h_{i+1}^{k}+h_{i}^{k+1}-h_{i}^{k}+\alpha \bar{V}\left(h_{i+1}^{k+1}-h_{i}^{k+1}\right) \pm 2 \Delta t \bar{V} S_{0}+\alpha \frac{\bar{A}}{\bar{B}}\left(V_{i+1}^{k+1}-V_{i}^{k+1}\right) \pm \frac{2 \Delta t q_{L A T}}{B}=0
\end{aligned}
$$

rearranjando em função de k e k+1 


$$
h_{i+1}^{k+1}+h_{i}^{k+1}+\alpha \bar{V} h_{i+1}^{k+1}-\alpha \bar{V} h_{i}^{k+1}+\alpha \frac{\bar{A}}{\bar{B}} V_{i+1}^{k+1}-\alpha \frac{\bar{A}}{\bar{B}} V_{i}^{k+1}=h_{i}^{k}+h_{i+1}^{k} \pm 2 \Delta t \bar{V} S_{0} \pm \frac{2 \Delta t q_{L A T}}{B}
$$

como

$$
\overline{\mathrm{h}}=\frac{\mathrm{h}_{\mathrm{i}+1}^{\mathrm{k}}+\mathrm{h}_{\mathrm{i}}^{\mathrm{k}}}{2} \text {, então } h_{i+1}^{k}+h_{i}^{k}=2 \bar{h}
$$

substituindo e rearranjando

$$
-\alpha \frac{\bar{A}}{\bar{B}} V_{i}^{k+1}+(1-\alpha \bar{V}) h_{i}^{k+1}+\alpha \frac{\bar{A}}{\bar{B}} V_{i+1}^{k+1}+(1+\alpha \bar{V}) h_{i+1}^{k+1}=2 \bar{h} \pm 2 \Delta t \bar{V} S_{0} \pm \frac{2 \Delta t q_{L A T}}{B}
$$

denominando

$$
A_{J}=-\alpha \frac{\bar{A}}{\bar{B}} ; \quad B_{J}=(1-\alpha \bar{V}) ; \quad C_{J}=\alpha \frac{\bar{A}}{\bar{B}} ; \quad D_{J}=(1+\alpha \bar{V}) \quad \mathrm{e}
$$

$E_{J}=2 \bar{h} \pm 2 \Delta t \bar{V} S_{0}+\frac{2 \Delta t q_{L A T}}{B} \quad$ (para entrada de vazão lateral)

$E_{J}=2 \bar{h} \pm 2 \Delta t \bar{V} S_{0}-\frac{2 \Delta t q_{L A T}}{B} \quad$ (para saída de vazão lateral)

se não ocorre entrada e saída de vazão lateral, o termo $E_{J}$ fica

$$
E_{J}=2 \bar{h} \pm 2 \Delta t \bar{V} S_{0}
$$

$\mathrm{ou}$

$$
E_{J}=E_{J 1} \pm E_{J 2}
$$

sendo

$\mathrm{E}_{\mathrm{J} 2}=$ positivo (canal em aclive)

$\mathrm{E}_{\mathrm{J} 2}=$ negativo (canal em declive)

Considerando neste caso a hipótese de canal horizontal e ainda retangular, tem-se

$$
E_{J}=2 \bar{h} \quad \mathrm{com} \quad \begin{aligned}
& A_{J}=-\alpha \bar{h} \\
& C_{J}=+\alpha \bar{h}
\end{aligned}
$$

A equação discretizada da continuidade é da forma

$$
A_{J} V_{i}^{k+1}+B_{J} h_{i}^{k+1}+C_{J} V_{i+1}^{k+1}+D_{J} h_{i+1}^{k+1}=E_{J}
$$

(2) Quantidade de Movimento:

Substituindo o esquema de aproximação na equação (3.10) fica 


$$
\frac{1}{2}\left[\frac{V_{i+1}^{k+1}-V_{i+1}^{k}}{\Delta t}+\frac{V_{i}^{k+1}-V_{i}^{k}}{\Delta t}\right]+\bar{V}\left[\frac{V_{i+1}^{k+1}-V_{i}^{k+1}}{\Delta x}\right]+\frac{g}{C h^{2}}\left[\frac{V_{i+1}^{k+1}+V_{i}^{k+1}}{2}\right] \frac{|\vec{V}|}{R_{H}}+g\left[\frac{h_{i+1}^{k+1}-h_{i}^{k+1}}{\Delta x}\right]=0
$$

sendo as variáveis que caracterizam a média linearizadas no tempo k, em que as condições do escoamento são supostamente conhecidas. Multiplicando toda equação por $2 \Delta t$

$$
V_{i+1}^{k+1}-V_{i+1}^{k}+V_{i}^{k+1}-V_{i}^{k}+\frac{2 \Delta t}{\Delta x} \bar{V}\left(V_{i+1}^{k+1}-V_{i}^{k+1}\right)+\frac{g \Delta t|\vec{V}|}{C h^{2} R_{H}} V_{i}^{k+1}+\frac{g \Delta t|\vec{V}|}{C h^{2} R_{H}} V_{i+1}^{k+1}+\frac{2 \Delta t}{\Delta x} g\left(h_{i+1}^{k+1}-h_{i}^{k+1}\right)=0
$$

da equação (3.16), $\frac{2 \Delta t}{\Delta x}=\alpha$

$V_{i+1}^{k+1}-V_{i+1}^{k}+V_{i}^{k+1}-V_{i}^{k}+\alpha \bar{V}\left(V_{i+1}^{k+1}-V_{i}^{k+1}\right)+\frac{g \Delta t|\bar{V}|}{C h^{2} R_{H}} V_{i}^{k+1}+\frac{g \Delta t|\bar{V}|}{C h^{2} R_{H}} V_{i+1}^{k+1}+\alpha g\left(h_{i+1}^{k+1}-h_{i}^{k+1}\right)=0$

rearranjando em função de k e k+1

$V_{i+1}^{k+1}+V_{i}^{k+1}+\alpha \bar{V}\left(V_{i+1}^{k+1}-V_{i}^{k+1}\right)+\frac{g \Delta t|\bar{V}|}{C h^{2} R_{H}} V_{i}^{k+1}+\frac{g \Delta t|\bar{V}|}{C h^{2} R_{H}} V_{i+1}^{k+1}+\alpha g\left(h_{i+1}^{k+1}-h_{i}^{k+1}\right)=V_{i}^{k}+V_{i+1}^{k}$

como

$\bar{V}=\frac{V_{i+1}^{k}+V_{i}^{k}}{2}$, então $V_{i+1}^{k}+V_{i}^{k}=2 \bar{V}$, e portanto

$V_{i+1}^{k+1}+V_{i}^{k+1}+\alpha \bar{V} V_{i+1}^{k+1}-\alpha \bar{V} V_{i}^{k+1}+\frac{g \Delta t|\bar{V}|}{C h^{2} R_{H}} V_{i}^{k+1}+\frac{g \Delta t|\bar{V}|}{C h^{2} R_{H}} V_{i+1}^{k+1}+\alpha g h_{i+1}^{k+1}-\alpha g h_{i}^{k+1}=2 \bar{V}$

assim a equação discretizada fica

$$
\left(1-\alpha \bar{V}+\frac{g \Delta t|\bar{V}|}{C h^{2} R_{H}}\right) V_{i}^{k+1}-\alpha g h_{i}^{k+1}+\left(1+\alpha \bar{V}+\frac{g \Delta t|\bar{V}|}{C h^{2} R_{H}}\right) V_{i+1}^{k+1}+\alpha g h_{i+1}^{k+1}=2 \bar{V}
$$

chamando

$$
A_{J L}=\left(1-\alpha \bar{V}+\frac{g \Delta t|\bar{V}|}{C h^{2} R_{H}}\right) ; \quad B_{J L}=-\alpha g ; \quad C_{J L}=\left(1+\alpha \bar{V}+\frac{g \Delta t|\bar{V}|}{C h^{2} R_{H}}\right) ; \quad D_{J L}=\alpha g
$$

e $\quad E_{J L}=2 \bar{V}$ 
A equação discretizada é da forma

$$
A_{J L} V_{i}^{k+1}+B_{J L} h_{i}^{k+1}+C_{J L} V_{i+1}^{k+1}+D_{J L} h_{i+1}^{k+1}=E_{J L}
$$

\section{Aplicação do Método de Solução para o Caso-Teste}

Para um melhor entendimento do método de solução, preferiu-se apresentá-lo dentro da abordagem do exemplo em teste, facilitando sua generalização na ampliação do presente estudo, o que deve ser feito basicamente pela adaptação das características geométricas, das particularidades das seções discretas bem como das condições de contorno do problema em pauta.

Portanto, o caso aqui estudado, como citado anteriormente, consiste de um canal retangular que desemboca no mar, com um número discreto de seções $\mathrm{N}_{\mathrm{Z}}=5$ seções, enumeradas de jusante para montante, tendo as mesmas uma largura $\mathrm{Bi}=20 \mathrm{~m}$, sendo a extensão do canal $1=2000 \mathrm{~m}$. As condições de contorno do problema são o hidrograma de entrada a montante, e a equação da maré a jusante. Na FIGURA 13 é apresentado o esquema do caso em estudo

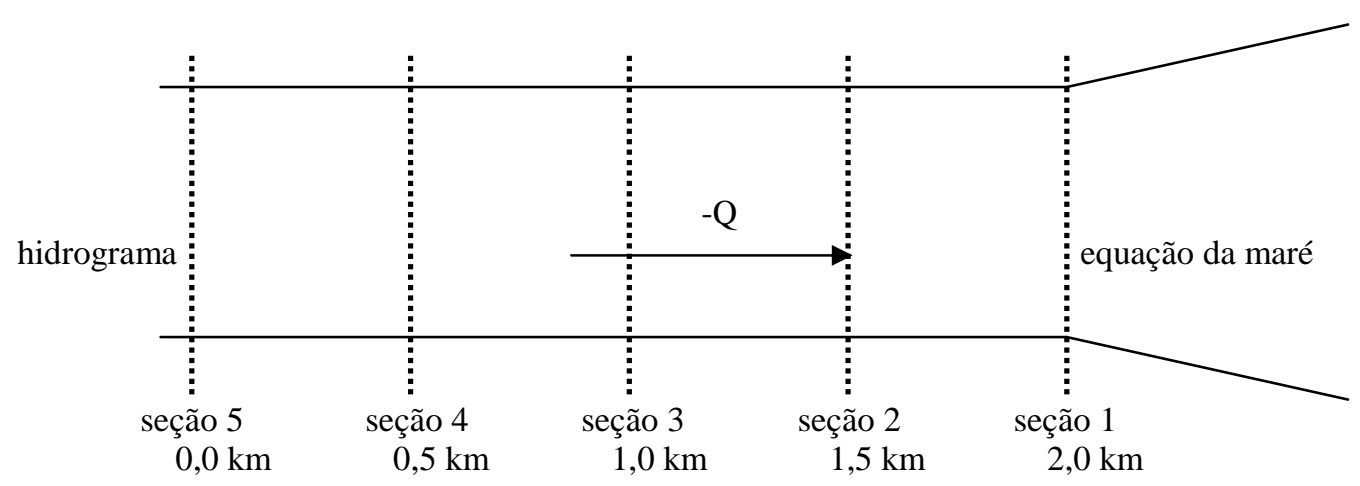

FIGURA 13 - Esquema do Caso Estudado para Teste do Modelo

Pelas equações matemáticas discretizadas anteriormente, tem-se o seguinte sistema: 


$$
\begin{aligned}
& A_{J 1} V_{1}^{2}+B_{J 1} h_{1}^{2}+C_{J 1} V_{2}^{2}+D_{J 1} h_{2}^{2}=E_{J 1} \\
& A_{J L 1} V_{1}^{2}+B_{J L 1} h_{1}^{2}+C_{J L 1} V_{2}^{2}+D_{J L 1} h_{2}^{2}=E_{J L 1} \\
& A_{J 2} V_{2}^{3}+B_{J 2} h_{2}^{3}+C_{J 2} V_{3}^{3}+D_{J 2} h_{3}^{3}=E_{J 2} \\
& A_{J L 2} V_{2}^{3}+B_{J L 2} h_{2}^{3}+C_{J L 2} V_{3}^{3}+D_{J L 2} h_{3}^{3}=E_{J L 2} \\
& A_{J 3} V_{3}^{4}+B_{J 3} h_{3}^{4}+C_{J 3} V_{4}^{4}+D_{J 3} h_{4}^{4}=E_{J 3} \\
& A_{J L 3} V_{3}^{4}+B_{J L 3} h_{3}^{4}+C_{J L 3} V_{4}^{4}+D_{J L 3} h_{4}^{4}=E_{J L 3} \\
& A_{J 4} V_{4}^{5}+B_{J 4} h_{4}^{5}+C_{J 4} V_{5}^{5}+D_{J 4} h_{5}^{5}=E_{J 4} \\
& A_{J L 4} V_{4}^{5}+B_{J L 4} h_{4}^{5}+C_{J L 4} V_{5}^{5}+D_{J L 4} h_{5}^{5}=E_{J L 4}
\end{aligned}
$$

onde os índices sobrescritos de $\mathrm{V}$ e h representam o tempo do cálculo, e os índices subscritos as seções consideradas no mesmo.Os valores de A,B,C,D e E são determinados pelas expressões desenvolvidas anteriormente em caráter explícito. Desta forma pode-se concluir que, para $\mathrm{N}_{\mathrm{Z}}=\mathrm{n}$ seções, o sistema é constituído por 2.(n-1)=equações e 2.n = incógntas ,o que representa neste caso um número de 8 equações e 10 incógnitas. Desta maneira, são necessárias mais duas equações para possibilitar a resolução do sistema, que são exatamente os contornos do problema. Introduzindo os contornos ao sistema, este fica

$$
\begin{aligned}
& h_{1}=F_{1} \\
& A_{J 1} V_{1}^{2}+B_{J 1} h_{1}^{2}+C_{J 1} V_{2}^{2}+D_{J 1} h_{2}^{2}=E_{J 1} \\
& A_{J L 1} V_{1}^{2}+B_{J L 1} h_{1}^{2}+C_{J L 1} V_{2}^{2}+D_{J L 1} h_{2}^{2}=E_{J L 1} \\
& A_{J 2} V_{2}^{3}+B_{J 2} h_{2}^{3}+C_{J 2} V_{3}^{3}+D_{J 2} h_{3}^{3}=E_{J 2} \\
& A_{J L 2} V_{2}^{3}+B_{J L 2} h_{2}^{3}+C_{J L 2} V_{3}^{3}+D_{J L 2} h_{3}^{3}=E_{J L 2} \\
& A_{J 3} V_{3}^{4}+B_{J 3} h_{3}^{4}+C_{J 3} V_{4}^{4}+D_{J 3} h_{4}^{4}=E_{J 3} \\
& A_{J L 3} V_{3}^{4}+B_{J L 3} h_{3}^{4}+C_{J L 3} V_{4}^{4}+D_{J L 3} h_{4}^{4}=E_{J L 3} \\
& A_{J 4} V_{4}^{5}+B_{J 4} h_{4}^{5}+C_{J 4} V_{5}^{5}+D_{J 4} h_{5}^{5}=E_{J 4} \\
& A_{J L 4} V_{4}^{5}+B_{J L 4} h_{4}^{5}+C_{J L 4} V_{5}^{5}+D_{J L 4} h_{5}^{5}=E_{J L 4} \\
& V_{5}=F_{5}
\end{aligned}
$$

Portanto, um sistema com 10 equações e 10 incógnitas. $\mathrm{F}_{1}=\mathrm{h}_{1}$ é obtido pela equação da maré a jusante dada por

$$
F_{1}=h_{1}=h_{\text {MARÉ }}=h_{\text {inic }}+A \operatorname{sen}\left[\left(\frac{2 \Pi}{T}\right) t\right]
$$

sendo:

$\mathrm{h}_{\text {inic }}=0,36 \mathrm{~m}=$ altura inicial da maré (quando.t=0h); 
$\mathrm{A}=1,60 \mathrm{~m}=$ amplitude da maré;

$\mathrm{T}=12 \mathrm{~h}=$ período da maré;

$\mathrm{t}=$ tempo do cálculo em horas

$\mathrm{F}_{5}=\mathrm{V}_{5}$, condição de contorno de montante, é determinado pela combinação de duas expressões. Primeiro, com a vazão lida do hidrograma de entrada para o tempo de cálculo considerado, determina-se a profundidade d'água iterativamente pela expressão de Manning dada por

$\frac{\mathrm{n} \cdot \mathrm{Q}}{\sqrt{\mathrm{S}_{0}}}=\mathrm{A} \cdot\left(\mathrm{R}_{\mathrm{H}}\right)^{2 / 3}$

como o canal é retangular, a expressão fica

$\frac{\mathrm{n} \cdot \mathrm{Q}}{\sqrt{\mathrm{S}_{0}}}=\left(\mathrm{b} \cdot \mathrm{h}_{5}\right) \cdot\left(\frac{\mathrm{b} \cdot \mathrm{h}_{5}}{\mathrm{~b}+2 \cdot \mathrm{h}_{5}}\right)^{2 / 3}$

onde

$\mathrm{n}=0,035=$ coeficiente de Manning;

So $=0,0001 \mathrm{~m} / \mathrm{m}=$ declividade de fundo do canal (quase nulo no primeiro trecho de montante);

$\mathrm{Q}=\operatorname{vazão}\left(\mathrm{m}^{3} / \mathrm{s}\right)$ lida do hidrograma de entrada;

$\mathrm{b}=\mathrm{Bi}=20 \mathrm{~m}=$ largura do canal

A determinação de $h_{5}$ se dá com a aplicação do método iterativo de Newton Raphson. Em segundo momento, de posse de $h_{5}$, determina-se $v_{5}=F_{5}$ pela expressão da continuidade como sendo

$F_{5}=V_{5}=-\frac{Q}{b \cdot h_{5}}$

Para a resolução do sistema, são dados ainda

Qi $=-1,00 \mathrm{~m}^{3} / \mathrm{s}=$ vazão inicial no canal (considerada negativa de montante para jusante);

$\mathrm{g}=9,81 \mathrm{~m} / \mathrm{s}^{2}=$ aceleração da gravidade;

$\mathrm{z}=500 \mathrm{~m}=$ espaçamento entre seções;

$\mathrm{Dt}=3600 \mathrm{~s}=$ intervalo de tempo de cálculo;

$\mathrm{Nt}=6$ = número de intervalos de tempo para cálculo 
Como a equação discreta do movimento é diretamente dependente do coeficiente de Chezzy (Ch), o mesmo é determinado por Manning de acordo com a expressão

$$
C h=\frac{1}{n} R_{H}^{1 / 6}
$$

onde n (coeficiente de Manning) e bi (largura do canal) são dados do problema, e $\mathrm{R}_{\mathrm{H}}$ (raio hidráulico) calculado explicitamente através da profundidade média $(\mathrm{hm})$ entre seções em função do tempo.

O sistema de equações supra descrito é resolvido manualmente por substituição para cada intervalo de tempo discreto, cujos resultados de $\mathrm{h}(\mathrm{x}, \mathrm{t})$ e $\mathrm{v}(\mathrm{x}, \mathrm{t})$ são comparados posteriormente com os obtidos pelo programa.

Com o propósito de implementar o modelo computacional para resolução e avaliação dos dados de saída do problema apresentado, na FIGURA 14 o sistema definido anteriormente é disposto em forma matricial.

Matriz A

$\left[\begin{array}{cccccccccc}1 & 0 & 0 & 0 & 0 & 0 & 0 & 0 & 0 & 0 \\ B_{J 1} & A_{J 1} & D_{J 1} & C_{J 1} & 0 & 0 & 0 & 0 & 0 & 0 \\ B_{J L 1} & A_{J L 1} & D_{J L 1} & C_{J L 1} & 0 & 0 & 0 & 0 & 0 & 0 \\ 0 & 0 & B_{J 2} & A_{J 2} & D_{J 2} & C_{J 2} & 0 & 0 & 0 & 0 \\ 0 & 0 & B_{J L 2} & A_{J L 2} & D_{J L 2} & C_{J L 2} & 0 & 0 & 0 & 0 \\ 0 & 0 & 0 & 0 & B_{J 3} & A_{J 3} & D_{J 3} & C_{J 3} & 0 & 0 \\ 0 & 0 & 0 & 0 & B_{J L 3} & A_{J L 3} & D_{J L 3} & C_{J L 3} & 0 & 0 \\ 0 & 0 & 0 & 0 & 0 & 0 & B_{J 4} & A_{J 4} & D_{J 4} & C_{J 4} \\ 0 & 0 & 0 & 0 & 0 & 0 & B_{J L 4} & A_{J L 4} & D_{J L 4} & C_{J L 4} \\ 0 & 0 & 0 & 0 & 0 & 0 & 0 & 0 & 0 & 1\end{array}\right] *\left[\begin{array}{c}h_{1} \\ V_{1} \\ h_{2} \\ V_{2} \\ h_{3} \\ V_{3} \\ h_{4} \\ V_{4} \\ h_{5} \\ V_{5}\end{array}\right]=\left[\begin{array}{c}F_{1} \\ E_{J 1} \\ E_{J L 1} \\ E_{J 2} \\ E_{J L 2} \\ E_{J 3} \\ E_{J L 3} \\ E_{J 4} \\ E_{J L 4} \\ F_{5}\end{array}\right]$ FIGURA 14 - Sistema da Solução Computacional

A matriz A e o vetor B são determinados explicitamente no tempo $\mathrm{K}$, e o vetor $\mathrm{U}$, que é a incógnita do problema, determinado pela resolução do sistema em caráter implícito no tempo $\mathrm{K}+1$. A resolução do sistema matricial é feita para cada intervalo de tempo estabelecido pela discretização temporal imposta para o problema. 
Como o modelo computacional está embasado na resolução do sistema apresentado na FIGURA 14, que tem dimensão variável, é apresentado na FIGURA 15 o diagrama de blocos característico do modelo.

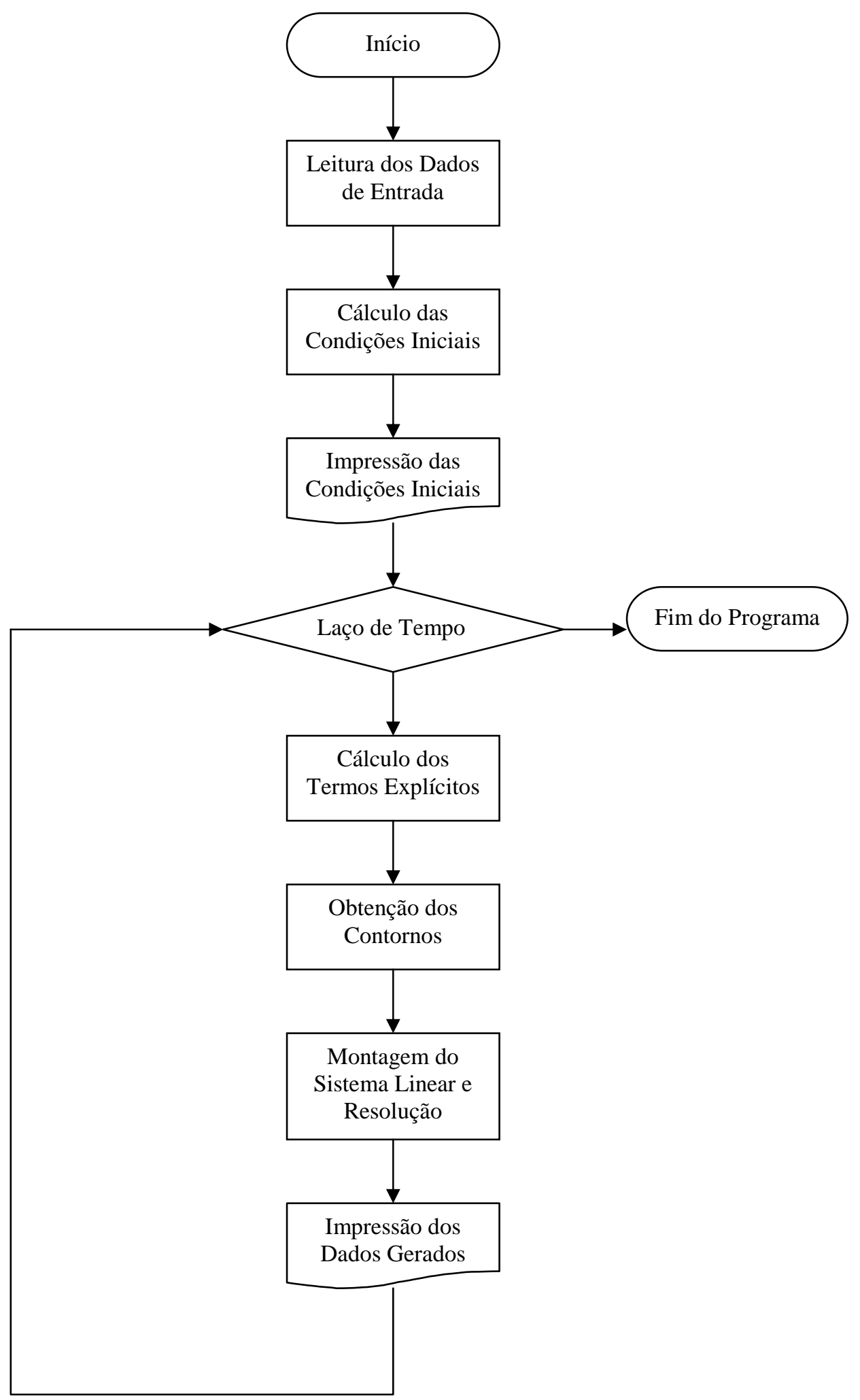




\section{Modelo Computacional}

O modelo desenvolvido em FORTRAM VISUAL é apresentado e comentado na seqüência.

\section{PROGRAM ESCOAMENTO TRANSIENTE EM CANAIS}

INTEGER cont,cont1,cont2

REAL*8 Hi,SAI,HID

REAL*8,ALLOCATABLE :: A(:),V(:),h(:),hm(:), Vm(:),Aj(:),Bj(:),

$\mathrm{Cj}(:), \operatorname{Dj}(:), \operatorname{Ej}(:), \operatorname{Ajl}(:), \operatorname{Bjl}(:), \operatorname{Cjl}(:), \operatorname{Djl}(:), \operatorname{Ejl}(:), Q(:)$,

$\operatorname{MATA}(:,:), \mathrm{B}(:), \mathrm{U}(:), \mathrm{BADC}(:,:), \mathrm{hj}(:), \mathrm{Vj}(:)$

Em primeiro momento são declaradas as variáveis e os vetores que serão utilizados no programa.Após esta etapa, são ativados os arquivos de entrada e saída de dados, sendo que o arquivo de saída será criado pelo programa.

\section{Ativando os Arquivos de Entrada e Saída \\ OPEN(1,FILE='HID.txt',STATUS='OLD') \\ OPEN(2,FILE='SAI.txt',STATUS='UNKNOWN') \\ OPEN(3,FILE='PARAM.txt',STATUS='OLD')}

os arquivos 'HID.txt' e 'PARAM.txt' são os dados do hidrograma de entrada a montante e parâmetros do problema respectivamente.

\section{Hid - Bloco de notas}

Arquivo Editar Pesquisar Ajuda

$6 \quad$ Dimensão do Arquivo Hidrograma

5., $\quad$ valor de $\mathrm{Q}(\mathrm{m} 3 / \mathrm{s})$ para $\mathrm{t}=1 \mathrm{~h}$;

7.6, valor de $\mathrm{Q}(\mathrm{m} 3 / \mathrm{s})$ para $\mathrm{t}=2 \mathrm{~h}$;

8.2, valor de $\mathrm{Q}(\mathrm{m} 3 / \mathrm{s})$ para $\mathrm{t}=3 \mathrm{~h}$;

6., $\quad$ valor de $\mathrm{Q}(\mathrm{m} 3 / \mathrm{s})$ para $\mathrm{t}=4 \mathrm{~h}$;

2.5, valor de $\mathrm{Q}(\mathrm{m} 3 / \mathrm{s})$ para $\mathrm{t}=5 \mathrm{~h}$;

1. valor de $\mathrm{Q}(\mathrm{m} 3 / \mathrm{s})$ para $\mathrm{t}=6 \mathrm{~h}$;

\begin{tabular}{|ll|}
\hline Param - Bloco de notas \\
\hline Arquivo & Editar Pesquisar Ajuda \\
\hline 9.81, & (m/s2)aceleração da gravidade \\
0.035, & coeficiente de Manning \\
0.0001, & (m/m)declividade de fundo \\
20, & (m)largura do canal \\
2000, & (m)comprimento do canal \\
1.60, & (m)amplitude da maré \\
12, & (h)período da maré \\
0.36, & (m)altura inicial da maré \\
500, & (m)espaçamento entre seções \\
3600, & (s)intervalo de tempo de cálculo \\
1, & (m3/s)vazão inicial no canal \\
5, & número de seções no canal \\
6, & número de intervalos de tempo \\
3.141592654 valor de Pi \\
\hline
\end{tabular}




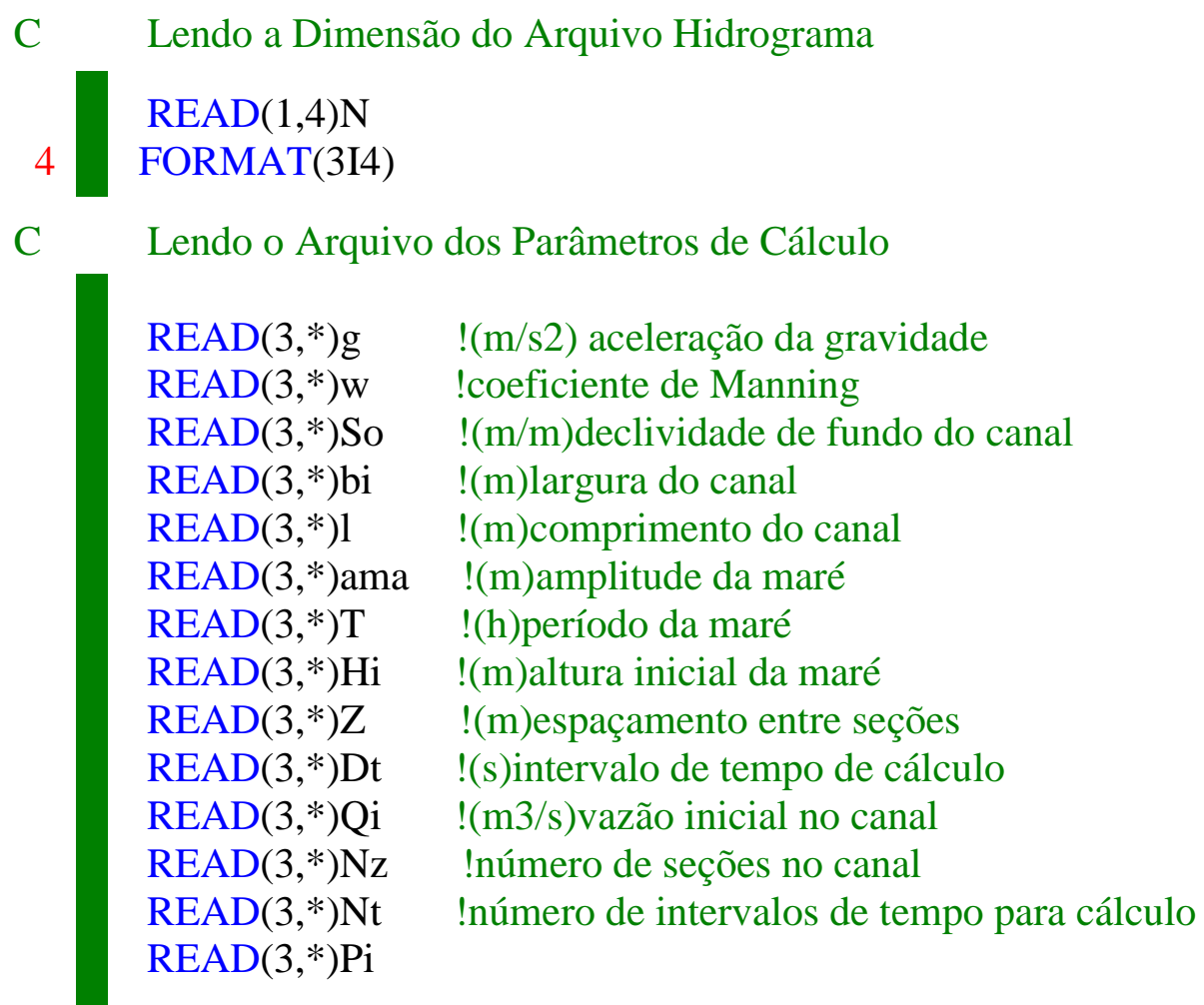

Como demonstrado, foi realizada a leitura da dimensão do arquivo 'HID.txt' e dos elementos do arquivo 'PARAM.txt'.Após este procedimento, é feita a atribuição da dimensão do sistema de matrizes e número de equações do sistema, de acordo com o número de seções discretizadas no arquivo de entrada e, então, os vetores utilizados no programa são alocados dinamicamente como demonstrado a seguir

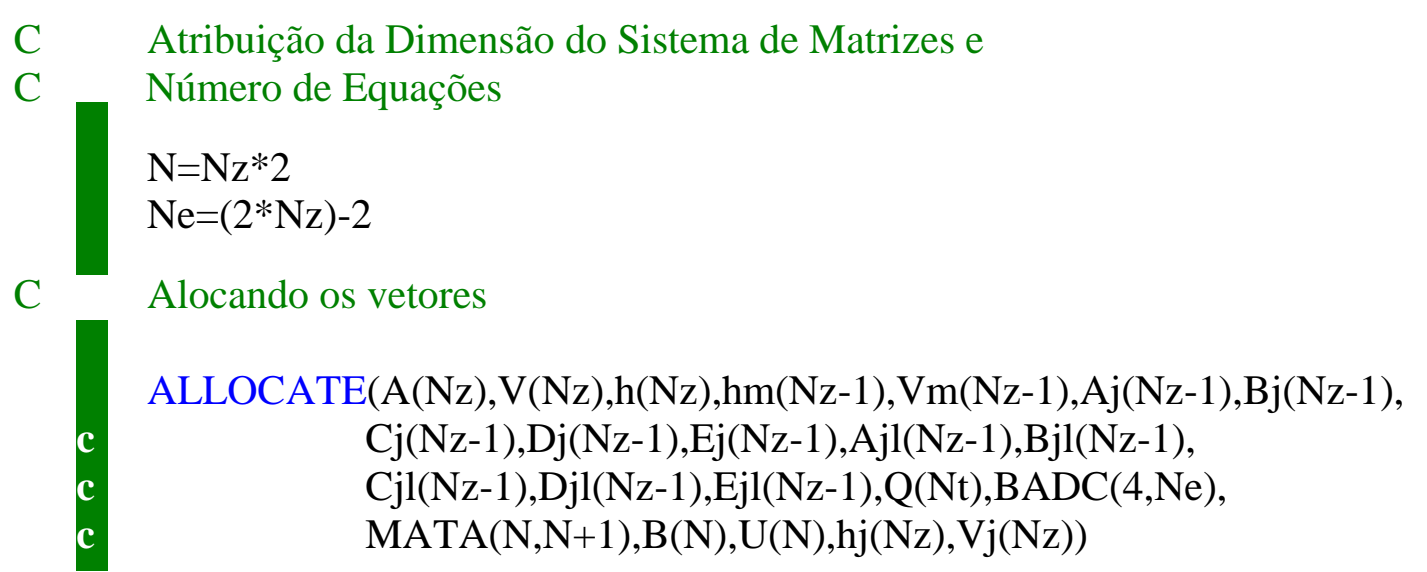

$\mathrm{Na}$ sequiência são calculadas as condições iniciais do escoamento, ou seja, $\mathrm{h}(\mathrm{m})$ e $\mathrm{V}(\mathrm{m} / \mathrm{s})$ iniciais. A rotina de Newton Raphson é utilizada para a determinação de $\mathrm{h}(\mathrm{m})$, e a velocidade $\mathrm{V}(\mathrm{m} / \mathrm{s})$ é obtida pela continuidade.Desta forma tem-se: 


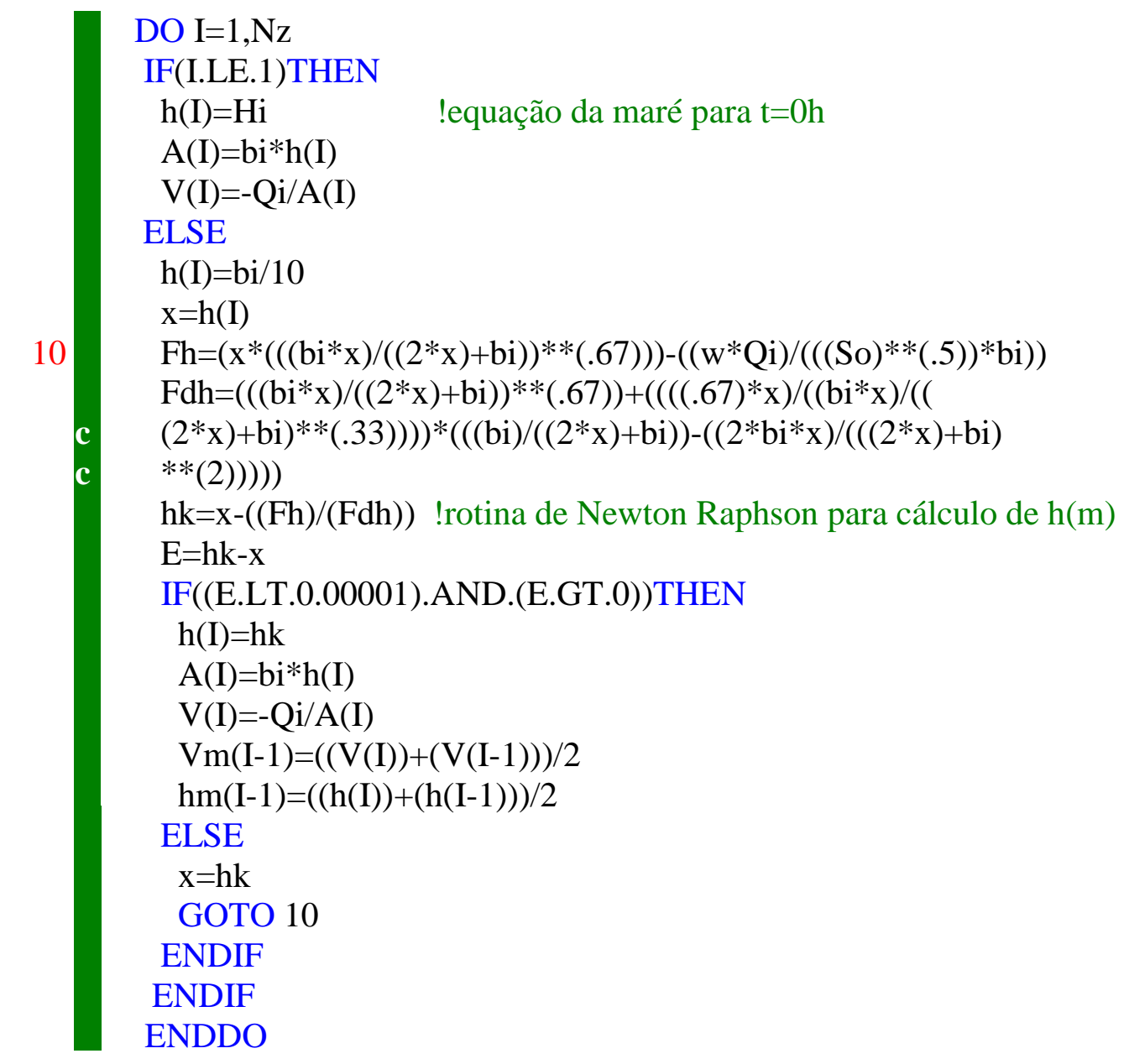

Observando que a vazão é caracterizada na expressão por um sinal negativo. Isto se dá simplesmente em função da convenção adotada inicialmente (vazão negativa de montante para jusante), ou seja, uma mudança de convenção, representaria uma resposta igual em módulo. Após o cálculo, os dados são escritos no arquivo de saída 'SAI.txt' de acordo com a rotina

C Gravando as Condições Iniciais em Arquivo

WRITE( 2 **)'MODELO UNIDIMENSIONAL P/ CÁLCULO DE TRANSIENTE HIDRÁULICO EM CANAIS RETANGULARES' WRITE $(2, *) "$ !pula uma linha WRITE( $\left(2,{ }^{*}\right)^{\prime}$ CONDIÇÕES INICIAIS DO ESCOAMENTO' WRITE( $\left(2,{ }^{*}\right) "$ !pula uma linha WRITE( $\left.2,{ }^{*}\right)^{\prime}$ ALTURA D'ÁGUA INICIAL - h(m)'

WRITE( $\left(2,{ }^{*}\right) "$ !pula uma linha DO I $=1, \mathrm{Nz}$ WRITE(2,15)I,h(I)

$15 \quad$ FORMAT('h',I1,':',F6.2) ENDDO 


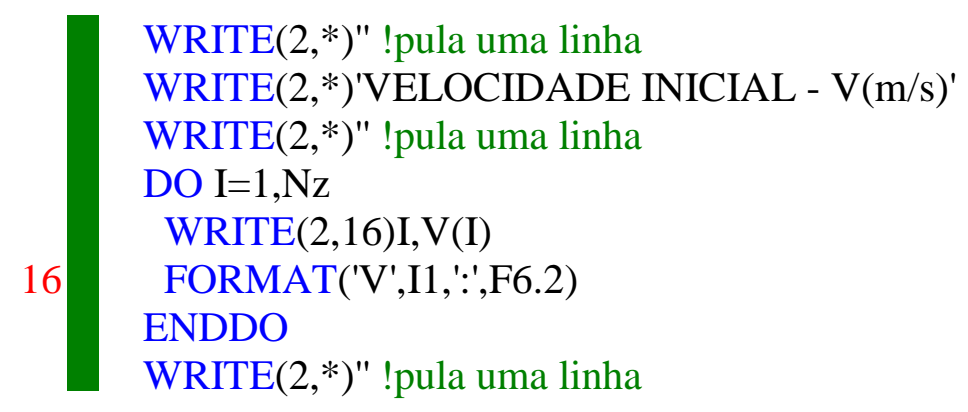

Sequencialmente é realizada a leitura do hidrograma, a partir do arquivo de entrada 'HID.txt'.

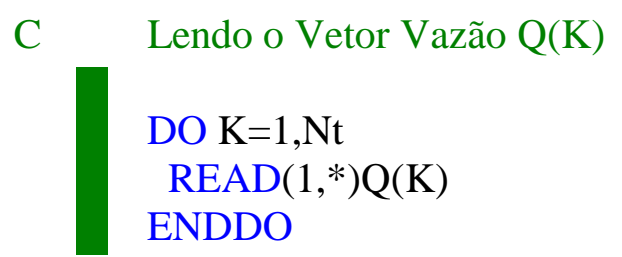

Lidos os dados de vazão, inicializa-se o cálculo dos vetores $A_{J}, B_{J}, C_{J}, D_{J}, E_{J}, A_{J L}, B_{J L}, C_{J L}$, $\mathrm{D}_{\mathrm{JL}}$ e $\mathrm{E}_{\mathrm{JL}}$, para cada intervalo de tempo, de acordo com a discretização temporal imposta na entrada e considerando os termos simplificados para hipótese de canal retangular, fundo plano e sem entrada lateral.Os procedimentos de cálculo desta parte do programa até o seu final, fazem parte de um mesmo laço DO, responsável pela variação temporal.

\section{Cálculo dos Vetores BADCE}

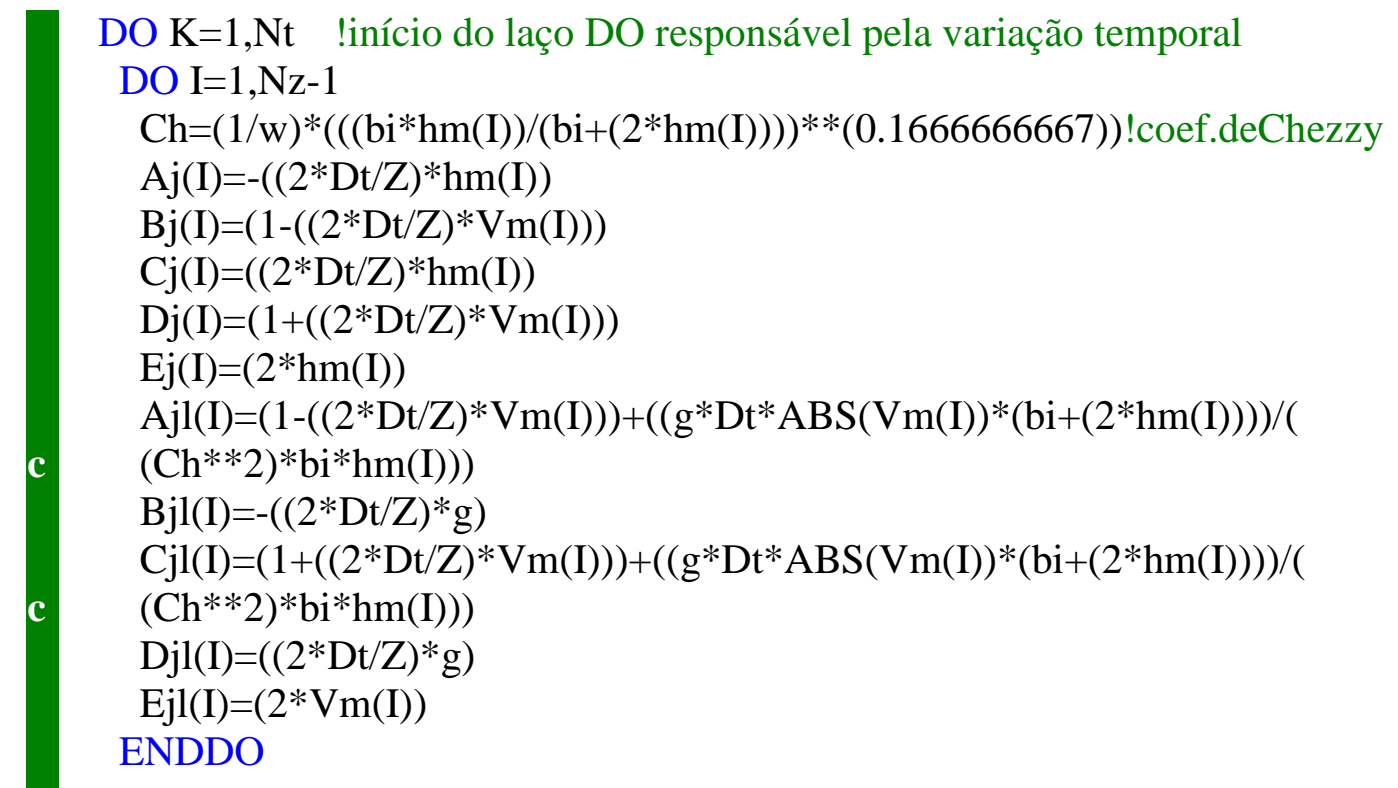

Os contornos F1 e Fn também são calculados dentro do mesmo intervalo de tempo, como segue 
C Cálculo dos Contornos F1 e Fn

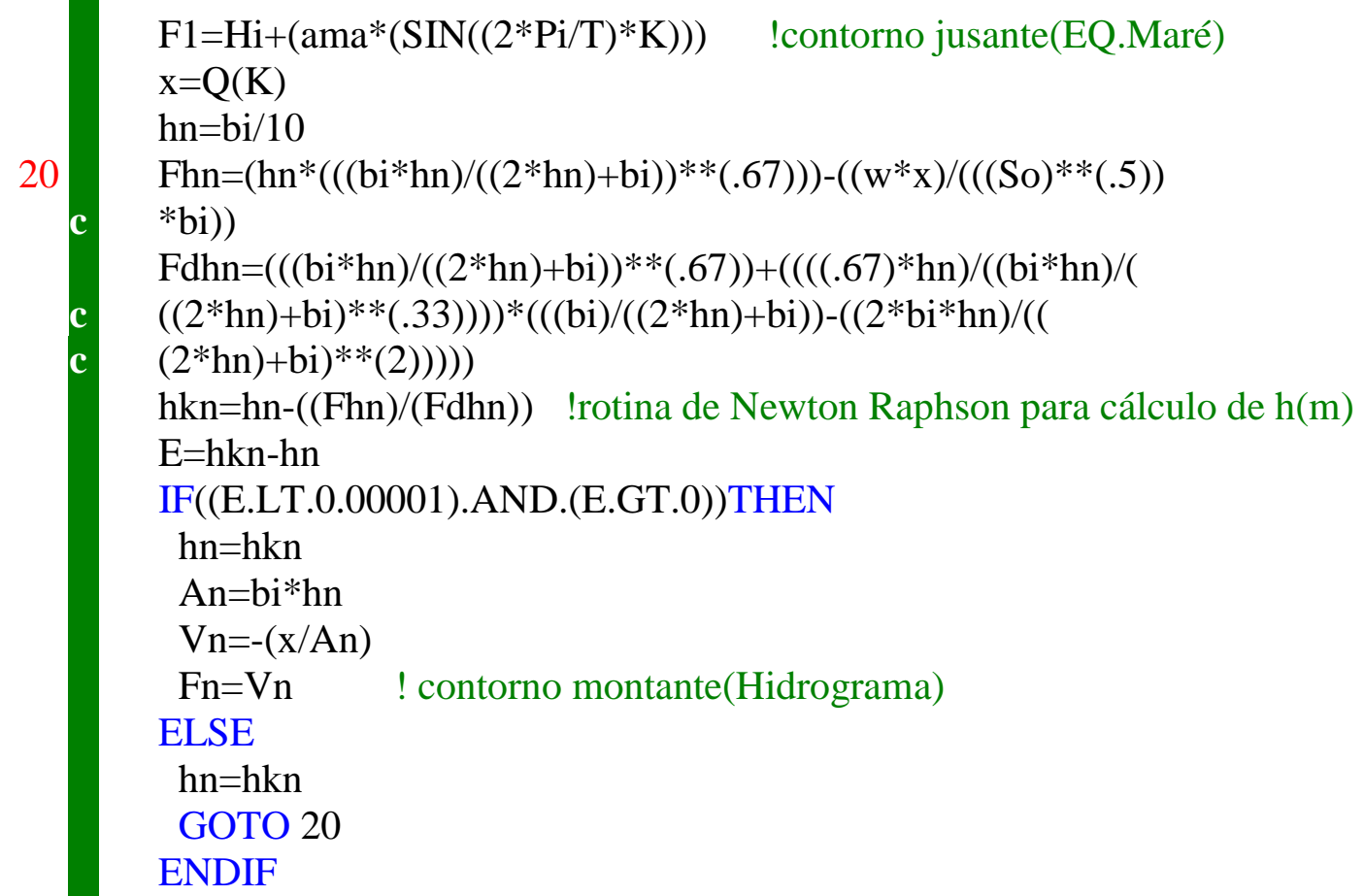

Para facilitar a alocação dos elementos da matriz A, utilizou-se uma matriz composta pelos vetores $B_{J}, B_{J L}, A_{J}, A_{J L}, D_{J}, D_{J L}, C_{J}$ e $C_{J L}$. Para tanto, a alocação destes elementos na matriz chamada de BADC, ocorreu-se da seguinte forma

\section{Alocação dos Elementos de BADC}

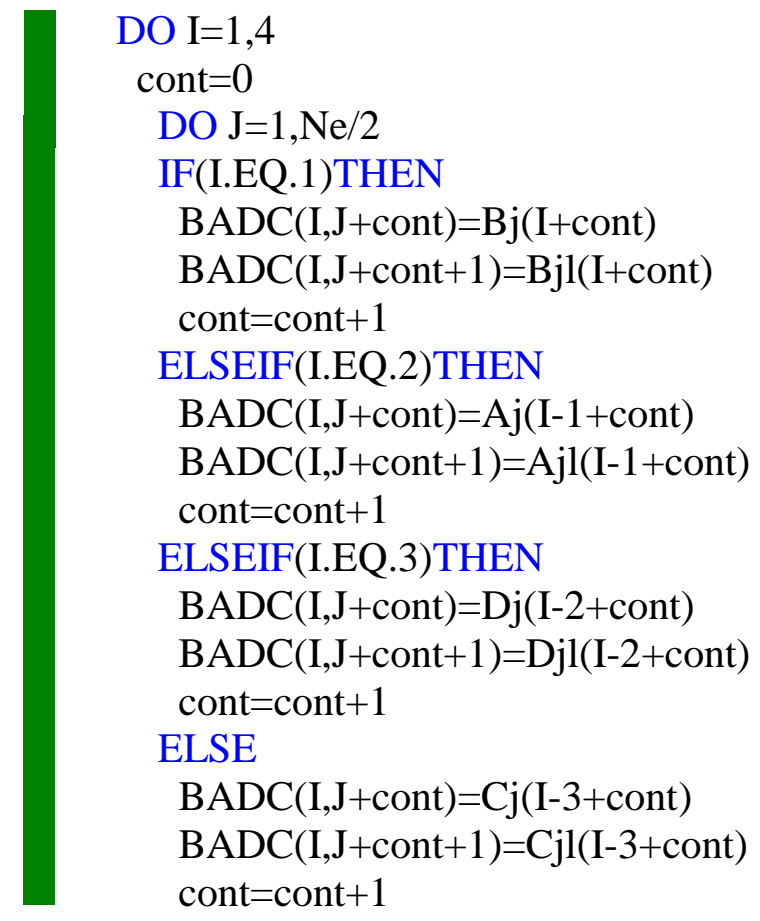




\section{ENDIF \\ ENDDO \\ ENDDO}

após este procedimento, a composição da matriz BADC fica

$$
\left[\begin{array}{llllllll}
\mathrm{B}_{\mathrm{J} 1} & \mathrm{~B}_{\mathrm{JL} 1} & \mathrm{~B}_{\mathrm{J} 2} & \mathrm{~B}_{\mathrm{JL} 2} & \mathrm{~B}_{\mathrm{J} 3} & \mathrm{~B}_{\mathrm{JL} 3} & \mathrm{~B}_{\mathrm{J} 4} & \mathrm{~B}_{\mathrm{JL} 4} \\
\mathrm{~A}_{\mathrm{J} 1} & \mathrm{~A}_{\mathrm{JL} 1} & \mathrm{~A}_{\mathrm{J} 2} & \mathrm{~A}_{\mathrm{JL} 2} & \mathrm{~A}_{\mathrm{J} 3} & \mathrm{~A}_{\mathrm{JL} 3} & \mathrm{~A}_{\mathrm{J} 4} & \mathrm{~A}_{\mathrm{JL} 4} \\
\mathrm{D}_{\mathrm{J} 1} & \mathrm{D}_{\mathrm{JL} 1} & \mathrm{D}_{\mathrm{J} 2} & \mathrm{D}_{\mathrm{JL} 2} & \mathrm{D}_{\mathrm{J} 3} & \mathrm{D}_{\mathrm{JL} 3} & \mathrm{D}_{\mathrm{J} 4} & \mathrm{D}_{\mathrm{JL} 4} \\
\mathrm{C}_{\mathrm{J} 1} & \mathrm{C}_{\mathrm{JL} 1} & \mathrm{C}_{\mathrm{J} 2} & \mathrm{C}_{\mathrm{JL} 2} & \mathrm{C}_{\mathrm{J} 3} & \mathrm{C}_{\mathrm{JL} 3} & \mathrm{C}_{\mathrm{J} 4} & \mathrm{C}_{\mathrm{JL} 4}
\end{array}\right]
$$

o próximo passo é a alocação da matriz A(MATA) a partir da matriz BADC, de acordo com a rotina seguinte

C Alocação dos Elementos de MATA

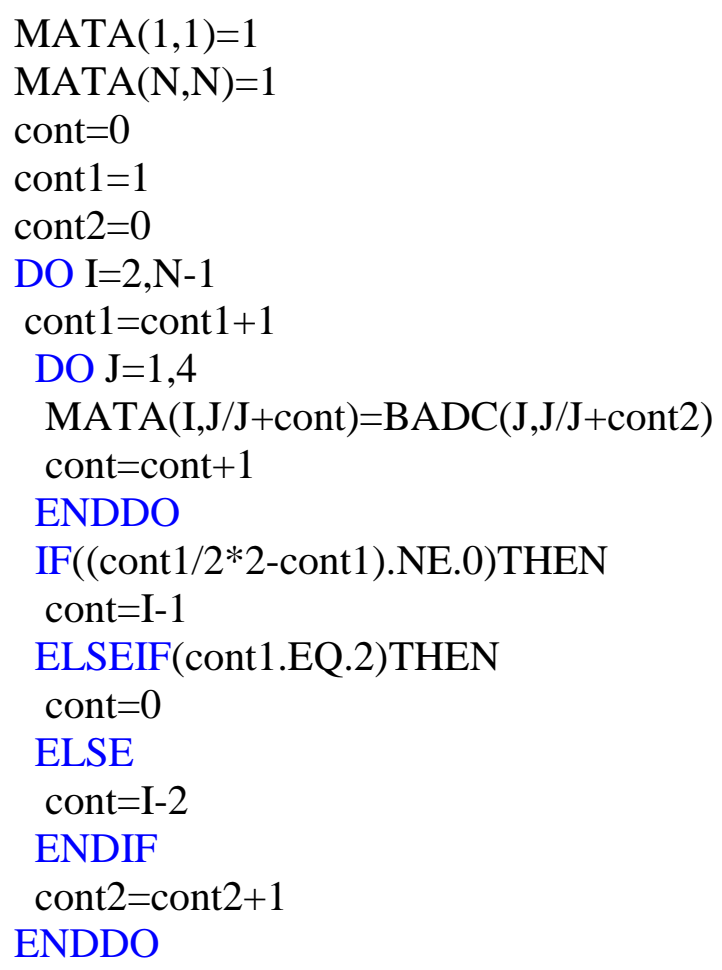

a alocação dos elementos do vetor $B$ é feita pela leitura dos vetores $E_{J}$ e $E_{J L}$, e ainda dos contornos do problema dados por $\mathrm{F}_{1}$ e $\mathrm{F}_{\mathrm{n}}$ 


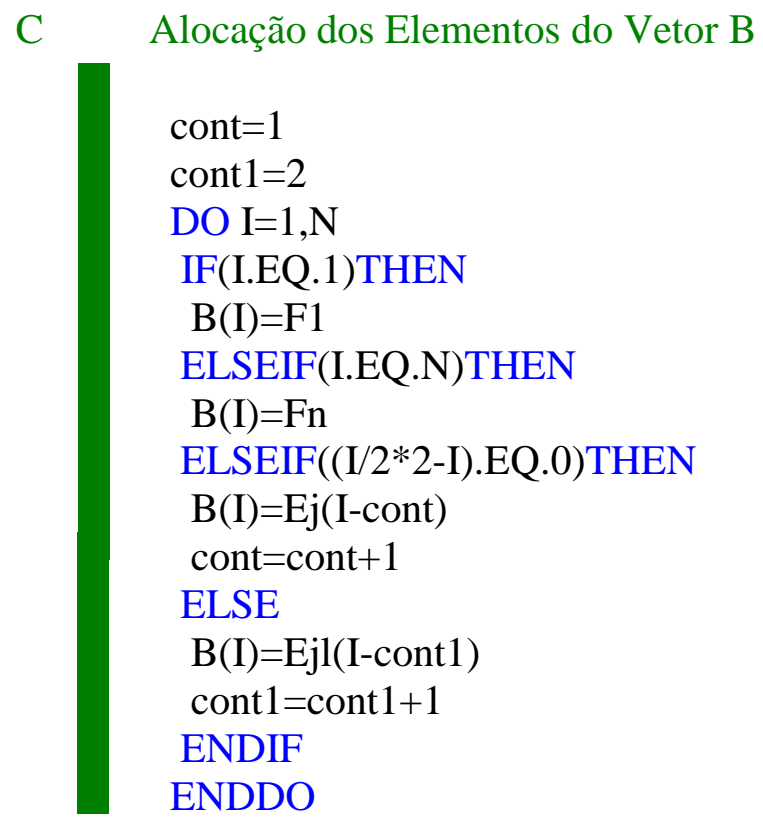

Para a resolução do sistema, utilizou-se o método de Gauss, que é um método geral. Lembrase que o emprego de qualquer outro método adequado resultaria em um maior ou menor esforço computacional, o que não é objetivado pelo escopo desta pesquisa. A sub rotina de cálculo é apresentada no Anexo p.140, extraída da apostila FORTRAN POWER STATION do Departamento de Engenharia de Estruturas da EESC-USP.

C Para Resolução do Sistema, o Vetor B entrará como sendo

C a última coluna de MATA, isto é, $(\mathrm{N}+1)$.

DO $\mathrm{I}=1, \mathrm{~N}$

$\operatorname{MATA}(\mathrm{I}, \mathrm{N}+1)=\mathrm{B}(\mathrm{I})$

ENDDO

Portanto a solução do vetor U é dada após a chamada da sub-rotina para resolução do sistema, cujos resultados serão armazenados posteriormente no arquivo de saída 'SAI.txt', de acordo com os seguintes passos

C Chamando Sub-rotina para resolução do sistema

CALL SOLVER(MATA,U,N) 
C Fim da resolução do sistema - Gravando o Resultado

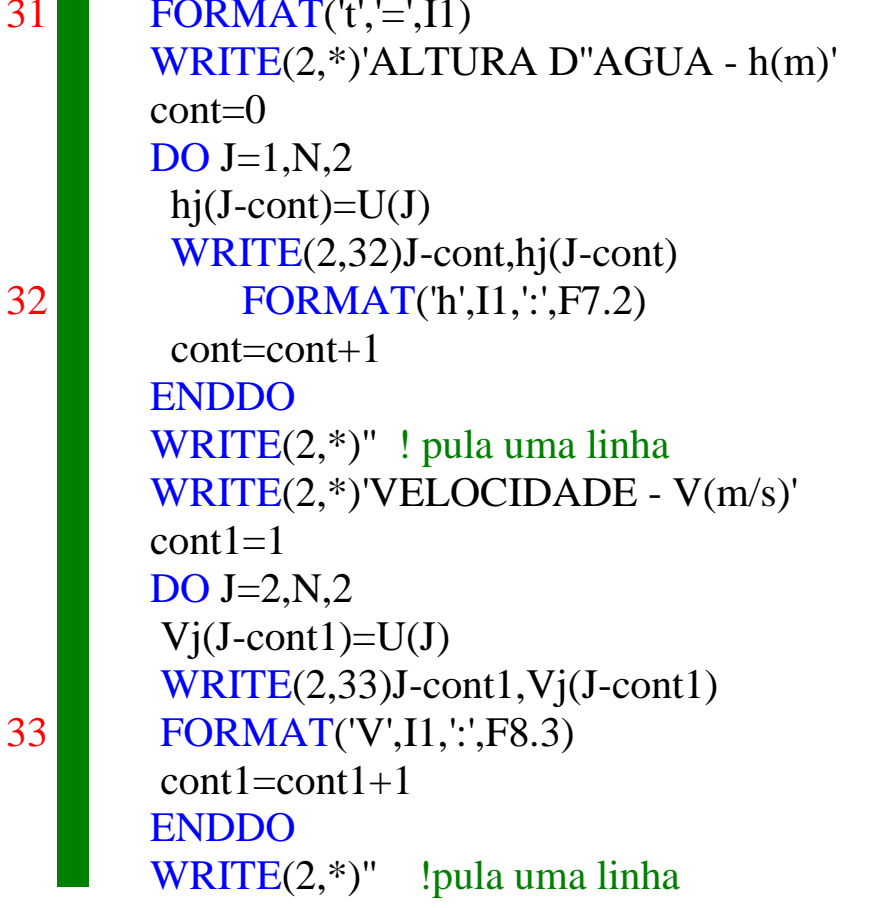

WRITE(2, *)'ALTURA D"AGUA - h(m)'

cont $=0$

$\mathrm{DO} \mathrm{J}=1, \mathrm{~N}, 2$

$\operatorname{hj}(\mathrm{J}-$ cont $)=\mathrm{U}(\mathrm{J})$

$\operatorname{RITE}(2,32) \mathrm{J}$-cont,hj(J-cont)

cont $=$ cont +1

ENDDO

WRITE(2,*)" ! pula uma linha

WRITE( $2, *)^{\prime} \mathrm{VELOCIDADE} \mathrm{-} \mathrm{V(m/s)'}$

cont $1=1$

$\mathrm{Vj}(\mathrm{J}-$ cont 1$)=\mathrm{U}(\mathrm{J})$

WRITE(2,33)J-cont $1, \mathrm{Vj}(\mathrm{J}-$ cont 1$)$

cont $1=$ cont $1+1$

ENDDO

WRITE $\left(2,{ }^{*}\right) "$ !pula uma linha

WRITE( $\left.2,{ }^{*}\right)$ 'RESOLUÇÃO DO SISTEMA'

WRITE $\left(2,{ }^{*}\right)$ 'TEMPO EM HORAS'

WRITE(2,31)K

FORMAT('t','=',I1)

Posteriormente a impressão do vetor U no arquivo de saída 'SAI.txt', as velocidades e profundidades médias $V_{m}(m / s)$ e $h_{m}(m)$ são recalculadas em função das velocidades e profundidades obtidas na resolução do sistema para cada seção no mesmo intervalo, e o laço DO que determina o cálculo de acordo com a discretização de tempo preestabelecida como dado de entrada, é fechado. Os arquivos de entrada e saída são fechados em seguida com a finalização do programa. Os passos descritos são ilustrados a seguir

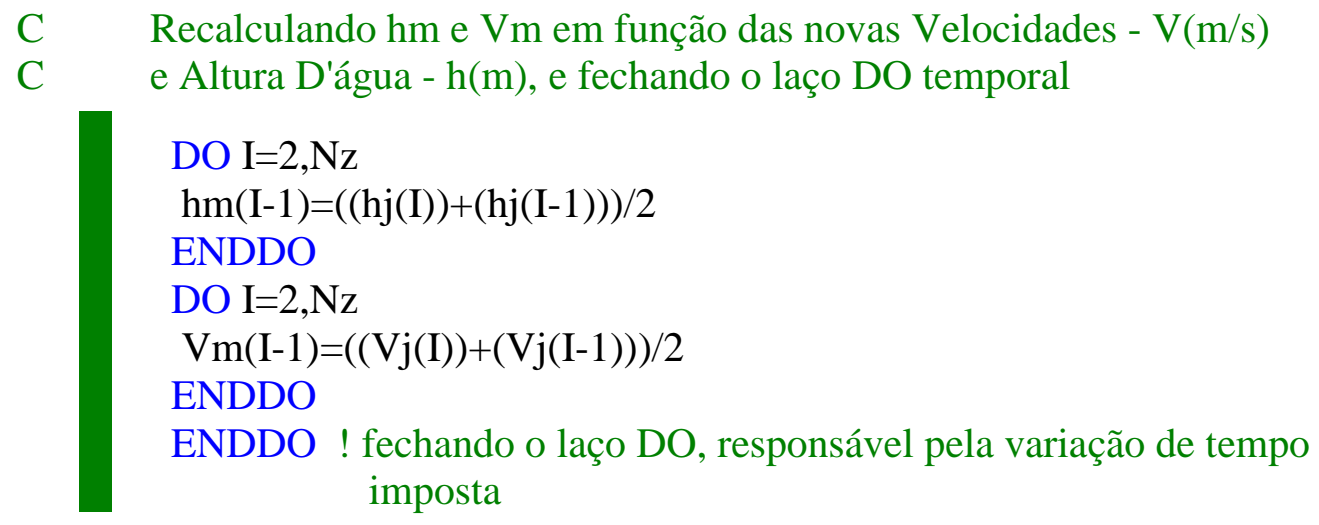




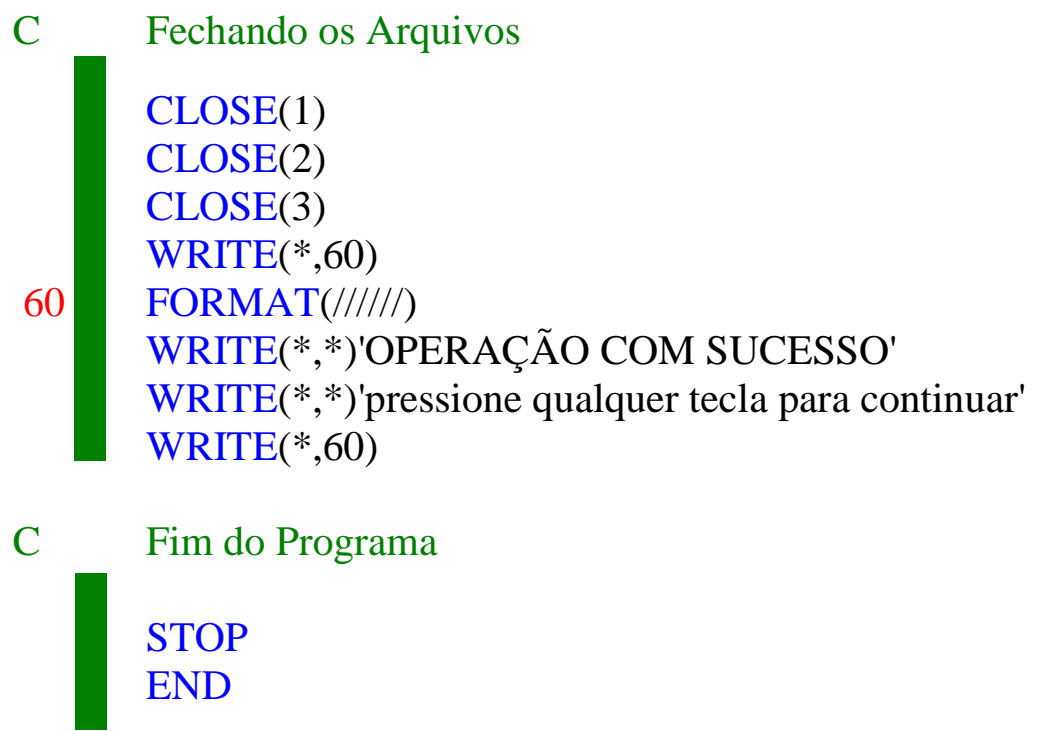

Após a aplicação do modelo computacional desenvolvido, foi possível determinar as profundidades e velocidades características das seções discretizadas em função da variação de tempo atribuída para o cálculo, cujos resultados são gravados no arquivo de saída 'SAI.txt'. 
- $1^{\circ}$ Caso : Canal de Alimentação da Usina Hidrelétrica Monjolinho

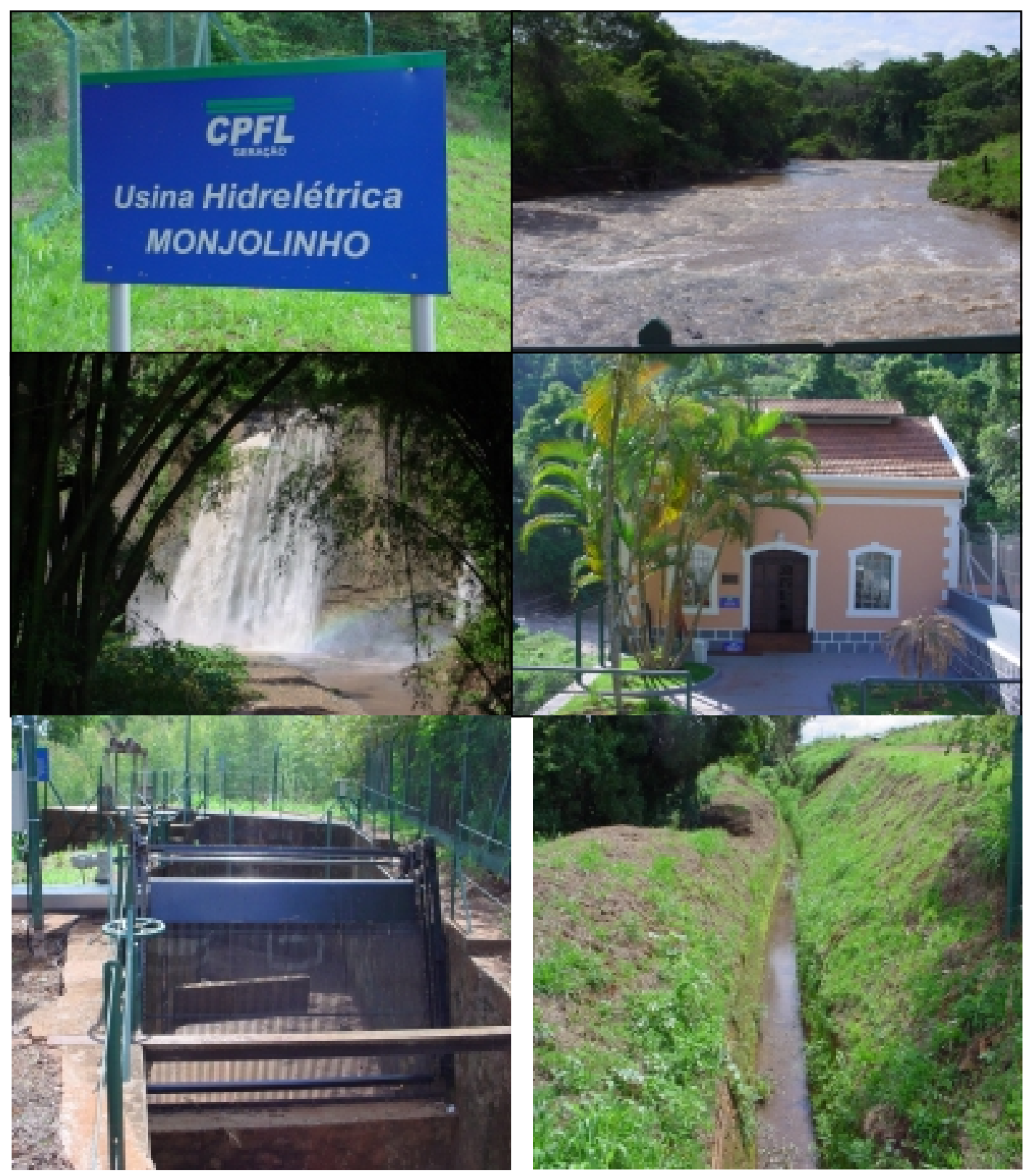

\section{Breve Histórico}

A Usina Monjolinho entrou em operação em 1893 e foi a primeira hidrelétrica a ser construída na América Latina (ESPÍNDOLA et al. 2000). De propriedade da "Companhia de Luz Elétrica de São Carlos", a usina operava na época com duas máquinas monofásicas de $50 \mathrm{kw}$, a demanda necessária para a população local. A queda de água era de 33 metros, com 
canal de adução de 250 metros. A Companhia Elétrica de São Carlos operou até 1907, quando foi substituída pela Companhia Paulista de Eletricidade - CPE.

O rápido crescimento da demanda de energia elétrica fez com que fosse construída em 1908 uma nova usina, utilizando todo o potencial da queda de água - 80 metros. A usina passou a operar com capacidade de $600 \mathrm{~kW}$, com duas máquinas trifásicas de $300 \mathrm{~kW}$ cada uma.

Apenas em 1973, no dia 5 de setembro, a Companhia Paulista de Eletricidade passou o controle acionário para a Companhia Paulista de Força e Luz - CPFL. Em 1986, a usina foi incluída no processo de semi-automação implantado pela CPFL, que tinha como objetivo aumentar a produção de energia elétrica.

Desativada desde 1995, a CPFL retoma a geração de energia da primeira usina hidrelétrica do Estado de São Paulo, a Monjolinho. Com a reforma e a revisão de todo o maquinário, a Monjolinho está pronta para voltar a gerar energia para a região de São Carlos.

A principal obra realizada na usina foi a reconstrução e a automação da barragem, o que aumentou a confiabilidade do sistema. Após a reinauguração, em 18 de setembro de 2002, a Monjolinho passará a operar com uma capacidade de $600 \mathrm{~kW}$ de potência, a mesma de 1995, quando foi desativada.

Como parte das obras de repotenciação da usina, a simulação de escoamento transiente em seu canal de adução, objeto de estudo desta pesquisa, permitirá a avaliação do sistema de adução, prever as obras de correção necessárias bem como dar subsídios para a automação do sistema. 


\section{Localização e Dados Técnicos}

Fonte: www.cpfl.com.br

Localização: Município de São Carlos - Estado de São Paulo, próximo ao bairro do Botafogo, localizada no acesso de terra que liga São Carlos e Ibaté, distante a 2,5 Km do Perímetro de São Carlos. Distância entre a sede e usina: 158,5 Km, sendo: 156,0 Km de Asfalto (SP-330/SP-310) e 2,5 Km de terra.

\section{Condições à Montante}

quant un

Volume total do reservatório $263 \mathrm{~m}^{3}$

Barragem concreto, tipo gravidade, extensão $30 \mathrm{~m}$

Altura barragem $4,0 \quad \mathrm{~m}$

Cota coroamento $104 \mathrm{~m}$

Nível d'água crítico 103,5 m

Nível d'água máximo $103,5 \mathrm{~m}$

Nível d'água mínimo $101 \mathrm{~m}$

Nível d'água máximo ocorrido $103 \mathrm{~m}$

Vazão diária máxima observada $20 \mathrm{~m}^{3} / \mathrm{s}$

Unidades Geradoras: $\quad$ Ano de instalação-1909 quant un

Número de unidades instaladas 2 un

Capacidade geradora nominal total.............................................................. $600 \quad \mathrm{~kW}$

Capacidade geradora efetiva total................................................................ $480 \quad \mathrm{~kW}$

Turbina: FRANCIS, eixo horizontal, rotor gêmeo regulador de velocidade quant un

Potência unitária. $380 \mathrm{cv}$

Queda líquida nominal. $80 \mathrm{~m}$

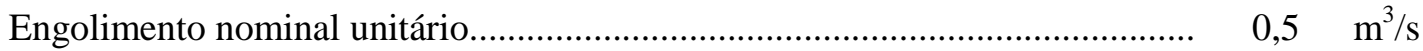

Velocidade $900 \mathrm{rpm}$

Fabricação : Voith 
quant un

Capacidade unitária. 375 kWA

Fator de potência $0,8 \quad-$

Tensão $2.300 \quad \mathrm{~V}$

Corrente $95 \quad \mathrm{~A}$

Fabricação : AEG

Órgãos de Descarga: $\quad$ quant un

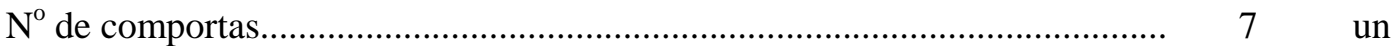

Dimensão do vão.............................................................................. 1,7x2 m

Capacidade de descarga no nível d'água máximo......................................... $10 \quad \mathrm{~m}^{3} / \mathrm{s}$

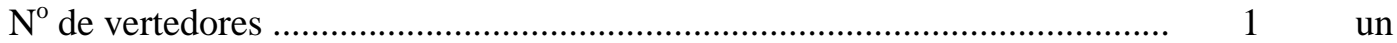

Dimensão total do vertedouro ............................................................... $12 \quad \mathrm{~m}$

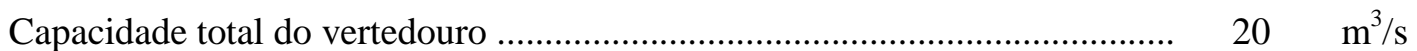

Canal de Adução: $\quad$ quant un

A céu aberto..................................................................................... $1350 \quad \mathrm{~m}$

Conduto Forçado: $\quad$ quant un

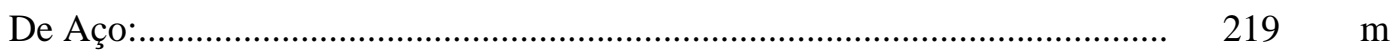

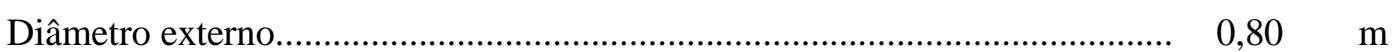

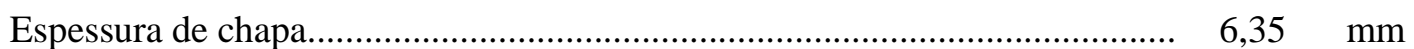

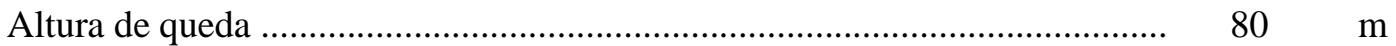

Condição de Jusante: $\quad$ quant un

Nível de água crítico no canal de fuga ....................................................... $31 \quad \mathrm{~m}$

Nível máximo no canal de fuga.................................................................... $29 \quad \mathrm{~m}$

Nível de água mínimo no canal de fuga....................................................... 27,8 m

Nível de água máximo no canal de fuga já registrado até 1979..................... 28,8 $\quad$ m 


\section{Procedimentos}

Além dos dados fornecidos pela CPFL, foi necessária a realização de levantamento topográfico para determinação dos dados de geometria do canal de adução. Através dos dados de topografia, foram determinadas as seções características para uma discretização espacial variável, de acordo com a necessidade de detalhamento. Em virtude do não detalhamento de todas as seções pela topografia, algumas delas foram levantadas por interpolação de cotas a partir da planta topográfica. Constatou-se pelo levantamento a pouca variação das dimensões do canal trapezoidal.

Caracterizada a geometria de todas as seções envolvidas, num total de trinta, cada uma foi dividida em elementos de área, onde foi possível determinar as equações reais de área, perímetro molhado e largura de superfície livre, todas funções da altura d'água. Para a utilização destes elementos geométricos ao modelo computacional, foi aplicada linha de tendência para cada uma das curvas obtidas e escolhida a função matemática mais adequada, através da utilização do método dos mínimos quadrados. As seções levantadas, suas funções, bem como os gráficos que retratam sua evolução, além da planta cadastral, são apresentados no APÊNDICE - Canal do Monjolinho.

A vazão utilizada para a geração de energia é de $0,517 \mathrm{~m}^{3} / \mathrm{s}$, sendo para tanto considerada como a vazão característica do regime permanente no canal de alimentação.

Para a aplicação do modelo computacional foram consideradas duas operações de controle:

A primeira simulação permite avaliar se, para uma condição de repouso no canal, uma abertura instantânea na turbina à jusante provoca ou não a entrada de ar no conduto forçado.

- $\quad$ A simulação seguinte permite demonstrar, a partir dos dados de regime permanente obtidos na simulação anterior, se uma interrupção repentina no escoamento, dada pela paralisação da turbina, ocorre ou não transbordamento no canal.

Para a primeira simulação (abertura da turbina), foi necessário para "chute" inicial da velocidade de jusante, uma das condições de contorno do problema, a utilização do Step-Method, cujo cálculo partiu de um ponto de controle de funcionamento do sistema na 
câmara de carga com y =1,95m. Através deste cálculo, foi possível determinar a velocidade de chegada na referida câmara $\mathrm{v}=0,251 \mathrm{~m} / \mathrm{s}$, e a altura d'água constante na entrada do canal $\mathrm{y}=0,59 \mathrm{~m}$. Com estas condições de contorno, é simulado a situação de abertura da turbina até se atingir o regime permanente, que naturalmente coincide com o determinado pelo Step-Method. Os dados de $\mathrm{h}(\mathrm{m})$ e $\mathrm{v}(\mathrm{m} / \mathrm{s})$, para regime permanente, "tirados" desta simulação, atuam como dados de entrada para a segunda análise (fechamento da turbina).

O modelo computacional aplicado neste caso, além de tornar possível a avaliação do sistema de adução como um todo, atua como subsídio na automação dos sistemas de controle para as diversas operações desejadas. Na FIGURA 16 é esboçado o esquema do caso em pauta. O canal apresenta geometria trapezoidal. Nas seções de 3 a 5 é composto por tubulação de aço em diâmetro de $1 \mathrm{~m}$ e, nas seções de 7 a 9 com dois tubos de aço em diâmetro de 0,80 m, com $10 \mathrm{~m}$ e $14 \mathrm{~m}$ de comprimento respectivamente. A discretização de espaço foi definida em 30 seções com espaçamentos $(\Delta x)$ variáveis. $O$ intervalo de tempo para cálculo $(\Delta \mathrm{t})$ foi discretizado a cada $10 \mathrm{~s}$ (dez segundos) num total de $2 \mathrm{~h}$ (duas horas).

\section{Esquema:}

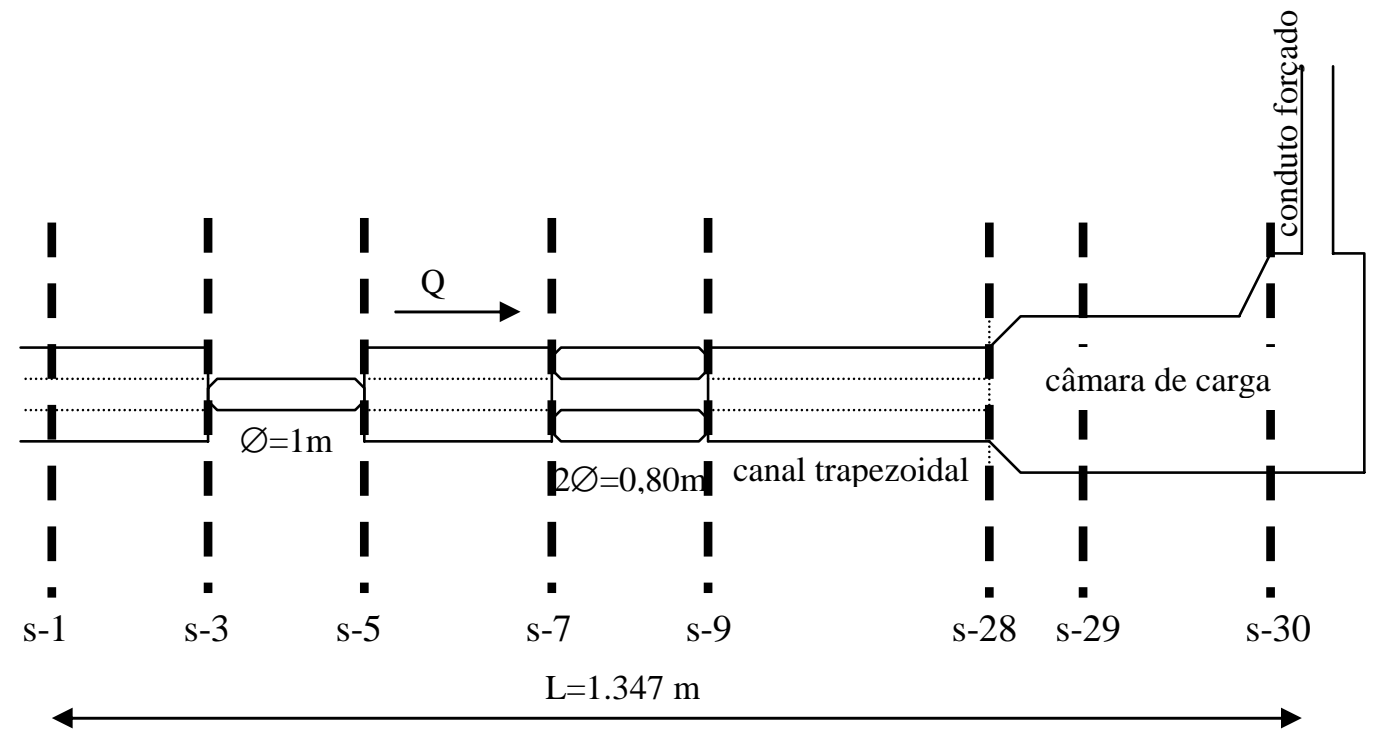

FIGURA 16 - Esquema do Canal de Alimentação da UHE-Monjolinho 


\section{Modelo Computacional}

O modelo computacional apresentado e comentado na seqüência, contempla as adequações e ajustes realizados a partir da configuração ilustrada em testando o modelo. Para tanto, várias rotinas comentadas anteriormente são mantidas. Assim, limitar-se-á a descrição dos tópicos não comuns e particulares deste caso.

- $\quad 1^{a}$ Simulação (Abertura da Turbina)

\section{PROGRAM ESCOAMENTO TRANSIENTE EM CANAIS}

INTEGER cont,cont1,cont2

REAL*8 SAI

REAL*8,ALLOCATABLE :: A(:),V(:),y(:),z(:),h(:),hm(:),Vm(:),

$\operatorname{Aj}(:), \operatorname{Bj}(:), \operatorname{Cj}(:), \operatorname{Dj}(:), \operatorname{Ej}(:), \operatorname{Ajl}(:), \operatorname{Bjl}(:), \operatorname{Cjl}(:), \operatorname{Djl}(:)$,

$\operatorname{Ejl}(:), \operatorname{MATA}(:,:), \mathrm{B}(:), \mathrm{U}(:), \mathrm{BADC}(:),), \operatorname{Rh}(:), \operatorname{Am}(:), \operatorname{Pm}(:)$,

$\mathrm{P}(:), \operatorname{hmin}(:), \operatorname{Bi}(:), \operatorname{Bim}(:), \operatorname{So}(:), \operatorname{Dx}(:)$

Declaração das variáveis e vetores do programa. Como o canal agora não é retangular e nem possui fundo horizontal, torna-se necessário a consideração dos parâmetros declividade de fundo (So), cotas de fundo (z), e alturas d'água (y e h). Os arquivos texto utilizados para a entrada e saída de dados são abertos na sequência

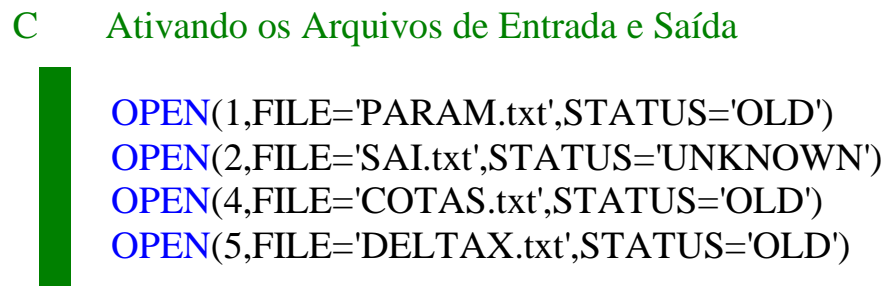

O arquivo 'COTAS.txt' são as cotas do fundo do canal em relação ao plano de referência, determinadas topograficamente. 'DELTAX.txt' é o arquivo que contém o espaçamento entre as seções, discretizadas convenientemente. 'PARAM.txt' são os parâmetros complementares e, o arquivo 'SAI.txt', os dados de saída cujo arquivo é criado pelo programa.

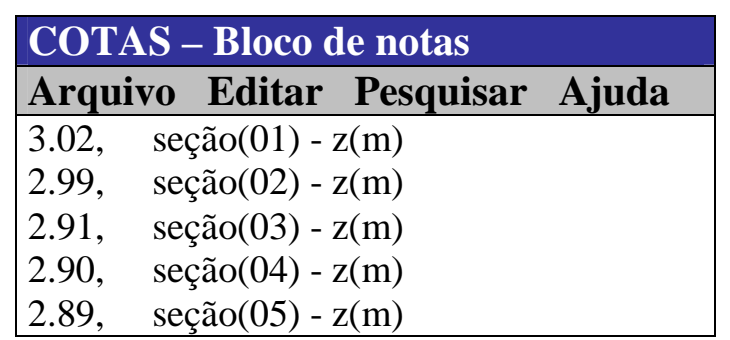

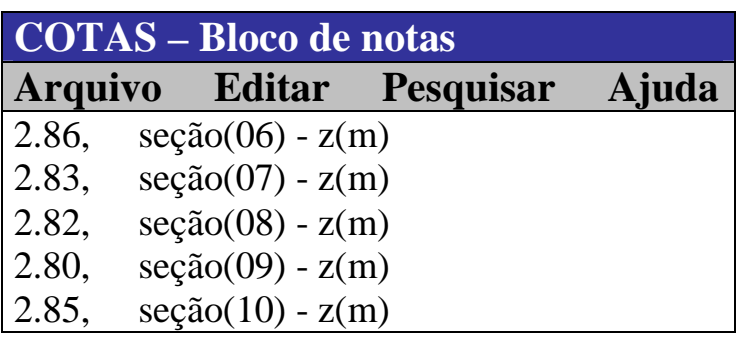




\begin{tabular}{|ll|}
\hline 2.81, & seção(11) - z(m) \\
2.71, & seção(12) - z(m) \\
2.59, & seção(13) - z(m) \\
2.58, & seção(14) - z(m) \\
2.66, & seção $(15)-z(m)$ \\
2.67, & seção(16) - z(m) \\
2.60, & seção $(17)-z(m)$ \\
2.62, & seção(18) - z(m) \\
2.52, & seção $(19)-z(m)$ \\
2.36, & seção(20) - z(m) \\
\hline
\end{tabular}

\begin{tabular}{|ll|}
\hline 2.44, & seção(21) - z(m) \\
2.42, & seção(22) - z(m) \\
2.30, & $\operatorname{seção(23)~-~z(m)~}$ \\
2.19, & $\operatorname{seção(24)~-~z(m)~}$ \\
2.11, & $\operatorname{seção(25)~-~z(m)~}$ \\
2.10, & $\operatorname{seção(26)~-~z(m)~}$ \\
2.07, & $\operatorname{seção(27)~-~z(m)~}$ \\
2.04, & $\operatorname{seção(28)~-~z(m)~}$ \\
1.97, & seção(29) - z(m) \\
1.00 & seção(30) - z(m) \\
\hline
\end{tabular}

\begin{tabular}{|ll|}
\hline PARAM - Bloco de notas \\
\hline Arquivo & Editar Pesquisar \\
\hline 9.81, & Ajuda \\
0.015, & coeficiente de Maceleracano da gravidade \\
1347, & (m)comprimento do canal \\
3.61, & (m)altura de repouso no canal $-\mathrm{h}(\mathrm{m})$ \\
0.251, & (m/s)velocidade na extremidade jusante - abertura da turbina \\
10, & ( $)$ intervalo de tempo de cálculo \\
0.00, & (m3/s)vazão inicial no canal \\
30, & número de seções no canal \\
720, & número de intervalos de tempo para cálculo \\
3.141592654 & valor de Pi \\
\hline
\end{tabular}

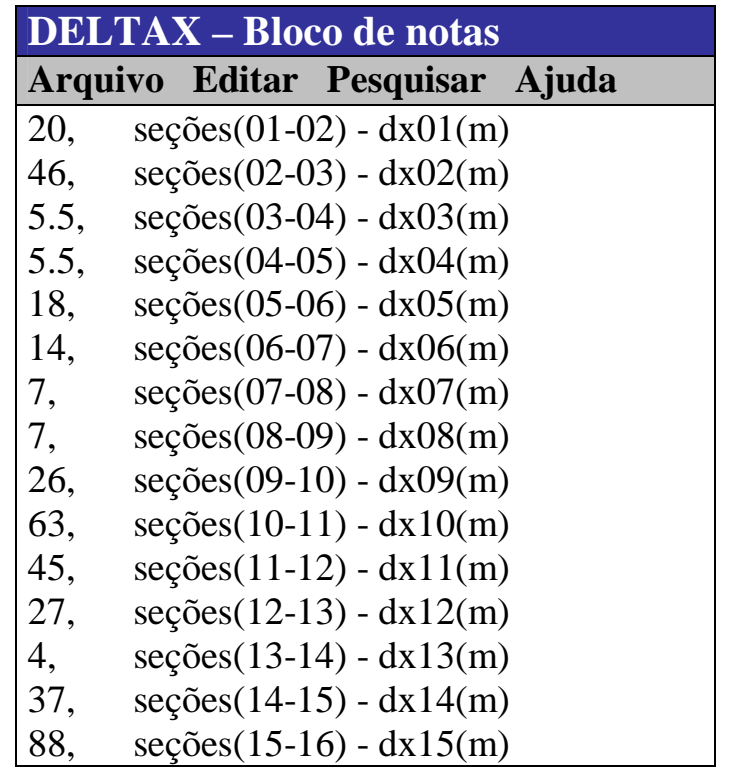

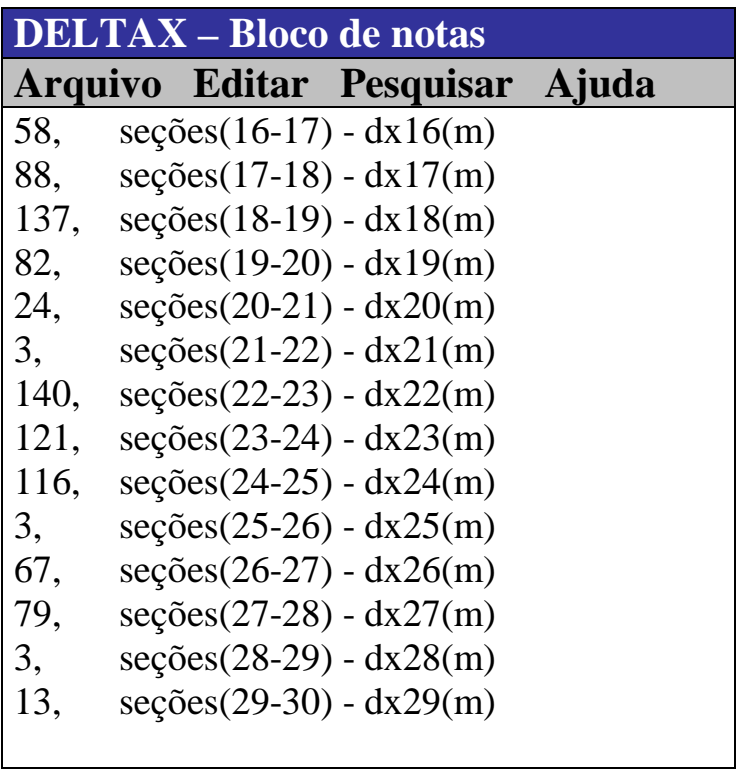

A seguir é realizada a leitura do arquivo 'PARAM.txt', feita a atribuição da dimensão das matrizes e número de equações, com a alocação dinâmica dos vetores pré-declarados em função desta atribuição. 
C Lendo o Arquivo dos Parâmetros de Cálculo

$\operatorname{READ}\left(1,{ }^{*}\right) \mathrm{g} \quad !(\mathrm{m} / \mathrm{s} 2)$ aceleração da gravidade

$\operatorname{READ}(1, *) \mathrm{w} \quad$ !coeficiente de Manning

$\operatorname{READ}(1, *) 1 \quad !(\mathrm{m})$ comprimento do canal

$\operatorname{READ}(1, *) \mathrm{hr} \quad$ !(m)altura d'água de repouso na seção montante

$\operatorname{READ}(1, *) \mathrm{Va} \quad !(\mathrm{m} / \mathrm{s})$ velocidade jusante de abertura da turbina

$\operatorname{READ}(1, *) \mathrm{Dt} \quad$ !(s)intervalo de tempo de cálculo

$\operatorname{READ}(1, *) \mathrm{Qi} \quad$ !(m3/s)vazão inicial no canal

$\operatorname{READ}(1, *) \mathrm{Nz} \quad$ !número de seções no canal

READ $(1, *) \mathrm{Nt} \quad$ !número de intervalos de tempo para cálculo

$\operatorname{READ}(1, *) \mathrm{Pi} \quad$ !valor de Pi

C Atribuição da Dimensão do Sistema de Matrizes e

C Número de Equações

$\mathrm{N}=\mathrm{Nz} * 2$

$\mathrm{Ne}=(2 * \mathrm{Nz})-2$

C Alocando os vetores

ALLOCATE(A(Nz),V(Nz),y(Nz),z(Nz),h(Nz),hm(Nz-1),Vm(Nz-1), $\mathrm{Aj}(\mathrm{Nz}-1), \mathrm{Bj}(\mathrm{Nz}-1), \mathrm{Cj}(\mathrm{Nz}-1), \mathrm{Dj}(\mathrm{Nz}-1), \mathrm{Ej}(\mathrm{Nz}-1)$,

Ajl(Nz-1),Bjl(Nz-1),Cjl(Nz-1),Djl(Nz-1),Ejl(Nz-1),

BADC(4,Ne),MATA(N,N+1),B(N),U(N),Rh(Nz-1),

$\mathrm{Am}(\mathrm{Nz}-1), \mathrm{Pm}(\mathrm{Nz}-1), \mathrm{P}(\mathrm{Nz}), \mathrm{hmin}(\mathrm{Nz}), \mathrm{Bi}(\mathrm{Nz})$,

$\operatorname{Bim}(\mathrm{Nz}-1), \mathrm{So}(\mathrm{Nz}-1), \mathrm{Dx}(\mathrm{Nz}-1))$

O vetor declividade dos trechos $\mathrm{So}(\mathrm{m} / \mathrm{m})$, é alocado em função das cotas e espaçamentos entre os mesmos. A altura d'água h(m), medida em relação ao plano de referência horizontal, é dada pela soma de $y(m)$ e $z(m)$.

C Lendo os Arquivos Cotas $\mathrm{z}(\mathrm{m})$, Alt y(m) e DELTAX dx (m), e Calculando

C as Declividades Médias $\mathrm{So}(\mathrm{m} / \mathrm{m})$ e a Altura D'água

C inicial $h(m)$.

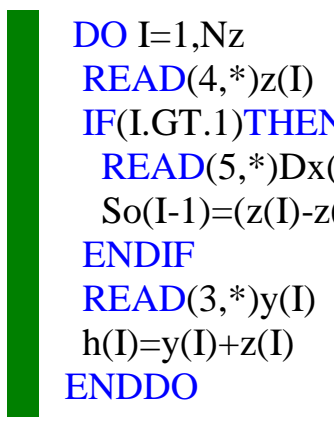

A partir das equações de geometria obtidas em função de $\mathrm{y}(\mathrm{m})$ (largura da superfície livre $\mathrm{Bi}(\mathrm{m})$, área hidráulica $\mathrm{A}\left(\mathrm{m}^{2}\right)$, perímetro molhado $\mathrm{P}(\mathrm{m})$ ), apresentadas no APÊNDICE - Canal do Monjolinho onde também são demonstrados as seções e sua 
localização, são determinadas as condições geométricas iniciais pela sub rotina GEO (ANEXO p.141-145) e suas médias. Na seqüência é obtida a velocidade média entre seções $\mathrm{V}(\mathrm{m} / \mathrm{s})$, bem como as respectivas alturas d'água $\mathrm{h}(\mathrm{m})$. São os dados conhecidos no tempo $\mathrm{k}$, necessários para o cálculo no tempo k+1.

C Chamando Sbrotina GEO para cálculo dos parâmetro geométricos e

C iniciais no canal

CALL GEO(y,P,A,Bi,Am,Pm,Bim,Rh,Nz)

C Calculo das velocidades iniciais $\mathrm{V}(\mathrm{m} / \mathrm{s})$,

C profundidades médias $\mathrm{hm}(\mathrm{m})$ e velocidades médias $\mathrm{Vm}(\mathrm{m} / \mathrm{s})$

$\mathrm{C}$ iniciais

$\mathrm{DO} \mathrm{I}=1, \mathrm{Nz}$

IF(I.EQ.1)THEN

$\mathrm{V}(\mathrm{I})=\mathrm{Qi} / \mathrm{A}(\mathrm{I})$

ELSE

$\mathrm{V}(\mathrm{I})=\mathrm{Qi} / \mathrm{A}(\mathrm{I})$

$\mathrm{Vm}(\mathrm{I}-1)=((\mathrm{V}(\mathrm{I}))+(\mathrm{V}(\mathrm{I}-1))) / 2$

$\mathrm{hm}(\mathrm{I}-1)=((\mathrm{h}(\mathrm{I}))+(\mathrm{h}(\mathrm{I}-1))) / 2$

ENDIF

ENDDO

As cotas, alturas d'água e velocidades iniciais são impressas no arquivo de saída 'SAI.txt'.

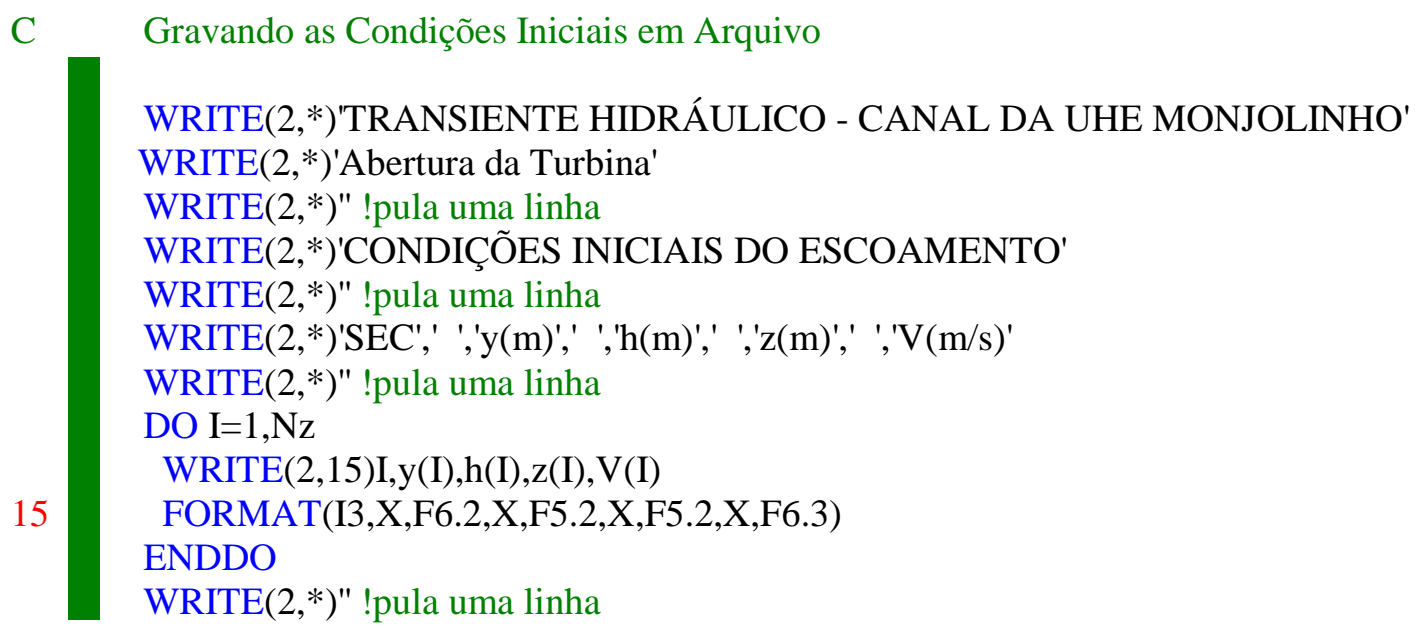

Iniciando o laço de variação temporal, são calculados os vetores BADCE e o coeficiente de Chezzy. O procedimento de cálculo é semelhante ao do caso retangular, ficando as equações $\mathrm{Aj}, \mathrm{Cj}$ e Ej, modificadas segundo as particularidades do caso estudado. Lembra-se que estas alterações foram previstas na discretização da equação da continuidade no teste do modelo. 


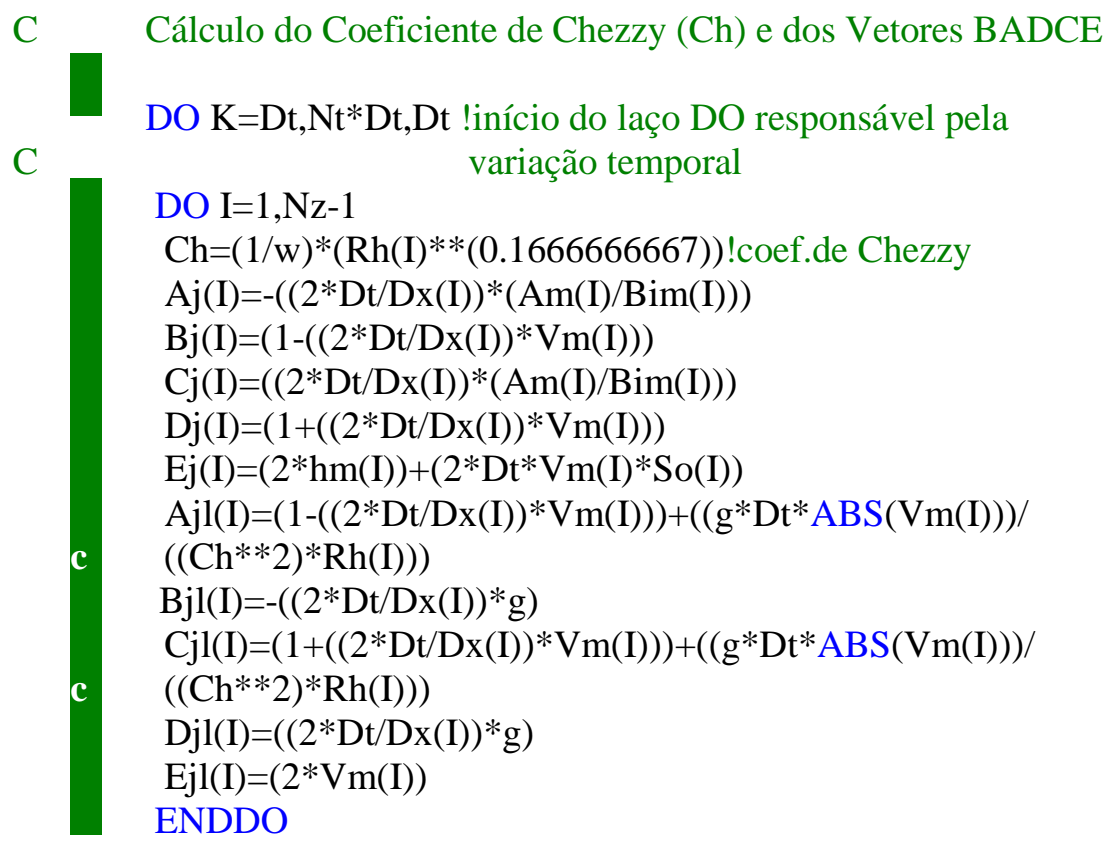

Os contornos do problema são a altura d'água do regime permanente à montante e velocidade de regime permanente à jusante $(\mathrm{hr}=3,61 \mathrm{~m} \mathrm{e} \mathrm{Va}=0.251 \mathrm{~m} / \mathrm{s})$.

C Atribuição aos Contornos F1 e F30

$\mathrm{F} 1=\mathrm{hr} \quad$ !contorno montante(entr.canal)

$\mathrm{F} 30=\mathrm{Va} \quad$ !contorno jusante(parada turbina)

Os passos seguintes do programa descrevem a montagem das matrizes e a chamada da sub rotina SOLVER (ANEXO p.140), para resolução do sistema. Como estas rotinas são idênticas às apresentadas no teste do modelo, não serão descritas.

Após a resolução do sistema, os resultados são impressos no arquivo 'SAI.txt' como segue

C Fim da resolução do sistema - Gravando o Resultado

1

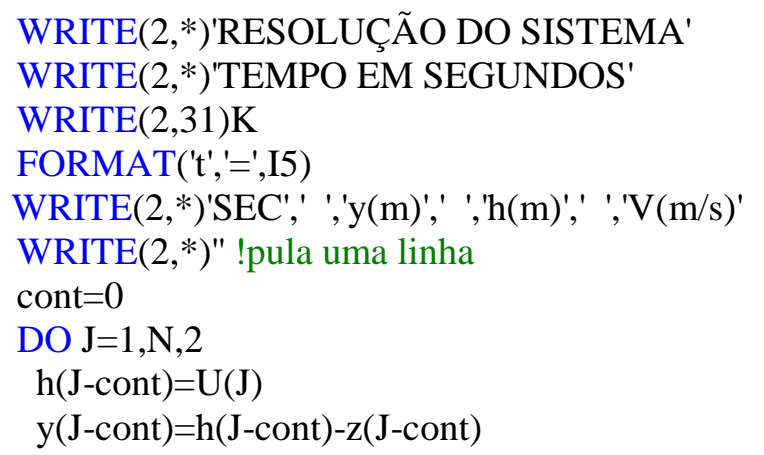




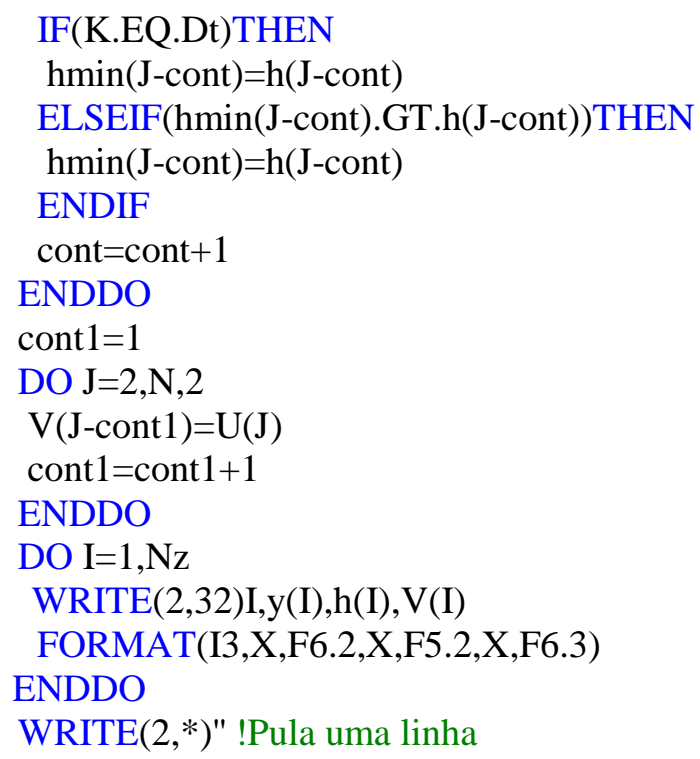

Nesta rotina, que armazena os valores de $h(m)$ e $V(m / s)$ para cada intervalo, observa-se que para cada valor de $\mathrm{h}(\mathrm{m})$ lido, é feita uma comparação com o valor de $\mathrm{hmin}(\mathrm{m})$, que é igual a $\mathrm{hr}(\mathrm{m})$ no início, de forma a imprimir os mínimos níveis atingidos no canal no decorrer do tempo.

Em seguida são recalculadas as variáveis geométricas, funções de $h(m)$ através da sub rotina GEO, bem como as novas alturas $\mathrm{h}(\mathrm{m})$, velocidades $\mathrm{V}(\mathrm{m} / \mathrm{s})$, e raios hidráulicos $\mathrm{Rh}(\mathrm{m}) . \mathrm{O}$ laço DO responsável pela variação temporal é fechado

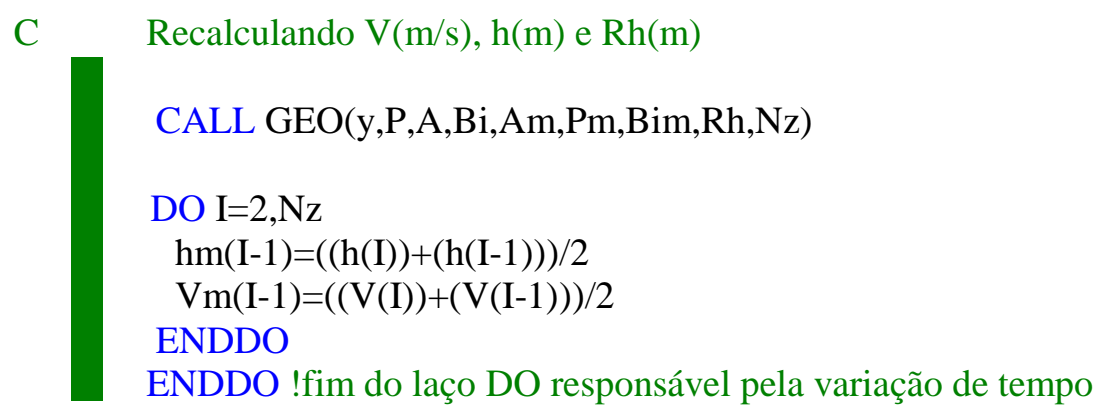

Posteriormente é gravado no vetor $\mathrm{hmin}(\mathrm{m})$, as mínimas alturas ocorridas. Os arquivos *.txt são fechados e encerrado o programa.

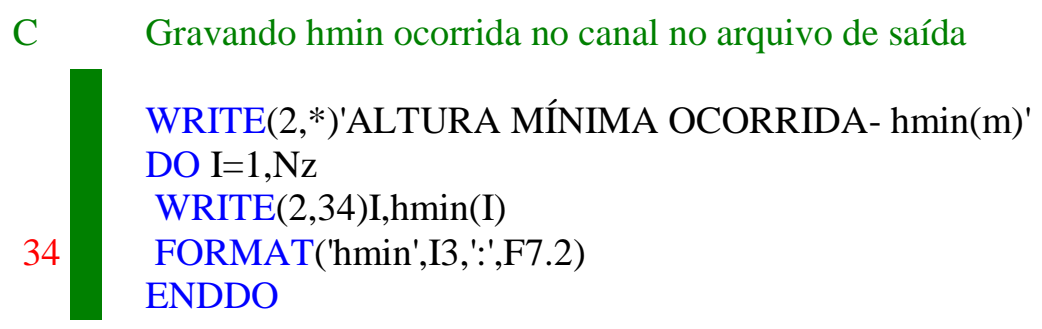


C Fechando os Arquivos

CLOSE(1)

CLOSE(2)

CLOSE(4)

CLOSE(5)

60

WRITE $(*, 60)$

FORMAT(IIII//)

WRITE $(*, *)$ 'OPERAÇÃO COM SUCESSO'

WRITE $(*, *) '$ pressione qualquer tecla para continuar'

$\operatorname{WRITE}(*, 60)$

C Fim do Programa

STOP

END

Com os dados de saída $\mathrm{z}(\mathrm{m}), \mathrm{h}(\mathrm{m}), \mathrm{hmin}(\mathrm{m}), \mathrm{y}(\mathrm{m})$ e $\mathrm{v}(\mathrm{m} / \mathrm{s})$ armazenados no arquivo 'SAI.txt', é possível avaliar o escoamento transiente para o presente caso, em manobra de abertura instantânea da turbina.

- $\quad 2^{\mathrm{a}}$ Simulação (Fechamento da Turbina)

Para simular a situação de fechamento instantâneo da turbina, considera-se a água em regime permanente no canal e, para tanto, as velocidades $\mathrm{V}(\mathrm{m} / \mathrm{s})$ e alturas $\mathrm{h}(\mathrm{m})$ obitdos na simulação anterior neste estado, são utilizados como dados de entrada em arquivos texto. $\mathrm{O}$ arquivo 'ALT.txt', são as alturas d'água $\mathrm{y}(\mathrm{m})$ do regime permanente. O arquivo 'VELO.txt', são as velocidades características do regime permanente. No arquivo 'PARAM.txt' são modificadas as condições de contorno do problema. Os demais arquivos de dados são mantidos.

\begin{tabular}{|ll|}
\hline PARAM - Bloco de notas \\
\hline Arquivo & Editar Pesquisar \\
\hline 9.81, & Ajuda \\
0.015, & coeficiente de Manning \\
1347, & (m)comprimento do canal \\
0.0, & (m/s)velocidade na extremidade jusante-parada da turbina \\
10, & (s)intervalo de tempo de cálculo \\
.517, & (m3/s)vazão inicial no canal \\
30, & número de seções no canal \\
720, & número de intervalos de tempo para cálculo \\
3.141592654 & valor de Pi \\
\hline
\end{tabular}




\begin{tabular}{|ll|}
\hline \multicolumn{2}{|l|}{ ALT - Bloco de notas } \\
\hline \multicolumn{2}{|l|}{ Arquivo Editar Pesquisar } \\
\hline 0.59, & seção(01) - y(m) \\
0.60, & seção(02) - y(m) \\
0.65, & seção(03) - y(m) \\
0.66, & seção(04) - y(m) \\
0.66, & seção(05) - y(m) \\
0.68, & seção(06) - y(m) \\
0.70, & seção(07) - y(m) \\
0.71, & seção(08) - y(m) \\
0.72, & seção(09) - y(m) \\
0.64, & seção(10) - y(m) \\
0.63, & seção(11) - y(m) \\
0.71, & seção(12) - y(m) \\
0.83, & seção(13) - y(m) \\
0.84, & seção(14) - y(m) \\
0.74, & seção(15) - y(m) \\
\hline
\end{tabular}

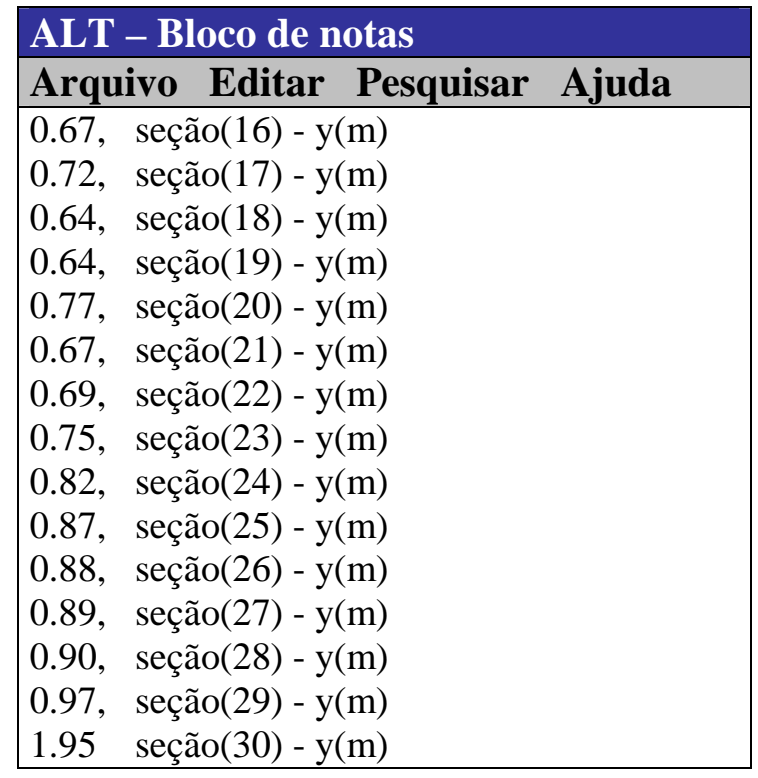

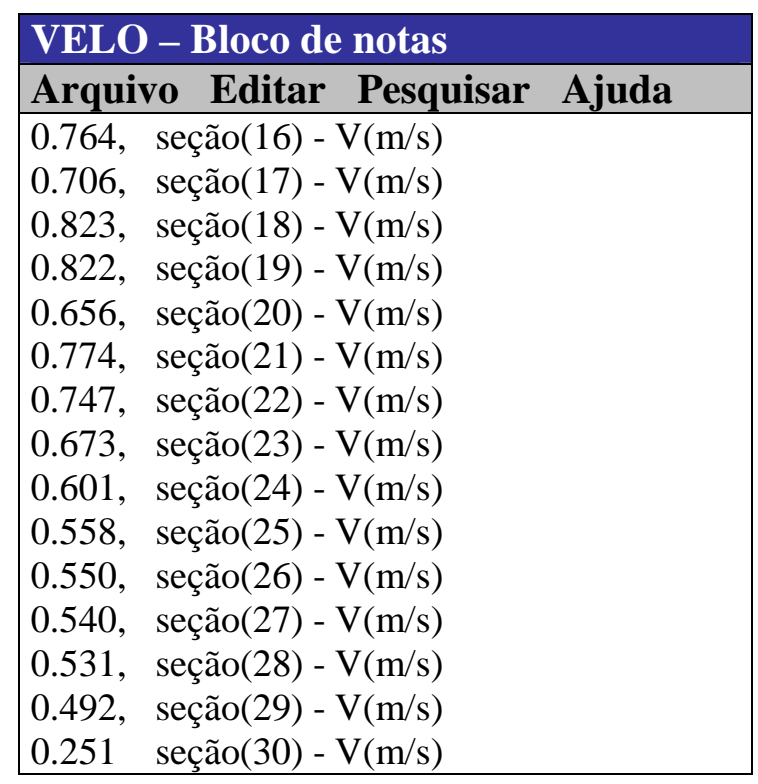

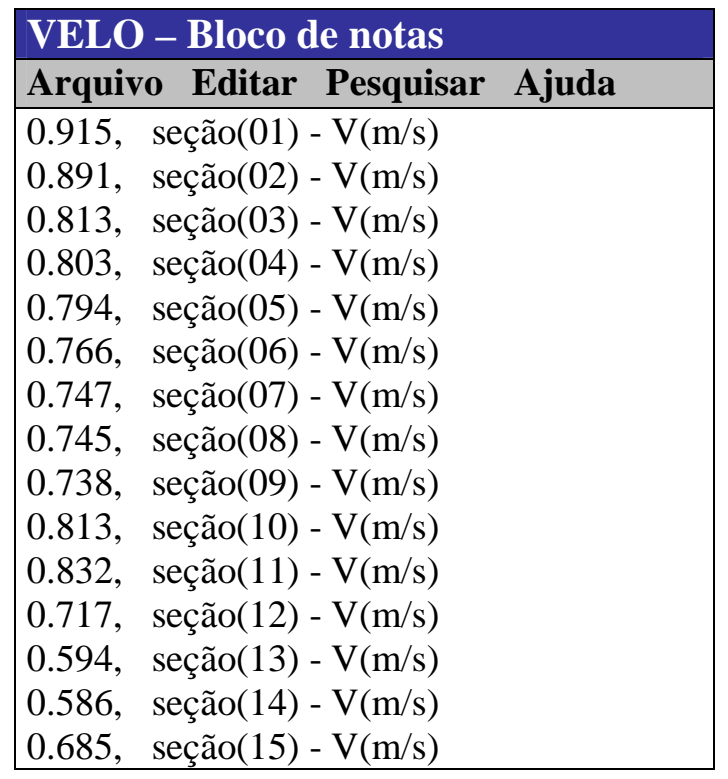

Vale ressaltar que o vetor hmin(Nz) definido para a $1^{\mathrm{a}}$ simulação, é substituído nesta etapa por $\mathrm{hmax}(\mathrm{Nz})$, de forma a se determinar posteriormente as máximas alturas ocorridas no canal $\mathrm{h}(\mathrm{m})$ ao longo do tempo, que deverá corresponder a altura de repouso $\mathrm{hr}(\mathrm{m})$ da simulação de abertura.

Após abertura dos arquivos de entrada '*.txt', lê-se o arquivo 'PARAM.txt' armazenando-se os valores em variáveis correspondentes. 
C Ativando os Arquivos de Entrada e Saída

OPEN(1,FILE='PARAM.txt',STATUS='OLD')

OPEN(2,FILE='SAI.txt',STATUS='UNKNOWN')

$\operatorname{OPEN}(3, \mathrm{FILE}=$ 'ALT.txt',STATUS='OLD')

OPEN(4,FILE='COTAS.txt',STATUS='OLD')

OPEN(5,FILE='DELTAX.txt',STATUS='OLD')

OPEN(6,FILE='VELO.txt',STATUS='OLD')

C Lendo o Arquivo dos Parâmetros de Cálculo

$\operatorname{READ}(1, *) \mathrm{g}$

$\operatorname{READ}(1, *) \mathrm{w}$

$\operatorname{READ}(1, *) 1$

$\operatorname{READ}(1, *) \mathrm{Vp}$

$\operatorname{READ}(1, *) \mathrm{Dt}$

$\operatorname{READ}(1, *) \mathrm{Qi}$

$\operatorname{READ}(1, *) \mathrm{Nz}$

$\operatorname{READ}(1, *) \mathrm{Nt}$

$\operatorname{READ}(1, *) \mathrm{Pi}$ $!(\mathrm{m} / \mathrm{s} 2)$ aceleração da gravidade

!coeficiente de Manning

!(m)comprimento do canal

$!(\mathrm{m} / \mathrm{s})$ velocidade jusante da parada da turbina

!(s)intervalo de tempo de cálculo

!(m3/s)vazão inicial no canal

!número de seções no canal

!número de intervalos de tempo para cálculo

!valor de Pi

Após a alocação dinâmica dos vetores definidos, demonstrados na simulação anterior, as declividades médias $\mathrm{So}(\mathrm{m} / \mathrm{m})$ e as alturas d'água $\mathrm{h}(\mathrm{m})$ são calculadas pela rotina

C Lendo os Arquivos Cotas z(m), Alt y(m) e DELTAX dx(m), e Calculando

C as Declividades Médias $\mathrm{So}(\mathrm{m} / \mathrm{m})$ e a Altura D'água

C inicial $\mathrm{h}(\mathrm{m})$.

DO I $=1, \mathrm{Nz}$

$\operatorname{READ}(4, *) \mathrm{z}(\mathrm{I})$

IF(I.GT.1)THEN

$\operatorname{READ}(5, *) \operatorname{Dx}(\mathrm{I}-1)$

$\operatorname{So}(\mathrm{I}-1)=(\mathrm{z}(\mathrm{I})-\mathrm{z}(\mathrm{I}-1)) / \mathrm{Dx}(\mathrm{I}-1)$

ENDIF

$\operatorname{READ}(3, *) \mathrm{y}(\mathrm{I})$

$\mathrm{h}(\mathrm{I})=\mathrm{y}(\mathrm{I})+\mathrm{z}(\mathrm{I})$

$\operatorname{READ}(6, *) \mathrm{v}(\mathrm{I})$

ENDDO

Após a chamada da sub rotina GEO as velocidades e alturas médias são calculadas.

C Calculo das profundidades médias $\mathrm{hm}(\mathrm{m}) \mathrm{e}$

C velocidades médias $\mathrm{Vm}(\mathrm{m} / \mathrm{s})$ iniciais

$\mathrm{DO} \mathrm{I}=2, \mathrm{Nz}$

$\mathrm{Vm}(\mathrm{I}-1)=((\mathrm{V}(\mathrm{I}))+(\mathrm{V}(\mathrm{I}-1))) / 2$

$\mathrm{hm}(\mathrm{I}-1)=((\mathrm{h}(\mathrm{I}))+(\mathrm{h}(\mathrm{I}-1))) / 2$

ENDDO 
Após a gravação das condições iniciais do escoamento, de acordo com os passos descritos na simulação anterior, parte-se para o cálculo dos vetores BADC e sequencialmente à montagem do sistema. Para tanto, os contornos são definidos

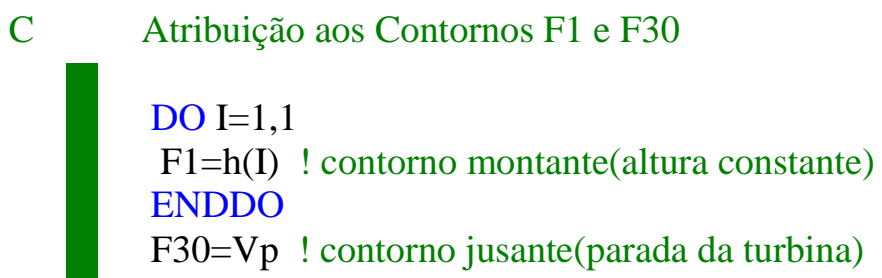

Os procedimentos para montagem e resolução do sistema matricial são mantidos. A impressão da resposta obtida para o arquivo de saída 'SAI.txt' também é da forma como apresentada anteriormente, com a substituição de hmin por hmax, com o propósito de se verificar o transbordamento no canal.

C Fim da resolução do sistema - Gravando o Resultado

WRITE $\left(2,{ }^{*}\right)$ 'RESOLUÇÃO DO SISTEMA'

WRITE $(2, *)$ 'TEMPO EM SEGUNDOS'

WRITE $(2,31) \mathrm{K}$

FORMAT('t','=',I5)

WRITE(2,*)'SEC',' ','y(m)',' ','h(m)',' ','V(m/s)'

WRITE $(2, *) "$ !pula uma linha

cont $=0$

DO J $=1, \mathrm{~N}, 2$

$\mathrm{h}(\mathrm{J}-$ cont $)=\mathrm{U}(\mathrm{J})$

$\operatorname{IF}(\mathrm{hmax}(\mathrm{J}$-cont $)$.LT.h(J-cont))THEN

$\mathrm{hmax}(\mathrm{J}-$ cont $)=\mathrm{h}(\mathrm{J}-$ cont $)$

ENDIF

$\mathrm{y}(\mathrm{J}-$ cont $)=\mathrm{h}(\mathrm{J}-$ cont $)-\mathrm{z}(\mathrm{J}-$ cont $)$

cont $=$ cont +1

ENDDO

cont $1=1$

DO J $=2, \mathrm{~N}, 2$

$\mathrm{V}(\mathrm{J}-\operatorname{cont} 1)=\mathrm{U}(\mathrm{J})$

cont $1=$ cont $1+1$

ENDDO

$\mathrm{DO} \mathrm{I}=1, \mathrm{Nz}$

IF((I.GE.3).AND.(I.LE.5))THEN

IF(y(I).GT.1.00)THEN

$\mathrm{y}(\mathrm{I})=1$

ENDIF

ELSEIF((I.GE.7).AND.(I.LE.9))THEN

IF(y(I).GT.0.80)THEN

$\mathrm{y}(\mathrm{I})=0.80$

ENDIF

ENDIF 


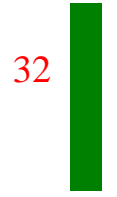

WRITE(2,32)I,y(I),h(I),V(I)

FORMAT(I3,X,F6.2,X,F5.2,X,F6.3)

ENDDO

WRITE(2,*)" !Pula uma linha

Nos trechos de 3 a 5 e de 7 a 9, as alturas calculadas são comparadas com a altura no tubo de forma a garantir o não extrapolamento de $\mathrm{h}(\mathrm{m})$ nestas seções.

São recalculadas na seqüência as variáveis geométricas, funções de $h(m)$ através da sub rotina GEO, bem como as novas alturas $h(m)$, velocidades $V(m / s)$, e raios hidráulicos $R h(m)$. O laço DO responsável pela variação temporal é fechado. É impresso finalmente no arquivo de saída as alturas máximas (hmax) ocorridas na simulação, de acordo com a rotina apresentada na $1^{a}$ simulação. Os arquivos de entrada e saída são fechados e o programa finalizado. 
- 20 Caso : Canal do Trabalhador
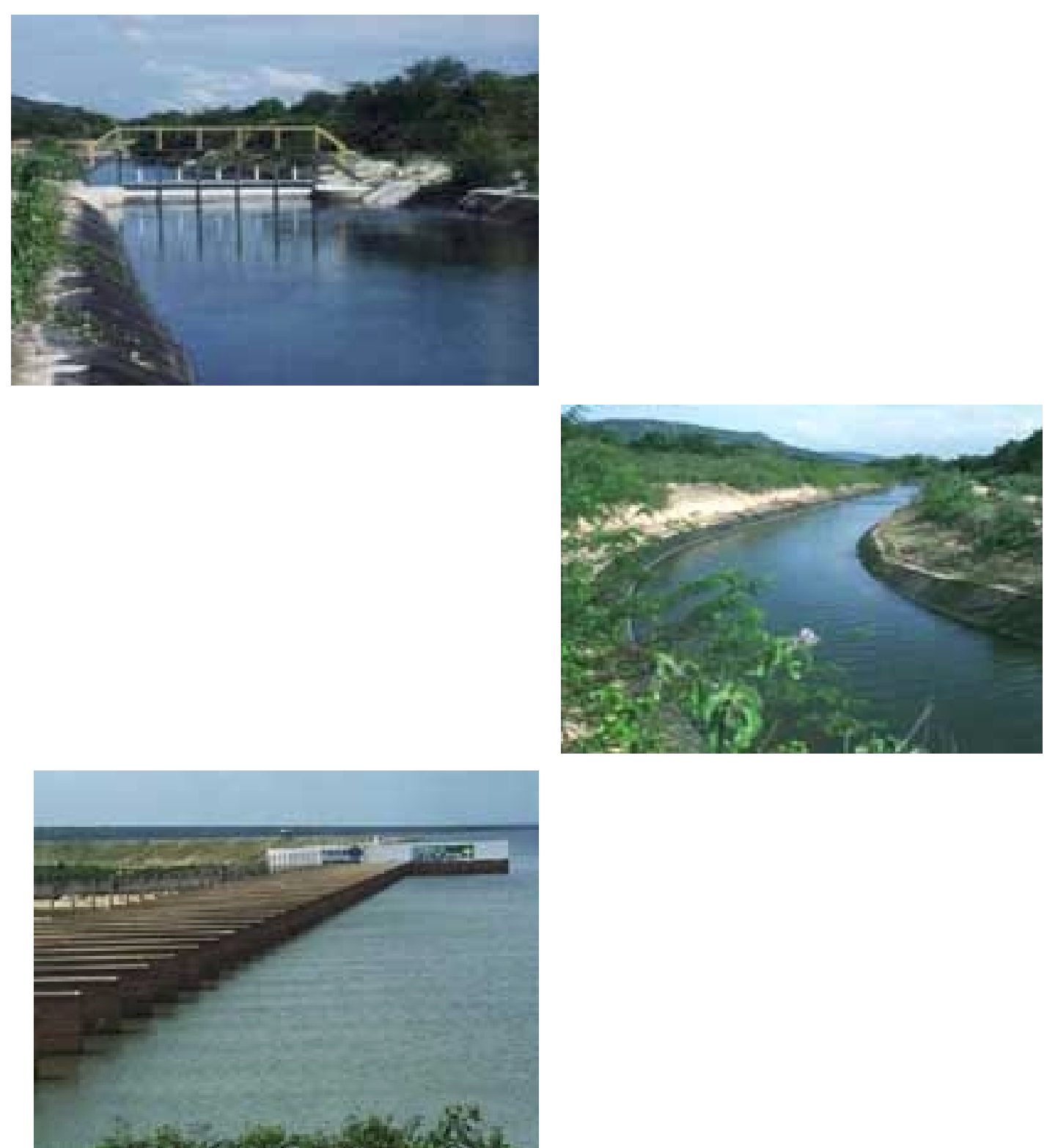

\section{Dados Gerais}

O Canal do Trabalhador foi construído pela CAGECE (Companhia de Água e Esgoto do Ceará) no ano de 1994, com projeto e supervisão das obras feitos pela Hidroterra. Foi uma obra de emergência realizada durante o governo Ciro Gomes, construída em apenas três meses e que salvou o abastecimento de água de Fortaleza-CE no ano supracitado. 
Devido a urgência da construção, o projeto foi sendo concebido e desenhado durante a própria construção. Assim, até o fim de 1994, não havia um projeto materializado por textos e desenhos como é comum em obras desse tipo, o que foi sendo realizado gradativamente no período pós obra. O Canal do Trabalhador possui um extensão aproximada de $100 \mathrm{~km}$. Seus elementos constituintes são:

- Canal de aproximação do Rio Jaguaribe até a Estação Elevatória de Itaiçaba;

- $\quad$ Estação Elevatória de Itaiçaba;

- $\quad$ Chaminé de Equilíbrio;

- $\quad$ Adutora de Itaiçaba;

- Canal;

- $\quad$ Sifão dos Macacos;

- Canal;

- $\quad$ Sifão Pirangí;

- Canal;

- $\quad$ Açude Pacajus;

- $\quad$ Canal de ligação do Açude Pacajus à Estação Elevatória do Açude Ererê;

- $\quad$ Estação Elevatória do Açude Ererê;

- $\quad$ Açude Ererê;

- $\quad$ Canal de ligação do Açude Ererê à Estação Elevatória do Canal do Pacoti;

- $\quad$ Estação Elevatória do Canal do Pacoti;

- $\quad$ Canal de ligação com o Açude Pacoti.

Todo o sistema que constitui o abastecimento de água da cidade de Fortaleza-CE, incluindo o Canal do Trabalhador, pode ser observado no esquema apresentado pela FIGURA 17.

O Canal do Trabalhador tem hoje funções de uso múltiplo e, segundo o Ministério da Integração Nacional, será interligado ao sistema de transposição das águas do rio São Francisco para o desenvolvimento do semi-árido nordestino. 


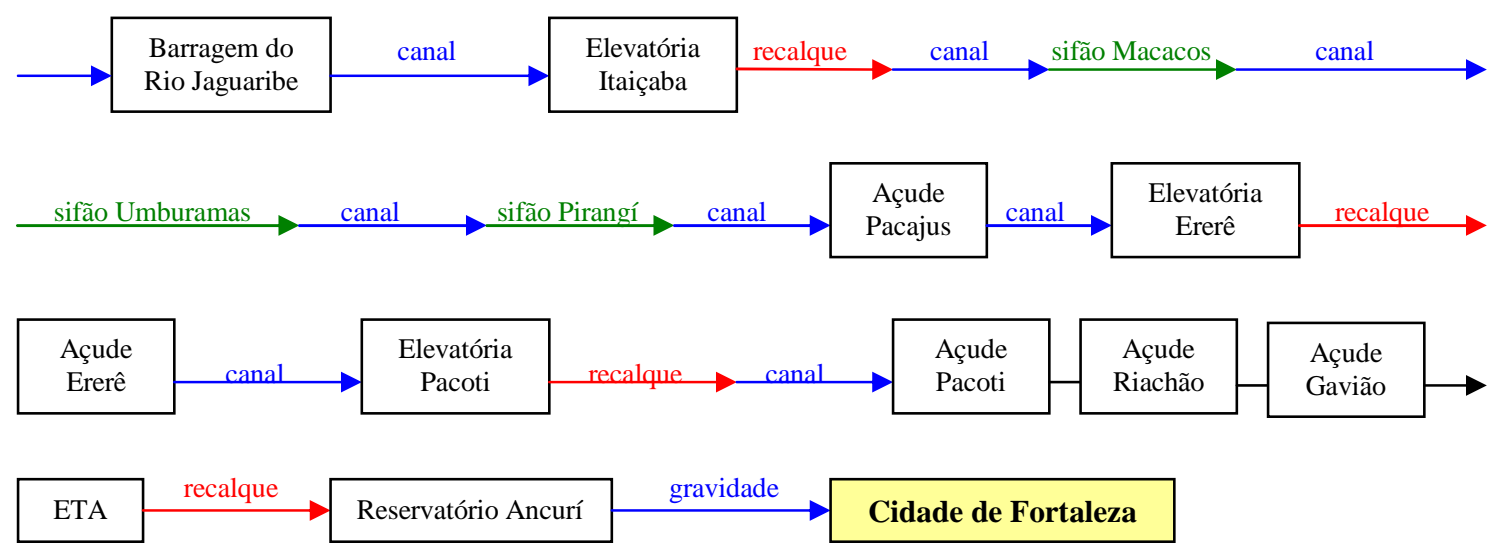

FIGURA 17 - Esquema do Sistema de Abastecimento de Água de Fortaleza

\section{Procedimentos}

Os dados utilizados foram disponibilizados pela Companhia de Gestão dos Recursos Hídricos do Estado do Ceará (COGERH). Estes dados consistem de plantas e perfis topográficos longitudinais e transversais e de cotas e características dos sifões. O trecho tomado para aplicação do modelo computacional inicia-se na elevatória de Itaiçaba, cuja linha de recalque apresenta uma extensão de $740 \mathrm{~m}$ e diâmetro de $1800 \mathrm{~mm}$, e termina no Açude Pacajus, perfazendo um total de $98.121 \mathrm{~m}$. O espaçamento entre seções seguiu a ordem de $1 \mathrm{Km}$ em sua maioria, alterando-se apenas nos trechos caracterizados pelos sifões, constituindo um total de cento e nove seções.

A partir da geometria característica de todas as seções envolvidas, cada uma foi dividida em elementos de área. Este procedimento permitiu determinar as equações reais de área, perímetro molhado e largura de superfície livre, em função da variação da altura d'água, utilizando planilha Excel 2000. Estas foram ajustadas posteriormente por funções matemáticas através do método dos mínimos quadrados. As seções, suas funções, bem como seus gráficos, além das plantas e perfis cadastrais, são apresentados no APÊNDICE - Canal do Trabalhador.

A vazão produzida pelo sistema de recalque, considerada na simulação, é de 3,00 $\mathrm{m}^{3} / \mathrm{s}$. A condição de contorno de jusante, açude Pacajus, foi considerada como uma subida linear da altura d'água no seu enchimento, baseada em condições geométricas aproximadas 
do mesmo, válida depois da chegada da onda na simulação de enchimento. Na simulação de esvaziamento, uma variação linear de descida da altura d'água é também considerada.

Com relação ao modelo matemático empregado(Saint Venant), o fato de atender à simulações que envolvam somente escoamentos livres, foi necessário e indispensável para a sua aplicação neste caso, simplificações nos trechos caracterizados pelos sifões, considerando que os mesmos trabalham sob pressão. Para tanto, foi considerado nestes trechos, tubos hipotéticos seguindo o desnível de entrada e saída dos sifões, os quais, apesar de não apresentarem exatamente a mesma característica de enchimento, permitem determinar de forma aproximada o tempo de percurso da onda.

Como dito, para a aplicação do modelo computacional foram consideradas duas situações:

Primeiro, com o canal vazio foi simulado o seu enchimento de forma a determinar o tempo aproximado de percurso da onda, o que facilita sua operação e viabiliza a implementação de controles automatizados. Para efeito matemático foi considerado uma pequena lâmina inicial de $2 \mathrm{~cm}$ em toda extensão do canal. Isto faz com que a área calculada não seja totalmente nula e conseqüentemente não anule o raio hidráulico. Como este último entra no equacionamento via equação do movimento no denominador, faz com que o termo tenda a infinito, se igual a zero, provocando erro matemático.

A simulação seguinte, que conjuntamente à primeira subsidia $o$ gerenciamento do sistema de controle, parte de uma situação de regime permanente quando num instante de tempo qualquer, o bombeamento em Itaiçaba é desligado. Desta maneira é possível avaliar o tempo em que a água no canal ainda supri a demanda em Pacajus.

O modelo computacional aplicado neste caso permite determinar o tempo de antecedência em que se deve ligar e desligar o bombeamento em Itaiçaba. Para uma avaliação geral do sistema, necessitar-se-ia de conhecer a variação real de nível em Pacajus $\mathrm{y}(\mathrm{t})$ e ainda dispor de um equacionamento matemático que pudesse prever a resolução simultânea de escoamentos livres e forçados para tratamento simultâneo dos trechos de canais e sifões. 
Na FIGURA 18 é esboçado o esquema do caso em pauta. O canal apresenta geometria trapezoidal. Nas seções 5 e 6 , de 27 a 31 e de 71 a 74, a composição é feita por tubos que representam os sifões. A discretização de espaço foi definida em 109 seções com espaçamentos $(\Delta \mathrm{x})$ em torno de $1 \mathrm{~km}$. O intervalo de tempo para cálculo $(\Delta \mathrm{t})$ foi discretizado a cada 3 min (três minutos) num total de 2 dias para enchimento, e a cada 30 min (trinta minutos) num total de 4 dias para esvaziamento.

\section{Esquema:}

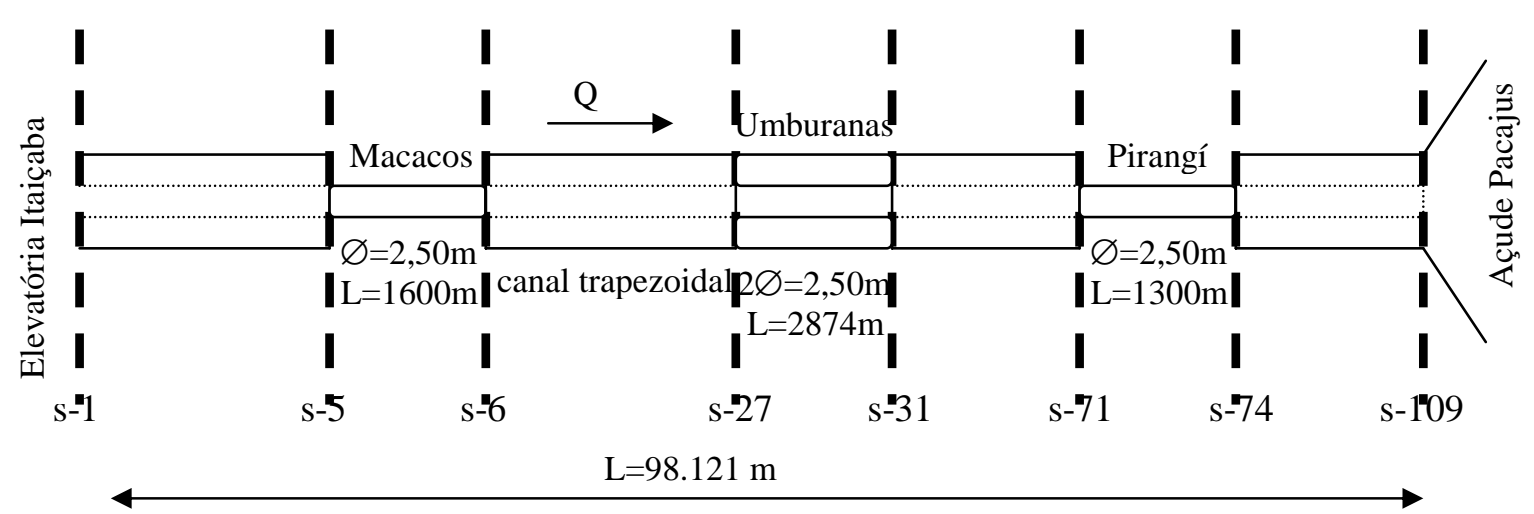

FIGURA 18 - Esquema do Canal do Trabalhador

\section{Modelo Computacional}

O modelo computacional apresentado e comentado na seqüência, contempla as adequações e ajustes realizados a partir da configuração apresentada no caso anterior, alterando basicamente a geometria e os contornos. Para tanto, várias rotinas comentadas anteriormente são mantidas. Assim, limitar-se-á a descrição dos tópicos não comuns e particulares deste caso. Com relação aos contornos, como à montante tem-se $\mathrm{V}(\mathrm{m} / \mathrm{s})$ e à jusante $\mathrm{h}(\mathrm{m})$, o inverso do caso anterior, preferiu-se inverter a montagem da matriz para que a seqüência numérica das seções fosse mantida. 
- $\quad 1^{\text {a }}$ Simulação (Enchimento do Canal)

\section{PROGRAM ESCOAMENTO TRANSIENTE EM CANAIS}

INTEGER cont,cont 1, cont2

REAL*8 SAI

REAL*8,ALLOCATABLE :: A(:),V(:),y(:),z(:),h(:),hm(:),Vm(:),

$\operatorname{Aj}(:), \operatorname{Bj}(:), \operatorname{Cj}(:), \operatorname{Dj}(:), \operatorname{Ej}(:), \operatorname{Ajl}(:), \operatorname{Bjl}(:), \operatorname{Cjl}(:), \operatorname{Djl}(:)$,

$\operatorname{Ejl}(:), \operatorname{MATA}(:,:), \mathrm{B}(:), \mathrm{U}(:), \operatorname{ABCD}(:,:), \operatorname{Rh}(:), \operatorname{Am}(:), \operatorname{Pm}(:)$,

$\mathrm{P}(:), \operatorname{hmax}(:), \operatorname{Bi}(:), \operatorname{Bim}(:), \operatorname{So}(:), \operatorname{Dx}(:), \mathrm{hj}(:)$

Declaração das variáveis e vetores do programa. Os arquivos texto utilizados para a entrada e saída de dados são abertos na sequência

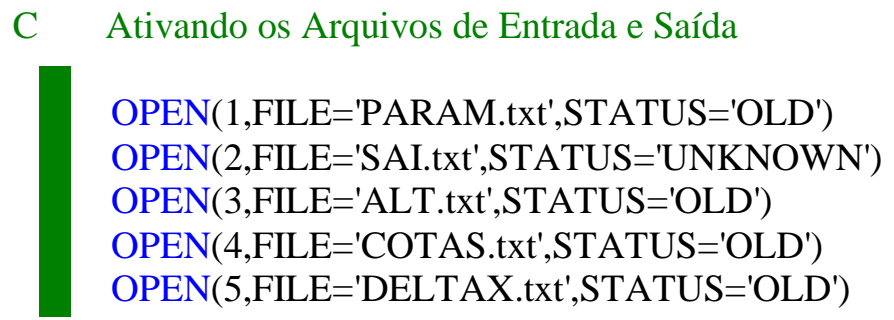

$\mathrm{O}$ arquivo de entrada 'ALT.txt' representa as alturas d'água $\mathrm{y}(\mathrm{m})$, obtidas no regime permanente. Como dito anteriormente, para fins matemáticos foi considerado uma lâmina inicial de $2 \mathrm{~cm}$ em toda a extensão do canal, com exceção do primeiro trecho que vai até o sifão Macacos onde o canal está em aclive. Neste trecho o canal possui água em nível horizontal e conseqüentemente com $\mathrm{y}(\mathrm{m})$ das seções de 1 a 4 variáveis conforme a declividade. O arquivo 'COTAS.txt' são as alturas do fundo do canal em relação ao plano de referência, determinadas topograficamente. 'DELTAX.txt' é o arquivo que contém o espaçamento entre as seções, discretizadas convenientemente. 'PARAM.txt' são os parâmetros complementares e, o arquivo 'SAI.txt', os dados de saída cujo arquivo é criado pelo programa.

\begin{tabular}{|ll|}
\hline \multicolumn{2}{|l||}{ ALT - Bloco de notas } \\
\hline Arquivo Editar Pesquisar & Ajuda \\
\hline 0.48, & seção(01) - y(m) \\
0.28, & seção(02) - y(m) \\
0.08, & seção(03) - y(m) \\
0.06, & seção(04) - y(m) \\
0.02, & seção(05) - y(m) \\
0.02, & seção(06) - y(m) \\
0.02, & seção(07) - y(m) \\
0.02, & seção(08) - y(m) \\
\hline
\end{tabular}

\begin{tabular}{|c|c|c|c|}
\hline \\
\hline \multicolumn{4}{|c|}{$\begin{array}{l}\text { COTAS - Bloco de notas } \\
\text { Arquivo Editar Pesquisar }\end{array}$} \\
\hline \multirow{2}{*}{\multicolumn{4}{|c|}{$\begin{array}{ll}23.94, & \text { seção(01) - z(m) } \\
24.14, & \text { secão(02) - z(m) }\end{array}$}} \\
\hline & & & \\
\hline \multicolumn{4}{|c|}{24.34, seção(03) - z(m) } \\
\hline \multicolumn{4}{|c|}{ 24.36, $\quad$ seção(04) - z(m) } \\
\hline \multicolumn{4}{|c|}{ 24.40, $\operatorname{seção(05)~-~z(m)~}$} \\
\hline \multicolumn{4}{|c|}{$23.00, \quad$ seção(06) - z(m) } \\
\hline \multirow{2}{*}{\multicolumn{4}{|c|}{$\begin{array}{ll}22.99, & \text { seção(07) - z(m) } \\
22.96, & \text { secão(08) - z(m) }\end{array}$}} \\
\hline & & & \\
\hline
\end{tabular}




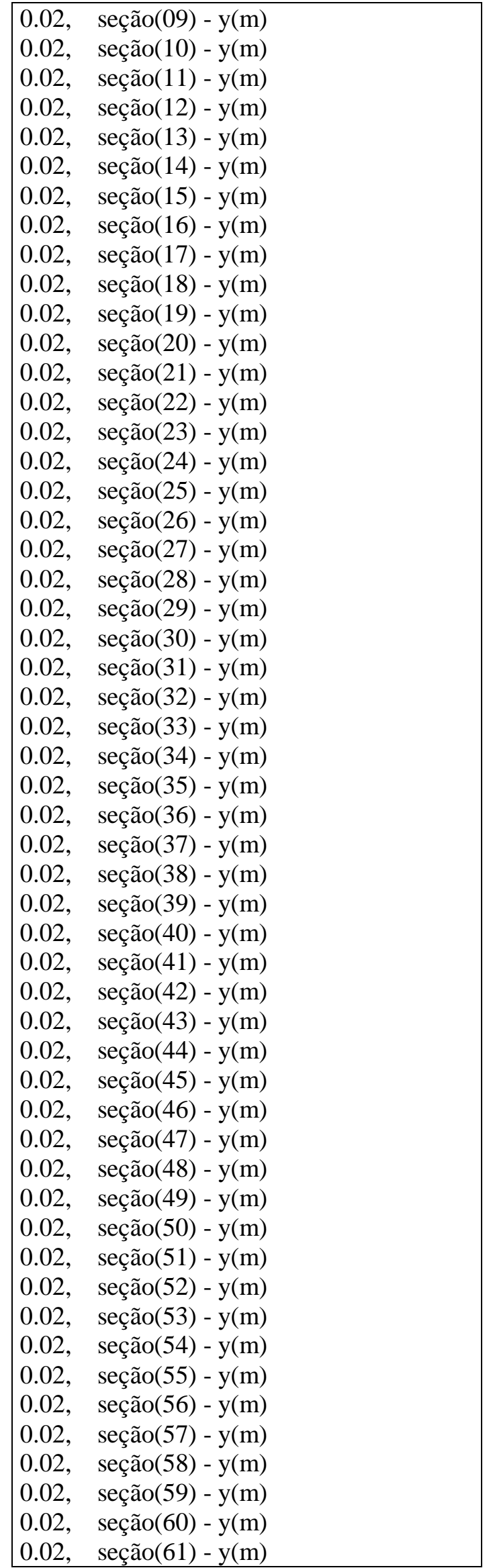

22.93, seção(09) - z(m)

22.90 , seção $(10)-z(m)$

22.88, seção $(11)-z(m)$

22.87, seção(12) - $z(m)$

22.86, seção(13) - z(m)

22.84, seção $(14)-z(m)$

22.83, seção(15) - $\mathrm{z}(\mathrm{m})$

22.81, seção(16) - $\mathrm{z}(\mathrm{m})$

22.80, seção(17) - z(m)

22.79, seção $(18)-z(m)$

22.77, seção(19) - z(m)

22.76, seção $(20)-z(m)$

22.74, seção $(21)-z(m)$

22.73, seção $(22)-z(m)$

22.72, seção $(23)-z(m)$

22.70, seção $(24)-z(m)$

22.62, seção $(25)-z(m)$

22.46, seção $(26)-z(m)$

22.44, seção $(27)-z(m)$

22.14, seção $(28)-z(m)$

21.92, seção(29) - $\mathrm{z}(\mathrm{m})$

21.70, seção $(30)-z(m)$

21.17, seção(31) - z(m)

21.15 , seção(32) - z(m)

21.14, seção(33) - z(m)

21.12, seção(34) - z(m)

21.11, seção(35) - $\mathrm{z}(\mathrm{m})$

21.09, seção(36) - z(m)

21.08 , seção $(37)-z(m)$

21.07, seção(38) - $z(m)$

21.05 , seção(39) - $z(m)$

21.04, seção $(40)-z(m)$

21.02, seção(41) - $\mathrm{z}(\mathrm{m})$

21.01, seção(42) - $\mathrm{z}(\mathrm{m})$

21.00, seção(43) - z(m)

20.99, seção(44) - z(m)

20.97, seção(45) - z(m)

20.96, seção(46) - z(m)

20.95, seção(47) - z(m)

20.94, seção(48) - $z(m)$

20.93, seção(49) - z(m)

20.91, seção(50) - $z(m)$

20.90, seção(51) - $z(m)$

20.89, seção $(52)-z(m)$

20.87, seção(53) - z(m)

20.86, seção(54) - z(m)

20.84, seção(55) - $\mathrm{z}(\mathrm{m})$

20.83, seção(56) - $\mathrm{z}(\mathrm{m})$

20.82, seção(57) - z(m)

20.81, seção(58) - z(m)

20.79, seção(59) - z(m)

20.78, seção(60) - z(m)

20.77 , seção $(61)-z(m)$ 


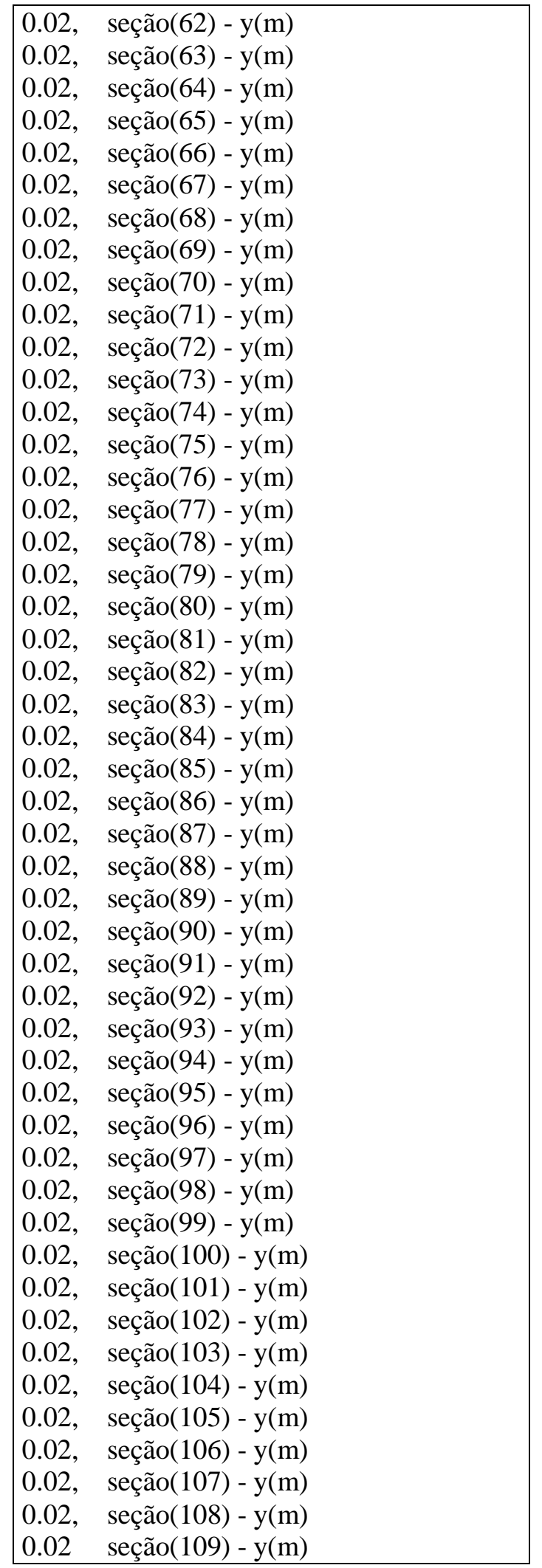

20.75, seção(62) - $\mathrm{z}(\mathrm{m})$

20.74, seção $(63)-z(m)$

20.72, seção(64) - z(m)

20.71, seção(65) - z(m)

20.70, seção(66) - z(m)

20.69, seção $(67)-z(m)$

20.68, seção $(68)-z(m)$

20.66, seção $(69)-z(m)$

20.65, seção(70) - z(m)

20.64, seção(71) - z(m)

20.41, seção(72) - z(m)

19.94, seção(73) - z(m)

19.42, seção(74) - z(m)

19.41, seção(75) - z(m)

19.38, seção(76) - z(m)

19.36, seção(77) - z(m)

19.34, seção(78) - z(m)

19.32, seção(79) - z(m)

19.31, seção $(80)-z(m)$

19.29 , seção $(81)-\mathrm{z}(\mathrm{m})$

19.28 , seção $(82)-z(m)$

19.27, seção $(83)-z(m)$

19.26, seção(84) - z(m)

19.24, seção $(85)-z(m)$

19.23, seção $(86)-z(m)$

19.22, seção $(87)-z(m)$

19.21, $\operatorname{seção(88)~-~z(m)~}$

19.19 , seção $(89)-z(m)$

19.18, seção(90) - z(m)

19.17, seção(91) - z(m)

19.16, seção(92) - z(m)

19.15, seção(93) - z(m)

19.14, seção(94) - z(m)

19.13, seção(95) - z(m)

19.12, seção(96) - z(m)

19.11, seção(97) - z(m)

19.10, seção(98) - z(m)

19.09, seção(99) - z(m)

19.08, seção(100) - z(m)

19.07, seção(101) - z(m)

19.06 , seção(102) - $z(m)$

19.05 , seção(103) - z(m)

19.04, seção(104) - z(m)

19.03, seção(105) - $z(m)$

19.02, seção(106) - $z(m)$

19.01, seção(107) - z(m)

19.00 , seção(108) - z(m)

19.00 seção(109) - z(m) 


\begin{tabular}{|ll|}
\hline \multicolumn{2}{|l|}{ PARAM - Bloco de notas } \\
\hline Arquivo $\quad$ Editar Pesquisar Ajuda \\
\hline 9.81, & (m/s2)aceleração da gravidade \\
0.015, & coeficiente de Manning \\
98.121, & (m)comprimento do canal \\
19.02, & (m)altura d'água à jusante (açude Pacajus) \\
180, & (s)intervalo de tempo de cálculo \\
0.00, & (m3/s)vazão inicial no canal \\
.600, & (m/s)velocidade na entrada do canal \\
109, & número de seções no canal \\
960, & número de intervalos de tempo para cálculo \\
3.141592654 & valor de Pi \\
\hline
\end{tabular}

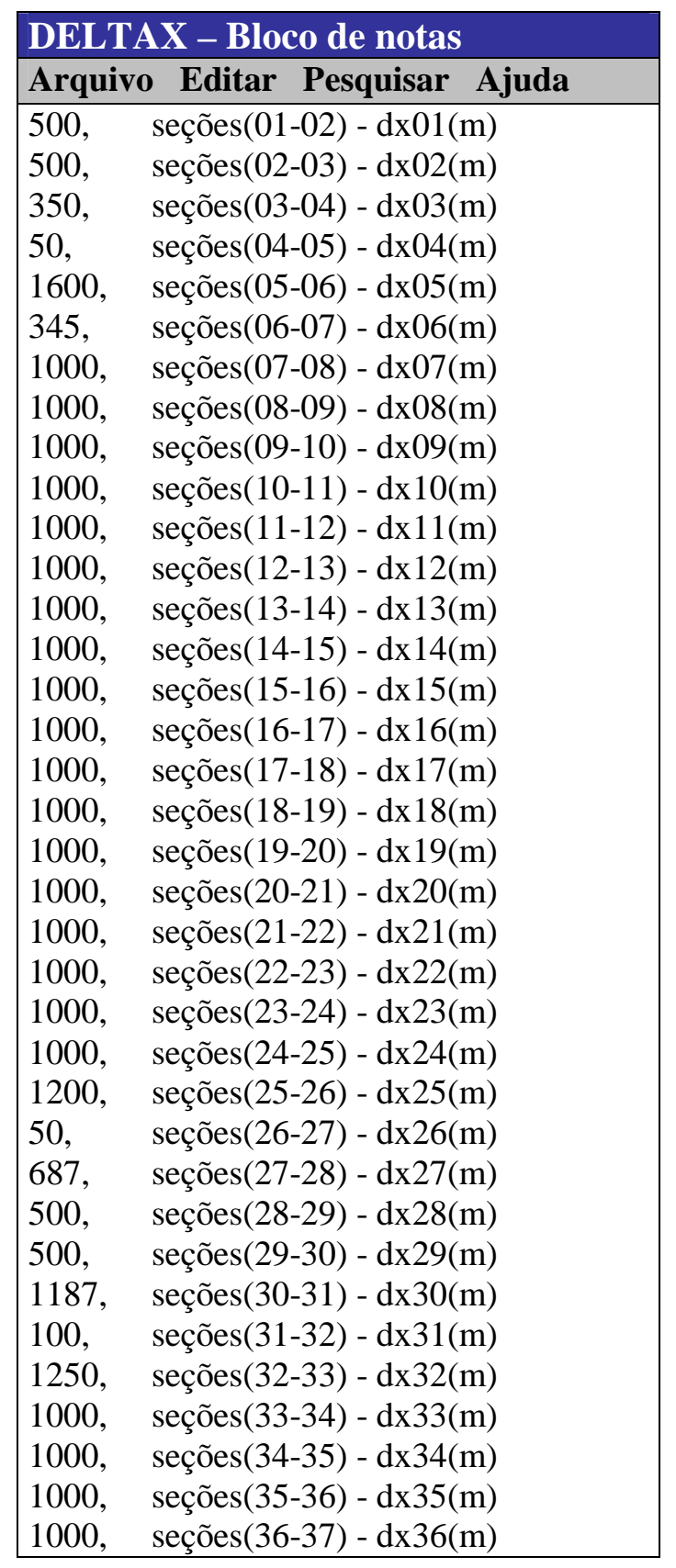

\begin{tabular}{|c|c|}
\hline \multicolumn{2}{|c|}{ DELTAX - Bloco de notas } \\
\hline Arquivo & o Editar Pesquisar Ajuda \\
\hline $1000, \quad s$ & seções $(55-56)-\mathrm{dx} 55(\mathrm{~m})$ \\
\hline 1000 & seções $(56-57)-d x 56(m)$ \\
\hline 1000 & seções $(57-58)-d x 57(m)$ \\
\hline 1000 & seções $(58-59)-$ dx58(m) \\
\hline 1000 & seções $(59-60)-d x 59(m)$ \\
\hline 1000 & $\operatorname{seções}(60-61)-d x 60(m)$ \\
\hline 1000 & $\operatorname{seções}(61-62)-d x 61(m)$ \\
\hline 1000 & $\operatorname{seções}(62-63)-d x 62(m)$ \\
\hline 1000 & seções $(63-64)$ - dx63(m) \\
\hline 1000 & $\operatorname{seções}(64-65)$ - dx64(m) \\
\hline 1000 & seções $(65-66)-d x 65(m)$ \\
\hline 1000 & seções $(66-67)$ - dx66(m) \\
\hline 1000 & seções $(67-68)-d x 67(m)$ \\
\hline 1000 & seções $(68-69)$ - dx68(m) \\
\hline 1000 & $\operatorname{seções}(69-70)-d x 69(m)$ \\
\hline 150 & seções $(70-71)-d x 70(m)$ \\
\hline 250 & seções(71-72) - dx71(m) \\
\hline 500 & seções(72-73) - dx72(m) \\
\hline 550 & seções(73-74) - dx73(m) \\
\hline 100, & seções(74-75) - dx74(m) \\
\hline & seções(75-76) - dx75(m) \\
\hline 1000, & seções(76-77) - dx76(m) \\
\hline 1000, & seções(77-78) - dx77(m) \\
\hline 1000, & seções(78-79) - dx78(m) \\
\hline 1000, & seções(79-80) - dx79(m) \\
\hline 1000 & $\operatorname{seções~}(80-81)-d x 80(m)$ \\
\hline 1000, & seções $(81-82)$ - dx81(m) \\
\hline 1000 & $\operatorname{seções}(82-83)$ - dx82(m) \\
\hline 1000, & seções $(83-84)$ - dx83(m) \\
\hline 1000, & seções $(84-85)$ - dx84(m) \\
\hline 1000, & seções $(85-86)$ - dx85(m) \\
\hline 1000, & seções (86-87) - dx86(m) \\
\hline 1000, & seções $(87-88)$ - dx87(m) \\
\hline 1000, & seções $(88-89)$ - dx88(m) \\
\hline 1000 & seções(89-90) - dx89(m) \\
\hline $1000, \quad s$ & seções $(90-91)-d x 90(m)$ \\
\hline
\end{tabular}




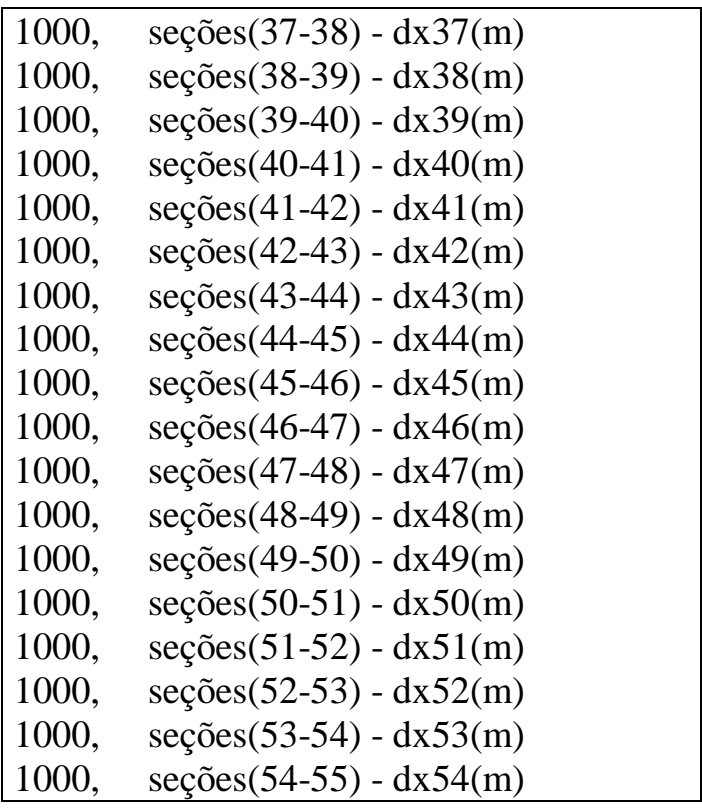

\begin{tabular}{|c|c|}
\hline $\begin{array}{l}1000, \\
1000, \\
1000, \\
1000, \\
1000, \\
1000, \\
1000, \\
1000, \\
1000, \\
1000, \\
1000, \\
1000, \\
1000, \\
1000, \\
1000, \\
1000, \\
1000, \\
2\end{array}$ & 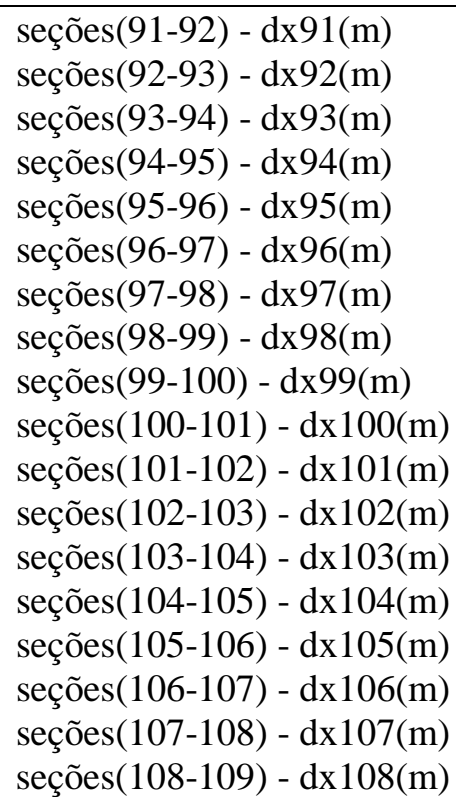 \\
\hline
\end{tabular}

A seguir é realizada a leitura do arquivo 'PARAM.txt', feita a atribuição da dimensão das matrizes e número de equações, com a alocação dinâmica dos vetores pré-declarados em função desta atribuição.

C Lendo o Arquivo dos Parâmetros de Cálculo
$\operatorname{READ}(1, *) \mathrm{g}$
$\operatorname{READ}(1, *) \mathrm{w}$
$\operatorname{READ}(1, *) 1$
$\operatorname{READ}(1, *)$ ha
$\operatorname{READ}(1, *) \mathrm{Dt}$
$\operatorname{READ}(1, *) \mathrm{Qi}$
$\operatorname{READ}(1, *) \mathrm{Va}$
$\operatorname{READ}(1, *) \mathrm{Nz}$
$\operatorname{READ}(1, *) \mathrm{Nt}$
$\operatorname{READ}(1, *) \mathrm{Pi}$
$!(\mathrm{m} / \mathrm{s} 2)$ aceleração da gravidade
!coeficiente de Manning
!(m)comprimento do canal
!(m) nível constante no Açude Pacajus
!(s)intervalo de tempo de cálculo
!(m3/s)vazão inicial no canal
$!(\mathrm{m} / \mathrm{s})$ velocidade na entrada do canal
!número de seções no canal
!número de intervalos de tempo para cálculo
!valor de Pi

C Atribuição da Dimensão do Sistema de Matrizes e

C Número de Equações

\section{$\mathrm{N}=\mathrm{Nz}^{*} 2$}

$\mathrm{Ne}=(2 * \mathrm{Nz})-2$

C Alocando os vetores

ALLOCATE(A(Nz),V(Nz),y(Nz),z(Nz),h(Nz),hm(Nz-1),Vm(Nz-1), $\mathrm{Aj}(\mathrm{Nz}-1), \mathrm{Bj}(\mathrm{Nz}-1), \mathrm{Cj}(\mathrm{Nz}-1), \mathrm{Dj}(\mathrm{Nz}-1), \mathrm{Ej}(\mathrm{Nz}-1)$, Ajl(Nz-1),Bjl(Nz-1),Cjl(Nz-1),Djl(Nz-1),Ejl(Nz-1), $\operatorname{ABCD}(4, \mathrm{Ne}), \operatorname{MATA}(\mathrm{N}, \mathrm{N}+1), \mathrm{B}(\mathrm{N}), \mathrm{U}(\mathrm{N}), \mathrm{Rh}(\mathrm{Nz}-1)$, $\mathrm{Am}(\mathrm{Nz}-1), \mathrm{Pm}(\mathrm{Nz}-1), \mathrm{P}(\mathrm{Nz}), \mathrm{hmax}(\mathrm{Nz}), \mathrm{Bi}(\mathrm{Nz})$, $\operatorname{Bim}(\mathrm{Nz}-1), \mathrm{So}(\mathrm{Nz}-1), \mathrm{Dx}(\mathrm{Nz}-1), \mathrm{hj}(\mathrm{Nz}))$ 
O vetor declividade dos trechos $\mathrm{So}(\mathrm{m} / \mathrm{m})$, é alocado em função das cotas e espaçamentos entre os mesmos. A altura d'água h(m), medida em relação ao plano de referência horizontal, é dada pela soma de $\mathrm{y}(\mathrm{m})$ e $\mathrm{z}(\mathrm{m})$.

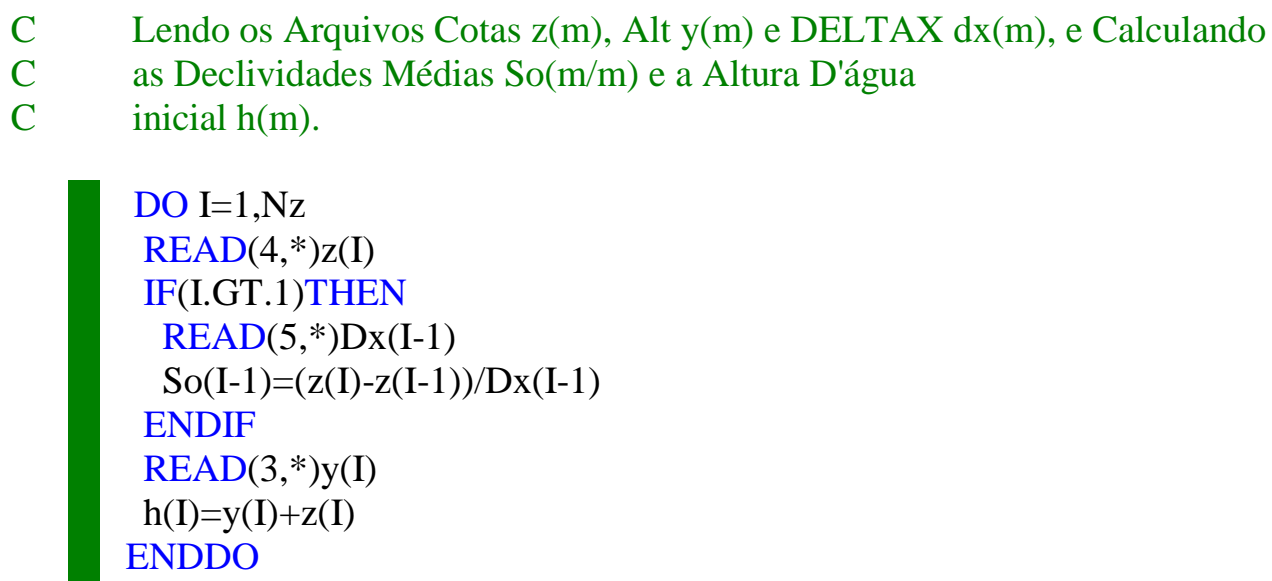

A partir das equações de geometria obtidas em função de $\mathrm{y}(\mathrm{m})$ (largura da superfície livre $\mathrm{Bi}(\mathrm{m})$, área hidráulica $\mathrm{A}\left(\mathrm{m}^{2}\right)$, perímetro molhado $\mathrm{P}(\mathrm{m})$ ) apresentadas no APÊNDICE Canal do Trabalhador, onde também é mostrado as seções e suas localizações, são determinadas as condições geométricas iniciais pela sub rotina GEO (ANEXO p.146-157) e suas médias. Em seqüência é obtida a velocidade média entre seções $\mathrm{v}(\mathrm{m} / \mathrm{s})$ bem como as respectivas alturas d'água $\mathrm{h}(\mathrm{m})$. São os dados conhecidos no tempo k, necessários para o cálculo no tempo k+1.

C Chamando Sbrotina GEO para cálculo dos parâmetro geométricos e

C hidráulicos iniciais no canal

CALL GEO(y,P,A,Bi,Am,Pm,Bim,Rh,Nz)

C Calculo das velocidades iniciais $\mathrm{V}(\mathrm{m} / \mathrm{s})$,

C profundidades médias $\mathrm{hm}(\mathrm{m})$ e velocidades médias $\mathrm{Vm}(\mathrm{m} / \mathrm{s})$

$\mathrm{C}$ iniciais

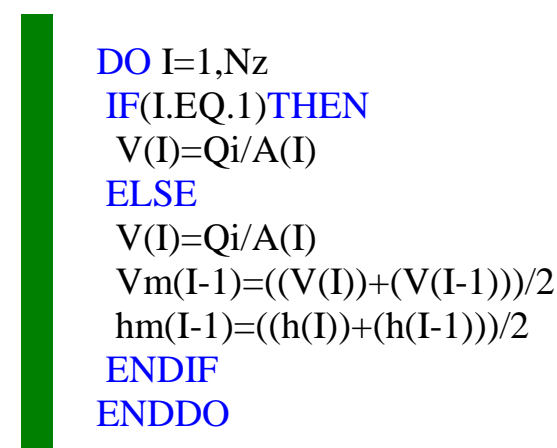

As cotas, alturas d'água e velocidades iniciais são impressas no arquivo de saída 'SAI.txt'. 
C

Gravando as Condições Iniciais em Arquivo

WRITE $(2, *)$ 'TRANSIENTE HIDRÁULICO - CANAL DO TRABALHADOR'

WRITE $(2, *)^{\prime}$ Enchimento do Canal'

$\operatorname{WRITE}(2, *) "$ !pula uma linha

WRITE $\left(2,{ }^{*}\right)$ 'CONDIÇÕES INICIAIS DO ESCOAMENTO'

WRITE $(2, *) "$ !pula uma linha

WRITE(2, *)'SEC,', ','y(m)',' ','h(m)',' ','z(m),', ','V(m/s)'

WRITE $(2, *) "$ !pula uma linha

DO I $=1, \mathrm{Nz}$

WRITE(2,15)I,y(I),h(I),z(I),V(I)

15

FORMAT(I3,X,F6.2,X,F5.2,X,F5.2,X,F6.3)

ENDDO

WRITE $\left(2,{ }^{*}\right)^{\prime}$ !pula uma linha

Nesta etapa é iniciado o laço de variação temporal. São calculados os vetores ABCDE e o coeficiente de Chezzy a exemplo do caso anterior.

C Cálculo do Coeficiente de Chezzy (Ch) e dos Vetores ABCDE

DO K=Dt,Nt*Dt,Dt !início do laço DO responsável pela

$\mathrm{C}$ variação temporal

DO I $=1, \mathrm{Nz}-1$

$\mathrm{Ch}=(1 / \mathrm{w}) *(\mathrm{Rh}(\mathrm{I}) * *(0.1666666667))$ !coef.de Chezzy

$\operatorname{Aj}(\mathrm{I})=-((2 * \operatorname{Dt} / \mathrm{Dx}(\mathrm{I})) *(\operatorname{Am}(\mathrm{I}) / \operatorname{Bim}(\mathrm{I})))$

$\operatorname{Bj}(\mathrm{I})=(1-((2 * \mathrm{Dt} / \mathrm{Dx}(\mathrm{I})) * \operatorname{Vm}(\mathrm{I})))$

$\mathrm{Cj}(\mathrm{I})=((2 * \mathrm{Dt} / \mathrm{Dx}(\mathrm{I})) *(\mathrm{Am}(\mathrm{I}) / \mathrm{Bim}(\mathrm{I})))$

$\mathrm{Dj}(\mathrm{I})=(1+((2 * \mathrm{Dt} / \mathrm{Dx}(\mathrm{I})) * \mathrm{Vm}(\mathrm{I})))$

$\mathrm{Ej}(\mathrm{I})=(2 * \mathrm{hm}(\mathrm{I}))+(2 * \mathrm{Dt} * \mathrm{Vm}(\mathrm{I}) * \mathrm{So}(\mathrm{I}))$

$\mathrm{Ajl}(\mathrm{I})=(1-((2 * \mathrm{Dt} / \mathrm{Dx}(\mathrm{I})) * \operatorname{Vm}(\mathrm{I})))+((\mathrm{g} * \mathrm{Dt} * \mathrm{ABS}(\mathrm{Vm}(\mathrm{I}))) /$

$\left.\left(\left(\mathrm{Ch}^{* * 2}\right) * \mathrm{Rh}(\mathrm{I})\right)\right)$

$\mathrm{Bj} 1(\mathrm{I})=-((2 * \mathrm{Dt} / \mathrm{Dx}(\mathrm{I})) * \mathrm{~g})$

$\mathrm{Cjl}(\mathrm{I})=(1+((2 * \mathrm{Dt} / \mathrm{Dx}(\mathrm{I})) * \operatorname{Vm}(\mathrm{I})))+((\mathrm{g} * \mathrm{Dt} * \mathrm{ABS}(\mathrm{Vm}(\mathrm{I}))) /$

$((\mathrm{Ch} * * 2) * \mathrm{Rh}(\mathrm{I})))$

$\operatorname{Djl}(\mathrm{I})=\left((2 * \mathrm{Dt} / \mathrm{Dx}(\mathrm{I}))^{*} \mathrm{~g}\right)$

$\mathrm{Ej} 1(\mathrm{I})=(2 * \operatorname{Vm}(\mathrm{I}))$

ENDDO

Os contornos do problema são a velocidade constante na entrada do canal e a altura variando após a chegada da onda no açude Pacajus.

C Atribuição aos Contornos F1 e Fn

$\mathrm{F} 1=\mathrm{Va}$ !contorno montante(entr.canal)

DO I=Nz,Nz

IF((K.GE.144180).AND.(K.LE.147600))THEN

$\mathrm{y} 1=0.0000008 * \mathrm{~K}$

$\mathrm{Fn}=\mathrm{z}(\mathrm{I})+\mathrm{y} 1$ ! contorno jusante(variação de nível no açude)

ELSEIF(K.GT.147600)THEN

y1 $=0.0000050 * \mathrm{~K}$ !contorno jusante(variação de nível no açude) 
$\mathrm{Fn}=\mathrm{z}(\mathrm{I})+\mathrm{y} 1$

ELSE

Fn=ha !contorno jusante(nível constante no açude)

ENDIF

ENDDO

Os passos seguintes do programa descrevem a montagem das matrizes e a chamada da sub rotina SOLVER (ANEXO p.140) para resolução do sistema. Neste caso, a montagem das matrizes ocorre na ordem inversa aos casos anteriores, de forma a possibilitar a seqüência numérica crescente nas seções, isto é, de montante para jusante. Desta forma, a rotina é descrita como segue:

Para facilitar a alocação dos elementos da matriz A, utilizou-se uma matriz composta pelos vetores $A_{J}, A_{J L}, B_{J}, B_{J L}, C_{J}, C_{J L}, D_{J}$ e $D_{J L}$. Para tanto, a alocação destes elementos na matriz chamada de $\mathrm{ABCD}$, ocorreu-se da seguinte forma

C Alocação dos Elementos de ABCD

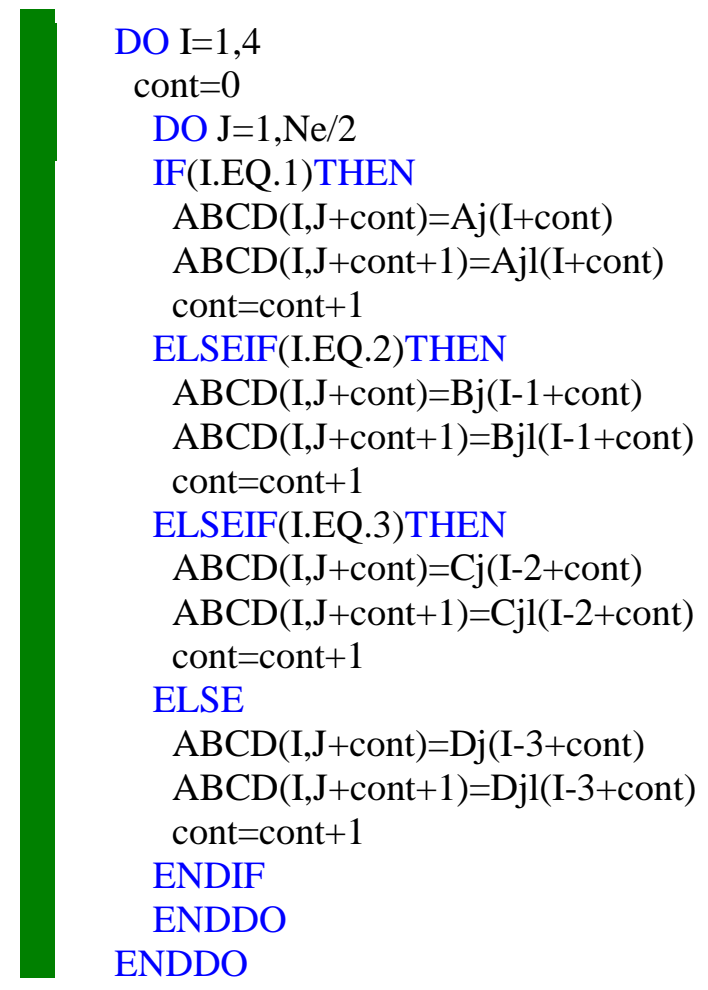

após este procedimento, a composição da matriz $\mathrm{ABCD}$ fica 


$$
\left[\begin{array}{llllllll}
A_{J 1} & A_{J L 1} & A_{J 2} & A_{J L 2} & ----- & A_{J L 107} & A_{J 108} & A_{J L 108} \\
B_{J 1} & B_{J L 1} & B_{J 2} & B_{J L 2} & ----- & B_{J L 107} & B_{J 108} & B_{J L 108} \\
C_{J 1} & C_{J L 1} & C_{J 2} & C_{J L 2} & ----- & C_{J L 107} & C_{J 108} & C_{J L 108} \\
D_{J 1} & D_{J L 1} & D_{J 2} & D_{J L 2} & ----- & D_{J L 107} & D_{J 108} & D_{J L 108}
\end{array}\right]
$$

o próximo passo é a alocação da matriz A a partir da matriz $\mathrm{ABCD}$, de acordo com a rotina seguinte

C Alocação dos Elementos de MATA

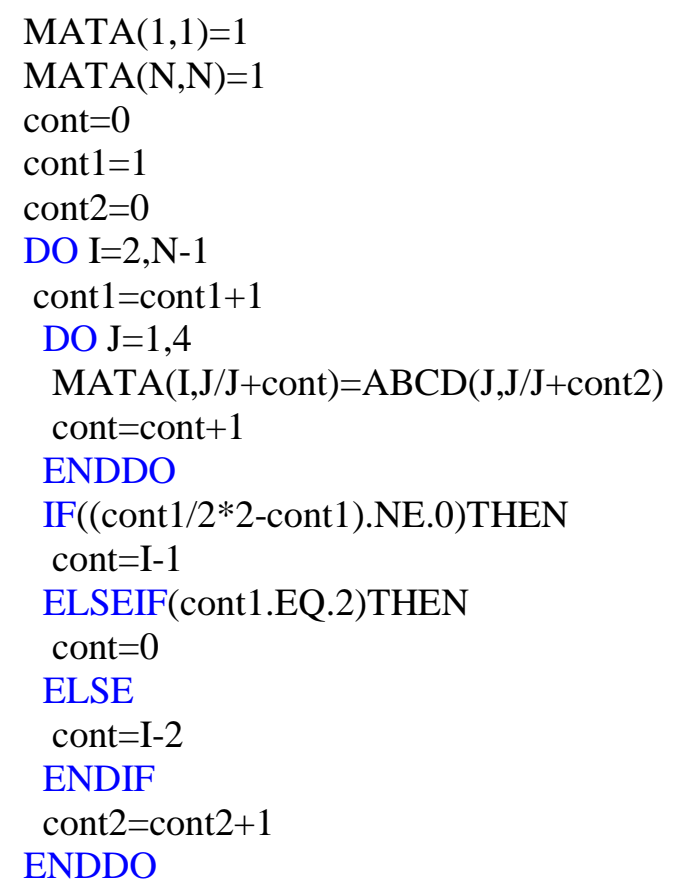

a alocação dos elementos do vetor $B$ é feita pela leitura dos vetores $E_{J}$ e $E_{J L}$, e ainda dos contornos do problema dados por $\mathrm{F}_{1}$ e $\mathrm{F}_{\mathrm{n}}$

C Alocação dos Elementos do Vetor B

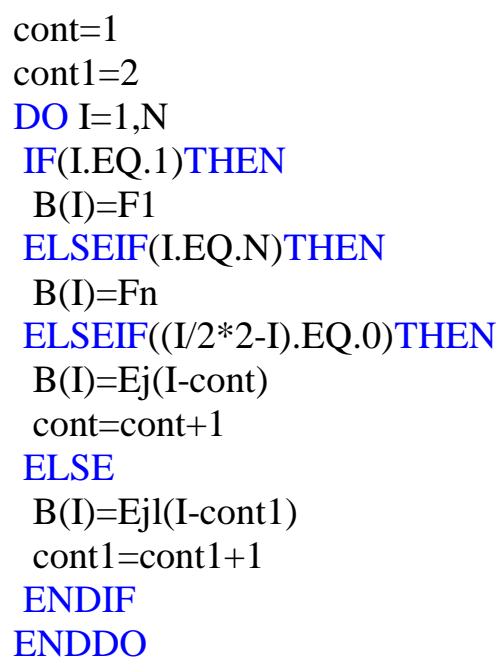


A resolução do sistema seguiu com a utilização da sub-rotina SOLVER. Assim:

C Para Resolução do Sistema, o Vetor B entrará como sendo

C a última coluna de MATA, isto é, $(\mathrm{N}+1)$.

I

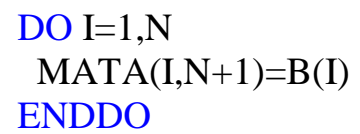

Portanto a solução do vetor U é dada após a chamada da sub-rotina para resolução do sistema, cujos resultados serão armazenados posteriormente no arquivo de saída 'SAI.txt', de acordo com os seguintes passos

C Chamando Sub-rotina para resolução do sistema

CALL SOLVER(MATA,U,N)

Após a resolução do sistema, os resultados são impressos no arquivo 'SAI.txt' como segue

C Fim da resolução do sistema - Gravando o Resultado

31

WRITE $\left(2,{ }^{*}\right)$ 'RESOLUÇÃO DO SISTEMA'

WRITE( $2, *)$ 'TEMPO EM SEGUNDOS'

WRITE(2,31)K

FORMAT('t','=',I6)

WRITE(2,*)'SEC',' ','y(m)',' ','h(m)',' ','V(m/s)'

WRITE $(2, *)^{*}$ !pula uma linha

cont $=0$

DO J $=1, \mathrm{~N}, 2$

$\mathrm{V}(\mathrm{J}$-cont $)=\mathrm{U}(\mathrm{J})$

cont $=$ cont +1

ENDDO

cont $1=1$

DO J $=2, \mathrm{~N}, 2$

$\operatorname{hj}(\mathrm{J}-\operatorname{cont} 1)=\mathrm{U}(\mathrm{J})$

cont $1=$ cont $1+1$

ENDDO

$\mathrm{DO} \mathrm{I}=1, \mathrm{Nz}$

IF(I.EQ.5)THEN

IF(hj(I).GT.26.97)THEN

$\mathrm{hj}(\mathrm{I})=26.97$

ENDIF

ENDIF

IF(I.EQ.6)THEN

IF(hj(I).GT.25.57)THEN

$\mathrm{hj}(\mathrm{I})=25.57$

ENDIF

ENDIF 


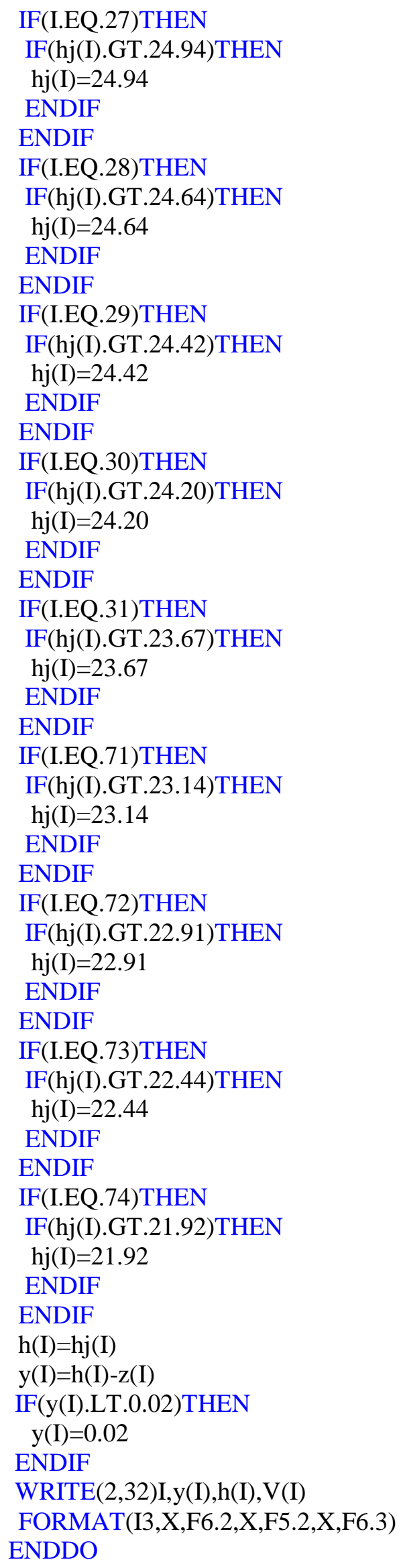


WRITE( $\left.2,{ }^{*}\right)^{\prime}$ !Pula uma linha

Nesta rotina, que armazena os valores de $h(m)$ e $V(m / s)$ para cada intervalo, observa-se que para cada valor de $\mathrm{h}(\mathrm{m})$ lido, é feita uma comparação com as seções caracterizadas por tubos, de forma a garantir que a altura nestas seções, não extrapole o banzo superior do tubo. Também, para fins matemáticos, todos os valores de $\mathrm{y}(\mathrm{m})$ são comparados com um mínimo estabelecido $(\mathrm{y}=2 \mathrm{~cm})$ que, se menor, assume o valor mínimo.

Em seguida são recalculadas as variáveis geométricas, funções de $h(m)$ através da sub rotina GEO. O laço DO responsável pela variação temporal é fechado

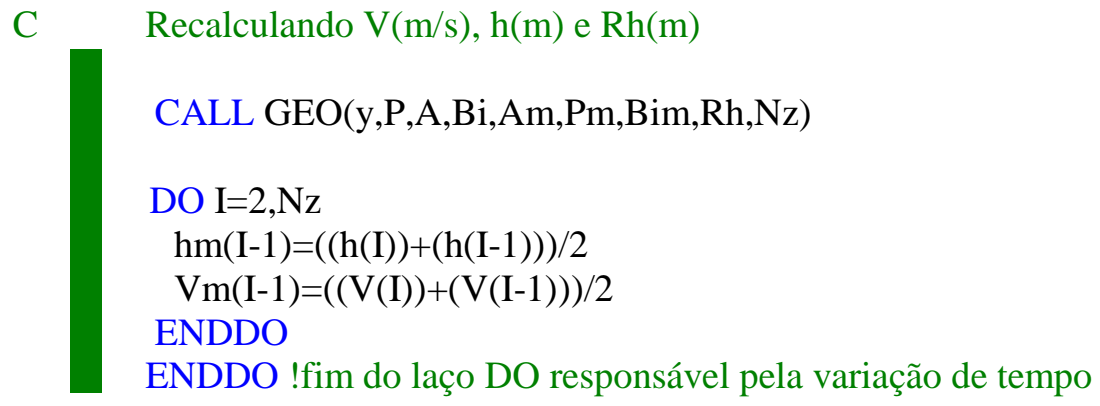

Os arquivos *.txt são fechados e encerrado o programa.

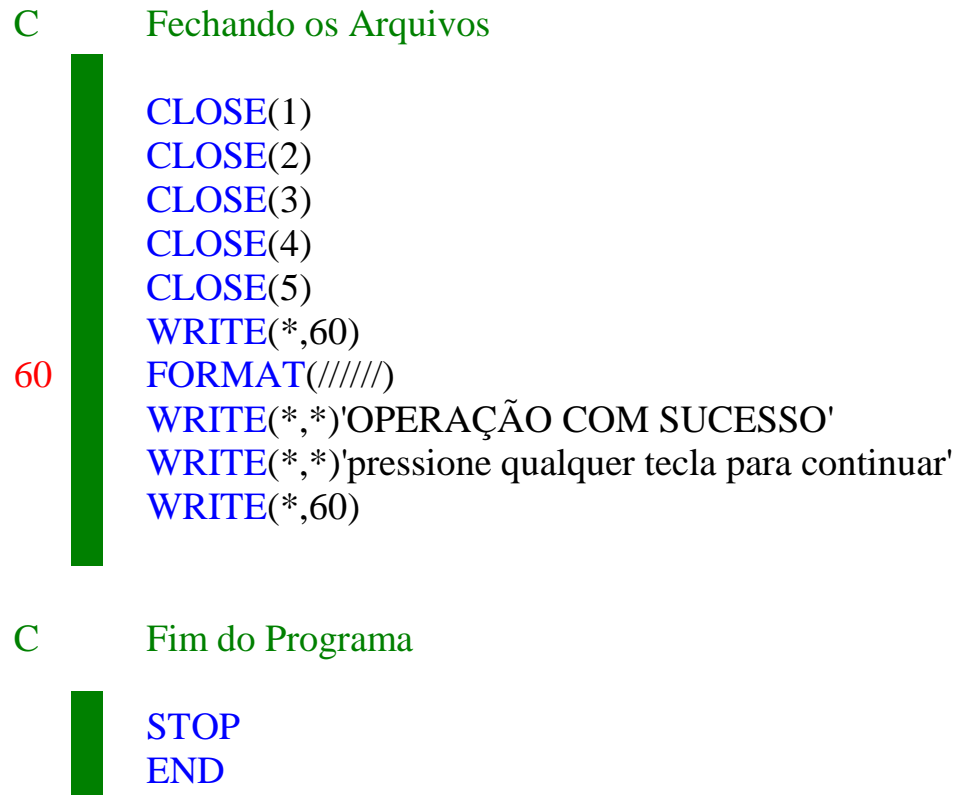


- $\quad 2^{\mathrm{a}}$ Simulação (Esvaziamento do canal)

Para simular a situação de esvaziamento do canal, manteve-se os passos descritos para a simulação de enchimento, alterando-se apenas as condições de contorno, sendo à montante $\mathrm{Va}=0 \mathrm{~m} / \mathrm{s}$ (desligamento das bombas) e à jusante $\mathrm{y}=-0.0000028 * t$; alturas d'água $\mathrm{y}(\mathrm{m})$ iniciais, sendo igual a altura de regime permanente; e as comparações das alturas $h(m)$ nos tubos, passando agora a uma comparação de todas as alturas das seções em cada intervalo com o mínimo de $\mathrm{h}=\mathrm{z}+\mathrm{y}$, sendo $\mathrm{y}=2 \mathrm{~cm}$.

A seguir, é apresentado as alterações ocorridas nos dados de entrada para esta simulação, bem como as rotinas que sofreram modificações nesta situação.

\begin{tabular}{|ll|}
\hline PARAM - Bloco de notas \\
\hline Arquivo Editar Pesquisar Ajuda \\
\hline 9.81, & (m/s2)aceleração da gravidade \\
0.015, & coeficiente de Manning \\
98.121, & (m)comprimento do canal \\
19.86, & (m)altura d'água à jusante (açude Pacajus) \\
1800, & (s)intervalo de tempo de cálculo \\
8.00 & (m3/s)vazão média em regime permanente \\
0.00, & (m/s)velocidade na entrada do canal \\
109, & número de seções no canal \\
192, & número de intervalos de tempo para cálculo \\
3.141592654 & valor de Pi \\
\hline
\end{tabular}

\begin{tabular}{|ll|}
\hline \multicolumn{3}{|l|}{ ALT - Bloco de notas } \\
\hline \multicolumn{2}{|l|}{ Arquivo } \\
\hline 2.32, & seção(01) - y(m) \\
2.08, & seção(02) - y(m) \\
1.82, & seção(03) - y(m) \\
1.74, & seção(04) - y(m) \\
1.69, & seção(05) - y(m) \\
2.57, & seção(06) - y(m) \\
2.72, & seção(07) - y(m) \\
2.71, & seção(08) - y(m) \\
2.70, & seção(09) - y(m) \\
2.69, & seção(10) - y(m) \\
2.67, & seção(11) - y(m) \\
2.63, & seção(12) - y(m) \\
2.60, & seção(13) - y(m) \\
2.57, & seção(14) - y(m) \\
2.53, & seção(15) - y(m) \\
2.49, & seção(16) - y(m) \\
2.45, & seção(17) - y(m) \\
2.40, & seção(18) - y(m) \\
\hline
\end{tabular}

\begin{tabular}{|lll|}
\hline \multicolumn{3}{|l|}{ ALT - Bloco de notas } \\
\hline Arquivo Editar Pesquisar & Ajuda \\
\hline 2.21, & seção(56) - y(m) & \\
2.18, & seção(57) - y(m) & \\
2.15, & seção(58) - y(m) & \\
2.13, & seção(59) - y(m) & \\
2.10, & seção(60) - y(m) & \\
2.06, & seção(61) - y(m) & \\
2.03, & seção(62) - y(m) & \\
1.99, & seção(63) - y(m) & \\
1.95, & seção(64) - y(m) & \\
1.90, & seção(65) - y(m) & \\
1.84, & seção(66) - y(m) \\
1.77, & seção(67) - y(m) & \\
1.69, & seção(68) - y(m) \\
1.60, & seção(69) - y(m) \\
1.47, & seção(70) - y(m) \\
1.46, & seção(71) - y(m) \\
1.64, & seção(72) - y(m) \\
2.05, & seção(73) - y(m) & \\
\hline
\end{tabular}




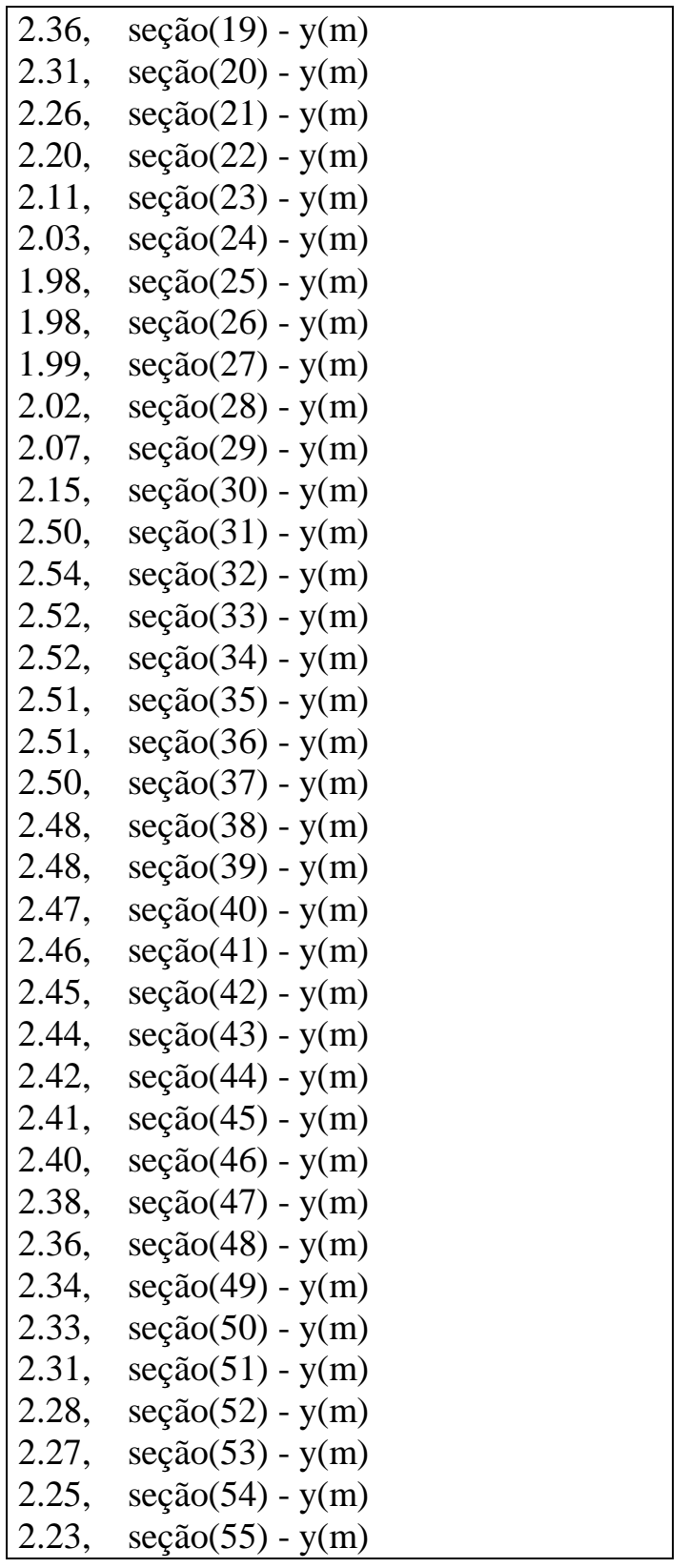

2.50, seção(74) - y(m)

2.51, seção(75) - y(m)

2.52, seção(76) - y(m)

2.50, seção(77) - y(m)

2.48, seção(78) - y(m)

2.47, seção(79) - y(m)

2.44, seção(80) - y(m)

2.42, $\operatorname{seção~}(81)-\mathrm{y}(\mathrm{m})$

2.40, seção(82) - y(m)

2.37, seção(83) - y(m)

2.34, seção(84) - y(m)

2.33, seção(85) - y(m)

2.30, seção(86) - y(m)

2.27, seção(87) - y(m)

2.24, $\quad$ seção(88) - y(m)

2.22, seção(89) - y(m)

2.19, seção(90) - y(m)

2.16, seção(91) - y(m)

2.13, seção(92) - y(m)

2.09, seção(93) - y(m)

2.06, seção(94) - y(m)

2.03, seção(95) - y(m)

1.99, seção(96) - y(m)

1.95, seção(97) - y(m)

1.91, seção(98) - y(m)

$1.87, \quad$ seção(99) - y(m)

1.82, seção(100)- y(m)

1.77, seção(101)- y(m)

1.72, seção(102)- $\mathrm{y}(\mathrm{m})$

1.66, seção(103)- y(m)

1.58, seção(104)- y(m)

1.50, seção(105)- y(m)

1.39, seção(106)- y(m)

1.25 , seção(107)- y(m)

0.87 , seção(108)- $\mathrm{y}(\mathrm{m})$

0.86 seção(109)- y(m)

C Atribuição aos Contornos F1 e Fn

$\mathrm{F} 1=\mathrm{Va}$ !contorno montante(velocidade na entrada do canal)

$\mathrm{DO} \mathrm{I}=\mathrm{Nz}, \mathrm{Nz}$

$\mathrm{y} 1=0.0000028 * \mathrm{~K}$

Fn=ha-y1 !contorno jusante(nível variável no açude)

ENDDO 


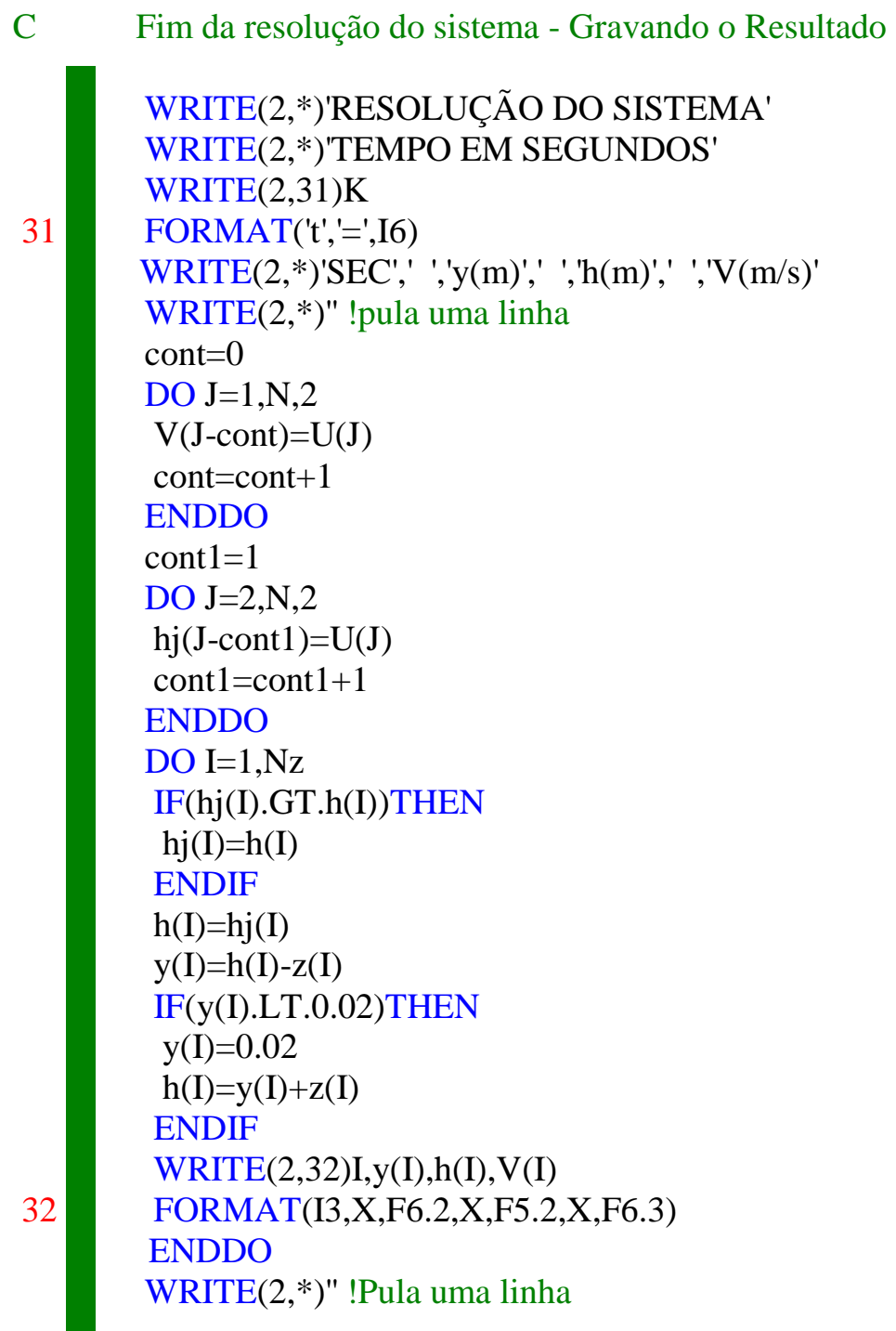

Nesta rotina, antes da impressão dos resultados de $\mathrm{h}(\mathrm{m}), \mathrm{y}(\mathrm{m})$ e $\mathrm{V}(\mathrm{m} / \mathrm{s})$ no arquivo de saída, os valores de $\mathrm{y}(\mathrm{m})$ obtidos são comparados com o valor mínimo de $2 \mathrm{~cm}$. Este valor foi definido na simulação anterior como o representativo do valor zero para fins matemáticos.

Os resultados de ambas simulações são demonstrados e comentados através dos gráficos elaborados para a visualização do fenômeno. 


\section{RESULTADOS}

Os gráficos apresentados na sequiência foram elaborados a partir dos dados de saída do modelo computacional, e esboçam a característica do escoamento transiente para os casos abordados.

Primeiramente são apresentados os gráficos referentes ao teste do modelo (canal retangular) e, na seqüência, os dois estudos de caso realizados: Canal de Alimentação da Usina do Monjolinho e Canal do Trabalhador respectivamente.

\section{- Teste do Modelo (canal retangular)}

Abaixo são apresentados os gráficos das alturas d'água e velocidades no canal ao longo do tempo, decorrentes de evolução da maré à jusante e de hidrograma de cheia à montante. Os dados de saída, gerados pelo modelo para esta simulação, podem ser observados no Anexo p.102-103.

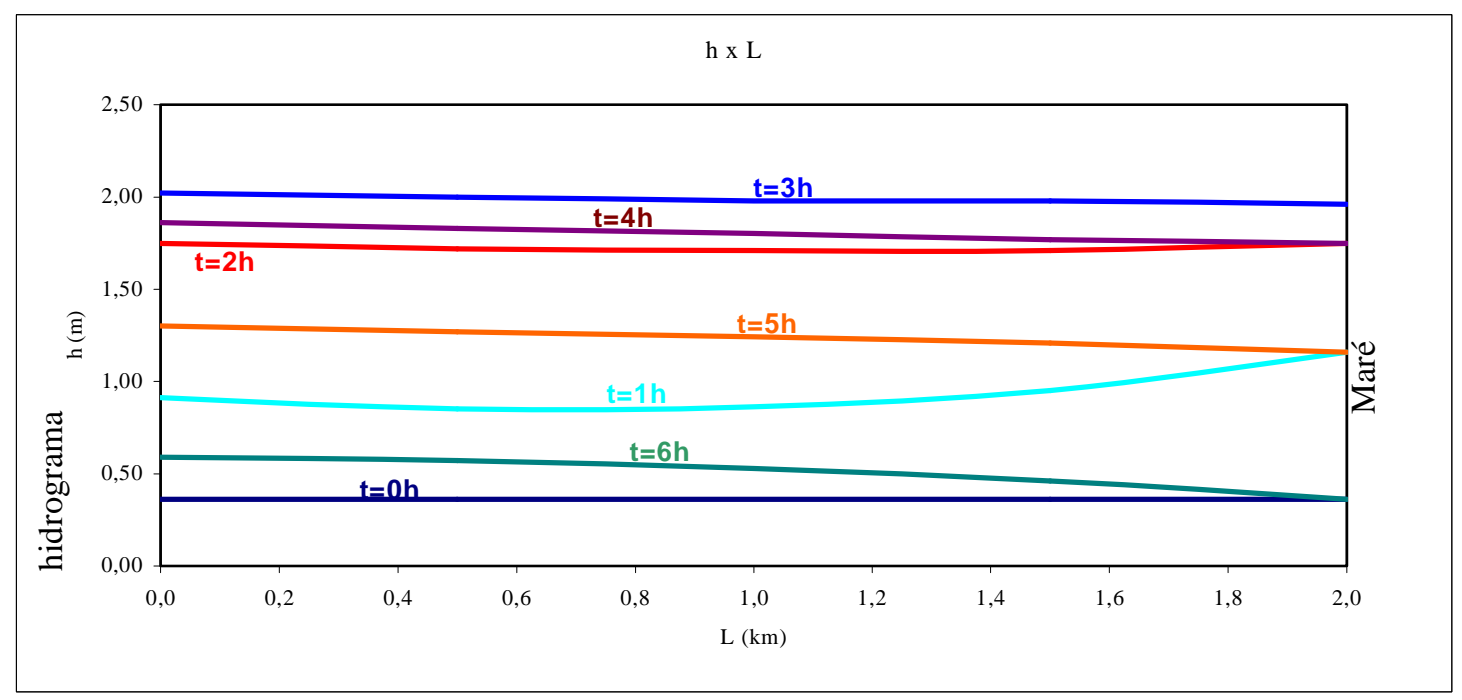

FIGURA 19 -Gráfico dos perfis d'água ao longo do tempo em toda extensão do canal, com tempo em horas t(h), altura d'água em metros $\mathbf{h}(\mathbf{m})$ e extensão do canal em quilômetros $L(k m)$.

Observando-se o gráfico, pode-se perceber o predomínio da maré entre os quilômetros 1 e 2 do canal (ou seções 1, 2 e 3) para t=1h de chuva, e entre os quilômetros 1,5 e 2 (ou seções 1 e 2) para $t=2 h$ de chuva. Após este intervalo, há predominância do escoamento de montante sobre todas as seções do canal. 


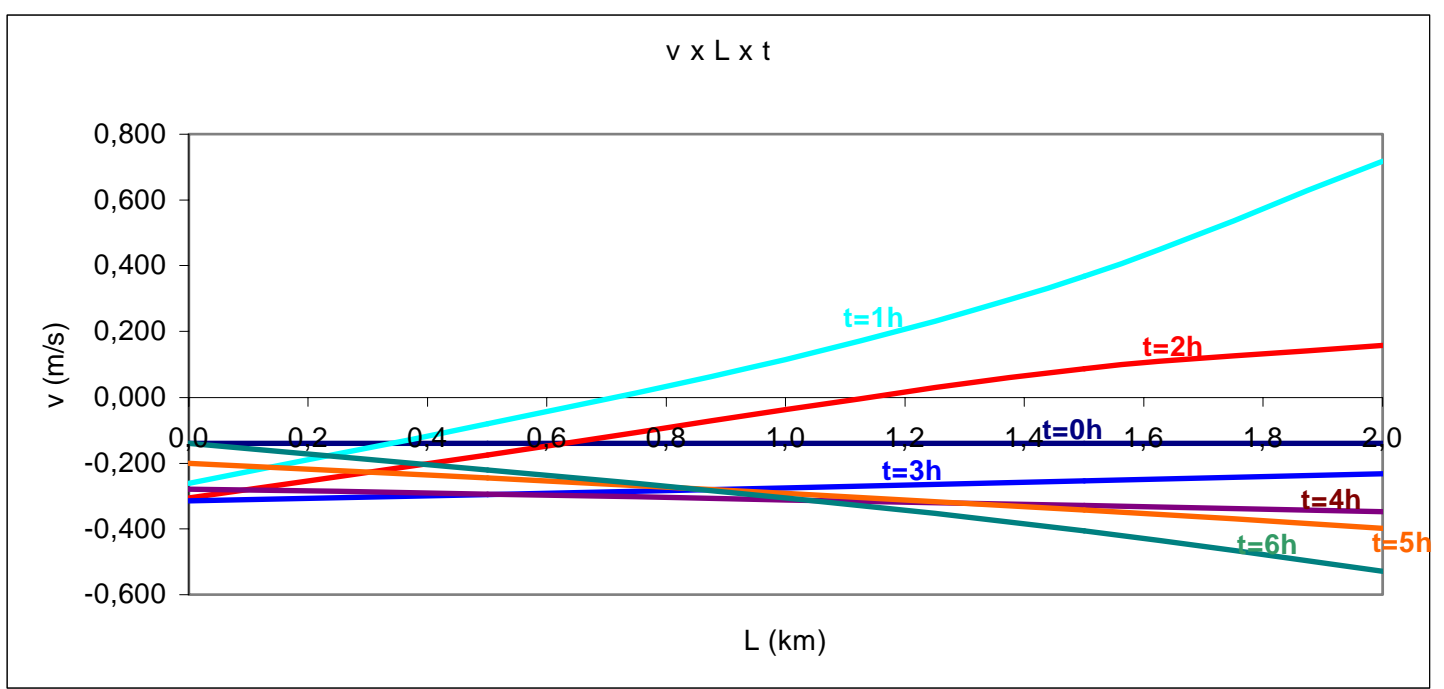

FIGURA 20 -Gráfico do perfil de velocidade ocorrida no canal no decorrer do tempo

A ocorrência de velocidades positivas se dá durante as duas primeiras horas de chuva, sendo entre os quilômetros 0,7 e 2,0 inclusive (ou seções de 1 a 3 ) na primeira hora, e entre os quilômetros 1,2 e 2 inclusive (ou seções 1 e 2) na segunda hora, evidenciando a influência da maré nestes trechos. Em um caso real, lançando-se a topografia, são identificados no gráfico os pontos de transbordamento.

\section{- $1^{\circ}$ CASO - Canal de Alimentação da Usina do Monjolinho}

Nesta abordagem foram analisadas duas situações específicas: interrupção do escoamento no canal pela paralisação brusca na turbina, abertura instantânea da turbina para uma condição de repouso absoluto no canal. Os dados de saída para ambas simulações podem ser observados no Anexo p.104-112. Os gráficos que demonstram o fenômeno são apresentados e comentados na sequiência.

\section{$1^{\text {a }}$ Simulação - abertura instantânea da turbina}

Esta simulação tem a finalidade específica de avaliar se há ocorrência de entrada de ar no conduto forçado. De acordo com o gráfico, verifica-se a não ocorrência do fenômeno. O escoamento volta ao regime permanente sem passar por um nível crítico à jusante que condicione a entrada de ar na tubulação forçada. Neste caso, as alturas mínimas (hmin) são iguais as alturas $h(m)$ no regime permanente. 


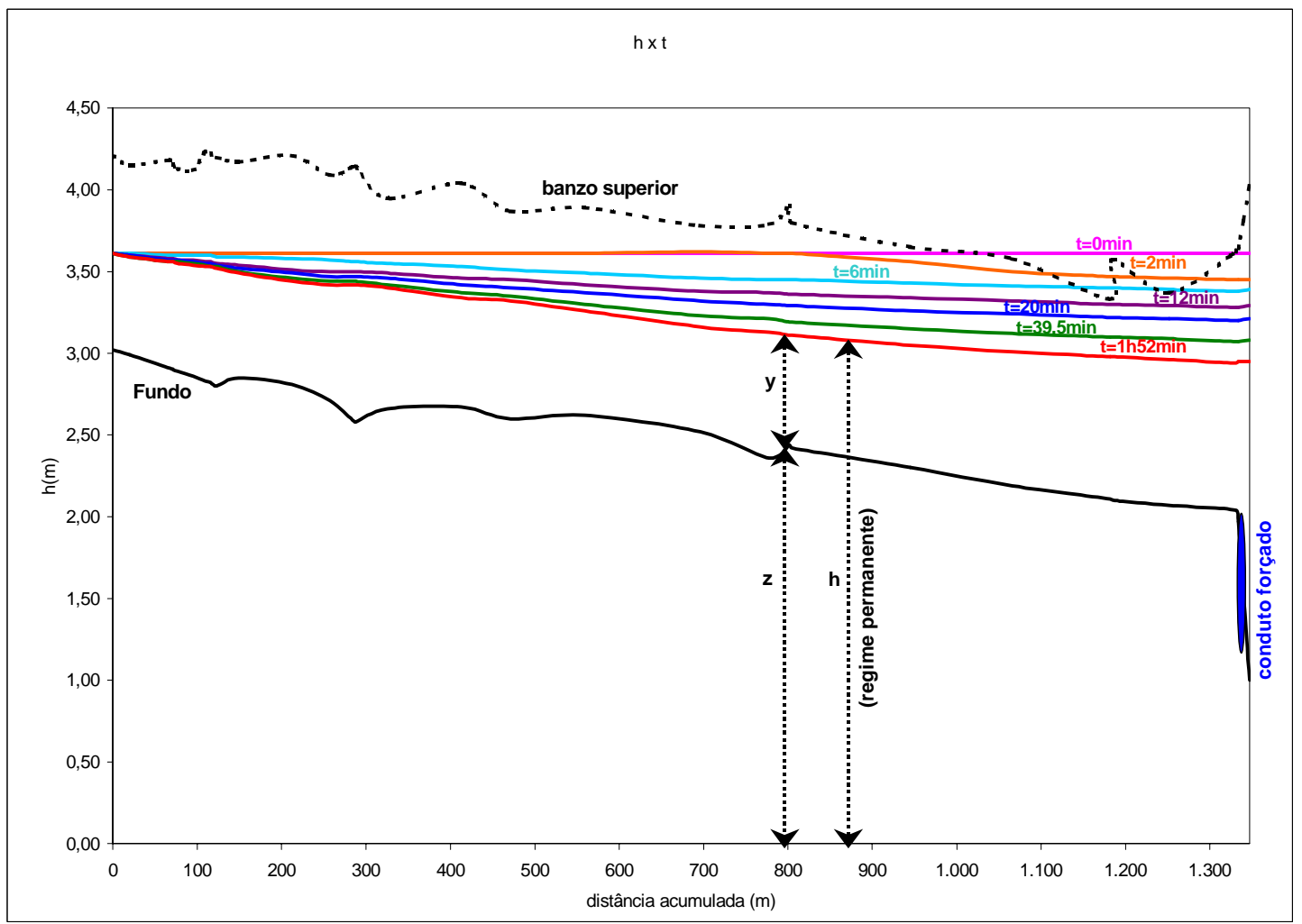

FIGURA 21 -Gráfico das alturas d'água $h(m)$ ocorridas no canal ao longo do tempo (manobra de abertura da turbina)

A partir de $1 \mathrm{~h} 52 \mathrm{~min}$, as alturas d'água $\mathrm{h}(\mathrm{m})$ no canal alcançam o regime permanente. Pode ser observado pelo gráfico da FIGURA 22, a não ocorrência da entrada de ar no conduto forçado, uma vez que a mínima altura registrada na extremidade jusante $(L=1347 \mathrm{~m})$, sequer atinge a cota do conduto forçado.

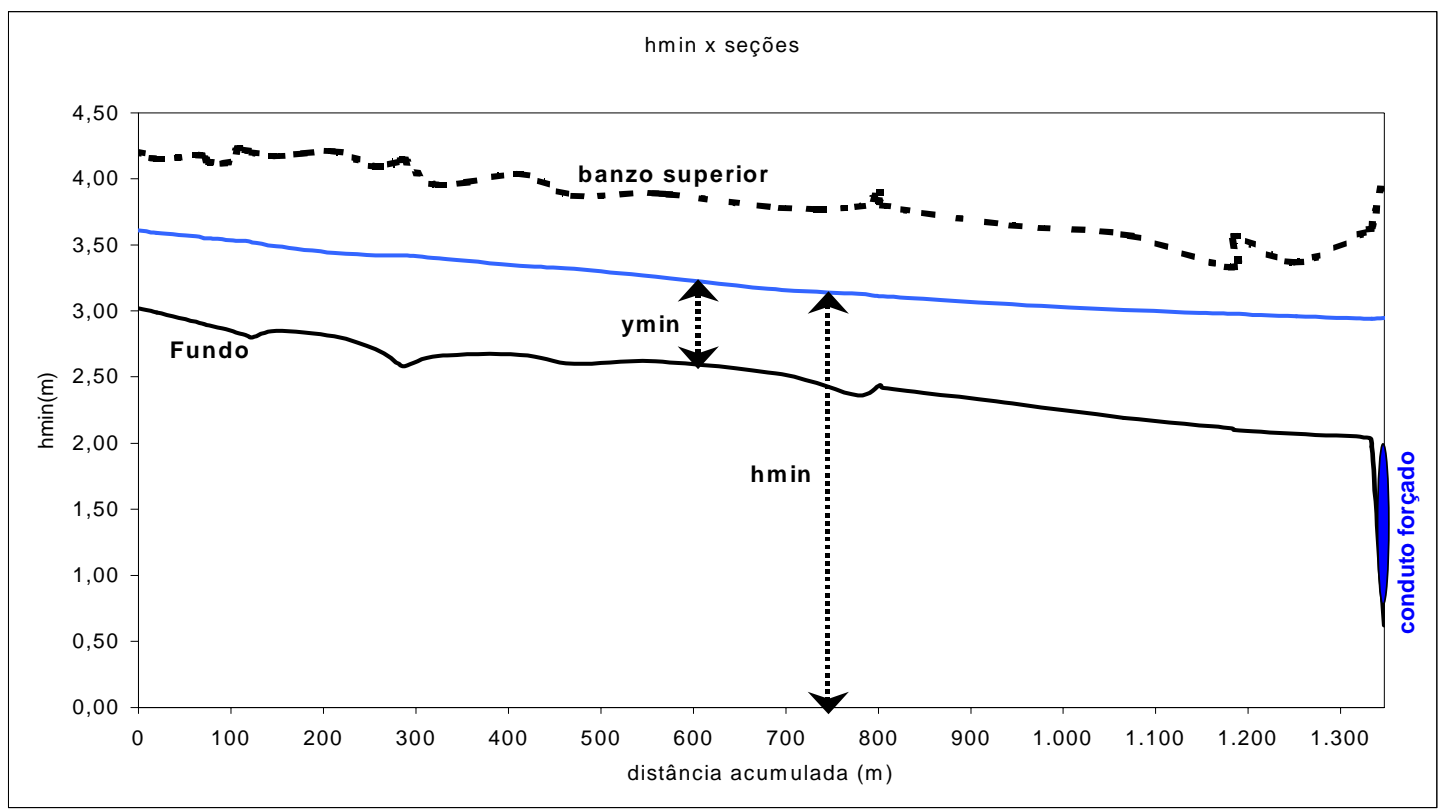

FIGURA 22 -Gráfico das alturas mínimas hmin(m) ocorridas 


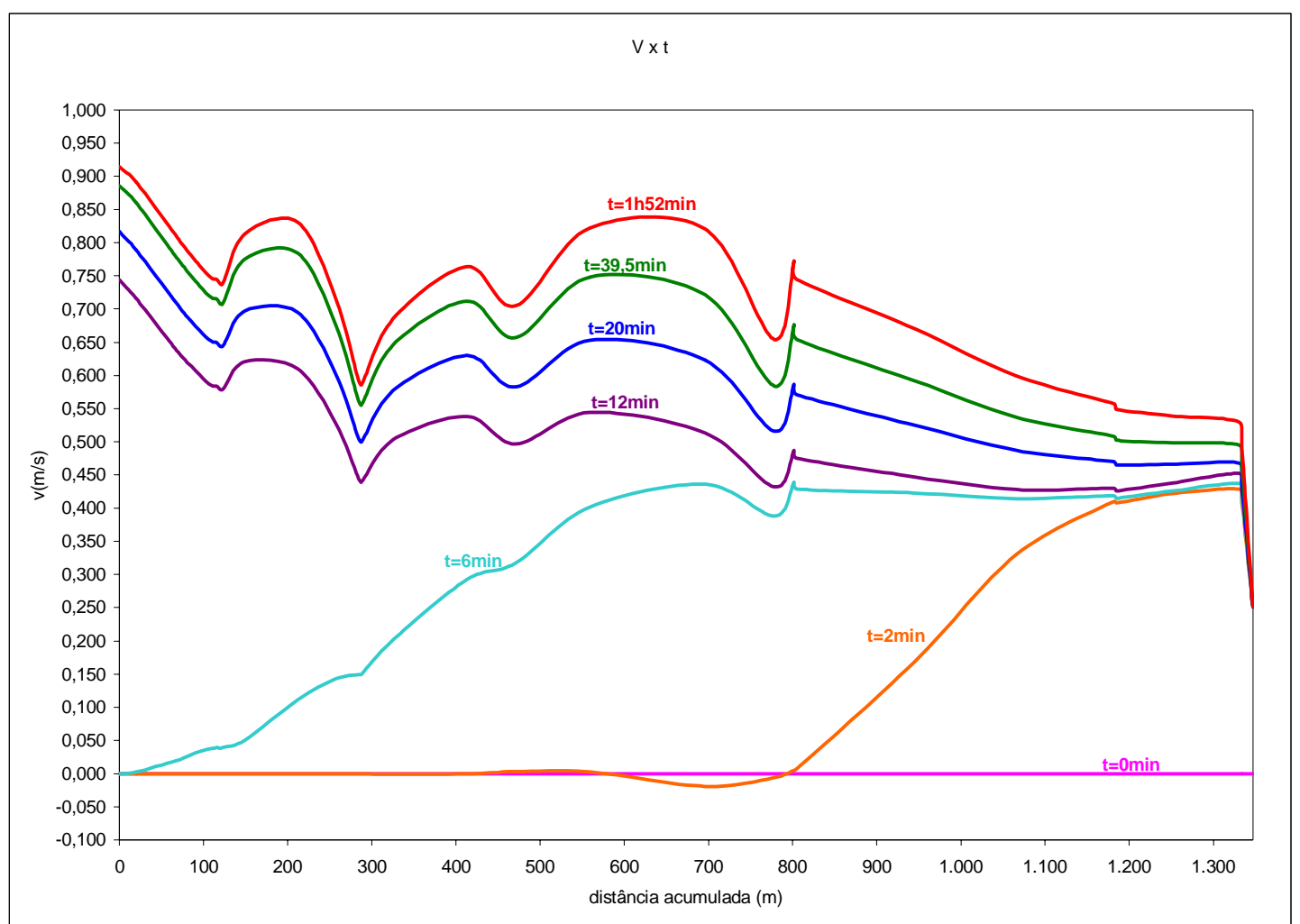

FIGURA 23 - Gráfico do perfil de velocidades V(m/s) nas seções do canal no tempo (manobra de abertura da turbina)

O gráfico mostra o efeito do movimento no canal após a abertura instantânea da turbina. A velocidade na extremidade jusante aumenta quase que instantaneamente enquanto que à montante, a água permanece em repouso no canal.

\section{$2^{\mathrm{a}}$ Simulação - fechamento brusco da turbina}

A partir dos dados de alturas e velocidades de regime permanente, obtidos pela simulação de abertura da turbina, esta simulação verifica o aumento da altura d'água no canal quando o estado de regime é interrompido pela paralisação brusca da turbina. Visa especificamente se ocorre ou não o transbordamento no sistema adutor.

Da mesma forma que a simulação anterior, os gráficos apresentados esboçam alguns momentos da evolução do perfil d'água no canal dentro do período de duas horas de simulação em intervalos de dez segundos. A partir de 49min, as alturas d'água h(m) no canal permanecem praticamente constantes, com pequena oscilação no perfil de velocidades. 


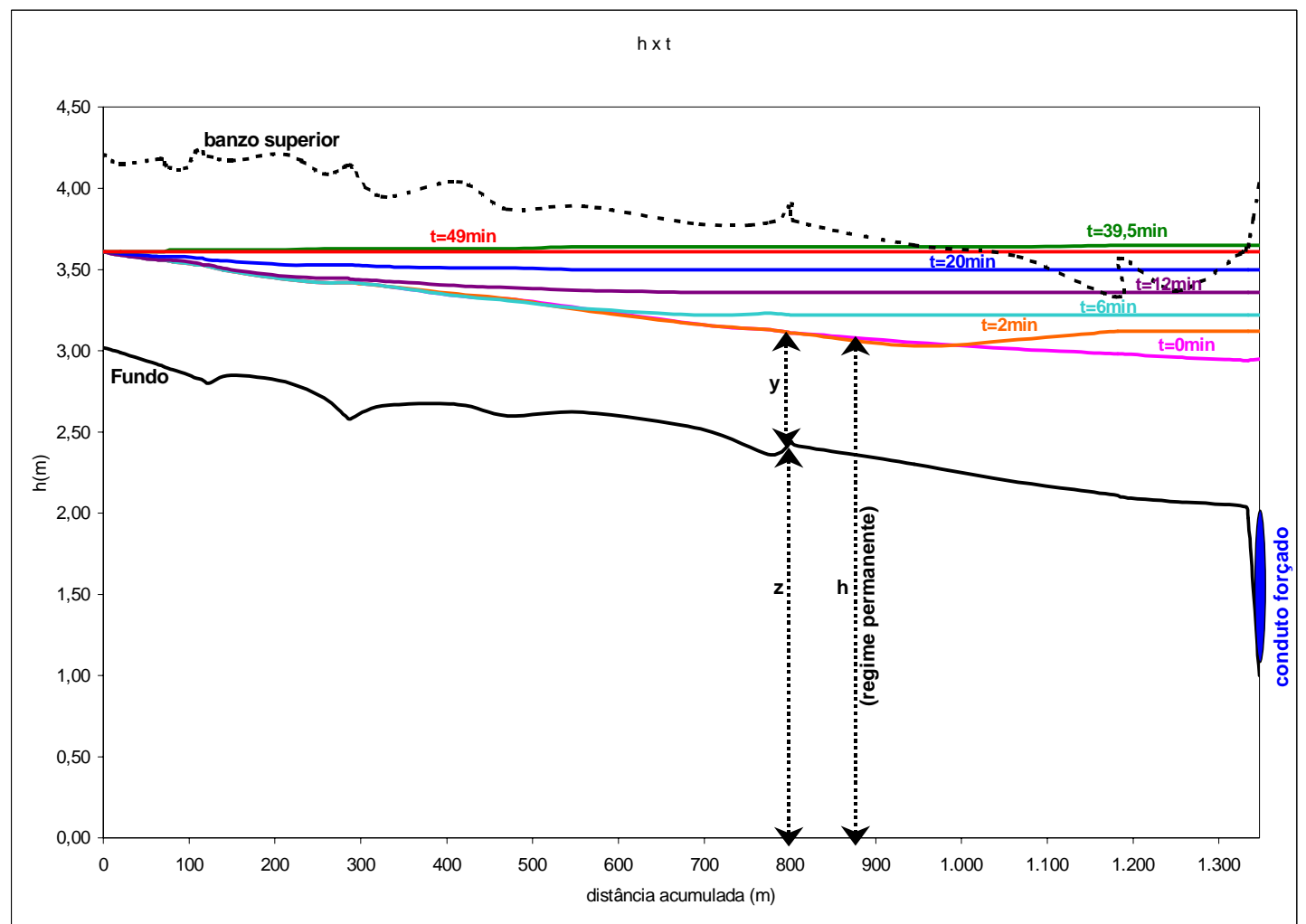

FIGURA 24 -Gráfico das alturas d'água $h(m)$ ocorridas nas seções do canal no tempo (manobra de fechamento da turbina)

Observa-se pelo gráfico das alturas a propagação da onda positiva de jusante, resultado do fechamento brusco da turbina. Verifica-se a ocorrência de transbordamento no canal entre $1 \mathrm{~km}$ e $1,3 \mathrm{~km}$, o que sugere a possibilidade de ter havido erosão, por águas pluviais, neste trecho de canal, durante o longo período em que ele esteve paralisado. A situação de repouso se dá após um período de 49 min. A máxima altura é mostrada no gráfico da FIGURA 25.

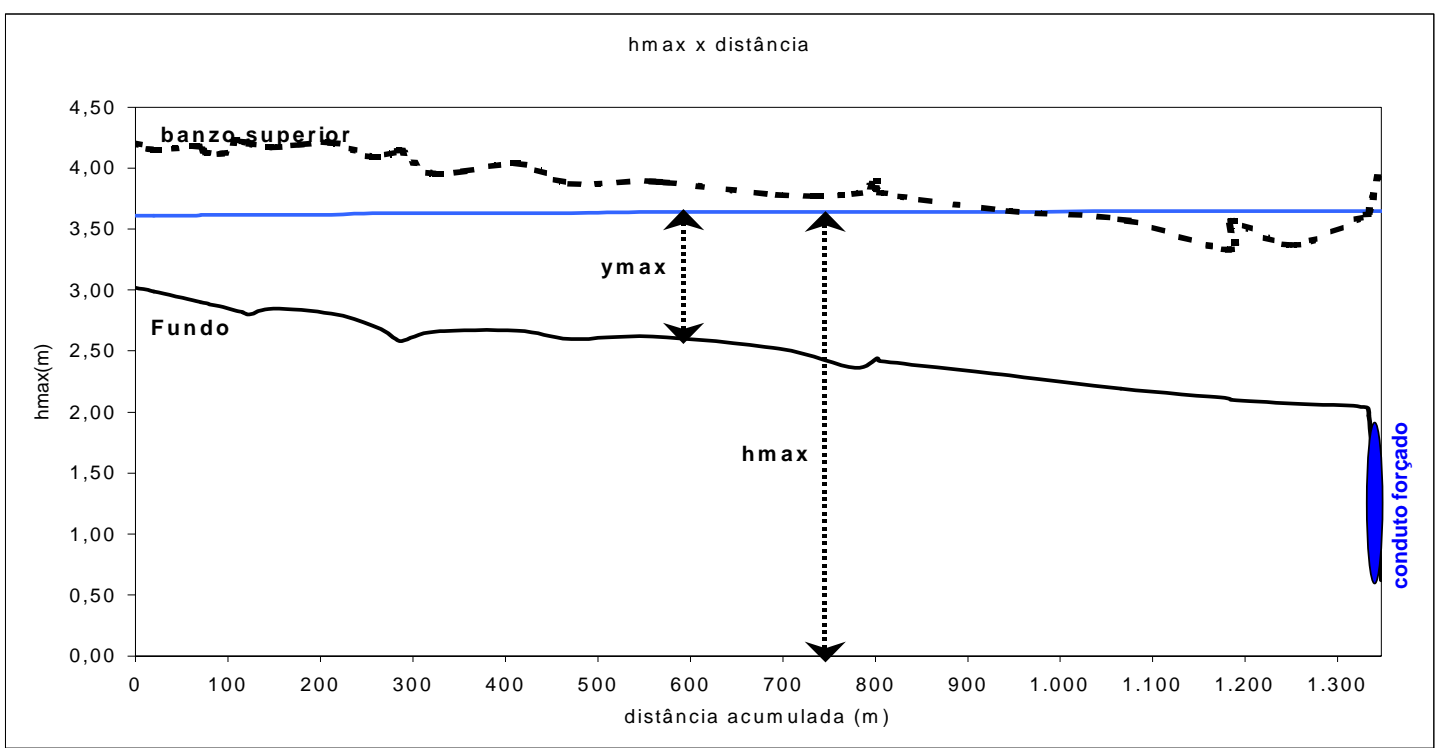

FIGURA 25 - Gráfico das máximas alturas d'água hmax(m) ocorridas nas seções do canal 


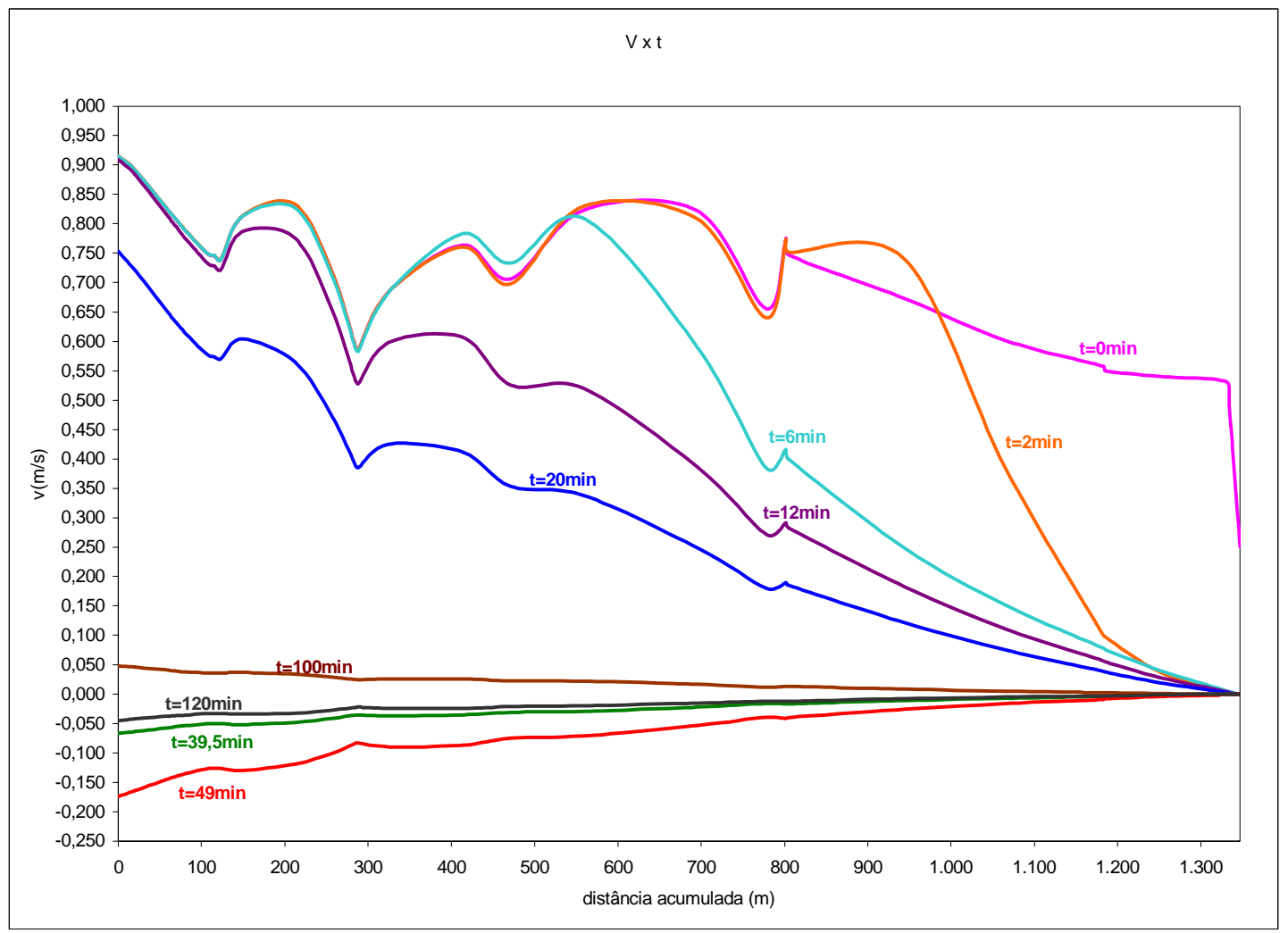

FIGURA 26 - Gráfico do perfil de velocidades $V(\mathrm{~m} / \mathrm{s})$ nas seções do canal no tempo (manobra de fechamento da turbina)

O gráfico das velocidades evidencia a característica do fenômeno. Como o movimento é lento (escoamento fluvial: $\mathrm{Fr}<1$ ), o efeito de jusante influencia diretamente o controle sobre o escoamento de montante. Nota-se a queda na velocidade de montante quando do fechamento instantâneo da turbina, somente após o tempo de $12 \mathrm{~min}$. Devido a caracterização de escoamento lento, com baixas velocidades, a variação no perfil d'água no tempo também é lenta o que é constatado no gráfico das alturas $\mathrm{h}(\mathrm{m})$. Pelo gráfico pode-se observar que após o período de $49 \mathrm{~min}$, as velocidades começam a oscilar, em função da onda de "vai e vem", próximas de $\mathrm{V}=0 \mathrm{~m} / \mathrm{s}$ até atingir o repouso. 


\section{- $\quad 2^{\circ}$ CASO - Canal do Trabalhador}

A aplicação do modelo neste caso visou determinar o transiente hidráulico no sistema para as situações de enchimento e esvaziamento do canal. Estas verificações permitem o planejamento, por exemplo, do tempo de liga e desliga do bombeamento à montante. Vale ressaltar que para a simulação de outras operações, resta a adequação dos dados de entrada e das condições de contorno.

Para expressar com maior rigor o que acontece no açude Pacajus, tanto no enchimento quanto no esvaziamento, torna-se necessário a aplicação de um contorno que represente a prática de uso do referido reservatório. Os dados de saída para ambas simulações podem ser observados no Anexo p.113-139. Os gráficos que demonstram o fenômeno são apresentados e comentados na seqüência.

\section{$1^{\text {a }}$ Simulação - Enchimento do Canal}

Os resultados apresentados mostram instantes da evolução do perfil d'água no canal dentro do período de dois dias de simulação em intervalos de três minutos.

Para a simulação de enchimento, após a chegada da onda no açude Pacajus (41h), o trecho final do canal entrará em regime permanente após algumas horas. No caso desta simulação, que considera uma variação linear da altura d'água no reservatório Pacajus, o regime permanente é atingido após $48 \mathrm{~h}$, tempo a partir do qual a vazão que entra no reservatório foi considerada igual à vazão que sai do mesmo. Em virtude do artifício numérico empregado, que considera lâmina inicial de $2 \mathrm{~cm}$ em toda extensão do canal, as velocidades de ocorrência, sobretudo nos momentos iniciais, não representam as velocidades reais do fenômeno. A evolução do perfil d'água pode ser observada no gráfico da FIGURA 27.

\section{$2^{\mathrm{a}}$ Simulação - Esvaziamento do Canal}

Nesta simulação, partindo-se da situação de regime permanente $(t=48 h)$, verificase o esvaziamento do sistema após a paralisação do bombeamento na estação elevatória de Itaiçaba. É possível observar pelo gráfico da FIGURA 28, a queda gradual das alturas d'água no canal, processando-se lentamente de montante para jusante. A variação na extremidade jusante só é "sentida", de maneira significativa, 36h após o desligamento das bombas. Observa-se que o canal está praticamente vazio num período de 96h ou 4 dias. 


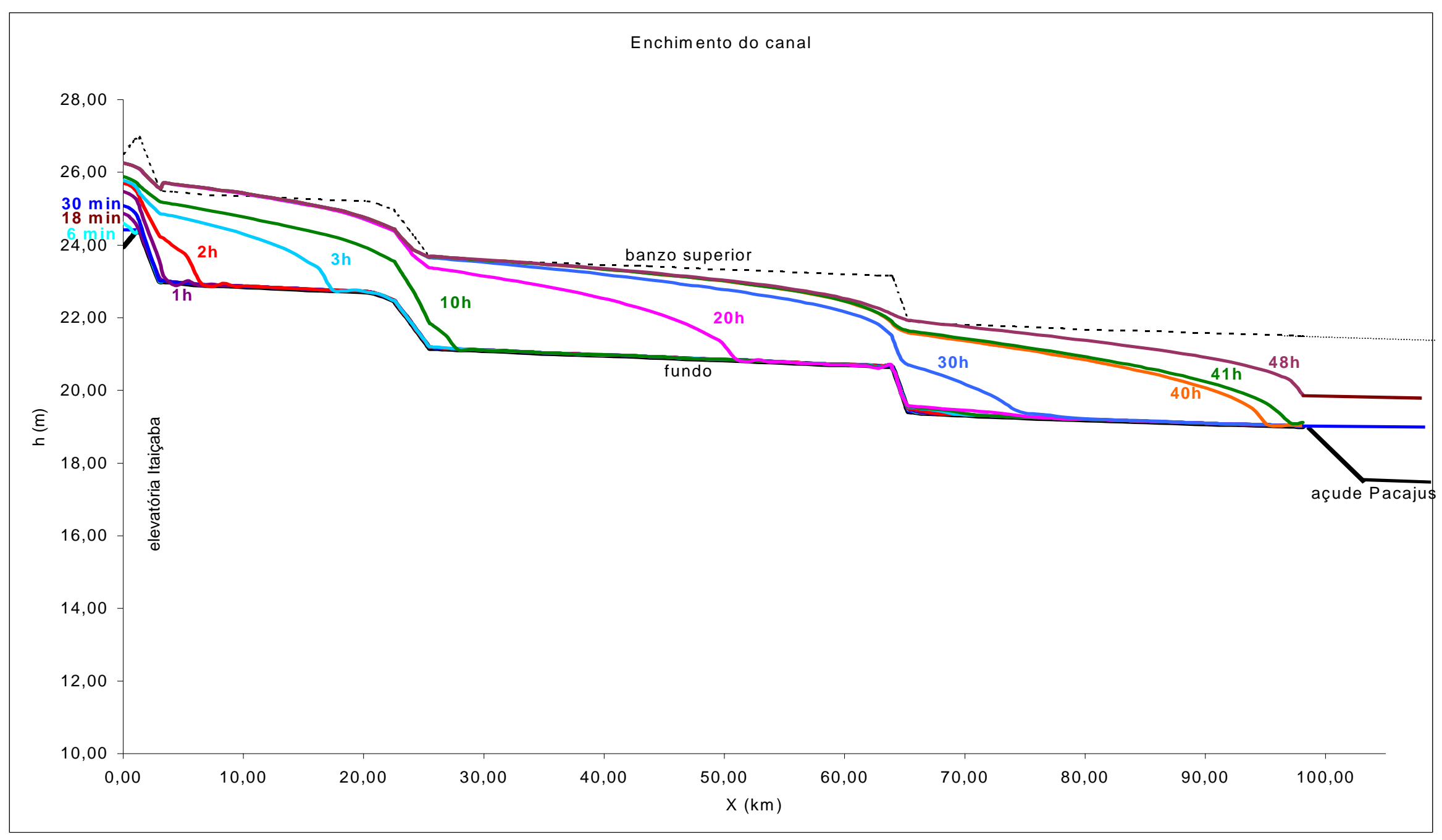

FIGURA 27 - Enchimento do Canal do Trabalhador ao longo do tempo 


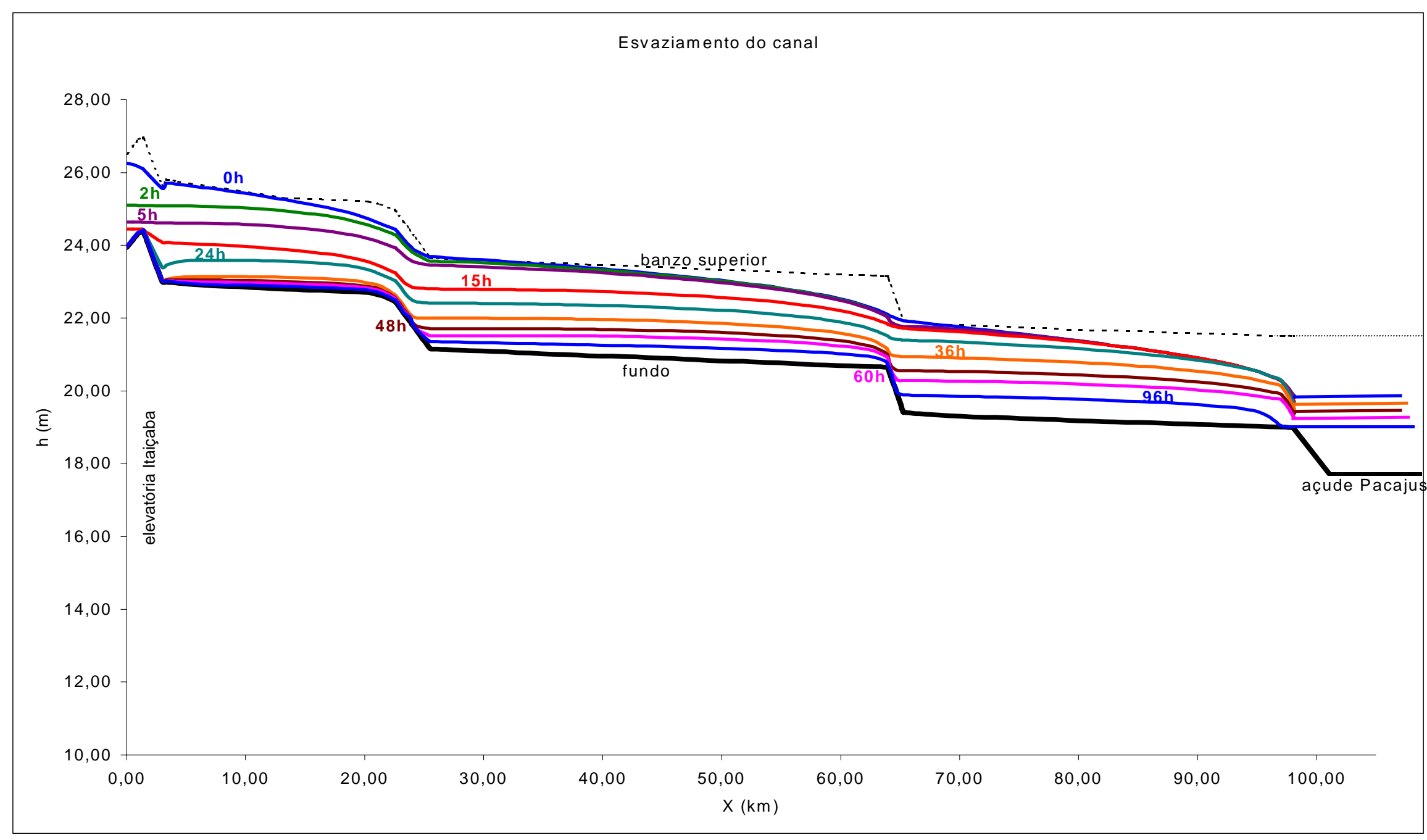

FIGURA 28 - Esvaziamento do Canal do Trabalhador ao longo do tempo 


\section{CONCLUSÕES}

Como conclusão deste trabalho, pode-se dizer que a meta inicial foi atingida com sucesso, face a resposta dada pelo modelo aqui implementado. Os dados de saída gerados pelo modelo computacional desenvolvido foram comparados com resultados previamente obtidos por um modelo simplificado, onde foi possível comprovar sua viabilidade de aplicação.

É valido ressaltar que a proposta deste trabalho era a de elaborar um modelo computacional, utilizando as equações de Saint-Venant, a partir de um caso relativamente simples, como forma de viabilizar a sua aplicação para outros casos de abordagem mais complexa e, para tanto, pode-se concluir que este objetivo foi atingido.

Para a aplicação do modelo computacional, apresentado por este estudo, em outros casos de abordagens mais complexas, resta a adaptação do programa para as particularidades geométricas e hidráulicas do canal estudado, tais como, tomadas d'água, vertedores laterais, sifões, geometria das seções, bem como as condições de contorno do problema particular.

Em se tratando de canais naturais (seções não prismáticas), vale ressaltar os cuidados que devem ser tomados quanto ao aspecto geométrico. Como a configuração geométrica das seções são aproximadas por funções matemáticas $(\mathrm{A}=\mathrm{f}(\mathrm{y}))$ e $\mathrm{P}=\mathrm{f}(\mathrm{y}))$, a correlação obtida deve ser analisada com critério para as máximas e mínimas alturas d'água atingidas na simulação, evitando-se a divergência de valores.

Uma das condições de contorno apresentada nos casos estudados é a velocidade em função do tempo $\mathrm{V}(\mathrm{t})$, objeto da discretização das equações de Saint-Venant. Este contorno pode ser substituído pela vazão em função do tempo $Q(t)$, dependendo da conveniência em cada abordagem, bastando rediscretizar as equações hidrodinâmicas em função da vazão.

Com relação ao esforço computacional exigido para o processamento, apesar de não ter sido objeto do presente estudo, poderá ser avaliado posteriormente com o propósito de se determinar o menor tempo requerido para tal, atingindo-se conseqüentemente a otimização do modelo empregado. 
Finalmente, as equações de Saint-Venant são desenvolvidas para análise de escoamento transiente em canais onde atue a pressão atmosférica ao longo de toda a superfície livre. Em casos onde há combinação destes com sistemas que funcionem sob pressão (Ex.: Canal do Trabalhador), resta a aplicação de modelos que permitam a resolução simultânea de situações desta natureza, ficando como proposta de estudo para pesquisas posteriores 
Dados de Saída da Simulação de Teste do Modelo

\section{Canal Retangular}

\begin{tabular}{|l|}
\hline Sai - Bloco de notas \\
\hline Arquivo Editar Pesquisar Ajuda \\
\hline MODELO UNIDIMENSIONAL P/ CÁLCULO DE TRANSIENTE HIDRÁULICO \\
EM CANAIS RETANGULARES \\
CONDIÇÕES INICIAIS DO ESCOAMENTO \\
ALTURA D'ÁGUA INICIAL - h(m) \\
h1: 0.36 \\
h2: 0.36 \\
h3: 0.36 \\
h4: 0.36 \\
h5: 0.36 \\
VELOCIDADE INICIAL - V(m/s) \\
V1: -0.14 \\
V2: -0.14 \\
V3: -0.14 \\
V4: -0.14 \\
V5: -0.14
\end{tabular}

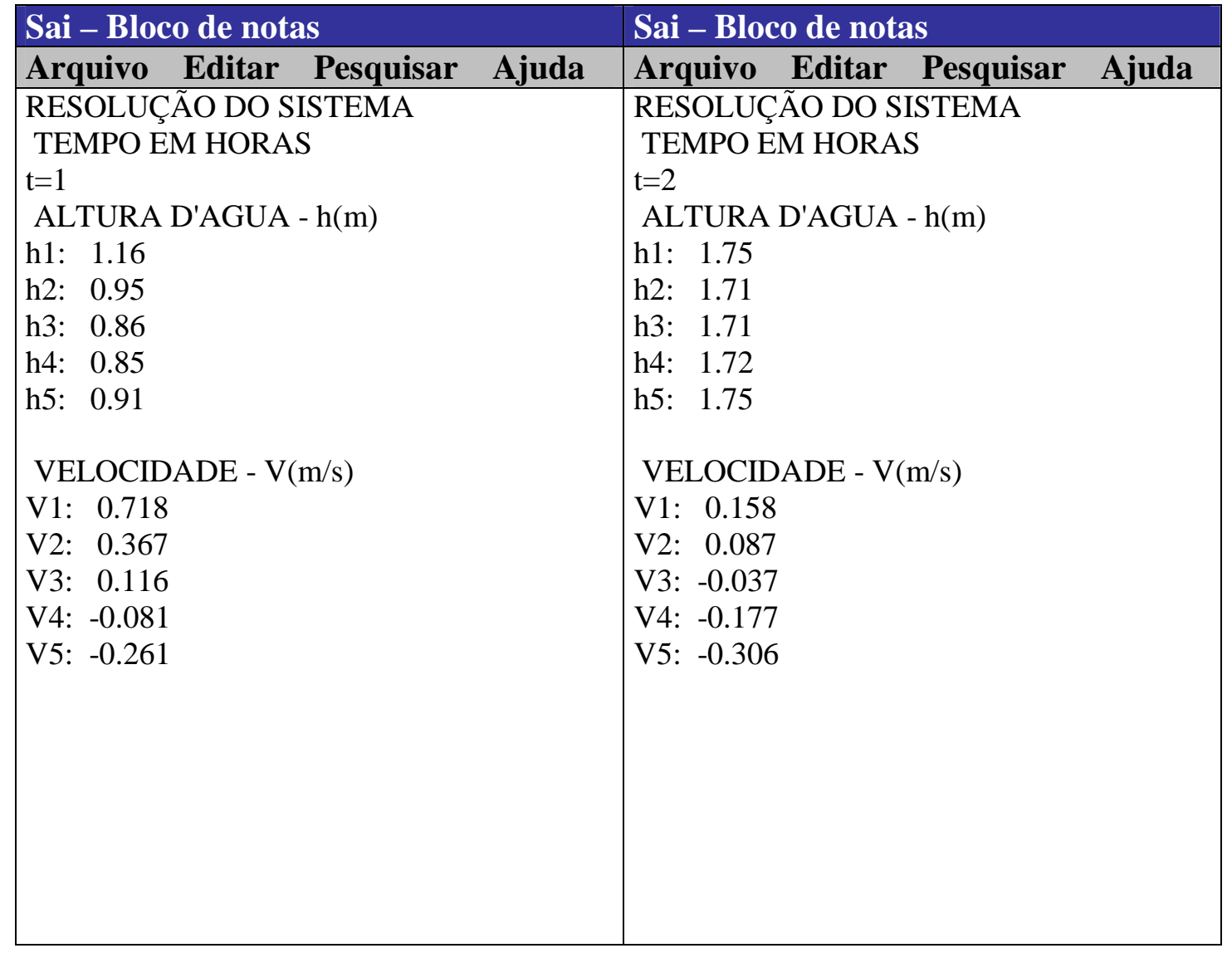




\begin{tabular}{|c|c|}
\hline Sai - Bloco de notas & Sai - Bloco de notas \\
\hline Arquivo Editar Pesquisar Ajuda & Arquivo Editar Pesquisar Ajuda \\
\hline RESOLUÇÃO DO SISTEMA & RESOLUÇÃO DO SISTEMA \\
\hline TEMPO EM HORAS & TEMPO EM HORAS \\
\hline & $t=4$ \\
\hline ALTURA D'AGUA - h(m) & ALTURA D'AGUA - h(m) \\
\hline h1: 1.96 & h1: 1.75 \\
\hline h2: 1.98 & h2: 1.77 \\
\hline h3: 1.98 & h3: 1.80 \\
\hline h4: 2.00 & h4: 1.83 \\
\hline h5: 2.02 & h5: 1.86 \\
\hline VELOCIDADE - V(m/s) & VELOCIDADE - V(m/s) \\
\hline V1: -0.233 & V1: -0.347 \\
\hline V2: -0.253 & V2: -0.329 \\
\hline V3: -0.275 & V3: -0.312 \\
\hline V4: -0.296 & V4: -0.295 \\
\hline V5: -0.314 & V5: -0.280 \\
\hline
\end{tabular}

\begin{tabular}{|c|c|}
\hline Sai - Bloco de notas & Sai - Bloco de notas \\
\hline Arquivo Editar Pesquisar Ajuda & Arquivo Editar Pesquisar Ajuda \\
\hline RESOLUÇÃO DO SISTEMA & RESOLUÇÃO DO SISTEMA \\
\hline TEMPO EM HORAS & TEMPO EM HORAS \\
\hline & $t=6$ \\
\hline ALTURA D'AGUA - h(m) & ALTURA D'AGUA - h(m) \\
\hline h1: 1.16 & h1: 0.36 \\
\hline h2: 1.21 & h2: 0.46 \\
\hline h3: 1.24 & h3: 0.53 \\
\hline h4: 1.27 & h4: 0.57 \\
\hline h5: 1.30 & h5: 0.59 \\
\hline VELOCIDADE - V(m/s) & VELOCIDADE - V(m/s) \\
\hline V1: -0.398 & V1: -0.529 \\
\hline V2: -0.343 & V2: -0.406 \\
\hline V3: -0.293 & V3: -0.307 \\
\hline V4: -0.246 & V4: -0.220 \\
\hline V5: -0.200 & V5: -0.140 \\
\hline
\end{tabular}


Dados de Saída do Modelo para o Canal de Alimentação da Usina Monjolinho Simulação de Abertura da Turbina

\begin{tabular}{|c|c|c|c|c|}
\hline \multicolumn{5}{|c|}{ Sai - Bloco de notas } \\
\hline \multicolumn{5}{|c|}{ Arquivo Editar Pesquisar Ajuda } \\
\hline \multicolumn{5}{|c|}{$\begin{array}{l}\text { TRANSIENTE HIDRÁULICO - CANAL DA UHE MONJOLINHO } \\
\text { Abertura da Turbina }\end{array}$} \\
\hline \multicolumn{5}{|c|}{ CONDIÇÕES INICIAIS DO ESCOAMENTO } \\
\hline $\mathrm{SEC}$ & $y(m)$ & $\mathrm{h}(\mathrm{m})$ & $\mathrm{z}(\mathrm{m})$ & $\mathrm{V}(\mathrm{m} / \mathrm{s})$ \\
\hline 1 & 0.59 & 3.61 & 3.02 & 0.000 \\
\hline 2 & 0.62 & 3.61 & 2.99 & 0.000 \\
\hline 3 & 0.70 & 3.61 & 2.91 & 0.000 \\
\hline 4 & 0.71 & 3.61 & 2.90 & 0.000 \\
\hline 5 & 0.72 & 3.61 & 2.89 & 0.000 \\
\hline 6 & 0.75 & 3.61 & 2.86 & 0.000 \\
\hline 7 & 0.78 & 3.61 & 2.83 & 0.000 \\
\hline 8 & 0.79 & 3.61 & 2.82 & 0.000 \\
\hline 9 & 0.81 & 3.61 & 2.80 & 0.000 \\
\hline 10 & 0.76 & 3.61 & 2.85 & 0.000 \\
\hline 11 & 0.80 & 3.61 & 2.81 & 0.000 \\
\hline 12 & 0.90 & 3.61 & 2.71 & 0.000 \\
\hline 13 & 1.02 & 3.61 & 2.59 & 0.000 \\
\hline 14 & 1.03 & 3.61 & 2.58 & 0.000 \\
\hline 15 & 0.95 & 3.61 & 2.66 & 0.000 \\
\hline 16 & 0.94 & 3.61 & 2.67 & 0.000 \\
\hline 17 & 1.01 & 3.61 & 2.60 & 0.000 \\
\hline 18 & 0.99 & 3.61 & 2.62 & 0.000 \\
\hline 19 & 1.09 & 3.61 & 2.52 & 0.000 \\
\hline 20 & 1.25 & 3.61 & 2.36 & 0.000 \\
\hline 21 & 1.17 & 3.61 & 2.44 & 0.000 \\
\hline 22 & 1.19 & 3.61 & 2.42 & 0.000 \\
\hline 23 & 1.31 & 3.61 & 2.30 & 0.000 \\
\hline 24 & 1.42 & 3.61 & 2.19 & 0.000 \\
\hline 25 & 1.50 & 3.61 & 2.11 & 0.000 \\
\hline 26 & 1.51 & 3.61 & 2.10 & 0.000 \\
\hline 27 & 1.54 & 3.61 & 2.07 & 0.000 \\
\hline 28 & 1.57 & 3.61 & 2.04 & 0.000 \\
\hline 29 & 1.64 & 3.61 & 1.97 & 0.000 \\
\hline 30 & 2.61 & 3.61 & 1.00 & 0.000 \\
\hline
\end{tabular}




\begin{tabular}{|c|c|c|c|c|c|c|c|c|c|}
\hline \multicolumn{5}{|c|}{ Sai - Bloco de notas } & \multicolumn{5}{|c|}{ Sai - Bloco de notas } \\
\hline \multicolumn{2}{|c|}{ Arquivo } & litar & Pesquisar & Ajuda & \multicolumn{5}{|c|}{ Arquivo Editar Pesquisar } \\
\hline \multicolumn{5}{|c|}{$\begin{array}{l}\text { RESOLUÇÃO } \\
\text { DO SISTEMA } \\
\text { TEMPO EM SEGUNDOS }\end{array}$} & \multicolumn{5}{|c|}{$\begin{array}{cl}\text { RESOLUÇÃO } & \text { DO SISTEMA } \\
\text { TEMPO EM } & \text { SEGUNDOS }\end{array}$} \\
\hline SEC & $y(m)$ & $h(m)$ & $\mathrm{V}(\mathrm{m} / \mathrm{s})$ & & SEC & $y(m)$ & $h(m)$ & $\mathrm{V}(\mathrm{m} / \mathrm{s})$ & \\
\hline 1 & 0.59 & 3.61 & 0.000 & & 1 & 0.59 & 3.61 & 0.000 & \\
\hline 2 & 0.62 & 3.61 & 0.000 & & 2 & 0.62 & 3.61 & 0.002 & \\
\hline 3 & 0.70 & 3.61 & 0.000 & & 3 & 0.69 & 3.60 & 0.019 & \\
\hline 4 & 0.71 & 3.61 & 0.000 & & 4 & 0.70 & 3.60 & 0.021 & \\
\hline 5 & 0.72 & 3.61 & 0.000 & & 5 & 0.71 & 3.60 & 0.024 & \\
\hline 6 & 0.75 & 3.61 & 0.000 & & 6 & 0.74 & 3.60 & 0.033 & \\
\hline 7 & 0.78 & 3.61 & 0.000 & & 7 & 0.77 & 3.60 & 0.038 & \\
\hline 8 & 0.79 & 3.61 & 0.000 & & 8 & 0.78 & 3.60 & 0.039 & \\
\hline 9 & 0.81 & 3.61 & 0.000 & & 9 & 0.79 & 3.59 & 0.039 & \\
\hline 10 & 0.76 & 3.61 & 0.000 & & 10 & 0.74 & 3.59 & 0.050 & \\
\hline 11 & 0.80 & 3.61 & 0.000 & & 11 & 0.77 & 3.58 & 0.111 & \\
\hline 12 & 0.90 & 3.61 & 0.000 & & 12 & 0.86 & 3.57 & 0.143 & \\
\hline 13 & 1.02 & 3.61 & 0.000 & & 13 & 0.97 & 3.56 & 0.149 & \\
\hline 14 & 1.03 & 3.61 & 0.000 & & 14 & 0.98 & 3.56 & 0.150 & \\
\hline 15 & 0.95 & 3.61 & -0.001 & & 15 & 0.89 & 3.55 & 0.201 & \\
\hline 16 & 0.94 & 3.61 & 0.000 & & 16 & 0.86 & 3.53 & 0.292 & \\
\hline 17 & 1.01 & 3.61 & 0.003 & & 17 & 0.91 & 3.51 & 0.317 & \\
\hline 18 & 0.99 & 3.61 & 0.002 & & 18 & 0.87 & 3.49 & 0.402 & \\
\hline 19 & 1.10 & 3.62 & -0.019 & & 19 & 0.94 & 3.46 & 0.436 & \\
\hline 20 & 1.25 & 3.61 & -0.006 & & 20 & 1.09 & 3.45 & 0.388 & \\
\hline 21 & 1.17 & 3.61 & 0.005 & & 21 & 1.01 & 3.45 & 0.439 & \\
\hline 22 & 1.19 & 3.61 & 0.007 & & 22 & 1.03 & 3.45 & 0.429 & \\
\hline 23 & 1.26 & 3.56 & 0.168 & & 23 & 1.13 & 3.43 & 0.423 & \\
\hline 24 & 1.31 & 3.50 & 0.330 & & 24 & 1.22 & 3.41 & 0.414 & \\
\hline 25 & 1.36 & 3.47 & 0.410 & & 25 & 1.29 & 3.40 & 0.419 & \\
\hline 26 & 1.37 & 3.47 & 0.408 & & 26 & 1.30 & 3.40 & 0.415 & \\
\hline 27 & 1.39 & 3.46 & 0.422 & & 27 & 1.32 & 3.39 & 0.426 & \\
\hline 28 & 1.41 & 3.45 & 0.429 & & 28 & 1.34 & 3.38 & 0.437 & \\
\hline 29 & 1.48 & 3.45 & 0.409 & & 29 & 1.41 & 3.38 & 0.416 & \\
\hline 30 & 2.45 & 3.45 & 0.251 & & 30 & 2.39 & 3.39 & 0.251 & \\
\hline
\end{tabular}

\begin{tabular}{|c|c|c|c|c|c|c|c|c|c|}
\hline \multicolumn{5}{|c|}{ Sai - Bloco de notas } & \multicolumn{5}{|c|}{ Sai - Bloco de notas } \\
\hline \multicolumn{2}{|c|}{ Arquivo } & \multicolumn{3}{|c|}{ Editar Pesquisar Ajuda } & \multicolumn{5}{|c|}{ Arquivo Editar Pesquisar } \\
\hline \multicolumn{5}{|c|}{$\begin{array}{ll}\text { RESOLUÇÃO } & \text { DO SISTEMA } \\
\text { TEMPO EM } & \text { SEGUNDOS } \\
t=720 & \end{array}$} & \multicolumn{5}{|c|}{$\begin{array}{l}\text { RESOLUÇÃO DO SISTEMA } \\
\text { TEMPO EM SEGUNDOS } \\
t=1200\end{array}$} \\
\hline $\mathrm{SEC}$ & $y(m$ & $h(m)$ & $\mathrm{V}(\mathrm{m} / \mathrm{s})$ & & SEC & $y(m)$ & $\mathrm{h}(\mathrm{m})$ & $\mathrm{V}(\mathrm{m} / \mathrm{s})$ & \\
\hline 1 & 0.5 & 3.61 & 0.744 & & 1 & 0.59 & 3.61 & 0.817 & \\
\hline 2 & 0.6 & 3.60 & 0.716 & & 2 & 0.61 & 3.60 & 0.789 & \\
\hline 3 & 0.6 & 3.58 & 0.641 & & 3 & 0.66 & 3.57 & 0.712 & \\
\hline 4 & 0.6 & 3.58 & 0.633 & & 4 & 0.67 & 3.57 & 0.703 & \\
\hline 5 & 0.6 & 3.57 & 0.625 & & 5 & 0.68 & 3.57 & 0.694 & \\
\hline 6 & 0.7 & 3.57 & 0.601 & & 6 & 0.70 & 3.56 & 0.668 & \\
\hline 7 & 0.7 & 3.56 & 0.585 & & 7 & 0.72 & 3.55 & 0.652 & \\
\hline 8 & 0.7 & 3.56 & 0.584 & & 8 & 0.73 & 3.55 & 0.650 & \\
\hline 9 & $0.7 !$ & 3.55 & 0.579 & & 9 & 0.74 & 3.54 & 0.644 & \\
\hline 10 & 0.6 & 3.54 & 0.621 & & 10 & 0.67 & 3.52 & 0.697 & \\
\hline 11 & 0.7 & 3.51 & 0.610 & & 11 & $0.6 \varepsilon$ & 3.49 & 0.695 & \\
\hline
\end{tabular}




\begin{tabular}{|c|c|c|c|c|c|c|c|}
\hline 12 & 0.79 & 3.50 & 0.528 & 12 & 0.76 & 3.47 & 0.602 \\
\hline 13 & 0.91 & 3.50 & 0.446 & 13 & 0.88 & 3.47 & 0.506 \\
\hline 14 & 0.92 & 3.50 & 0.440 & 14 & 0.89 & 3.47 & 0.500 \\
\hline 15 & 0.83 & 3.49 & 0.503 & 15 & 0.80 & 3.46 & 0.577 \\
\hline 16 & 0.79 & 3.46 & 0.538 & 16 & 0.75 & 3.42 & 0.630 \\
\hline 17 & 0.85 & 3.45 & 0.497 & 17 & 0.80 & 3.40 & 0.583 \\
\hline 18 & 0.80 & 3.42 & 0.544 & 18 & 0.75 & 3.37 & 0.653 \\
\hline 19 & 0.86 & 3.38 & 0.513 & 19 & 0.80 & 3.32 & 0.623 \\
\hline 20 & 1.01 & 3.37 & 0.432 & 20 & 0.94 & 3.30 & 0.516 \\
\hline 21 & 0.92 & 3.36 & 0.487 & 21 & 0.85 & 3.29 & 0.587 \\
\hline 22 & 0.94 & 3.36 & 0.475 & 22 & 0.87 & 3.29 & 0.571 \\
\hline 23 & 1.04 & 3.34 & 0.447 & 23 & 0.96 & 3.26 & 0.525 \\
\hline 24 & 1.13 & 3.32 & 0.428 & 24 & 1.05 & 3.24 & 0.487 \\
\hline 25 & 1.19 & 3.30 & 0.430 & 25 & 1.11 & 3.22 & 0.470 \\
\hline 26 & 1.20 & 3.30 & 0.426 & 26 & 1.12 & 3.22 & 0.465 \\
\hline 27 & 1.22 & 3.29 & 0.438 & 27 & 1.14 & 3.21 & 0.466 \\
\hline 28 & 1.24 & 3.28 & 0.452 & 28 & 1.16 & 3.20 & 0.468 \\
\hline 29 & 1.31 & 3.28 & 0.428 & 29 & 1.23 & 3.20 & 0.441 \\
\hline 30 & 2.29 & 3.29 & 0.251 & 30 & 2.21 & 3.21 & 0.251 \\
\hline
\end{tabular}

\begin{tabular}{|c|c|c|c|c|c|c|c|c|}
\hline \multicolumn{4}{|c|}{ Sai - Bloco de notas } & \multicolumn{5}{|c|}{ Sai - Bloco de notas } \\
\hline \multicolumn{2}{|c|}{ Arquivo } & litar & esquisar & \multicolumn{5}{|c|}{ Arquivo Editar Pesquisar } \\
\hline \multicolumn{4}{|c|}{$\begin{array}{l}\text { TEMPO EM SEGUNDOS } \\
t=2370\end{array}$} & \multicolumn{5}{|c|}{$\begin{array}{l}\text { RESOLUÇÃO } \text { DO SISTEMA } \\
\text { TEMPO EM } \\
t=6720\end{array}$} \\
\hline SEC & $y(m)$ & $h(m)$ & $\mathrm{V}(\mathrm{m} / \mathrm{s})$ & SEC & $y(m)$ & $h(m)$ & $\mathrm{V}(\mathrm{m} / \mathrm{s})$ & \\
\hline 1 & 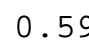 & 3.61 & 0.886 & 1 & 0.59 & 3.61 & 0.915 & \\
\hline 2 & 0.60 & 3.59 & 0.860 & 2 & 0.60 & 3.59 & 0.891 & \\
\hline 3 & 0.65 & 3.56 & 0.781 & 3 & 0.65 & 3.56 & 0.813 & \\
\hline 4 & 0.66 & 3.56 & 0.772 & 4 & 0.66 & 3.56 & 0.803 & \\
\hline 5 & 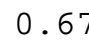 & 3.56 & 0.763 & 5 & 0.66 & 3.55 & 0.794 & \\
\hline 6 & 0.69 & 3.55 & 0.735 & 6 & 0.68 & 3.54 & 0.766 & \\
\hline 7 & 0.71 & 3.54 & 0.717 & 7 & 0.70 & 3.53 & 0.747 & \\
\hline 8 & 0.71 & 3.53 & 0.715 & 8 & 0.71 & 3.53 & 0.745 & \\
\hline 9 & 0.73 & 3.53 & 0.708 & 9 & 0.72 & 3.52 & 0.738 & \\
\hline 10 & 0.65 & 3.50 & 0.775 & 10 & 0.64 & 3.49 & 0.813 & \\
\hline 11 & 0.65 & 3.46 & 0.784 & 11 & 0.63 & 3.44 & 0.831 & \\
\hline 12 & 0.73 & 3.44 & 0.676 & 12 & 0.71 & 3.42 & 0.716 & \\
\hline 13 & 0.85 & 3.44 & 0.563 & 13 & 0.83 & 3.42 & 0.594 & \\
\hline 14 & 0.86 & 3.44 & 0.556 & 14 & 0.84 & 3.42 & 0.586 & \\
\hline 15 & 0.76 & 3.42 & 0.646 & 15 & 0.74 & 3.40 & 0.685 & \\
\hline 16 & 0.70 & 3.37 & 0.712 & 16 & 0.67 & 3.34 & 0.764 & \\
\hline 17 & 0.75 & 3.35 & 0.657 & 17 & 0.72 & 3.32 & 0.705 & \\
\hline 18 & 0.68 & 3.30 & 0.748 & 18 & 0.64 & 3.26 & 0.822 & \\
\hline 19 & 0.71 & 3.23 & 0.721 & 19 & 0.64 & 3.16 & 0.820 & \\
\hline 20 & 0.85 & 3.21 & 0.584 & 20 & 0.77 & 3.13 & 0.654 & \\
\hline 21 & 0.75 & 3.19 & 0.675 & 21 & 0.67 & 3.11 & 0.772 & \\
\hline 22 & 0.77 & 3.19 & 0.654 & 22 & 0.69 & 3.11 & 0.745 & \\
\hline 23 & 0.85 & 3.15 & 0.592 & 23 & 0.75 & 3.05 & 0.671 & \\
\hline 24 & 0.93 & 3.12 & 0.537 & 24 & 0.82 & 3.01 & 0.599 & \\
\hline 25 & 0.99 & 3.10 & 0.508 & 25 & 0.87 & 2.98 & 0.557 & \\
\hline 26 & 1.00 & 3.10 & 0.502 & 26 & 0.88 & 2.98 & 0.549 & \\
\hline
\end{tabular}




\begin{tabular}{|llll|llll|}
\hline 27 & 1.02 & 3.09 & 0.498 & 27 & 0.89 & 2.96 & 0.539 \\
28 & 1.03 & 3.07 & 0.495 & 28 & 0.90 & 2.94 & 0.530 \\
29 & 1.10 & 3.07 & 0.463 & 29 & 0.98 & 2.95 & 0.492 \\
30 & 2.08 & 3.08 & 0.251 & 30 & 1.95 & 2.95 & 0.251 \\
\hline
\end{tabular}

\begin{tabular}{|c|c|c|c|}
\hline \multicolumn{4}{|c|}{ Sai - Bloco de notas } \\
\hline Arquiv & vo & ditar & Pesquisar Ajuda \\
\hline \multicolumn{4}{|c|}{ ALTURA MÍNIMA OCORRIDA- hmin(m) } \\
\hline hmin & 1: & 3.61 & \\
\hline hmin & $2:$ & 3.59 & \\
\hline hmin & 3: & 3.56 & \\
\hline hmin & 4: & 3.56 & \\
\hline hmin & 5: & 3.55 & \\
\hline hmin & 6: & 3.54 & \\
\hline hmin & 7: & 3.53 & \\
\hline hmin & 8: & 3.53 & \\
\hline hmin & 9: & 3.52 & \\
\hline hmin 1 & 10: & 3.49 & \\
\hline hmin 1 & 11: & 3.44 & \\
\hline hmin 1 & 12: & 3.42 & \\
\hline hmin 1 & 13: & 3.42 & \\
\hline hmin 1 & 14: & 3.42 & \\
\hline hmin 1 & 15: & 3.40 & \\
\hline hmin 1 & 16: & 3.34 & \\
\hline hmin 1 & 17: & 3.32 & \\
\hline hmin 1 & 18: & 3.26 & \\
\hline hmin 1 & 19: & 3.16 & \\
\hline hmin 2 & $20:$ & 3.13 & \\
\hline hmin 2 & 21: & 3.11 & \\
\hline hmin 2 & 22: & 3.11 & \\
\hline hmin 2 & 23: & 3.05 & \\
\hline $\operatorname{hmin} 2$ & $24:$ & 3.01 & \\
\hline hmin 2 & 25: & 2.98 & \\
\hline hmin 2 & 26: & 2.98 & \\
\hline hmin 2 & $27:$ & 2.96 & \\
\hline hmin 2 & 28: & 2.94 & \\
\hline hmin 2 & 29: & 2.94 & \\
\hline hmin 3 & $30:$ & 2.95 & \\
\hline
\end{tabular}


Dados de Saída do Modelo para o Canal de Alimentação da Usina Monjolinho

\section{Simulação de Fechamento da Turbina}

\begin{tabular}{|c|c|c|c|c|}
\hline \multicolumn{5}{|c|}{ Sai - Bloco de notas } \\
\hline \multicolumn{5}{|c|}{ Arquivo Editar Pesquisar Ajuda } \\
\hline \multicolumn{5}{|c|}{$\begin{array}{l}\text { TRANSIENTE HIDRÁULICO - CANAL DA UHE MONJOLINHO } \\
\text { Fechamento da Turbina }\end{array}$} \\
\hline \multicolumn{5}{|c|}{ CONDIÇÕES INICIAIS DO ESCOAMENTO } \\
\hline $\mathrm{SEC}$ & $y(m)$ & $\mathrm{h}(\mathrm{m})$ & $z(m)$ & $\mathrm{V}(\mathrm{m} / \mathrm{s})$ \\
\hline 1 & 0.59 & 3.61 & 3.02 & 0.915 \\
\hline 2 & 0.60 & 3.59 & 2.99 & 0.891 \\
\hline 3 & 0.65 & 3.56 & 2.91 & 0.813 \\
\hline 4 & 0.66 & 3.56 & 2.90 & 0.803 \\
\hline 5 & 0.66 & 3.55 & 2.89 & 0.794 \\
\hline 6 & 0.68 & 3.54 & 2.86 & 0.766 \\
\hline 7 & 0.70 & 3.53 & 2.83 & 0.747 \\
\hline 8 & 0.71 & 3.53 & 2.82 & 0.745 \\
\hline 9 & 0.72 & 3.52 & 2.80 & 0.738 \\
\hline 10 & 0.64 & 3.49 & 2.85 & 0.813 \\
\hline 11 & 0.63 & 3.44 & 2.81 & 0.832 \\
\hline 12 & 0.71 & 3.42 & 2.71 & 0.717 \\
\hline 13 & 0.83 & 3.42 & 2.59 & 0.594 \\
\hline 14 & 0.84 & 3.42 & 2.58 & 0.586 \\
\hline 15 & 0.74 & 3.40 & 2.66 & 0.685 \\
\hline 16 & 0.67 & 3.34 & 2.67 & 0.764 \\
\hline 17 & 0.72 & 3.32 & 2.60 & 0.706 \\
\hline 18 & 0.64 & 3.26 & 2.62 & 0.823 \\
\hline 19 & 0.64 & 3.16 & 2.52 & 0.822 \\
\hline 20 & 0.77 & 3.13 & 2.36 & 0.656 \\
\hline 21 & 0.67 & 3.11 & 2.44 & 0.774 \\
\hline 22 & 0.69 & 3.11 & 2.42 & 0.747 \\
\hline 23 & 0.75 & 3.05 & 2.30 & 0.673 \\
\hline 24 & 0.82 & 3.01 & 2.19 & 0.601 \\
\hline 25 & 0.87 & 2.98 & 2.11 & 0.558 \\
\hline 26 & 0.88 & 2.98 & 2.10 & 0.550 \\
\hline 27 & 0.89 & 2.96 & 2.07 & 0.540 \\
\hline 28 & 0.90 & 2.94 & 2.04 & 0.531 \\
\hline 29 & 0.97 & 2.94 & 1.97 & 0.492 \\
\hline 30 & 1.95 & 2.95 & 1.00 & 0.251 \\
\hline
\end{tabular}




\begin{tabular}{|c|c|c|c|c|c|c|c|c|c|}
\hline \multicolumn{5}{|c|}{ Sai - Bloco de notas } & \multicolumn{5}{|c|}{ Sai - Bloco de notas } \\
\hline \multicolumn{2}{|c|}{ Arquivo } & litar & Pesquisar & Ajuda & \multicolumn{5}{|c|}{ Arquivo Editar Pesquisar } \\
\hline \multicolumn{4}{|c|}{$\begin{array}{l}\text { RESOLUÇÃO DO SISTEMA } \\
\text { TEMPO EM SEGUNDOS }\end{array}$} & & $\begin{array}{l}\text { RESO } \\
\text { TEM } \\
t=\end{array}$ & 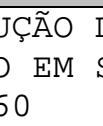 & $\begin{array}{l}\text { SIS } \\
\text { EGUNDC }\end{array}$ & SA & \\
\hline SEC & $y(m)$ & $h(m)$ & $\mathrm{V}(\mathrm{m} / \mathrm{s})$ & & SEC & $y(m)$ & $h(m)$ & $\mathrm{V}(\mathrm{m} / \mathrm{s})$ & \\
\hline 1 & 0.59 & 3.6 & 0.916 & & 1 & 0.59 & 3.61 & 0.915 & \\
\hline 2 & 0.60 & 3.5 & 0.892 & & 2 & 0.60 & 3.59 & 0.891 & \\
\hline 3 & 0.65 & 3.5 & 0.813 & & 3 & 0.65 & 3.56 & 0.813 & \\
\hline 4 & 0.66 & 3.5 & 0.804 & & 4 & 0.66 & 3.56 & 0.804 & \\
\hline 5 & 0.66 & 3.55 & 0.795 & & 5 & 0.66 & 3.55 & 0.794 & \\
\hline 6 & 0.68 & 3.5 & 0.767 & & 6 & 0.68 & 3.54 & 0.766 & \\
\hline 7 & 0.70 & 3.53 & 0.748 & & 7 & 0.70 & 3.53 & 0.748 & \\
\hline 8 & 0.71 & 3.53 & 0.746 & & 8 & 0.71 & 3.53 & 0.746 & \\
\hline 9 & 0.72 & 3.52 & 0.739 & & 9 & 0.72 & 3.52 & 0.738 & \\
\hline 10 & 0.64 & 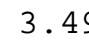 & 0.814 & & 10 & 0.64 & 3.49 & 0.813 & \\
\hline 11 & 0.63 & 3.4 & 0.833 & & 11 & 0.63 & 3.44 & 0.827 & \\
\hline 12 & 0.71 & 3.42 & 0.717 & & 12 & 0.71 & 3.42 & 0.711 & \\
\hline 13 & 0.83 & 3.42 & 0.594 & & 13 & 0.83 & 3.42 & 0.591 & \\
\hline 14 & 0.84 & 3.42 & 0.586 & & 14 & 0.84 & 3.42 & 0.583 & \\
\hline 15 & 0.74 & 3.46 & 0.685 & & 15 & 0.74 & 3.40 & 0.684 & \\
\hline 16 & 0.68 & 3.35 & 0.761 & & 16 & 0.67 & 3.34 & 0.783 & \\
\hline 17 & 0.72 & 3.32 & 0.698 & & 17 & 0.71 & 3.31 & 0.733 & \\
\hline 18 & 0.63 & 3.25 & 0.830 & & 18 & 0.64 & 3.26 & 0.809 & \\
\hline 19 & 0.64 & 3.1 & 0.808 & & 19 & 0.70 & 3.22 & 0.589 & \\
\hline 20 & 0.77 & 3.13 & 0.640 & & 20 & 0.87 & 3.23 & 0.384 & \\
\hline 21 & 0.67 & 3.11 & 0.773 & & 21 & 0.78 & 3.22 & 0.416 & \\
\hline 22 & 0.69 & 3.11 & 0.752 & & 22 & 0.80 & 3.22 & 0.400 & \\
\hline 23 & 0.73 & 3.03 & 0.739 & & 23 & 0.92 & 3.22 & 0.248 & \\
\hline 24 & 0.88 & $3.0^{\circ}$ & 0.383 & & 24 & 1.03 & 3.22 & 0.151 & \\
\hline 25 & 1.01 & 3.12 & 0.102 & & 25 & 1.11 & 3.22 & 0.079 & \\
\hline 26 & 1.02 & 3.12 & 0.097 & & 26 & 1.12 & 3.22 & 0.076 & \\
\hline 27 & 1.06 & 3.13 & 0.037 & & 27 & 1.15 & 3.22 & 0.040 & \\
\hline 28 & 1.08 & 3.12 & 0.005 & & 28 & 1.18 & 3.22 & 0.006 & \\
\hline 29 & 1.15 & 3.12 & 0.003 & & 29 & 1.25 & 3.22 & 0.004 & \\
\hline 30 & 2.12 & 3.12 & 0.000 & & 30 & 2.22 & 3.22 & 0.000 & \\
\hline
\end{tabular}

\begin{tabular}{|c|c|c|c|c|c|c|c|c|c|}
\hline \multicolumn{5}{|c|}{ Sai - Bloco de notas } & \multicolumn{5}{|c|}{ Sai - Bloco de notas } \\
\hline \multicolumn{2}{|c|}{ Arquivo } & Editar & Pesquisar & Ajuda & \multicolumn{5}{|c|}{ Arquivo Editar Pesquisar Ajuda } \\
\hline \multicolumn{5}{|c|}{$\begin{array}{l}\text { RESOLUÇÃO DO SISTEMA } \\
\text { TEMPO EM } \\
t=720\end{array}$} & \multicolumn{5}{|c|}{$\begin{array}{l}\text { RESOLUÇÃO DO SISTEMA } \\
\text { TEMPO EM SEGUNDOS } \\
t=1200\end{array}$} \\
\hline SEC & $y(m$ & $h(m)$ & $\mathrm{V}(\mathrm{m} / \mathrm{s})$ & & SEC & $y(m)$ & $\mathrm{h}(\mathrm{m})$ & $\mathrm{V}(\mathrm{m} / \mathrm{s})$ & \\
\hline 1 & 0.5 & 3.61 & 0.909 & & 1 & 0.59 & 3.61 & 0.753 & \\
\hline 2 & 0.6 & 3.59 & 0.884 & & 2 & 0.61 & 3.60 & 0.721 & \\
\hline 3 & 0.6 & 3.56 & 0.801 & & 3 & 0.67 & 3.58 & 0.638 & \\
\hline 4 & 0.6 & 3.56 & 0.791 & & 4 & 0.68 & 3.58 & 0.629 & \\
\hline 5 & 0.6 & 3.56 & 0.781 & & 5 & 0.69 & 3.58 & 0.620 & \\
\hline 6 & 0.6 & 3.55 & 0.751 & & 6 & 0.72 & 3.58 & 0.592 & \\
\hline 7 & 0.7 & 3.54 & 0.731 & & 7 & 0.74 & 3.57 & 0.576 & \\
\hline 8 & 0.7 & 3.53 & 0.728 & & 8 & 0.75 & 3.57 & 0.574 & \\
\hline 9 & 0.7 & 3.53 & 0.721 & & 9 & 0.76 & 3.56 & 0.570 & \\
\hline 10 & 0.6 & 3.50 & 0.787 & & 10 & 0.70 & 3.55 & 0.604 & \\
\hline 11 & 0.6 & 3.46 & 0.776 & & 11 & 0.72 & 3.53 & 0.565 & \\
\hline
\end{tabular}




\begin{tabular}{|c|c|c|c|c|c|c|c|}
\hline 12 & 0.74 & 3.45 & 0.653 & 12 & 0.82 & 3.53 & 0.472 \\
\hline 13 & 0.86 & 3.45 & 0.536 & 13 & 0.94 & 3.53 & 0.391 \\
\hline 14 & 0.86 & 3.44 & 0.528 & 14 & 0.95 & 3.53 & 0.385 \\
\hline 15 & 0.77 & 3.43 & 0.598 & 15 & 0.86 & 3.52 & 0.425 \\
\hline 16 & 0.73 & 3.40 & 0.607 & 16 & 0.84 & 3.51 & 0.412 \\
\hline 17 & 0.79 & 3.39 & 0.526 & 17 & 0.91 & 3.51 & 0.354 \\
\hline 18 & 0.75 & 3.37 & 0.520 & 18 & 0.88 & 3.50 & 0.338 \\
\hline 19 & 0.84 & 3.36 & 0.386 & 19 & 0.98 & 3.50 & 0.249 \\
\hline 20 & 1.00 & 3.36 & 0.272 & 20 & 1.14 & 3.50 & 0.180 \\
\hline 21 & 0.92 & 3.36 & 0.292 & 21 & 1.06 & 3.50 & 0.190 \\
\hline 22 & 0.94 & 3.36 & 0.283 & 22 & 1.08 & 3.50 & 0.185 \\
\hline 23 & 1.06 & 3.36 & 0.182 & 23 & 1.20 & 3.50 & 0.121 \\
\hline 24 & 1.17 & 3.36 & 0.111 & 24 & 1.31 & 3.50 & 0.075 \\
\hline 25 & 1.25 & 3.36 & 0.057 & 25 & 1.39 & 3.50 & 0.039 \\
\hline 26 & 1.26 & 3.36 & 0.055 & 26 & 1.40 & 3.50 & 0.038 \\
\hline 27 & 1.29 & 3.36 & 0.028 & 27 & 1.43 & 3.50 & 0.019 \\
\hline 28 & 1.32 & 3.36 & 0.004 & 28 & 1.46 & 3.50 & 0.003 \\
\hline 29 & 1.39 & 3.36 & 0.003 & 29 & 1.53 & 3.50 & 0.002 \\
\hline 30 & 2.36 & 3.36 & 0.000 & 30 & 2.50 & 3.50 & 0.000 \\
\hline
\end{tabular}

\begin{tabular}{|c|c|c|c|c|c|c|c|c|c|}
\hline \multicolumn{5}{|c|}{ Sai - Bloco de notas } & \multicolumn{5}{|c|}{ Sai - Bloco de notas } \\
\hline \multicolumn{2}{|c|}{ Arquivo } & Editar & Pesquisar & Ajuda & \multicolumn{5}{|c|}{ Arquivo Editar Pesquisar } \\
\hline \multicolumn{5}{|c|}{$\begin{array}{l}\text { TEMPO EM SEGUNDOS } \\
t=2370\end{array}$} & \multicolumn{5}{|c|}{$\begin{array}{l}\text { RESOLUÇÃO DO SISTEMA } \\
\text { TEMPO EM } \\
t=2940\end{array}$} \\
\hline SEC & $\mathrm{y}(\mathrm{m})$ & $h(m)$ & $\mathrm{V}(\mathrm{m} / \mathrm{s})$ & & SEC & $\mathrm{y}(\mathrm{m})$ & $h(m)$ & $\mathrm{V}(\mathrm{m} / \mathrm{s})$ & \\
\hline 1 & 0.5 & 3.61 & -0.067 & & 1 & 0.59 & 3.61 & -0.174 & \\
\hline 2 & 0.62 & 3.61 & -0.064 & & 2 & 0.62 & 3.61 & -0.164 & \\
\hline 3 & $0.7 C$ & 3.61 & -0.056 & & 3 & 0.70 & 3.61 & -0.141 & \\
\hline 4 & 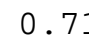 & 3.61 & -0.055 & & 4 & 0.71 & 3.61 & -0.139 & \\
\hline 5 & 0.73 & 3.62 & -0.054 & & 5 & 0.72 & 3.61 & -0.137 & \\
\hline 6 & 0.76 & 3.62 & -0.052 & & 6 & 0.75 & 3.61 & -0.130 & \\
\hline 7 & $0.7 £$ & 3.62 & -0.050 & & 7 & 0.78 & 3.61 & -0.126 & \\
\hline 8 & 0.80 & 3.62 & -0.050 & & 8 & 0.79 & 3.61 & -0.126 & \\
\hline 9 & 0.80 & 3.62 & -0.050 & & 9 & 0.80 & 3.61 & -0.126 & \\
\hline 10 & 0.77 & 3.62 & -0.052 & & 10 & 0.76 & 3.61 & -0.130 & \\
\hline 11 & 0.8 & 3.62 & -0.048 & & 11 & 0.80 & 3.61 & -0.119 & \\
\hline 12 & 0.92 & 3.63 & -0.041 & & 12 & 0.90 & 3.61 & -0.101 & \\
\hline 13 & 1.0 & 3.63 & -0.035 & & 13 & 1.02 & 3.61 & -0.084 & \\
\hline 14 & 1.05 & 3.63 & -0.035 & & 14 & 1.03 & 3.61 & -0.083 & \\
\hline 15 & $0.9^{\circ}$ & 3.63 & -0.037 & & 15 & 0.95 & 3.61 & -0.090 & \\
\hline 16 & 0.9 & 3.63 & -0.035 & & 16 & 0.94 & 3.61 & -0.087 & \\
\hline 17 & 1.03 & 3.63 & -0.031 & & 17 & 1.01 & 3.61 & -0.075 & \\
\hline 18 & 1.02 & 3.64 & -0.029 & & 18 & 0.99 & 3.61 & -0.071 & \\
\hline 19 & 1.12 & 3.64 & -0.022 & & 19 & 1.09 & 3.61 & -0.053 & \\
\hline 20 & $1.2 \varepsilon$ & 3.64 & -0.016 & & 20 & 1.25 & 3.61 & -0.039 & \\
\hline 21 & 1.26 & 3.64 & -0.017 & & 21 & 1.17 & 3.61 & -0.041 & \\
\hline 22 & 1.22 & 3.64 & -0.017 & & 22 & 1.19 & 3.61 & -0.040 & \\
\hline 23 & 1.3 & 3.64 & -0.011 & & 23 & 1.31 & 3.61 & -0.026 & \\
\hline 24 & 1.45 & 3.64 & -0.007 & & 24 & 1.42 & 3.61 & -0.016 & \\
\hline 25 & 1.5 & 3.65 & -0.004 & & 25 & 1.50 & 3.61 & -0.009 & \\
\hline 26 & 1.5 & 3.65 & -0.004 & & 26 & 1.51 & 3.61 & -0.008 & \\
\hline
\end{tabular}




\begin{tabular}{|c|c|c|c|c|c|}
\hline 27 & 1.58 & $3.65-0.002$ & 27 & 1.54 & $3.61-0.004$ \\
\hline 28 & 1.61 & 3.650 .000 & 28 & 1.57 & $3.61-0.001$ \\
\hline 29 & 1.68 & 0.000 & 29 & 1.64 & 3.610 .000 \\
\hline 30 & 2.65 & 0.000 & 30 & 2.61 & 0.000 \\
\hline
\end{tabular}

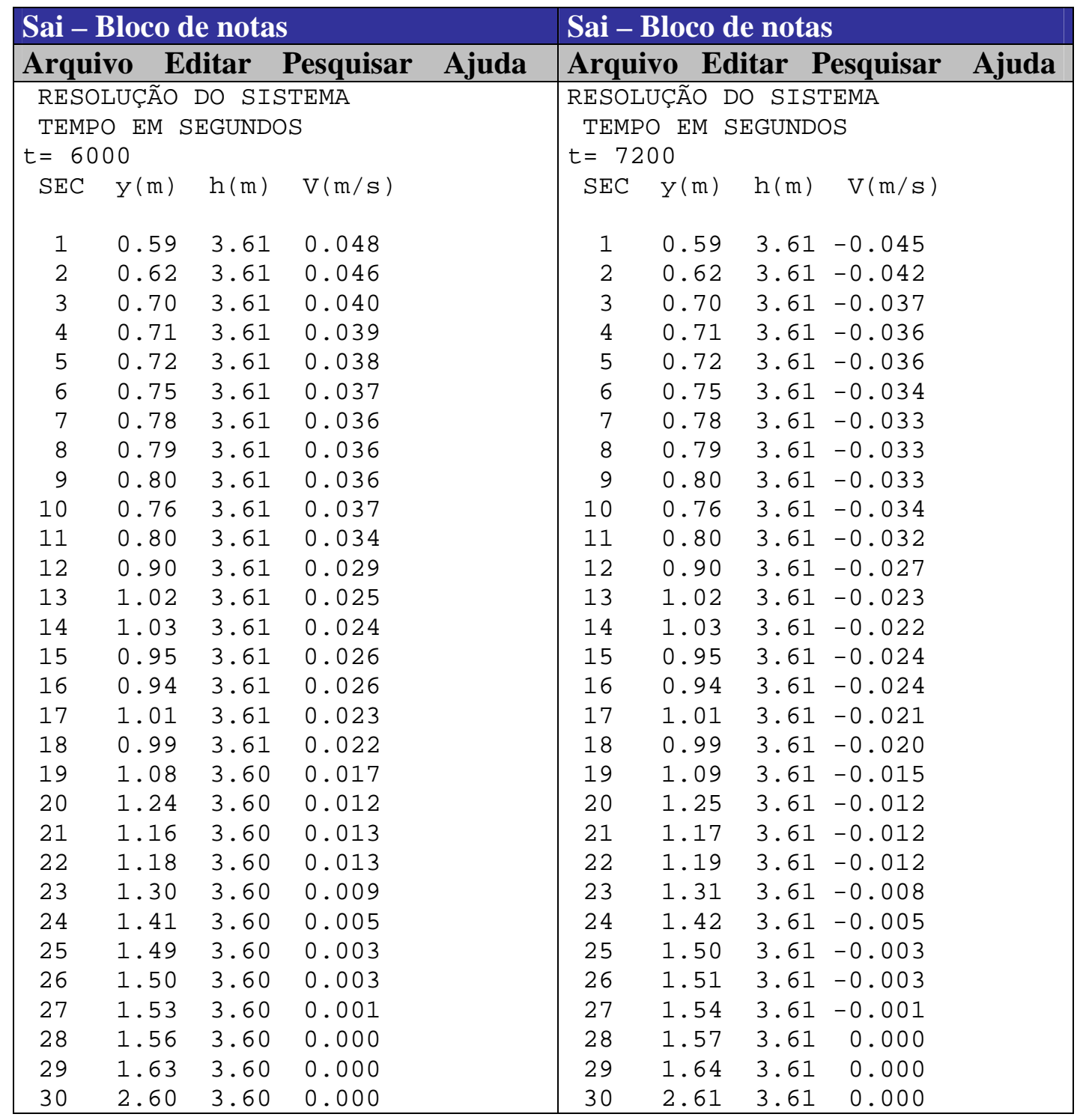




\begin{tabular}{|c|c|c|c|}
\hline \multicolumn{4}{|c|}{ Sai - Bloco de notas } \\
\hline Arquiv & vo & Editar & Pesquisar Ajuda \\
\hline \multicolumn{4}{|c|}{ ALTURA MÁXIMA OCORRIDA- hmax (m) } \\
\hline hmax & 1: & 3.61 & \\
\hline hmax & 2: & 3.61 & \\
\hline hmax & 3: & 3.61 & \\
\hline hmax & 4: & 3.62 & \\
\hline hmax & 5: & 3.62 & \\
\hline$h \max$ & 6: & 3.62 & \\
\hline hmax & $7:$ & 3.62 & \\
\hline hmax & 8: & 3.62 & \\
\hline hmax & 9: & 3.62 & \\
\hline hmax 1 & 10: & 3.62 & \\
\hline hmax 1 & 11: & 3.62 & \\
\hline hmax 1 & 12: & 3.63 & \\
\hline hmax 1 & 13: & 3.63 & \\
\hline hmax 1 & 14: & 3.63 & \\
\hline hmax 1 & 15: & 3.63 & \\
\hline hmax 1 & 16: & 3.63 & \\
\hline hmax 1 & 17: & 3.63 & \\
\hline hmax 1 & 18: & 3.64 & \\
\hline hmax 1 & 19: & 3.64 & \\
\hline hmax 2 & 20: & 3.64 & \\
\hline hmax 2 & 21: & 3.64 & \\
\hline hmax 2 & 22: & 3.64 & \\
\hline hmax 2 & 23: & 3.64 & \\
\hline hmax 2 & $24:$ & 3.65 & \\
\hline hmax 2 & 25: & 3.65 & \\
\hline hmax 2 & 26: & 3.65 & \\
\hline hmax 2 & 27: & 3.65 & \\
\hline hmax 2 & 28: & 3.65 & \\
\hline hmax 2 & 29 : & 3.65 & \\
\hline hmax 3 & $30:$ & 3.65 & \\
\hline
\end{tabular}


Dados de Saída do Modelo para o Canal do Trabalhador

Simulação de Enchimento do Canal

\begin{tabular}{|c|c|c|c|c|}
\hline \multicolumn{5}{|c|}{ Sai - Bloco de notas } \\
\hline \multicolumn{5}{|c|}{ Arquivo Editar Pesquisar Ajuda } \\
\hline \multicolumn{5}{|c|}{$\begin{array}{l}\text { TRANSIENTE HIDRÁULICO - CANAL DO TRABALHADOR } \\
\text { Enchimento do Canal }\end{array}$} \\
\hline \multicolumn{2}{|c|}{ COND IÇÕES } & INICIF & AIS DO & ESCOAMENTO \\
\hline SEC & $y(m)$ & $h(m)$ & $\mathrm{z}(\mathrm{m})$ & $\mathrm{V}(\mathrm{m} / \mathrm{s})$ \\
\hline 1 & 0.48 & 24.42 & 23.94 & 0.000 \\
\hline 2 & 0.28 & 24.42 & 24.14 & 0.000 \\
\hline 3 & 0.08 & 24.42 & 24.34 & 0.000 \\
\hline 4 & 0.06 & 24.42 & 24.36 & 0.000 \\
\hline 5 & 0.02 & 24.42 & 24.40 & 0.000 \\
\hline 6 & 0.02 & 23.02 & 23.00 & 0.000 \\
\hline 7 & 0.02 & 23.01 & 22.99 & 0.000 \\
\hline 8 & 0.02 & 22.98 & 22.96 & 0.000 \\
\hline 9 & 0.02 & 22.95 & 22.93 & 0.000 \\
\hline 10 & 0.02 & 22.92 & 22.90 & 0.000 \\
\hline 11 & 0.02 & 22.90 & 22.88 & 0.000 \\
\hline 12 & 0.02 & 22.89 & 22.87 & 0.000 \\
\hline 13 & 0.02 & 22.88 & 22.86 & 0.000 \\
\hline 14 & 0.02 & 22.86 & 22.84 & 0.000 \\
\hline 15 & 0.02 & 22.85 & 22.83 & 0.000 \\
\hline 16 & 0.02 & 22.83 & 22.81 & 0.000 \\
\hline 17 & 0.02 & 22.82 & 22.80 & 0.000 \\
\hline 18 & 0.02 & 22.81 & 22.79 & 0.000 \\
\hline 19 & 0.02 & 22.79 & 22.77 & 0.000 \\
\hline 20 & 0.02 & 22.78 & 22.76 & 0.000 \\
\hline 21 & 0.02 & 22.76 & 22.74 & 0.000 \\
\hline 22 & 0.02 & 22.75 & 22.73 & 0.000 \\
\hline 23 & 0.02 & 22.74 & 22.72 & 0.000 \\
\hline 24 & 0.02 & 22.72 & 22.70 & 0.000 \\
\hline 25 & 0.02 & 22.64 & 22.62 & 0.000 \\
\hline 26 & 0.02 & 22.48 & 22.46 & 0.000 \\
\hline 27 & 0.02 & 22.46 & 22.44 & 0.000 \\
\hline 28 & 0.02 & 22.16 & 22.14 & 0.000 \\
\hline 29 & 0.02 & 21.94 & 21.92 & 0.000 \\
\hline 30 & 0.02 & 21.72 & 21.70 & 0.000 \\
\hline 31 & 0.02 & 21.19 & 21.17 & 0.000 \\
\hline 32 & 0.02 & 21.17 & 21.15 & 0.000 \\
\hline 33 & 0.02 & 21.16 & 21.14 & 0.000 \\
\hline 34 & 0.02 & 21.14 & 21.12 & 0.000 \\
\hline 35 & 0.02 & 21.13 & 21.11 & 0.000 \\
\hline 36 & 0.02 & 21.11 & 21.09 & 0.000 \\
\hline 37 & 0.02 & 21.10 & 21.08 & 0.000 \\
\hline 38 & 0.02 & 21.09 & 21.07 & 0.000 \\
\hline 39 & 0.02 & 21.07 & 21.05 & 0.000 \\
\hline 40 & 0.02 & 21.06 & 21.04 & 0.000 \\
\hline 41 & 0.02 & 21.04 & 21.02 & 0.000 \\
\hline 42 & 0.02 & 21.03 & 21.01 & 0.000 \\
\hline 43 & 0.02 & 21.02 & 21.00 & 0.000 \\
\hline 44 & 0.02 & 21.01 & 20.99 & 0.000 \\
\hline 45 & 0.02 & 20.99 & 20.97 & 0.000 \\
\hline 46 & 0.02 & 20.98 & 20.96 & 0.000 \\
\hline
\end{tabular}




\begin{tabular}{|c|c|c|c|c|}
\hline 47 & 0.02 & 20.97 & 20.95 & 0.000 \\
\hline 48 & 0.02 & 20.96 & 20.94 & 0.000 \\
\hline 49 & 0.02 & 20.95 & 20.93 & 0.000 \\
\hline 50 & 0.02 & 20.93 & 20.91 & 0.000 \\
\hline 51 & 0.02 & 20.92 & 20.90 & 0.000 \\
\hline 52 & 0.02 & 20.91 & 20.89 & 0.000 \\
\hline 53 & 0.02 & 20.89 & 20.87 & 0.000 \\
\hline 54 & 0.02 & 20.88 & 20.86 & 0.000 \\
\hline 55 & 0.02 & 20.86 & 20.84 & 0.000 \\
\hline 56 & 0.02 & 20.85 & 20.83 & 0.000 \\
\hline 57 & 0.02 & 20.84 & 20.82 & 0.000 \\
\hline 58 & 0.02 & 20.83 & 20.81 & 0.000 \\
\hline 59 & 0.02 & 20.81 & 20.79 & 0.000 \\
\hline 60 & 0.02 & 20.80 & 20.78 & 0.000 \\
\hline 61 & 0.02 & 20.79 & 20.77 & 0.000 \\
\hline 62 & 0.02 & 20.77 & 20.75 & 0.000 \\
\hline 63 & 0.02 & 20.76 & 20.74 & 0.000 \\
\hline 64 & 0.02 & 20.74 & 20.72 & 0.000 \\
\hline 65 & 0.02 & 20.73 & 20.71 & 0.000 \\
\hline 66 & 0.02 & 20.72 & 20.70 & 0.000 \\
\hline 67 & 0.02 & 20.71 & 20.69 & 0.000 \\
\hline 68 & 0.02 & 20.70 & 20.68 & 0.000 \\
\hline 69 & 0.02 & 20.68 & 20.66 & 0.000 \\
\hline 70 & 0.02 & 20.67 & 20.65 & 0.000 \\
\hline 71 & 0.02 & 20.66 & 20.64 & 0.000 \\
\hline 72 & 0.02 & 20.43 & 20.41 & 0.000 \\
\hline 73 & 0.02 & 19.96 & 19.94 & 0.000 \\
\hline 74 & 0.02 & 19.44 & 19.42 & 0.000 \\
\hline 75 & 0.02 & 19.43 & 19.41 & 0.000 \\
\hline 76 & 0.02 & 19.40 & 19.38 & 0.000 \\
\hline 77 & 0.02 & 19.38 & 19.36 & 0.000 \\
\hline 78 & 0.02 & 19.36 & 19.34 & 0.000 \\
\hline 79 & 0.02 & 19.34 & 19.32 & 0.000 \\
\hline 80 & 0.02 & 19.33 & 19.31 & 0.000 \\
\hline 81 & 0.02 & 19.31 & 19.29 & 0.000 \\
\hline 82 & 0.02 & 19.30 & 19.28 & 0.000 \\
\hline 83 & 0.02 & 19.29 & 19.27 & 0.000 \\
\hline 84 & 0.02 & 19.28 & 19.26 & 0.000 \\
\hline 85 & 0.02 & 19.26 & 19.24 & 0.000 \\
\hline 86 & 0.02 & 19.25 & 19.23 & 0.000 \\
\hline 87 & 0.02 & 19.24 & 19.22 & 0.000 \\
\hline 88 & 0.02 & 19.23 & 19.21 & 0.000 \\
\hline 89 & 0.02 & 19.21 & 19.19 & 0.000 \\
\hline 90 & 0.02 & 19.20 & 19.18 & 0.000 \\
\hline 91 & 0.02 & 19.19 & 19.17 & 0.000 \\
\hline 92 & 0.02 & 19.18 & 19.16 & 0.000 \\
\hline 93 & 0.02 & 19.17 & 19.15 & 0.000 \\
\hline 94 & 0.02 & 19.16 & 19.14 & 0.000 \\
\hline 95 & 0.02 & 19.15 & 19.13 & 0.000 \\
\hline 96 & 0.02 & 19.14 & 19.12 & 0.000 \\
\hline 97 & 0.02 & 19.13 & 19.11 & 0.000 \\
\hline 98 & 0.02 & 19.12 & 19.10 & 0.000 \\
\hline 99 & 0.02 & 19.11 & 19.09 & 0.000 \\
\hline 100 & 0.02 & 19.10 & 19.08 & 0.000 \\
\hline 101 & 0.02 & 19.09 & 19.07 & 0.000 \\
\hline 102 & 0.02 & 19.08 & 19.06 & 0.000 \\
\hline 103 & 0.02 & 19.07 & 19.05 & 0.000 \\
\hline 104 & 0.02 & 19.06 & 19.04 & 0.000 \\
\hline 105 & 0.02 & 19.05 & 19.03 & 0.000 \\
\hline
\end{tabular}




\begin{tabular}{|lllll}
\hline 106 & 0.02 & 19.04 & 19.02 & 0.000 \\
107 & 0.02 & 19.03 & 19.01 & 0.000 \\
108 & 0.02 & 19.02 & 19.00 & 0.000 \\
109 & 0.00 & 19.00 & 19.00 & 0.000
\end{tabular}

\begin{tabular}{|c|c|c|c|c|c|c|c|c|c|}
\hline \multicolumn{5}{|c|}{ Sai - Bloco de notas } & \multicolumn{5}{|c|}{ Sai - Bloco de notas } \\
\hline \multicolumn{2}{|c|}{ Arquivo } & Editar & Pesquisar & Ajuda & Arqu & vo $\mathbf{E}$ & ditar 1 & Pesquisar & Ajuda \\
\hline \multicolumn{5}{|c|}{ RESOLUÇÃO DO SISTEMA } & 37 & 0.02 & 21.10 & 0.014 & \\
\hline \multicolumn{5}{|c|}{ TEMPO EM SEGUNDOS } & 38 & 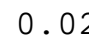 & 21.09 & 0.034 & \\
\hline$t=$ & 360 & & & & 39 & 0.02 & 21.07 & 0.049 & \\
\hline \multirow{2}{*}{$\mathrm{SEC}$} & $\mathrm{y}(\mathrm{m}$ & $h(m)$ & $\mathrm{V}(\mathrm{m} / \mathrm{s})$ & & 40 & 0.02 & 21.06 & 0.013 & \\
\hline & & & & & 41 & 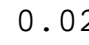 & 21.04 & 0.037 & \\
\hline 1 & 0.6 & 624.60 & 0.600 & & 42 & 0.02 & 21.03 & 0.011 & \\
\hline 2 & 0.3 & 524.49 & 0.390 & & 43 & 0.02 & 21.02 & 0.026 & \\
\hline 3 & 0.0 & 224.32 & 0.763 & & 44 & 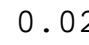 & 21.01 & 0.033 & \\
\hline 4 & 0.1 & 324.49 & -0.832 & & 45 & 0.02 & 20.99 & 0.036 & \\
\hline 5 & 0.0 & 824.48 & 0.805 & & 46 & 0.02 & 20.98 & 0.014 & \\
\hline 6 & 0.0 & 223.00 & -0.321 & & 47 & 0.02 & 20.97 & 0.021 & \\
\hline 7 & 0.0 & 423.03 & 0.336 & & 48 & 0.02 & 20.96 & 0.031 & \\
\hline 8 & 0.0 & 222.96 & -0.294 & & 49 & 0.02 & 20.95 & 0.010 & \\
\hline 9 & 0.0 & $\begin{array}{l}422.97 \\
\end{array}$ & 0.320 & & 50 & 0.02 & 20.93 & 0.008 & \\
\hline 10 & 0.0 & 222.91 & -0.196 & & 51 & 0.02 & 20.92 & 0.008 & \\
\hline 11 & 0.0 & 322.91 & 0.217 & & 52 & 0.02 & 20.91 & 0.028 & \\
\hline 12 & 0.0 & 222.88 & -0.165 & & 53 & 0.02 & 20.89 & 0.035 & \\
\hline 13 & 0.0 & 322.89 & 0.191 & & 54 & 0.02 & 20.88 & 0.030 & \\
\hline 14 & 0.0 & 222.85 & -0.086 & & 55 & 0.02 & 20.86 & 0.056 & \\
\hline 15 & 0.0 & 222.85 & 0.116 & & 56 & 0.02 & 20.85 & 0.000 & \\
\hline 16 & 0.0 & 222.83 & -0.061 & & 57 & 0.02 & 20.84 & 0.039 & \\
\hline 17 & 0.0 & 222.82 & 0.082 & & 58 & 0.02 & 20.83 & -0.013 & \\
\hline 18 & 0.0 & 222.81 & -0.028 & & 59 & 0.02 & 20.81 & 0.052 & \\
\hline 19 & 0.0 & $2 \quad 22.79$ & 0.074 & & 60 & 0.02 & 20.80 & -0.031 & \\
\hline 20 & 0.0 & 222.78 & -0.021 & & 61 & 0.02 & 20.79 & 0.081 & \\
\hline 21 & 0.0 & 222.76 & 0.068 & & 62 & 0.03 & 20.78 & -0.041 & \\
\hline 22 & 0.0 & 222.75 & -0.044 & & 63 & 0.02 & 20.75 & 0.111 & \\
\hline 23 & 0.0 & $2 \quad 22.74$ & 0.083 & & 64 & 0.03 & 20.75 & -0.071 & \\
\hline 24 & 0.0 & $2 \quad 22.72$ & -0.019 & & 65 & 0.02 & 20.72 & 0.129 & \\
\hline 25 & 0.0 & 222.64 & 0.038 & & 66 & 0.03 & 20.73 & -0.126 & \\
\hline 26 & 0.0 & 222.48 & -0.033 & & 67 & 0.02 & 20.70 & 0.240 & \\
\hline 27 & 0.0 & 222.46 & 0.036 & & 68 & 0.04 & 20.72 & -0.248 & \\
\hline 28 & 0.0 & 222.16 & -0.028 & & 69 & 0.02 & 20.66 & 0.376 & \\
\hline 29 & 0.0 & $2 \quad 21.94$ & 0.038 & & 70 & 0.05 & 20.70 & -0.393 & \\
\hline 30 & 0.0 & 221.72 & -0.028 & & 71 & 0.02 & 20.62 & 0.456 & \\
\hline 31 & 0.0 & 221.19 & 0.041 & & 72 & 0.02 & 20.42 & -0.237 & \\
\hline 32 & 0.0 & 321.18 & 0.031 & & 73 & 0.02 & 19.94 & 0.386 & \\
\hline 33 & 0.0 & 221.15 & 0.020 & & 74 & 0.05 & 19.47 & 0.030 & \\
\hline 34 & 0.0 & $2 \quad 21.14$ & 0.016 & & 75 & 0.05 & 19.46 & 0.135 & \\
\hline 35 & 0.0 & 221.13 & 0.016 & & 76 & 0.02 & 19.39 & 0.023 & \\
\hline 36 & 0.0 & 221.11 & 0.024 & & 77 & 0.02 & 19.38 & 0.008 & \\
\hline
\end{tabular}




\begin{tabular}{|rrrr|rrrr|}
\hline 78 & 0.02 & 19.36 & 0.036 & 94 & 0.02 & 19.16 & 0.025 \\
79 & 0.02 & 19.34 & -0.004 & 95 & 0.02 & 19.15 & 0.021 \\
80 & 0.02 & 19.33 & 0.044 & 96 & 0.02 & 19.14 & 0.020 \\
81 & 0.02 & 19.31 & 0.015 & 97 & 0.02 & 19.13 & 0.015 \\
82 & 0.02 & 19.30 & 0.041 & 98 & 0.02 & 19.12 & 0.020 \\
83 & 0.02 & 19.29 & -0.006 & 99 & 0.02 & 19.11 & 0.012 \\
84 & 0.02 & 19.28 & 0.041 & 100 & 0.02 & 19.10 & 0.017 \\
85 & 0.02 & 19.26 & 0.028 & 101 & 0.02 & 19.09 & 0.021 \\
86 & 0.02 & 19.25 & 0.029 & 102 & 0.02 & 19.08 & 0.031 \\
87 & 0.02 & 19.24 & 0.006 & 103 & 0.02 & 19.07 & 0.015 \\
88 & 0.02 & 19.23 & 0.047 & 104 & 0.02 & 19.06 & 0.005 \\
89 & 0.02 & 19.21 & 0.038 & 105 & 0.02 & 19.05 & 0.025 \\
90 & 0.02 & 19.20 & 0.021 & 106 & 0.02 & 19.04 & 0.017 \\
91 & 0.02 & 19.19 & 0.023 & 107 & 0.02 & 19.03 & 0.027 \\
92 & 0.02 & 19.18 & 0.024 & 108 & 0.02 & 19.02 & 0.022 \\
93 & 0.02 & 19.17 & 0.021 & 109 & 0.02 & 19.02 & 0.022 \\
\hline
\end{tabular}

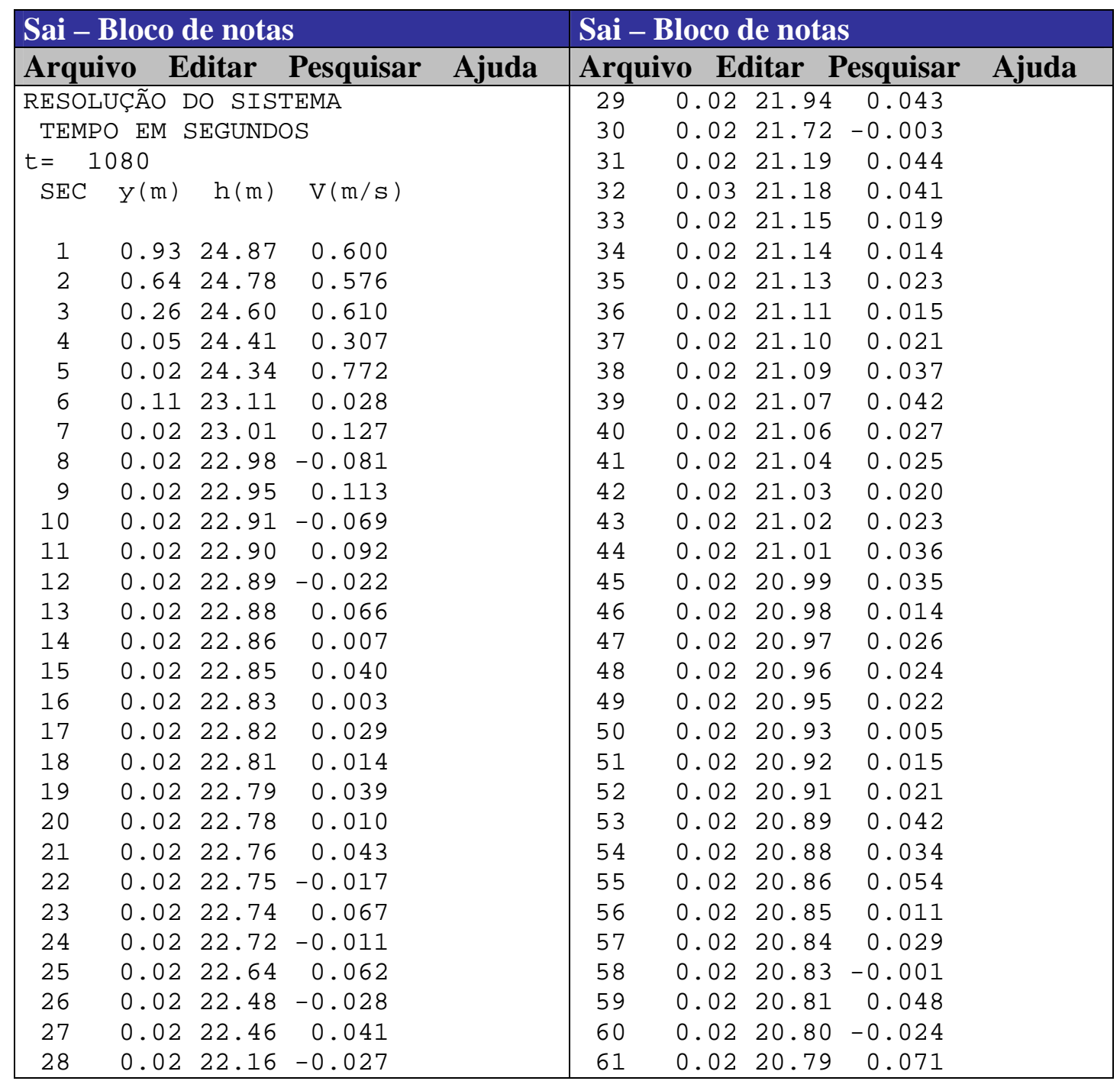




\begin{tabular}{|c|c|c|c|c|c|c|c|}
\hline 62 & 0.02 & 20.77 & -0.029 & 86 & 0.02 & 19.25 & 0.023 \\
\hline 63 & 0.02 & 20.75 & 0.094 & 87 & 0.02 & 19.24 & 0.014 \\
\hline 64 & 0.03 & 20.75 & -0.047 & 88 & 0.02 & 19.23 & 0.043 \\
\hline 65 & 0.02 & 20.72 & 0.101 & 89 & 0.02 & 19.21 & 0.042 \\
\hline 66 & 0.03 & 20.73 & -0.082 & 90 & 0.02 & 19.20 & 0.026 \\
\hline 67 & 0.02 & 20.70 & 0.165 & 91 & 0.02 & 19.19 & 0.022 \\
\hline 68 & 0.03 & 20.71 & -0.148 & 92 & 0.02 & 19.18 & 0.026 \\
\hline 69 & 0.02 & 20.66 & 0.248 & 93 & 0.02 & 19.17 & 0.023 \\
\hline 70 & 0.04 & 20.69 & -0.305 & 94 & 0.02 & 19.16 & 0.025 \\
\hline 71 & 0.02 & 20.59 & 0.472 & 95 & 0.02 & 19.15 & 0.023 \\
\hline 72 & 0.04 & 20.45 & -0.201 & 96 & 0.02 & 19.14 & 0.018 \\
\hline 73 & 0.02 & 19.90 & 0.502 & 97 & 0.02 & 19.13 & 0.018 \\
\hline 74 & 0.08 & 19.50 & 0.201 & 98 & 0.02 & 19.12 & 0.017 \\
\hline 75 & 0.07 & 19.48 & 0.193 & 99 & 0.02 & 19.11 & 0.015 \\
\hline 76 & 0.02 & 19.40 & 0.045 & 100 & 0.02 & 19.10 & 0.013 \\
\hline 77 & 0.02 & 19.38 & 0.008 & 101 & 0.02 & 19.09 & 0.026 \\
\hline 78 & 0.02 & 19.36 & 0.036 & 102 & 0.02 & 19.08 & 0.031 \\
\hline 79 & 0.02 & 19.34 & -0.003 & 103 & 0.02 & 19.07 & 0.017 \\
\hline 80 & 0.02 & 19.33 & 0.037 & 104 & 0.02 & 19.06 & 0.007 \\
\hline 81 & 0.02 & 19.31 & 0.023 & 105 & 0.02 & 19.05 & 0.022 \\
\hline 82 & 0.02 & 19.30 & 0.028 & 106 & 0.02 & 19.04 & 0.021 \\
\hline 83 & 0.02 & 19.29 & 0.008 & 107 & 0.02 & 19.03 & 0.025 \\
\hline 84 & 0.02 & 19.28 & 0.030 & 108 & 0.02 & 19.02 & 0.028 \\
\hline 85 & 0.02 & 19.26 & 0.036 & 109 & 0.02 & 19.02 & 0.028 \\
\hline
\end{tabular}

\begin{tabular}{|c|c|c|c|c|c|c|c|c|c|}
\hline \multicolumn{5}{|c|}{ Sai - Bloco de notas } & \multicolumn{5}{|c|}{ Sai - Bloco de notas } \\
\hline \multicolumn{4}{|c|}{ Arquivo Editar Pesquisar } & Ajuda & Arqu & o $\mathbf{E}$ & litar I & squisar & Ajuda \\
\hline \multicolumn{5}{|c|}{ RESOLUÇÃO DO SISTEMA } & 26 & 0.02 & 22.48 & 0.003 & \\
\hline \multicolumn{5}{|c|}{ TEMPO EM SEGUNDOS } & 27 & 0.02 & 22.46 & 0.010 & \\
\hline \multicolumn{5}{|c|}{$t=1800$} & 28 & 0.02 & 22.16 & 0.034 & \\
\hline \multirow{2}{*}{\multicolumn{3}{|c|}{$\mathrm{SEC} \quad \mathrm{y}(\mathrm{m}) \quad \mathrm{h}(\mathrm{m})$}} & $\mathrm{V}(\mathrm{m} / \mathrm{s})$ & & 29 & 0.02 & 21.94 & 0.056 & \\
\hline & & & & & 30 & 0.02 & 21.72 & 0.039 & \\
\hline 1 & 1.15 & 525.09 & 0.600 & & 31 & 0.02 & 21.19 & 0.031 & \\
\hline 2 & 0.88 & 325.02 & 0.643 & & 32 & 0.03 & 21.18 & 0.061 & \\
\hline 3 & 0.54 & 24.88 & 0.730 & & 33 & 0.02 & 21.15 & 0.007 & \\
\hline 4 & 0.31 & 24.67 & 0.879 & & 34 & 0.03 & 21.15 & 0.021 & \\
\hline 5 & 0.20 & 24.60 & 1.112 & & 35 & 0.02 & 21.13 & 0.018 & \\
\hline 6 & 0.03 & 323.03 & -0.014 & & 36 & 0.02 & 21.11 & 0.019 & \\
\hline 7 & 0.04 & 23.03 & 0.069 & & 37 & 0.02 & 21.10 & 0.019 & \\
\hline 8 & 0.02 & 22.97 & 0.015 & & 38 & 0.02 & 21.09 & 0.039 & \\
\hline 9 & 0.03 & 322.96 & 0.020 & & 39 & 0.02 & 21.07 & 0.038 & \\
\hline 10 & 0.02 & 22.92 & 0.034 & & 40 & 0.02 & 21.06 & 0.030 & \\
\hline 11 & 0.02 & 22.90 & -0.001 & & 41 & 0.02 & 21.04 & 0.024 & \\
\hline 12 & 0.02 & 22.89 & 0.048 & & 42 & 0.02 & 21.03 & 0.021 & \\
\hline 13 & 0.02 & 22.87 & 0.028 & & 43 & 0.02 & 21.02 & 0.024 & \\
\hline 14 & 0.02 & 22.86 & 0.024 & & 44 & 0.02 & 21.01 & 0.034 & \\
\hline 15 & 0.02 & 22.85 & 0.039 & & 45 & 0.02 & 20.99 & 0.035 & \\
\hline 16 & 0.02 & 22.83 & 0.001 & & 46 & 0.02 & 20.98 & 0.015 & \\
\hline 17 & 0.02 & 22.82 & 0.035 & & 47 & 0.02 & 20.97 & 0.026 & \\
\hline 18 & 0.02 & 22.81 & 0.007 & & 48 & 0.02 & 20.96 & 0.022 & \\
\hline 19 & 0.02 & 22.79 & 0.046 & & 49 & 0.02 & 20.95 & 0.025 & \\
\hline 20 & 0.02 & 22.78 & 0.009 & & 50 & 0.02 & 20.93 & 0.003 & \\
\hline 21 & 0.02 & 22.76 & 0.038 & & 51 & 0.02 & 20.92 & 0.018 & \\
\hline 22 & 0.02 & 22.75 & -0.005 & & 52 & 0.02 & 20.91 & 0.019 & \\
\hline 23 & 0.02 & 22.74 & 0.044 & & 53 & 0.02 & 20.89 & 0.044 & \\
\hline 24 & 0.02 & 22.72 & 0.023 & & 54 & 0.02 & 20.88 & 0.032 & \\
\hline 25 & 0.02 & 22.64 & 0.036 & & 55 & 0.02 & 20.86 & 0.054 & \\
\hline
\end{tabular}




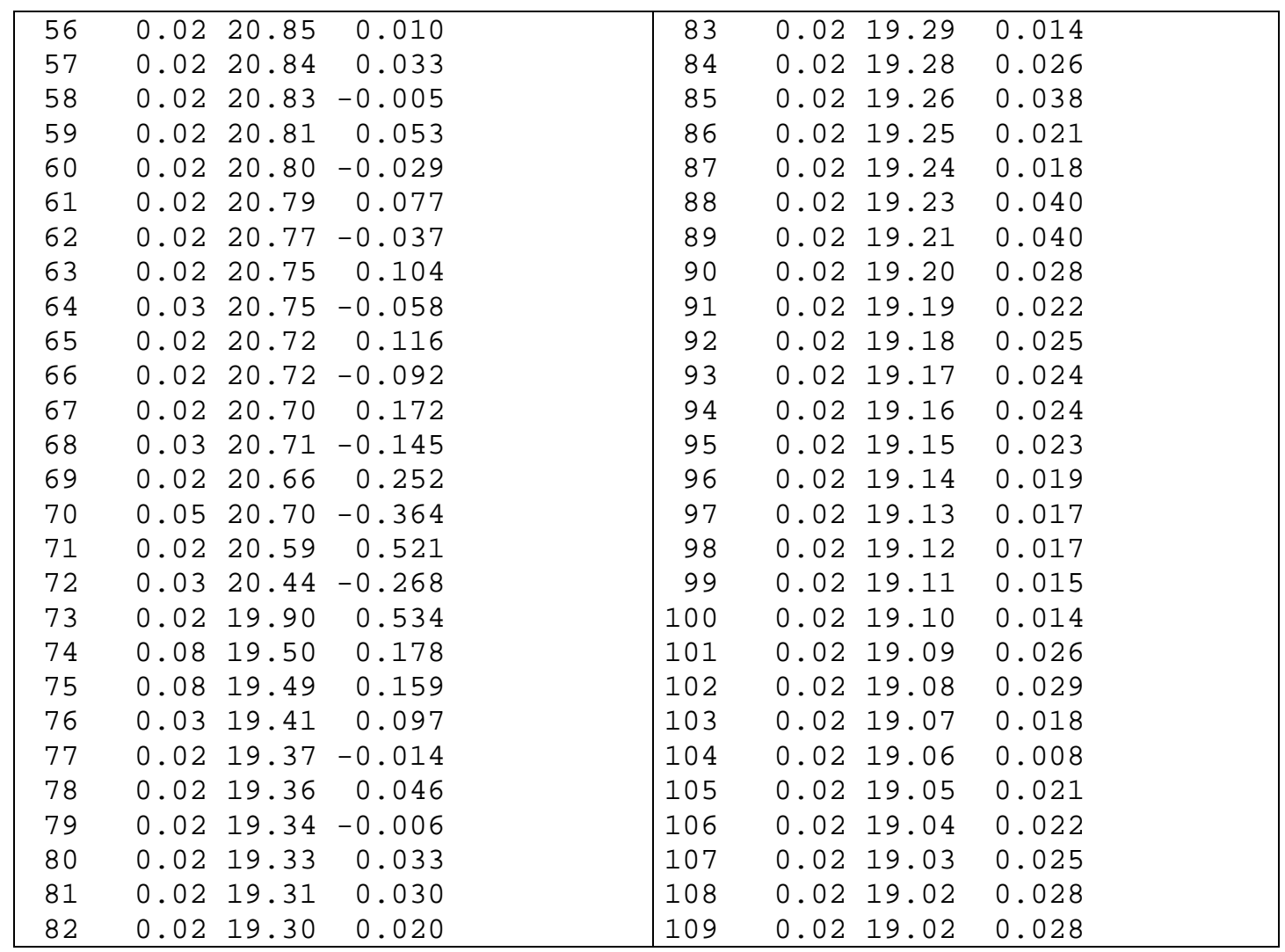

\begin{tabular}{|c|c|c|c|c|c|c|c|c|c|}
\hline \multicolumn{5}{|c|}{ Sai - Bloco de notas } & \multicolumn{5}{|c|}{ Sai - Bloco de notas } \\
\hline \multicolumn{3}{|c|}{ Arquivo Editar } & Pesquisar & Ajuda & Arqu & vo $\mathbf{E}$ & litar $\mathbf{P}$ & esquisar & Ajuda \\
\hline \multicolumn{5}{|c|}{ RESOLUÇÃO DO SISTEMA } & 21 & 0.02 & 22.76 & 0.029 & \\
\hline \multicolumn{5}{|c|}{ TEMPO EM SEGUNDOS } & 22 & 0.02 & 22.75 & 0.000 & \\
\hline \multicolumn{5}{|c|}{$t=3600$} & 23 & 0.02 & 22.74 & 0.049 & \\
\hline \multirow{2}{*}{\multicolumn{3}{|c|}{$\mathrm{SEC} \quad \mathrm{y}(\mathrm{m}) \quad \mathrm{h}(\mathrm{m})$}} & $\mathrm{V}(\mathrm{m} / \mathrm{s})$ & & 24 & 0.02 & 22.72 & 0.010 & \\
\hline & & & & & 25 & 0.02 & 22.64 & 0.042 & \\
\hline 1 & 1.5 & 325.47 & 0.600 & & 26 & 0.02 & 22.48 & -0.002 & \\
\hline 2 & 1.2 & 25.41 & 0.692 & & 27 & 0.02 & 22.46 & 0.018 & \\
\hline 3 & 0.9 & 525.29 & 0.912 & & 28 & 0.02 & 22.16 & 0.014 & \\
\hline 4 & 0.7 & 325.09 & 1.191 & & 29 & 0.02 & 21.94 & 0.083 & \\
\hline 5 & 0.5 & 9 24.99 & 1.541 & & 30 & 0.02 & 21.72 & -0.019 & \\
\hline 6 & 0.5 & 323.58 & 0.371 & & 31 & 0.02 & 21.19 & 0.025 & \\
\hline 7 & 0.1 & 23.16 & 0.973 & & 32 & 0.04 & 21.19 & 0.032 & \\
\hline 8 & 0.0 & 22.89 & -0.623 & & 33 & 0.02 & 21.15 & 0.036 & \\
\hline 9 & 0.0 & 323.01 & 0.489 & & 34 & 0.02 & 21.14 & 0.002 & \\
\hline 10 & 0.0 & 22.88 & -0.319 & & 35 & 0.02 & 21.13 & 0.032 & \\
\hline 11 & 0.0 & 522.93 & 0.237 & & 36 & 0.02 & 21.11 & 0.008 & \\
\hline 12 & 0.0 & 22.87 & -0.092 & & 37 & 0.02 & 21.10 & 0.028 & \\
\hline 13 & 0.0 & 22.88 & 0.041 & & 38 & 0.02 & 21.08 & 0.034 & \\
\hline 14 & 0.0 & 22.86 & 0.035 & & 39 & 0.02 & 21.07 & 0.037 & \\
\hline 15 & 0.0 & 22.85 & 0.017 & & 40 & 0.02 & 21.06 & 0.030 & \\
\hline 16 & 0.0 & 22.83 & 0.025 & & 41 & 0.02 & 21.04 & 0.024 & \\
\hline 17 & 0.0 & 22.82 & 0.013 & & 42 & 0.02 & 21.03 & 0.020 & \\
\hline 18 & 0.0 & 222.81 & 0.025 & & 43 & 0.02 & 21.02 & 0.027 & \\
\hline 19 & 0.0 & 22.79 & 0.028 & & 44 & 0.02 & 21.01 & 0.032 & \\
\hline 20 & 0.0 & 22.78 & 0.020 & & 45 & 0.02 & 20.99 & 0.033 & \\
\hline
\end{tabular}




\begin{tabular}{|c|c|c|c|c|c|c|c|}
\hline 46 & 0.02 & 20.98 & 0.018 & 78 & 0.02 & 19.36 & 0.009 \\
\hline 47 & 0.02 & 20.97 & 0.026 & 79 & 0.02 & 19.34 & 0.027 \\
\hline 48 & 0.02 & 20.96 & 0.020 & 80 & 0.02 & 19.33 & 0.013 \\
\hline 49 & 0.02 & 20.95 & 0.026 & 81 & 0.02 & 19.31 & 0.039 \\
\hline 50 & 0.02 & 20.93 & 0.002 & 82 & 0.02 & 19.30 & 0.019 \\
\hline 51 & 0.02 & 20.92 & 0.019 & 83 & 0.02 & 19.29 & 0.014 \\
\hline 52 & 0.02 & 20.91 & 0.018 & 84 & 0.02 & 19.28 & 0.029 \\
\hline 53 & 0.02 & 20.89 & 0.045 & 85 & 0.02 & 19.26 & 0.032 \\
\hline 54 & 0.02 & 20.88 & 0.030 & 86 & 0.02 & 19.25 & 0.023 \\
\hline 55 & 0.02 & 20.86 & 0.054 & 87 & 0.02 & 19.24 & 0.022 \\
\hline 56 & 0.02 & 20.85 & 0.007 & 88 & 0.02 & 19.22 & 0.038 \\
\hline 57 & 0.02 & 20.84 & 0.039 & 89 & 0.02 & 19.21 & 0.037 \\
\hline 58 & 0.02 & 20.83 & -0.010 & 90 & 0.02 & 19.20 & 0.030 \\
\hline 59 & 0.02 & 20.81 & 0.058 & 91 & 0.02 & 19.19 & 0.023 \\
\hline 60 & 0.02 & 20.80 & -0.033 & 92 & 0.02 & 19.18 & 0.023 \\
\hline 61 & 0.02 & 20.78 & 0.084 & 93 & 0.02 & 19.17 & 0.024 \\
\hline 62 & 0.03 & 20.78 & -0.046 & 94 & 0.02 & 19.16 & 0.024 \\
\hline 63 & 0.02 & 20.75 & 0.118 & 95 & 0.02 & 19.15 & 0.023 \\
\hline 64 & 0.03 & 20.75 & -0.075 & 96 & 0.02 & 19.14 & 0.019 \\
\hline 65 & 0.02 & 20.72 & 0.138 & 97 & 0.02 & 19.13 & 0.017 \\
\hline 66 & 0.02 & 20.72 & -0.112 & 98 & 0.02 & 19.12 & 0.017 \\
\hline 67 & 0.02 & 20.70 & 0.193 & 99 & 0.02 & 19.11 & 0.015 \\
\hline 68 & 0.03 & 20.71 & -0.159 & 100 & 0.02 & 19.10 & 0.015 \\
\hline 69 & 0.02 & 20.66 & 0.276 & 101 & 0.02 & 19.09 & 0.025 \\
\hline 70 & 0.05 & 20.70 & -0.406 & 102 & 0.02 & 19.08 & 0.026 \\
\hline 71 & 0.02 & 20.59 & 0.551 & 103 & 0.02 & 19.07 & 0.018 \\
\hline 72 & 0.03 & 20.44 & -0.296 & 104 & 0.02 & 19.06 & 0.009 \\
\hline 73 & 0.02 & 19.88 & 0.568 & 105 & 0.02 & 19.05 & 0.019 \\
\hline 74 & 0.08 & 19.50 & 0.144 & 106 & 0.02 & 19.04 & 0.023 \\
\hline 75 & 0.09 & 19.50 & 0.131 & 107 & 0.02 & 19.03 & 0.025 \\
\hline 76 & 0.05 & 19.43 & 0.117 & 108 & 0.02 & 19.02 & 0.026 \\
\hline 77 & 0.02 & 19.37 & 0.023 & 109 & 0.02 & 19.02 & 0.026 \\
\hline
\end{tabular}

\begin{tabular}{|c|c|c|c|c|c|c|c|}
\hline \multicolumn{4}{|c|}{ Sai - Bloco de notas } & \multicolumn{4}{|c|}{ Sai - Bloco de notas } \\
\hline \multicolumn{2}{|c|}{ Arquivo ] } & ditar & Pesquisar Ajuda & Arquivo & Editar & esquisar & Ajuda \\
\hline & 150 & $.02 \quad 22.85$ & 0.062 & \\
\hline \multicolumn{4}{|c|}{ TEMPO EM SEGUNDOS } & 16 & $.02 \quad 22.83$ & -0.010 & \\
\hline \multicolumn{4}{|c|}{$t=7200$} & 17 & $.02 \quad 22.82$ & 0.042 & \\
\hline \multirow[t]{2}{*}{$\mathrm{SEC}$} & $y(m)$ & $h(m)$ & $\mathrm{V}(\mathrm{m} / \mathrm{s})$ & 18 & $.02 \quad 22.80$ & 0.017 & \\
\hline & & & & 19 & .0322 .80 & 0.018 & \\
\hline 1 & 1.76 & 25.70 & 0.600 & 20 & $.02 \quad 22.77$ & 0.050 & \\
\hline 2 & 1.51 & 25.65 & 0.739 & 21 & $.03 \quad 22.77$ & -0.018 & \\
\hline 3 & 1.18 & 25.52 & 1.016 & 22 & $.02 \quad 22.74$ & 0.060 & \\
\hline 4 & 0.98 & 25.34 & 1.296 & 23 & $.02 \quad 22.74$ & -0.018 & \\
\hline 5 & 0.87 & 25.27 & 1.515 & 24 & $.02 \quad 22.71$ & 0.093 & \\
\hline 6 & 1.26 & 24.26 & 0.809 & 25 & .0322 .65 & -0.064 & \\
\hline 7 & 1.20 & 24.19 & 0.825 & 26 & $.02 \quad 22.48$ & 0.118 & \\
\hline 8 & 0.97 & 23.93 & 0.913 & 27 & $.03 \quad 22.47$ & -0.002 & \\
\hline 9 & 0.73 & 23.66 & 0.735 & 28 & $.02 \quad 22.14$ & 0.004 & \\
\hline 10 & 0.10 & 23.00 & 0.863 & 29 & .0421 .96 & 0.084 & \\
\hline 11 & 0.02 & 22.85 & -0.587 & 30 & .0221 .70 & 0.013 & \\
\hline 12 & 0.08 & 22.95 & 0.341 & 31 & .0321 .20 & 0.073 & \\
\hline 13 & 0.02 & 22.85 & -0.102 & 32 & .0421 .19 & 0.057 & \\
\hline 14 & 0.03 & 22.87 & 0.023 & 33 & $.02 \quad 21.16$ & 0.029 & \\
\hline
\end{tabular}




\begin{tabular}{|c|c|c|c|c|c|c|c|}
\hline 34 & 0.02 & 21.14 & 0.008 & 72 & 0.04 & 20.45 & -0.321 \\
\hline 35 & 0.02 & 21.13 & 0.027 & 73 & 0.02 & 19.89 & 0.575 \\
\hline 36 & 0.02 & 21.11 & 0.011 & 74 & 0.09 & 19.51 & 0.146 \\
\hline 37 & 0.02 & 21.10 & 0.029 & 75 & 0.09 & 19.50 & 0.127 \\
\hline 38 & 0.02 & 21.08 & 0.031 & 76 & 0.08 & 19.46 & 0.096 \\
\hline 39 & 0.02 & 21.07 & 0.034 & 77 & 0.03 & 19.39 & 0.082 \\
\hline 40 & 0.02 & 21.06 & 0.032 & 78 & 0.02 & 19.35 & -0.006 \\
\hline 41 & 0.02 & 21.04 & 0.024 & 79 & 0.03 & 19.35 & 0.027 \\
\hline 42 & 0.02 & 21.03 & 0.021 & 80 & 0.02 & 19.32 & 0.026 \\
\hline 43 & 0.02 & 21.02 & 0.028 & 81 & 0.02 & 19.31 & 0.024 \\
\hline 44 & 0.02 & 21.01 & 0.031 & 82 & 0.02 & 19.30 & 0.024 \\
\hline 45 & 0.02 & 20.99 & 0.030 & 83 & 0.02 & 19.29 & 0.017 \\
\hline 46 & 0.02 & 20.98 & 0.021 & 84 & 0.02 & 19.27 & 0.028 \\
\hline 47 & 0.02 & 20.97 & 0.027 & 85 & 0.02 & 19.26 & 0.029 \\
\hline 48 & 0.02 & 20.96 & 0.018 & 86 & 0.02 & 19.25 & 0.023 \\
\hline 49 & 0.02 & 20.95 & 0.026 & 87 & 0.02 & 19.24 & 0.026 \\
\hline 50 & 0.02 & 20.93 & 0.002 & 88 & 0.02 & 19.22 & 0.035 \\
\hline 51 & 0.02 & 20.92 & 0.020 & 89 & 0.02 & 19.21 & 0.033 \\
\hline 52 & 0.02 & 20.91 & 0.018 & 90 & 0.02 & 19.20 & 0.030 \\
\hline 53 & 0.02 & 20.89 & 0.045 & 91 & 0.02 & 19.19 & 0.026 \\
\hline 54 & 0.02 & 20.88 & 0.026 & 92 & 0.02 & 19.18 & 0.023 \\
\hline 55 & 0.02 & 20.86 & 0.053 & 93 & 0.02 & 19.17 & 0.024 \\
\hline 56 & 0.03 & 20.86 & 0.005 & 94 & 0.02 & 19.16 & 0.024 \\
\hline 57 & 0.02 & 20.84 & 0.045 & 95 & 0.02 & 19.15 & 0.022 \\
\hline 58 & 0.02 & 20.83 & -0.013 & 96 & 0.02 & 19.14 & 0.019 \\
\hline 59 & 0.02 & 20.81 & 0.060 & 97 & 0.02 & 19.13 & 0.018 \\
\hline 60 & 0.02 & 20.80 & -0.034 & 98 & 0.02 & 19.12 & 0.017 \\
\hline 61 & 0.02 & 20.78 & 0.087 & 99 & 0.02 & 19.11 & 0.014 \\
\hline 62 & 0.03 & 20.78 & -0.052 & 100 & 0.02 & 19.10 & 0.017 \\
\hline 63 & 0.02 & 20.75 & 0.125 & 101 & 0.02 & 19.09 & 0.024 \\
\hline 64 & 0.03 & 20.75 & -0.084 & 102 & 0.02 & 19.08 & 0.024 \\
\hline 65 & 0.02 & 20.72 & 0.148 & 103 & 0.02 & 19.07 & 0.018 \\
\hline 66 & 0.02 & 20.72 & -0.119 & 104 & 0.02 & 19.06 & 0.012 \\
\hline 67 & 0.02 & 20.70 & 0.200 & 105 & 0.02 & 19.05 & 0.017 \\
\hline 68 & 0.02 & 20.70 & -0.159 & 106 & 0.02 & 19.04 & 0.023 \\
\hline 69 & 0.02 & 20.66 & 0.275 & 107 & 0.02 & 19.03 & 0.025 \\
\hline 70 & 0.06 & 20.71 & -0.420 & 108 & 0.02 & 19.02 & 0.025 \\
\hline 71 & 0.02 & 20.60 & 0.569 & 109 & 0.02 & 19.02 & 0.025 \\
\hline
\end{tabular}

\begin{tabular}{|c|c|c|c|c|c|c|c|c|c|}
\hline \multicolumn{5}{|c|}{ Sai - Bloco de notas } & \multicolumn{5}{|c|}{ Sai - Bloco de notas } \\
\hline \multicolumn{2}{|c|}{ Arquivo } & Editar & Pesquisar & Ajuda & Arqu & vo $E$ & ditar & esquisar & Ajuda \\
\hline \multicolumn{5}{|c|}{ RESOLUÇÃO DO SISTEMA } & 9 & 1.78 & 24.71 & 0.633 & \\
\hline \multirow{2}{*}{\multicolumn{5}{|c|}{$\begin{array}{l}\text { TEMPO EM SEGUNDOS } \\
t=21600\end{array}$}} & 10 & 1.73 & 24.63 & 0.631 & \\
\hline & & & & & 11 & 1.67 & 24.55 & 0.635 & \\
\hline \multirow{2}{*}{ SEC } & $\mathrm{y}(\mathrm{m})$ & n) $h(m)$ & $\mathrm{V}(\mathrm{m} / \mathrm{s})$ & & 12 & 1.59 & 24.46 & 0.645 & \\
\hline & & & & & 13 & 1.51 & 24.37 & 0.655 & \\
\hline 1 & 1.8 & $34 \quad 25.78$ & 0.600 & & 14 & 1.43 & 24.27 & 0.661 & \\
\hline 2 & $1.5 \xi$ & $8 \quad 25.72$ & 0.739 & & 15 & 1.33 & 24.16 & 0.675 & \\
\hline 3 & 1.2 & $7 \quad 25.61$ & 0.999 & & 16 & 1.23 & 24.04 & 0.680 & \\
\hline 4 & 1.16 & 025.46 & 1.207 & & 17 & 1.11 & 23.91 & 0.691 & \\
\hline 5 & 1.01 & 125.41 & 1.344 & & 18 & 0.96 & 23.75 & 0.719 & \\
\hline 6 & 1.88 & $8 \quad 24.88$ & 0.630 & & 19 & 0.76 & 23.53 & 0.793 & \\
\hline 7 & 1.8 & 624.85 & 0.632 & & 20 & 0.57 & 23.33 & 0.598 & \\
\hline 8 & 1.82 & 224.78 & 0.633 & & 21 & 0.05 & 22.79 & 0.522 & \\
\hline
\end{tabular}




\begin{tabular}{|c|c|c|c|c|c|c|c|}
\hline 22 & 0.02 & 22.73 & -0.372 & 66 & 0.02 & 20.72 & -0.151 \\
\hline 23 & 0.05 & 22.77 & 0.271 & 67 & 0.02 & 20.69 & 0.258 \\
\hline 24 & 0.02 & 22.70 & -0.126 & 68 & 0.02 & 20.70 & -0.226 \\
\hline 25 & 0.03 & 22.65 & 0.178 & 69 & 0.02 & 20.64 & 0.360 \\
\hline 26 & 0.02 & 22.46 & -0.097 & 70 & 0.06 & 20.71 & -0.513 \\
\hline 27 & 0.03 & 22.47 & 0.035 & 71 & 0.02 & 20.59 & 0.644 \\
\hline 28 & 0.02 & 22.16 & 0.077 & 72 & 0.04 & 20.45 & -0.404 \\
\hline 29 & 0.02 & 21.94 & -0.038 & 73 & 0.02 & 19.88 & 0.639 \\
\hline 30 & 0.02 & 21.72 & 0.084 & 74 & 0.12 & 19.54 & 0.141 \\
\hline 31 & 0.03 & 21.20 & 0.042 & 75 & 0.13 & 19.54 & 0.124 \\
\hline 32 & 0.05 & 21.20 & 0.035 & 76 & 0.13 & 19.51 & 0.100 \\
\hline 33 & 0.03 & 21.17 & 0.042 & 77 & 0.11 & 19.47 & 0.105 \\
\hline 34 & 0.03 & 21.15 & 0.013 & 78 & 0.08 & 19.42 & 0.082 \\
\hline 35 & 0.02 & 21.13 & 0.025 & 79 & 0.02 & 19.34 & 0.046 \\
\hline 36 & 0.02 & 21.11 & 0.013 & 80 & 0.02 & 19.32 & 0.005 \\
\hline 37 & 0.02 & 21.10 & 0.029 & 81 & 0.02 & 19.31 & 0.027 \\
\hline 38 & 0.02 & 21.08 & 0.032 & 82 & 0.02 & 19.30 & 0.023 \\
\hline 39 & 0.02 & 21.07 & 0.030 & 83 & 0.02 & 19.29 & 0.020 \\
\hline 40 & 0.02 & 21.06 & 0.029 & 84 & 0.02 & 19.27 & 0.029 \\
\hline 41 & 0.02 & 21.04 & 0.027 & 85 & 0.02 & 19.26 & 0.025 \\
\hline 42 & 0.02 & 21.03 & 0.024 & 86 & 0.03 & 19.26 & 0.022 \\
\hline 43 & 0.02 & 21.02 & 0.030 & 87 & 0.02 & 19.24 & 0.030 \\
\hline 44 & 0.02 & 21.00 & 0.028 & 88 & 0.02 & 19.22 & 0.034 \\
\hline 45 & 0.02 & 20.99 & 0.028 & 89 & 0.02 & 19.21 & 0.029 \\
\hline 46 & 0.02 & 20.98 & 0.020 & 90 & 0.02 & 19.20 & 0.028 \\
\hline 47 & 0.02 & 20.97 & 0.030 & 91 & 0.02 & 19.19 & 0.028 \\
\hline 48 & 0.02 & 20.96 & 0.017 & 92 & 0.02 & 19.18 & 0.026 \\
\hline 49 & 0.02 & 20.95 & 0.027 & 93 & 0.02 & 19.17 & 0.024 \\
\hline 50 & 0.02 & 20.93 & 0.003 & 94 & 0.02 & 19.16 & 0.023 \\
\hline 51 & 0.02 & 20.92 & 0.024 & 95 & 0.02 & 19.15 & 0.022 \\
\hline 52 & 0.02 & 20.90 & 0.017 & 96 & 0.02 & 19.14 & 0.020 \\
\hline 53 & 0.02 & 20.88 & 0.046 & 97 & 0.02 & 19.13 & 0.019 \\
\hline 54 & 0.02 & 20.88 & 0.018 & 98 & 0.02 & 19.12 & 0.017 \\
\hline 55 & 0.02 & 20.86 & 0.052 & 99 & 0.02 & 19.11 & 0.015 \\
\hline 56 & 0.03 & 20.86 & -0.001 & 100 & 0.02 & 19.10 & 0.019 \\
\hline 57 & 0.02 & 20.84 & 0.057 & 101 & 0.02 & 19.09 & 0.022 \\
\hline 58 & 0.02 & 20.83 & -0.016 & 102 & 0.02 & 19.08 & 0.020 \\
\hline 59 & 0.02 & 20.81 & 0.066 & 103 & 0.03 & 19.08 & 0.016 \\
\hline 60 & 0.02 & 20.80 & -0.044 & 104 & 0.02 & 19.06 & 0.017 \\
\hline 61 & 0.02 & 20.78 & 0.104 & 105 & 0.02 & 19.05 & 0.018 \\
\hline 62 & 0.02 & 20.77 & -0.068 & 106 & 0.02 & 19.04 & 0.021 \\
\hline 63 & 0.02 & 20.75 & 0.144 & 107 & 0.02 & 19.03 & 0.024 \\
\hline 64 & 0.03 & 20.75 & -0.107 & 108 & 0.02 & 19.02 & 0.024 \\
\hline 65 & 0.02 & 20.72 & 0.177 & 109 & 0.02 & 19.02 & 0.024 \\
\hline
\end{tabular}

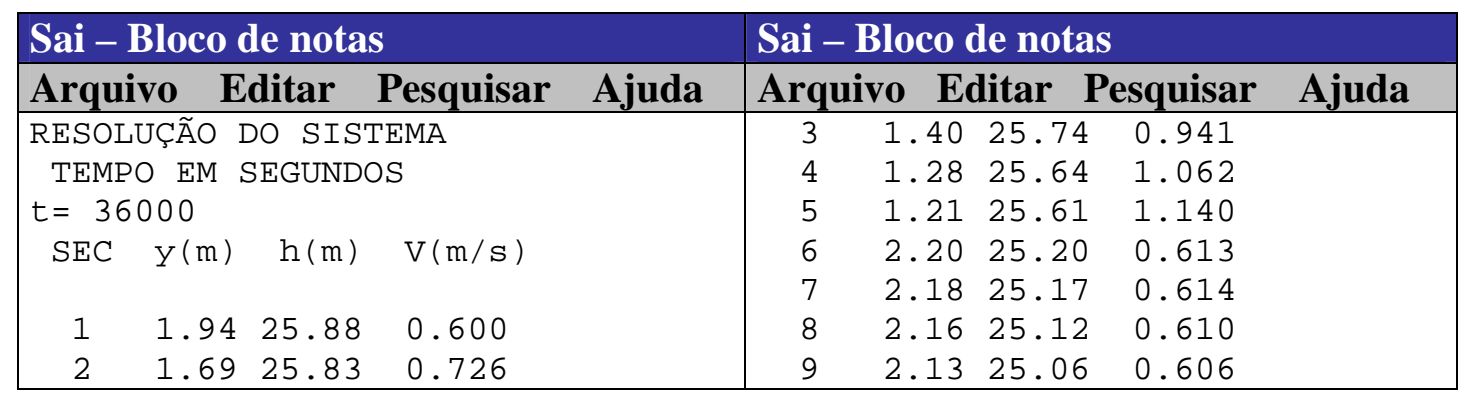




\begin{tabular}{|c|c|c|c|c|c|c|c|}
\hline 10 & 2.10 & 25.00 & 0.602 & 60 & 0.02 & 20.80 & -0.048 \\
\hline 11 & 2.06 & 24.94 & 0.602 & 61 & 0.02 & 20.78 & 0.107 \\
\hline 12 & 2.01 & 24.88 & 0.607 & 62 & 0.02 & 20.77 & -0.070 \\
\hline 13 & 1.96 & 24.82 & 0.613 & 63 & 0.02 & 20.74 & 0.149 \\
\hline 14 & 1.91 & 24.75 & 0.615 & 64 & 0.02 & 20.74 & -0.113 \\
\hline 15 & 1.85 & 24.68 & 0.623 & 65 & 0.02 & 20.72 & 0.184 \\
\hline 16 & 1.80 & 24.61 & 0.625 & 66 & 0.02 & 20.72 & -0.161 \\
\hline 17 & 1.74 & 24.54 & 0.633 & 67 & 0.02 & 20.68 & 0.272 \\
\hline 18 & 1.68 & 24.47 & 0.642 & 68 & 0.02 & 20.69 & -0.242 \\
\hline 19 & 1.63 & 24.40 & 0.643 & 69 & 0.02 & 20.63 & 0.379 \\
\hline 20 & 1.56 & 24.32 & 0.649 & 70 & 0.06 & 20.71 & -0.536 \\
\hline 21 & 1.50 & 24.24 & 0.653 & 71 & 0.02 & 20.59 & 0.668 \\
\hline 22 & 1.42 & 24.15 & 0.667 & 72 & 0.04 & 20.45 & -0.428 \\
\hline 23 & 1.32 & 24.04 & 0.697 & 73 & 0.02 & 19.88 & 0.661 \\
\hline 24 & 1.21 & 23.91 & 0.737 & 74 & 0.13 & 19.55 & 0.130 \\
\hline 25 & 1.13 & 23.75 & 0.754 & 75 & 0.14 & 19.55 & 0.115 \\
\hline 26 & 1.09 & 23.55 & 0.716 & 76 & 0.14 & 19.52 & 0.093 \\
\hline 27 & 1.10 & 23.54 & 0.701 & 77 & 0.14 & 19.50 & 0.099 \\
\hline 28 & 1.04 & 23.18 & 0.694 & 78 & 0.12 & 19.46 & 0.092 \\
\hline 29 & 0.99 & 22.91 & 0.699 & 79 & 0.10 & 19.42 & 0.091 \\
\hline 30 & 0.95 & 22.65 & 0.634 & 80 & 0.05 & 19.36 & 0.085 \\
\hline 31 & 0.69 & 21.86 & 0.766 & 81 & 0.02 & 19.31 & 0.037 \\
\hline 32 & 0.68 & 21.83 & 0.753 & 82 & 0.02 & 19.30 & 0.011 \\
\hline 33 & 0.37 & 21.51 & 0.653 & 83 & 0.02 & 19.29 & 0.020 \\
\hline 34 & 0.02 & 21.13 & 0.139 & 84 & 0.02 & 19.27 & 0.031 \\
\hline 35 & 0.02 & 21.13 & -0.165 & 85 & 0.02 & 19.26 & 0.024 \\
\hline 36 & 0.03 & 21.12 & 0.205 & 86 & 0.03 & 19.26 & 0.022 \\
\hline 37 & 0.02 & 21.08 & -0.135 & 87 & 0.02 & 19.24 & 0.030 \\
\hline 38 & 0.02 & 21.09 & 0.119 & 88 & 0.02 & 19.22 & 0.034 \\
\hline 39 & 0.02 & 21.07 & -0.007 & 89 & 0.02 & 19.21 & 0.029 \\
\hline 40 & 0.02 & 21.06 & 0.034 & 90 & 0.03 & 19.21 & 0.027 \\
\hline 41 & 0.02 & 21.04 & 0.026 & 91 & 0.02 & 19.19 & 0.027 \\
\hline 42 & 0.02 & 21.03 & 0.023 & 92 & 0.02 & 19.18 & 0.027 \\
\hline 43 & 0.02 & 21.02 & 0.033 & 93 & 0.02 & 19.17 & 0.026 \\
\hline 44 & 0.02 & 21.00 & 0.027 & 94 & 0.02 & 19.16 & 0.024 \\
\hline 45 & 0.02 & 20.99 & 0.027 & 95 & 0.02 & 19.15 & 0.022 \\
\hline 46 & 0.03 & 20.99 & 0.020 & 96 & 0.02 & 19.14 & 0.020 \\
\hline 47 & 0.02 & 20.97 & 0.030 & 97 & 0.02 & 19.13 & 0.019 \\
\hline 48 & 0.02 & 20.96 & 0.018 & 98 & 0.02 & 19.12 & 0.017 \\
\hline 49 & 0.02 & 20.95 & 0.027 & 99 & 0.02 & 19.11 & 0.016 \\
\hline 50 & 0.02 & 20.93 & 0.004 & 100 & 0.02 & 19.10 & 0.019 \\
\hline 51 & 0.02 & 20.92 & 0.026 & 101 & 0.02 & 19.09 & 0.021 \\
\hline 52 & 0.02 & 20.90 & 0.018 & 102 & 0.02 & 19.08 & 0.018 \\
\hline 53 & 0.02 & 20.88 & 0.044 & 103 & 0.03 & 19.08 & 0.015 \\
\hline 54 & 0.02 & 20.87 & 0.015 & 104 & 0.02 & 19.06 & 0.018 \\
\hline 55 & 0.02 & 20.86 & 0.049 & 105 & 0.02 & 19.05 & 0.020 \\
\hline 56 & 0.03 & 20.86 & -0.004 & 106 & 0.02 & 19.04 & 0.022 \\
\hline 57 & 0.03 & 20.85 & 0.059 & 107 & 0.02 & 19.03 & 0.023 \\
\hline 58 & 0.02 & 20.83 & -0.016 & 108 & 0.02 & 19.02 & 0.022 \\
\hline 59 & 0.02 & 20.81 & 0.071 & 109 & 0.02 & 19.02 & 0.022 \\
\hline
\end{tabular}




\begin{tabular}{|c|c|c|c|c|c|c|c|c|c|}
\hline \multicolumn{5}{|c|}{ Sai - Bloco de notas } & \multicolumn{5}{|c|}{ Sai - Bloco de notas } \\
\hline \multicolumn{2}{|c|}{ Arquivo } & ditar & Pesquisar & Ajuda & Arqu & O Ec & litar & esquisar & Ajuda \\
\hline \multicolumn{5}{|c|}{ RESOLUÇÃO DO SISTEMA } & 53 & 0.96 & 21.83 & 0.636 & \\
\hline \multicolumn{5}{|c|}{ TEMPO EM SEGUNDOS } & 54 & 0.82 & 21.68 & 0.644 & \\
\hline \multicolumn{5}{|c|}{$t=72000$} & 55 & 0.66 & 21.50 & 0.655 & \\
\hline \multirow{2}{*}{ SEC } & $y(m)$ & $\mathrm{h}(\mathrm{m})$ & $\mathrm{V}(\mathrm{m} / \mathrm{s})$ & & 56 & 0.48 & 21.31 & 0.519 & \\
\hline & & & & & 57 & 0.08 & 20.90 & 0.578 & \\
\hline 1 & 2.32 & 26.26 & 0.600 & & 58 & 0.02 & 20.79 & -0.385 & \\
\hline 2 & 2.08 & 26.22 & 0.705 & & 59 & 0.06 & 20.85 & 0.285 & \\
\hline 3 & 1.82 & 26.16 & 0.858 & & 60 & 0.02 & 20.78 & -0.167 & \\
\hline 4 & 1.74 & 26.10 & 0.913 & & 61 & 0.02 & 20.79 & 0.129 & \\
\hline 5 & 1.68 & 26.08 & 0.953 & & 62 & 0.02 & 20.76 & -0.058 & \\
\hline 6 & 2.57 & 25.57 & 0.633 & & 63 & 0.02 & 20.74 & 0.136 & \\
\hline 7 & 2.71 & 25.70 & 0.575 & & 64 & 0.02 & 20.74 & -0.101 & \\
\hline 8 & 2.70 & 25.66 & 0.577 & & 65 & 0.02 & 20.71 & 0.187 & \\
\hline 9 & 2.69 & 25.62 & 0.580 & & 66 & 0.02 & 20.71 & -0.164 & \\
\hline 10 & 2.68 & 25.58 & 0.583 & & 67 & 0.02 & 20.67 & 0.288 & \\
\hline 11 & 2.65 & 25.53 & 0.590 & & 68 & 0.02 & 20.67 & -0.252 & \\
\hline 12 & 2.62 & 25.49 & 0.604 & & 69 & 0.02 & 20.61 & 0.396 & \\
\hline 13 & 2.58 & 25.44 & 0.619 & & 70 & 0.07 & 20.72 & -0.565 & \\
\hline 14 & 2.55 & 25.39 & 0.629 & & 71 & 0.02 & 20.59 & 0.704 & \\
\hline 15 & 2.50 & 25.33 & 0.645 & & 72 & 0.04 & 20.45 & -0.468 & \\
\hline 16 & 2.47 & 25.28 & 0.657 & & 73 & 0.02 & 19.88 & 0.689 & \\
\hline 17 & 2.42 & 25.22 & 0.674 & & 74 & 0.15 & 19.57 & 0.129 & \\
\hline 18 & 2.37 & 25.16 & 0.693 & & 75 & 0.16 & 19.57 & 0.114 & \\
\hline 19 & 2.33 & 25.10 & 0.706 & & 76 & 0.17 & 19.55 & 0.093 & \\
\hline 20 & 2.28 & 25.04 & 0.725 & & 77 & 0.17 & 19.53 & 0.098 & \\
\hline 21 & 2.23 & 24.97 & 0.744 & & 78 & 0.16 & 19.50 & 0.093 & \\
\hline 22 & 2.16 & 24.89 & 0.773 & & 79 & 0.16 & 19.48 & 0.094 & \\
\hline 23 & 2.08 & 24.80 & 0.817 & & 80 & 0.14 & 19.45 & 0.096 & \\
\hline 24 & 1.98 & 24.68 & 0.867 & & 81 & 0.13 & 19.42 & 0.091 & \\
\hline 25 & 1.93 & 24.55 & 0.896 & & 82 & 0.12 & 19.40 & 0.086 & \\
\hline 26 & 1.93 & 24.39 & 0.895 & & 83 & 0.10 & 19.37 & 0.081 & \\
\hline 27 & 1.94 & 24.38 & 0.886 & & 84 & 0.06 & 19.32 & 0.084 & \\
\hline 28 & 1.94 & 24.08 & 0.880 & & 85 & 0.04 & 19.28 & 0.058 & \\
\hline 29 & 1.95 & 23.87 & 0.865 & & 86 & 0.03 & 19.26 & 0.030 & \\
\hline 30 & 1.97 & 23.67 & 0.832 & & 87 & 0.02 & 19.24 & 0.026 & \\
\hline 31 & 2.20 & 23.37 & 0.604 & & 88 & 0.02 & 19.22 & 0.034 & \\
\hline 32 & 2.22 & 23.37 & 0.597 & & 89 & 0.02 & 19.21 & 0.029 & \\
\hline 33 & 2.18 & 23.32 & 0.600 & & 90 & 0.03 & 19.21 & 0.027 & \\
\hline 34 & 2.15 & 23.27 & 0.600 & & 91 & 0.03 & 19.20 & 0.027 & \\
\hline 35 & 2.10 & 23.21 & 0.605 & & 92 & 0.02 & 19.18 & 0.027 & \\
\hline 36 & 2.07 & 23.16 & 0.604 & & 93 & 0.02 & 19.17 & 0.026 & \\
\hline 37 & 2.03 & 23.11 & 0.607 & & 94 & 0.02 & 19.16 & 0.025 & \\
\hline 38 & 1.98 & 23.05 & 0.610 & & 95 & 0.02 & 19.15 & 0.023 & \\
\hline 39 & 1.95 & 23.00 & 0.609 & & 96 & 0.02 & 19.14 & 0.021 & \\
\hline 40 & 1.90 & 22.94 & 0.612 & & 97 & 0.02 & 19.13 & 0.020 & \\
\hline 41 & 1.86 & 22.88 & 0.609 & & 98 & 0.02 & 19.12 & 0.018 & \\
\hline 42 & 1.81 & 22.82 & 0.610 & & 99 & 0.02 & 19.11 & 0.017 & \\
\hline 43 & 1.76 & 22.76 & 0.611 & & 100 & 0.02 & 19.10 & 0.020 & \\
\hline 44 & 1.70 & 22.69 & 0.614 & & 101 & 0.02 & 19.09 & 0.020 & \\
\hline 45 & 1.64 & 22.61 & 0.612 & & 102 & 0.02 & 19.08 & 0.018 & \\
\hline 46 & 1.58 & 22.54 & 0.614 & & 103 & 0.03 & 19.08 & 0.015 & \\
\hline 47 & 1.51 & 22.46 & 0.617 & & 104 & 0.02 & 19.06 & 0.019 & \\
\hline 48 & 1.43 & 22.37 & 0.620 & & 105 & 0.02 & 19.05 & 0.022 & \\
\hline 49 & 1.35 & 22.28 & 0.627 & & 106 & 0.02 & 19.04 & 0.023 & \\
\hline 50 & 1.27 & 22.18 & 0.626 & & 107 & 0.02 & 19.03 & 0.022 & \\
\hline 51 & 1.18 & 22.08 & 0.630 & & 108 & 0.02 & 19.02 & 0.020 & \\
\hline 52 & 1.07 & 21.96 & 0.637 & & 109 & 0.02 & 19.02 & 0.020 & \\
\hline
\end{tabular}




\begin{tabular}{|c|c|c|c|c|c|c|c|c|c|}
\hline \multicolumn{5}{|c|}{ Sai - Bloco de notas } & \multicolumn{5}{|c|}{ Sai - Bloco de notas } \\
\hline \multicolumn{2}{|c|}{ Arquivo } & ditar & Pesquisar & Ajuda & Arqu & o $\quad \mathbf{E}$ & litar I & squisar & Ajuda \\
\hline \multicolumn{5}{|c|}{ RESOLUÇÃO DO SISTEMA } & 46 & 2.24 & 23.20 & 0.512 & \\
\hline \multicolumn{5}{|c|}{ TEMPO EM SEGUNDOS } & 47 & 2.21 & 23.16 & 0.516 & \\
\hline \multicolumn{5}{|c|}{$t=108000$} & 48 & 2.18 & 23.12 & 0.520 & \\
\hline \multirow[t]{2}{*}{ SEC } & $y(m)$ & $h(m)$ & $\mathrm{V}(\mathrm{m} / \mathrm{s})$ & & 49 & 2.15 & 23.08 & 0.524 & \\
\hline & & & & & 50 & 2.13 & 23.04 & 0.524 & \\
\hline 1 & 2.32 & 26.26 & 0.600 & & 51 & 2.10 & 23.00 & 0.528 & \\
\hline 2 & 2.08 & 26.22 & 0.705 & & 52 & 2.07 & 22.96 & 0.532 & \\
\hline 3 & 1.82 & 26.16 & 0.858 & & 53 & 2.04 & 22.91 & 0.532 & \\
\hline 4 & 1.74 & 26.10 & 0.913 & & 54 & 2.01 & 22.87 & 0.535 & \\
\hline 5 & 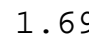 & 26.09 & 0.952 & & 55 & 1.99 & 22.83 & 0.535 & \\
\hline 6 & 2.57 & 25.57 & 0.626 & & 56 & 1.95 & 22.78 & 0.538 & \\
\hline 7 & 2.72 & 25.71 & 0.565 & & 57 & 1.92 & 22.74 & 0.542 & \\
\hline 8 & 2.71 & 25.67 & 0.567 & & 58 & 1.88 & 22.69 & 0.547 & \\
\hline 9 & 2.70 & 25.63 & 0.570 & & 59 & 1.84 & 22.63 & 0.548 & \\
\hline 10 & 2.69 & 25.59 & 0.573 & & 60 & 1.80 & 22.58 & 0.554 & \\
\hline 11 & 2.67 & 25.55 & 0.581 & & 61 & 1.76 & 22.53 & 0.561 & \\
\hline 12 & 2.63 & 25.50 & 0.595 & & 62 & 1.72 & 22.47 & 0.565 & \\
\hline 13 & 2.60 & 25.46 & 0.610 & & 63 & 1.66 & 22.40 & 0.574 & \\
\hline 14 & 2.57 & 25.41 & 0.621 & & 64 & 1.62 & 22.34 & 0.581 & \\
\hline 15 & 2.52 & 25.35 & 0.636 & & 65 & 1.56 & 22.27 & 0.597 & \\
\hline 16 & 2.49 & 25.30 & 0.649 & & 66 & 1.48 & 22.18 & 0.620 & \\
\hline 17 & 2.44 & 25.24 & 0.666 & & 67 & 1.40 & 22.09 & 0.652 & \\
\hline 18 & 2.39 & 25.18 & 0.686 & & 68 & 1.29 & 21.97 & 0.705 & \\
\hline 19 & 2.36 & 25.13 & 0.700 & & 69 & 1.16 & 21.82 & 0.786 & \\
\hline 20 & 2.31 & 125.07 & 0.720 & & 70 & 0.90 & 21.55 & 1.046 & \\
\hline 21 & 2.26 & 525.00 & 0.739 & & 71 & 0.82 & 21.46 & 1.173 & \\
\hline 22 & 2.20 & 24.93 & 0.769 & & 72 & 0.80 & 21.21 & 1.199 & \\
\hline 23 & 2.11 & 124.83 & 0.812 & & 73 & 0.90 & 20.84 & 0.996 & \\
\hline 24 & 2.02 & 24.72 & 0.862 & & 74 & 1.28 & 20.70 & 0.608 & \\
\hline 25 & 1.98 & 324.60 & 0.890 & & 75 & 1.28 & 20.69 & 0.604 & \\
\hline 26 & 1.98 & 324.44 & 0.888 & & 76 & 1.24 & 20.62 & 0.593 & \\
\hline 27 & 1.99 & 24.43 & 0.880 & & 77 & 1.16 & 20.52 & 0.590 & \\
\hline 28 & 2.02 & 24.16 & 0.849 & & 78 & 1.07 & 20.41 & 0.588 & \\
\hline 29 & 2.06 & $5 \quad 23.98$ & 0.801 & & 79 & 0.97 & 20.29 & 0.585 & \\
\hline 30 & 2.14 & 423.84 & 0.727 & & 80 & 0.85 & 20.16 & 0.582 & \\
\hline 31 & 2.48 & 323.65 & 0.493 & & 81 & 0.73 & 20.02 & 0.559 & \\
\hline 32 & 2.50 & 23.65 & 0.488 & & 82 & 0.59 & 19.87 & 0.528 & \\
\hline 33 & 2.48 & 323.62 & 0.491 & & 83 & 0.42 & 19.69 & 0.458 & \\
\hline 34 & 2.47 & 723.59 & 0.491 & & 84 & 0.22 & 19.48 & 0.335 & \\
\hline 35 & 2.45 & 523.56 & 0.494 & & 85 & 0.13 & 19.37 & 0.113 & \\
\hline 36 & 2.44 & 423.53 & 0.493 & & 86 & 0.11 & 19.34 & 0.066 & \\
\hline 37 & 2.42 & 23.50 & 0.496 & & 87 & 0.09 & 19.31 & 0.087 & \\
\hline 38 & 2.40 & 23.47 & 0.499 & & 88 & 0.06 & 19.27 & 0.088 & \\
\hline 39 & 2.38 & 323.43 & 0.499 & & 89 & 0.05 & 19.24 & 0.067 & \\
\hline 40 & 2.36 & 523.40 & 0.501 & & 90 & 0.04 & 19.22 & 0.048 & \\
\hline 41 & 2.35 & 523.37 & 0.501 & & 91 & 0.03 & 19.20 & 0.032 & \\
\hline 42 & 2.33 & 323.34 & 0.503 & & 92 & 0.03 & 19.19 & 0.026 & \\
\hline 43 & 2.31 & 123.31 & 0.506 & & 93 & 0.02 & 19.17 & 0.026 & \\
\hline 44 & 2.28 & 23.27 & 0.509 & & 94 & 0.03 & 19.17 & 0.025 & \\
\hline 45 & 2.27 & 23.24 & 0.509 & & 95 & 0.03 & 19.16 & 0.024 & \\
\hline
\end{tabular}




\begin{tabular}{|rlll|llll|}
\hline 96 & 0.03 & 19.15 & 0.022 & 103 & 0.03 & 19.08 & 0.016 \\
97 & 0.03 & 19.14 & 0.021 & 104 & 0.02 & 19.06 & 0.019 \\
98 & 0.02 & 19.12 & 0.020 & 105 & 0.02 & 19.05 & 0.023 \\
99 & 0.02 & 19.11 & 0.018 & 106 & 0.02 & 19.04 & 0.023 \\
100 & 0.02 & 19.10 & 0.021 & 107 & 0.02 & 19.03 & 0.023 \\
101 & 0.02 & 19.09 & 0.021 & 108 & 0.02 & 19.02 & 0.021 \\
102 & 0.02 & 19.08 & 0.018 & 109 & 0.02 & 19.02 & 0.021 \\
\hline
\end{tabular}

\begin{tabular}{|c|c|c|c|c|c|c|c|c|c|}
\hline \multicolumn{5}{|c|}{ Sai - Bloco de notas } & \multicolumn{5}{|c|}{ Sai - Bloco de notas } \\
\hline \multicolumn{2}{|c|}{ Arquivo } & ditar & Pesquisar & Ajuda & Arq & vo $E$ & ditar I & esquisar & Ajuda \\
\hline \multicolumn{5}{|c|}{ RESOLUÇÃO DO SISTEMA } & 41 & 2.45 & 23.47 & 0.447 & \\
\hline \multirow{2}{*}{\multicolumn{5}{|c|}{$\begin{array}{l}\text { TEMPO EM SEGUNDOS } \\
t=144000\end{array}$}} & 42 & 2.44 & 23.45 & 0.450 & \\
\hline & & & & & 43 & 2.42 & 23.42 & 0.454 & \\
\hline \multirow{2}{*}{$\mathrm{SEC}$} & $y(m)$ & $h(m)$ & $\mathrm{V}(\mathrm{m} / \mathrm{s})$ & & 44 & 2.41 & 23.40 & 0.458 & \\
\hline & & & & & 45 & 2.40 & 23.37 & 0.460 & \\
\hline 1 & 2.32 & 26.26 & 0.600 & & 46 & 2.38 & 23.34 & 0.464 & \\
\hline 2 & 2.08 & 26.22 & 0.705 & & 47 & 2.36 & 23.31 & 0.469 & \\
\hline 3 & 1.82 & 26.16 & 0.858 & & 48 & 2.34 & 23.28 & 0.475 & \\
\hline 4 & 1.74 & 26.10 & 0.913 & & 49 & 2.32 & 23.25 & 0.480 & \\
\hline 5 & 1.69 & 26.09 & 0.952 & & 50 & 2.31 & 23.22 & 0.483 & \\
\hline 6 & 2.57 & 25.57 & 0.626 & & 51 & 2.28 & 23.18 & 0.489 & \\
\hline 7 & 2.72 & 25.71 & 0.564 & & 52 & 2.26 & 23.15 & 0.495 & \\
\hline 8 & 2.71 & 25.67 & 0.567 & & 53 & 2.25 & 23.12 & 0.499 & \\
\hline 9 & 2.70 & 25.63 & 0.570 & & 54 & 2.22 & 23.08 & 0.505 & \\
\hline 10 & 2.69 & 25.59 & 0.573 & & 55 & 2.21 & 23.05 & 0.509 & \\
\hline 11 & 2.67 & 25.55 & 0.580 & & 56 & 2.18 & 23.01 & 0.515 & \\
\hline 12 & 2.63 & 25.50 & 0.594 & & 57 & 2.15 & 22.97 & 0.524 & \\
\hline 13 & 2.60 & 25.46 & 0.609 & & 58 & 2.12 & 22.93 & 0.534 & \\
\hline 14 & 2.57 & 25.41 & 0.620 & & 59 & 2.09 & 22.88 & 0.541 & \\
\hline 15 & 2.53 & 25.36 & 0.636 & & 60 & 2.06 & 22.84 & 0.553 & \\
\hline 16 & 2.49 & 25.30 & 0.648 & & 61 & 2.02 & 22.79 & 0.566 & \\
\hline 17 & 2.45 & 25.25 & 0.665 & & 62 & 1.99 & 22.74 & 0.578 & \\
\hline 18 & 2.40 & 25.19 & 0.685 & & 63 & 1.94 & 22.68 & 0.595 & \\
\hline 19 & 2.36 & 25.13 & 0.699 & & 64 & 1.90 & 22.62 & 0.611 & \\
\hline 20 & 2.31 & 25.07 & 0.719 & & 65 & 1.84 & 22.55 & 0.637 & \\
\hline 21 & 2.26 & 25.00 & 0.738 & & 66 & 1.77 & 22.47 & 0.671 & \\
\hline 22 & 2.20 & 24.93 & 0.768 & & 67 & 1.68 & 22.37 & 0.714 & \\
\hline 23 & 2.11 & 24.83 & 0.811 & & 68 & 1.58 & 22.26 & 0.777 & \\
\hline 24 & 2.03 & 24.73 & 0.861 & & 69 & 1.46 & 22.12 & 0.859 & \\
\hline 25 & 1.98 & 24.60 & 0.889 & & 70 & 1.25 & 21.90 & 1.036 & \\
\hline 26 & 1.98 & 24.44 & 0.887 & & 71 & 1.20 & 21.84 & 1.083 & \\
\hline 27 & 1.99 & 24.43 & 0.878 & & 72 & 1.34 & 21.75 & 0.944 & \\
\hline 28 & 2.02 & 24.16 & 0.846 & & 73 & 1.71 & 21.65 & 0.706 & \\
\hline 29 & 2.07 & 23.99 & 0.796 & & 74 & 2.17 & 21.59 & 0.557 & \\
\hline 30 & 2.15 & 23.85 & 0.722 & & 75 & 2.17 & 21.58 & 0.555 & \\
\hline 31 & 2.50 & 23.67 & 0.436 & & 76 & 2.17 & 21.55 & 0.549 & \\
\hline 32 & 2.53 & 23.68 & 0.430 & & 77 & 2.14 & 21.50 & 0.549 & \\
\hline 33 & 2.52 & 23.66 & 0.433 & & 78 & 2.11 & 21.45 & 0.548 & \\
\hline 34 & 2.52 & 23.64 & 0.433 & & 79 & 2.09 & 21.41 & 0.548 & \\
\hline 35 & 2.50 & 23.61 & 0.436 & & 80 & 2.05 & 21.36 & 0.550 & \\
\hline 36 & 2.50 & 23.59 & 0.437 & & 81 & 2.02 & 21.31 & 0.548 & \\
\hline 37 & 2.49 & 23.57 & 0.439 & & 82 & 1.98 & 21.26 & 0.550 & \\
\hline 38 & 2.48 & 23.55 & 0.443 & & 83 & 1.94 & 21.21 & 0.552 & \\
\hline 39 & 2.47 & 23.52 & 0.443 & & 84 & 1.90 & 21.16 & 0.555 & \\
\hline 40 & 2.46 & 23.50 & 0.447 & & 85 & 1.87 & 21.11 & 0.552 & \\
\hline
\end{tabular}




\begin{tabular}{|rrrr|rrrr|}
\hline 86 & 1.83 & 21.06 & 0.553 & 98 & 1.15 & 20.25 & 0.564 \\
87 & 1.78 & 21.00 & 0.557 & 99 & 1.07 & 20.16 & 0.565 \\
88 & 1.73 & 20.94 & 0.558 & 100 & 0.98 & 20.06 & 0.564 \\
89 & 1.70 & 20.89 & 0.555 & 101 & 0.88 & 19.95 & 0.557 \\
90 & 1.65 & 20.83 & 0.555 & 102 & 0.76 & 19.82 & 0.547 \\
91 & 1.60 & 20.77 & 0.556 & 103 & 0.61 & 19.66 & 0.576 \\
92 & 1.54 & 20.70 & 0.557 & 104 & 0.40 & 19.44 & 0.495 \\
93 & 1.49 & 20.64 & 0.558 & 105 & 0.04 & 19.07 & 0.354 \\
94 & 1.43 & 20.57 & 0.559 & 106 & 0.02 & 19.02 & -0.214 \\
95 & 1.37 & 20.50 & 0.560 & 107 & 0.04 & 19.05 & 0.129 \\
96 & 1.30 & 20.42 & 0.561 & 108 & 0.02 & 19.02 & -0.033 \\
97 & 1.23 & 20.34 & 0.562 & 109 & 0.02 & 19.02 & -0.033 \\
\hline
\end{tabular}

\begin{tabular}{|c|c|c|c|c|c|c|c|c|}
\hline \multicolumn{4}{|c|}{ Sai - Bloco de notas } & \multicolumn{5}{|c|}{ Sai - Bloco de notas } \\
\hline \multicolumn{2}{|c|}{ Arquivo } & ditar & Pesquisar Ajuda & Arqu & vo E & litar $\mathrm{F}$ & esquisar & Ajuda \\
\hline \multicolumn{4}{|c|}{ RESOLUÇÃO DO SISTEMA } & 38 & 2.48 & 23.55 & 0.441 & \\
\hline \multicolumn{4}{|c|}{ TEMPO EM SEGUNDOS } & 39 & 2.47 & 23.52 & 0.441 & \\
\hline \multicolumn{4}{|c|}{$t=147960$} & 40 & 2.46 & 23.50 & 0.445 & \\
\hline \multirow[t]{2}{*}{ SEC } & $y(m)$ & $h(m)$ & $\mathrm{V}(\mathrm{m} / \mathrm{s})$ & 41 & 2.46 & 23.48 & 0.445 & \\
\hline & & & & 42 & 2.44 & 23.45 & 0.448 & \\
\hline 1 & 2.32 & 26.26 & 0.600 & 43 & 2.43 & 23.43 & 0.452 & \\
\hline 2 & 2.08 & 26.22 & 0.705 & 44 & 2.41 & 23.40 & 0.456 & \\
\hline 3 & 1.82 & 26.16 & 0.858 & 45 & 2.40 & 23.37 & 0.458 & \\
\hline 4 & 1.74 & 26.10 & 0.913 & 46 & 2.38 & 23.34 & 0.462 & \\
\hline 5 & 1.69 & 26.09 & 0.952 & 47 & 2.36 & 23.31 & 0.467 & \\
\hline 6 & 2.57 & 25.57 & 0.626 & 48 & 2.34 & 23.28 & 0.473 & \\
\hline 7 & 2.72 & 25.71 & 0.564 & 49 & 2.32 & 23.25 & 0.479 & \\
\hline 8 & 2.71 & 25.67 & 0.567 & 50 & 2.31 & 23.22 & 0.481 & \\
\hline 9 & 2.70 & 25.63 & 0.570 & 51 & 2.29 & 23.19 & 0.487 & \\
\hline 10 & 2.69 & 25.59 & 0.573 & 52 & 2.26 & 23.15 & 0.494 & \\
\hline 11 & 2.67 & 25.55 & 0.580 & 53 & 2.25 & 23.12 & 0.497 & \\
\hline 12 & 2.63 & 25.50 & 0.594 & 54 & 2.23 & 23.09 & 0.504 & \\
\hline 13 & 2.60 & 25.46 & 0.609 & 55 & 2.21 & 23.05 & 0.507 & \\
\hline 14 & 2.57 & 25.41 & 0.620 & 56 & 2.19 & 23.02 & 0.514 & \\
\hline 15 & 2.53 & 25.36 & 0.636 & 57 & 2.16 & 22.98 & 0.523 & \\
\hline 16 & 2.49 & 25.30 & 0.648 & 58 & 2.12 & 22.93 & 0.533 & \\
\hline 17 & 2.45 & 25.25 & 0.665 & 59 & 2.10 & 22.89 & 0.540 & \\
\hline 18 & 2.40 & 25.19 & 0.685 & 60 & 2.07 & 22.85 & 0.552 & \\
\hline 19 & 2.36 & 25.13 & 0.699 & 61 & 2.03 & 22.80 & 0.565 & \\
\hline 20 & 2.31 & 25.07 & 0.719 & 62 & 1.99 & 22.74 & 0.577 & \\
\hline 21 & 2.26 & 25.00 & 0.738 & 63 & 1.95 & 22.69 & 0.594 & \\
\hline 22 & 2.20 & 24.93 & 0.768 & 64 & 1.91 & 22.63 & 0.610 & \\
\hline 23 & 2.11 & 24.83 & 0.811 & 65 & 1.85 & 22.56 & 0.636 & \\
\hline 24 & 2.03 & 24.73 & 0.861 & 66 & 1.78 & 22.48 & 0.669 & \\
\hline 25 & 1.98 & 24.60 & 0.889 & 67 & 1.70 & 22.39 & 0.711 & \\
\hline 26 & 1.98 & 24.44 & 0.887 & 68 & 1.59 & 22.27 & 0.772 & \\
\hline 27 & 1.99 & 24.43 & 0.878 & 69 & 1.48 & 22.14 & 0.850 & \\
\hline 28 & 2.02 & 24.16 & 0.846 & 70 & 1.28 & 21.93 & 1.010 & \\
\hline 29 & 2.07 & 23.99 & 0.797 & 71 & 1.24 & 21.88 & 1.050 & \\
\hline 30 & 2.15 & 23.85 & 0.722 & 72 & 1.39 & 21.80 & 0.912 & \\
\hline 31 & 2.50 & 23.67 & 0.434 & 73 & 1.77 & 21.71 & 0.687 & \\
\hline 32 & 2.53 & 23.68 & 0.428 & 74 & 2.22 & 21.64 & 0.552 & \\
\hline 33 & 2.52 & 23.66 & 0.431 & 75 & 2.23 & 21.64 & 0.550 & \\
\hline 34 & 2.52 & 23.64 & 0.431 & 76 & 2.23 & 21.61 & 0.544 & \\
\hline 35 & 2.51 & 23.62 & 0.434 & 77 & 2.20 & 21.56 & 0.544 & \\
\hline 36 & 2.50 & 23.59 & 0.435 & 78 & 2.18 & 21.52 & 0.543 & \\
\hline 37 & 2.49 & 23.57 & 0.438 & 79 & 2.15 & 21.47 & 0.543 & \\
\hline
\end{tabular}




\begin{tabular}{|llll|rrrr|}
\hline 80 & 2.12 & 21.43 & 0.545 & 95 & 1.50 & 20.63 & 0.556 \\
81 & 2.09 & 21.38 & 0.543 & 96 & 1.44 & 20.56 & 0.557 \\
82 & 2.05 & 21.33 & 0.545 & 97 & 1.38 & 20.49 & 0.557 \\
83 & 2.02 & 21.29 & 0.547 & 98 & 1.31 & 20.41 & 0.558 \\
84 & 1.98 & 21.24 & 0.549 & 99 & 1.24 & 20.33 & 0.559 \\
85 & 1.95 & 21.19 & 0.546 & 100 & 1.17 & 20.25 & 0.559 \\
86 & 1.91 & 21.14 & 0.548 & 101 & 1.09 & 20.16 & 0.553 \\
87 & 1.87 & 21.09 & 0.551 & 102 & 1.00 & 20.06 & 0.573 \\
88 & 1.82 & 21.03 & 0.553 & 103 & 0.92 & 19.97 & 0.485 \\
89 & 1.79 & 20.98 & 0.550 & 104 & 0.74 & 19.78 & 0.726 \\
90 & 1.75 & 20.93 & 0.550 & 105 & 0.69 & 19.72 & 0.293 \\
91 & 1.70 & 20.87 & 0.551 & 106 & 0.35 & 19.37 & 1.059 \\
92 & 1.65 & 20.81 & 0.552 & 107 & 0.23 & 19.24 & -0.042 \\
93 & 1.60 & 20.75 & 0.554 & 108 & 0.74 & 19.74 & -1.729 \\
94 & 1.55 & 20.69 & 0.555 & 109 & 0.74 & 19.74 & -1.743 \\
\hline
\end{tabular}

\begin{tabular}{|c|c|c|c|c|c|c|c|c|c|}
\hline \multicolumn{5}{|c|}{ Sai - Bloco de notas } & \multicolumn{5}{|c|}{ Sai - Bloco de notas } \\
\hline \multicolumn{3}{|c|}{ Arquivo Editar } & Pesquisar & Ajuda & Arqu & vo Ec & litar 1 & squisar & Ajuda \\
\hline \multicolumn{5}{|c|}{ RESOLUÇÃO DO SISTEMA } & 36 & 2.51 & 23.60 & 0.428 & \\
\hline \multirow{2}{*}{\multicolumn{5}{|c|}{$\begin{array}{l}\text { TEMPO EM SEGUNDOS } \\
\mathrm{t}=172800\end{array}$}} & 37 & 2.50 & 23.58 & 0.431 & \\
\hline & & & & & 38 & 2.48 & 23.55 & 0.434 & \\
\hline \multirow{2}{*}{$\mathrm{SEC}$} & $y(m)$ & $\mathrm{h}(\mathrm{m})$ & $\mathrm{V}(\mathrm{m} / \mathrm{s})$ & & 39 & 2.48 & 23.53 & 0.435 & \\
\hline & & & & & 40 & 2.47 & 23.51 & 0.438 & \\
\hline 1 & 2.32 & 26.26 & 0.600 & & 41 & 2.46 & 23.48 & 0.439 & \\
\hline 2 & 2.08 & $3 \quad 26.22$ & 0.705 & & 42 & 2.45 & 23.46 & 0.442 & \\
\hline 3 & 1.82 & 26.16 & 0.858 & & 43 & 2.44 & 23.44 & 0.445 & \\
\hline 4 & 1.74 & 26.10 & 0.913 & & 44 & 2.42 & 23.41 & 0.449 & \\
\hline 5 & 1.69 & 926.09 & 0.952 & & 45 & 2.41 & 23.38 & 0.451 & \\
\hline 6 & 2.57 & 25.57 & 0.626 & & 46 & 2.40 & 23.36 & 0.456 & \\
\hline 7 & 2.72 & 25.71 & 0.564 & & 47 & 2.38 & 23.33 & 0.460 & \\
\hline 8 & 2.71 & 25.67 & 0.567 & & 48 & 2.36 & 23.30 & 0.466 & \\
\hline 9 & 2.70 & 25.63 & 0.570 & & 49 & 2.34 & 23.27 & 0.471 & \\
\hline 10 & 2.69 & 925.59 & 0.573 & & 50 & 2.33 & 23.24 & 0.474 & \\
\hline 11 & 2.67 & 25.55 & 0.580 & & 51 & 2.31 & 23.21 & 0.480 & \\
\hline 12 & 2.63 & 325.50 & 0.594 & & 52 & 2.28 & 23.17 & 0.486 & \\
\hline 13 & 2.60 & 25.46 & 0.609 & & 53 & 2.27 & 23.14 & 0.489 & \\
\hline 14 & 2.57 & 25.41 & 0.620 & & 54 & 2.25 & 23.11 & 0.496 & \\
\hline 15 & 2.53 & 325.36 & 0.636 & & 55 & 2.23 & 23.07 & 0.499 & \\
\hline 16 & 2.49 & 25.30 & 0.648 & & 56 & 2.21 & 23.04 & 0.506 & \\
\hline 17 & 2.45 & 25.25 & 0.665 & & 57 & 2.18 & 23.00 & 0.515 & \\
\hline 18 & 2.40 & 25.19 & 0.685 & & 58 & 2.15 & 22.96 & 0.524 & \\
\hline 19 & 2.36 & 525.13 & 0.699 & & 59 & 2.13 & 22.92 & 0.531 & \\
\hline 20 & 2.31 & 25.07 & 0.719 & & 60 & 2.10 & 22.88 & 0.542 & \\
\hline 21 & 2.26 & 525.00 & 0.738 & & 61 & 2.06 & 22.83 & 0.554 & \\
\hline 22 & 2.20 & 24.93 & 0.768 & & 62 & 2.03 & 22.78 & 0.564 & \\
\hline 23 & 2.11 & 24.83 & 0.811 & & 63 & 1.99 & 22.73 & 0.580 & \\
\hline 24 & 2.03 & 324.73 & 0.861 & & 64 & 1.95 & 22.67 & 0.594 & \\
\hline 25 & 1.98 & 324.60 & 0.889 & & 65 & 1.90 & 22.61 & 0.616 & \\
\hline 26 & 1.98 & 324.44 & 0.887 & & 66 & 1.84 & 22.54 & 0.642 & \\
\hline 27 & 1.99 & 24.43 & 0.878 & & 67 & 1.77 & 22.46 & 0.676 & \\
\hline 28 & 2.02 & 24.16 & 0.846 & & 68 & 1.69 & 22.37 & 0.720 & \\
\hline 29 & 2.07 & 23.99 & 0.797 & & 69 & 1.60 & 22.26 & 0.768 & \\
\hline 30 & 2.15 & 523.85 & 0.722 & & 70 & 1.47 & 22.12 & 0.847 & \\
\hline 31 & 2.50 & 23.67 & 0.429 & & 71 & 1.46 & 22.10 & 0.859 & \\
\hline 32 & 2.54 & 23.69 & 0.422 & & 72 & 1.64 & 22.05 & 0.747 & \\
\hline 33 & 2.52 & 23.66 & 0.425 & & 73 & 2.05 & 21.99 & 0.590 & \\
\hline 34 & 2.52 & 23.64 & 0.425 & & 74 & 2.50 & 21.92 & 0.531 & \\
\hline 35 & 2.51 & 23.62 & 0.428 & & 75 & 2.51 & 21.92 & 0.529 & \\
\hline
\end{tabular}




\begin{tabular}{|llll|rrrr|}
\hline 76 & 2.52 & 21.90 & 0.524 & 93 & 2.09 & 21.24 & 0.535 \\
77 & 2.50 & 21.86 & 0.523 & 94 & 2.06 & 21.20 & 0.538 \\
78 & 2.48 & 21.82 & 0.523 & 95 & 2.03 & 21.16 & 0.542 \\
79 & 2.47 & 21.79 & 0.521 & 96 & 1.99 & 21.11 & 0.546 \\
80 & 2.44 & 21.75 & 0.523 & 97 & 1.95 & 21.06 & 0.550 \\
81 & 2.42 & 21.71 & 0.521 & 98 & 1.91 & 21.01 & 0.556 \\
82 & 2.40 & 21.68 & 0.522 & 99 & 1.87 & 20.96 & 0.563 \\
83 & 2.37 & 21.64 & 0.524 & 100 & 1.82 & 20.90 & 0.570 \\
84 & 2.34 & 21.60 & 0.526 & 101 & 1.77 & 20.84 & 0.581 \\
85 & 2.33 & 21.57 & 0.524 & 102 & 1.72 & 20.78 & 0.594 \\
86 & 2.30 & 21.53 & 0.525 & 103 & 1.66 & 20.71 & 0.612 \\
87 & 2.27 & 21.49 & 0.528 & 104 & 1.58 & 20.62 & 0.638 \\
88 & 2.24 & 21.45 & 0.529 & 105 & 1.50 & 20.53 & 0.675 \\
89 & 2.22 & 21.41 & 0.527 & 106 & 1.39 & 20.41 & 0.729 \\
90 & 2.19 & 21.37 & 0.529 & 107 & 1.25 & 20.26 & 0.824 \\
91 & 2.16 & 21.33 & 0.531 & 108 & 0.87 & 19.87 & 1.279 \\
92 & 2.13 & 21.29 & 0.533 & 109 & 0.86 & 19.86 & 1.282 \\
\hline
\end{tabular}




\section{Dados de Saída do Modelo para o Canal do Trabalhador}

\section{Simulação de Esvaziamento do Canal}

\begin{tabular}{|c|c|c|c|c|}
\hline \multicolumn{5}{|c|}{ Sai - Bloco de notas } \\
\hline \multicolumn{5}{|c|}{ Arquivo Editar Pesquisar Ajuda } \\
\hline \multicolumn{5}{|c|}{$\begin{array}{l}\text { TRANSIENTE HIDRÁULICO - CANAL DO TRABALHADOR } \\
\text { Esvaziamento do Canal }\end{array}$} \\
\hline \multicolumn{2}{|c|}{ CONDIÇÕES } & \multicolumn{3}{|c|}{ INICIAIS DO ESCOAMENTO } \\
\hline SEC & $y(m)$ & $h(m)$ & $\mathrm{z}(\mathrm{m})$ & $\mathrm{V}(\mathrm{m} / \mathrm{s})$ \\
\hline 1 & 2.32 & 26.26 & 23.94 & 0.448 \\
\hline 2 & 2.08 & 26.22 & 24.14 & 0.526 \\
\hline 3 & 1.82 & 26.16 & 24.34 & 0.638 \\
\hline 4 & 1.74 & 26.10 & 24.36 & 0.681 \\
\hline 5 & 1.69 & 26.09 & 24.40 & 2.259 \\
\hline 6 & 2.57 & 25.57 & 23.00 & 1.610 \\
\hline 7 & 2.72 & 25.71 & 22.99 & 0.359 \\
\hline 8 & 2.71 & 25.67 & 22.96 & 0.361 \\
\hline 9 & 2.70 & 25.63 & 22.93 & 0.363 \\
\hline 10 & 2.69 & 25.59 & 22.90 & 0.365 \\
\hline 11 & 2.67 & 25.55 & 22.88 & 0.375 \\
\hline 12 & 2.63 & 25.50 & 22.87 & 0.363 \\
\hline 13 & 2.60 & 25.46 & 22.86 & 0.389 \\
\hline 14 & 2.57 & 25.41 & 22.84 & 0.396 \\
\hline 15 & 2.53 & 25.36 & 22.83 & 0.369 \\
\hline 16 & 2.49 & 25.30 & 22.81 & 0.372 \\
\hline 17 & 2.45 & 25.25 & 22.80 & 0.374 \\
\hline 18 & 2.40 & 25.19 & 22.79 & 0.381 \\
\hline 19 & 2.36 & 25.13 & 22.77 & 0.223 \\
\hline 20 & 2.31 & 25.07 & 22.76 & 0.377 \\
\hline 21 & 2.26 & 25.00 & 22.74 & 0.283 \\
\hline 22 & 2.20 & 24.93 & 22.73 & 0.439 \\
\hline 23 & 2.11 & 24.83 & 22.72 & 0.433 \\
\hline 24 & 2.03 & 24.73 & 22.70 & 0.487 \\
\hline 25 & 1.98 & 24.60 & 22.62 & 0.543 \\
\hline 26 & 1.98 & 24.44 & 22.46 & 0.543 \\
\hline 27 & 1.99 & 24.43 & 22.44 & 2.213 \\
\hline 28 & 2.02 & 24.16 & 22.14 & 2.168 \\
\hline 29 & 2.07 & 23.99 & 21.92 & 2.098 \\
\hline 30 & 2.15 & 23.85 & 21.70 & 1.993 \\
\hline 31 & 2.50 & 23.67 & 21.17 & 1.632 \\
\hline 32 & 2.54 & 23.69 & 21.15 & 0.158 \\
\hline 33 & 2.52 & 23.66 & 21.14 & 0.362 \\
\hline 34 & 2.52 & 23.64 & 21.12 & 0.351 \\
\hline 35 & 2.51 & 23.62 & 21.11 & 0.352 \\
\hline 36 & 2.51 & 23.60 & 21.09 & 0.328 \\
\hline 37 & 2.50 & 23.58 & 21.08 & 0.330 \\
\hline 38 & 2.48 & 23.55 & 21.07 & 0.374 \\
\hline 39 & 2.48 & 23.53 & 21.05 & 0.374 \\
\hline 40 & 2.47 & 23.51 & 21.04 & 0.307 \\
\hline 41 & 2.46 & 23.48 & 21.02 & 0.309 \\
\hline 42 & 2.45 & 23.46 & 21.01 & 0.311 \\
\hline 43 & 2.44 & 23.44 & 21.00 & 0.376 \\
\hline 44 & 2.42 & 23.41 & 20.99 & 0.381 \\
\hline 45 & 2.41 & 23.38 & 20.97 & 0.383 \\
\hline 46 & 2.40 & 23.36 & 20.96 & 0.413 \\
\hline
\end{tabular}




\begin{tabular}{|c|c|c|c|c|}
\hline 47 & 2.38 & 23.33 & 20.95 & 0.418 \\
\hline 48 & 2.36 & 23.30 & 20.94 & 0.419 \\
\hline 49 & 2.34 & 23.27 & 20.93 & 0.449 \\
\hline 50 & 2.33 & 23.24 & 20.91 & 0.380 \\
\hline 51 & 2.31 & 23.21 & 20.90 & 0.449 \\
\hline 52 & 2.28 & 23.17 & 20.89 & 0.446 \\
\hline 53 & 2.27 & 23.14 & 20.87 & 0.430 \\
\hline 54 & 2.25 & 23.11 & 20.86 & 0.471 \\
\hline 55 & 2.23 & 23.07 & 20.84 & 0.434 \\
\hline 56 & 2.21 & 23.04 & 20.83 & 0.409 \\
\hline 57 & 2.18 & 23.00 & 20.82 & 0.468 \\
\hline 58 & 2.15 & 22.96 & 20.81 & 0.478 \\
\hline 59 & 2.13 & 22.92 & 20.79 & 0.475 \\
\hline 60 & 2.10 & 22.88 & 20.78 & 0.501 \\
\hline 61 & 2.06 & 22.83 & 20.77 & 0.515 \\
\hline 62 & 2.03 & 22.78 & 20.75 & 0.505 \\
\hline 63 & 1.99 & 22.73 & 20.74 & 0.503 \\
\hline 64 & 1.95 & 22.67 & 20.72 & 0.554 \\
\hline 65 & 1.90 & 22.61 & 20.71 & 0.566 \\
\hline 66 & 1.84 & 22.54 & 20.70 & 0.582 \\
\hline 67 & 1.77 & 22.46 & 20.69 & 0.612 \\
\hline 68 & 1.69 & 22.37 & 20.68 & 0.635 \\
\hline 69 & 1.60 & 22.26 & 20.66 & 0.527 \\
\hline 70 & 1.47 & 22.12 & 20.65 & 0.750 \\
\hline 71 & 1.46 & 22.10 & 20.64 & 2.682 \\
\hline 72 & 1.64 & 22.05 & 20.41 & 2.337 \\
\hline 73 & 2.05 & 21.99 & 19.94 & 1.860 \\
\hline 74 & 2.50 & 21.92 & 19.42 & 1.626 \\
\hline 75 & 2.51 & 21.92 & 19.41 & 0.370 \\
\hline 76 & 2.52 & 21.90 & 19.38 & 0.400 \\
\hline 77 & 2.50 & 21.86 & 19.36 & 0.405 \\
\hline 78 & 2.48 & 21.82 & 19.34 & 0.419 \\
\hline 79 & 2.47 & 21.79 & 19.32 & 0.377 \\
\hline 80 & 2.44 & 21.75 & 19.31 & 0.380 \\
\hline 81 & 2.42 & 21.71 & 19.29 & 0.397 \\
\hline 82 & 2.40 & 21.68 & 19.28 & 0.405 \\
\hline 83 & 2.37 & 21.64 & 19.27 & 0.440 \\
\hline 84 & 2.34 & 21.60 & 19.26 & 0.391 \\
\hline 85 & 2.33 & 21.57 & 19.24 & 0.390 \\
\hline 86 & 2.30 & 21.53 & 19.23 & 0.430 \\
\hline 87 & 2.27 & 21.49 & 19.22 & 0.441 \\
\hline 88 & 2.24 & 21.45 & 19.21 & 0.435 \\
\hline 89 & 2.22 & 21.41 & 19.19 & 0.441 \\
\hline 90 & 2.19 & 21.37 & 19.18 & 0.429 \\
\hline 91 & 2.16 & 21.33 & 19.17 & 0.437 \\
\hline 92 & 2.13 & 21.29 & 19.16 & 0.446 \\
\hline 93 & 2.09 & 21.24 & 19.15 & 0.458 \\
\hline 94 & 2.06 & 21.20 & 19.14 & 0.468 \\
\hline 95 & 2.03 & 21.16 & 19.13 & 0.477 \\
\hline 96 & 1.99 & 21.11 & 19.12 & 0.507 \\
\hline 97 & 1.95 & 21.06 & 19.11 & 0.521 \\
\hline 98 & 1.91 & 21.01 & 19.10 & 0.536 \\
\hline 99 & 1.87 & 20.96 & 19.09 & 0.537 \\
\hline 100 & 1.82 & 20.90 & 19.08 & 0.557 \\
\hline 101 & 1.77 & 20.84 & 19.07 & 0.597 \\
\hline 102 & 1.72 & 20.78 & 19.06 & 0.613 \\
\hline 103 & 1.66 & 20.71 & 19.05 & 0.818 \\
\hline 104 & 1.58 & 20.62 & 19.04 & 0.769 \\
\hline 105 & 1.50 & 20.53 & 19.03 & 0.814 \\
\hline
\end{tabular}




\begin{tabular}{|lllll|}
\hline 106 & 1.39 & 20.41 & 19.02 & 0.830 \\
107 & 1.25 & 20.26 & 19.01 & 1.037 \\
108 & 0.87 & 19.87 & 19.00 & 1.621 \\
109 & 0.86 & 19.86 & 19.00 & 1.644 \\
\hline
\end{tabular}

\begin{tabular}{|c|c|c|c|c|c|c|c|c|c|}
\hline \multicolumn{5}{|c|}{ Sai - Bloco de notas } & \multicolumn{5}{|c|}{ Sai - Bloco de notas } \\
\hline \multicolumn{3}{|c|}{ Arquivo Editar } & Pesquisar & Ajuda & Arqu & vo Ec & litar I & squisar & Ajuda \\
\hline \multicolumn{5}{|c|}{ RESOLUÇÃO DO SISTEMA } & 37 & 2.43 & 23.51 & 0.393 & \\
\hline \multicolumn{5}{|c|}{ TEMPO EM SEGUNDOS } & 38 & 2.42 & 23.49 & 0.395 & \\
\hline \multicolumn{5}{|c|}{$t=7200$} & 39 & 2.42 & 23.47 & 0.395 & \\
\hline \multirow[t]{2}{*}{$\mathrm{SEC}$} & $y(m)$ & $\mathrm{h}(\mathrm{m})$ & $V(m / s)$ & & 40 & 2.41 & 23.45 & 0.399 & \\
\hline & & & & & 41 & 2.41 & 23.43 & 0.401 & \\
\hline 1 & 1.16 & 25.10 & 0.000 & & 42 & 2.40 & 23.41 & 0.405 & \\
\hline 2 & 0.96 & 25.10 & 0.042 & & 43 & 2.39 & 23.39 & 0.410 & \\
\hline 3 & 0.75 & 25.09 & 0.111 & & 44 & 2.38 & 23.37 & 0.416 & \\
\hline 4 & 0.73 & 25.09 & 0.150 & & 45 & 2.37 & 23.34 & 0.420 & \\
\hline 5 & 0.69 & 25.09 & 0.168 & & 46 & 2.36 & 23.32 & 0.426 & \\
\hline 6 & 2.08 & 25.08 & 0.085 & & 47 & 2.34 & 23.29 & 0.433 & \\
\hline 7 & 2.09 & 25.08 & 0.096 & & 48 & 2.33 & 23.27 & 0.440 & \\
\hline 8 & 2.12 & 25.08 & 0.132 & & 49 & 2.31 & 23.24 & 0.448 & \\
\hline 9 & 2.15 & 25.08 & 0.167 & & 50 & 2.30 & 23.21 & 0.453 & \\
\hline 10 & 2.17 & 25.07 & 0.202 & & 51 & 2.28 & 23.18 & 0.460 & \\
\hline 11 & 2.18 & 25.06 & 0.238 & & 52 & 2.26 & 23.15 & 0.469 & \\
\hline 12 & 2.18 & 25.05 & 0.281 & & 53 & 2.25 & 23.12 & 0.474 & \\
\hline 13 & 2.18 & 25.04 & 0.323 & & 54 & 2.23 & 23.09 & 0.482 & \\
\hline 14 & 2.18 & 25.02 & 0.358 & & 55 & 2.22 & 23.06 & 0.487 & \\
\hline 15 & 2.17 & 25.00 & 0.396 & & 56 & 2.19 & 23.02 & 0.495 & \\
\hline 16 & 2.16 & 24.97 & 0.430 & & 57 & 2.17 & 22.99 & 0.505 & \\
\hline 17 & 2.14 & 24.94 & 0.467 & & 58 & 2.14 & 22.95 & 0.516 & \\
\hline 18 & 2.12 & 24.91 & 0.505 & & 59 & 2.12 & 22.91 & 0.524 & \\
\hline 19 & 2.10 & 24.87 & 0.538 & & 60 & 2.09 & 22.87 & 0.536 & \\
\hline 20 & 2.07 & 24.83 & 0.576 & & 61 & 2.05 & 22.82 & 0.550 & \\
\hline 21 & 2.04 & 24.78 & 0.614 & & 62 & 2.02 & 22.77 & 0.562 & \\
\hline 22 & 1.99 & 24.72 & 0.661 & & 63 & 1.98 & 22.72 & 0.579 & \\
\hline 23 & 1.92 & 24.64 & 0.721 & & 64 & 1.94 & 22.66 & 0.595 & \\
\hline 24 & 1.85 & 24.55 & 0.786 & & 65 & 1.88 & 22.59 & 0.619 & \\
\hline 25 & 1.82 & 24.44 & 0.831 & & 66 & 1.82 & 22.52 & 0.649 & \\
\hline 26 & 1.83 & 24.29 & 0.853 & & 67 & 1.75 & 22.44 & 0.688 & \\
\hline 27 & 1.85 & 24.29 & 0.846 & & 68 & 1.66 & 22.34 & 0.740 & \\
\hline 28 & 1.90 & 24.04 & 0.811 & & 69 & 1.56 & 22.22 & 0.803 & \\
\hline 29 & 1.97 & 23.89 & 0.756 & & 70 & 1.41 & 22.06 & 0.916 & \\
\hline 30 & 2.06 & 23.76 & 0.673 & & 71 & 1.38 & 22.02 & 0.938 & \\
\hline 31 & 2.39 & 23.56 & 0.422 & & 72 & 1.48 & 21.89 & 0.809 & \\
\hline 32 & 2.41 & 23.56 & 0.417 & & 73 & 1.87 & 21.81 & 0.604 & \\
\hline 33 & 2.41 & 23.55 & 0.404 & & 74 & 2.34 & 21.76 & 0.499 & \\
\hline 34 & 2.43 & 23.55 & 0.396 & & 75 & 2.35 & 21.76 & 0.495 & \\
\hline 35 & 2.43 & 23.54 & 0.394 & & 76 & 2.38 & 21.76 & 0.477 & \\
\hline 36 & 2.43 & 23.52 & 0.392 & & 77 & 2.39 & 21.75 & 0.464 & \\
\hline
\end{tabular}




\begin{tabular}{|llll|rrrr|}
\hline 78 & 2.39 & 21.73 & 0.456 & 94 & 2.06 & 21.20 & 0.528 \\
79 & 2.39 & 21.71 & 0.452 & 95 & 2.03 & 21.16 & 0.534 \\
80 & 2.38 & 21.69 & 0.454 & 96 & 1.99 & 21.11 & 0.541 \\
81 & 2.38 & 21.67 & 0.454 & 97 & 1.95 & 21.06 & 0.548 \\
82 & 2.36 & 21.64 & 0.459 & 98 & 1.91 & 21.01 & 0.556 \\
83 & 2.34 & 21.61 & 0.465 & 99 & 1.87 & 20.96 & 0.565 \\
84 & 2.32 & 21.58 & 0.471 & 100 & 1.82 & 20.90 & 0.575 \\
85 & 2.31 & 21.55 & 0.474 & 101 & 1.77 & 20.84 & 0.586 \\
86 & 2.29 & 21.52 & 0.481 & 102 & 1.72 & 20.78 & 0.601 \\
87 & 2.26 & 21.48 & 0.489 & 103 & 1.66 & 20.71 & 0.622 \\
88 & 2.24 & 21.45 & 0.497 & 104 & 1.58 & 20.62 & 0.650 \\
89 & 2.22 & 21.41 & 0.501 & 105 & 1.50 & 20.53 & 0.687 \\
90 & 2.19 & 21.37 & 0.507 & 106 & 1.39 & 20.41 & 0.742 \\
91 & 2.16 & 21.33 & 0.513 & 107 & 1.25 & 20.26 & 0.837 \\
92 & 2.13 & 21.29 & 0.519 & 108 & 0.84 & 19.84 & 1.376 \\
93 & 2.09 & 21.24 & 0.524 & 109 & 0.84 & 19.84 & 1.380 \\
\hline
\end{tabular}

\begin{tabular}{|c|c|c|c|c|c|c|c|c|c|}
\hline \multicolumn{5}{|c|}{ Sai - Bloco de notas } & \multicolumn{5}{|c|}{ Sai - Bloco de notas } \\
\hline \multicolumn{2}{|c|}{ Arquivo } & ditar & Pesquisar & Ajuda & Arq & vo $\mathbf{E}$ & litar & esquisar & Ajuda \\
\hline \multicolumn{5}{|c|}{ RESOLUÇÃO DO SISTEMA } & 29 & 1.68 & 23.60 & 0.555 & \\
\hline \multicolumn{5}{|c|}{ TEMPO EM SEGUNDOS } & 30 & 1.83 & 23.53 & 0.458 & \\
\hline \multicolumn{5}{|c|}{$t=18000$} & 31 & 2.28 & 23.45 & 0.269 & \\
\hline \multirow{2}{*}{ SEC } & $y(m)$ & $h(m)$ & $\mathrm{V}(\mathrm{m} / \mathrm{s})$ & & 32 & 2.30 & 23.45 & 0.267 & \\
\hline & & & & & 33 & 2.30 & 23.44 & 0.280 & \\
\hline 1 & 0.70 & 24.64 & 0.000 & & 34 & 2.31 & 23.43 & 0.289 & \\
\hline 2 & 0.50 & 24.64 & 0.037 & & 35 & 2.31 & 23.42 & 0.299 & \\
\hline 3 & 0.30 & 24.64 & 0.118 & & 36 & 2.32 & 23.41 & 0.306 & \\
\hline 4 & 0.27 & 24.63 & 0.172 & & 37 & 2.31 & 23.39 & 0.316 & \\
\hline 5 & 0.23 & 24.63 & 0.206 & & 38 & 2.31 & 23.38 & 0.325 & \\
\hline 6 & 1.62 & 24.62 & 0.078 & & 39 & 2.32 & 23.37 & 0.332 & \\
\hline 7 & 1.63 & 24.62 & 0.087 & & 40 & 2.31 & 23.35 & 0.341 & \\
\hline 8 & 1.65 & 24.61 & 0.114 & & 41 & 2.32 & 23.34 & 0.348 & \\
\hline 9 & 1.68 & 24.61 & 0.140 & & 42 & 2.31 & 23.32 & 0.356 & \\
\hline 10 & 1.71 & 24.61 & 0.165 & & 43 & 2.30 & 23.30 & 0.365 & \\
\hline 11 & 1.72 & 24.60 & 0.192 & & 44 & 2.30 & 23.29 & 0.373 & \\
\hline 12 & 1.72 & 24.59 & 0.223 & & 45 & 2.30 & 23.27 & 0.380 & \\
\hline 13 & 1.72 & 24.58 & 0.253 & & 46 & 2.29 & 23.25 & 0.389 & \\
\hline 14 & 1.72 & 24.56 & 0.280 & & 47 & 2.27 & 23.22 & 0.397 & \\
\hline 15 & 1.72 & 24.55 & 0.310 & & 48 & 2.26 & 23.20 & 0.406 & \\
\hline 16 & 1.72 & 24.53 & 0.338 & & 49 & 2.25 & 23.18 & 0.416 & \\
\hline 17 & 1.70 & 24.50 & 0.369 & & 50 & 2.24 & 23.15 & 0.422 & \\
\hline 18 & 1.69 & 24.48 & 0.401 & & 51 & 2.22 & 23.12 & 0.431 & \\
\hline 19 & 1.68 & 24.45 & 0.429 & & 52 & 2.21 & 23.10 & 0.441 & \\
\hline 20 & 1.65 & 24.41 & 0.462 & & 53 & 2.20 & 23.07 & 0.447 & \\
\hline 21 & 1.63 & 24.37 & 0.494 & & 54 & 2.18 & 23.04 & 0.456 & \\
\hline 22 & 1.59 & 24.32 & 0.536 & & 55 & 2.17 & 23.01 & 0.462 & \\
\hline 23 & 1.54 & 24.26 & 0.590 & & 56 & 2.15 & 22.98 & 0.472 & \\
\hline 24 & 1.48 & 24.18 & 0.651 & & 57 & 2.13 & 22.95 & 0.483 & \\
\hline 25 & 1.46 & 24.08 & 0.693 & & 58 & 2.10 & 22.91 & 0.495 & \\
\hline 26 & 1.48 & 23.94 & 0.711 & & 59 & 2.08 & 22.87 & 0.504 & \\
\hline 27 & 1.49 & 23.93 & 0.703 & & 60 & 2.05 & 22.83 & 0.518 & \\
\hline 28 & 1.58 & 23.72 & 0.639 & & 61 & 2.02 & 22.79 & 0.533 & \\
\hline
\end{tabular}




\begin{tabular}{|llll|rrrr|}
\hline 62 & 1.99 & 22.74 & 0.545 & 86 & 2.29 & 21.52 & 0.479 \\
63 & 1.95 & 22.69 & 0.564 & 87 & 2.26 & 21.48 & 0.487 \\
64 & 1.92 & 22.64 & 0.581 & 88 & 2.24 & 21.45 & 0.495 \\
65 & 1.86 & 22.57 & 0.607 & 89 & 2.22 & 21.41 & 0.499 \\
66 & 1.80 & 22.50 & 0.638 & 90 & 2.19 & 21.37 & 0.505 \\
67 & 1.73 & 22.42 & 0.678 & 91 & 2.16 & 21.33 & 0.511 \\
68 & 1.64 & 22.32 & 0.731 & 92 & 2.13 & 21.29 & 0.517 \\
69 & 1.54 & 22.20 & 0.794 & 93 & 2.09 & 21.24 & 0.522 \\
70 & 1.40 & 22.05 & 0.904 & 94 & 2.06 & 21.20 & 0.526 \\
71 & 1.37 & 22.01 & 0.925 & 95 & 2.03 & 21.16 & 0.532 \\
72 & 1.48 & 21.89 & 0.797 & 96 & 1.99 & 21.11 & 0.538 \\
73 & 1.87 & 21.81 & 0.596 & 97 & 1.95 & 21.06 & 0.545 \\
74 & 2.34 & 21.76 & 0.492 & 98 & 1.91 & 21.01 & 0.552 \\
75 & 2.35 & 21.76 & 0.488 & 99 & 1.87 & 20.96 & 0.560 \\
76 & 2.38 & 21.76 & 0.471 & 100 & 1.82 & 20.90 & 0.569 \\
77 & 2.39 & 21.75 & 0.459 & 101 & 1.77 & 20.84 & 0.580 \\
78 & 2.39 & 21.73 & 0.452 & 102 & 1.72 & 20.78 & 0.593 \\
79 & 2.39 & 21.71 & 0.449 & 103 & 1.66 & 20.71 & 0.613 \\
80 & 2.38 & 21.69 & 0.452 & 104 & 1.58 & 20.62 & 0.641 \\
81 & 2.38 & 21.67 & 0.453 & 105 & 1.50 & 20.53 & 0.678 \\
82 & 2.36 & 21.64 & 0.458 & 106 & 1.39 & 20.41 & 0.732 \\
83 & 2.34 & 21.61 & 0.464 & 107 & 1.25 & 20.26 & 0.827 \\
84 & 2.32 & 21.58 & 0.470 & 108 & 0.81 & 19.81 & 1.432 \\
85 & 2.31 & 21.55 & 0.472 & 109 & 0.81 & 19.81 & 1.437 \\
\hline
\end{tabular}

\begin{tabular}{|c|c|c|c|c|c|c|c|c|c|}
\hline \multicolumn{5}{|c|}{ Sai - Bloco de notas } & \multicolumn{5}{|c|}{ Sai - Bloco de notas } \\
\hline \multicolumn{2}{|c|}{ Arquivo } & ditar & Pesquisar & Ajuda & Arqu & o $\mathbf{E}$ & litar 1 & esquisar & Ajuda \\
\hline \multicolumn{5}{|c|}{ RESOLUÇÃO DO SISTEMA } & 26 & 0.79 & 23.25 & 0.575 & \\
\hline \multicolumn{5}{|c|}{ TEMPO EM SEGUNDOS } & 27 & 0.80 & 23.24 & 0.564 & \\
\hline \multicolumn{5}{|c|}{$t=54000$} & 28 & 0.85 & 22.99 & 0.505 & \\
\hline \multirow[t]{2}{*}{$\mathrm{SEC}$} & $y(m)$ & $h(m)$ & $\mathrm{V}(\mathrm{m} / \mathrm{s})$ & & 29 & 0.96 & 22.88 & 0.373 & \\
\hline & & & & & 30 & 1.13 & 22.83 & 0.244 & \\
\hline 1 & 0.51 & 24.45 & 0.000 & & 31 & 1.64 & 22.81 & 0.102 & \\
\hline 2 & 0.31 & 24.45 & -0.013 & & 32 & 1.66 & 22.81 & 0.101 & \\
\hline 3 & 0.11 & 24.45 & -0.066 & & 33 & 1.66 & 22.80 & 0.114 & \\
\hline 4 & 0.09 & 24.45 & -0.129 & & 34 & 1.68 & 22.80 & 0.124 & \\
\hline 5 & 0.02 & 24.42 & 1.033 & & 35 & 1.69 & 22.80 & 0.134 & \\
\hline 6 & 1.08 & 24.08 & 0.211 & & 36 & 1.70 & 22.79 & 0.143 & \\
\hline 7 & 1.09 & 24.08 & 0.213 & & 37 & 1.71 & 22.79 & 0.153 & \\
\hline 8 & 1.10 & 24.06 & 0.217 & & 38 & 1.72 & 22.79 & 0.163 & \\
\hline 9 & 1.12 & 24.05 & 0.222 & & 39 & 1.73 & 22.78 & 0.172 & \\
\hline 10 & 1.13 & 24.03 & 0.227 & & 40 & 1.74 & 22.78 & 0.182 & \\
\hline 11 & 1.13 & 24.01 & 0.236 & & 41 & 1.75 & 22.77 & 0.191 & \\
\hline 12 & 1.13 & 24.00 & 0.247 & & 42 & 1.75 & 22.76 & 0.201 & \\
\hline 13 & 1.12 & 23.98 & 0.259 & & 43 & 1.76 & 22.76 & 0.211 & \\
\hline 14 & 1.12 & 23.96 & 0.269 & & 44 & 1.76 & 22.75 & 0.222 & \\
\hline 15 & 1.10 & 23.93 & 0.284 & & 45 & 1.77 & 22.74 & 0.230 & \\
\hline 16 & 1.10 & 23.91 & 0.295 & & 46 & 1.77 & 22.73 & 0.241 & \\
\hline 17 & 1.08 & 23.88 & 0.311 & & 47 & 1.77 & 22.72 & 0.252 & \\
\hline 18 & 1.06 & 23.85 & 0.329 & & 48 & 1.76 & 22.70 & 0.263 & \\
\hline 19 & 1.05 & 23.82 & 0.342 & & 49 & 1.76 & 22.69 & 0.274 & \\
\hline 20 & 1.02 & 23.78 & 0.361 & & 50 & 1.77 & 22.68 & 0.283 & \\
\hline 21 & 1.00 & 23.74 & 0.380 & & 51 & 1.76 & 22.66 & 0.294 & \\
\hline 22 & 0.96 & 23.69 & 0.409 & & 52 & 1.75 & 22.64 & 0.305 & \\
\hline 23 & 0.91 & 23.63 & 0.452 & & 53 & 1.76 & 22.63 & 0.314 & \\
\hline 24 & 0.84 & 23.54 & 0.507 & & 54 & 1.75 & 22.61 & 0.325 & \\
\hline 25 & 0.80 & 23.42 & 0.550 & & 55 & 1.75 & 22.59 & 0.334 & \\
\hline
\end{tabular}




\begin{tabular}{|c|c|c|c|c|c|c|c|}
\hline 56 & 1.74 & 22.57 & 0.345 & 83 & 2.27 & 21.54 & 0.420 \\
\hline 57 & 1.73 & 22.55 & 0.358 & 84 & 2.26 & 21.52 & 0.427 \\
\hline 58 & 1.71 & 22.52 & 0.372 & 85 & 2.25 & 21.49 & 0.431 \\
\hline 59 & 1.71 & 22.50 & 0.384 & 86 & 2.24 & 21.47 & 0.439 \\
\hline 60 & 1.69 & 22.47 & 0.398 & 87 & 2.22 & 21.44 & 0.447 \\
\hline 61 & 1.67 & 22.44 & 0.415 & 88 & 2.20 & 21.41 & 0.455 \\
\hline 62 & 1.65 & 22.40 & 0.429 & 89 & 2.19 & 21.38 & 0.460 \\
\hline 63 & 1.62 & 22.36 & 0.448 & 90 & 2.17 & 21.35 & 0.468 \\
\hline 64 & 1.60 & 22.32 & 0.465 & 91 & 2.14 & 21.31 & 0.477 \\
\hline 65 & 1.56 & 22.27 & 0.490 & 92 & 2.12 & 21.28 & 0.486 \\
\hline 66 & 1.52 & 22.22 & 0.519 & 93 & 2.09 & 21.24 & 0.496 \\
\hline 67 & 1.46 & 22.15 & 0.555 & 94 & 2.06 & 21.20 & 0.505 \\
\hline 68 & 1.39 & 22.07 & 0.601 & 95 & 2.03 & 21.16 & 0.514 \\
\hline 69 & 1.32 & 21.98 & 0.652 & 96 & 1.99 & 21.11 & 0.524 \\
\hline 70 & 1.21 & 21.86 & 0.737 & 97 & 1.95 & 21.06 & 0.533 \\
\hline 71 & 1.19 & 21.83 & 0.750 & 98 & 1.91 & 21.01 & 0.542 \\
\hline 72 & 1.38 & 21.79 & 0.628 & 99 & 1.87 & 20.96 & 0.553 \\
\hline 73 & 1.81 & 21.75 & 0.464 & 100 & 1.82 & 20.90 & 0.563 \\
\hline 74 & 2.30 & 21.72 & 0.382 & 101 & 1.77 & 20.84 & 0.574 \\
\hline 75 & 2.31 & 21.72 & 0.381 & 102 & 1.72 & 20.78 & 0.588 \\
\hline 76 & 2.32 & 21.70 & 0.381 & 103 & 1.66 & 20.71 & 0.608 \\
\hline 77 & 2.32 & 21.68 & 0.386 & 104 & 1.58 & 20.62 & 0.635 \\
\hline 78 & 2.32 & 21.66 & 0.390 & 105 & 1.50 & 20.53 & 0.669 \\
\hline 79 & 2.32 & 21.64 & 0.395 & 106 & 1.39 & 20.41 & 0.716 \\
\hline 80 & 2.31 & 21.62 & 0.402 & 107 & 1.25 & 20.26 & 0.794 \\
\hline 81 & 2.30 & 21.59 & 0.406 & 108 & 0.71 & 19.71 & 1.634 \\
\hline 82 & 2.29 & 21.57 & 0.413 & 109 & 0.71 & 19.71 & 1.646 \\
\hline
\end{tabular}

\begin{tabular}{|c|c|c|c|c|c|c|c|c|c|}
\hline \multicolumn{5}{|c|}{ Sai - Bloco de notas } & \multicolumn{5}{|c|}{ Sai - Bloco de notas } \\
\hline \multicolumn{3}{|c|}{ Arquivo Editar } & Pesquisar & Ajuda & Arqu & vo Ed & litar $\mathbf{P}$ & esquisar & Ajuda \\
\hline \multicolumn{5}{|c|}{ RESOLUÇÃO DO SISTEMA } & 21 & 0.74 & 23.48 & 0.266 & \\
\hline \multicolumn{5}{|c|}{ TEMPO EM SEGUNDOS } & 22 & 0.72 & 23.45 & 0.302 & \\
\hline \multicolumn{5}{|c|}{$t=86400$} & 23 & 0.68 & 23.40 & 0.349 & \\
\hline \multirow[t]{2}{*}{$\mathrm{SEC}$} & $\mathrm{y}(\mathrm{m}$ & $h(m)$ & $\mathrm{V}(\mathrm{m} / \mathrm{s})$ & & 24 & 0.62 & 23.32 & 0.409 & \\
\hline & & & & & 25 & 0.59 & 23.21 & 0.459 & \\
\hline 1 & 0.0 & 23.96 & 0.000 & & 26 & 0.57 & 23.03 & 0.501 & \\
\hline 2 & 0.0 & 24.16 & -0.769 & & 27 & 0.58 & 23.02 & 0.490 & \\
\hline 3 & 0.0 & 24.36 & 0.728 & & 28 & 0.59 & 22.73 & 0.499 & \\
\hline 4 & 0.0 & 24.38 & -1.334 & & 29 & 0.63 & 22.55 & 0.450 & \\
\hline 5 & 0.0 & 24.42 & 1.428 & & 30 & 0.75 & 22.45 & 0.290 & \\
\hline 6 & 0.3 & 923.39 & 0.128 & & 31 & 1.24 & 22.41 & 0.072 & \\
\hline 7 & 0.4 & $5 \quad 23.45$ & 0.039 & & 32 & 1.26 & 22.41 & 0.072 & \\
\hline 8 & 0.5 & 9 23.55 & -0.064 & & 33 & 1.27 & 22.41 & 0.084 & \\
\hline 9 & 0.6 & 23.58 & -0.070 & & 34 & 1.29 & 22.41 & 0.092 & \\
\hline 10 & 0.6 & 323.58 & -0.041 & & 35 & 1.30 & 22.41 & 0.102 & \\
\hline 11 & 0.7 & 23.58 & -0.007 & & 36 & 1.31 & 22.40 & 0.110 & \\
\hline 12 & 0.7 & 23.58 & 0.022 & & 37 & 1.32 & 22.40 & 0.119 & \\
\hline 13 & 0.7 & 23.58 & 0.048 & & 38 & 1.33 & 22.40 & 0.128 & \\
\hline 14 & 0.7 & 23.58 & 0.074 & & 39 & 1.34 & 22.39 & 0.136 & \\
\hline 15 & 0.7 & 23.57 & 0.101 & & 40 & 1.35 & 22.39 & 0.145 & \\
\hline 16 & 0.7 & $5 \quad 23.57$ & 0.127 & & 41 & 1.36 & 22.38 & 0.152 & \\
\hline 17 & 0.7 & $5 \quad 23.56$ & 0.156 & & 42 & 1.37 & 22.38 & 0.161 & \\
\hline 18 & 0.7 & $5 \quad 23.55$ & 0.185 & & 43 & 1.37 & 22.37 & 0.169 & \\
\hline 19 & 0.7 & $5 \quad 23.53$ & 0.210 & & 44 & 1.38 & 22.37 & 0.178 & \\
\hline 20 & 0.7 & 523.51 & 0.239 & & 45 & 1.39 & 22.36 & 0.186 & \\
\hline
\end{tabular}




\begin{tabular}{|c|c|c|c|c|c|c|c|}
\hline 46 & 1.39 & 22.35 & 0.195 & 78 & 2.03 & 21.37 & 0.286 \\
\hline 47 & 1.39 & 22.34 & 0.204 & 79 & 2.03 & 21.35 & 0.292 \\
\hline 48 & 1.39 & 22.33 & 0.214 & 80 & 2.03 & 21.34 & 0.300 \\
\hline 49 & 1.39 & 22.32 & 0.223 & 81 & 2.03 & 21.32 & 0.306 \\
\hline 50 & 1.40 & 22.31 & 0.231 & 82 & 2.03 & 21.31 & 0.313 \\
\hline 51 & 1.39 & 22.29 & 0.241 & 83 & 2.02 & 21.29 & 0.321 \\
\hline 52 & 1.39 & 22.28 & 0.250 & 84 & 2.01 & 21.27 & 0.329 \\
\hline 53 & 1.39 & 22.26 & 0.258 & 85 & 2.02 & 21.26 & 0.335 \\
\hline 54 & 1.39 & 22.25 & 0.268 & 86 & 2.01 & 21.24 & 0.343 \\
\hline 55 & 1.39 & 22.23 & 0.275 & 87 & 2.00 & 21.22 & 0.352 \\
\hline 56 & 1.39 & 22.22 & 0.285 & 88 & 1.99 & 21.20 & 0.360 \\
\hline 57 & 1.38 & 22.20 & 0.296 & 89 & 1.99 & 21.18 & 0.366 \\
\hline 58 & 1.37 & 22.18 & 0.309 & 90 & 1.98 & 21.16 & 0.374 \\
\hline 59 & 1.36 & 22.15 & 0.318 & 91 & 1.96 & 21.13 & 0.383 \\
\hline 60 & 1.35 & 22.13 & 0.331 & 92 & 1.95 & 21.11 & 0.393 \\
\hline 61 & 1.33 & 22.10 & 0.346 & 93 & 1.93 & 21.08 & 0.403 \\
\hline 62 & 1.32 & 22.07 & 0.358 & 94 & 1.91 & 21.05 & 0.413 \\
\hline 63 & 1.29 & 22.03 & 0.376 & 95 & 1.89 & 21.02 & 0.424 \\
\hline 64 & 1.28 & 22.00 & 0.391 & 96 & 1.87 & 20.99 & 0.436 \\
\hline 65 & 1.24 & 21.95 & 0.414 & 97 & 1.85 & 20.96 & 0.448 \\
\hline 66 & 1.20 & 21.90 & 0.442 & 98 & 1.82 & 20.92 & 0.462 \\
\hline 67 & 1.15 & 21.84 & 0.477 & 99 & 1.79 & 20.88 & 0.476 \\
\hline 68 & 1.09 & 21.77 & 0.524 & 100 & 1.76 & 20.84 & 0.492 \\
\hline 69 & 1.01 & 21.67 & 0.582 & 101 & 1.72 & 20.79 & 0.510 \\
\hline 70 & 0.88 & 21.53 & 0.695 & 102 & 1.68 & 20.74 & 0.531 \\
\hline 71 & 0.86 & 21.50 & 0.720 & 103 & 1.63 & 20.68 & 0.557 \\
\hline 72 & 1.04 & 21.45 & 0.562 & 104 & 1.57 & 20.61 & 0.590 \\
\hline 73 & 1.48 & 21.42 & 0.372 & 105 & 1.50 & 20.53 & 0.630 \\
\hline 74 & 1.98 & 21.40 & 0.274 & 106 & 1.39 & 20.41 & 0.677 \\
\hline 75 & 1.99 & 21.40 & 0.273 & 107 & 1.25 & 20.26 & 0.740 \\
\hline 76 & 2.01 & 21.39 & 0.274 & 108 & 0.63 & 19.63 & 1.785 \\
\hline 77 & 2.02 & 21.38 & 0.280 & 109 & 0.62 & 19.62 & 1.812 \\
\hline
\end{tabular}

\begin{tabular}{|c|c|c|c|c|c|c|c|c|c|}
\hline \multicolumn{5}{|c|}{ Sai - Bloco de notas } & \multicolumn{5}{|c|}{ Sai - Bloco de notas } \\
\hline \multicolumn{5}{|c|}{ Arquivo Editar Pesquisar } & Arqu & O Ec & litar & esquisar & Ajuda \\
\hline \multirow{2}{*}{\multicolumn{5}{|c|}{$\begin{array}{l}\text { RESOLUÇÃO DO SISTEMA } \\
\text { TEMPO EM } \\
\text { SEGUNDOS }\end{array}$}} & 15 & 0.30 & 23.13 & 0.052 & \\
\hline & & & & & 16 & 0.32 & 23.13 & 0.065 & \\
\hline \multicolumn{5}{|c|}{$t=129600$} & 17 & 0.32 & 23.12 & 0.079 & \\
\hline \multirow{2}{*}{$\mathrm{SEC}$} & $\mathrm{y}(\mathrm{m}$ & ) $\mathrm{h}(\mathrm{m})$ & $\mathrm{V}(\mathrm{m} / \mathrm{s})$ & & 18 & 0.32 & 23.11 & 0.093 & \\
\hline & & & & & 19 & 0.33 & 23.10 & 0.105 & \\
\hline 1 & 0.0 & 223.96 & 0.000 & & 20 & 0.33 & 23.09 & 0.119 & \\
\hline 2 & 0.0 & 224.16 & -0.508 & & 21 & 0.33 & 23.07 & 0.132 & \\
\hline 3 & 0.0 & 224.36 & -0.641 & & 22 & 0.32 & 23.05 & 0.153 & \\
\hline 4 & 0.0 & 224.38 & -0.819 & & 23 & 0.30 & 23.02 & 0.180 & \\
\hline 5 & 0.0 & 224.42 & 0.791 & & 24 & 0.26 & 22.96 & 0.218 & \\
\hline 6 & 0.0 & $2 \quad 23.02$ & 0.096 & & 25 & 0.26 & 22.88 & 0.239 & \\
\hline 7 & 0.0 & $8 \quad 23.07$ & -0.079 & & 26 & 0.19 & 22.65 & 0.362 & \\
\hline 8 & 0.1 & $6 \quad 23.12$ & -0.030 & & 27 & 0.19 & 22.63 & 0.356 & \\
\hline 9 & 0.2 & 023.13 & -0.031 & & 28 & 0.20 & 22.34 & 0.350 & \\
\hline 10 & 0.2 & $4 \quad 23.14$ & -0.018 & & 29 & 0.20 & 22.12 & 0.381 & \\
\hline 11 & 0.2 & $6 \quad 23.14$ & -0.004 & & 30 & 0.31 & 22.01 & 0.183 & \\
\hline 12 & 0.2 & $7 \quad 23.14$ & 0.010 & & 31 & 0.83 & 22.00 & 0.014 & \\
\hline 13 & 0.2 & $8 \quad 23.14$ & 0.025 & & 32 & 0.85 & 22.00 & 0.014 & \\
\hline 14 & 0.2 & 923.13 & 0.038 & & 33 & 0.86 & 22.00 & 0.027 & \\
\hline
\end{tabular}




\begin{tabular}{|c|c|c|c|c|c|c|c|}
\hline 34 & 0.88 & 22.00 & 0.037 & 72 & 0.59 & 21.00 & 0.581 \\
\hline 35 & 0.89 & 22.00 & 0.046 & 73 & 1.01 & 20.95 & 0.287 \\
\hline 36 & 0.91 & 22.00 & 0.055 & 74 & 1.52 & 20.94 & 0.178 \\
\hline 37 & 0.91 & 21.99 & 0.064 & 75 & 1.53 & 20.94 & 0.177 \\
\hline 38 & 0.92 & 21.99 & 0.073 & 76 & 1.56 & 20.94 & 0.180 \\
\hline 39 & 0.94 & 21.99 & 0.081 & 77 & 1.57 & 20.93 & 0.187 \\
\hline 40 & 0.95 & 21.99 & 0.090 & 78 & 1.58 & 20.92 & 0.194 \\
\hline 41 & 0.97 & 21.99 & 0.097 & 79 & 1.59 & 20.91 & 0.201 \\
\hline 42 & 0.97 & 21.98 & 0.106 & 80 & 1.59 & 20.90 & 0.209 \\
\hline 43 & 0.98 & 21.98 & 0.114 & 81 & 1.61 & 20.90 & 0.215 \\
\hline 44 & 0.98 & 21.97 & 0.123 & 82 & 1.61 & 20.89 & 0.223 \\
\hline 45 & 1.00 & 21.97 & 0.130 & 83 & 1.60 & 20.87 & 0.231 \\
\hline 46 & 1.00 & 21.96 & 0.139 & 84 & 1.60 & 20.86 & 0.239 \\
\hline 47 & 1.01 & 21.96 & 0.147 & 85 & 1.61 & 20.85 & 0.245 \\
\hline 48 & 1.01 & 21.95 & 0.156 & 86 & 1.61 & 20.84 & 0.254 \\
\hline 49 & 1.01 & 21.94 & 0.165 & 87 & 1.61 & 20.83 & 0.262 \\
\hline 50 & 1.02 & 21.93 & 0.172 & 88 & 1.60 & 20.81 & 0.271 \\
\hline 51 & 1.02 & 21.92 & 0.181 & 89 & 1.61 & 20.80 & 0.277 \\
\hline 52 & 1.02 & 21.91 & 0.190 & 90 & 1.60 & 20.78 & 0.285 \\
\hline 53 & 1.03 & 21.90 & 0.196 & 91 & 1.59 & 20.76 & 0.295 \\
\hline 54 & 1.02 & 21.88 & 0.205 & 92 & 1.59 & 20.75 & 0.304 \\
\hline 55 & 1.03 & 21.87 & 0.211 & 93 & 1.58 & 20.73 & 0.314 \\
\hline 56 & 1.03 & 21.86 & 0.220 & 94 & 1.57 & 20.71 & 0.324 \\
\hline 57 & 1.02 & 21.84 & 0.230 & 95 & 1.55 & 20.68 & 0.334 \\
\hline 58 & 1.01 & 21.82 & 0.241 & 96 & 1.54 & 20.66 & 0.345 \\
\hline 59 & 1.01 & 21.80 & 0.249 & 97 & 1.52 & 20.63 & 0.357 \\
\hline 60 & 1.00 & 21.78 & 0.260 & 98 & 1.50 & 20.60 & 0.370 \\
\hline 61 & 0.99 & 21.76 & 0.273 & 99 & 1.48 & 20.57 & 0.384 \\
\hline 62 & 0.98 & 21.73 & 0.283 & 100 & 1.46 & 20.54 & 0.398 \\
\hline 63 & 0.97 & 21.71 & 0.298 & 101 & 1.43 & 20.50 & 0.415 \\
\hline 64 & 0.95 & 21.67 & 0.311 & 102 & 1.40 & 20.46 & 0.434 \\
\hline 65 & 0.93 & 21.64 & 0.331 & 103 & 1.36 & 20.41 & 0.456 \\
\hline 66 & 0.89 & 21.59 & 0.355 & 104 & 1.32 & 20.36 & 0.485 \\
\hline 67 & 0.85 & 21.54 & 0.386 & 105 & 1.26 & 20.29 & 0.521 \\
\hline 68 & 0.79 & 21.47 & 0.431 & 106 & 1.19 & 20.21 & 0.568 \\
\hline 69 & 0.71 & 21.37 & 0.494 & 107 & 1.09 & 20.10 & 0.636 \\
\hline 70 & 0.53 & 21.18 & 0.700 & 108 & 0.51 & 19.51 & 1.577 \\
\hline 71 & 0.47 & 21.11 & 0.804 & 109 & 0.50 & 19.50 & 1.604 \\
\hline
\end{tabular}

\begin{tabular}{|c|c|c|c|c|c|c|c|c|c|}
\hline \multicolumn{5}{|c|}{ Sai - Bloco de notas } & \multicolumn{5}{|c|}{ Sai - Bloco de notas } \\
\hline \multicolumn{3}{|c|}{ Arquivo Editar } & Pesquisar & Ajuda & Arqu & vo 1 & ditar $\mathbf{P}$ & esquisar & Ajuda \\
\hline \multicolumn{5}{|c|}{ RESOLUÇÃO DO SISTEMA } & 9 & 0.1 & 23.04 & 0.021 & \\
\hline \multicolumn{5}{|c|}{ TEMPO EM SEGUNDOS } & 10 & 0.1 & 23.04 & 0.025 & \\
\hline \multicolumn{5}{|c|}{$t=172800$} & 11 & 0.1 & 23.04 & 0.031 & \\
\hline \multirow[t]{2}{*}{$\mathrm{SEC}$} & $y(m$ & $h(m)$ & $\mathrm{V}(\mathrm{m} / \mathrm{s})$ & & 12 & 0.1 & 23.03 & 0.038 & \\
\hline & & & & & 13 & 0.1 & 23.03 & 0.044 & \\
\hline 1 & 0.0 & 223.96 & 0.000 & & 14 & 0.1 & 23.03 & 0.048 & \\
\hline 2 & 0.0 & 224.16 & -0.337 & & 15 & 0.1 & 23.02 & 0.055 & \\
\hline 3 & 0.0 & 224.36 & -0.400 & & 16 & 0.2 & 23.01 & 0.059 & \\
\hline 4 & 0.0 & 224.38 & -0.467 & & 17 & 0.2 & 23.00 & 0.067 & \\
\hline 5 & 0.0 & $2 \quad 24.42$ & 0.460 & & 18 & 0.2 & 22.99 & 0.075 & \\
\hline 6 & 0.0 & $2 \quad 23.02$ & 0.203 & & 19 & 0.2 & 22.98 & 0.080 & \\
\hline 7 & 0.0 & 523.04 & 0.071 & & 20 & 0.2 & 22.97 & 0.089 & \\
\hline 8 & 0.0 & 823.04 & 0.018 & & 21 & 0.2 & 22.96 & 0.094 & \\
\hline
\end{tabular}




\begin{tabular}{|c|c|c|c|c|c|c|c|}
\hline 22 & 0.21 & 22.94 & 0.108 & 66 & 0.69 & 21.39 & 0.279 \\
\hline 23 & 0.19 & 22.91 & 0.127 & 67 & 0.65 & 21.34 & 0.303 \\
\hline 24 & 0.16 & 22.86 & 0.155 & 68 & 0.60 & 21.28 & 0.338 \\
\hline 25 & 0.17 & 22.79 & 0.155 & 69 & 0.54 & 21.20 & 0.387 \\
\hline 26 & 0.11 & 22.57 & 0.274 & 70 & 0.38 & 21.03 & 0.584 \\
\hline 27 & 0.11 & 22.55 & 0.277 & 71 & 0.31 & 20.95 & 0.723 \\
\hline 28 & 0.10 & 22.24 & 0.314 & 72 & 0.29 & 20.70 & 0.792 \\
\hline 29 & 0.12 & 22.04 & 0.251 & 73 & 0.63 & 20.57 & 0.278 \\
\hline 30 & 0.09 & 21.79 & 0.381 & 74 & 1.14 & 20.56 & 0.131 \\
\hline 31 & 0.54 & 21.71 & -0.021 & 75 & 1.15 & 20.56 & 0.131 \\
\hline 32 & 0.56 & 21.71 & -0.019 & 76 & 1.18 & 20.56 & 0.133 \\
\hline 33 & 0.57 & 21.71 & -0.005 & 77 & 1.19 & 20.55 & 0.139 \\
\hline 34 & 0.59 & 21.71 & 0.005 & 78 & 1.21 & 20.55 & 0.145 \\
\hline 35 & 0.60 & 21.71 & 0.015 & 79 & 1.22 & 20.54 & 0.151 \\
\hline 36 & 0.62 & 21.71 & 0.025 & 80 & 1.22 & 20.53 & 0.158 \\
\hline 37 & 0.63 & 21.71 & 0.034 & 81 & 1.24 & 20.53 & 0.163 \\
\hline 38 & 0.64 & 21.71 & 0.043 & 82 & 1.24 & 20.52 & 0.170 \\
\hline 39 & 0.66 & 21.71 & 0.050 & 83 & 1.24 & 20.51 & 0.177 \\
\hline 40 & 0.67 & 21.71 & 0.059 & 84 & 1.24 & 20.50 & 0.185 \\
\hline 41 & 0.69 & 21.71 & 0.066 & 85 & 1.25 & 20.49 & 0.190 \\
\hline 42 & 0.70 & 21.71 & 0.074 & 86 & 1.25 & 20.48 & 0.197 \\
\hline 43 & 0.70 & 21.70 & 0.082 & 87 & 1.25 & 20.47 & 0.205 \\
\hline 44 & 0.71 & 21.70 & 0.090 & 88 & 1.25 & 20.46 & 0.212 \\
\hline 45 & 0.73 & 21.70 & 0.096 & 89 & 1.26 & 20.45 & 0.217 \\
\hline 46 & 0.73 & 21.69 & 0.103 & 90 & 1.26 & 20.44 & 0.225 \\
\hline 47 & 0.74 & 21.69 & 0.111 & 91 & 1.25 & 20.42 & 0.232 \\
\hline 48 & 0.74 & 21.68 & 0.119 & 92 & 1.25 & 20.41 & 0.241 \\
\hline 49 & 0.74 & 21.67 & 0.127 & 93 & 1.24 & 20.39 & 0.249 \\
\hline 50 & 0.75 & 21.66 & 0.132 & 94 & 1.24 & 20.38 & 0.258 \\
\hline 51 & 0.76 & 21.66 & 0.140 & 95 & 1.23 & 20.36 & 0.267 \\
\hline 52 & 0.76 & 21.65 & 0.148 & 96 & 1.22 & 20.34 & 0.276 \\
\hline 53 & 0.77 & 21.64 & 0.153 & 97 & 1.21 & 20.32 & 0.286 \\
\hline 54 & 0.77 & 21.63 & 0.160 & 98 & 1.20 & 20.30 & 0.297 \\
\hline 55 & 0.78 & 21.62 & 0.165 & 99 & 1.18 & 20.27 & 0.308 \\
\hline 56 & 0.78 & 21.61 & 0.172 & 100 & 1.16 & 20.24 & 0.321 \\
\hline 57 & 0.77 & 21.59 & 0.180 & 101 & 1.14 & 20.21 & 0.335 \\
\hline 58 & 0.77 & 21.58 & 0.189 & 102 & 1.12 & 20.18 & 0.350 \\
\hline 59 & 0.77 & 21.56 & 0.196 & 103 & 1.09 & 20.14 & 0.369 \\
\hline 60 & 0.76 & 21.54 & 0.205 & 104 & 1.05 & 20.09 & 0.392 \\
\hline 61 & 0.75 & 21.52 & 0.215 & 105 & 1.01 & 20.04 & 0.422 \\
\hline 62 & 0.75 & 21.50 & 0.223 & 106 & 0.95 & 19.97 & 0.459 \\
\hline 63 & 0.74 & 21.48 & 0.235 & 107 & 0.87 & 19.88 & 0.514 \\
\hline 64 & 0.73 & 21.45 & 0.244 & 108 & 0.38 & 19.38 & 1.302 \\
\hline 65 & 0.71 & 21.42 & 0.260 & 109 & 0.38 & 19.38 & 1.325 \\
\hline
\end{tabular}

\begin{tabular}{|c|c|c|c|c|c|c|c|c|}
\hline \multicolumn{4}{|c|}{ Sai - Bloco de notas } & \multicolumn{5}{|c|}{ Sai - Bloco de notas } \\
\hline \multirow{2}{*}{\multicolumn{4}{|c|}{$\begin{array}{l}\text { Arquivo Editar Pesquisar } \\
\text { RESOLUCÃO DO SISTEMA }\end{array}$}} & Arquivo & Ed & litar I & Pesquisar & Ajuda \\
\hline & & & & $3 \quad 0$ & .02 & 24.36 & -0.414 & \\
\hline \multicolumn{4}{|c|}{ TEMPO EM SEGUNDOS } & 4 & .02 & 24.38 & -0.462 & \\
\hline \multicolumn{4}{|c|}{$t=216000$} & 5 & .02 & 24.42 & 0.448 & \\
\hline \multirow[t]{2}{*}{$\mathrm{SEC}$} & $y(m)$ & $\mathrm{V}(\mathrm{m} / \mathrm{s})$ & & 6 & .02 & 23.02 & 0.237 & \\
\hline & & & & 7 & .03 & 23.02 & 0.079 & \\
\hline 1 & $0.02 \quad 23.96$ & 0.000 & & 8 & .05 & 23.01 & 0.027 & \\
\hline 2 & $0.02 \quad 24.16$ & -0.305 & & 9 & .07 & 23.00 & 0.025 & \\
\hline
\end{tabular}




\begin{tabular}{|c|c|c|c|c|c|c|c|}
\hline 10 & 0.09 & 22.99 & 0.027 & 60 & 0.59 & 21.37 & 0.165 \\
\hline 11 & 0.11 & 22.99 & 0.031 & 61 & 0.59 & 21.36 & 0.174 \\
\hline 12 & 0.12 & 22.99 & 0.037 & 62 & 0.59 & 21.34 & 0.179 \\
\hline 13 & 0.12 & 22.98 & 0.042 & 63 & 0.58 & 21.32 & 0.189 \\
\hline 14 & 0.13 & 22.97 & 0.044 & 64 & 0.58 & 21.30 & 0.196 \\
\hline 15 & 0.14 & 22.97 & 0.049 & 65 & 0.56 & 21.27 & 0.208 \\
\hline 16 & 0.15 & 22.96 & 0.052 & 66 & 0.54 & 21.24 & 0.224 \\
\hline 17 & 0.15 & 22.95 & 0.058 & 67 & 0.52 & 21.21 & 0.242 \\
\hline 18 & 0.15 & 22.94 & 0.064 & 68 & 0.48 & 21.16 & 0.270 \\
\hline 19 & 0.16 & 22.93 & 0.066 & 69 & 0.43 & 21.09 & 0.308 \\
\hline 20 & 0.16 & 22.92 & 0.073 & 70 & 0.29 & 20.94 & 0.469 \\
\hline 21 & 0.16 & 22.90 & 0.076 & 71 & 0.24 & 20.88 & 0.573 \\
\hline 22 & 0.15 & 22.88 & 0.087 & 72 & 0.17 & 20.58 & 0.859 \\
\hline 23 & 0.14 & 22.86 & 0.102 & 73 & 0.37 & 20.31 & 0.337 \\
\hline 24 & 0.12 & 22.82 & 0.126 & 74 & 0.87 & 20.29 & 0.109 \\
\hline 25 & 0.13 & 22.75 & 0.123 & 75 & 0.88 & 20.29 & 0.109 \\
\hline 26 & 0.09 & 22.55 & 0.205 & 76 & 0.91 & 20.29 & 0.110 \\
\hline 27 & 0.09 & 22.53 & 0.192 & 77 & 0.93 & 20.29 & 0.115 \\
\hline 28 & 0.05 & 22.19 & 0.328 & 78 & 0.94 & 20.28 & 0.119 \\
\hline 29 & 0.12 & 22.04 & 0.103 & 79 & 0.95 & 20.27 & 0.124 \\
\hline 30 & 0.02 & 21.72 & 0.512 & 80 & 0.96 & 20.27 & 0.130 \\
\hline 31 & 0.35 & 21.52 & -0.020 & 81 & 0.97 & 20.26 & 0.134 \\
\hline 32 & 0.37 & 21.52 & -0.018 & 82 & 0.98 & 20.26 & 0.140 \\
\hline 33 & 0.38 & 21.52 & -0.006 & 83 & 0.98 & 20.25 & 0.146 \\
\hline 34 & 0.40 & 21.52 & 0.004 & 84 & 0.98 & 20.24 & 0.152 \\
\hline 35 & 0.41 & 21.52 & 0.012 & 85 & 0.99 & 20.23 & 0.156 \\
\hline 36 & 0.43 & 21.52 & 0.020 & 86 & 1.00 & 20.23 & 0.162 \\
\hline 37 & 0.44 & 21.52 & 0.028 & 87 & 1.00 & 20.22 & 0.169 \\
\hline 38 & 0.45 & 21.52 & 0.035 & 88 & 1.00 & 20.21 & 0.175 \\
\hline 39 & 0.47 & 21.52 & 0.041 & 89 & 1.01 & 20.20 & 0.178 \\
\hline 40 & 0.48 & 21.52 & 0.048 & 90 & 1.01 & 20.19 & 0.184 \\
\hline 41 & 0.50 & 21.52 & 0.053 & 91 & 1.00 & 20.17 & 0.191 \\
\hline 42 & 0.51 & 21.52 & 0.060 & 92 & 1.00 & 20.16 & 0.197 \\
\hline 43 & 0.51 & 21.51 & 0.066 & 93 & 1.00 & 20.15 & 0.204 \\
\hline 44 & 0.52 & 21.51 & 0.072 & 94 & 1.00 & 20.14 & 0.211 \\
\hline 45 & 0.54 & 21.51 & 0.077 & 95 & 0.99 & 20.12 & 0.218 \\
\hline 46 & 0.54 & 21.50 & 0.083 & 96 & 0.98 & 20.10 & 0.226 \\
\hline 47 & 0.55 & 21.50 & 0.089 & 97 & 0.98 & 20.09 & 0.234 \\
\hline 48 & 0.55 & 21.49 & 0.096 & 98 & 0.97 & 20.07 & 0.242 \\
\hline 49 & 0.56 & 21.49 & 0.102 & 99 & 0.96 & 20.05 & 0.251 \\
\hline 50 & 0.57 & 21.48 & 0.106 & 100 & 0.94 & 20.02 & 0.261 \\
\hline 51 & 0.57 & 21.47 & 0.113 & 101 & 0.93 & 20.00 & 0.272 \\
\hline 52 & 0.57 & 21.46 & 0.119 & 102 & 0.91 & 19.97 & 0.284 \\
\hline 53 & 0.59 & 21.46 & 0.123 & 103 & 0.89 & 19.94 & 0.297 \\
\hline 54 & 0.59 & 21.45 & 0.129 & 104 & 0.86 & 19.90 & 0.315 \\
\hline 55 & 0.60 & 21.44 & 0.133 & 105 & 0.83 & 19.86 & 0.336 \\
\hline 56 & 0.60 & 21.43 & 0.139 & 106 & 0.78 & 19.80 & 0.362 \\
\hline 57 & 0.60 & 21.42 & 0.145 & 107 & 0.73 & 19.74 & 0.397 \\
\hline 58 & 0.59 & 21.40 & 0.153 & 108 & 0.26 & 19.26 & 1.187 \\
\hline 59 & 0.60 & 21.39 & 0.157 & 109 & 0.26 & 19.26 & 1.227 \\
\hline
\end{tabular}




\begin{tabular}{|c|c|c|c|c|c|c|c|c|c|}
\hline \multicolumn{5}{|c|}{ Sai - Bloco de notas } & \multicolumn{5}{|c|}{ Sai - Bloco de notas } \\
\hline \multicolumn{3}{|c|}{ Arquivo Editar } & Pesquisar & Ajuda & Arquivo & $\mathbf{0} \mathbf{E}$ & litar I & Pesquisar & Ajuda \\
\hline \multicolumn{5}{|c|}{ RESOLUÇÃO DO SISTEMA } & $53 \quad 0$ & 0.33 & 21.20 & 0.092 & \\
\hline \multirow{2}{*}{\multicolumn{5}{|c|}{$\begin{array}{l}\text { TEMPO EM SEGUNDOS } \\
t=345600\end{array}$}} & 54 & 0.33 & 21.19 & 0.095 & \\
\hline & & & & & 55 & 0.34 & 21.18 & 0.095 & \\
\hline \multirow{2}{*}{$\mathrm{SEC}$} & $y(m)$ & $\mathrm{h}(\mathrm{m})$ & $\mathrm{V}(\mathrm{m} / \mathrm{s})$ & & 56 & 0.34 & 21.17 & 0.098 & \\
\hline & & & & & 57 & 0.34 & 21.16 & 0.102 & \\
\hline 1 & 0.02 & 223.96 & 0.000 & & 58 & 0.34 & 21.15 & 0.106 & \\
\hline 2 & 0.02 & 224.16 & -0.300 & & 59 & 0.35 & 21.14 & 0.107 & \\
\hline 3 & 0.02 & 224.36 & -0.408 & & 60 & 0.35 & 21.13 & 0.111 & \\
\hline 4 & 0.02 & 224.38 & -0.454 & & 61 & 0.34 & 21.11 & 0.116 & \\
\hline 5 & 0.02 & 224.42 & 0.442 & & 62 & 0.35 & 21.10 & 0.118 & \\
\hline 6 & 0.02 & 223.02 & 0.262 & & 63 & 0.34 & 21.08 & 0.123 & \\
\hline 7 & 0.03 & $\begin{array}{l}323.02 \\
\end{array}$ & 0.101 & & 64 & 0.34 & 21.06 & 0.125 & \\
\hline 8 & 0.02 & 222.98 & 0.022 & & 65 & 0.34 & 21.05 & 0.132 & \\
\hline 9 & 0.02 & 22.95 & 0.023 & & 66 & 0.32 & 21.02 & 0.141 & \\
\hline 10 & 0.03 & 322.93 & 0.020 & & 67 & 0.31 & 21.00 & 0.151 & \\
\hline 11 & 0.04 & $\begin{array}{l}42.92 \\
\end{array}$ & 0.023 & & 68 & 0.29 & 20.97 & 0.166 & \\
\hline 12 & 0.04 & 22.91 & 0.027 & & 69 & 0.26 & 20.92 & 0.186 & \\
\hline 13 & 0.05 & 522.91 & 0.030 & & 70 & 0.15 & 20.80 & 0.318 & \\
\hline 14 & 0.06 & 522.90 & 0.030 & & 71 & 0.07 & 20.71 & 0.562 & \\
\hline 15 & 0.06 & 522.89 & 0.033 & & 72 & 0.12 & 20.53 & 0.372 & \\
\hline 16 & 0.07 & 22.88 & 0.033 & & 73 & 0.05 & 19.99 & 0.705 & \\
\hline 17 & 0.07 & 22.87 & 0.038 & & 74 & 0.47 & 19.89 & 0.106 & \\
\hline 18 & 0.07 & 22.86 & 0.043 & & 75 & 0.48 & 19.89 & 0.104 & \\
\hline 19 & 0.08 & 322.85 & 0.042 & & 76 & 0.50 & 19.88 & 0.101 & \\
\hline 20 & 0.08 & 322.84 & 0.047 & & 77 & 0.52 & 19.88 & 0.102 & \\
\hline 21 & 0.09 & 922.83 & 0.046 & & 78 & 0.53 & 19.87 & 0.103 & \\
\hline 22 & 0.08 & 322.81 & 0.055 & & 79 & 0.54 & 19.86 & 0.104 & \\
\hline 23 & 0.08 & 322.80 & 0.064 & & 80 & 0.54 & 19.85 & 0.107 & \\
\hline 24 & 0.06 & 522.76 & 0.082 & & 81 & 0.56 & 19.85 & 0.108 & \\
\hline 25 & 0.07 & 722.69 & 0.078 & & 82 & 0.56 & 19.84 & 0.111 & \\
\hline 26 & 0.05 & 522.51 & 0.126 & & 83 & 0.56 & 19.83 & 0.114 & \\
\hline 27 & 0.06 & 522.50 & 0.100 & & 84 & 0.56 & 19.82 & 0.118 & \\
\hline 28 & 0.02 & 22.16 & 0.275 & & 85 & 0.57 & 19.81 & 0.118 & \\
\hline 29 & 0.10 & 22.02 & 0.089 & & 86 & 0.57 & 19.80 & 0.122 & \\
\hline 30 & 0.02 & 21.72 & 0.436 & & 87 & 0.58 & 19.80 & 0.125 & \\
\hline 31 & 0.18 & 321.35 & 0.064 & & 88 & 0.58 & 19.79 & 0.129 & \\
\hline 32 & 0.20 & 21.35 & 0.058 & & 89 & 0.59 & 19.78 & 0.130 & \\
\hline 33 & 0.20 & 21.34 & 0.060 & & 90 & 0.59 & 19.77 & 0.133 & \\
\hline 34 & 0.22 & 21.34 & 0.059 & & 91 & 0.59 & 19.76 & 0.137 & \\
\hline 35 & 0.22 & 21.33 & 0.061 & & 92 & 0.59 & 19.75 & 0.141 & \\
\hline 36 & 0.23 & 321.32 & 0.060 & & 93 & 0.58 & 19.73 & 0.145 & \\
\hline 37 & 0.24 & 421.32 & 0.062 & & 94 & 0.58 & 19.72 & 0.150 & \\
\hline 38 & 0.24 & 21.31 & 0.065 & & 95 & 0.58 & 19.71 & 0.154 & \\
\hline 39 & 0.25 & 21.30 & 0.064 & & 96 & 0.57 & 19.69 & 0.159 & \\
\hline 40 & 0.26 & 21.30 & 0.066 & & 97 & 0.57 & 19.68 & 0.165 & \\
\hline 41 & 0.27 & 21.29 & 0.066 & & 98 & 0.56 & 19.66 & 0.171 & \\
\hline 42 & 0.28 & 21.29 & 0.068 & & 99 & 0.55 & 19.64 & 0.178 & \\
\hline 43 & 0.28 & 21.28 & 0.071 & & 100 & 0.54 & 19.62 & 0.186 & \\
\hline 44 & 0.28 & 21.27 & 0.073 & & 101 & 0.52 & 19.59 & 0.195 & \\
\hline 45 & 0.30 & 21.27 & 0.073 & & 102 & 0.51 & 19.57 & 0.205 & \\
\hline 46 & 0.30 & 21.26 & 0.076 & & 103 & 0.49 & 19.54 & 0.219 & \\
\hline 47 & 0.30 & 21.25 & 0.078 & & 104 & 0.45 & 19.49 & 0.241 & \\
\hline 48 & 0.31 & 21.25 & 0.081 & & 105 & 0.40 & 19.43 & 0.278 & \\
\hline 49 & 0.31 & 21.24 & 0.084 & & 106 & 0.26 & 19.28 & 0.356 & \\
\hline 50 & 0.32 & 21.23 & 0.085 & & 107 & 0.02 & 19.03 & -0.089 & \\
\hline 51 & 0.32 & 21.22 & 0.088 & & 108 & 0.02 & 19.02 & 0.415 & \\
\hline 52 & 0.32 & 21.21 & 0.092 & & 109 & 0.02 & 19.02 & 0.514 & \\
\hline
\end{tabular}


C SUB ROTINA PARA RESOLUÇÃO DO SISTEMA DE EQUAÇÕES

C LINEARES

SUBROUTINE SOLVER(R,U,N)

INTEGER N

REAL*8 R(N,N+1),U(N),SOMAT

DO $360 \mathrm{I}=1, \mathrm{~N}$

IF(I.GT.1)THEN

DO $330 \mathrm{~K}=\mathrm{I}, \mathrm{N}$

SOMAT $=0$

DO $325 \mathrm{~J}=1$,(I-1)

SOMAT $=\mathrm{SOMAT}+\mathrm{R}(\mathrm{K},(\mathrm{I}-\mathrm{J})) * \mathrm{R}((\mathrm{I}-\mathrm{J}), \mathrm{I})$

CONTINUE

$\mathrm{R}(\mathrm{K}, \mathrm{I})=\mathrm{R}(\mathrm{K}, \mathrm{I})-\mathrm{SOMAT}$

330

CONTINUE

ENDIF

DO $350 \mathrm{~K}=(\mathrm{I}+1),(\mathrm{N}+1)$

SOMAT $=0$

IF(I.GT.1)THEN

DO $340 \mathrm{~J}=1$,(I-1)

SOMAT $=$ SOMAT $+\mathrm{R}(\mathrm{I},(\mathrm{I}-\mathrm{J})) * \mathrm{R}((\mathrm{I}-\mathrm{J}), \mathrm{K})$

340

CONTINUE

ENDIF

$\mathrm{R}(\mathrm{I}, \mathrm{K})=(\mathrm{R}(\mathrm{I}, \mathrm{K})-\mathrm{SOMAT}) / \mathrm{R}(\mathrm{I}, \mathrm{I})$

350

CONTINUE

360 CONTINUE

$\mathrm{U}(\mathrm{N})=-\mathrm{R}(\mathrm{N},(\mathrm{N}+1))$

DO $380 \mathrm{I}=(\mathrm{N}-1), 1,-1$

$\mathrm{U}(\mathrm{I})=0$

SOMAT $=0$

DO $370 \mathrm{~J}=(\mathrm{I}+1), \mathrm{N}$

SOMAT $=$ SOMAT $+\mathrm{R}(\mathrm{I}, \mathrm{J}) * \mathrm{U}(\mathrm{J})$

370

CONTINUE

$\mathrm{U}(\mathrm{I})=-\mathrm{R}(\mathrm{I},(\mathrm{N}+1))-\mathrm{SOMAT}$

380 CONTINUE

DO $390 \mathrm{I}=\mathrm{N}, 1,-1$

$\mathrm{U}(\mathrm{I})=-\mathrm{U}(\mathrm{I})$

390

CONTINUE

RETURN

END 
C SUB ROTINA PARA DETERMINAÇÃO DA GEOMETRIA

C CANAL DE ALIMENTAÇÃO DA USINA DE MONJOLINHO

\section{SUBROUTINE GEO(y,P,A,Bi,Am,Pm,Bim,Rh,Nz)}

INTEGER Nz

REAL *8 y(Nz),P(Nz),A(Nz),Bi(Nz),Am(Nz-1),Pm(Nz-1),Bim(Nz-1),

$\mathrm{Rh}(\mathrm{Nz}-1)$

DO I $=1, \mathrm{Nz}$

IF(I.EQ.1)THEN

$\mathrm{A}(\mathrm{I})=0.4107 *(\mathrm{y}(\mathrm{I}) * 2)+0.7221 * \mathrm{y}(\mathrm{I})+0.008$

$\mathrm{P}(\mathrm{I})=2.14 * \mathrm{y}(\mathrm{I})+0.758$

$\mathrm{Bi}(\mathrm{I})=0.75 * \mathrm{y}(\mathrm{I})+0.76$

ELSEIF(I.EQ.2)THEN

$\mathrm{A}(\mathrm{I})=0.4107 *(\mathrm{y}(\mathrm{I}) * 2)+0.7221 * \mathrm{y}(\mathrm{I})+0.008$

$\mathrm{P}(\mathrm{I})=2.14 * \mathrm{y}(\mathrm{I})+0.758$

$\operatorname{Bi}(\mathrm{I})=0.75 * \mathrm{y}(\mathrm{I})+0.76$

$\operatorname{Bim}(\mathrm{I}-1)=((\mathrm{Bi}(\mathrm{I}))+(\mathrm{Bi}(\mathrm{I}-1))) / 2$

$\mathrm{Am}(\mathrm{I}-1)=((\mathrm{A}(\mathrm{I}))+(\mathrm{A}(\mathrm{I}-1))) / 2$

$\mathrm{Pm}(\mathrm{I}-1)=((\mathrm{P}(\mathrm{I}))+(\mathrm{P}(\mathrm{I}-1))) / 2$

$\mathrm{Rh}(\mathrm{I}-1)=((\mathrm{Am}(\mathrm{I}-1)) /(\mathrm{Pm}(\mathrm{I}-1)))$

ELSEIF(I.EQ.3)THEN

$\mathrm{A}(\mathrm{I})=-0.8333 *(\mathrm{y}(\mathrm{I}) * * 3)+1.25 *(\mathrm{y}(\mathrm{I}) * 2)+0.3833 * \mathrm{y}(\mathrm{I})-0.01$

$\mathrm{P}(\mathrm{I})=5.5208 *(\mathrm{y}(\mathrm{I}) * * 3)-8.1161 *(\mathrm{y}(\mathrm{I}) * * 2)+5.656 * \mathrm{y}(\mathrm{I})+0.074$

$\mathrm{Bi}(\mathrm{I})=-3.8214 *(\mathrm{y}(\mathrm{I}) * 2)+3.6957 * \mathrm{y}(\mathrm{I})+0.176$

$\operatorname{Bim}(\mathrm{I}-1)=((\operatorname{Bi}(\mathrm{I}))+(\operatorname{Bi}(\mathrm{I}-1))) / 2$

$\operatorname{Am}(\mathrm{I}-1)=((\mathrm{A}(\mathrm{I}))+(\mathrm{A}(\mathrm{I}-1))) / 2$

$\mathrm{Pm}(\mathrm{I}-1)=((\mathrm{P}(\mathrm{I}))+(\mathrm{P}(\mathrm{I}-1))) / 2$

$\mathrm{Rh}(\mathrm{I}-1)=((\mathrm{Am}(\mathrm{I}-1)) /(\mathrm{Pm}(\mathrm{I}-1)))$

ELSEIF(I.EQ.4)THEN

$\mathrm{A}(\mathrm{I})=-0.8333 *(\mathrm{y}(\mathrm{I}) * * 3)+1.25 *(\mathrm{y}(\mathrm{I}) * 2)+0.3833 * \mathrm{y}(\mathrm{I})-0.01$

$\mathrm{P}(\mathrm{I})=5.5208 *(\mathrm{y}(\mathrm{I}) * * 3)-8.1161 *(\mathrm{y}(\mathrm{I}) * * 2)+5.656 * \mathrm{y}(\mathrm{I})+0.074$

$\mathrm{Bi}(\mathrm{I})=-3.8214 *(\mathrm{y}(\mathrm{I}) * * 2)+3.6957 * \mathrm{y}(\mathrm{I})+0.176$

$\operatorname{Bim}(\mathrm{I}-1)=((\operatorname{Bi}(\mathrm{I}))+(\mathrm{Bi}(\mathrm{I}-1))) / 2$

$\mathrm{Am}(\mathrm{I}-1)=((\mathrm{A}(\mathrm{I}))+(\mathrm{A}(\mathrm{I}-1))) / 2$

$\mathrm{Pm}(\mathrm{I}-1)=((\mathrm{P}(\mathrm{I}))+(\mathrm{P}(\mathrm{I}-1))) / 2$

$\mathrm{Rh}(\mathrm{I}-1)=((\mathrm{Am}(\mathrm{I}-1)) /(\mathrm{Pm}(\mathrm{I}-1)))$

ELSEIF(I.EQ.5)THEN

$\mathrm{A}(\mathrm{I})=-0.8333 *(\mathrm{y}(\mathrm{I}) * * 3)+1.25 *(\mathrm{y}(\mathrm{I}) * * 2)+0.3833 * \mathrm{y}(\mathrm{I})-0.01$

$\mathrm{P}(\mathrm{I})=5.5208 *(\mathrm{y}(\mathrm{I}) * * 3)-8.1161 *(\mathrm{y}(\mathrm{I}) * * 2)+5.656 * \mathrm{y}(\mathrm{I})+0.074$

$\mathrm{Bi}(\mathrm{I})=-3.8214 *(\mathrm{y}(\mathrm{I}) * * 2)+3.6957 * \mathrm{y}(\mathrm{I})+0.176$

$\operatorname{Bim}(\mathrm{I}-1)=((\operatorname{Bi}(\mathrm{I}))+(\operatorname{Bi}(\mathrm{I}-1))) / 2$

$\mathrm{Am}(\mathrm{I}-1)=((\mathrm{A}(\mathrm{I}))+(\mathrm{A}(\mathrm{I}-1))) / 2$

$\mathrm{Pm}(\mathrm{I}-1)=((\mathrm{P}(\mathrm{I}))+(\mathrm{P}(\mathrm{I}-1))) / 2$

$\operatorname{Rh}(\mathrm{I}-1)=((\operatorname{Am}(\mathrm{I}-1)) /(\operatorname{Pm}(\mathrm{I}-1)))$

ELSEIF(I.EQ.6)THEN

$\mathrm{A}(\mathrm{I})=0.375 *(\mathrm{y}(\mathrm{I}) * 2)+0.755^{*} \mathrm{y}(\mathrm{I})+0.002$

$\mathrm{P}(\mathrm{I})=2.13 * \mathrm{y}(\mathrm{I})+0.762$

$\mathrm{Bi}(\mathrm{I})=0.75^{*} \mathrm{y}(\mathrm{I})+0.76$

$\operatorname{Bim}(\mathrm{I}-1)=((\operatorname{Bi}(\mathrm{I}))+(\operatorname{Bi}(\mathrm{I}-1))) / 2$

$\mathrm{Am}(\mathrm{I}-1)=((\mathrm{A}(\mathrm{I}))+(\mathrm{A}(\mathrm{I}-1))) / 2$

$\mathrm{Pm}(\mathrm{I}-1)=((\mathrm{P}(\mathrm{I}))+(\mathrm{P}(\mathrm{I}-1))) / 2$

$\mathrm{Rh}(\mathrm{I}-1)=((\mathrm{Am}(\mathrm{I}-1)) /(\mathrm{Pm}(\mathrm{I}-1)))$ 


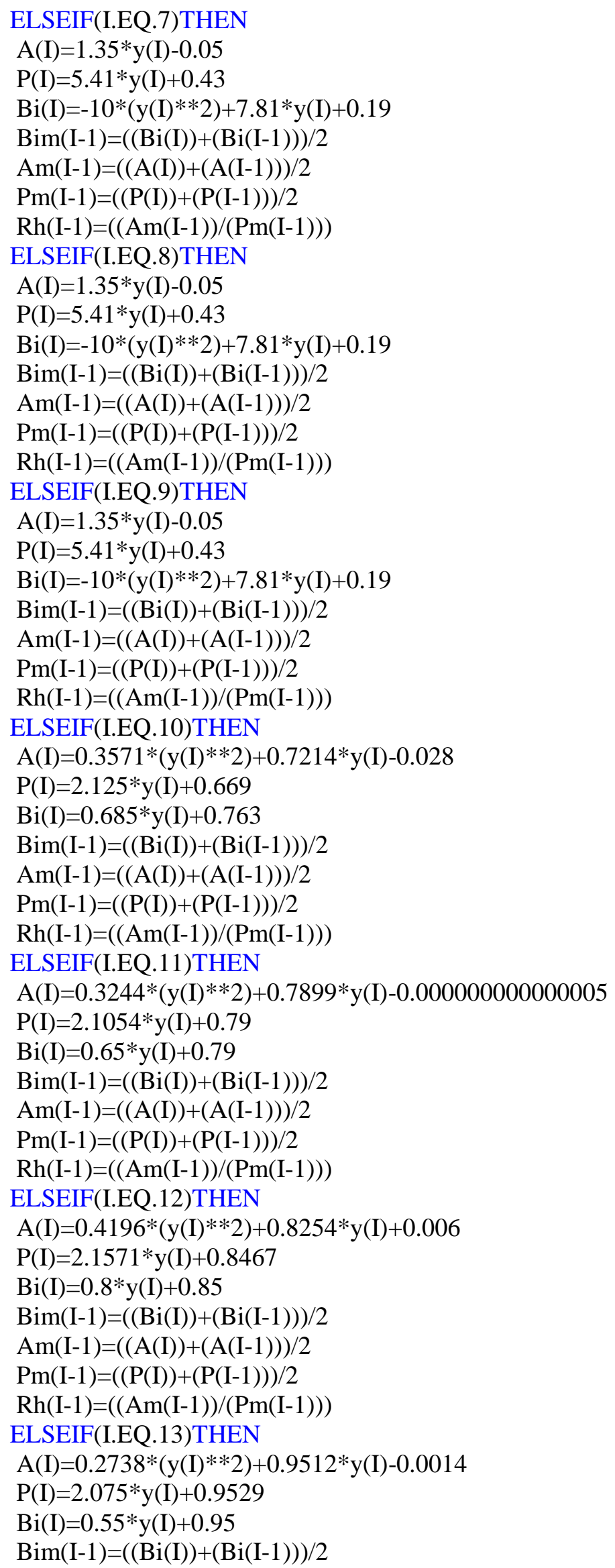


$\mathrm{Am}(\mathrm{I}-1)=((\mathrm{A}(\mathrm{I}))+(\mathrm{A}(\mathrm{I}-1))) / 2$

$\mathrm{Pm}(\mathrm{I}-1)=((\mathrm{P}(\mathrm{I}))+(\mathrm{P}(\mathrm{I}-1))) / 2$

$\operatorname{Rh}(\mathrm{I}-1)=((\mathrm{Am}(\mathrm{I}-1)) /(\mathrm{Pm}(\mathrm{I}-1)))$

ELSEIF(I.EQ.14)THEN

$\mathrm{A}(\mathrm{I})=0.2946 *(\mathrm{y}(\mathrm{I}) * * 2)+0.7875^{*} \mathrm{y}(\mathrm{I})-0.000000000000004$

$\mathrm{P}(\mathrm{I})=2.0857 * \mathrm{y}(\mathrm{I})+0.79$

$\mathrm{Bi}(\mathrm{I})=0.5911 * \mathrm{y}(\mathrm{I})+0.79$

$\operatorname{Bim}(\mathrm{I}-1)=((\operatorname{Bi}(\mathrm{I}))+(\mathrm{Bi}(\mathrm{I}-1))) / 2$

$\mathrm{Am}(\mathrm{I}-1)=((\mathrm{A}(\mathrm{I}))+(\mathrm{A}(\mathrm{I}-1))) / 2$

$\mathrm{Pm}(\mathrm{I}-1)=((\mathrm{P}(\mathrm{I}))+(\mathrm{P}(\mathrm{I}-1))) / 2$

$\operatorname{Rh}(\mathrm{I}-1)=((\mathrm{Am}(\mathrm{I}-1)) /(\mathrm{Pm}(\mathrm{I}-1)))$

ELSEIF(I.EQ.15)THEN

$\mathrm{A}(\mathrm{I})=0.25 *(\mathrm{y}(\mathrm{I}) * 2)+0.8729 * \mathrm{y}(\mathrm{I})-0.006$

$\mathrm{P}(\mathrm{I})=2.08 * \mathrm{y}(\mathrm{I})+0.8473$

$\mathrm{Bi}(\mathrm{I})=0.5314 * \mathrm{y}(\mathrm{I})+0.8513$

$\operatorname{Bim}(\mathrm{I}-1)=((\operatorname{Bi}(\mathrm{I}))+(\operatorname{Bi}(\mathrm{I}-1))) / 2$

$\mathrm{Am}(\mathrm{I}-1)=((\mathrm{A}(\mathrm{I}))+(\mathrm{A}(\mathrm{I}-1))) / 2$

$\mathrm{Pm}(\mathrm{I}-1)=((\mathrm{P}(\mathrm{I}))+(\mathrm{P}(\mathrm{I}-1))) / 2$

$\operatorname{Rh}(\mathrm{I}-1)=((\operatorname{Am}(\mathrm{I}-1)) /(\operatorname{Pm}(\mathrm{I}-1)))$

ELSEIF(I.EQ.16)THEN

$\mathrm{A}(\mathrm{I})=0.4464 *(\mathrm{y}(\mathrm{I}) * 2)+0.7893 * \mathrm{y}(\mathrm{I})+0.004$

$\mathrm{P}(\mathrm{I})=2.2 * \mathrm{y}(\mathrm{I})+0.79$

$\mathrm{Bi}(\mathrm{I})=0.91 * \mathrm{y}(\mathrm{I})+0.786$

$\operatorname{Bim}(\mathrm{I}-1)=((\mathrm{Bi}(\mathrm{I}))+(\mathrm{Bi}(\mathrm{I}-1))) / 2$

$\mathrm{Am}(\mathrm{I}-1)=((\mathrm{A}(\mathrm{I}))+(\mathrm{A}(\mathrm{I}-1))) / 2$

$\mathrm{Pm}(\mathrm{I}-1)=((\mathrm{P}(\mathrm{I}))+(\mathrm{P}(\mathrm{I}-1))) / 2$

$\mathrm{Rh}(\mathrm{I}-1)=((\mathrm{Am}(\mathrm{I}-1)) /(\mathrm{Pm}(\mathrm{I}-1)))$

ELSEIF(I.EQ.17)THEN

$\mathrm{A}(\mathrm{I})=0.4196 *(\mathrm{y}(\mathrm{I}) * 2)+0.7996 * \mathrm{y}(\mathrm{I})-0.006$

$\mathrm{P}(\mathrm{I})=2.1771 * \mathrm{y}(\mathrm{I})+0.786$

$\mathrm{Bi}(\mathrm{I})=0.85 * \mathrm{y}(\mathrm{I})+0.79$

$\operatorname{Bim}(\mathrm{I}-1)=((\operatorname{Bi}(\mathrm{I}))+(\mathrm{Bi}(\mathrm{I}-1))) / 2$

$\mathrm{Am}(\mathrm{I}-1)=((\mathrm{A}(\mathrm{I}))+(\mathrm{A}(\mathrm{I}-1))) / 2$

$\mathrm{Pm}(\mathrm{I}-1)=((\mathrm{P}(\mathrm{I}))+(\mathrm{P}(\mathrm{I}-1))) / 2$

$\mathrm{Rh}(\mathrm{I}-1)=((\operatorname{Am}(\mathrm{I}-1)) /(\mathrm{Pm}(\mathrm{I}-1)))$

ELSEIF(I.EQ.18)THEN

$\mathrm{A}(\mathrm{I})=0.4196 *(\mathrm{y}(\mathrm{I}) * 2)+0.7996 * \mathrm{y}(\mathrm{I})-0.006$

$\mathrm{P}(\mathrm{I})=2.1771 * \mathrm{y}(\mathrm{I})+0.786$

$\mathrm{Bi}(\mathrm{I})=0.85 * \mathrm{y}(\mathrm{I})+0.79$

$\operatorname{Bim}(\mathrm{I}-1)=((\mathrm{Bi}(\mathrm{I}))+(\mathrm{Bi}(\mathrm{I}-1))) / 2$

$\mathrm{Am}(\mathrm{I}-1)=((\mathrm{A}(\mathrm{I}))+(\mathrm{A}(\mathrm{I}-1))) / 2$

$\mathrm{Pm}(\mathrm{I}-1)=((\mathrm{P}(\mathrm{I}))+(\mathrm{P}(\mathrm{I}-1))) / 2$

$\mathrm{Rh}(\mathrm{I}-1)=((\mathrm{Am}(\mathrm{I}-1)) /(\mathrm{Pm}(\mathrm{I}-1)))$

ELSEIF(I.EQ.19)THEN

$\mathrm{A}(\mathrm{I})=0.4196 *(\mathrm{y}(\mathrm{I}) * 2)+0.7996 * \mathrm{y}(\mathrm{I})-0.006$

$\mathrm{P}(\mathrm{I})=2.1771 * \mathrm{y}(\mathrm{I})+0.786$

$\mathrm{Bi}(\mathrm{I})=0.85 * \mathrm{y}(\mathrm{I})+0.79$

$\operatorname{Bim}(\mathrm{I}-1)=((\operatorname{Bi}(\mathrm{I}))+(\operatorname{Bi}(\mathrm{I}-1))) / 2$

$\mathrm{Am}(\mathrm{I}-1)=((\mathrm{A}(\mathrm{I}))+(\mathrm{A}(\mathrm{I}-1))) / 2$

$\mathrm{Pm}(\mathrm{I}-1)=((\mathrm{P}(\mathrm{I}))+(\mathrm{P}(\mathrm{I}-1))) / 2$

$\mathrm{Rh}(\mathrm{I}-1)=((\operatorname{Am}(\mathrm{I}-1)) /(\mathrm{Pm}(\mathrm{I}-1)))$

ELSEIF(I.EQ.20)THEN

$\mathrm{A}(\mathrm{I})=0.2768 *(\mathrm{y}(\mathrm{I}) * * 2)+0.9768 * \mathrm{y}(\mathrm{I})-0.0471$ 
$\mathrm{P}(\mathrm{I})=2.1482 * \mathrm{y}(\mathrm{I})+0.8014$

$\operatorname{Bi}(\mathrm{I})=0.75 * \mathrm{y}(\mathrm{I})+0.79$

$\operatorname{Bim}(\mathrm{I}-1)=((\operatorname{Bi}(\mathrm{I}))+(\operatorname{Bi}(\mathrm{I}-1))) / 2$

$\mathrm{Am}(\mathrm{I}-1)=((\mathrm{A}(\mathrm{I}))+(\mathrm{A}(\mathrm{I}-1))) / 2$

$\mathrm{Pm}(\mathrm{I}-1)=((\mathrm{P}(\mathrm{I}))+(\mathrm{P}(\mathrm{I}-1))) / 2$

$\operatorname{Rh}(\mathrm{I}-1)=((\operatorname{Am}(\mathrm{I}-1)) /(\operatorname{Pm}(\mathrm{I}-1)))$

ELSEIF(I.EQ.21)THEN

$\mathrm{A}(\mathrm{I})=0.2946 *(\mathrm{y}(\mathrm{I}) * 2)+1.0696 * \mathrm{y}(\mathrm{I})+0.0043$

$\mathrm{P}(\mathrm{I})=2.0839 * \mathrm{y}(\mathrm{I})+1.0786$

$\mathrm{Bi}(\mathrm{I})=0.5786^{*} \mathrm{y}(\mathrm{I})+1.0829$

$\operatorname{Bim}(\mathrm{I}-1)=((\operatorname{Bi}(\mathrm{I}))+(\operatorname{Bi}(\mathrm{I}-1))) / 2$

$\mathrm{Am}(\mathrm{I}-1)=((\mathrm{A}(\mathrm{I}))+(\mathrm{A}(\mathrm{I}-1))) / 2$

$\mathrm{Pm}(\mathrm{I}-1)=((\mathrm{P}(\mathrm{I}))+(\mathrm{P}(\mathrm{I}-1))) / 2$

$\mathrm{Rh}(\mathrm{I}-1)=((\mathrm{Am}(\mathrm{I}-1)) /(\mathrm{Pm}(\mathrm{I}-1)))$

ELSEIF(I.EQ.22)THEN

$\mathrm{A}(\mathrm{I})=0.3929 *(\mathrm{y}(\mathrm{I}) * * 2)+1.0386 * \mathrm{y}(\mathrm{I})-0.002$

$\mathrm{P}(\mathrm{I})=2.15^{*} \mathrm{y}(\mathrm{I})+1.03$

$\mathrm{Bi}(\mathrm{I})=0.7971 * \mathrm{y}(\mathrm{I})+1.0253$

$\operatorname{Bim}(\mathrm{I}-1)=((\operatorname{Bi}(\mathrm{I}))+(\operatorname{Bi}(\mathrm{I}-1))) / 2$

$\mathrm{Am}(\mathrm{I}-1)=((\mathrm{A}(\mathrm{I}))+(\mathrm{A}(\mathrm{I}-1))) / 2$

$\mathrm{Pm}(\mathrm{I}-1)=((\mathrm{P}(\mathrm{I}))+(\mathrm{P}(\mathrm{I}-1))) / 2$

$\operatorname{Rh}(\mathrm{I}-1)=((\mathrm{Am}(\mathrm{I}-1)) /(\mathrm{Pm}(\mathrm{I}-1)))$

ELSEIF(I.EQ.23)THEN

$\mathrm{A}(\mathrm{I})=0.375^{*}(\mathrm{y}(\mathrm{I}) * * 2)+0.825^{*} \mathrm{y}(\mathrm{I})-0.01$

$\mathrm{P}(\mathrm{I})=2.15 * \mathrm{y}(\mathrm{I})+0.79$

$\operatorname{Bi}(\mathrm{I})=0.8 * \mathrm{y}(\mathrm{I})+0.79$

$\operatorname{Bim}(\mathrm{I}-1)=((\operatorname{Bi}(\mathrm{I}))+(\operatorname{Bi}(\mathrm{I}-1))) / 2$

$\mathrm{Am}(\mathrm{I}-1)=((\mathrm{A}(\mathrm{I}))+(\mathrm{A}(\mathrm{I}-1))) / 2$

$\mathrm{Pm}(\mathrm{I}-1)=((\mathrm{P}(\mathrm{I}))+(\mathrm{P}(\mathrm{I}-1))) / 2$

$\mathrm{Rh}(\mathrm{I}-1)=((\mathrm{Am}(\mathrm{I}-1)) /(\mathrm{Pm}(\mathrm{I}-1)))$

ELSEIF(I.EQ.24)THEN

$\mathrm{A}(\mathrm{I})=0.375 *(\mathrm{y}(\mathrm{I}) * 2)+0.825 * \mathrm{y}(\mathrm{I})-0.01$

$\mathrm{P}(\mathrm{I})=2.15^{*} \mathrm{y}(\mathrm{I})+0.79$

$\mathrm{Bi}(\mathrm{I})=0.8 * \mathrm{y}(\mathrm{I})+0.79$

$\operatorname{Bim}(\mathrm{I}-1)=((\operatorname{Bi}(\mathrm{I}))+(\operatorname{Bi}(\mathrm{I}-1))) / 2$

$\mathrm{Am}(\mathrm{I}-1)=((\mathrm{A}(\mathrm{I}))+(\mathrm{A}(\mathrm{I}-1))) / 2$

$\mathrm{Pm}(\mathrm{I}-1)=((\mathrm{P}(\mathrm{I}))+(\mathrm{P}(\mathrm{I}-1))) / 2$

$\mathrm{Rh}(\mathrm{I}-1)=((\mathrm{Am}(\mathrm{I}-1)) /(\mathrm{Pm}(\mathrm{I}-1)))$

ELSEIF(I.EQ.25)THEN

$\mathrm{A}(\mathrm{I})=0.375 *(\mathrm{y}(\mathrm{I}) * * 2)+0.825 * \mathrm{y}(\mathrm{I})-0.01$

$\mathrm{P}(\mathrm{I})=2.15^{*} \mathrm{y}(\mathrm{I})+0.79$

$\mathrm{Bi}(\mathrm{I})=0.8 * \mathrm{y}(\mathrm{I})+0.79$

$\operatorname{Bim}(\mathrm{I}-1)=((\operatorname{Bi}(\mathrm{I}))+(\operatorname{Bi}(\mathrm{I}-1))) / 2$

$\mathrm{Am}(\mathrm{I}-1)=((\mathrm{A}(\mathrm{I}))+(\mathrm{A}(\mathrm{I}-1))) / 2$

$\operatorname{Pm}(\mathrm{I}-1)=((\mathrm{P}(\mathrm{I}))+(\mathrm{P}(\mathrm{I}-1))) / 2$

$\mathrm{Rh}(\mathrm{I}-1)=((\mathrm{Am}(\mathrm{I}-1)) /(\mathrm{Pm}(\mathrm{I}-1)))$

ELSEIF(I.EQ.26)THEN

$\mathrm{A}(\mathrm{I})=0.3542 *(\mathrm{y}(\mathrm{I}) * * 2)+0.6744 * \mathrm{y}(\mathrm{I})-0.0086$

$\mathrm{P}(\mathrm{I})=2.1286 * \mathrm{y}(\mathrm{I})+0.6514$

$\mathrm{Bi}(\mathrm{I})=0.7339 * \mathrm{y}(\mathrm{I})+0.65$

$\operatorname{Bim}(\mathrm{I}-1)=((\operatorname{Bi}(\mathrm{I}))+(\operatorname{Bi}(\mathrm{I}-1))) / 2$

$\mathrm{Am}(\mathrm{I}-1)=((\mathrm{A}(\mathrm{I}))+(\mathrm{A}(\mathrm{I}-1))) / 2$

$\mathrm{Pm}(\mathrm{I}-1)=((\mathrm{P}(\mathrm{I}))+(\mathrm{P}(\mathrm{I}-1))) / 2$ 
$\operatorname{Rh}(\mathrm{I}-1)=((\mathrm{Am}(\mathrm{I}-1)) /(\operatorname{Pm}(\mathrm{I}-1)))$

ELSEIF(I.EQ.27)THEN

$\mathrm{A}(\mathrm{I})=0.4196 * \mathrm{y}(\mathrm{I}) * * 2)+0.6625 * \mathrm{y}(\mathrm{I})+0.0000000000000008$

$\mathrm{P}(\mathrm{I})=2.1686 * \mathrm{y}(\mathrm{I})+0.6687$

$\mathrm{Bi}(\mathrm{I})=0.8371 * \mathrm{y}(\mathrm{I})+0.664$

$\operatorname{Bim}(\mathrm{I}-1)=((\operatorname{Bi}(\mathrm{I}))+(\operatorname{Bi}(\mathrm{I}-1))) / 2$

$\mathrm{Am}(\mathrm{I}-1)=((\mathrm{A}(\mathrm{I}))+(\mathrm{A}(\mathrm{I}-1))) / 2$

$\operatorname{Pm}(\mathrm{I}-1)=((\mathrm{P}(\mathrm{I}))+(\mathrm{P}(\mathrm{I}-1))) / 2$

$\mathrm{Rh}(\mathrm{I}-1)=((\mathrm{Am}(\mathrm{I}-1)) /(\mathrm{Pm}(\mathrm{I}-1)))$

ELSEIF(I.EQ.28)THEN

$\mathrm{A}(\mathrm{I})=1.95 * \mathrm{y}(\mathrm{I})$

$\mathrm{P}(\mathrm{I})=2 * \mathrm{y}(\mathrm{I})+1.95$

$\operatorname{Bi}(\mathrm{I})=1.95$

$\operatorname{Bim}(\mathrm{I}-1)=((\operatorname{Bi}(\mathrm{I}))+(\operatorname{Bi}(\mathrm{I}-1))) / 2$

$\mathrm{Am}(\mathrm{I}-1)=((\mathrm{A}(\mathrm{I}))+(\mathrm{A}(\mathrm{I}-1))) / 2$

$\mathrm{Pm}(\mathrm{I}-1)=((\mathrm{P}(\mathrm{I}))+(\mathrm{P}(\mathrm{I}-1))) / 2$

$\mathrm{Rh}(\mathrm{I}-1)=((\mathrm{Am}(\mathrm{I}-1)) /(\mathrm{Pm}(\mathrm{I}-1)))$

ELSEIF(I.EQ.29)THEN

$\mathrm{A}(\mathrm{I})=2.85 * \mathrm{y}(\mathrm{I})$

$\mathrm{P}(\mathrm{I})=2 * \mathrm{y}(\mathrm{I})+2.85$

$\mathrm{Bi}(\mathrm{I})=2.85$

$\operatorname{Bim}(\mathrm{I}-1)=((\operatorname{Bi}(\mathrm{I}))+(\operatorname{Bi}(\mathrm{I}-1))) / 2$

$\mathrm{Am}(\mathrm{I}-1)=((\mathrm{A}(\mathrm{I}))+(\mathrm{A}(\mathrm{I}-1))) / 2$

$\mathrm{Pm}(\mathrm{I}-1)=((\mathrm{P}(\mathrm{I}))+(\mathrm{P}(\mathrm{I}-1))) / 2$

$\mathrm{Rh}(\mathrm{I}-1)=((\mathrm{Am}(\mathrm{I}-1)) /(\mathrm{Pm}(\mathrm{I}-1)))$

ELSEIF(I.EQ.Nz)THEN

$\mathrm{A}(\mathrm{I})=3.41 * \mathrm{y}(\mathrm{I})+0.000000000000002$

$\mathrm{P}(\mathrm{I})=2 * \mathrm{y}(\mathrm{I})+3.41$

$\mathrm{Bi}(\mathrm{I})=3.41$

$\operatorname{Bim}(\mathrm{I}-1)=((\operatorname{Bi}(\mathrm{I}))+(\operatorname{Bi}(\mathrm{I}-1))) / 2$

$\mathrm{Am}(\mathrm{I}-1)=((\mathrm{A}(\mathrm{I}))+(\mathrm{A}(\mathrm{I}-1))) / 2$

$\operatorname{Pm}(\mathrm{I}-1)=((\mathrm{P}(\mathrm{I}))+(\mathrm{P}(\mathrm{I}-1))) / 2$

$\mathrm{Rh}(\mathrm{I}-1)=((\mathrm{Am}(\mathrm{I}-1)) /(\mathrm{Pm}(\mathrm{I}-1)))$

ENDIF

ENDDO

RETURN

END 
C SUB ROTINA PARA DETERMINAÇÃO DA GEOMETRIA

C CANAL DO TRABALHADOR

\section{SUBROUTINE GEO(y,P,A,Bi,Am,Pm,Bim,Rh,Nz)}

INTEGER Nz

REAL *8 y(Nz),P(Nz),A(Nz),Bi(Nz),Am(Nz-1),Pm(Nz-1),Bim(Nz-1),

$\mathrm{Rh}(\mathrm{Nz}-1)$

DO I $=1, \mathrm{Nz}$

IF(I.GE.1.AND.I.LE.4)THEN

$\mathrm{A}(\mathrm{I})=1.62 *(\mathrm{y}(\mathrm{I}) * 2)+3.97 * \mathrm{y}(\mathrm{I})-0.06$

$\mathrm{P}(\mathrm{I})=3.79 * \mathrm{y}(\mathrm{I})+3.9767$

$\operatorname{Bi}(\mathrm{I})=3.23 * \mathrm{y}(\mathrm{I})+3.9933$

IF(I.GT.1)THEN

$\operatorname{Bim}(\mathrm{I}-1)=((\operatorname{Bi}(\mathrm{I}))+(\operatorname{Bi}(\mathrm{I}-1))) / 2$

$\operatorname{Am}(\mathrm{I}-1)=((\mathrm{A}(\mathrm{I}))+(\mathrm{A}(\mathrm{I}-1))) / 2$

$\operatorname{Pm}(\mathrm{I}-1)=((\mathrm{P}(\mathrm{I}))+(\mathrm{P}(\mathrm{I}-1))) / 2$

$\operatorname{Rh}(\mathrm{I}-1)=((\mathrm{Am}(\mathrm{I}-1)) /(\mathrm{Pm}(\mathrm{I}-1)))$

ENDIF

ELSEIF(I.GE.5.AND.I.LE.6)THEN !Sifão Macacos

$\mathrm{A}(\mathrm{I})=-0.3696 *(\mathrm{y}(\mathrm{I}) * * 3)+1.3888 *(\mathrm{y}(\mathrm{I}) * * 2)+0.8088 * \mathrm{y}(\mathrm{I})-0.0081$

$\mathrm{P}(\mathrm{I})=0.9396 *(\mathrm{y}(\mathrm{I}) * * 3)-3.5215 *(\mathrm{y}(\mathrm{I}) * * 2)+5.9914 * \mathrm{y}(\mathrm{I})+0.1002$

$\mathrm{Bi}(\mathrm{I})=-0.8951 *(\mathrm{y}(\mathrm{I}) * * 4)+4.4718 *(\mathrm{y}(\mathrm{I}) * * 3)-8.5128 *(\mathrm{y}(\mathrm{I}) * * 2)+$

$7.3159 * \mathrm{y}(\mathrm{I})+0.0392$

$\operatorname{Bim}(\mathrm{I}-1)=((\operatorname{Bi}(\mathrm{I}))+(\operatorname{Bi}(\mathrm{I}-1))) / 2$

$\operatorname{Am}(\mathrm{I}-1)=((\mathrm{A}(\mathrm{I}))+(\mathrm{A}(\mathrm{I}-1))) / 2$

$\mathrm{Pm}(\mathrm{I}-1)=((\mathrm{P}(\mathrm{I}))+(\mathrm{P}(\mathrm{I}-1))) / 2$

$\mathrm{Rh}(\mathrm{I}-1)=((\mathrm{Am}(\mathrm{I}-1)) /(\mathrm{Pm}(\mathrm{I}-1)))$

ELSEIF(I.GE.7.AND.I.LE.10)THEN

$\mathrm{A}(\mathrm{I})=1.52 * \mathrm{y}(\mathrm{I}) * 2)+4.06 * \mathrm{y}(\mathrm{I})-0.03$

$\mathrm{P}(\mathrm{I})=3.61 * \mathrm{y}(\mathrm{I})+4.0867$

$\mathrm{Bi}(\mathrm{I})=3 * \mathrm{y}(\mathrm{I})+4.1$

$\operatorname{Bim}(\mathrm{I}-1)=((\operatorname{Bi}(\mathrm{I}))+(\mathrm{Bi}(\mathrm{I}-1))) / 2$

$\mathrm{Am}(\mathrm{I}-1)=((\mathrm{A}(\mathrm{I}))+(\mathrm{A}(\mathrm{I}-1))) / 2$

$\mathrm{Pm}(\mathrm{I}-1)=((\mathrm{P}(\mathrm{I}))+(\mathrm{P}(\mathrm{I}-1))) / 2$

$\operatorname{Rh}(\mathrm{I}-1)=((\operatorname{Am}(\mathrm{I}-1)) /(\operatorname{Pm}(\mathrm{I}-1)))$

ELSEIF(I.EQ.11)THEN

$\mathrm{A}(\mathrm{I})=1.7 *(\mathrm{y}(\mathrm{I}) * 2)+3.45 * \mathrm{y}(\mathrm{I})-0.01$

$\mathrm{P}(\mathrm{I})=3.97 * \mathrm{y}(\mathrm{I})+3.4167$

$\mathrm{Bi}(\mathrm{I})=3.42 * \mathrm{y}(\mathrm{I})+3.42$

$\operatorname{Bim}(\mathrm{I}-1)=((\mathrm{Bi}(\mathrm{I}))+(\mathrm{Bi}(\mathrm{I}-1))) / 2$

$\mathrm{Am}(\mathrm{I}-1)=((\mathrm{A}(\mathrm{I}))+(\mathrm{A}(\mathrm{I}-1))) / 2$

$\operatorname{Pm}(\mathrm{I}-1)=((\mathrm{P}(\mathrm{I}))+(\mathrm{P}(\mathrm{I}-1))) / 2$

$\mathrm{Rh}(\mathrm{I}-1)=((\mathrm{Am}(\mathrm{I}-1)) /(\mathrm{Pm}(\mathrm{I}-1)))$

ELSEIF(I.EQ.12)THEN

$\mathrm{A}(\mathrm{I})=1.54 * \mathrm{y}(\mathrm{I}) * * 2)+4.27 * \mathrm{y}(\mathrm{I})+0.17$

$\mathrm{P}(\mathrm{I})=3.72 * \mathrm{y}(\mathrm{I})+4.22$

$\mathrm{Bi}(\mathrm{I})=1.5 *(\mathrm{y}(\mathrm{I}) * * 2)+0.87 * \mathrm{y}(\mathrm{I})+4.97$

$\operatorname{Bim}(\mathrm{I}-1)=((\operatorname{Bi}(\mathrm{I}))+(\operatorname{Bi}(\mathrm{I}-1))) / 2$

$\mathrm{Am}(\mathrm{I}-1)=((\mathrm{A}(\mathrm{I}))+(\mathrm{A}(\mathrm{I}-1))) / 2$

$\mathrm{Pm}(\mathrm{I}-1)=((\mathrm{P}(\mathrm{I}))+(\mathrm{P}(\mathrm{I}-1))) / 2$

$\operatorname{Rh}(\mathrm{I}-1)=((\operatorname{Am}(\mathrm{I}-1)) /(\operatorname{Pm}(\mathrm{I}-1)))$

ELSEIF(I.GE.13.AND.I.LE.14)THEN 
$\mathrm{A}(\mathrm{I})=1.6 * \mathrm{y}(\mathrm{I}) * 2)+3.72 * \mathrm{y}(\mathrm{I})+0.08$

$\mathrm{P}(\mathrm{I})=3.77 * \mathrm{y}(\mathrm{I})+3.7367$

$\mathrm{Bi}(\mathrm{I})=3.2 * \mathrm{y}(\mathrm{I})+3.72$

$\operatorname{Bim}(\mathrm{I}-1)=((\operatorname{Bi}(\mathrm{I}))+(\mathrm{Bi}(\mathrm{I}-1))) / 2$

$\mathrm{Am}(\mathrm{I}-1)=((\mathrm{A}(\mathrm{I}))+(\mathrm{A}(\mathrm{I}-1))) / 2$

$\operatorname{Pm}(\mathrm{I}-1)=((\mathrm{P}(\mathrm{I}))+(\mathrm{P}(\mathrm{I}-1))) / 2$

$\mathrm{Rh}(\mathrm{I}-1)=((\mathrm{Am}(\mathrm{I}-1)) /(\mathrm{Pm}(\mathrm{I}-1)))$

ELSEIF(I.EQ.15)THEN

$\mathrm{A}(\mathrm{I})=1.66 * \mathrm{y}(\mathrm{I}) * * 2)+4.35 * \mathrm{y}(\mathrm{I})+0.05$

$\mathrm{P}(\mathrm{I})=3.91 * \mathrm{y}(\mathrm{I})+4.2967$

$\mathrm{Bi}(\mathrm{I})=3.35^{*} \mathrm{y}(\mathrm{I})+4.3133$

$\operatorname{Bim}(\mathrm{I}-1)=((\operatorname{Bi}(\mathrm{I}))+(\operatorname{Bi}(\mathrm{I}-1))) / 2$

$\mathrm{Am}(\mathrm{I}-1)=((\mathrm{A}(\mathrm{I}))+(\mathrm{A}(\mathrm{I}-1))) / 2$

$\mathrm{Pm}(\mathrm{I}-1)=((\mathrm{P}(\mathrm{I}))+(\mathrm{P}(\mathrm{I}-1))) / 2$

$\mathrm{Rh}(\mathrm{I}-1)=((\operatorname{Am}(\mathrm{I}-1)) /(\mathrm{Pm}(\mathrm{I}-1)))$

ELSEIF(I.EQ.16)THEN

$\mathrm{A}(\mathrm{I})=1.52 *(\mathrm{y}(\mathrm{I}) * * 2)+4.86 * \mathrm{y}(\mathrm{I})-0.04$

$\mathrm{P}(\mathrm{I})=3.62 * \mathrm{y}(\mathrm{I})+4.88$

$\mathrm{Bi}(\mathrm{I})=3.02 * \mathrm{y}(\mathrm{I})+4.88$

$\operatorname{Bim}(\mathrm{I}-1)=((\operatorname{Bi}(\mathrm{I}))+(\mathrm{Bi}(\mathrm{I}-1))) / 2$

$\mathrm{Am}(\mathrm{I}-1)=((\mathrm{A}(\mathrm{I}))+(\mathrm{A}(\mathrm{I}-1))) / 2$

$\mathrm{Pm}(\mathrm{I}-1)=((\mathrm{P}(\mathrm{I}))+(\mathrm{P}(\mathrm{I}-1))) / 2$

$\operatorname{Rh}(\mathrm{I}-1)=((\operatorname{Am}(\mathrm{I}-1)) /(\operatorname{Pm}(\mathrm{I}-1)))$

ELSEIF(I.EQ.17)THEN

$\mathrm{A}(\mathrm{I})=1.52 *(\mathrm{y}(\mathrm{I}) * 2)+5 * \mathrm{y}(\mathrm{I})+0.03$

$\mathrm{P}(\mathrm{I})=3.64 * \mathrm{y}(\mathrm{I})+5$

$\operatorname{Bi}(\mathrm{I})=3.05^{*} \mathrm{y}(\mathrm{I})+4.9867$

$\operatorname{Bim}(\mathrm{I}-1)=((\mathrm{Bi}(\mathrm{I}))+(\mathrm{Bi}(\mathrm{I}-1))) / 2$

$\mathrm{Am}(\mathrm{I}-1)=((\mathrm{A}(\mathrm{I}))+(\mathrm{A}(\mathrm{I}-1))) / 2$

$\operatorname{Pm}(\mathrm{I}-1)=((\mathrm{P}(\mathrm{I}))+(\mathrm{P}(\mathrm{I}-1))) / 2$

$\mathrm{Rh}(\mathrm{I}-1)=((\mathrm{Am}(\mathrm{I}-1)) /(\mathrm{Pm}(\mathrm{I}-1)))$

ELSEIF(I.EQ.18)THEN

$\mathrm{A}(\mathrm{I})=1.54 * \mathrm{y}(\mathrm{I}) * 2)+5.01 * \mathrm{y}(\mathrm{I})+0.08$

$\mathrm{P}(\mathrm{I})=3.67 * \mathrm{y}(\mathrm{I})+5.0267$

$\mathrm{Bi}(\mathrm{I})=3.08 * \mathrm{y}(\mathrm{I})+5.02$

$\operatorname{Bim}(\mathrm{I}-1)=((\mathrm{Bi}(\mathrm{I}))+(\mathrm{Bi}(\mathrm{I}-1))) / 2$

$\operatorname{Am}(\mathrm{I}-1)=((\mathrm{A}(\mathrm{I}))+(\mathrm{A}(\mathrm{I}-1))) / 2$

$\mathrm{Pm}(\mathrm{I}-1)=((\mathrm{P}(\mathrm{I}))+(\mathrm{P}(\mathrm{I}-1))) / 2$

$\mathrm{Rh}(\mathrm{I}-1)=((\operatorname{Am}(\mathrm{I}-1)) /(\mathrm{Pm}(\mathrm{I}-1)))$

ELSEIF(I.EQ.19)THEN

$\mathrm{A}(\mathrm{I})=1.76 *(\mathrm{y}(\mathrm{I}) * 2)+11.06 * \mathrm{y}(\mathrm{I})+0.04$

$\mathrm{P}(\mathrm{I})=4.05 * \mathrm{y}(\mathrm{I})+11.073$

$\mathrm{Bi}(\mathrm{I})=3.52 * \mathrm{y}(\mathrm{I})+11.06$

$\operatorname{Bim}(\mathrm{I}-1)=((\mathrm{Bi}(\mathrm{I}))+(\mathrm{Bi}(\mathrm{I}-1))) / 2$

$\mathrm{Am}(\mathrm{I}-1)=((\mathrm{A}(\mathrm{I}))+(\mathrm{A}(\mathrm{I}-1))) / 2$

$\mathrm{Pm}(\mathrm{I}-1)=((\mathrm{P}(\mathrm{I}))+(\mathrm{P}(\mathrm{I}-1))) / 2$

$\mathrm{Rh}(\mathrm{I}-1)=((\mathrm{Am}(\mathrm{I}-1)) /(\mathrm{Pm}(\mathrm{I}-1)))$

ELSEIF(I.EQ.20)THEN

$\mathrm{A}(\mathrm{I})=1.56 *(\mathrm{y}(\mathrm{I}) * 2)+5.5 * \mathrm{y}(\mathrm{I})+0.17$

$\mathrm{P}(\mathrm{I})=3.71 * \mathrm{y}(\mathrm{I})+5.5167$

$\mathrm{Bi}(\mathrm{I})=3.12 * \mathrm{y}(\mathrm{I})+5.5$

$\operatorname{Bim}(\mathrm{I}-1)=((\mathrm{Bi}(\mathrm{I}))+(\mathrm{Bi}(\mathrm{I}-1))) / 2$

$\mathrm{Am}(\mathrm{I}-1)=((\mathrm{A}(\mathrm{I}))+(\mathrm{A}(\mathrm{I}-1))) / 2$ 
$\mathrm{Pm}(\mathrm{I}-1)=((\mathrm{P}(\mathrm{I}))+(\mathrm{P}(\mathrm{I}-1))) / 2$

$\mathrm{Rh}(\mathrm{I}-1)=((\mathrm{Am}(\mathrm{I}-1)) /(\mathrm{Pm}(\mathrm{I}-1)))$

ELSEIF(I.EQ.21)THEN

$\mathrm{A}(\mathrm{I})=1.5 *(\mathrm{y}(\mathrm{I}) * 2)+9.17 * \mathrm{y}(\mathrm{I})-0.08$

$\mathrm{P}(\mathrm{I})=3.6^{*} \mathrm{y}(\mathrm{I})+9.17$

$\mathrm{Bi}(\mathrm{I})=2.99 * \mathrm{y}(\mathrm{I})+9.1767$

$\operatorname{Bim}(\mathrm{I}-1)=((\operatorname{Bi}(\mathrm{I}))+(\operatorname{Bi}(\mathrm{I}-1))) / 2$

$\mathrm{Am}(\mathrm{I}-1)=((\mathrm{A}(\mathrm{I}))+(\mathrm{A}(\mathrm{I}-1))) / 2$

$\mathrm{Pm}(\mathrm{I}-1)=((\mathrm{P}(\mathrm{I}))+(\mathrm{P}(\mathrm{I}-1))) / 2$

$\operatorname{Rh}(\mathrm{I}-1)=((\operatorname{Am}(\mathrm{I}-1)) /(\mathrm{Pm}(\mathrm{I}-1)))$

ELSEIF(I.EQ.22)THEN

$\mathrm{A}(\mathrm{I})=1.7 *(\mathrm{y}(\mathrm{I}) * * 2)+4.55 * \mathrm{y}(\mathrm{I})-0.02$

$\mathrm{P}(\mathrm{I})=3.94 * \mathrm{y}(\mathrm{I})+4.55$

$\mathrm{Bi}(\mathrm{I})=3.4 * \mathrm{y}(\mathrm{I})+4.55$

$\operatorname{Bim}(\mathrm{I}-1)=((\operatorname{Bi}(\mathrm{I}))+(\operatorname{Bi}(\mathrm{I}-1))) / 2$

$\mathrm{Am}(\mathrm{I}-1)=((\mathrm{A}(\mathrm{I}))+(\mathrm{A}(\mathrm{I}-1))) / 2$

$\mathrm{Pm}(\mathrm{I}-1)=((\mathrm{P}(\mathrm{I}))+(\mathrm{P}(\mathrm{I}-1))) / 2$

$\mathrm{Rh}(\mathrm{I}-1)=((\mathrm{Am}(\mathrm{I}-1)) /(\mathrm{Pm}(\mathrm{I}-1)))$

ELSEIF(I.EQ.23)THEN

$\mathrm{A}(\mathrm{I})=1.6 * \mathrm{y}(\mathrm{I}) * * 2)+5.3 * \mathrm{y}(\mathrm{I})+0.19$

$\mathrm{P}(\mathrm{I})=3.74 * \mathrm{y}(\mathrm{I})+5.4167$

$\mathrm{Bi}(\mathrm{I})=3.16 * \mathrm{y}(\mathrm{I})+5.3533$

$\operatorname{Bim}(\mathrm{I}-1)=((\operatorname{Bi}(\mathrm{I}))+(\operatorname{Bi}(\mathrm{I}-1))) / 2$

$\mathrm{Am}(\mathrm{I}-1)=((\mathrm{A}(\mathrm{I}))+(\mathrm{A}(\mathrm{I}-1))) / 2$

$\mathrm{Pm}(\mathrm{I}-1)=((\mathrm{P}(\mathrm{I}))+(\mathrm{P}(\mathrm{I}-1))) / 2$

$\mathrm{Rh}(\mathrm{I}-1)=((\operatorname{Am}(\mathrm{I}-1)) /(\operatorname{Pm}(\mathrm{I}-1)))$

ELSEIF(I.EQ.24)THEN

$\mathrm{A}(\mathrm{I})=1.52 *(\mathrm{y}(\mathrm{I}) * 2)+5.02 * \mathrm{y}(\mathrm{I})-0.04$

$\mathrm{P}(\mathrm{I})=3.65^{*} \mathrm{y}(\mathrm{I})+4.9833$

$\mathrm{Bi}(\mathrm{I})=3.05 * \mathrm{y}(\mathrm{I})+5.0167$

$\operatorname{Bim}(\mathrm{I}-1)=((\operatorname{Bi}(\mathrm{I}))+(\mathrm{Bi}(\mathrm{I}-1))) / 2$

$\mathrm{Am}(\mathrm{I}-1)=((\mathrm{A}(\mathrm{I}))+(\mathrm{A}(\mathrm{I}-1))) / 2$

$\mathrm{Pm}(\mathrm{I}-1)=((\mathrm{P}(\mathrm{I}))+(\mathrm{P}(\mathrm{I}-1))) / 2$

$\mathrm{Rh}(\mathrm{I}-1)=((\mathrm{Am}(\mathrm{I}-1)) /(\mathrm{Pm}(\mathrm{I}-1)))$

ELSEIF(I.GE.25.AND.I.LE.26)THEN

$\mathrm{A}(\mathrm{I})=1.62 *(\mathrm{y}(\mathrm{I}) * 2)+4.27 * \mathrm{y}(\mathrm{I})-0.08$

$\mathrm{P}(\mathrm{I})=3.79 * \mathrm{y}(\mathrm{I})+4.2733$

$\mathrm{Bi}(\mathrm{I})=3.22 * \mathrm{y}(\mathrm{I})+4.29$

$\operatorname{Bim}(\mathrm{I}-1)=((\operatorname{Bi}(\mathrm{I}))+(\operatorname{Bi}(\mathrm{I}-1))) / 2$

$\mathrm{Am}(\mathrm{I}-1)=((\mathrm{A}(\mathrm{I}))+(\mathrm{A}(\mathrm{I}-1))) / 2$

$\operatorname{Pm}(\mathrm{I}-1)=((\mathrm{P}(\mathrm{I}))+(\mathrm{P}(\mathrm{I}-1))) / 2$

$\operatorname{Rh}(\mathrm{I}-1)=((\operatorname{Am}(\mathrm{I}-1)) /(\operatorname{Pm}(\mathrm{I}-1)))$

ELSEIF(I.GE.27.AND.I.LE.31)THEN !Sifão Umburanas

$\mathrm{A}(\mathrm{I})=-0.0924 *(\mathrm{y}(\mathrm{I}) * * 3)+0.6944 *(\mathrm{y}(\mathrm{I}) * * 2)+0.8088 * \mathrm{y}(\mathrm{I})-0.0162$

$\mathrm{P}(\mathrm{I})=0.2349 *(\mathrm{y}(\mathrm{I}) * * 3)-1.7607 *(\mathrm{y}(\mathrm{I}) * * 2)+5.9914 * \mathrm{y}(\mathrm{I})+0.2004$

$\mathrm{Bi}(\mathrm{I})=-0.1124 *(\mathrm{y}(\mathrm{I}) * * 4)+1.1245 *(\mathrm{y}(\mathrm{I}) * * 3)-4.2823 *(\mathrm{y}(\mathrm{I}) * * 2)+$

$7.3555 * \mathrm{y}(\mathrm{I})+0.0601$

$\operatorname{Bim}(\mathrm{I}-1)=((\operatorname{Bi}(\mathrm{I}))+(\operatorname{Bi}(\mathrm{I}-1))) / 2$

$\operatorname{Am}(\mathrm{I}-1)=((\mathrm{A}(\mathrm{I}))+(\mathrm{A}(\mathrm{I}-1))) / 2$

$\mathrm{Pm}(\mathrm{I}-1)=((\mathrm{P}(\mathrm{I}))+(\mathrm{P}(\mathrm{I}-1))) / 2$

$\mathrm{Rh}(\mathrm{I}-1)=((\mathrm{Am}(\mathrm{I}-1)) /(\mathrm{Pm}(\mathrm{I}-1)))$

ELSEIF(I.EQ.32)THEN

$\mathrm{A}(\mathrm{I})=1.9 *(\mathrm{y}(\mathrm{I}) * 2)+15.09 * \mathrm{y}(\mathrm{I})-0.01$ 
$\mathrm{P}(\mathrm{I})=4.2 * \mathrm{y}(\mathrm{I})+15.147$

$\operatorname{Bi}(\mathrm{I})=3.69 * \mathrm{y}(\mathrm{I})+15.167$

$\operatorname{Bim}(\mathrm{I}-1)=((\operatorname{Bi}(\mathrm{I}))+(\mathrm{Bi}(\mathrm{I}-1))) / 2$

$\operatorname{Am}(\mathrm{I}-1)=((\mathrm{A}(\mathrm{I}))+(\mathrm{A}(\mathrm{I}-1))) / 2$

$\operatorname{Pm}(\mathrm{I}-1)=((\mathrm{P}(\mathrm{I}))+(\mathrm{P}(\mathrm{I}-1))) / 2$

$\operatorname{Rh}(\mathrm{I}-1)=((\mathrm{Am}(\mathrm{I}-1)) /(\mathrm{Pm}(\mathrm{I}-1)))$

ELSEIF(I.EQ.33)THEN

$\mathrm{A}(\mathrm{I})=1.52 *(\mathrm{y}(\mathrm{I}) * * 2)+4.92 * \mathrm{y}(\mathrm{I})+0.04$

$\mathrm{P}(\mathrm{I})=3.64 * \mathrm{y}(\mathrm{I})+4.91$

$\mathrm{Bi}(\mathrm{I})=3.05 * \mathrm{y}(\mathrm{I})+4.9067$

$\operatorname{Bim}(\mathrm{I}-1)=((\operatorname{Bi}(\mathrm{I}))+(\operatorname{Bi}(\mathrm{I}-1))) / 2$

$\mathrm{Am}(\mathrm{I}-1)=((\mathrm{A}(\mathrm{I}))+(\mathrm{A}(\mathrm{I}-1))) / 2$

$\mathrm{Pm}(\mathrm{I}-1)=((\mathrm{P}(\mathrm{I}))+(\mathrm{P}(\mathrm{I}-1))) / 2$

$\mathrm{Rh}(\mathrm{I}-1)=((\operatorname{Am}(\mathrm{I}-1)) /(\mathrm{Pm}(\mathrm{I}-1)))$

ELSEIF(I.GE.34.AND.I.LE.35)THEN

$\mathrm{A}(\mathrm{I})=1.4 *(\mathrm{y}(\mathrm{I}) * 2)+5.54 * \mathrm{y}(\mathrm{I})-0.03$

$\mathrm{P}(\mathrm{I})=3.52 * \mathrm{y}(\mathrm{I})+5.4133$

$\mathrm{Bi}(\mathrm{I})=2.89 * \mathrm{y}(\mathrm{I})+5.43$

$\operatorname{Bim}(\mathrm{I}-1)=((\operatorname{Bi}(\mathrm{I}))+(\mathrm{Bi}(\mathrm{I}-1))) / 2$

$\mathrm{Am}(\mathrm{I}-1)=((\mathrm{A}(\mathrm{I}))+(\mathrm{A}(\mathrm{I}-1))) / 2$

$\mathrm{Pm}(\mathrm{I}-1)=((\mathrm{P}(\mathrm{I}))+(\mathrm{P}(\mathrm{I}-1))) / 2$

$\mathrm{Rh}(\mathrm{I}-1)=((\operatorname{Am}(\mathrm{I}-1)) /(\mathrm{Pm}(\mathrm{I}-1)))$

ELSEIF(I.GE.36.AND.I.LE.37)THEN

$\mathrm{A}(\mathrm{I})=1.42 *(\mathrm{y}(\mathrm{I}) * * 2)+6.15 * \mathrm{y}(\mathrm{I})+0.01$

$\mathrm{P}(\mathrm{I})=3.53 * \mathrm{y}(\mathrm{I})+6.0133$

$\mathrm{Bi}(\mathrm{I})=2.9 * \mathrm{y}(\mathrm{I})+6.09$

$\operatorname{Bim}(\mathrm{I}-1)=((\mathrm{Bi}(\mathrm{I}))+(\mathrm{Bi}(\mathrm{I}-1))) / 2$

$\mathrm{Am}(\mathrm{I}-1)=((\mathrm{A}(\mathrm{I}))+(\mathrm{A}(\mathrm{I}-1))) / 2$

$\mathrm{Pm}(\mathrm{I}-1)=((\mathrm{P}(\mathrm{I}))+(\mathrm{P}(\mathrm{I}-1))) / 2$

$\operatorname{Rh}(\mathrm{I}-1)=((\operatorname{Am}(\mathrm{I}-1)) /(\operatorname{Pm}(\mathrm{I}-1)))$

ELSEIF(I.GE.38.AND.I.LE.39)THEN

$\mathrm{A}(\mathrm{I})=1.46 *(\mathrm{y}(\mathrm{I}) * * 2)+4.91 * \mathrm{y}(\mathrm{I})+0.22$

$\mathrm{P}(\mathrm{I})=3.56 * \mathrm{y}(\mathrm{I})+4.8633$

$\mathrm{Bi}(\mathrm{I})=2.92 * \mathrm{y}(\mathrm{I})+4.9067$

$\operatorname{Bim}(\mathrm{I}-1)=((\mathrm{Bi}(\mathrm{I}))+(\mathrm{Bi}(\mathrm{I}-1))) / 2$

$\mathrm{Am}(\mathrm{I}-1)=((\mathrm{A}(\mathrm{I}))+(\mathrm{A}(\mathrm{I}-1))) / 2$

$\mathrm{Pm}(\mathrm{I}-1)=((\mathrm{P}(\mathrm{I}))+(\mathrm{P}(\mathrm{I}-1))) / 2$

$\operatorname{Rh}(\mathrm{I}-1)=((\operatorname{Am}(\mathrm{I}-1)) /(\operatorname{Pm}(\mathrm{I}-1)))$

ELSEIF(I.GE.40.AND.I.LE.42)THEN

$\mathrm{A}(\mathrm{I})=1.66 *(\mathrm{y}(\mathrm{I}) * * 2)+6.41 * \mathrm{y}(\mathrm{I})+0.06$

$\mathrm{P}(\mathrm{I})=3.92 * \mathrm{y}(\mathrm{I})+6.34$

$\mathrm{Bi}(\mathrm{I})=3.36 * \mathrm{y}(\mathrm{I})+6.38$

$\operatorname{Bim}(\mathrm{I}-1)=((\mathrm{Bi}(\mathrm{I}))+(\mathrm{Bi}(\mathrm{I}-1))) / 2$

$\mathrm{Am}(\mathrm{I}-1)=((\mathrm{A}(\mathrm{I}))+(\mathrm{A}(\mathrm{I}-1))) / 2$

$\operatorname{Pm}(\mathrm{I}-1)=((\mathrm{P}(\mathrm{I}))+(\mathrm{P}(\mathrm{I}-1))) / 2$

$\mathrm{Rh}(\mathrm{I}-1)=((\mathrm{Am}(\mathrm{I}-1)) /(\mathrm{Pm}(\mathrm{I}-1)))$

ELSEIF(I.GE.43.AND.I.LE.45)THEN

$\mathrm{A}(\mathrm{I})=1.62 * \mathrm{y}(\mathrm{I}) * * 2)+4.71 * \mathrm{y}(\mathrm{I})+0.12$

$\mathrm{P}(\mathrm{I})=3.79 * \mathrm{y}(\mathrm{I})+4.7367$

$\mathrm{Bi}(\mathrm{I})=3.22 * \mathrm{y}(\mathrm{I})+4.73$

$\operatorname{Bim}(\mathrm{I}-1)=((\operatorname{Bi}(\mathrm{I}))+(\mathrm{Bi}(\mathrm{I}-1))) / 2$

$\operatorname{Am}(\mathrm{I}-1)=((\mathrm{A}(\mathrm{I}))+(\mathrm{A}(\mathrm{I}-1))) / 2$

$\mathrm{Pm}(\mathrm{I}-1)=((\mathrm{P}(\mathrm{I}))+(\mathrm{P}(\mathrm{I}-1))) / 2$ 
$\mathrm{Rh}(\mathrm{I}-1)=((\mathrm{Am}(\mathrm{I}-1)) /(\operatorname{Pm}(\mathrm{I}-1)))$

ELSEIF(I.GE.46.AND.I.LE.47)THEN

$\mathrm{A}(\mathrm{I})=1.5 *(\mathrm{y}(\mathrm{I}) * 2)+4.45^{*} \mathrm{y}(\mathrm{I})+0.03$

$\mathrm{P}(\mathrm{I})=3.6^{*} \mathrm{y}(\mathrm{I})+4.45$

$\mathrm{Bi}(\mathrm{I})=2.99 * \mathrm{y}(\mathrm{I})+4.4533$

$\operatorname{Bim}(\mathrm{I}-1)=((\operatorname{Bi}(\mathrm{I}))+(\operatorname{Bi}(\mathrm{I}-1))) / 2$

$\mathrm{Am}(\mathrm{I}-1)=((\mathrm{A}(\mathrm{I}))+(\mathrm{A}(\mathrm{I}-1))) / 2$

$\mathrm{Pm}(\mathrm{I}-1)=((\mathrm{P}(\mathrm{I}))+(\mathrm{P}(\mathrm{I}-1))) / 2$

$\mathrm{Rh}(\mathrm{I}-1)=((\mathrm{Am}(\mathrm{I}-1)) /(\mathrm{Pm}(\mathrm{I}-1)))$

ELSEIF(I.EQ.48)THEN

$\mathrm{A}(\mathrm{I})=1.6 *(\mathrm{y}(\mathrm{I}) * * 2)+4.22 * \mathrm{y}(\mathrm{I})+0.2$

$\mathrm{P}(\mathrm{I})=3.77 * \mathrm{y}(\mathrm{I})+4.2233$

$\mathrm{Bi}(\mathrm{I})=3.19 * \mathrm{y}(\mathrm{I})+4.2267$

$\operatorname{Bim}(\mathrm{I}-1)=((\operatorname{Bi}(\mathrm{I}))+(\operatorname{Bi}(\mathrm{I}-1))) / 2$

$\mathrm{Am}(\mathrm{I}-1)=((\mathrm{A}(\mathrm{I}))+(\mathrm{A}(\mathrm{I}-1))) / 2$

$\mathrm{Pm}(\mathrm{I}-1)=((\mathrm{P}(\mathrm{I}))+(\mathrm{P}(\mathrm{I}-1))) / 2$

$\mathrm{Rh}(\mathrm{I}-1)=((\mathrm{Am}(\mathrm{I}-1)) /(\mathrm{Pm}(\mathrm{I}-1)))$

ELSEIF(I.EQ.49)THEN

$\mathrm{A}(\mathrm{I})=1.58 *(\mathrm{y}(\mathrm{I}) * 2)+3.95 * \mathrm{y}(\mathrm{I})-0.08$

$\mathrm{P}(\mathrm{I})=3.71 * \mathrm{y}(\mathrm{I})+3.9567$

$\mathrm{Bi}(\mathrm{I})=3.13 * \mathrm{y}(\mathrm{I})+3.9733$

$\operatorname{Bim}(\mathrm{I}-1)=((\operatorname{Bi}(\mathrm{I}))+(\operatorname{Bi}(\mathrm{I}-1))) / 2$

$\operatorname{Am}(\mathrm{I}-1)=((\mathrm{A}(\mathrm{I}))+(\mathrm{A}(\mathrm{I}-1))) / 2$

$\mathrm{Pm}(\mathrm{I}-1)=((\mathrm{P}(\mathrm{I}))+(\mathrm{P}(\mathrm{I}-1))) / 2$

$\mathrm{Rh}(\mathrm{I}-1)=((\mathrm{Am}(\mathrm{I}-1)) /(\mathrm{Pm}(\mathrm{I}-1)))$

ELSEIF(I.EQ.50)THEN

$\mathrm{A}(\mathrm{I})=1.44 * \mathrm{y}(\mathrm{I}) * 2)+5.68 * \mathrm{y}(\mathrm{I})-0.02$

$\mathrm{P}(\mathrm{I})=3.46 * \mathrm{y}(\mathrm{I})+5.72$

$\mathrm{Bi}(\mathrm{I})=2.82 * \mathrm{y}(\mathrm{I})+5.74$

$\operatorname{Bim}(\mathrm{I}-1)=((\operatorname{Bi}(\mathrm{I}))+(\operatorname{Bi}(\mathrm{I}-1))) / 2$

$\mathrm{Am}(\mathrm{I}-1)=((\mathrm{A}(\mathrm{I}))+(\mathrm{A}(\mathrm{I}-1))) / 2$

$\mathrm{Pm}(\mathrm{I}-1)=((\mathrm{P}(\mathrm{I}))+(\mathrm{P}(\mathrm{I}-1))) / 2$

$\mathrm{Rh}(\mathrm{I}-1)=((\mathrm{Am}(\mathrm{I}-1)) /(\mathrm{Pm}(\mathrm{I}-1)))$

ELSEIF(I.EQ.51)THEN

$\mathrm{A}(\mathrm{I})=1.46 *(\mathrm{y}(\mathrm{I}) * 2)+4.37 * \mathrm{y}(\mathrm{I})-0.08$

$\mathrm{P}(\mathrm{I})=3.54 * \mathrm{y}(\mathrm{I})+4.33$

$\mathrm{Bi}(\mathrm{I})=2.92 * \mathrm{y}(\mathrm{I})+4.37$

$\operatorname{Bim}(\mathrm{I}-1)=((\operatorname{Bi}(\mathrm{I}))+(\operatorname{Bi}(\mathrm{I}-1))) / 2$

$\mathrm{Am}(\mathrm{I}-1)=((\mathrm{A}(\mathrm{I}))+(\mathrm{A}(\mathrm{I}-1))) / 2$

$\mathrm{Pm}(\mathrm{I}-1)=((\mathrm{P}(\mathrm{I}))+(\mathrm{P}(\mathrm{I}-1))) / 2$

$\mathrm{Rh}(\mathrm{I}-1)=((\mathrm{Am}(\mathrm{I}-1)) /(\mathrm{Pm}(\mathrm{I}-1)))$

ELSEIF(I.EQ.52)THEN

$\mathrm{A}(\mathrm{I})=1.34 *(\mathrm{y}(\mathrm{I}) * * 2)+4.77 * \mathrm{y}(\mathrm{I})+0.1$

$\mathrm{P}(\mathrm{I})=3.31 * \mathrm{y}(\mathrm{I})+4.8367$

$\mathrm{Bi}(\mathrm{I})=2.63 * \mathrm{y}(\mathrm{I})+4.8233$

$\operatorname{Bim}(\mathrm{I}-1)=((\operatorname{Bi}(\mathrm{I}))+(\operatorname{Bi}(\mathrm{I}-1))) / 2$

$\mathrm{Am}(\mathrm{I}-1)=((\mathrm{A}(\mathrm{I}))+(\mathrm{A}(\mathrm{I}-1))) / 2$

$\mathrm{Pm}(\mathrm{I}-1)=((\mathrm{P}(\mathrm{I}))+(\mathrm{P}(\mathrm{I}-1))) / 2$

$\mathrm{Rh}(\mathrm{I}-1)=((\mathrm{Am}(\mathrm{I}-1)) /(\mathrm{Pm}(\mathrm{I}-1)))$

ELSEIF(I.EQ.53)THEN

$\mathrm{A}(\mathrm{I})=1.3 *(\mathrm{y}(\mathrm{I}) * * 2)+5.21 * \mathrm{y}(\mathrm{I})+0.09$

$\mathrm{P}(\mathrm{I})=3.28 * \mathrm{y}(\mathrm{I})+5.20$

$\operatorname{Bi}(\mathrm{I})=2.6^{*} \mathrm{y}(\mathrm{I})+5.21$ 


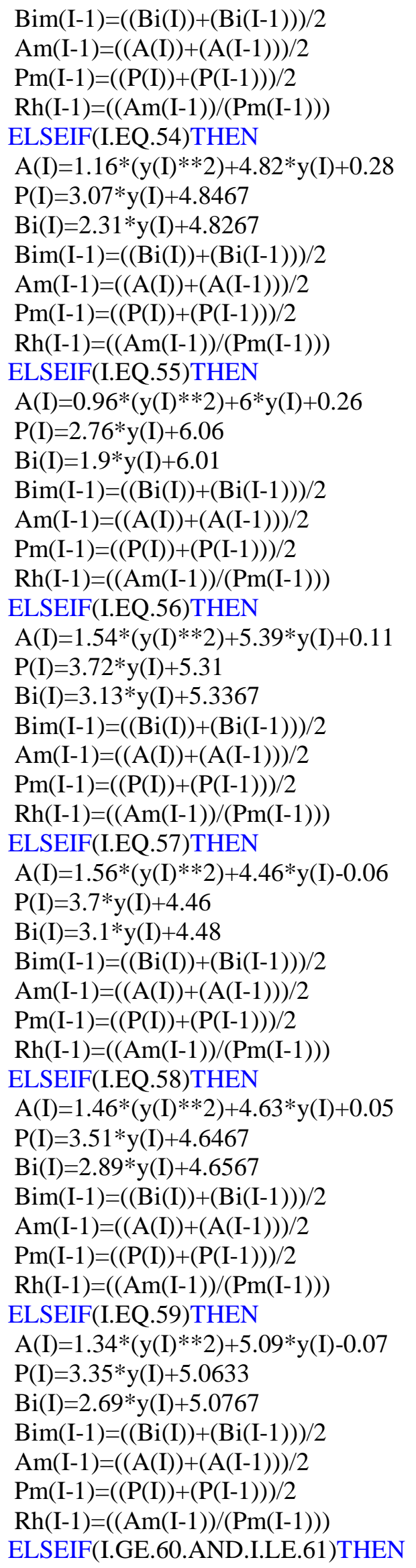


$\mathrm{A}(\mathrm{I})=1.38 *(\mathrm{y}(\mathrm{I}) * * 2)+4.69 * \mathrm{y}(\mathrm{I})+0.03$

$\mathrm{P}(\mathrm{I})=3.39 * \mathrm{y}(\mathrm{I})+4.7167$

$\operatorname{Bi}(\mathrm{I})=2.74 * \mathrm{y}(\mathrm{I})+4.72$

$\operatorname{Bim}(\mathrm{I}-1)=((\operatorname{Bi}(\mathrm{I}))+(\mathrm{Bi}(\mathrm{I}-1))) / 2$

$\mathrm{Am}(\mathrm{I}-1)=((\mathrm{A}(\mathrm{I}))+(\mathrm{A}(\mathrm{I}-1))) / 2$

$\operatorname{Pm}(\mathrm{I}-1)=((\mathrm{P}(\mathrm{I}))+(\mathrm{P}(\mathrm{I}-1))) / 2$

$\mathrm{Rh}(\mathrm{I}-1)=((\mathrm{Am}(\mathrm{I}-1)) /(\mathrm{Pm}(\mathrm{I}-1)))$

ELSEIF(I.EQ.62)THEN

$\mathrm{A}(\mathrm{I})=1.52 *(\mathrm{y}(\mathrm{I}) * 2)+4.7 * \mathrm{y}(\mathrm{I})+0.03$

$\mathrm{P}(\mathrm{I})=3.68 * \mathrm{y}(\mathrm{I})+4.66$

$\mathrm{Bi}(\mathrm{I})=3.09 * \mathrm{y}(\mathrm{I})+4.6533$

$\operatorname{Bim}(\mathrm{I}-1)=((\operatorname{Bi}(\mathrm{I}))+(\operatorname{Bi}(\mathrm{I}-1))) / 2$

$\mathrm{Am}(\mathrm{I}-1)=((\mathrm{A}(\mathrm{I}))+(\mathrm{A}(\mathrm{I}-1))) / 2$

$\operatorname{Pm}(\mathrm{I}-1)=((\mathrm{P}(\mathrm{I}))+(\mathrm{P}(\mathrm{I}-1))) / 2$

$\mathrm{Rh}(\mathrm{I}-1)=((\mathrm{Am}(\mathrm{I}-1)) /(\mathrm{Pm}(\mathrm{I}-1)))$

ELSEIF(I.EQ.63)THEN

$\mathrm{A}(\mathrm{I})=1.58 *(\mathrm{y}(\mathrm{I}) * * 2)+4.79 * \mathrm{y}(\mathrm{I})+0.11$

$\mathrm{P}(\mathrm{I})=3.69 * \mathrm{y}(\mathrm{I})+4.82$

$\mathrm{Bi}(\mathrm{I})=3.11 * \mathrm{y}(\mathrm{I})+4.8333$

$\operatorname{Bim}(\mathrm{I}-1)=((\operatorname{Bi}(\mathrm{I}))+(\operatorname{Bi}(\mathrm{I}-1))) / 2$

$\mathrm{Am}(\mathrm{I}-1)=((\mathrm{A}(\mathrm{I}))+(\mathrm{A}(\mathrm{I}-1))) / 2$

$\mathrm{Pm}(\mathrm{I}-1)=((\mathrm{P}(\mathrm{I}))+(\mathrm{P}(\mathrm{I}-1))) / 2$

$\mathrm{Rh}(\mathrm{I}-1)=((\mathrm{Am}(\mathrm{I}-1)) /(\mathrm{Pm}(\mathrm{I}-1)))$

ELSEIF(I.EQ.64)THEN

$\mathrm{A}(\mathrm{I})=1.52 *(\mathrm{y}(\mathrm{I}) * 2)+4.42 * \mathrm{y}(\mathrm{I})+0.05$

$\mathrm{P}(\mathrm{I})=3.64 * \mathrm{y}(\mathrm{I})+4.42$

$\mathrm{Bi}(\mathrm{I})=3.03 * \mathrm{y}(\mathrm{I})+4.4333$

$\operatorname{Bim}(\mathrm{I}-1)=((\operatorname{Bi}(\mathrm{I}))+(\mathrm{Bi}(\mathrm{I}-1))) / 2$

$\mathrm{Am}(\mathrm{I}-1)=((\mathrm{A}(\mathrm{I}))+(\mathrm{A}(\mathrm{I}-1))) / 2$

$\mathrm{Pm}(\mathrm{I}-1)=((\mathrm{P}(\mathrm{I}))+(\mathrm{P}(\mathrm{I}-1))) / 2$

$\mathrm{Rh}(\mathrm{I}-1)=((\mathrm{Am}(\mathrm{I}-1)) /(\mathrm{Pm}(\mathrm{I}-1)))$

ELSEIF(I.EQ.65)THEN

$\mathrm{A}(\mathrm{I})=1.64 *(\mathrm{y}(\mathrm{I}) * 2)+4.36 * \mathrm{y}(\mathrm{I})-0.06$

$\mathrm{P}(\mathrm{I})=3.83 * \mathrm{y}(\mathrm{I})+4.35$

$\mathrm{Bi}(\mathrm{I})=3.26 * \mathrm{y}(\mathrm{I})+4.3767$

$\operatorname{Bim}(\mathrm{I}-1)=((\operatorname{Bi}(\mathrm{I}))+(\operatorname{Bi}(\mathrm{I}-1))) / 2$

$\mathrm{Am}(\mathrm{I}-1)=((\mathrm{A}(\mathrm{I}))+(\mathrm{A}(\mathrm{I}-1))) / 2$

$\mathrm{Pm}(\mathrm{I}-1)=((\mathrm{P}(\mathrm{I}))+(\mathrm{P}(\mathrm{I}-1))) / 2$

$\mathrm{Rh}(\mathrm{I}-1)=((\mathrm{Am}(\mathrm{I}-1)) /(\operatorname{Pm}(\mathrm{I}-1)))$

ELSEIF(I.EQ.66)THEN

$\mathrm{A}(\mathrm{I})=1.6 * \mathrm{y}(\mathrm{I}) * * 2)+4.48 * \mathrm{y}(\mathrm{I})+0.08$

$\mathrm{P}(\mathrm{I})=3.77 * \mathrm{y}(\mathrm{I})+4.4733$

$\mathrm{Bi}(\mathrm{I})=3.19 * \mathrm{y}(\mathrm{I})+4.4833$

$\operatorname{Bim}(\mathrm{I}-1)=((\operatorname{Bi}(\mathrm{I}))+(\mathrm{Bi}(\mathrm{I}-1))) / 2$

$\mathrm{Am}(\mathrm{I}-1)=((\mathrm{A}(\mathrm{I}))+(\mathrm{A}(\mathrm{I}-1))) / 2$

$\mathrm{Pm}(\mathrm{I}-1)=((\mathrm{P}(\mathrm{I}))+(\mathrm{P}(\mathrm{I}-1))) / 2$

$\mathrm{Rh}(\mathrm{I}-1)=((\mathrm{Am}(\mathrm{I}-1)) /(\mathrm{Pm}(\mathrm{I}-1)))$

ELSEIF(I.EQ.67)THEN

$\mathrm{A}(\mathrm{I})=1.7 *(\mathrm{y}(\mathrm{I}) * 2)+4.31 * \mathrm{y}(\mathrm{I})+0.12$

$\mathrm{P}(\mathrm{I})=3.91 * \mathrm{y}(\mathrm{I})+4.34$

$\mathrm{Bi}(\mathrm{I})=3.35 * \mathrm{y}(\mathrm{I})+4.35$

$\operatorname{Bim}(\mathrm{I}-1)=((\operatorname{Bi}(\mathrm{I}))+(\operatorname{Bi}(\mathrm{I}-1))) / 2$

$\mathrm{Am}(\mathrm{I}-1)=((\mathrm{A}(\mathrm{I}))+(\mathrm{A}(\mathrm{I}-1))) / 2$ 
$\mathrm{Pm}(\mathrm{I}-1)=((\mathrm{P}(\mathrm{I}))+(\mathrm{P}(\mathrm{I}-1))) / 2$

$\mathrm{Rh}(\mathrm{I}-1)=((\mathrm{Am}(\mathrm{I}-1)) /(\mathrm{Pm}(\mathrm{I}-1)))$

ELSEIF(I.EQ.68)THEN

$\mathrm{A}(\mathrm{I})=1.58 *(\mathrm{y}(\mathrm{I}) * * 2)+4.79 * \mathrm{y}(\mathrm{I})-0.01$

$\mathrm{P}(\mathrm{I})=3.75^{*} \mathrm{y}(\mathrm{I})+4.7567$

$\mathrm{Bi}(\mathrm{I})=3.17 * \mathrm{y}(\mathrm{I})+4.77$

$\operatorname{Bim}(\mathrm{I}-1)=((\operatorname{Bi}(\mathrm{I}))+(\operatorname{Bi}(\mathrm{I}-1))) / 2$

$\mathrm{Am}(\mathrm{I}-1)=((\mathrm{A}(\mathrm{I}))+(\mathrm{A}(\mathrm{I}-1))) / 2$

$\mathrm{Pm}(\mathrm{I}-1)=((\mathrm{P}(\mathrm{I}))+(\mathrm{P}(\mathrm{I}-1))) / 2$

$\operatorname{Rh}(\mathrm{I}-1)=((\operatorname{Am}(\mathrm{I}-1)) /(\mathrm{Pm}(\mathrm{I}-1)))$

ELSEIF(I.EQ.69)THEN

$\mathrm{A}(\mathrm{I})=1.7 *(\mathrm{y}(\mathrm{I}) * * 2)+6.75 * \mathrm{y}(\mathrm{I})+0.03$

$\mathrm{P}(\mathrm{I})=3.93 * \mathrm{y}(\mathrm{I})+6.7133$

$\mathrm{Bi}(\mathrm{I})=3.38 * \mathrm{y}(\mathrm{I})+6.7433$

$\operatorname{Bim}(\mathrm{I}-1)=((\mathrm{Bi}(\mathrm{I}))+(\mathrm{Bi}(\mathrm{I}-1))) / 2$

$\mathrm{Am}(\mathrm{I}-1)=((\mathrm{A}(\mathrm{I}))+(\mathrm{A}(\mathrm{I}-1))) / 2$

$\mathrm{Pm}(\mathrm{I}-1)=((\mathrm{P}(\mathrm{I}))+(\mathrm{P}(\mathrm{I}-1))) / 2$

$\mathrm{Rh}(\mathrm{I}-1)=((\mathrm{Am}(\mathrm{I}-1)) /(\mathrm{Pm}(\mathrm{I}-1)))$

ELSEIF(I.EQ.70)THEN

$\mathrm{A}(\mathrm{I})=1.56 *(\mathrm{y}(\mathrm{I}) * 2)+4.94 * \mathrm{y}(\mathrm{I})+0.03$

$\mathrm{P}(\mathrm{I})=3.72 * \mathrm{y}(\mathrm{I})+4.8933$

$\mathrm{Bi}(\mathrm{I})=3.13 * \mathrm{y}(\mathrm{I})+4.9133$

$\operatorname{Bim}(\mathrm{I}-1)=((\operatorname{Bi}(\mathrm{I}))+(\operatorname{Bi}(\mathrm{I}-1))) / 2$

$\mathrm{Am}(\mathrm{I}-1)=((\mathrm{A}(\mathrm{I}))+(\mathrm{A}(\mathrm{I}-1))) / 2$

$\operatorname{Pm}(\mathrm{I}-1)=((\mathrm{P}(\mathrm{I}))+(\mathrm{P}(\mathrm{I}-1))) / 2$

$\mathrm{Rh}(\mathrm{I}-1)=((\mathrm{Am}(\mathrm{I}-1)) /(\operatorname{Pm}(\mathrm{I}-1)))$

ELSEIF(I.GE.71.AND.I.LE.74)THEN !Sifão Pirangí

$\mathrm{A}(\mathrm{I})=-0.3696 *(\mathrm{y}(\mathrm{I}) * * 3)+1.3888 *(\mathrm{y}(\mathrm{I}) * * 2)+0.8088 * \mathrm{y}(\mathrm{I})-0.0081$

$\mathrm{P}(\mathrm{I})=0.9396 *(\mathrm{y}(\mathrm{I}) * * 3)-3.5215 *(\mathrm{y}(\mathrm{I}) * * 2)+5.9914 * \mathrm{y}(\mathrm{I})+0.1002$

$\mathrm{Bi}(\mathrm{I})=-0.8951 *(\mathrm{y}(\mathrm{I}) * * 4)+4.4718 *(\mathrm{y}(\mathrm{I}) * * 3)-8.5128 *(\mathrm{y}(\mathrm{I}) * * 2)+$

$7.3159 * \mathrm{y}(\mathrm{I})+0.0392$

$\operatorname{Bim}(\mathrm{I}-1)=((\operatorname{Bi}(\mathrm{I}))+(\operatorname{Bi}(\mathrm{I}-1))) / 2$

$\mathrm{Am}(\mathrm{I}-1)=((\mathrm{A}(\mathrm{I}))+(\mathrm{A}(\mathrm{I}-1))) / 2$

$\mathrm{Pm}(\mathrm{I}-1)=((\mathrm{P}(\mathrm{I}))+(\mathrm{P}(\mathrm{I}-1))) / 2$

$\mathrm{Rh}(\mathrm{I}-1)=((\mathrm{Am}(\mathrm{I}-1)) /(\mathrm{Pm}(\mathrm{I}-1)))$

ELSEIF(I.EQ.75)THEN

$\mathrm{A}(\mathrm{I})=1.44 *(\mathrm{y}(\mathrm{I}) * 2)+4.94 * \mathrm{y}(\mathrm{I})+0.15$

$\mathrm{P}(\mathrm{I})=3.49 * \mathrm{y}(\mathrm{I})+4.9567$

$\mathrm{Bi}(\mathrm{I})=2.86 * \mathrm{y}(\mathrm{I})+4.96$

$\operatorname{Bim}(\mathrm{I}-1)=((\operatorname{Bi}(\mathrm{I}))+(\mathrm{Bi}(\mathrm{I}-1))) / 2$

$\mathrm{Am}(\mathrm{I}-1)=((\mathrm{A}(\mathrm{I}))+(\mathrm{A}(\mathrm{I}-1))) / 2$

$\mathrm{Pm}(\mathrm{I}-1)=((\mathrm{P}(\mathrm{I}))+(\mathrm{P}(\mathrm{I}-1))) / 2$

$\mathrm{Rh}(\mathrm{I}-1)=((\mathrm{Am}(\mathrm{I}-1)) /(\mathrm{Pm}(\mathrm{I}-1)))$

ELSEIF(I.GE.76.AND.I.LE.77)THEN

$\mathrm{A}(\mathrm{I})=1.62 *(\mathrm{y}(\mathrm{I}) * 2)+3.83 * \mathrm{y}(\mathrm{I})+0.05$

$\mathrm{P}(\mathrm{I})=3.82 * \mathrm{y}(\mathrm{I})+3.81$

$\mathrm{Bi}(\mathrm{I})=3.25 * \mathrm{y}(\mathrm{I})+3.8167$

$\operatorname{Bim}(\mathrm{I}-1)=((\operatorname{Bi}(\mathrm{I}))+(\operatorname{Bi}(\mathrm{I}-1))) / 2$

$\mathrm{Am}(\mathrm{I}-1)=((\mathrm{A}(\mathrm{I}))+(\mathrm{A}(\mathrm{I}-1))) / 2$

$\mathrm{Pm}(\mathrm{I}-1)=((\mathrm{P}(\mathrm{I}))+(\mathrm{P}(\mathrm{I}-1))) / 2$

$\mathrm{Rh}(\mathrm{I}-1)=((\mathrm{Am}(\mathrm{I}-1)) /(\mathrm{Pm}(\mathrm{I}-1)))$

ELSEIF(I.EQ.78)THEN

$\mathrm{A}(\mathrm{I})=1.7 *(\mathrm{y}(\mathrm{I}) * * 2)+3.51 * \mathrm{y}(\mathrm{I})-0.06$ 
$\mathrm{P}(\mathrm{I})=3.96 * \mathrm{y}(\mathrm{I})+3.48$

$\mathrm{Bi}(\mathrm{I})=3.42 * \mathrm{y}(\mathrm{I})+3.5$

$\operatorname{Bim}(\mathrm{I}-1)=((\operatorname{Bi}(\mathrm{I}))+(\operatorname{Bi}(\mathrm{I}-1))) / 2$

$\mathrm{Am}(\mathrm{I}-1)=((\mathrm{A}(\mathrm{I}))+(\mathrm{A}(\mathrm{I}-1))) / 2$

$\operatorname{Pm}(\mathrm{I}-1)=((\mathrm{P}(\mathrm{I}))+(\mathrm{P}(\mathrm{I}-1))) / 2$

$\operatorname{Rh}(\mathrm{I}-1)=((\operatorname{Am}(\mathrm{I}-1)) /(\operatorname{Pm}(\mathrm{I}-1)))$

ELSEIF(I.EQ.79)THEN

$\mathrm{A}(\mathrm{I})=1.74 * \mathrm{y}(\mathrm{I}) * 2)+4.29 * \mathrm{y}(\mathrm{I})$

$\mathrm{P}(\mathrm{I})=4.02 * \mathrm{y}(\mathrm{I})+4.27$

$\mathrm{Bi}(\mathrm{I})=3.48 * \mathrm{y}(\mathrm{I})+4.29$

$\operatorname{Bim}(\mathrm{I}-1)=((\operatorname{Bi}(\mathrm{I}))+(\operatorname{Bi}(\mathrm{I}-1))) / 2$

$\mathrm{Am}(\mathrm{I}-1)=((\mathrm{A}(\mathrm{I}))+(\mathrm{A}(\mathrm{I}-1))) / 2$

$\mathrm{Pm}(\mathrm{I}-1)=((\mathrm{P}(\mathrm{I}))+(\mathrm{P}(\mathrm{I}-1))) / 2$

$\operatorname{Rh}(\mathrm{I}-1)=((\mathrm{Am}(\mathrm{I}-1)) /(\mathrm{Pm}(\mathrm{I}-1)))$

ELSEIF(I.EQ.80)THEN

$\mathrm{A}(\mathrm{I})=1.46 *(\mathrm{y}(\mathrm{I}) * * 2)+5.05 * \mathrm{y}(\mathrm{I})+0.02$

$\mathrm{P}(\mathrm{I})=3.57 * \mathrm{y}(\mathrm{I})+5.0133$

$\mathrm{Bi}(\mathrm{I})=2.96 * \mathrm{y}(\mathrm{I})+5.01$

$\operatorname{Bim}(\mathrm{I}-1)=((\mathrm{Bi}(\mathrm{I}))+(\mathrm{Bi}(\mathrm{I}-1))) / 2$

$\mathrm{Am}(\mathrm{I}-1)=((\mathrm{A}(\mathrm{I}))+(\mathrm{A}(\mathrm{I}-1))) / 2$

$\mathrm{Pm}(\mathrm{I}-1)=((\mathrm{P}(\mathrm{I}))+(\mathrm{P}(\mathrm{I}-1))) / 2$

$\mathrm{Rh}(\mathrm{I}-1)=((\mathrm{Am}(\mathrm{I}-1)) /(\mathrm{Pm}(\mathrm{I}-1)))$

ELSEIF(I.EQ.81)THEN

$\mathrm{A}(\mathrm{I})=1.64 * \mathrm{y}(\mathrm{I}) * 2)+4.32 * \mathrm{y}(\mathrm{I})+0.1$

$\mathrm{P}(\mathrm{I})=3.88 * \mathrm{y}(\mathrm{I})+4.28$

$\mathrm{Bi}(\mathrm{I})=3.33 * \mathrm{y}(\mathrm{I})+4.2667$

$\operatorname{Bim}(\mathrm{I}-1)=((\mathrm{Bi}(\mathrm{I}))+(\mathrm{Bi}(\mathrm{I}-1))) / 2$

$\mathrm{Am}(\mathrm{I}-1)=((\mathrm{A}(\mathrm{I}))+(\mathrm{A}(\mathrm{I}-1))) / 2$

$\mathrm{Pm}(\mathrm{I}-1)=((\mathrm{P}(\mathrm{I}))+(\mathrm{P}(\mathrm{I}-1))) / 2$

$\mathrm{Rh}(\mathrm{I}-1)=((\mathrm{Am}(\mathrm{I}-1)) /(\mathrm{Pm}(\mathrm{I}-1)))$

ELSEIF(I.EQ.82)THEN

$\mathrm{A}(\mathrm{I})=1.54 * \mathrm{y}(\mathrm{I}) * 2)+4.49 * \mathrm{y}(\mathrm{I})+0.09$

$\mathrm{P}(\mathrm{I})=3.67 * \mathrm{y}(\mathrm{I})+4.4933$

$\mathrm{Bi}(\mathrm{I})=3.08 * \mathrm{y}(\mathrm{I})+4.49$

$\operatorname{Bim}(\mathrm{I}-1)=((\mathrm{Bi}(\mathrm{I}))+(\mathrm{Bi}(\mathrm{I}-1))) / 2$

$\mathrm{Am}(\mathrm{I}-1)=((\mathrm{A}(\mathrm{I}))+(\mathrm{A}(\mathrm{I}-1))) / 2$

$\mathrm{Pm}(\mathrm{I}-1)=((\mathrm{P}(\mathrm{I}))+(\mathrm{P}(\mathrm{I}-1))) / 2$

$\mathrm{Rh}(\mathrm{I}-1)=((\mathrm{Am}(\mathrm{I}-1)) /(\mathrm{Pm}(\mathrm{I}-1)))$

ELSEIF(I.EQ.83)THEN

$\mathrm{A}(\mathrm{I})=1.56 *(\mathrm{y}(\mathrm{I}) * 2)+4 * \mathrm{y}(\mathrm{I})-0.04$

$\mathrm{P}(\mathrm{I})=3.71 * \mathrm{y}(\mathrm{I})+3.9767$

$\mathrm{Bi}(\mathrm{I})=3.12 * \mathrm{y}(\mathrm{I})+4$

$\operatorname{Bim}(\mathrm{I}-1)=((\operatorname{Bi}(\mathrm{I}))+(\operatorname{Bi}(\mathrm{I}-1))) / 2$

$\mathrm{Am}(\mathrm{I}-1)=((\mathrm{A}(\mathrm{I}))+(\mathrm{A}(\mathrm{I}-1))) / 2$

$\operatorname{Pm}(\mathrm{I}-1)=((\mathrm{P}(\mathrm{I}))+(\mathrm{P}(\mathrm{I}-1))) / 2$

$\mathrm{Rh}(\mathrm{I}-1)=((\mathrm{Am}(\mathrm{I}-1)) /(\mathrm{Pm}(\mathrm{I}-1)))$

ELSEIF(I.EQ.84)THEN

$\mathrm{A}(\mathrm{I})=1.6 *(\mathrm{y}(\mathrm{I}) * * 2)+4.98 * \mathrm{y}(\mathrm{I})+0.06$

$\mathrm{P}(\mathrm{I})=3.77 * \mathrm{y}(\mathrm{I})+4.9767$

$\mathrm{Bi}(\mathrm{I})=3.19 * \mathrm{y}(\mathrm{I})+4.9867$

$\operatorname{Bim}(\mathrm{I}-1)=((\mathrm{Bi}(\mathrm{I}))+(\mathrm{Bi}(\mathrm{I}-1))) / 2$

$\mathrm{Am}(\mathrm{I}-1)=((\mathrm{A}(\mathrm{I}))+(\mathrm{A}(\mathrm{I}-1))) / 2$

$\mathrm{Pm}(\mathrm{I}-1)=((\mathrm{P}(\mathrm{I}))+(\mathrm{P}(\mathrm{I}-1))) / 2$ 
$\mathrm{Rh}(\mathrm{I}-1)=((\mathrm{Am}(\mathrm{I}-1)) /(\mathrm{Pm}(\mathrm{I}-1)))$

ELSEIF(I.EQ.85)THEN

$\mathrm{A}(\mathrm{I})=1.44 *(\mathrm{y}(\mathrm{I}) * * 2)+5.38 * \mathrm{y}(\mathrm{I})+0.17$

$\mathrm{P}(\mathrm{I})=3.54 * \mathrm{y}(\mathrm{I})+5.35$

$\mathrm{Bi}(\mathrm{I})=2.92 * \mathrm{y}(\mathrm{I})+5.34$

$\operatorname{Bim}(\mathrm{I}-1)=((\operatorname{Bi}(\mathrm{I}))+(\operatorname{Bi}(\mathrm{I}-1))) / 2$

$\mathrm{Am}(\mathrm{I}-1)=((\mathrm{A}(\mathrm{I}))+(\mathrm{A}(\mathrm{I}-1))) / 2$

$\mathrm{Pm}(\mathrm{I}-1)=((\mathrm{P}(\mathrm{I}))+(\mathrm{P}(\mathrm{I}-1))) / 2$

$\mathrm{Rh}(\mathrm{I}-1)=((\mathrm{Am}(\mathrm{I}-1)) /(\mathrm{Pm}(\mathrm{I}-1)))$

ELSEIF(I.EQ.86)THEN

$\mathrm{A}(\mathrm{I})=1.96 *(\mathrm{y}(\mathrm{I}) * * 2)+3.54 * \mathrm{y}(\mathrm{I})+0.08$

$\mathrm{P}(\mathrm{I})=4.39 * \mathrm{y}(\mathrm{I})+3.5567$

$\mathrm{Bi}(\mathrm{I})=3.9 * \mathrm{y}(\mathrm{I})+3.55$

$\operatorname{Bim}(\mathrm{I}-1)=((\operatorname{Bi}(\mathrm{I}))+(\operatorname{Bi}(\mathrm{I}-1))) / 2$

$\mathrm{Am}(\mathrm{I}-1)=((\mathrm{A}(\mathrm{I}))+(\mathrm{A}(\mathrm{I}-1))) / 2$

$\mathrm{Pm}(\mathrm{I}-1)=((\mathrm{P}(\mathrm{I}))+(\mathrm{P}(\mathrm{I}-1))) / 2$

$\mathrm{Rh}(\mathrm{I}-1)=((\mathrm{Am}(\mathrm{I}-1)) /(\mathrm{Pm}(\mathrm{I}-1)))$

ELSEIF(I.EQ.87)THEN

$\mathrm{A}(\mathrm{I})=1.6 *(\mathrm{y}(\mathrm{I}) * * 2)+4.38 * \mathrm{y}(\mathrm{I})-0.03$

$\mathrm{P}(\mathrm{I})=3.78 * \mathrm{y}(\mathrm{I})+4.35$

$\mathrm{Bi}(\mathrm{I})=3.21 * \mathrm{y}(\mathrm{I})+4.3633$

$\operatorname{Bim}(\mathrm{I}-1)=((\operatorname{Bi}(\mathrm{I}))+(\operatorname{Bi}(\mathrm{I}-1))) / 2$

$\mathrm{Am}(\mathrm{I}-1)=((\mathrm{A}(\mathrm{I}))+(\mathrm{A}(\mathrm{I}-1))) / 2$

$\mathrm{Pm}(\mathrm{I}-1)=((\mathrm{P}(\mathrm{I}))+(\mathrm{P}(\mathrm{I}-1))) / 2$

$\mathrm{Rh}(\mathrm{I}-1)=((\operatorname{Am}(\mathrm{I}-1)) /(\operatorname{Pm}(\mathrm{I}-1)))$

ELSEIF(I.GE.88.AND.I.LE.89)THEN

$\mathrm{A}(\mathrm{I})=1.44 *(\mathrm{y}(\mathrm{I}) * * 2)+4.88 * \mathrm{y}(\mathrm{I})+0.23$

$\mathrm{P}(\mathrm{I})=3.51 * \mathrm{y}(\mathrm{I})+4.8433$

$\mathrm{Bi}(\mathrm{I})=2.88 * \mathrm{y}(\mathrm{I})+4.88$

$\operatorname{Bim}(\mathrm{I}-1)=((\operatorname{Bi}(\mathrm{I}))+(\mathrm{Bi}(\mathrm{I}-1))) / 2$

$\mathrm{Am}(\mathrm{I}-1)=((\mathrm{A}(\mathrm{I}))+(\mathrm{A}(\mathrm{I}-1))) / 2$

$\operatorname{Pm}(\mathrm{I}-1)=((\mathrm{P}(\mathrm{I}))+(\mathrm{P}(\mathrm{I}-1))) / 2$

$\operatorname{Rh}(\mathrm{I}-1)=((\mathrm{Am}(\mathrm{I}-1)) /(\operatorname{Pm}(\mathrm{I}-1)))$

ELSEIF(I.GE.90.AND.I.LE.95)THEN

$\mathrm{A}(\mathrm{I})=1.68 *(\mathrm{y}(\mathrm{I}) * 2)+4.8 * \mathrm{y}(\mathrm{I})+0.09$

$\mathrm{P}(\mathrm{I})=3.9 * \mathrm{y}(\mathrm{I})+4.82$

$\mathrm{Bi}(\mathrm{I})=3.36 * \mathrm{y}(\mathrm{I})+4.8$

$\operatorname{Bim}(\mathrm{I}-1)=((\operatorname{Bi}(\mathrm{I}))+(\operatorname{Bi}(\mathrm{I}-1))) / 2$

$\mathrm{Am}(\mathrm{I}-1)=((\mathrm{A}(\mathrm{I}))+(\mathrm{A}(\mathrm{I}-1))) / 2$

$\mathrm{Pm}(\mathrm{I}-1)=((\mathrm{P}(\mathrm{I}))+(\mathrm{P}(\mathrm{I}-1))) / 2$

$\mathrm{Rh}(\mathrm{I}-1)=((\mathrm{Am}(\mathrm{I}-1)) /(\mathrm{Pm}(\mathrm{I}-1)))$

ELSEIF(I.GE.96.AND.I.LE.98)THEN

$\mathrm{A}(\mathrm{I})=1.56 *(\mathrm{y}(\mathrm{I}) * 2)+4.82 * \mathrm{y}(\mathrm{I})+0.02$

$\mathrm{P}(\mathrm{I})=3.72 * \mathrm{y}(\mathrm{I})+4.79$

$\operatorname{Bi}(\mathrm{I})=3.14 * \mathrm{y}(\mathrm{I})+4.79$

$\operatorname{Bim}(\mathrm{I}-1)=((\operatorname{Bi}(\mathrm{I}))+(\operatorname{Bi}(\mathrm{I}-1))) / 2$

$\mathrm{Am}(\mathrm{I}-1)=((\mathrm{A}(\mathrm{I}))+(\mathrm{A}(\mathrm{I}-1))) / 2$

$\mathrm{Pm}(\mathrm{I}-1)=((\mathrm{P}(\mathrm{I}))+(\mathrm{P}(\mathrm{I}-1))) / 2$

$\operatorname{Rh}(\mathrm{I}-1)=((\operatorname{Am}(\mathrm{I}-1)) /(\mathrm{Pm}(\mathrm{I}-1)))$

ELSEIF(I.GE.99.AND.I.LE.100)THEN

$\mathrm{A}(\mathrm{I})=1.48 *(\mathrm{y}(\mathrm{I}) * 2)+5.2 * \mathrm{y}(\mathrm{I})-0.01$

$\mathrm{P}(\mathrm{I})=3.61 * \mathrm{y}(\mathrm{I})+5.1633$

$\operatorname{Bi}(\mathrm{I})=3.01 * \mathrm{y}(\mathrm{I})+5.1533$ 


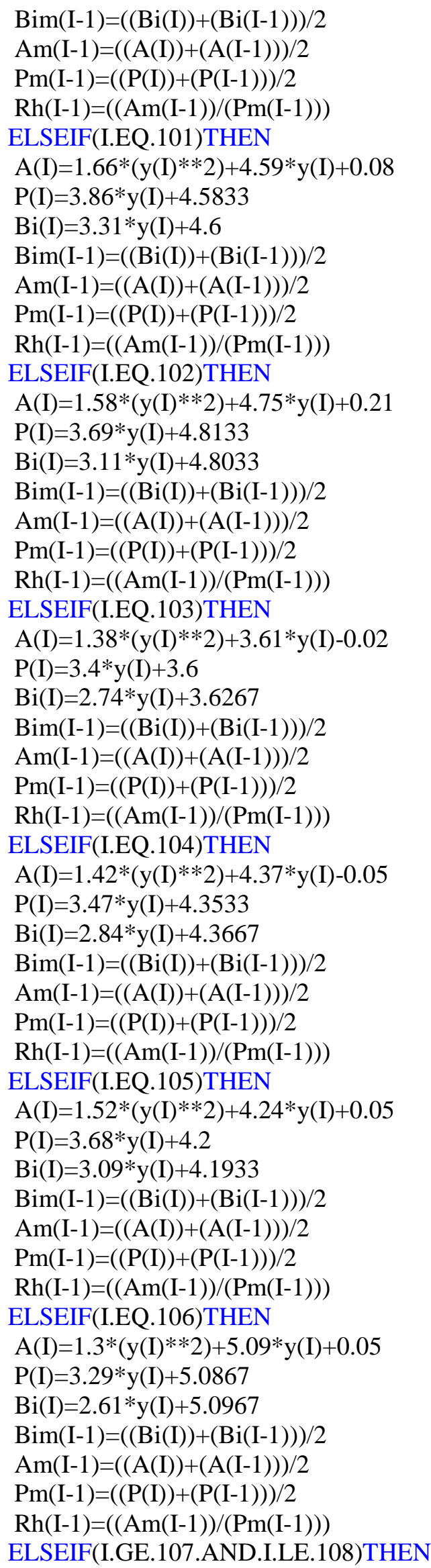


$\mathrm{A}(\mathrm{I})=1.42 *(\mathrm{y}(\mathrm{I}) * * 2)+4.31 * \mathrm{y}(\mathrm{I})+0.11$

$\mathrm{P}(\mathrm{I})=3.51 * \mathrm{y}(\mathrm{I})+4.2767$

$\mathrm{Bi}(\mathrm{I})=2.89 * \mathrm{y}(\mathrm{I})+4.2733$

$\operatorname{Bim}(\mathrm{I}-1)=((\mathrm{Bi}(\mathrm{I}))+(\mathrm{Bi}(\mathrm{I}-1))) / 2$

$\mathrm{Am}(\mathrm{I}-1)=((\mathrm{A}(\mathrm{I}))+(\mathrm{A}(\mathrm{I}-1))) / 2$

$\operatorname{Pm}(\mathrm{I}-1)=((\mathrm{P}(\mathrm{I}))+(\mathrm{P}(\mathrm{I}-1))) / 2$

$\operatorname{Rh}(\mathrm{I}-1)=((\mathrm{Am}(\mathrm{I}-1)) /(\mathrm{Pm}(\mathrm{I}-1)))$

ELSEIF(I.EQ.Nz)THEN !Açude Pacajus

$\mathrm{A}(\mathrm{I})=1.42 *(\mathrm{y}(\mathrm{I}) * * 2)+4.31 * \mathrm{y}(\mathrm{I})+0.11$

$\mathrm{P}(\mathrm{I})=3.51 * \mathrm{y}(\mathrm{I})+4.2767$

$\mathrm{Bi}(\mathrm{I})=2.89 * \mathrm{y}(\mathrm{I})+4.2733$

$\operatorname{Bim}(\mathrm{I}-1)=((\operatorname{Bi}(\mathrm{I}))+(\operatorname{Bi}(\mathrm{I}-1))) / 2$

$\operatorname{Am}(\mathrm{I}-1)=((\mathrm{A}(\mathrm{I}))+(\mathrm{A}(\mathrm{I}-1))) / 2$

$\mathrm{Pm}(\mathrm{I}-1)=((\mathrm{P}(\mathrm{I}))+(\mathrm{P}(\mathrm{I}-1))) / 2$

$\mathrm{Rh}(\mathrm{I}-1)=((\mathrm{Am}(\mathrm{I}-1)) /(\mathrm{Pm}(\mathrm{I}-1)))$

ENDIF

ENDDO

RETURN

END 


\section{REFERÊNCIAS BIBLIOGRÁFICAS}

AMEIN, M. (1966), Stream Flow Routing on Computer by Characteristics, Water Research, vol $2, n^{\circ} 1$

AMEIN, M. \& CHU, H.L. (1975), Implicit Numerical Modeling of Unsteady Flows, Journal of the Hidraulics Division, HY6

AMEIN, M. \& FANG, C.S. (1970), Implicit Flood Routing in Natural Channels, Journal of the Hidraulics Division, HY12

CHAUDHRY, M. H. (1993) Open Channel Flow. Prentice Hall, New Jersey, 481p

CHOW, V. T. (1973), Open Channel Hydraulics, McGraw-Hill Book Company, 680p.

CUNGE, J. A.; HOLLY, F. \& VERWEY, A. (1980), Practical Aspects of Computational Rivers Hydraulics. Pitman Publ. Ltd, London

CUNHA, A. (1993) Métodos Numéricos: Para as Engenharias e Ciências Aplicadas, Campinas SP, Editora da UNICAMP, Cap.3, p. 77-95.

DOOGE, J.C.I.(1986), Theory of Flood Routing, cap 3 - River Flow Modelling and Forecasting, Netherlands, D.Reidel

ESPÍNDOLA, E. L. G.; SILVA, J. S. V.; MARINELLI, C. E.; ABDON, M. M. (2000), A Bacia Hidrográfica do Monjolinho:Uma Abordagem Ecossistêmica e a Visão Interdisciplinar, São Carlos SP. RIMA Editora, 184p.

FORTUNA, A. O. (2000), Técnicas Computacionais para Dinâmica dos Fluidos: Conceitos Básicos e Aplicações, EDUSP, 426p.

FREAD, D.L. (1973), Technique for Implicit Dynamic in River with Tributaries. Water Resources Research, vol 9, $\mathrm{n}^{\circ} 4$ 
FRENCH, R. H. (1986) Open Channel Hydraulics. McGraw-Hill International Editions, New York, 705p

GRIJSEN, J.G (1986), River Flow Simulation, cap 9 - River Flow Modelling and Forecasting, Netherlands, D.Reidel

GUANARATNAM, D.J. (1970), Numerical Solution of Unsteady Flow in Open Channels, Tese Doutorado - Massachusetts Institute of Technology, 261p

HENDERSON, F. M (1966), Open Channel Flow, Macmillan Publishing, Inc, New York, $522 \mathrm{p}$.

HROMADKA II, T.V. et al (1985), Computer Methods in Water Resources, Lighthouse Publitions

JORGENSEN, S. E.(1986), Fundamentals of Ecological Modelling. Copenhagen, Elsevier Science Publishers B. V.

LAI, C. (1988), Comprehensive Method of Characteristics Models for Flow Simulation, Journal of the Hidraulics Engineering, vol 114, $n^{\circ} 9$

LIGGETT, J.A. e CUNGE, J.A. (1975), Unsteady Flow in Open Channels, Cap 4 - Volume I - editado por K.Mahmood e V.Yevjevich, 484p.

LIGHTHILL, M.J. \& WHITHMAM, G.B.(1955), On Kinematic Waves I: Flood Movement in long Rivers, Proc, Royal Society (London),A229:281-316

PONCE, V.M. et al (1978), Applicability of Kinematic and Difusion Models, Journal of the Hidraulics Division, HY7

PONCE, V.M. et al (1978), Convergence of Four-Point Implicit Water Wave Models, Journal of the Hidraulics Division, HY7

PORTO, R. M. (1999), Hidráulica Básica, EESC-USP São Carlos SP - Projeto Reenge, $519 \mathrm{p}$. 
QUEIROZ, O.M. (1991), Propagação de Cheias: Aplicação do Modelo Onda Cinemática, Dissertação de Mestrado EESC-USP, 85p.

RAGAN, R.M. (1966), Laboratory Evaluation of a Numerical Flood Routing Technique for Channels Subjet to Lateral Inflow, Water Resources Research, vol 2, $\mathrm{n}^{\circ} 1$

RANGA RAJU, K.G. (1981), Flow Through Open Channels, McGraw-Hill Publishing Company Limited, 330p.

RIGHETTO, A. M. (1998), Hidrologia e Recursos Hídricos, EESC-USP São Carlos SP Projeto Reenge, $819 p$.

STREETER, V.L. (1975), Mecânica dos Fluidos, McGraw Hill do Brasil Ltda., São Paulo, $736 \mathrm{p}$

STREETER, V.L. et al (1978), Fluid Transiente, New York: McGraw-Hill International Book. Co 384p

TUCCI, C.E.M. (1986), Modelos Matemáticos em Hidrologia e Hidráulica, Revista Brasileira de Engenharia, ABRH, Tomo 2/3. 139 p.

TUCCI, C.E.M. (1987), Modelos Determinísticos, cap.3 - Métodos Numéricos em Recursos Hídricos, Rio de Janeiro, ABRH

TUCCI, C.E.M. (1998), Modelos Hidrológicos, Editora da Universidade Federal do Rio Grande do Sul - ABRH, 669p

WENDLAND, E. \& RÜBER, O. (1998), Hydrogeologishe Modelle. Lehrstuhl für Hydrogeologie, Ruhr-Universitat Bochum, 141p

WOOLLHISER, D.A. \& LIGGETT, J.A. (1967),Unsteady one-dimensional flow over a plane - the rising hydrograph. Water Resources Research, 3, nº3, 753-771

WROBEL, L.C. (1989), Métodos Numéricos em Recursos Hídricos, Rio de Janeiro ABRH, cap.1 
Caso 1: Canal do Monjolinho ( Seções características - esc.gráfica)

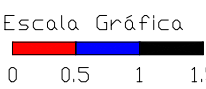

SEÇã $\square 1$

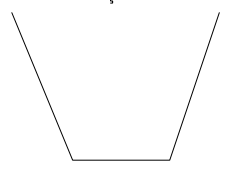

SEÇUEES 7, 8 e 9

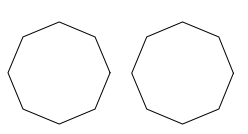

SEÇã 13
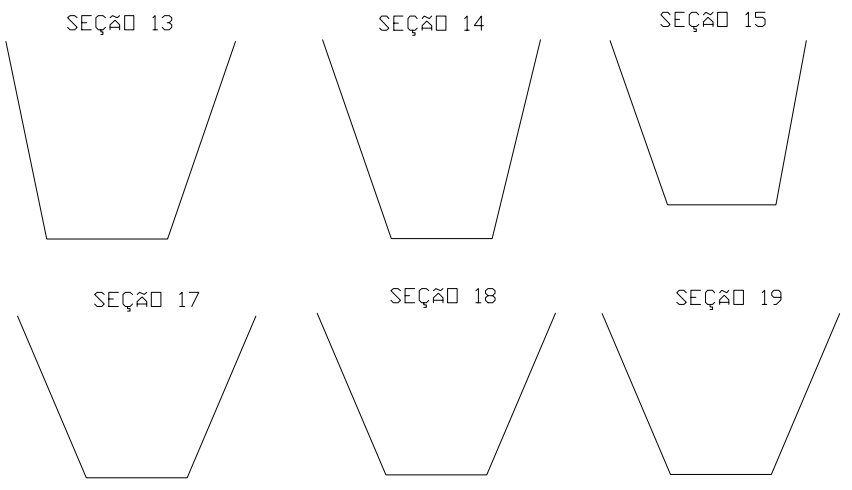

SEČ̃̃ 23
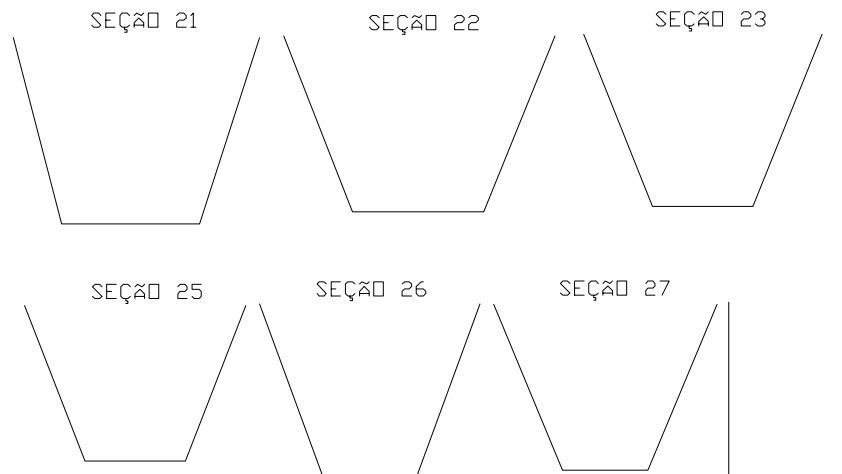
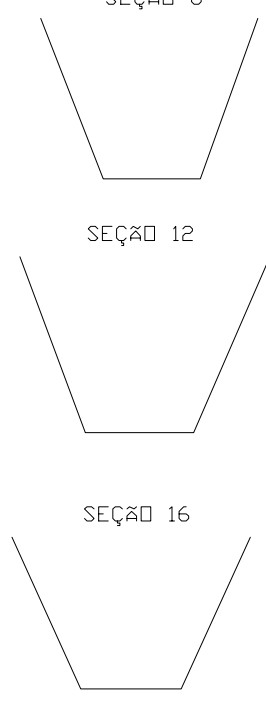

SEÇã 12

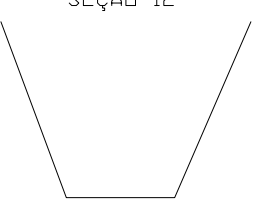

SEÇã $\square 0$

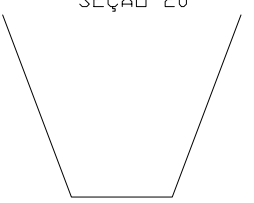

SEÇã 24

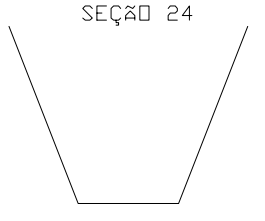

SEÇã̃ 28
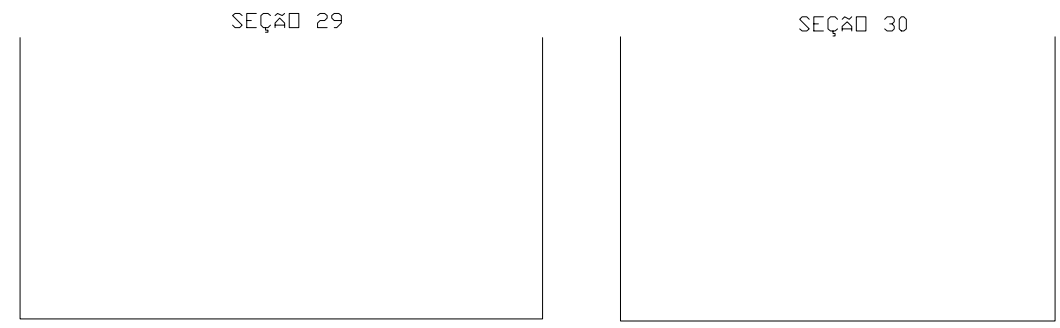
Caso 1: Canal da Usina Hidroelétrica Monjolinho (Equações de Geometria)

SEÇÕES 01 e 02
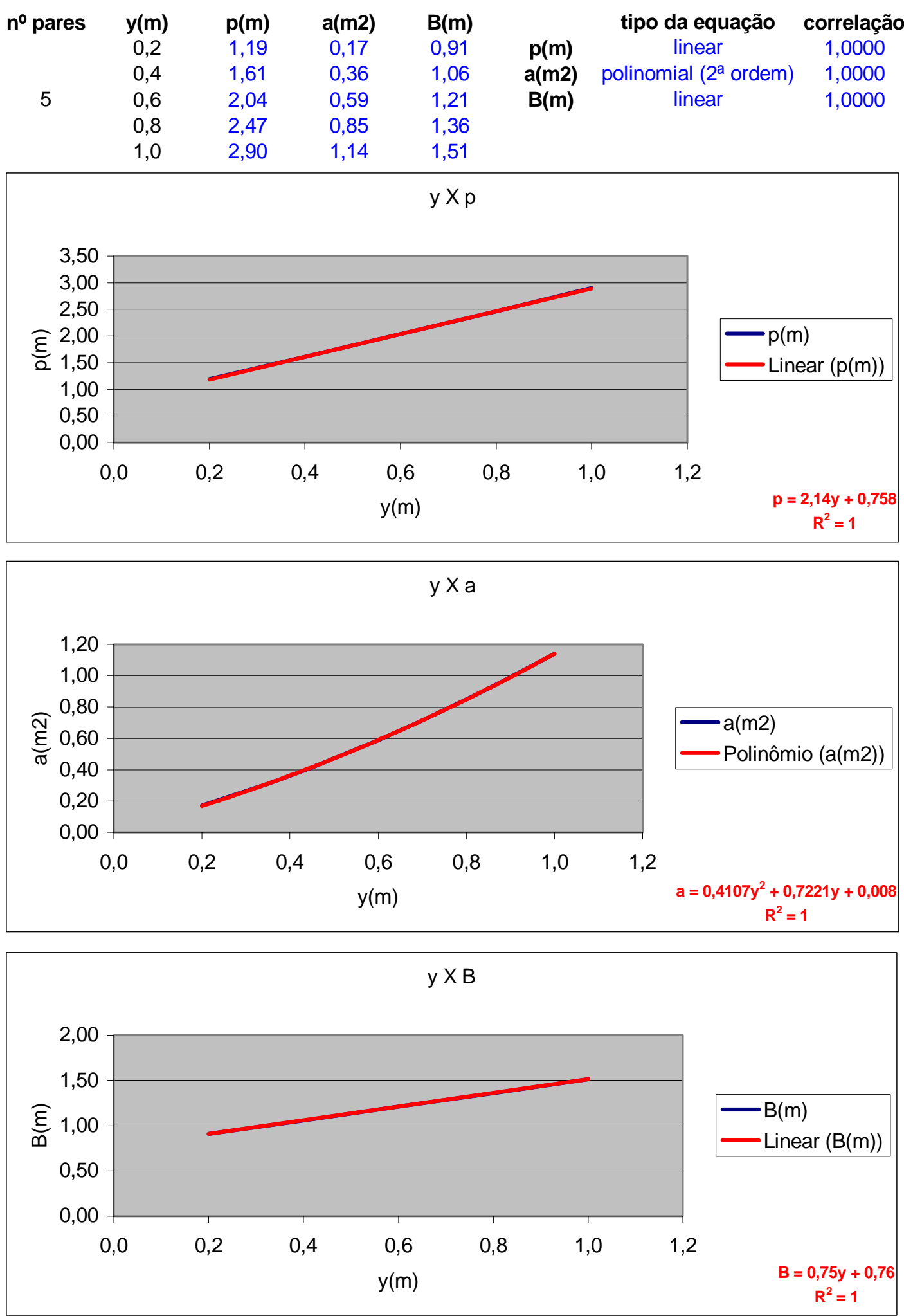


\section{SEÇÕES 03, 04 e 05}
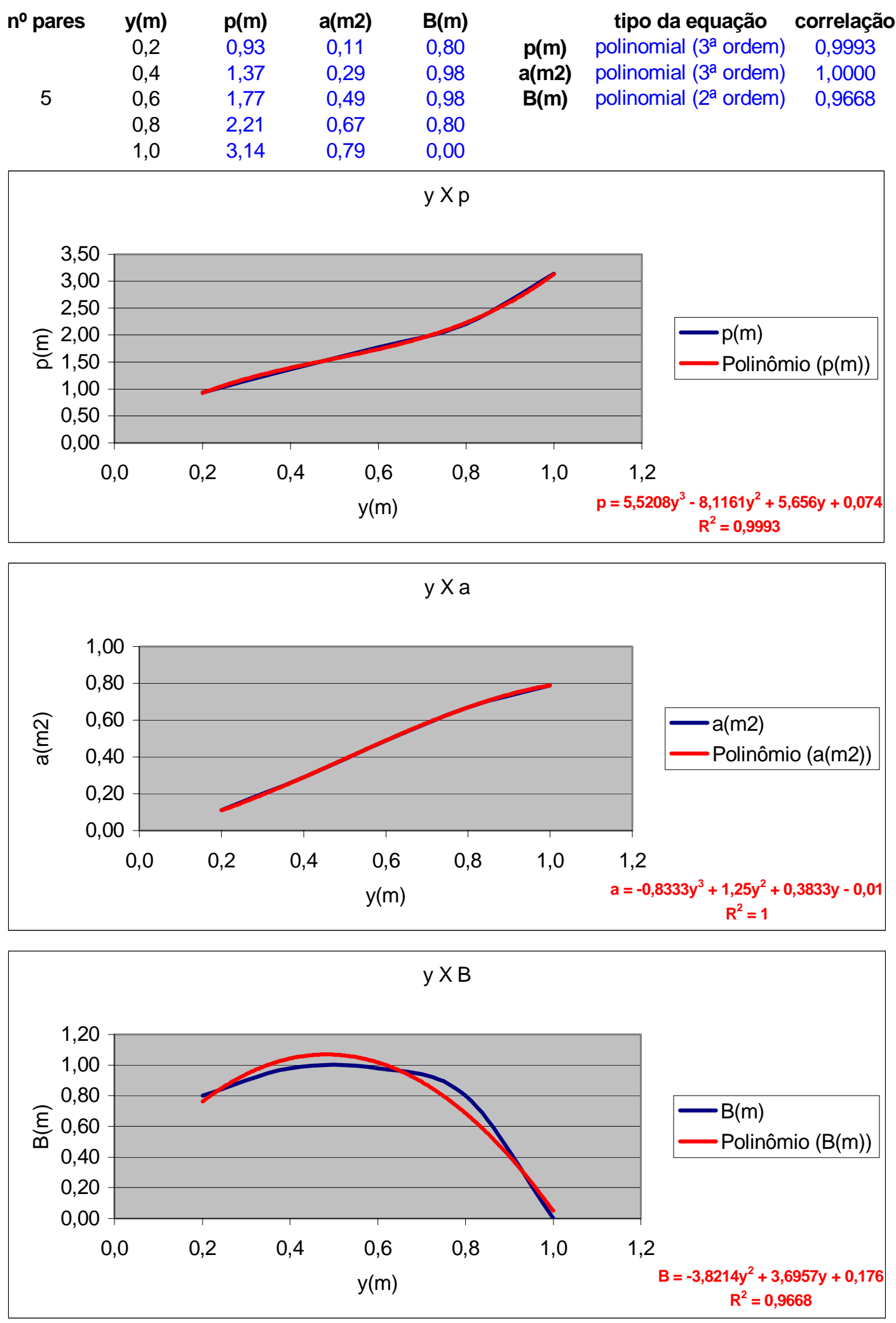


\section{SEÇÃO 06}
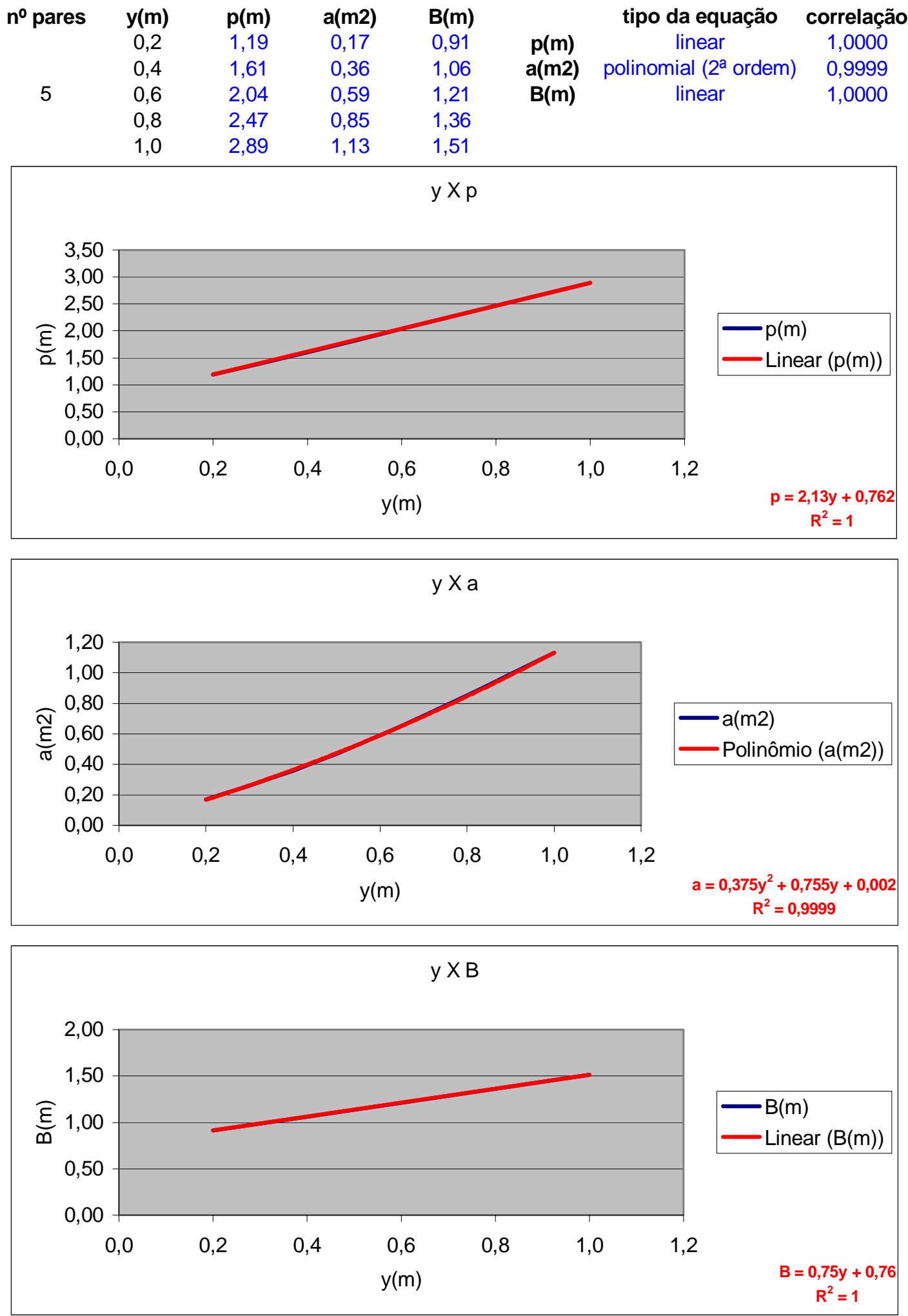


\section{SEÇÕES 07, 08 e 09}

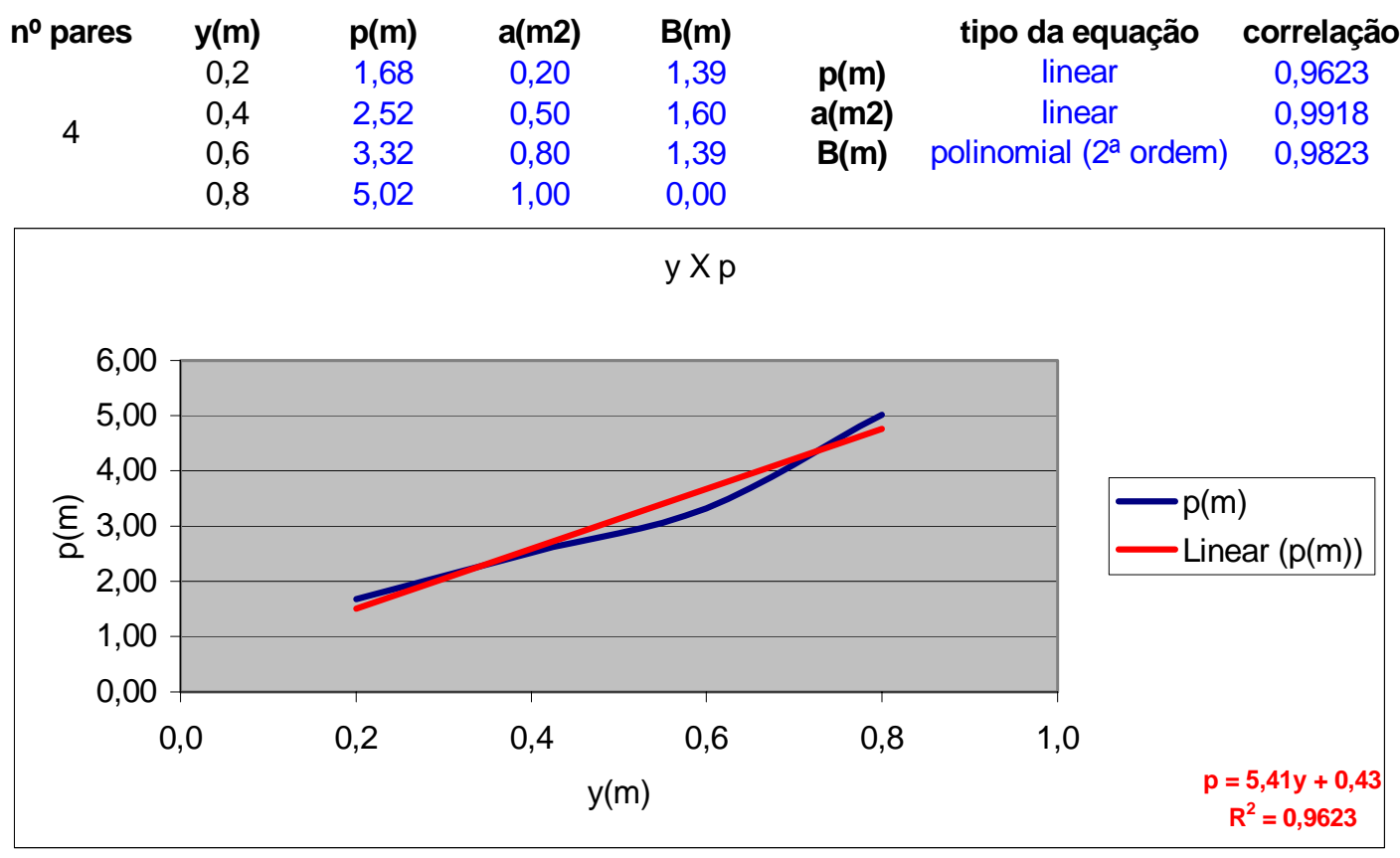

$$
y \times a
$$
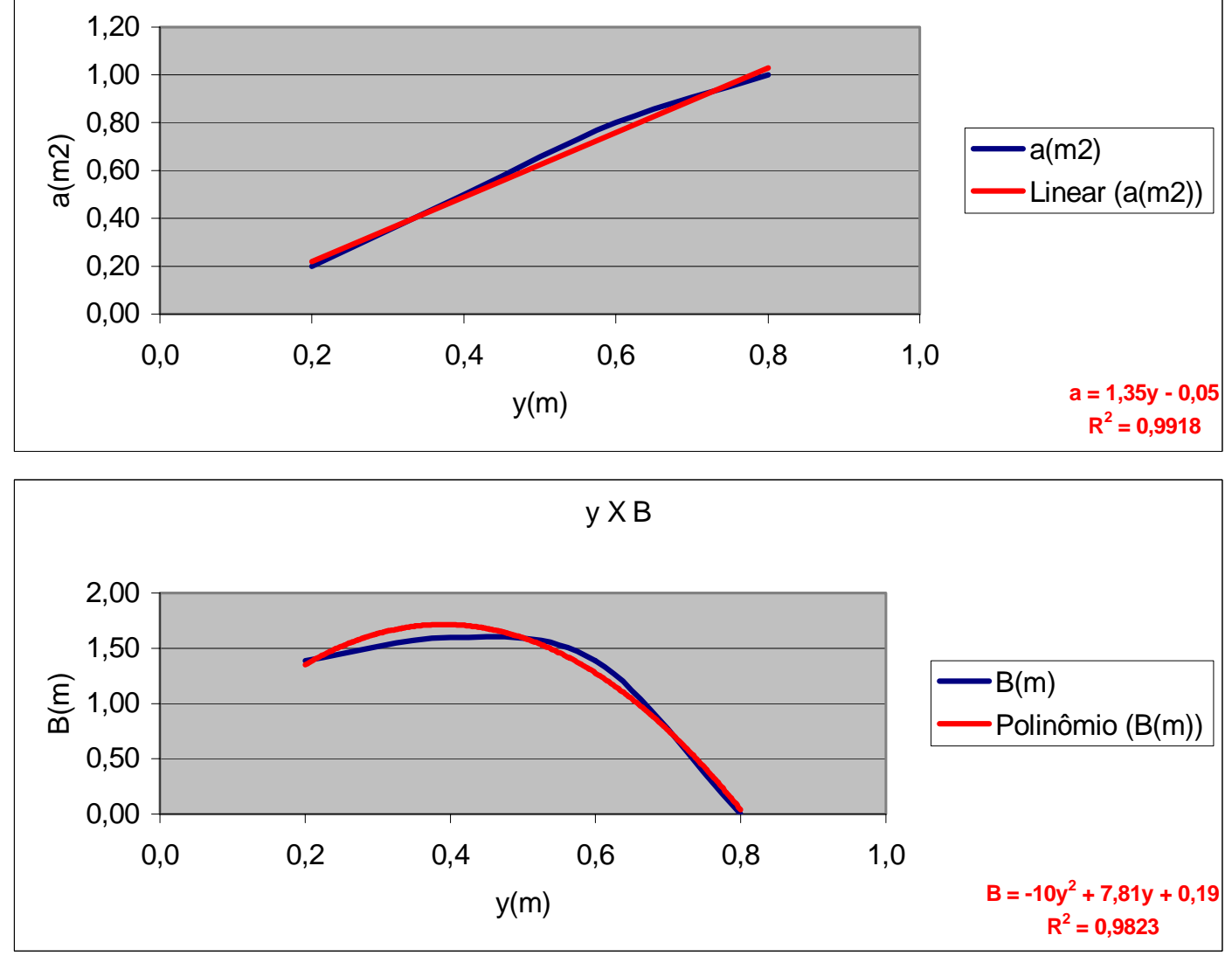
SEÇÃO 10
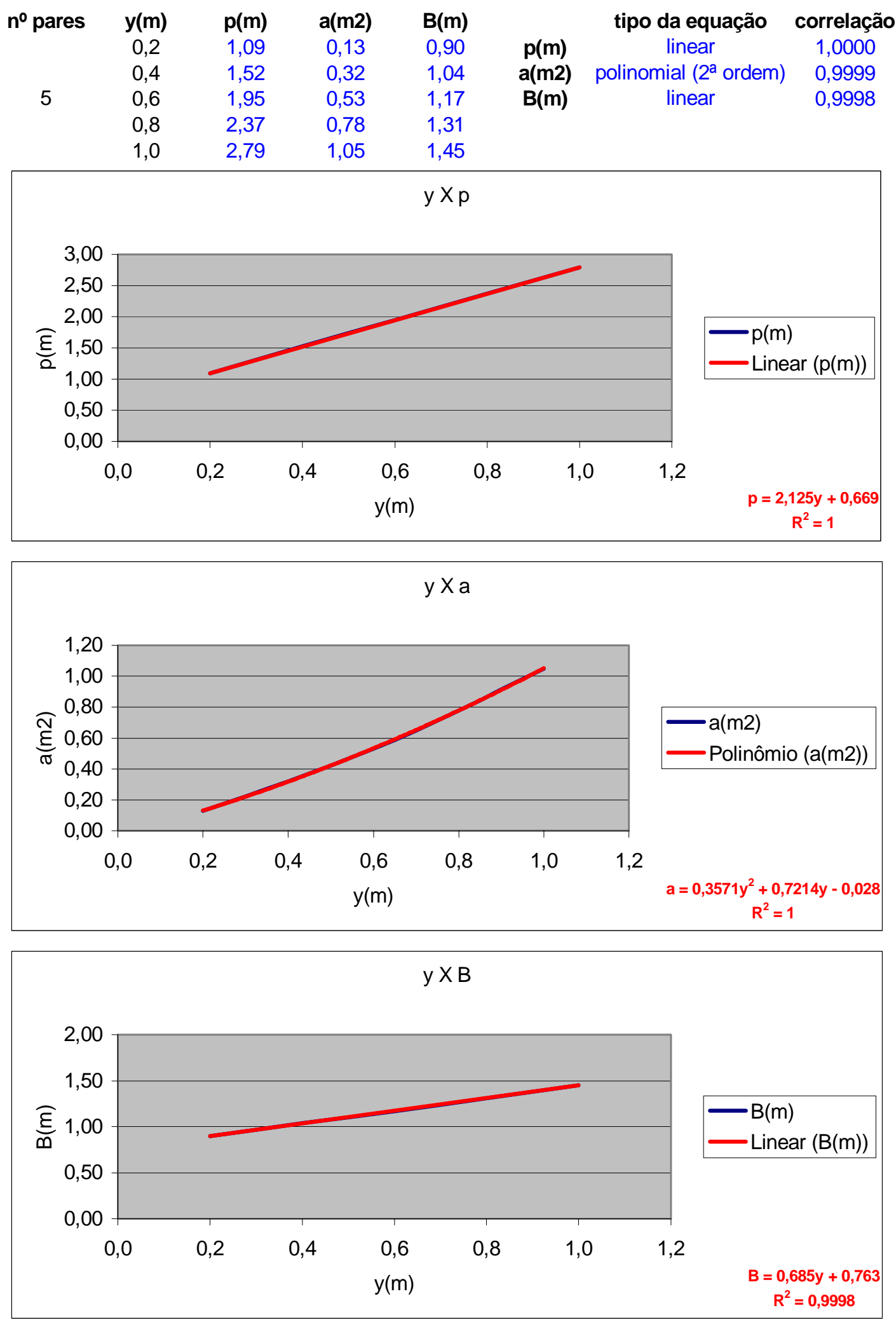


\section{SEÇÃO 11}

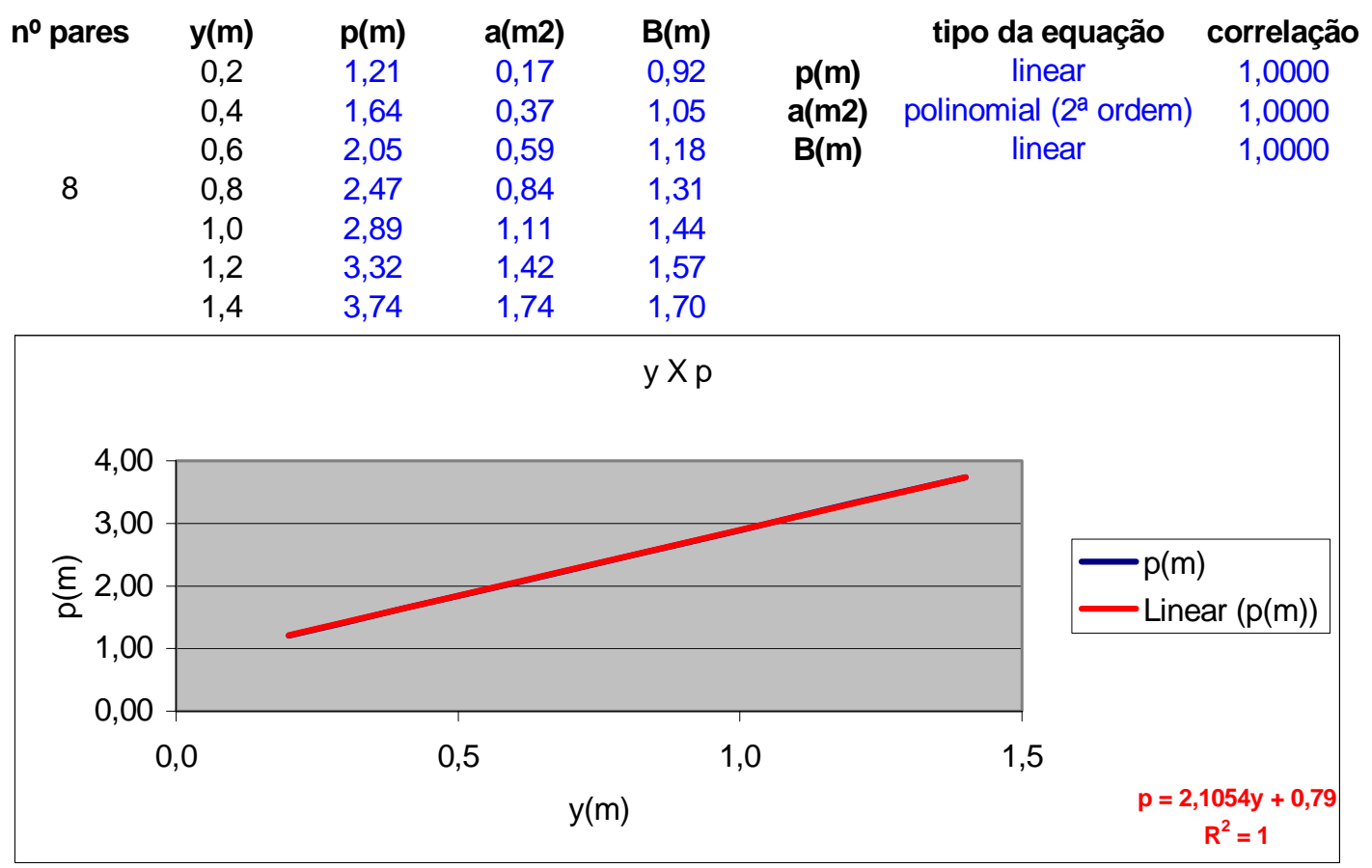

$y X a$
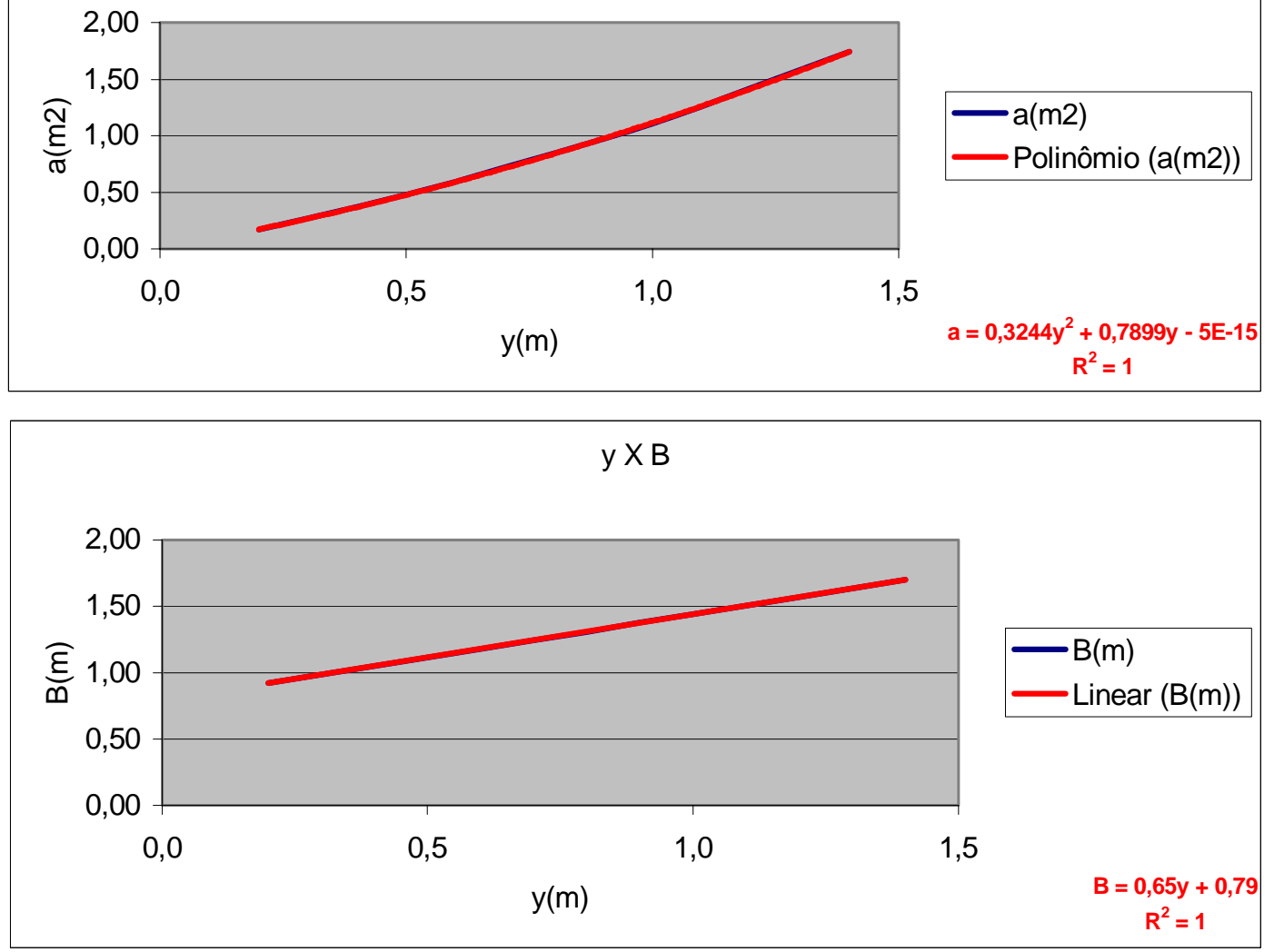


\section{SEÇÃO 12}
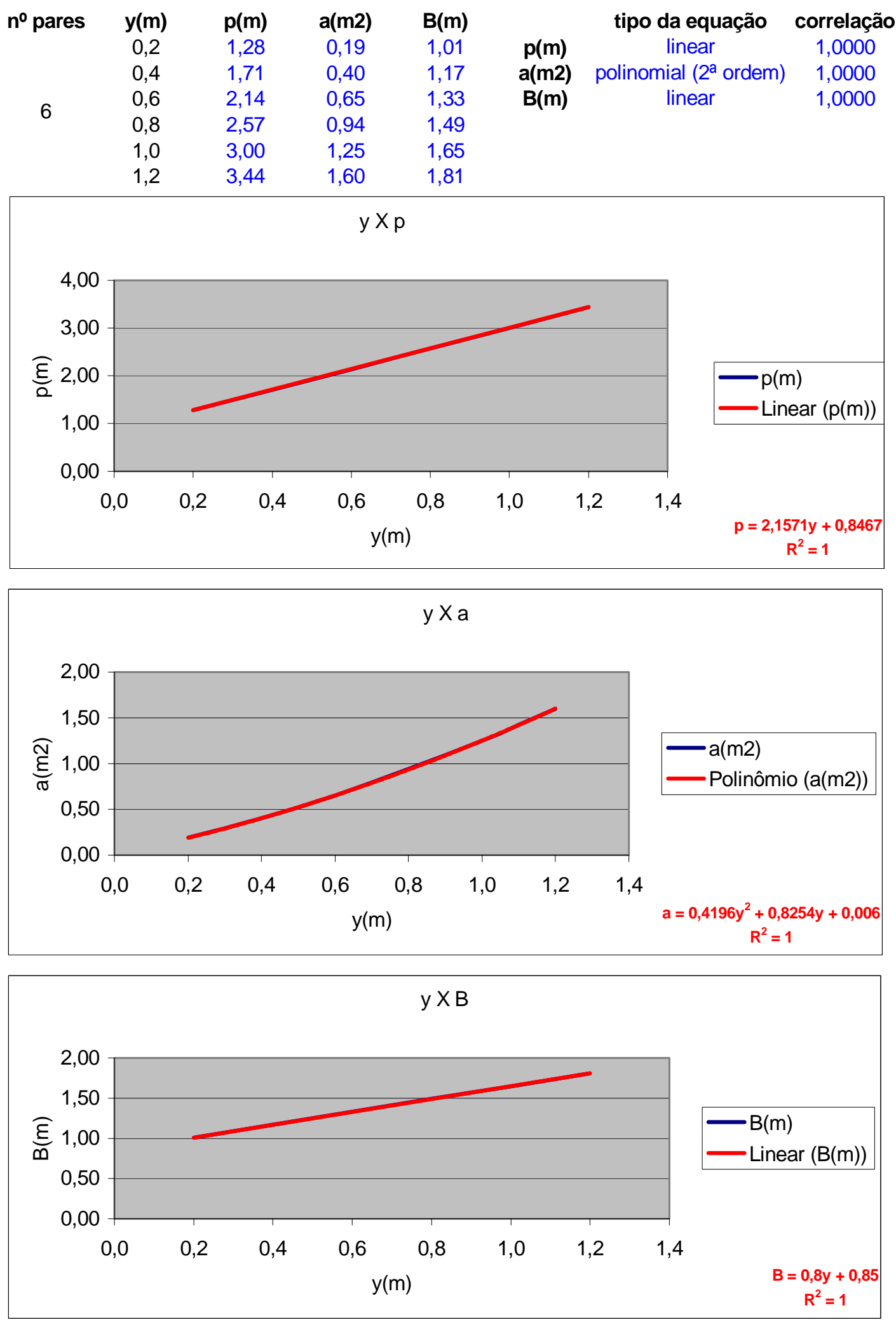
SEÇÃO 13

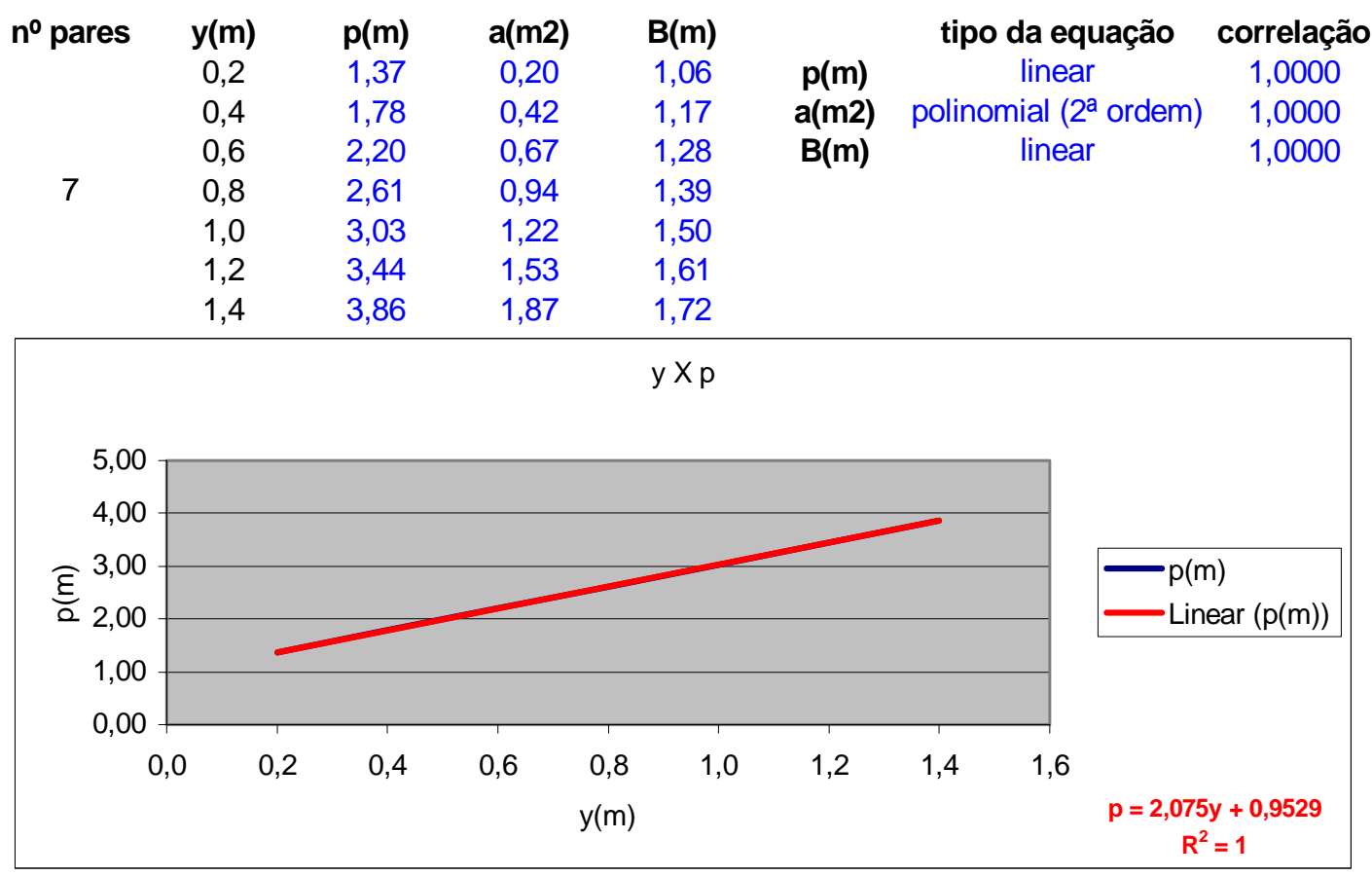

y X a

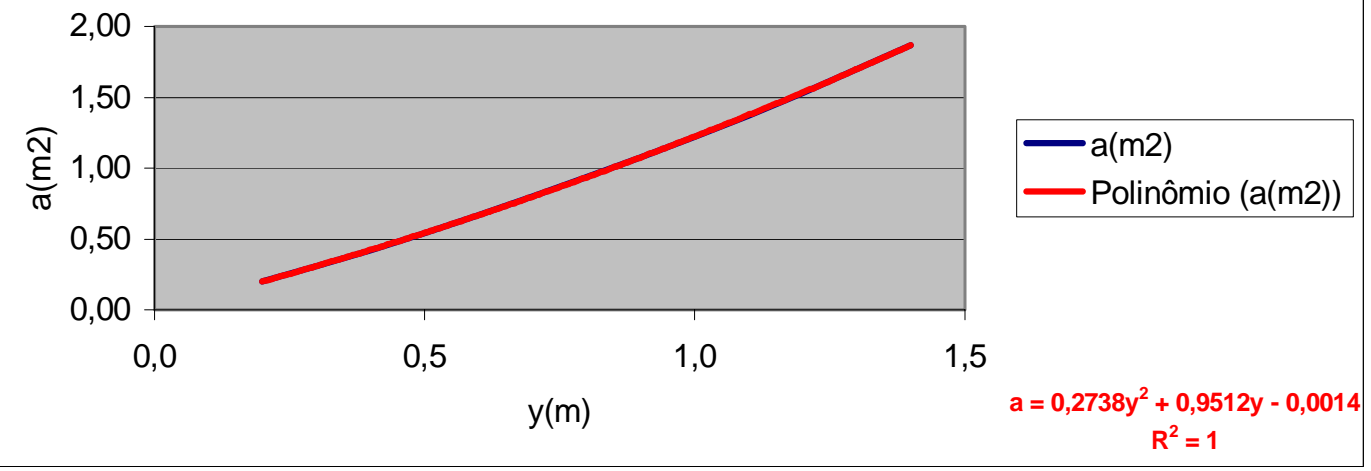

$y X B$

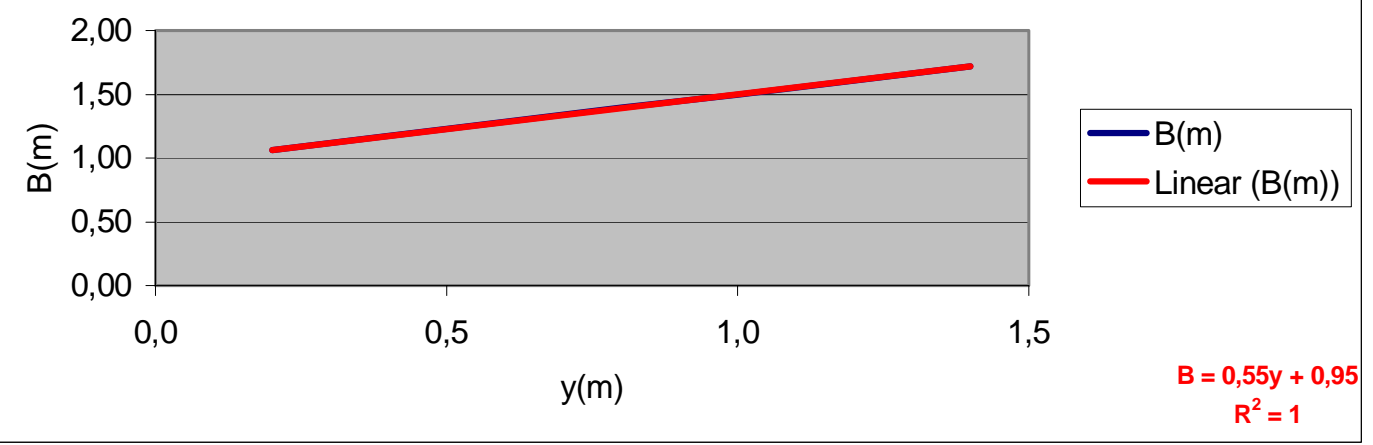




\section{SEÇÃO 14}
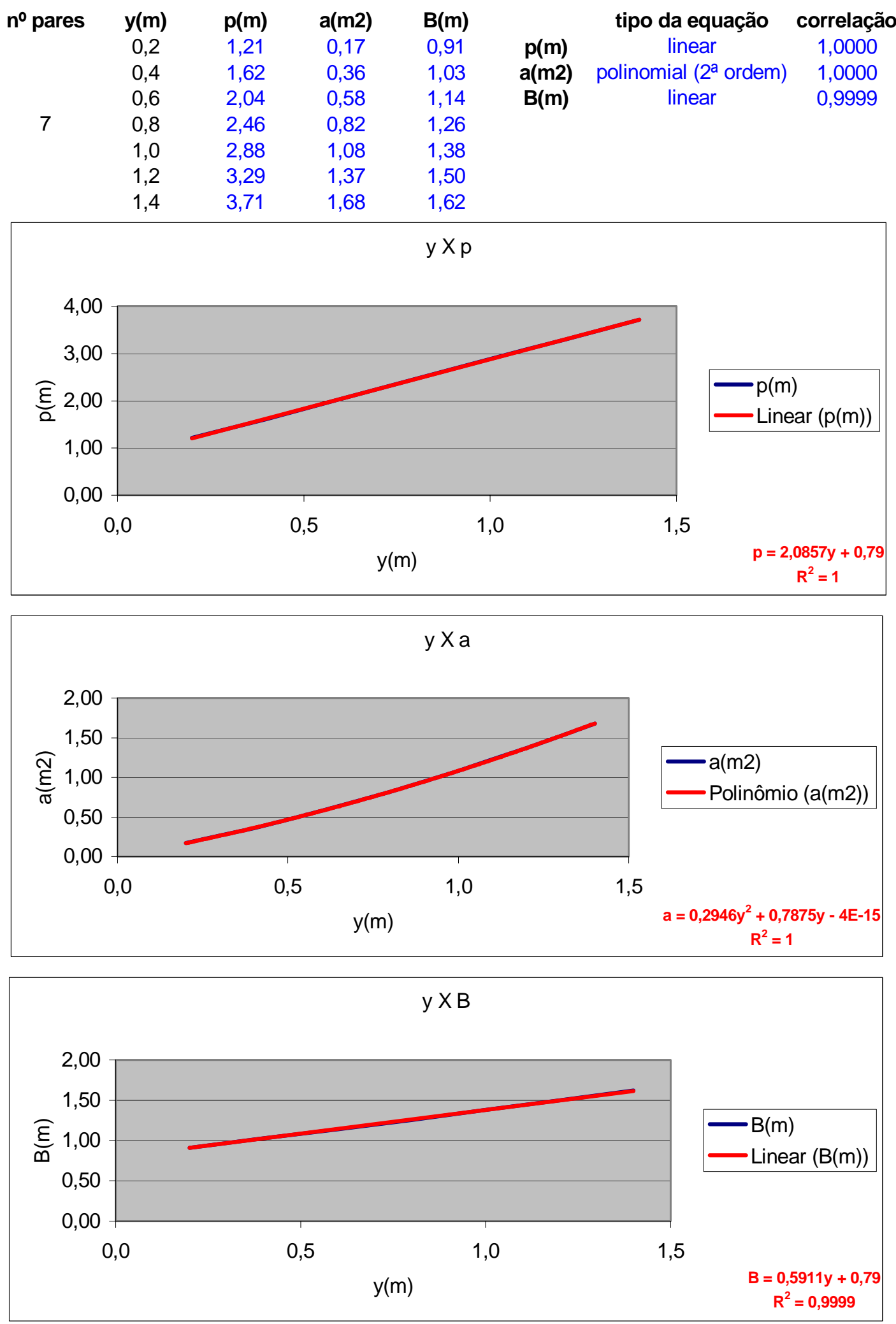
SEÇÃO 15
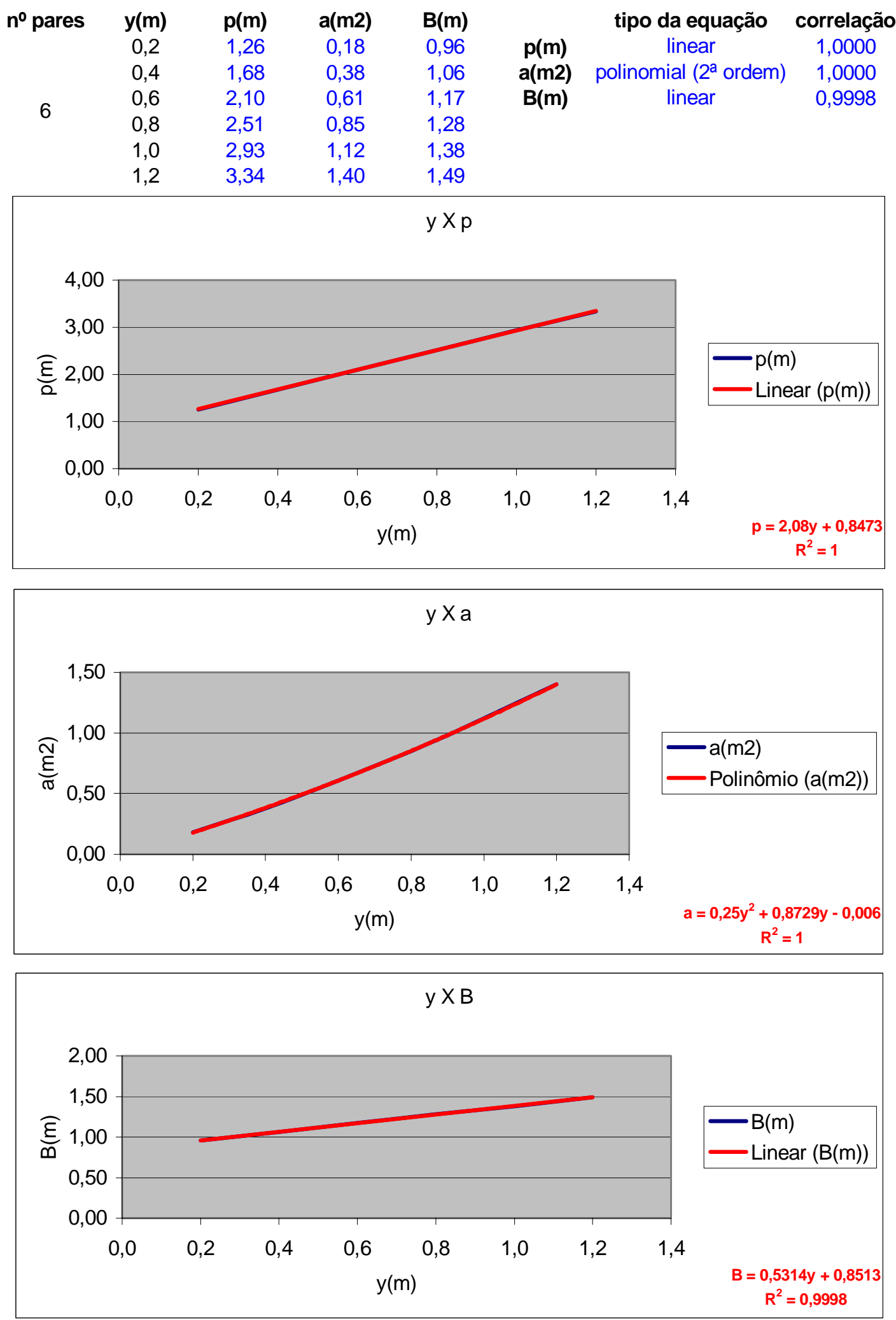


\section{SEÇÃO 16}
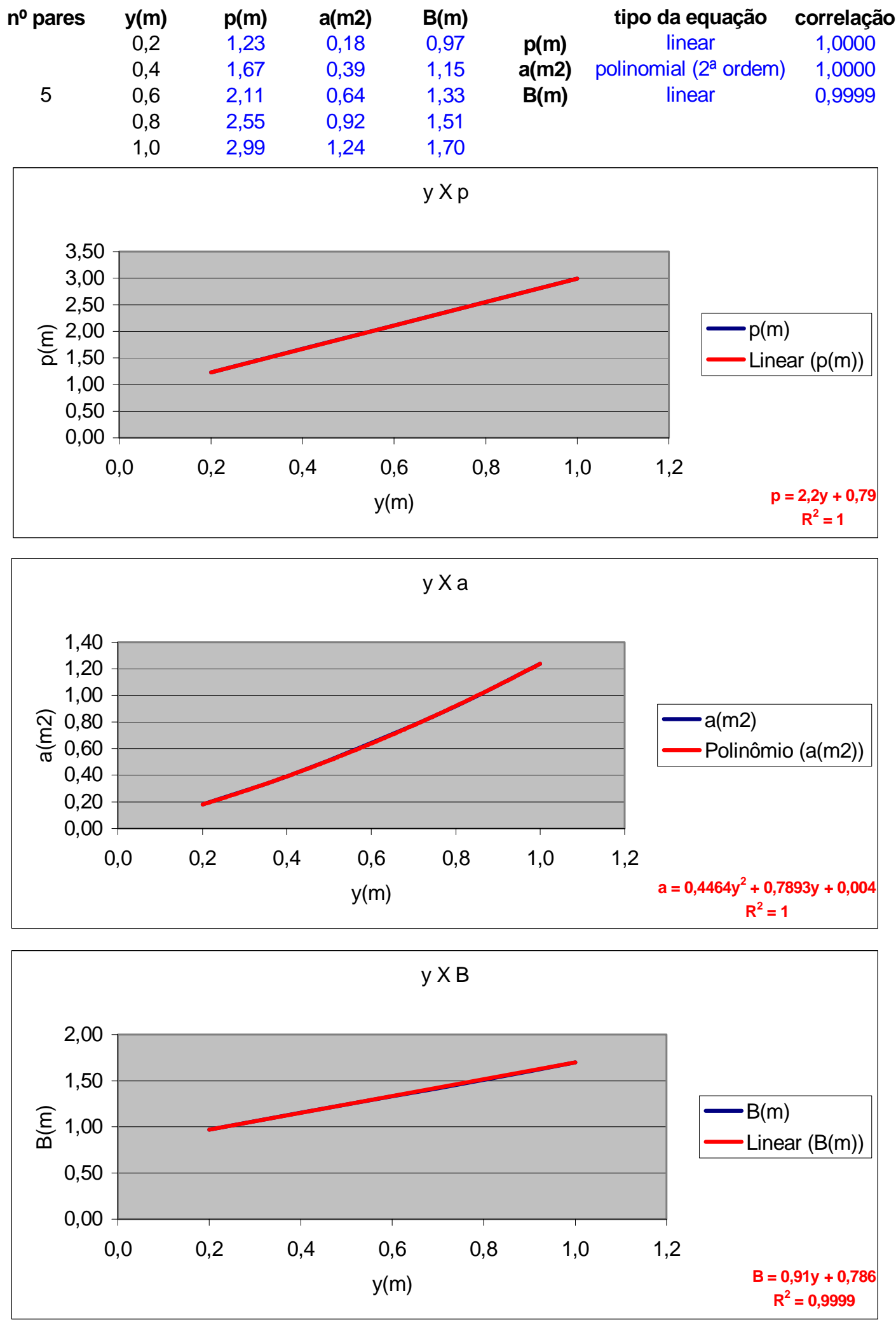


\section{SEÇÕES 17, 18 e 19}
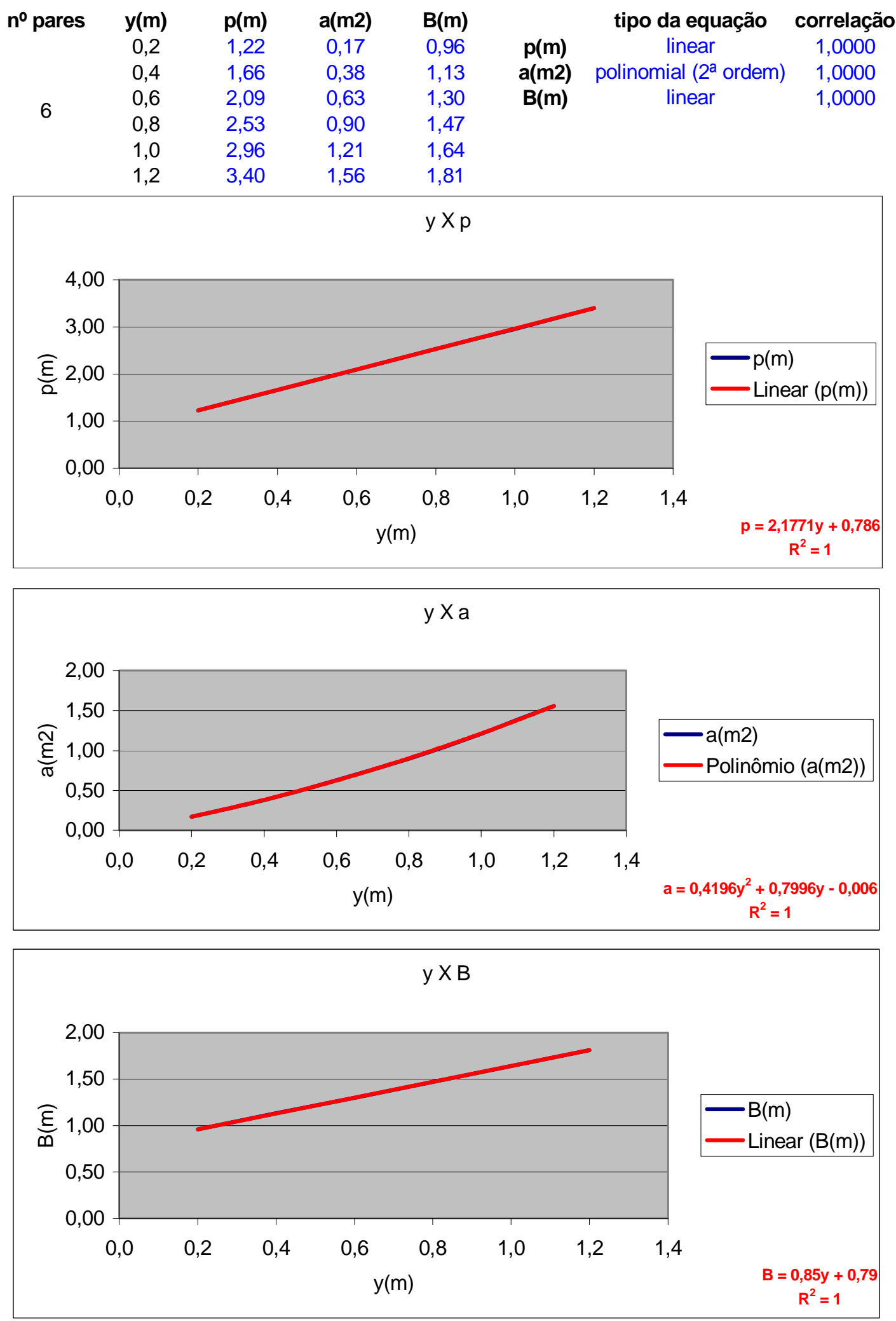
SEÇÃO 20
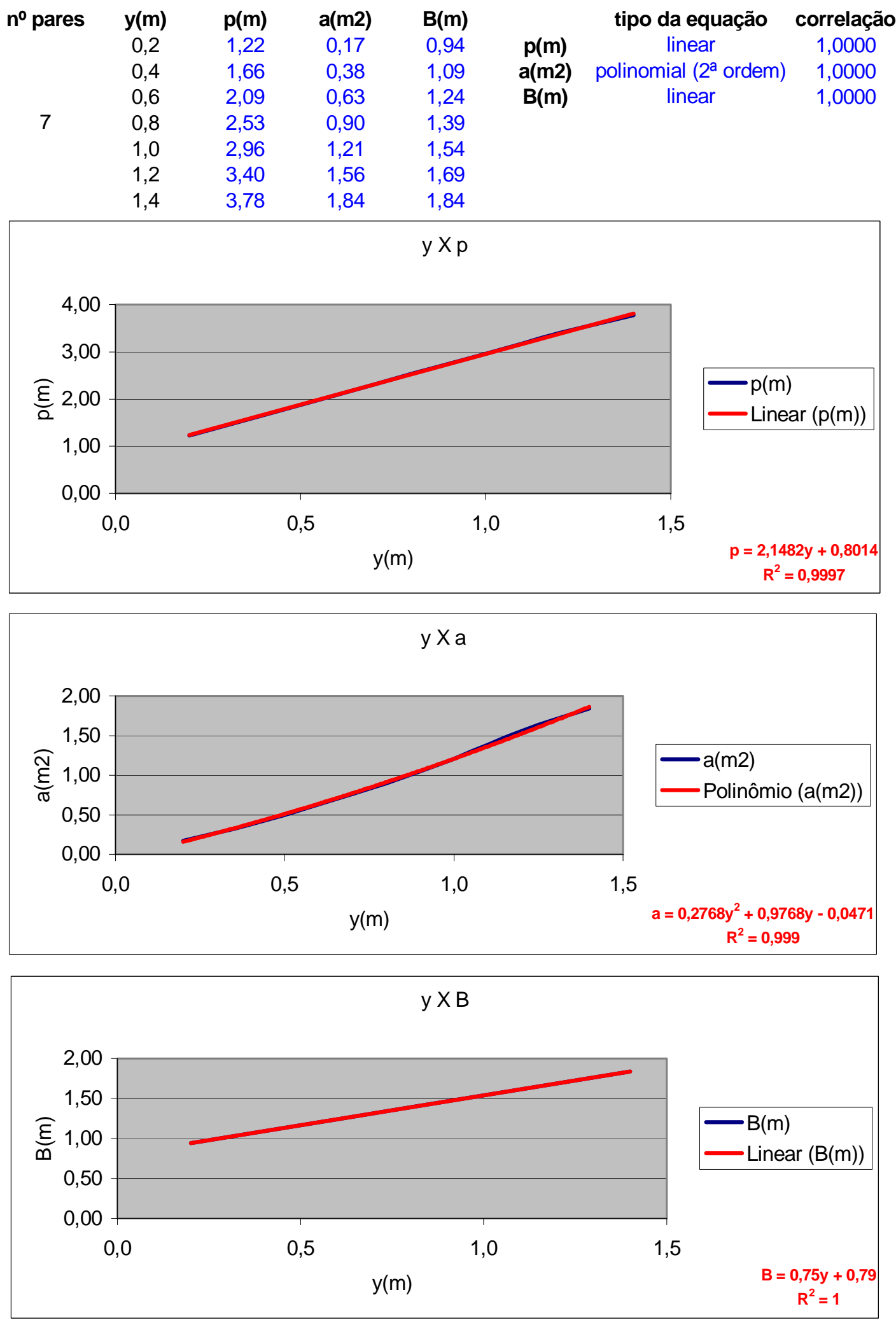


\section{SEÇÃO 21}
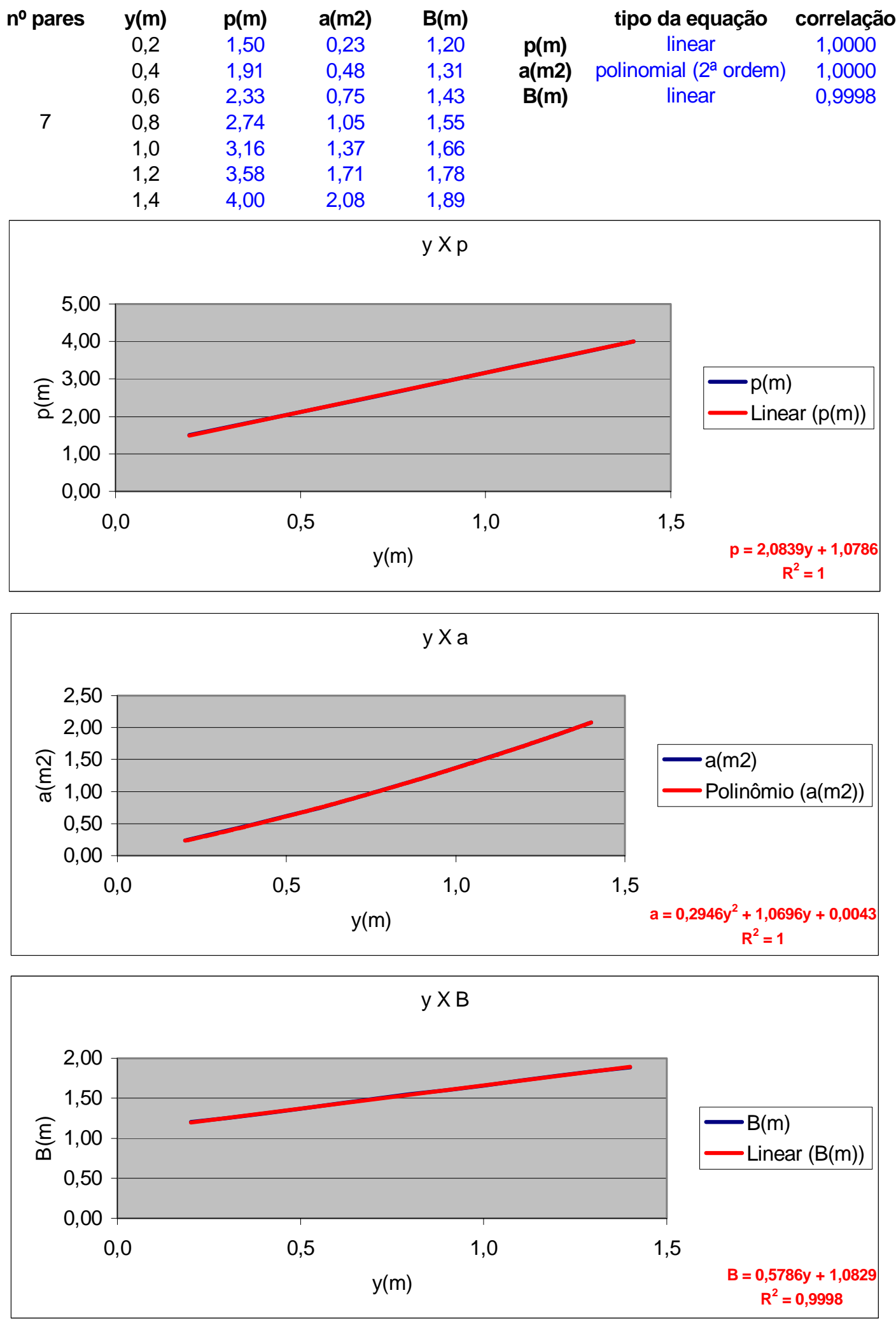
SEÇÃO 22

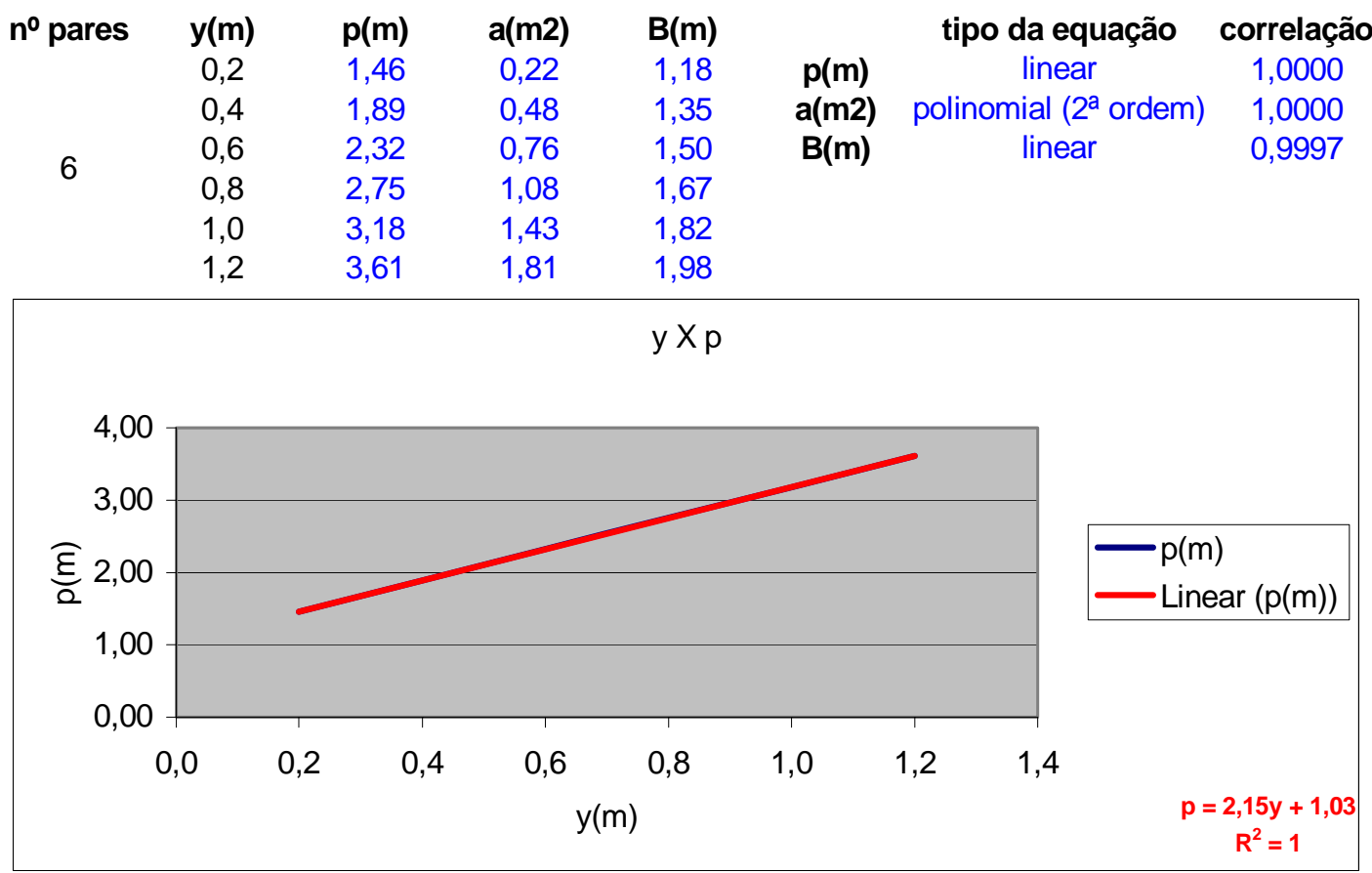

$$
y X a
$$
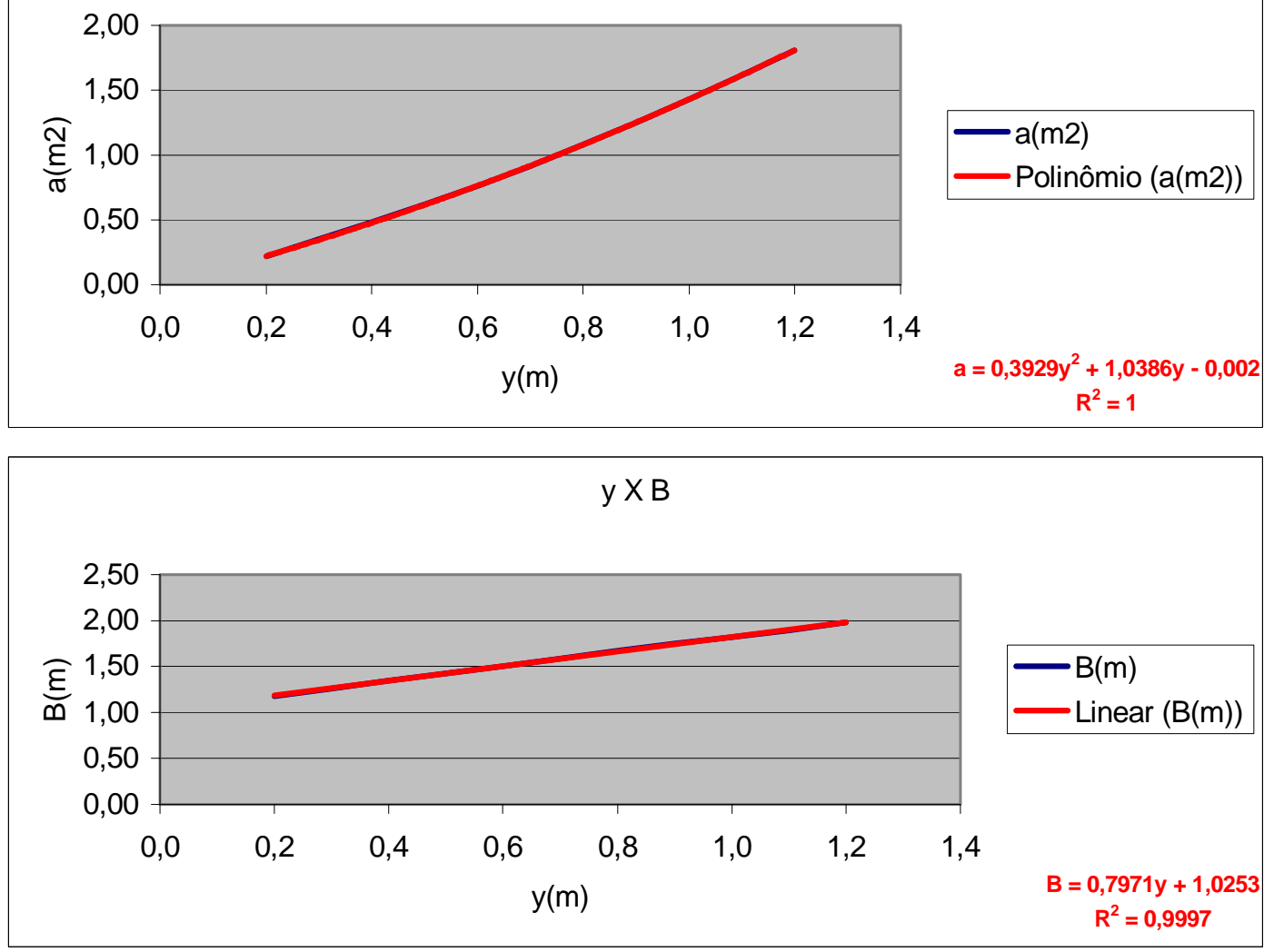


\section{SEÇÕES 23, 24 e 25}

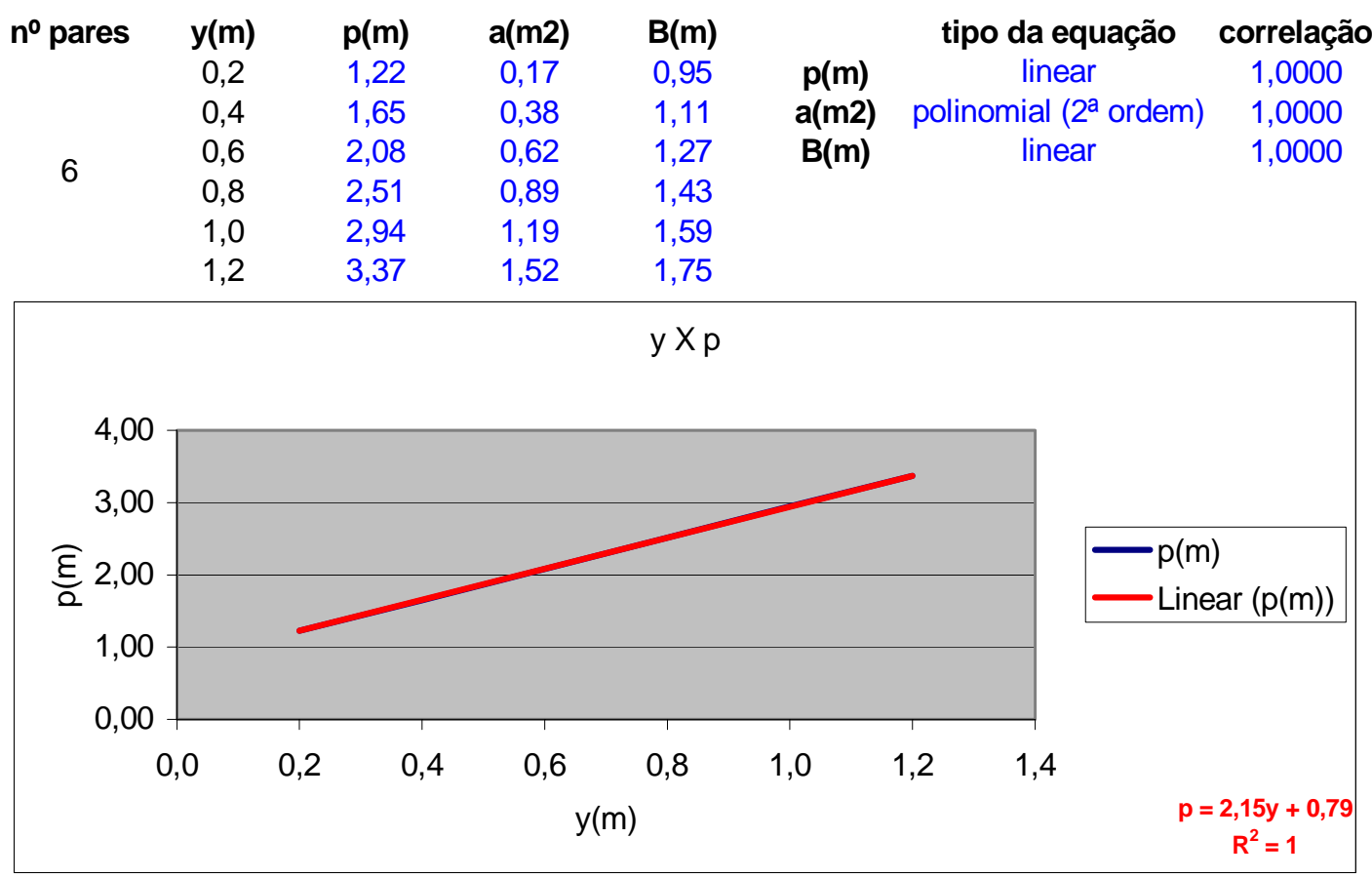

$$
y \times a
$$
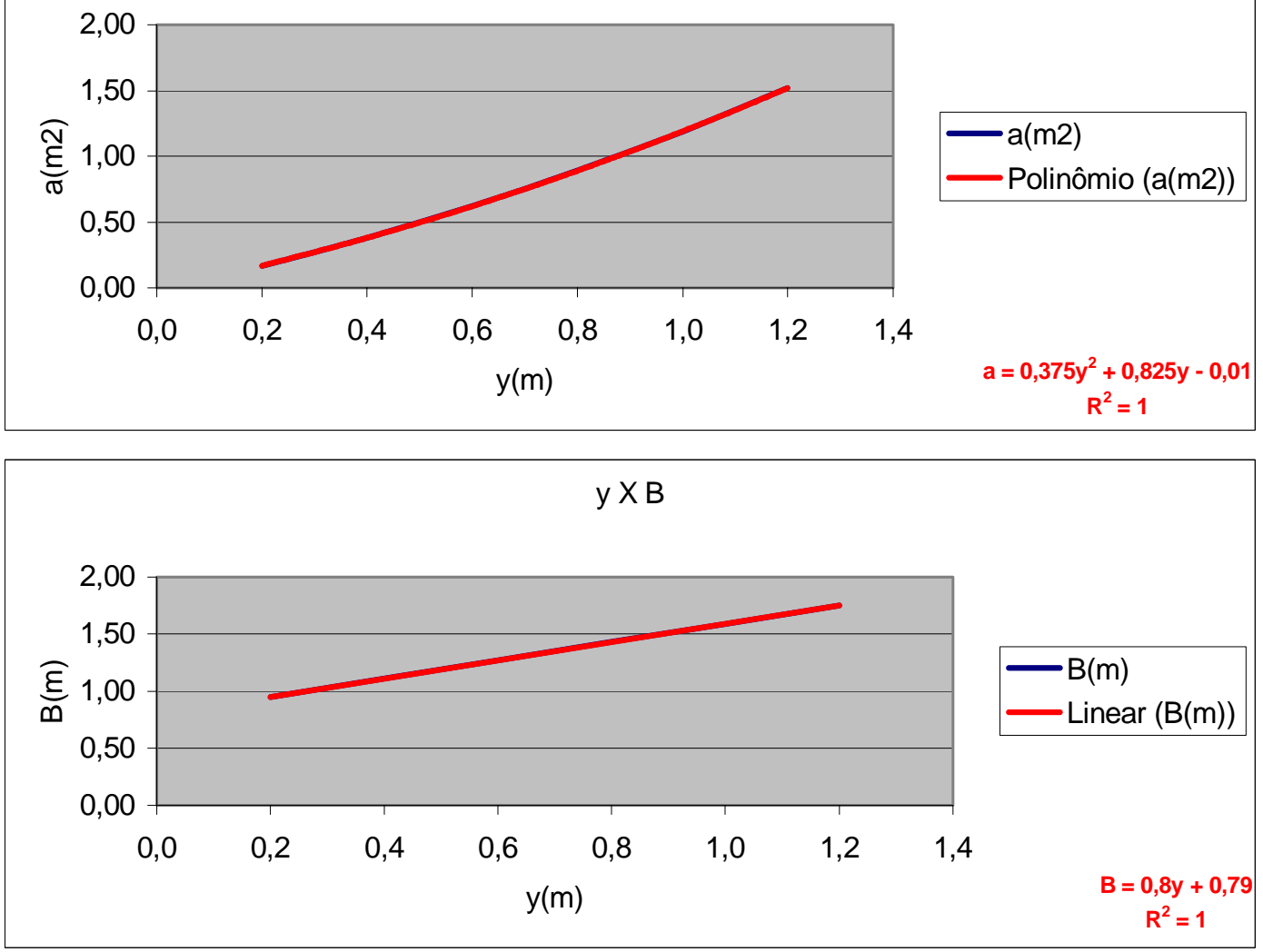
SEÇÃO 26
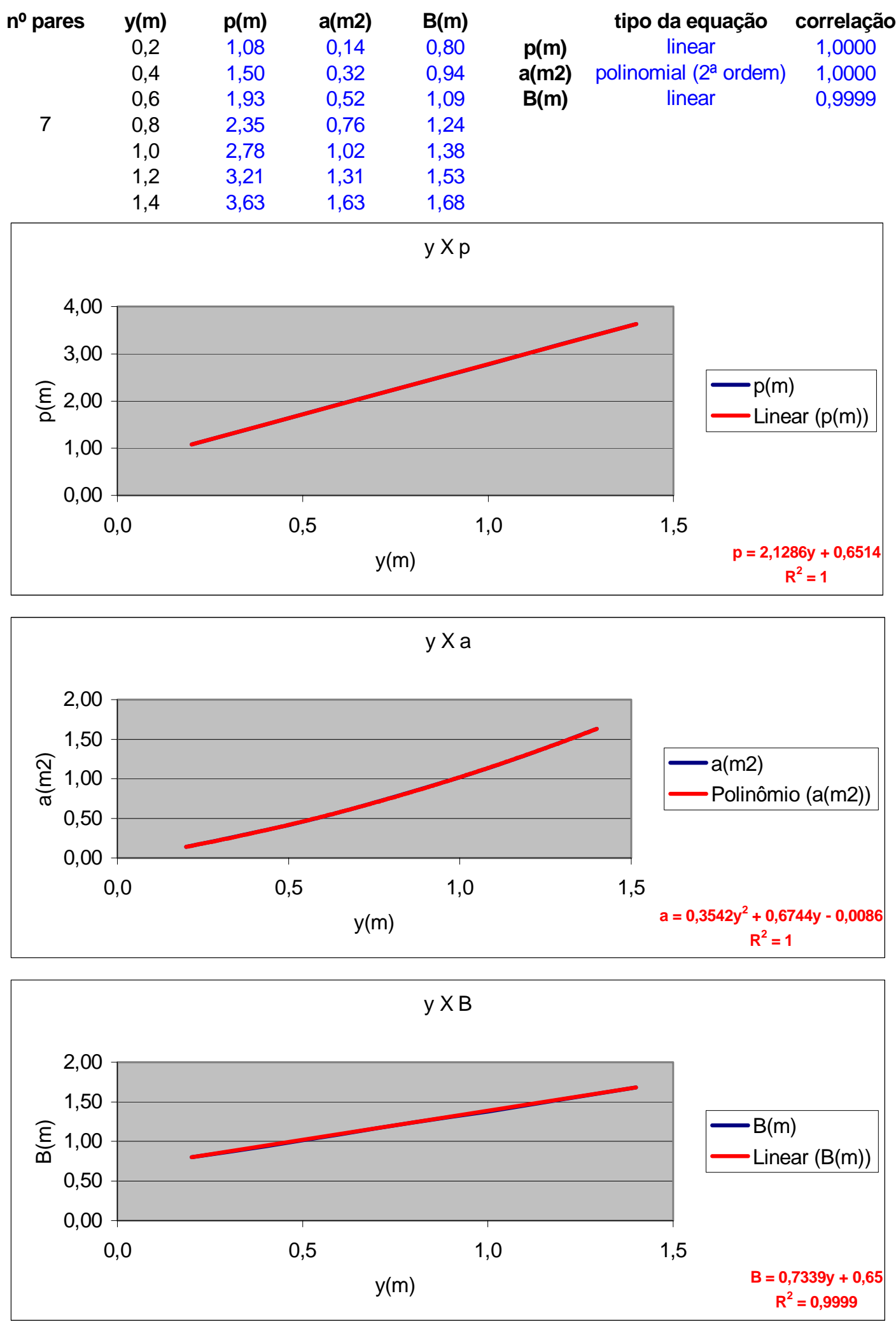


\section{SEÇÃO 27}

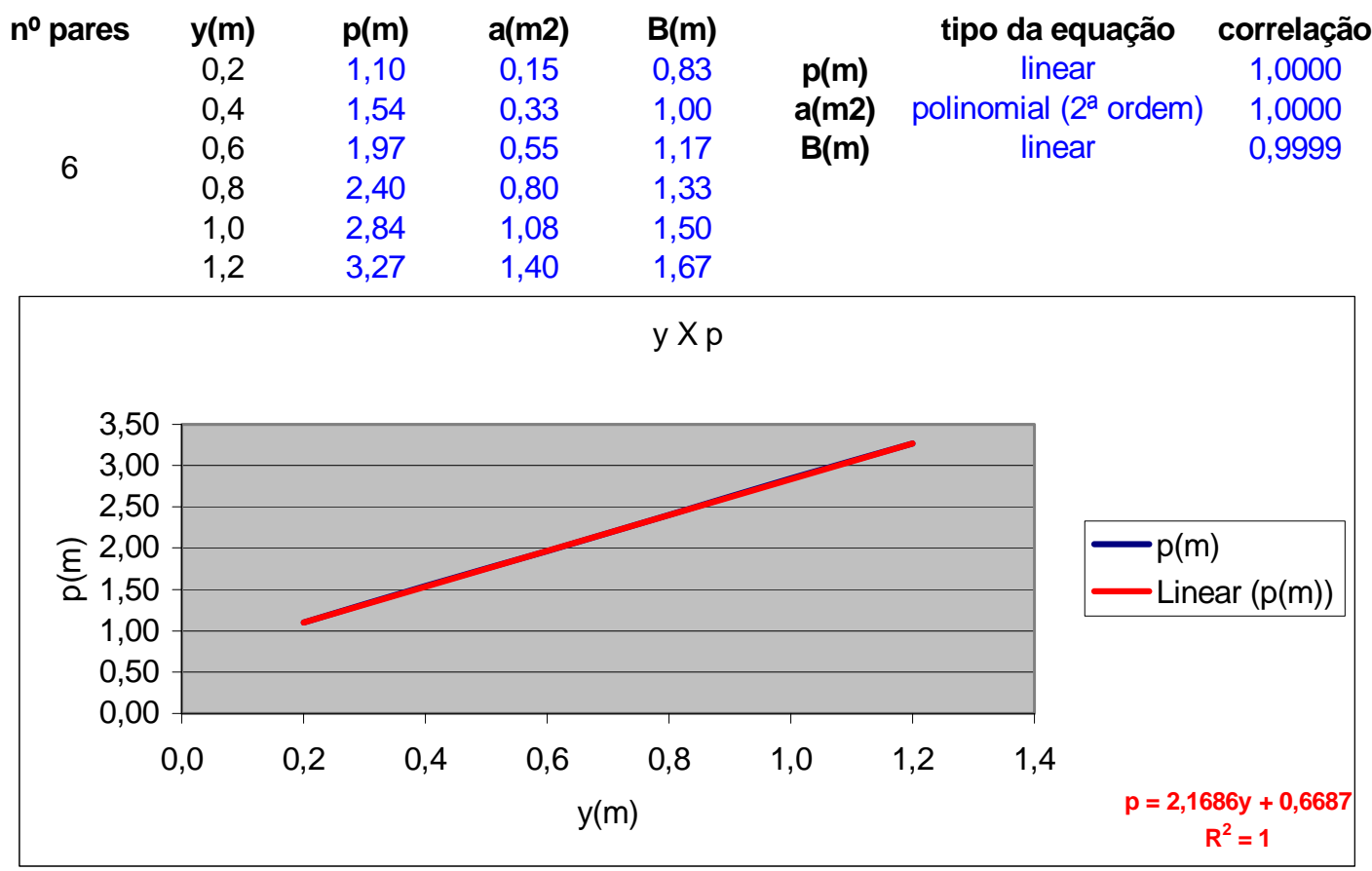

\section{y X a}
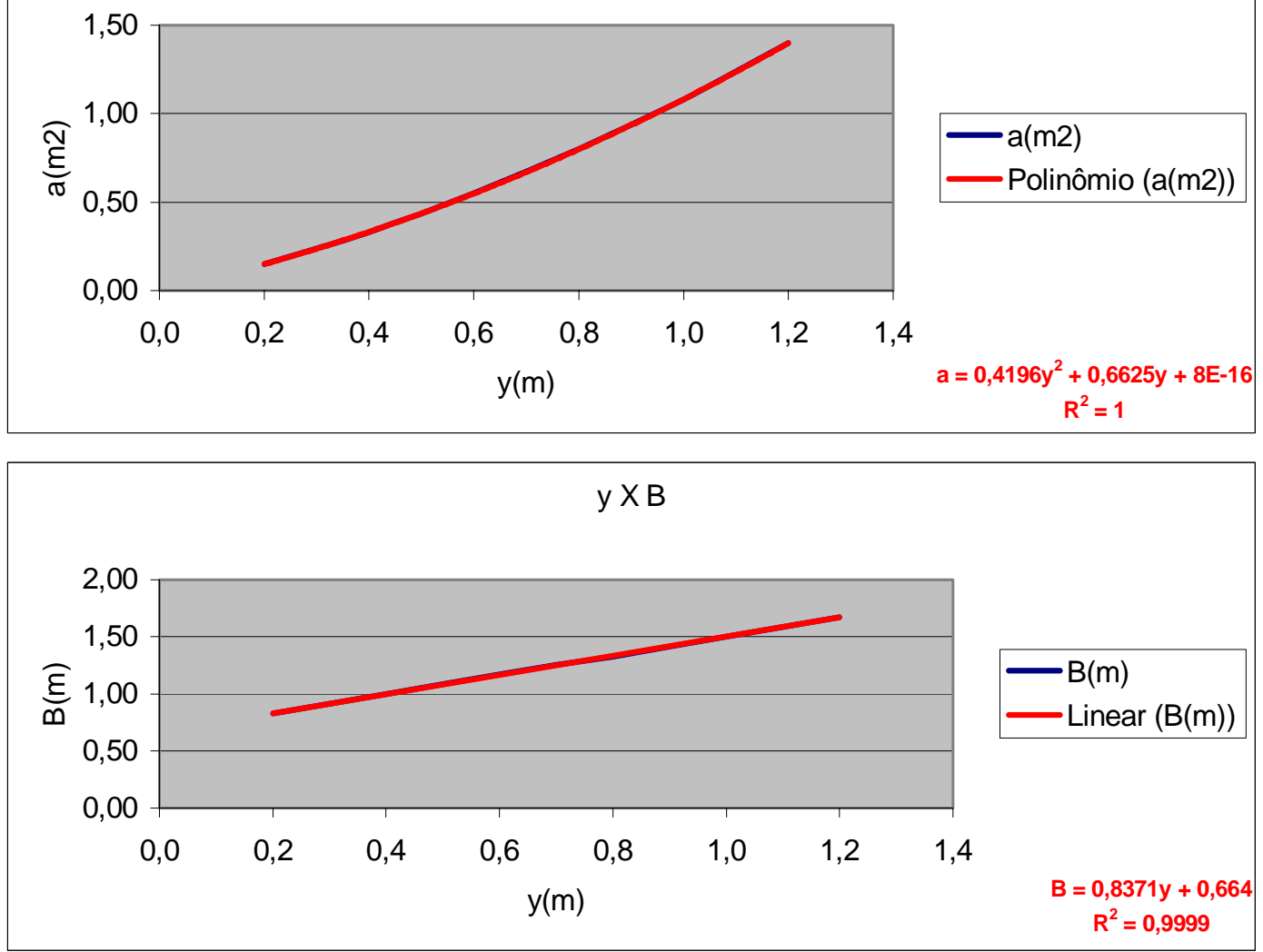


\section{SEÇÃO 28}
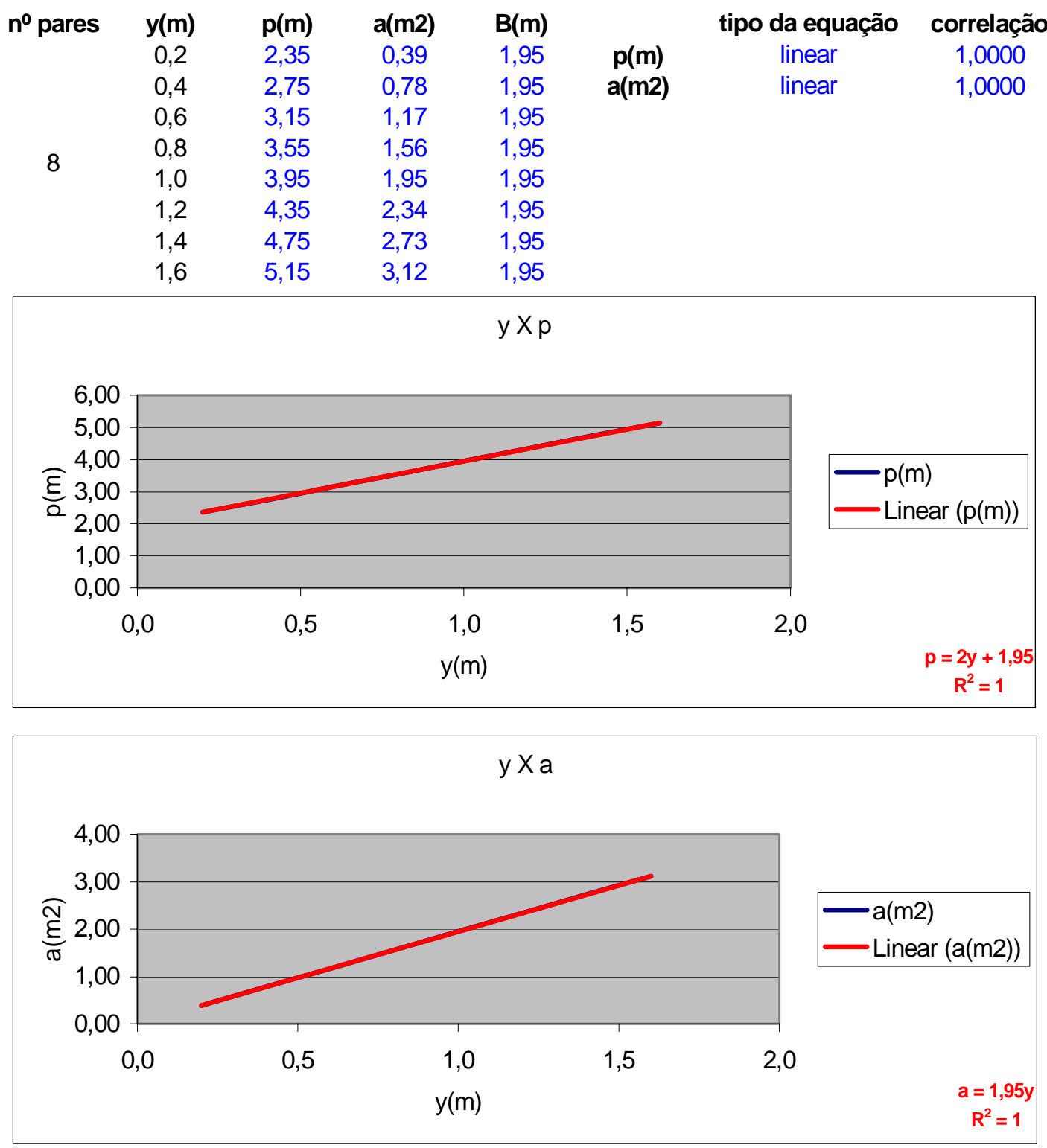


\section{SEÇÃO 29}

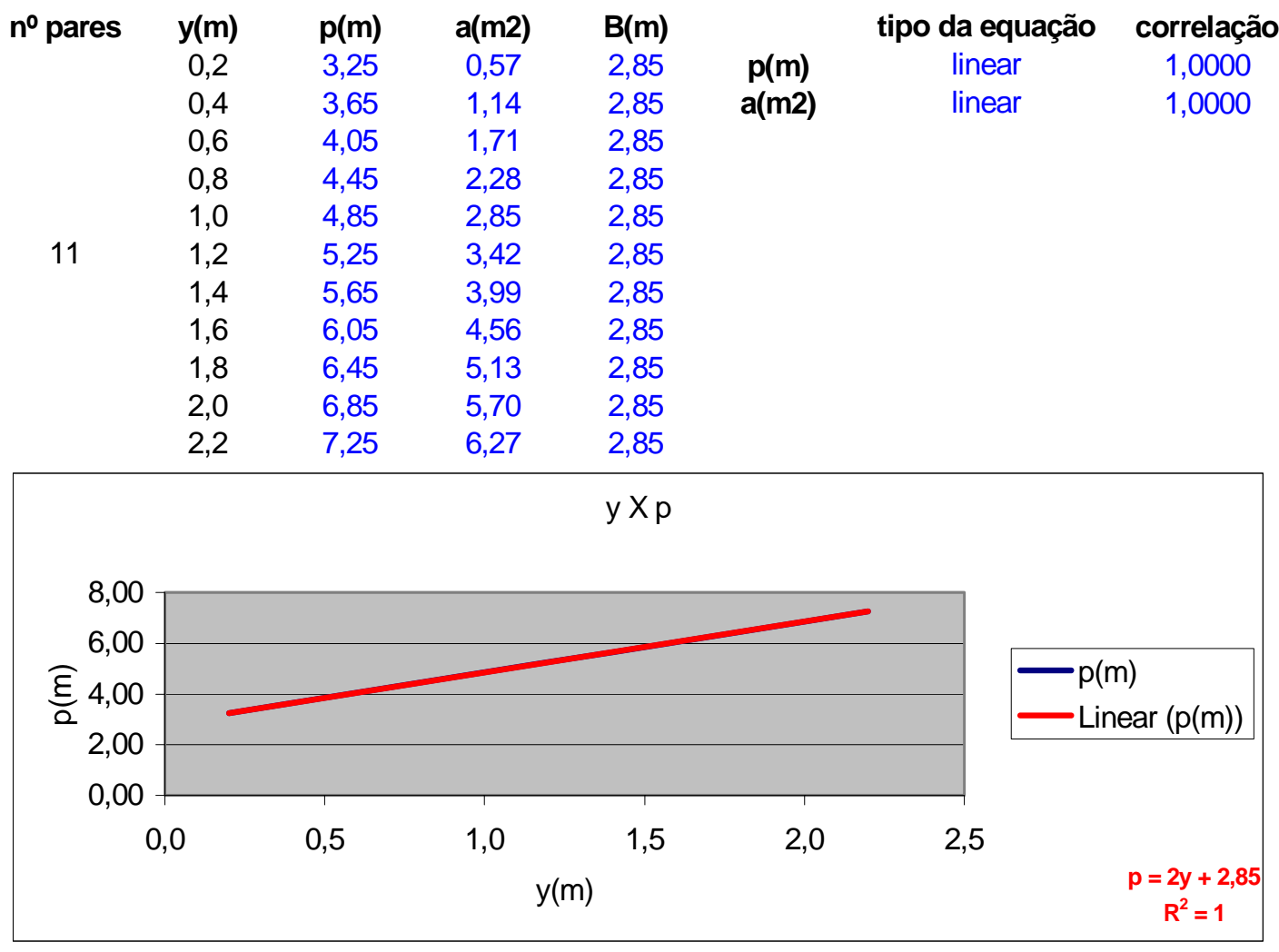

yXa

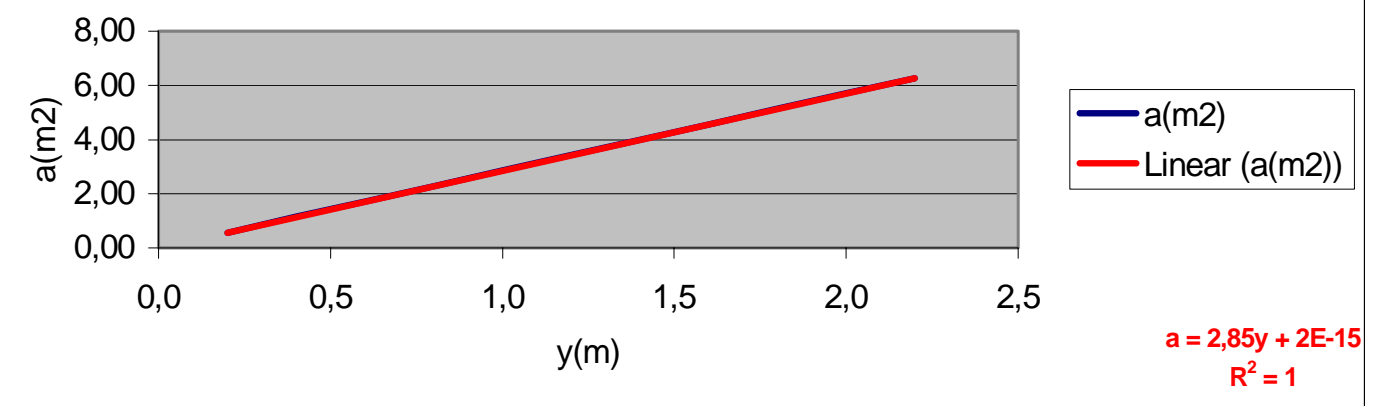


SEÇÃO 30

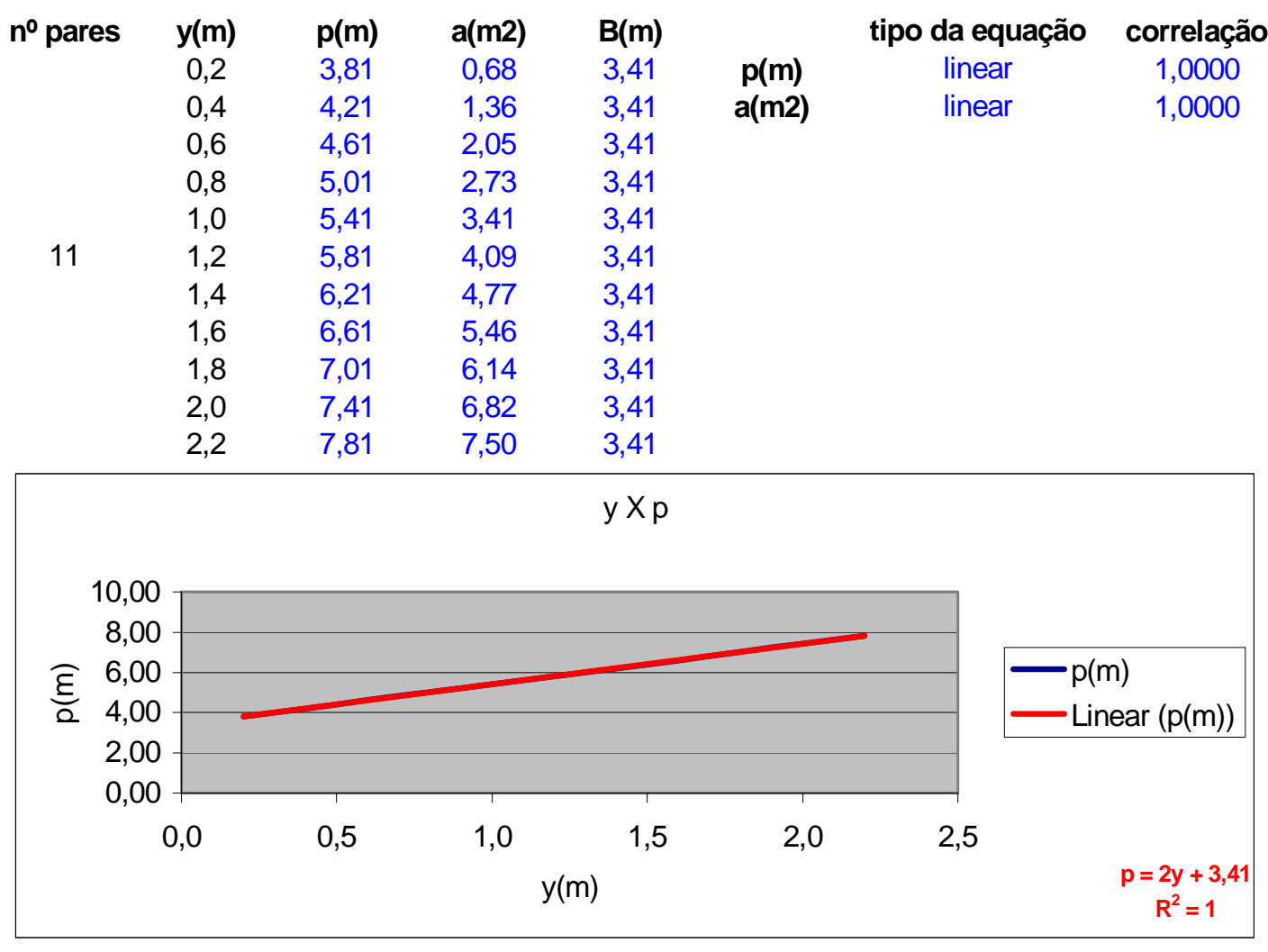

$y \times a$

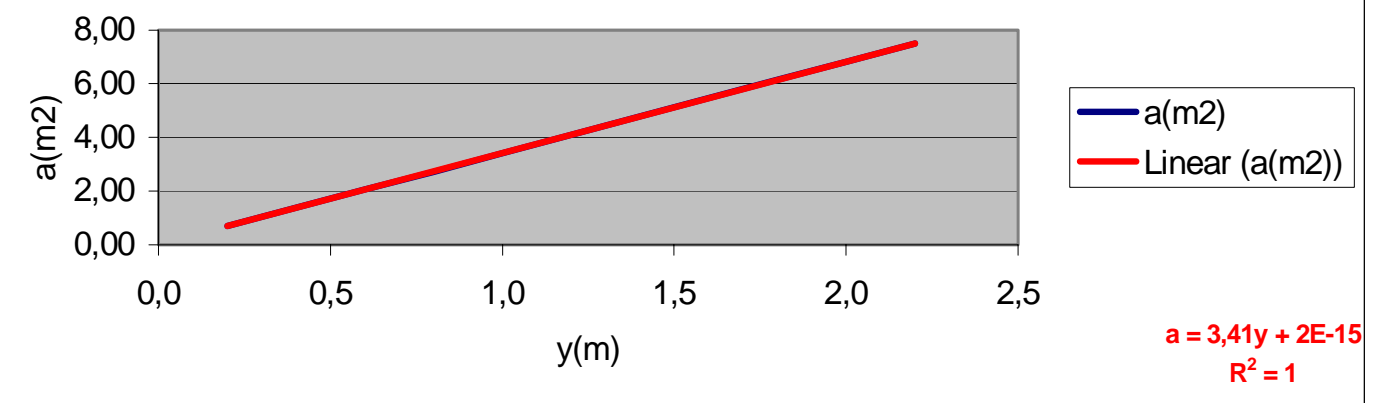


Caso 2: Canal do Trabalhador ( Seções características - esc.gráfica)
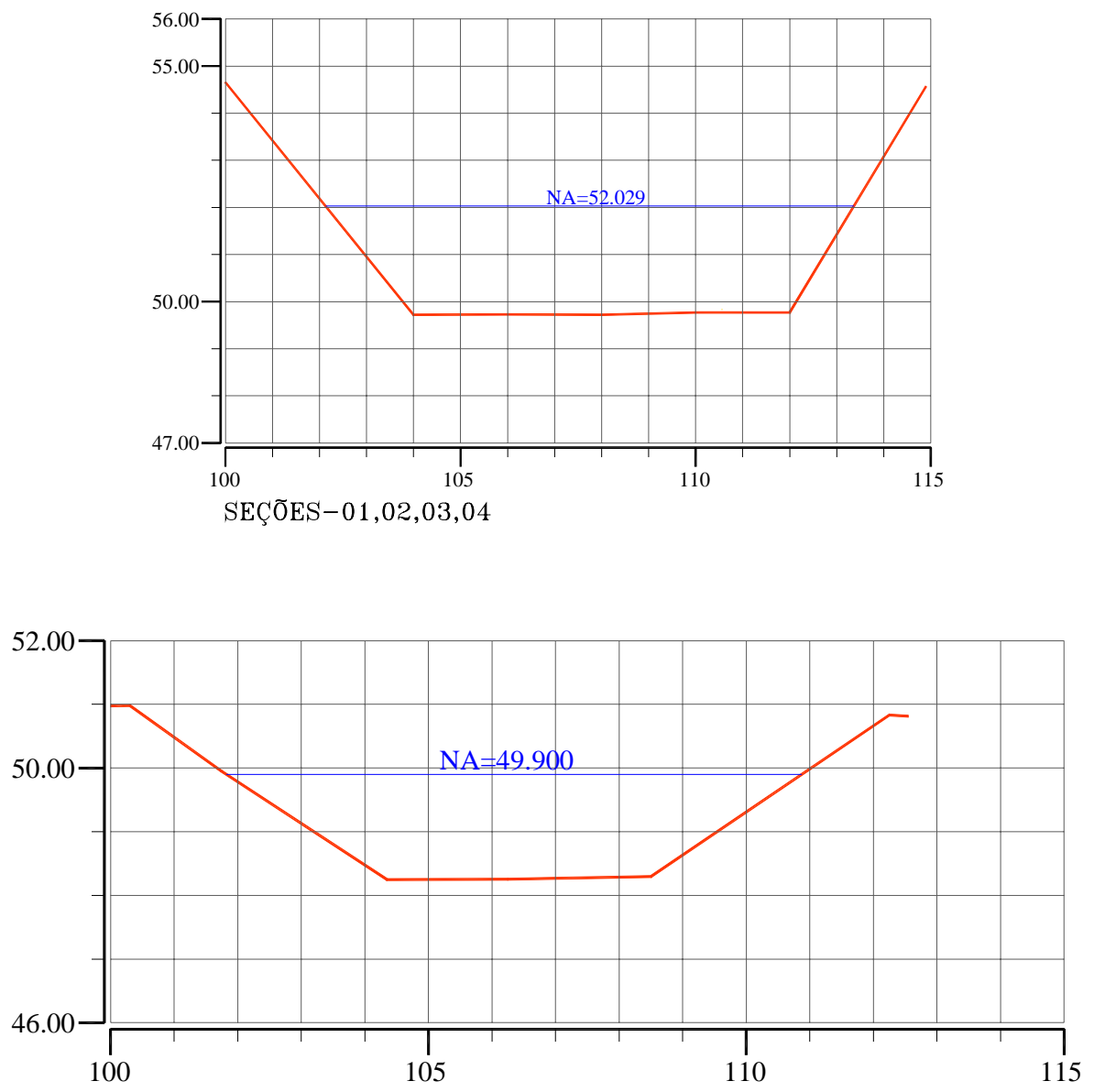

SEÇOES-07,08,09,10

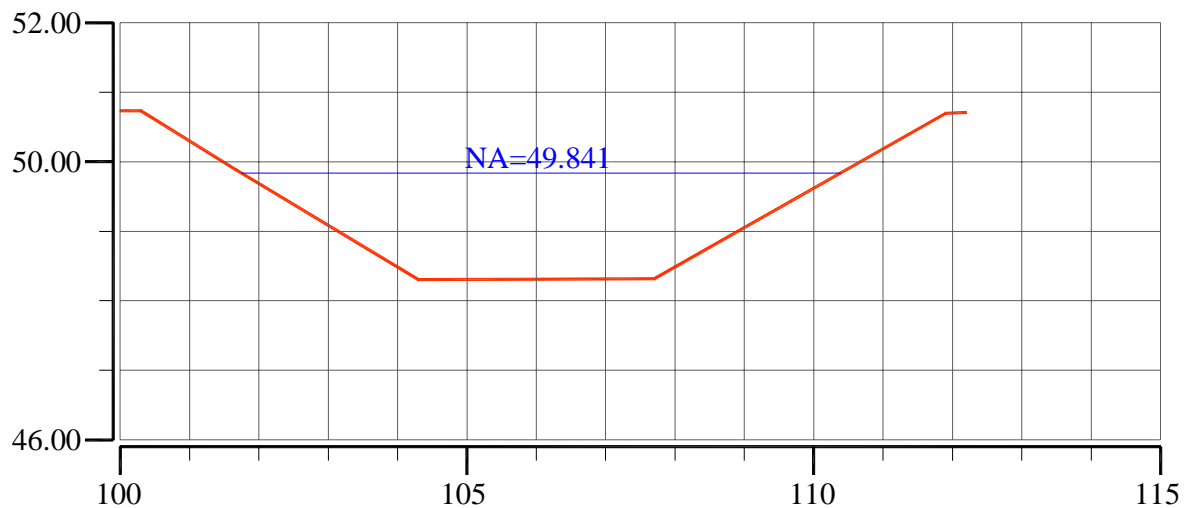

SEÇÃO-1 1 


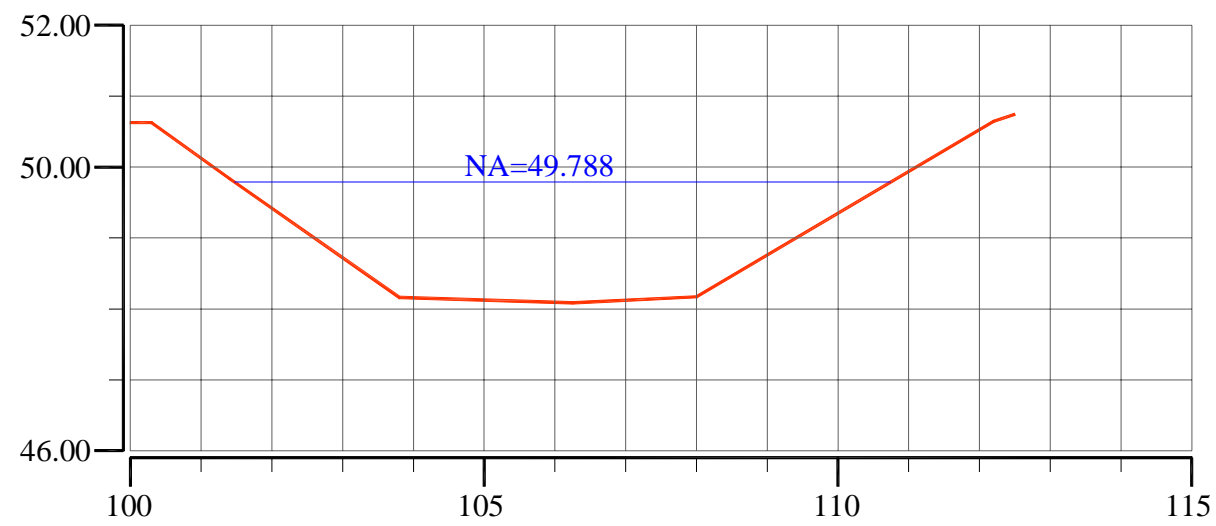

SEÇ̃̃O-12

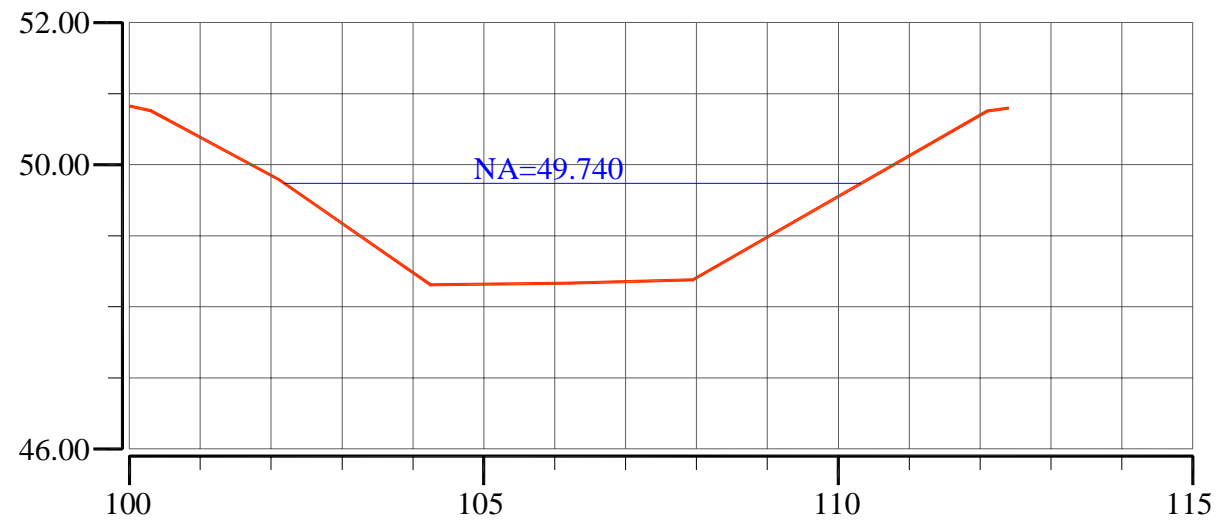

SECOES-13,14

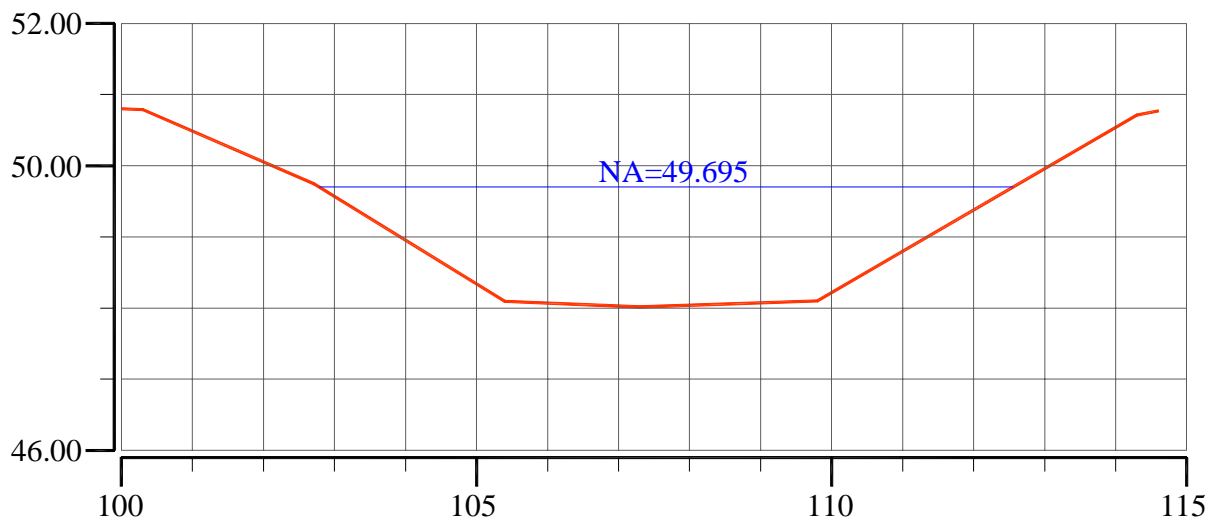

SEÇÃO-15 

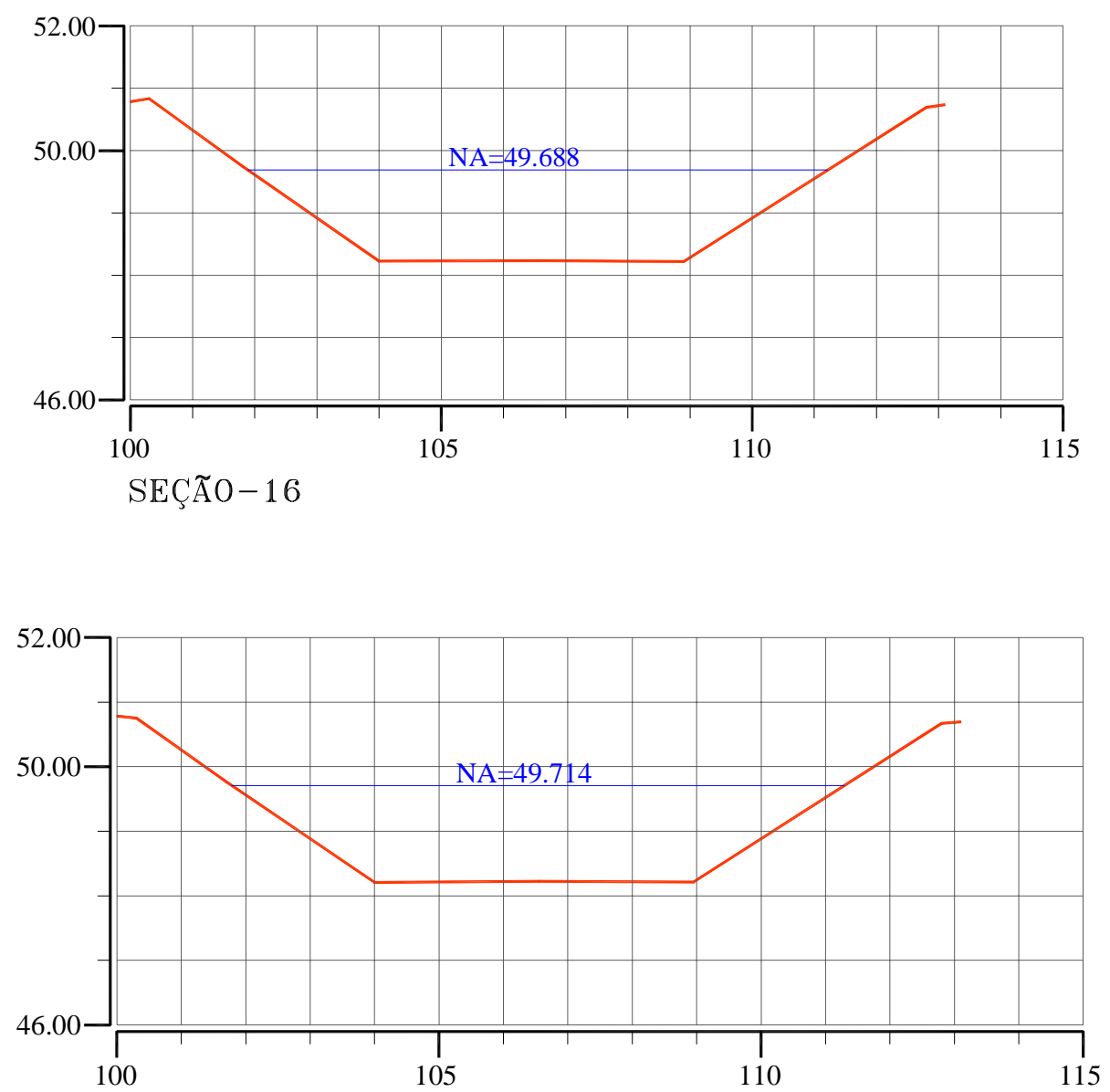

SEÇÃO-17

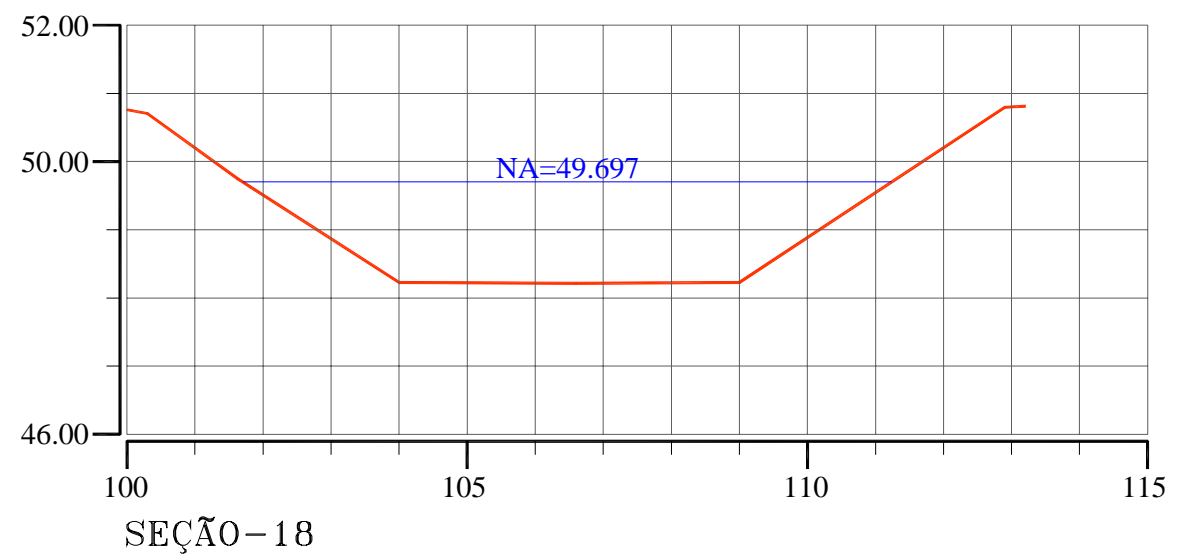



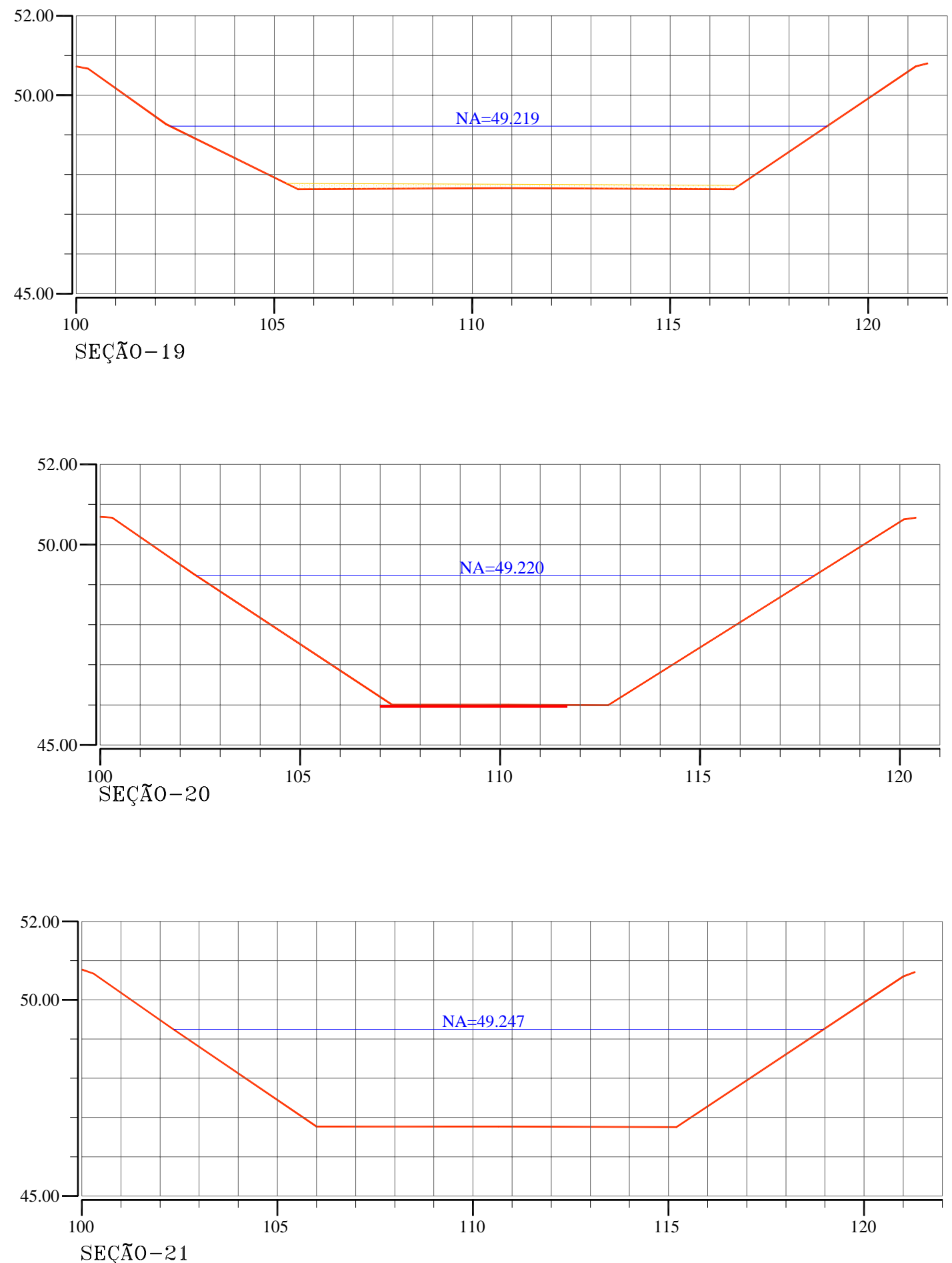


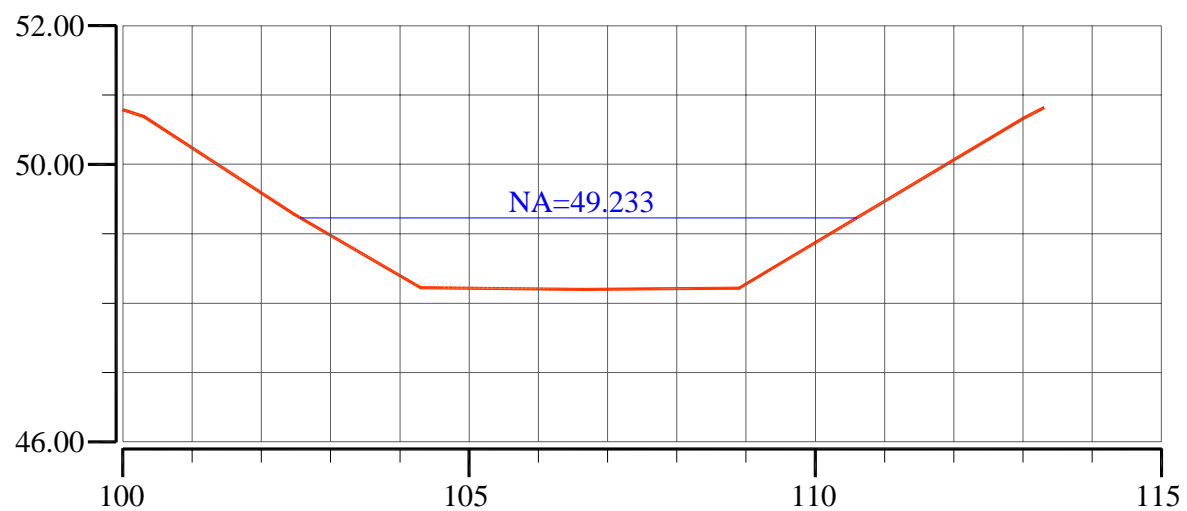

SEÇÃO-22

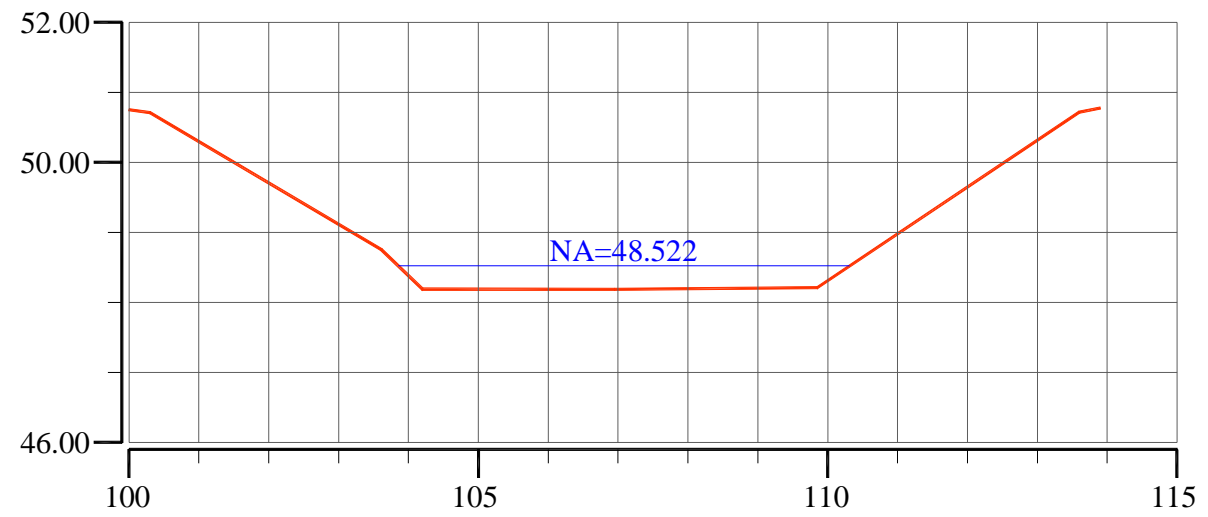

SEÇÃO-23

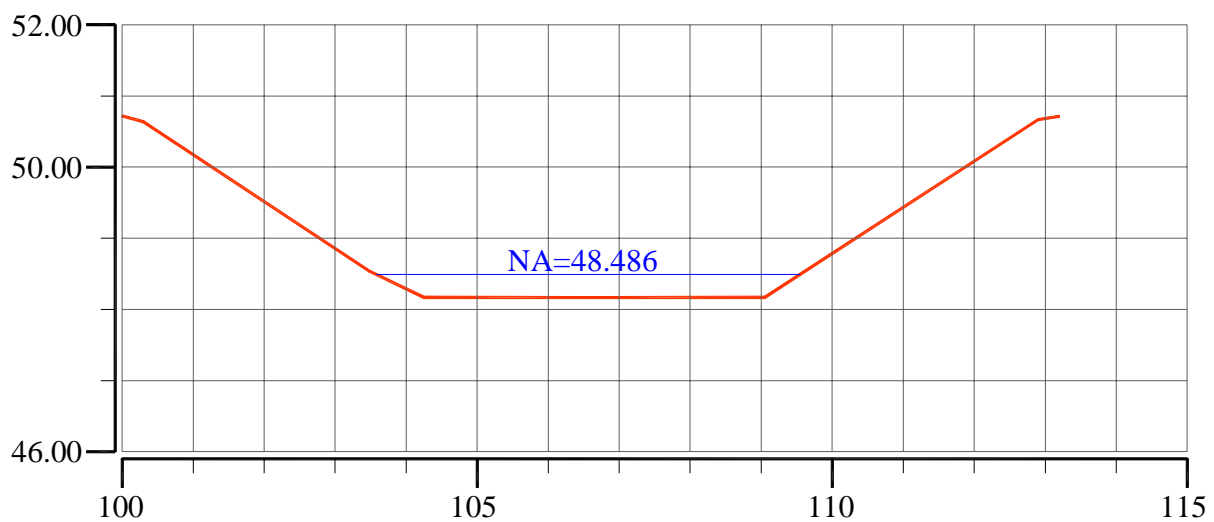

SEÇÃO-24 

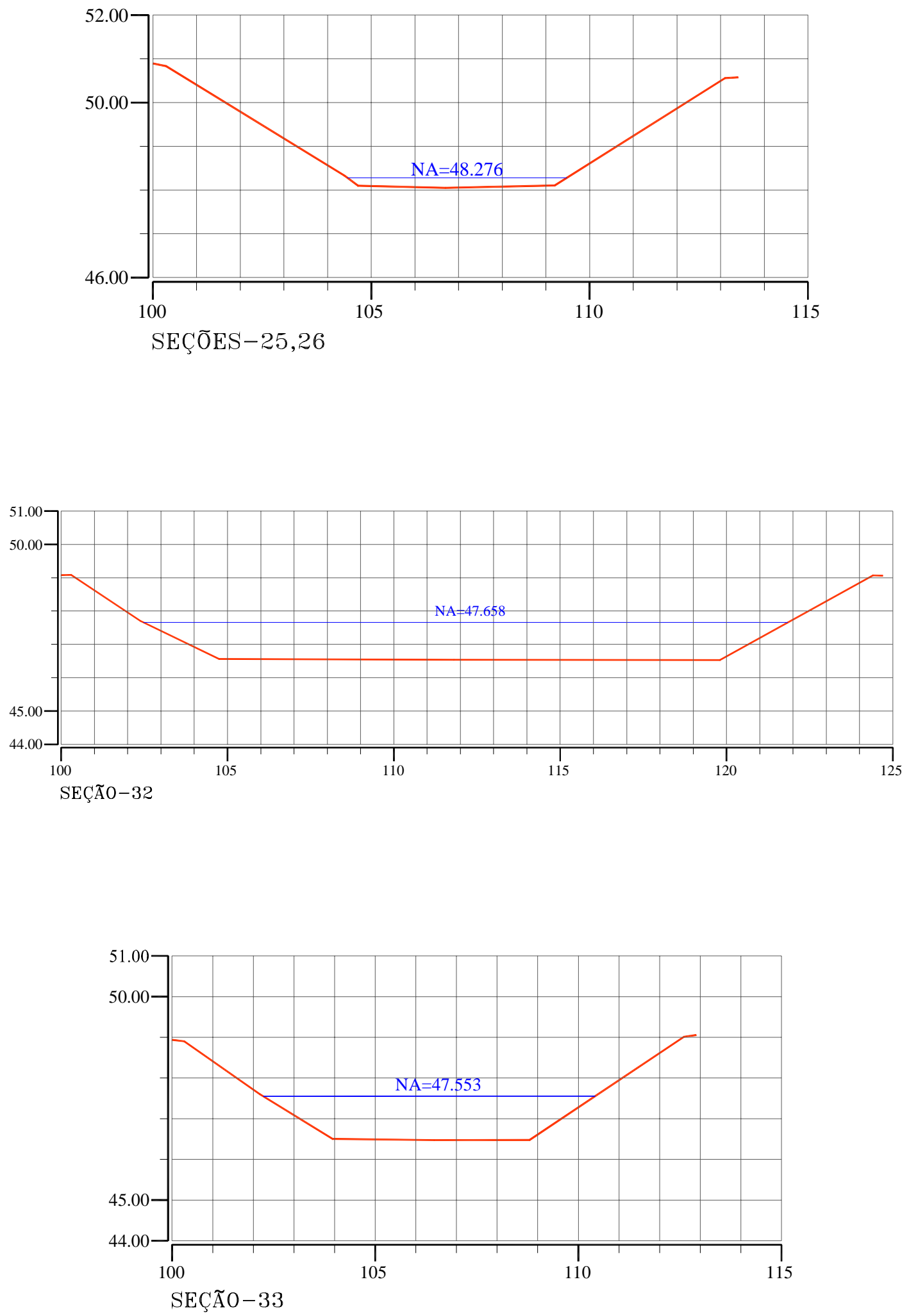


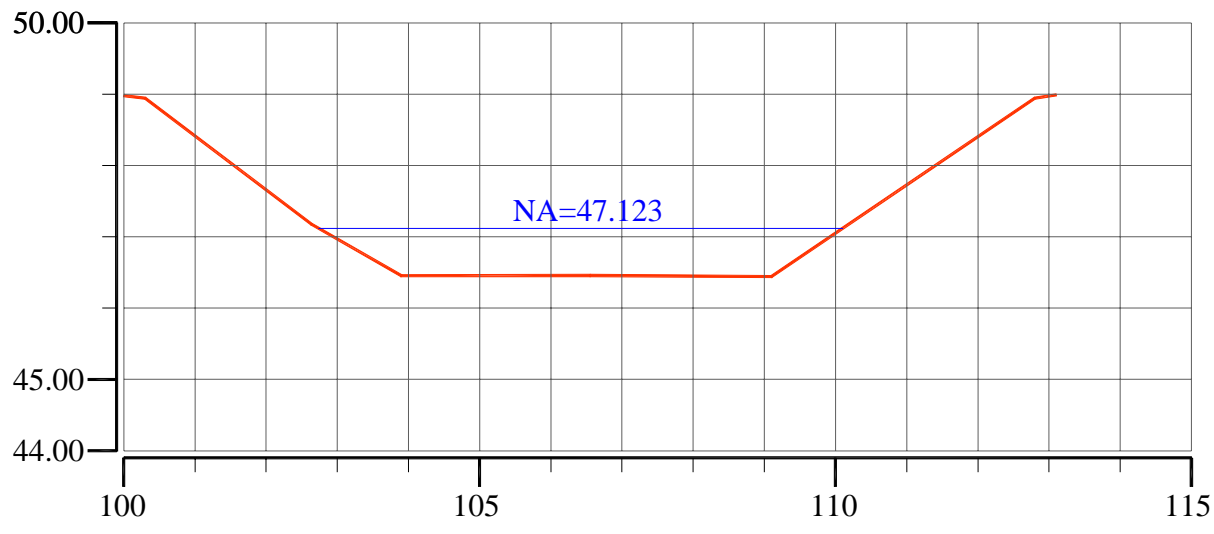

SEÇÕES-34,35

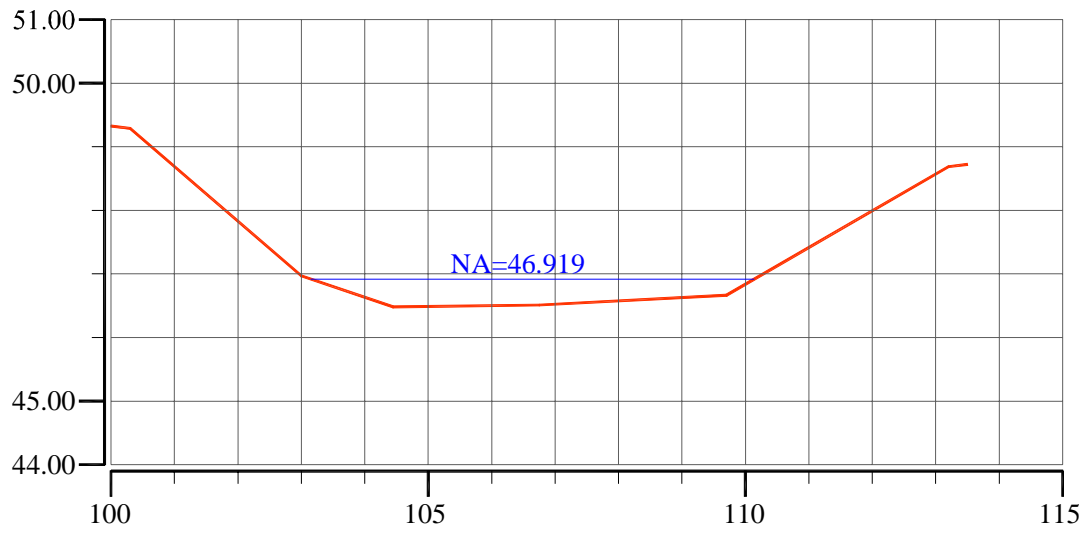

SECOES-36,37

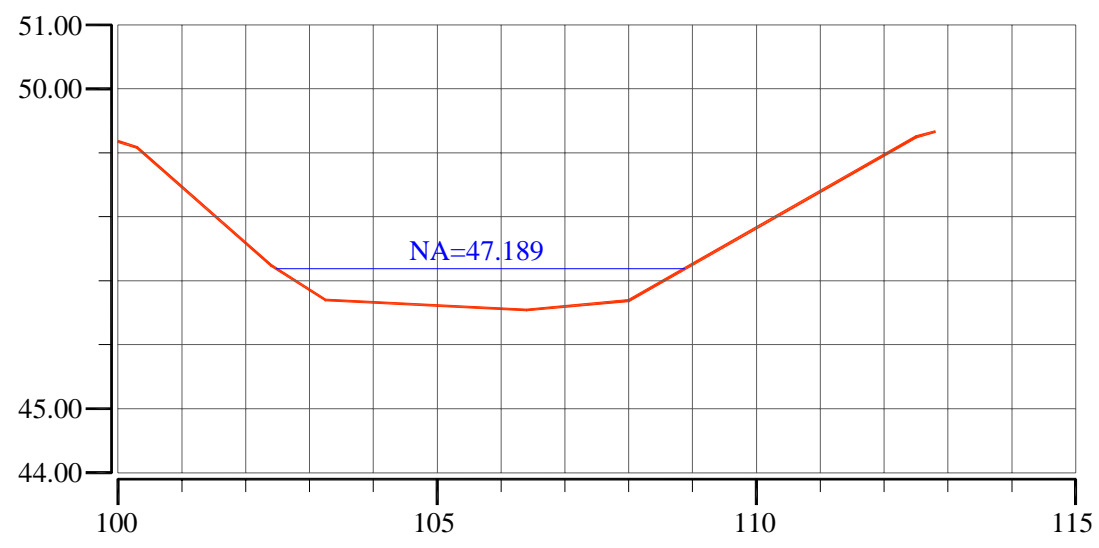

SEÇÕES-38,39 


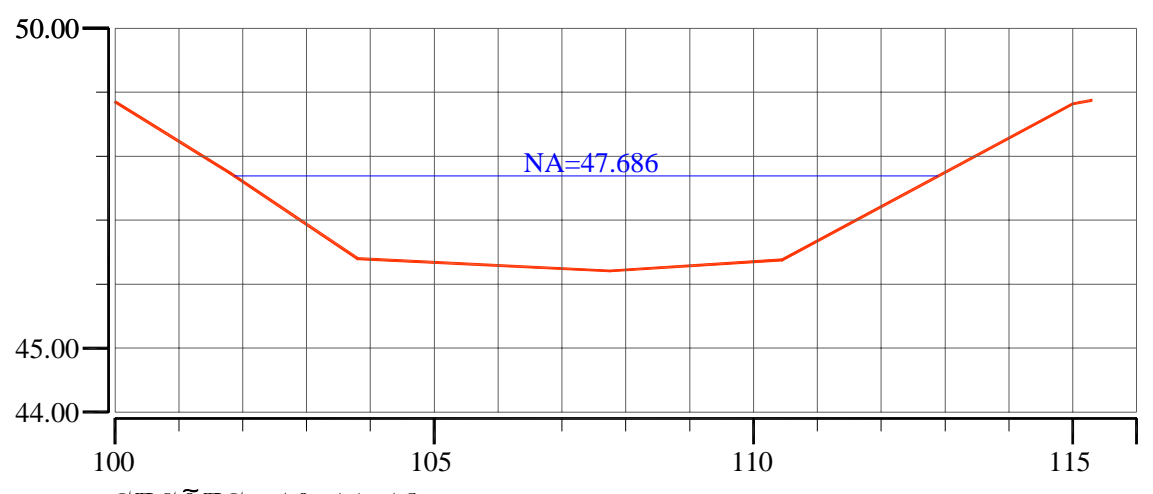

SEÇÕES-40,41,42

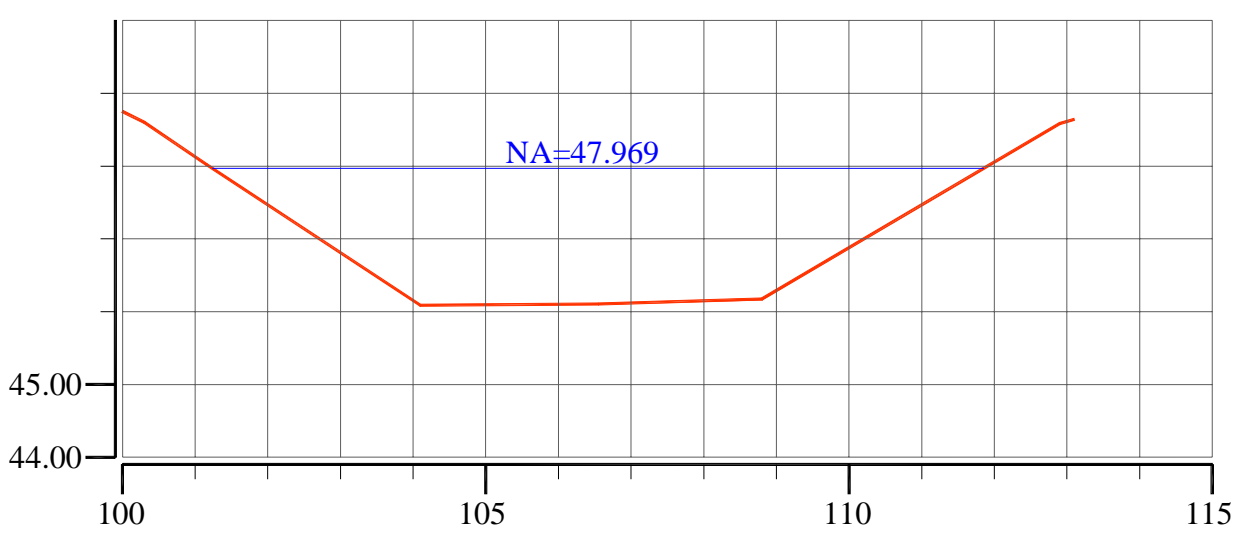

SEÇÕES-43,44,45

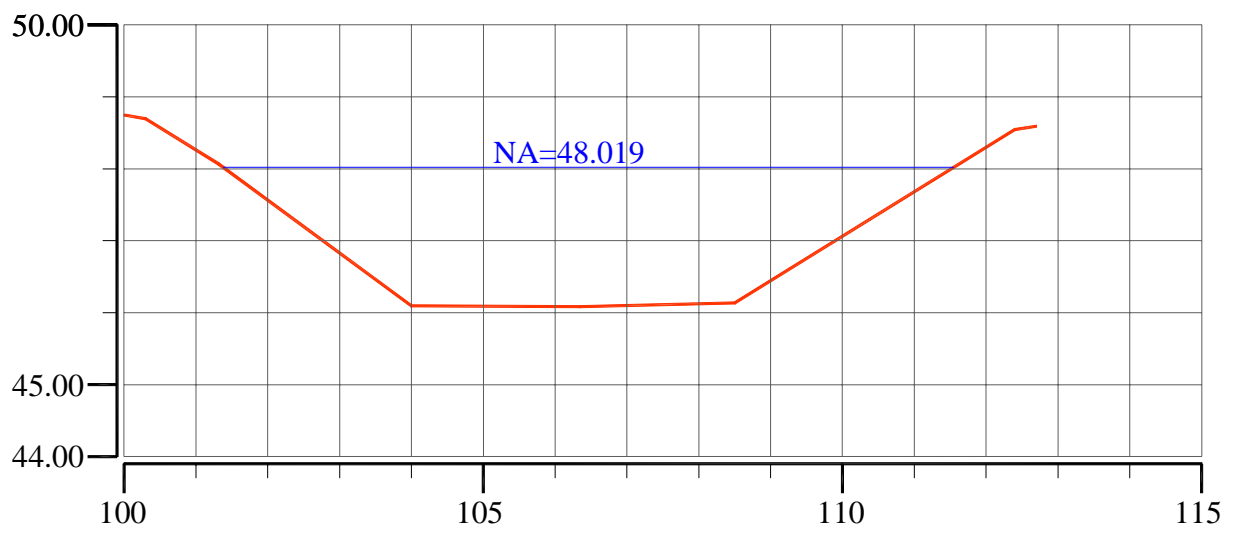

SEÇÕES-46,47,48 


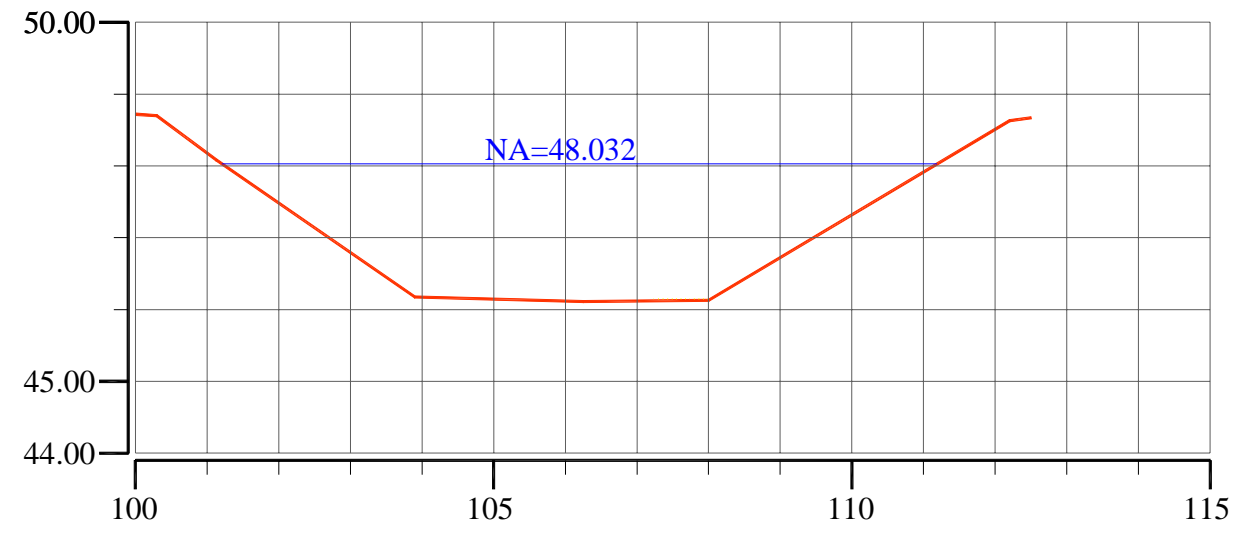

SEÇ̃̃O-49

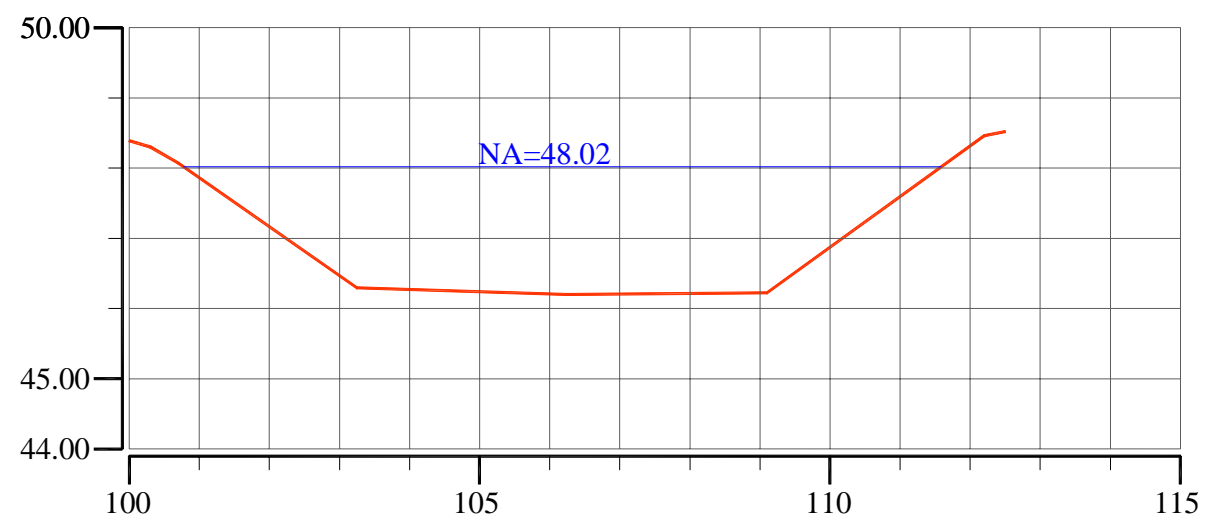

SEÇ̃̃O-50

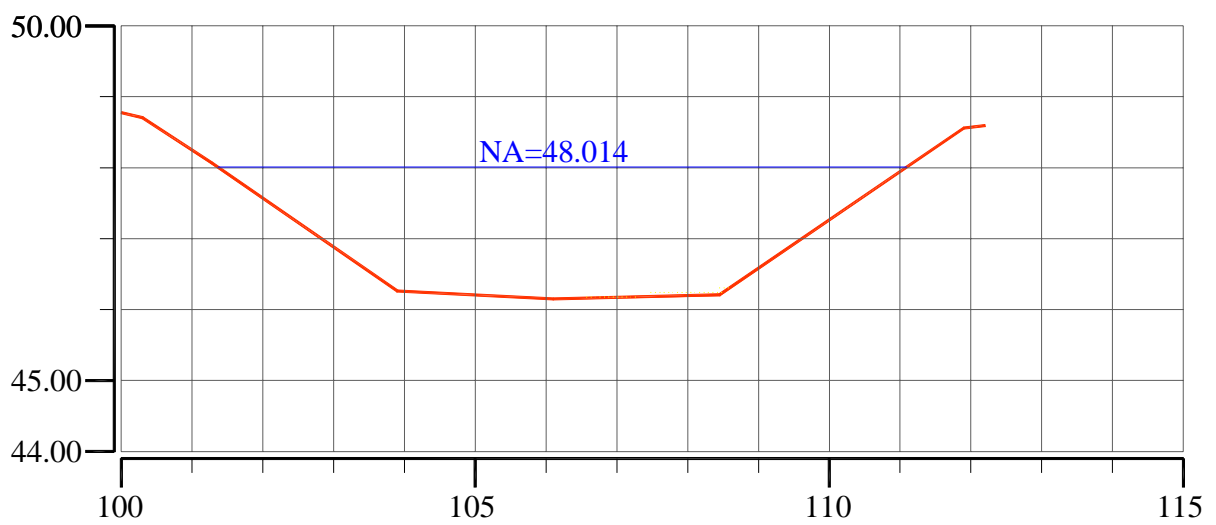

SEÇÃO-51 


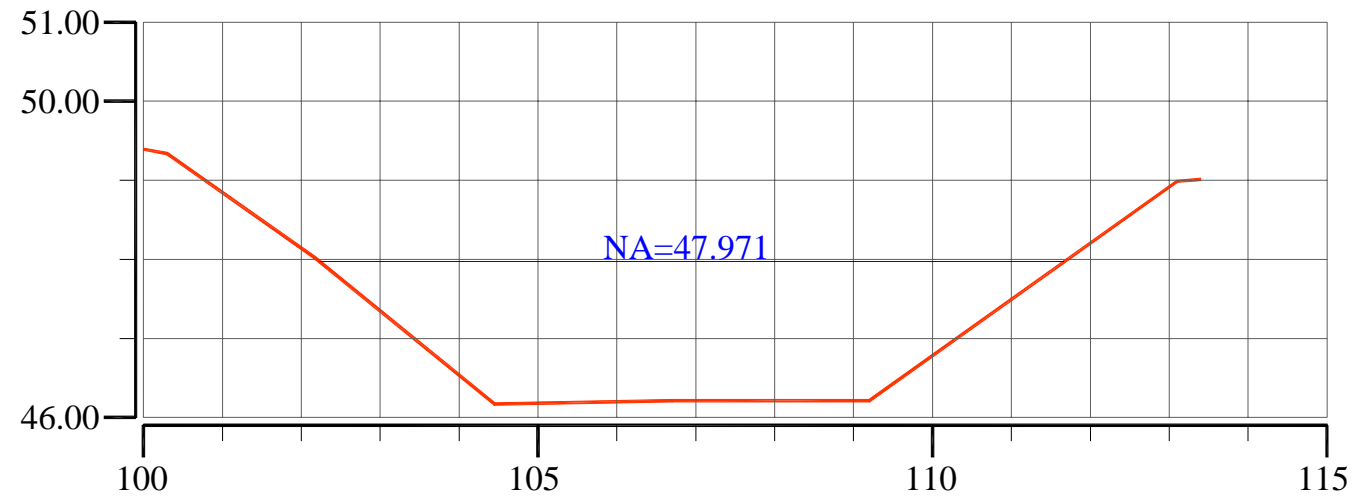

SEÇ̃̃O-52

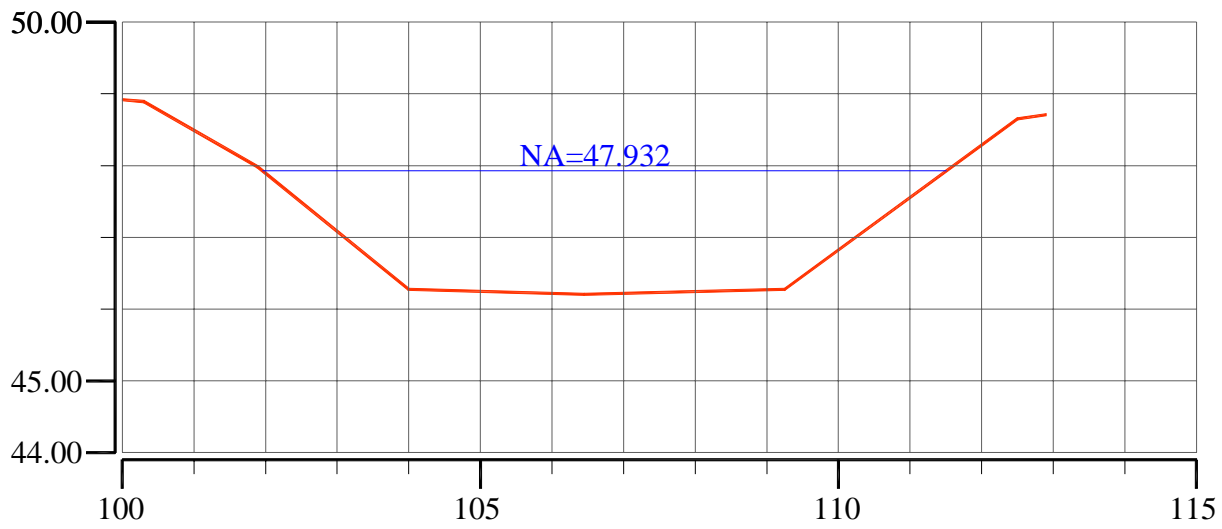

SEÇÃO-53

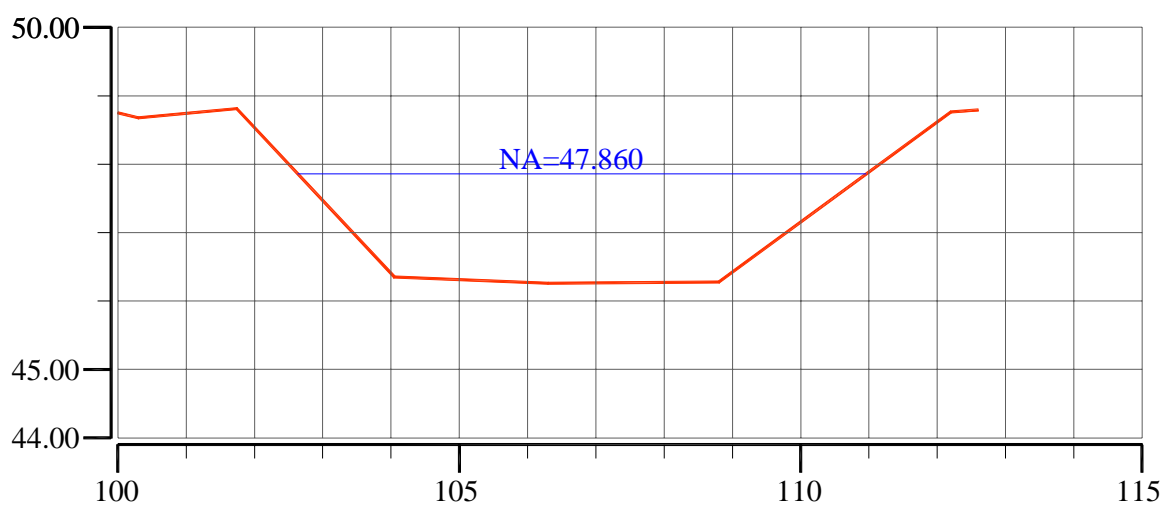

SEÇÃO-54 


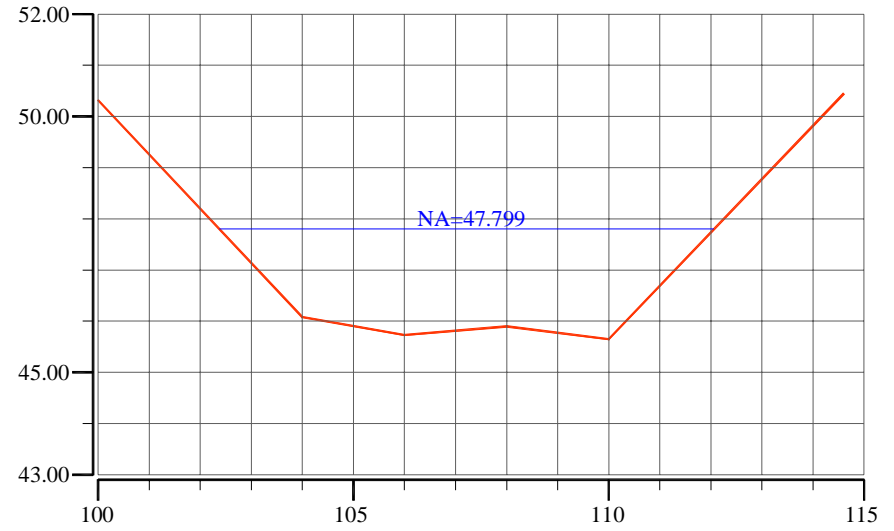

SEÇÃO-55

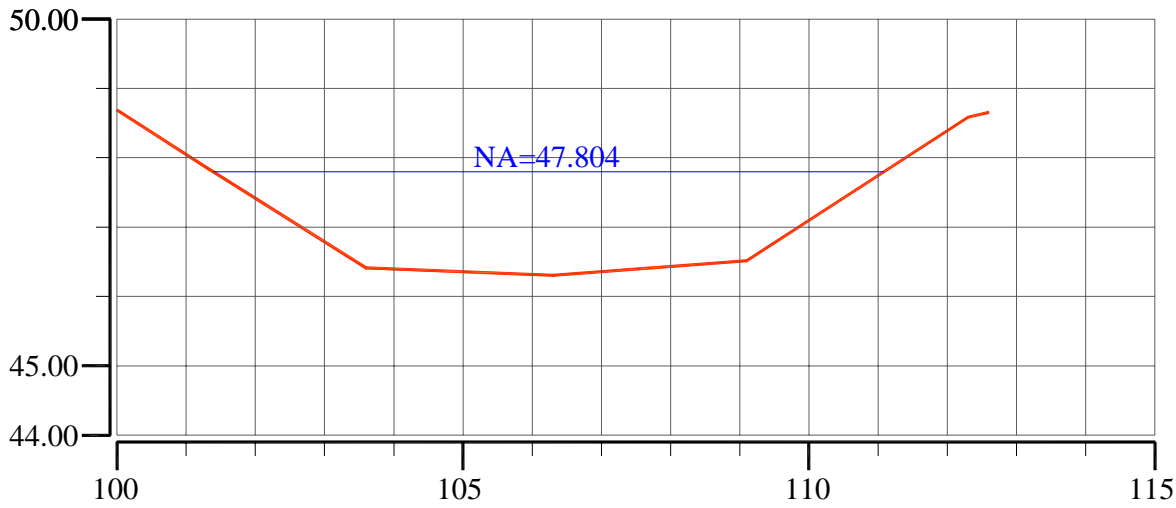

SECÃO-56

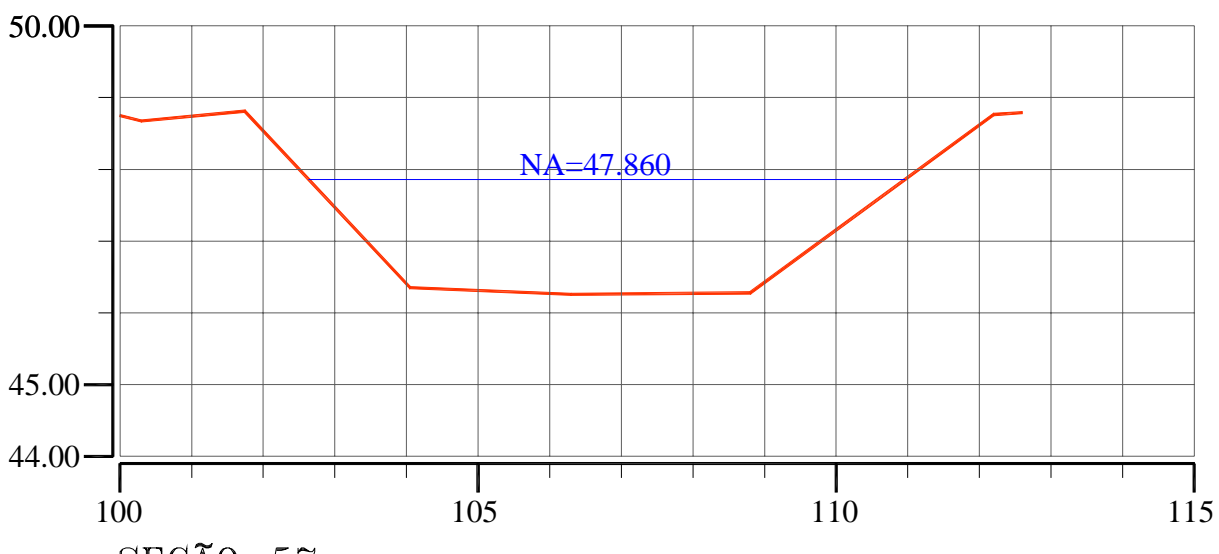

SEÇÃO-5Y 


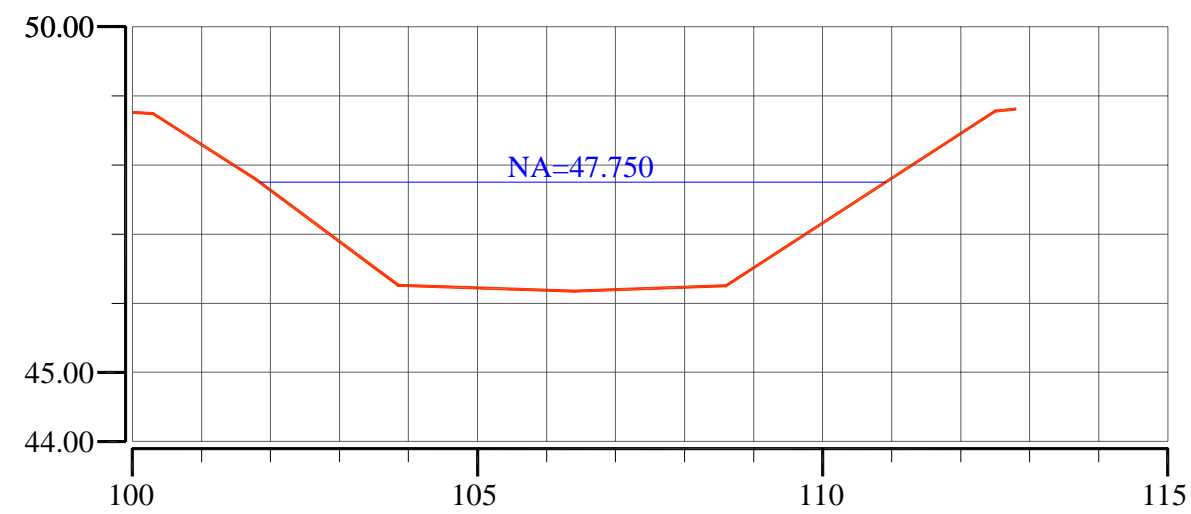

SEÇÃO-58
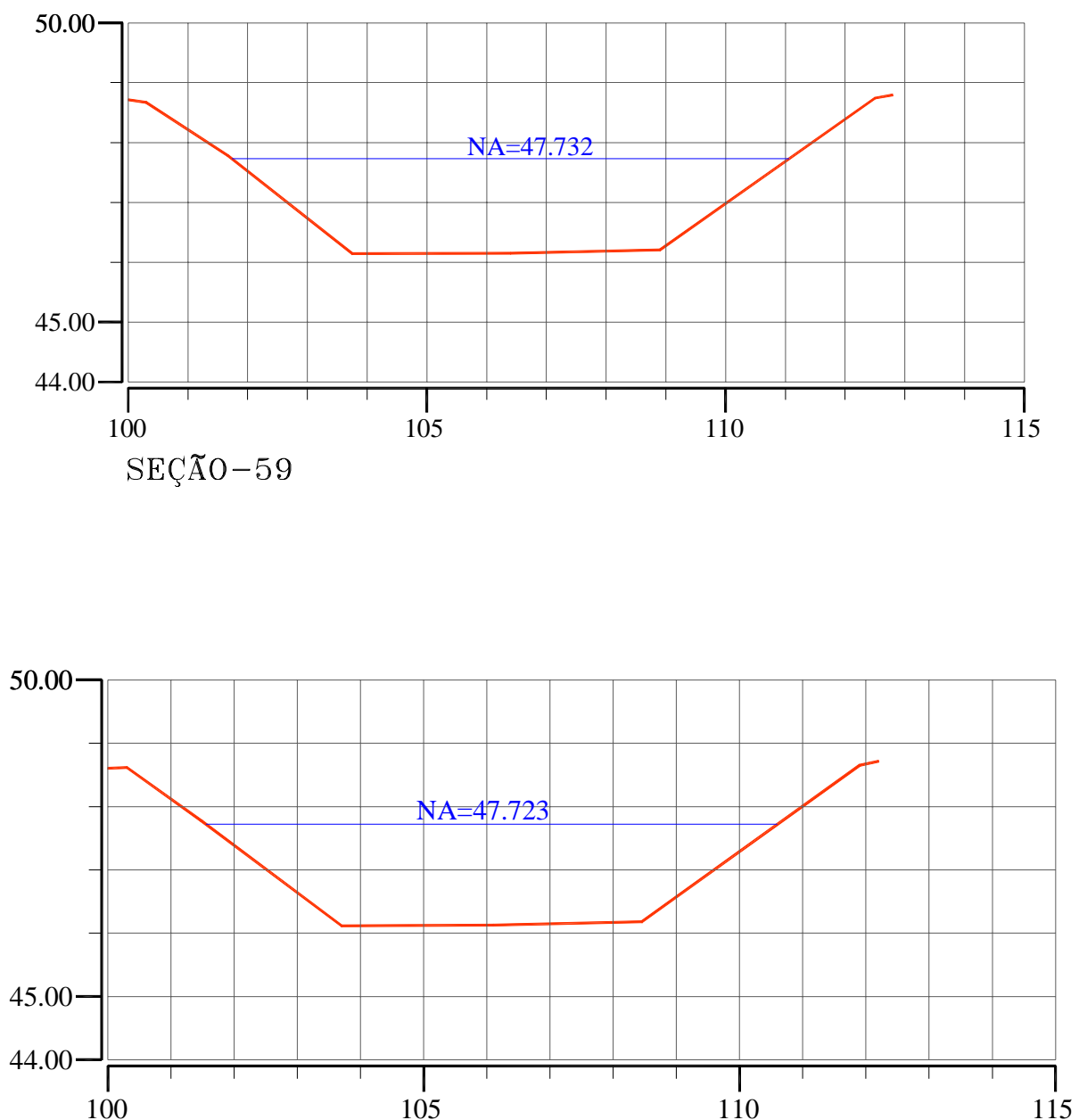

SEÇÕES-60,61 


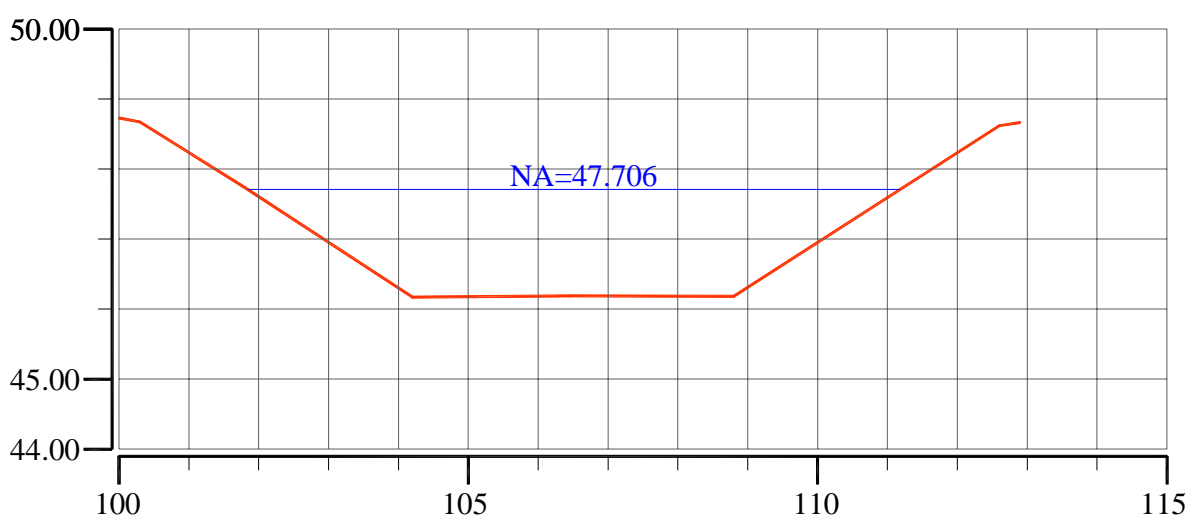

SEÇÃO-62

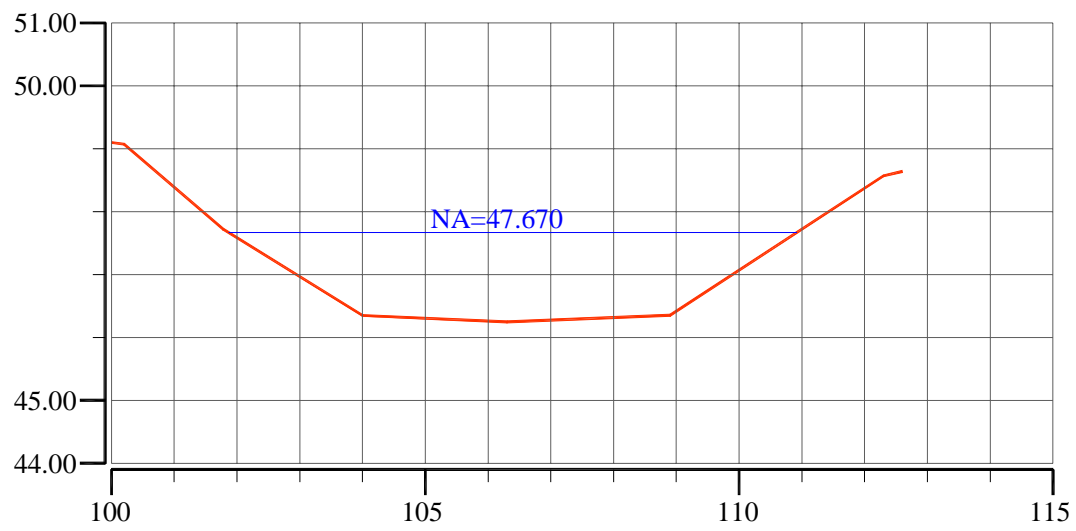

SEÇÃO-63

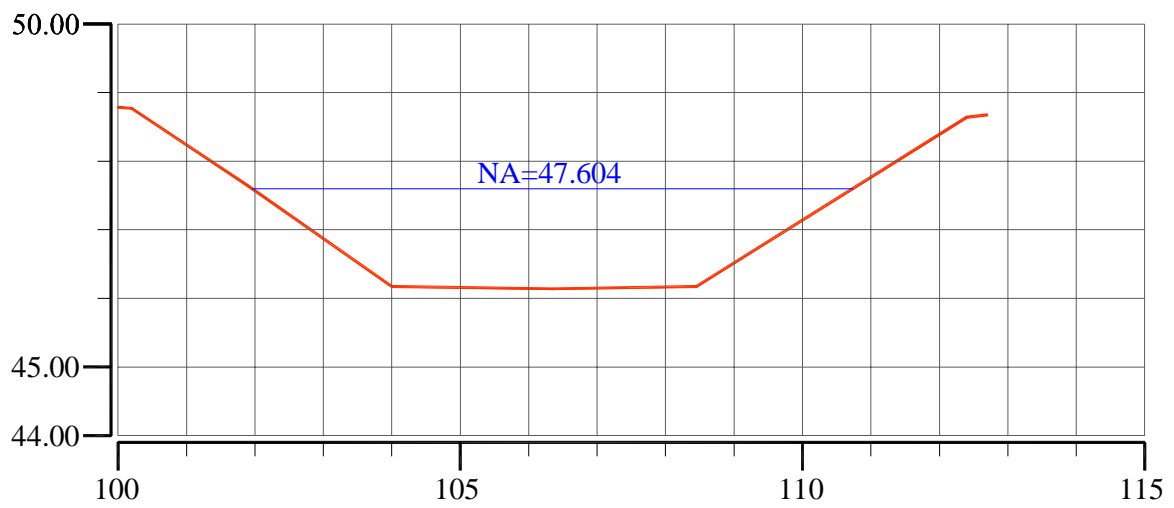

SEÇÃO-64 

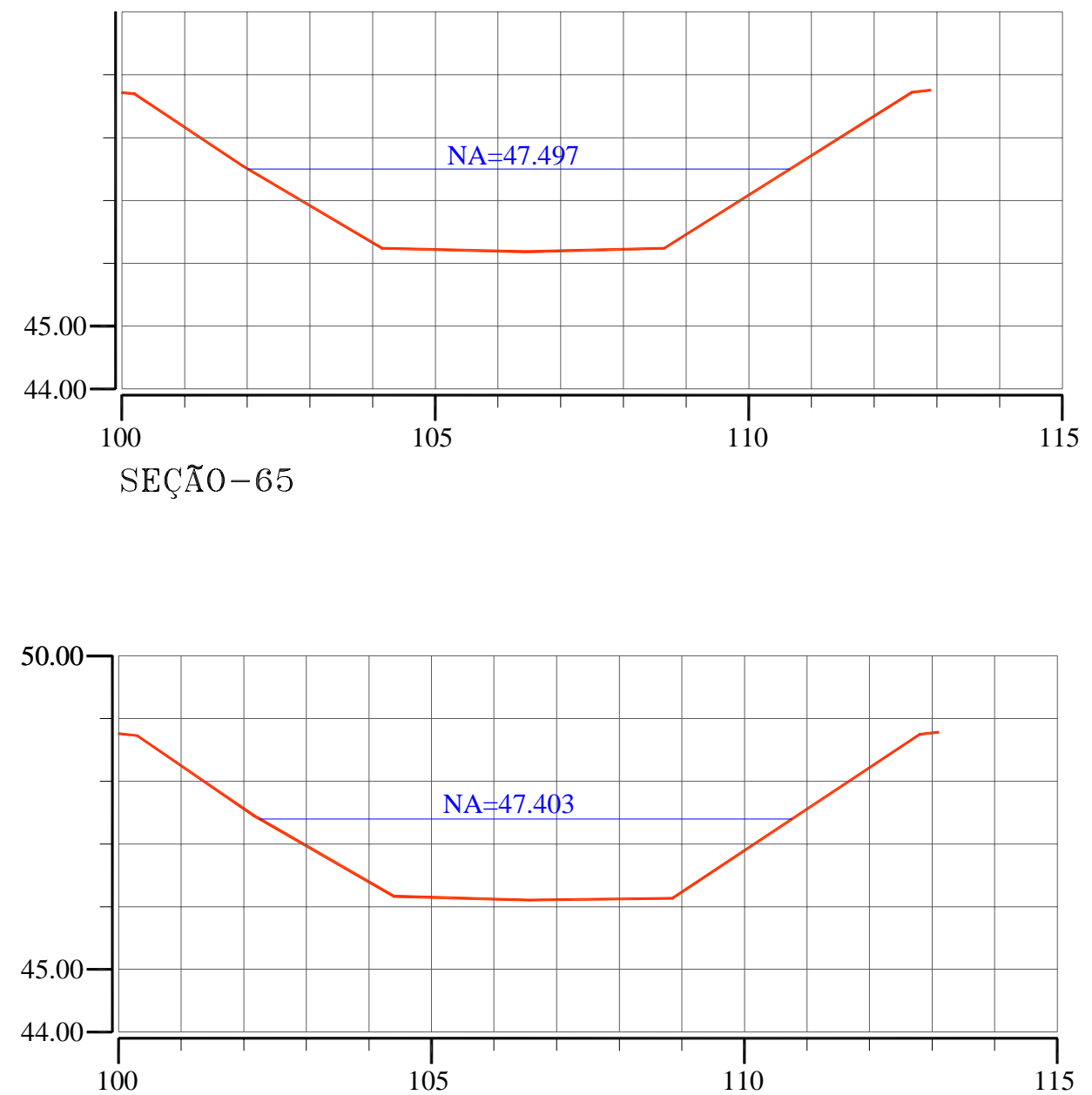

SEÇ̃̃O-66

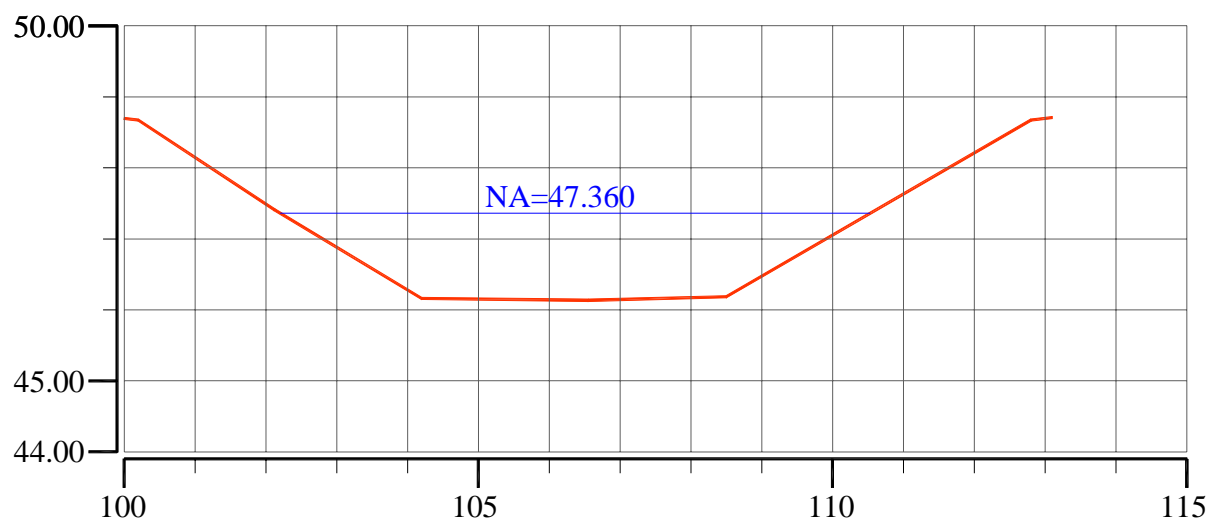

SEÇÃO-6? 


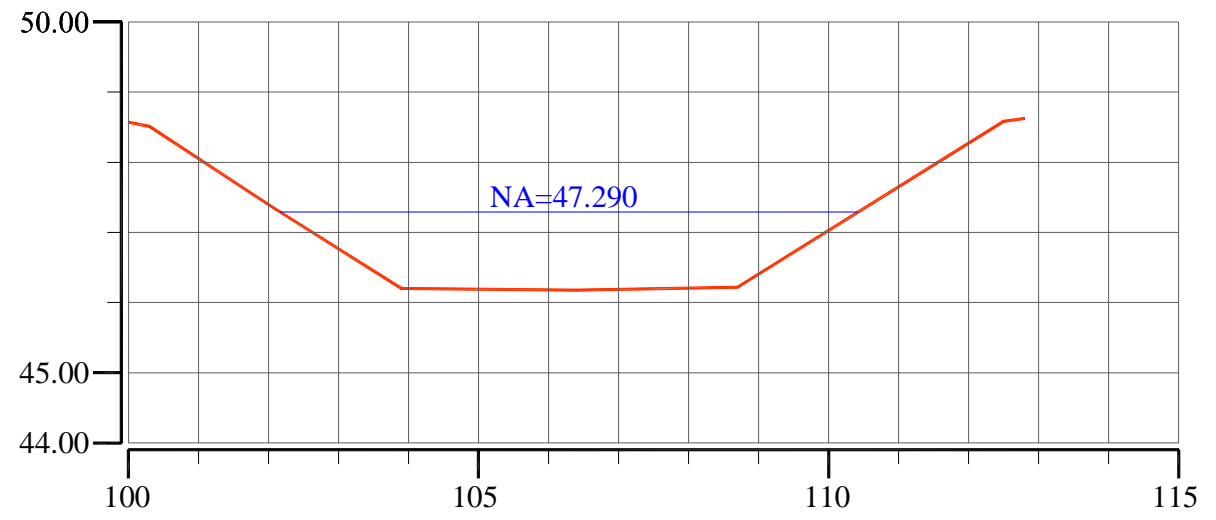

SEÇÃO-68
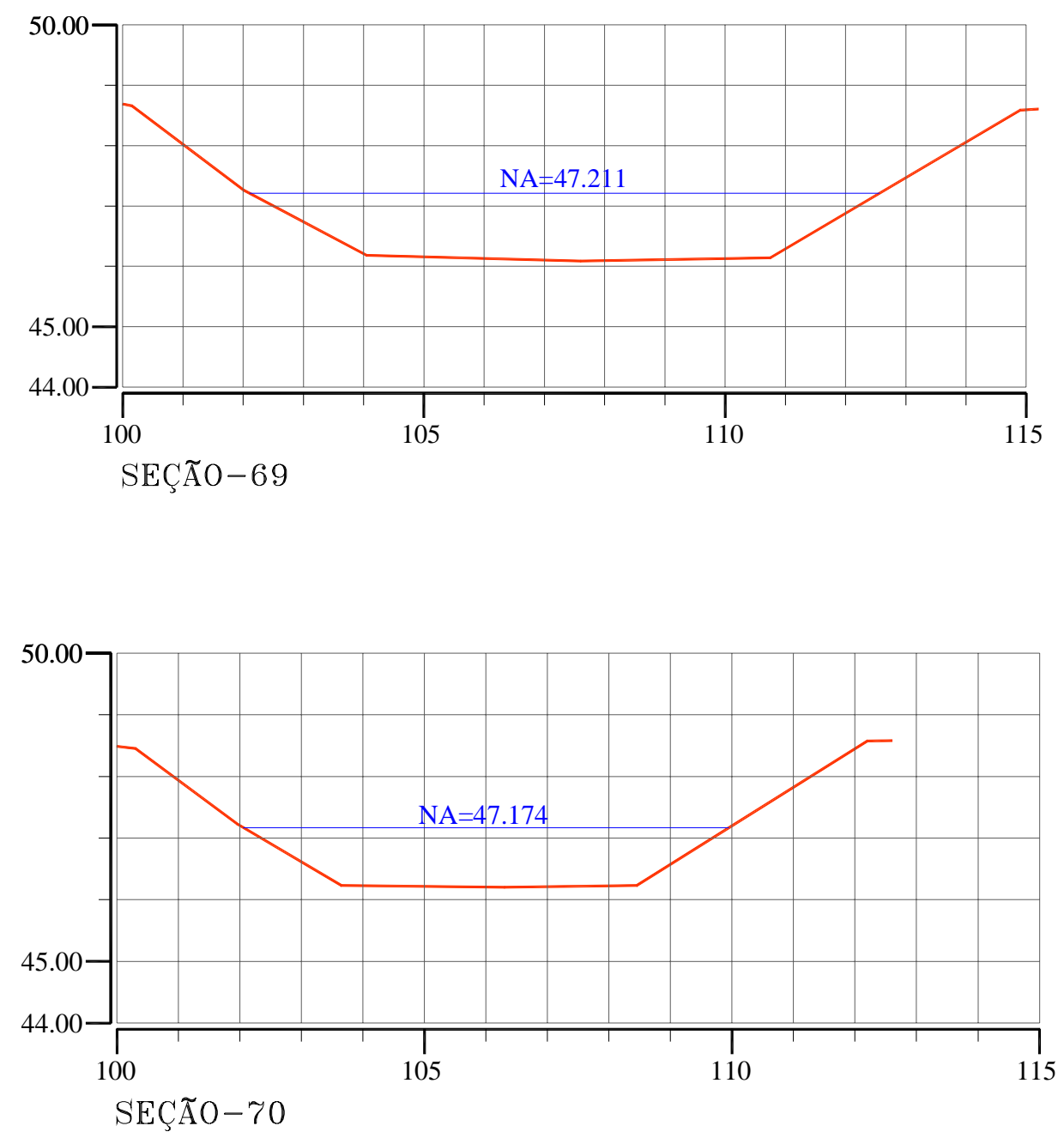

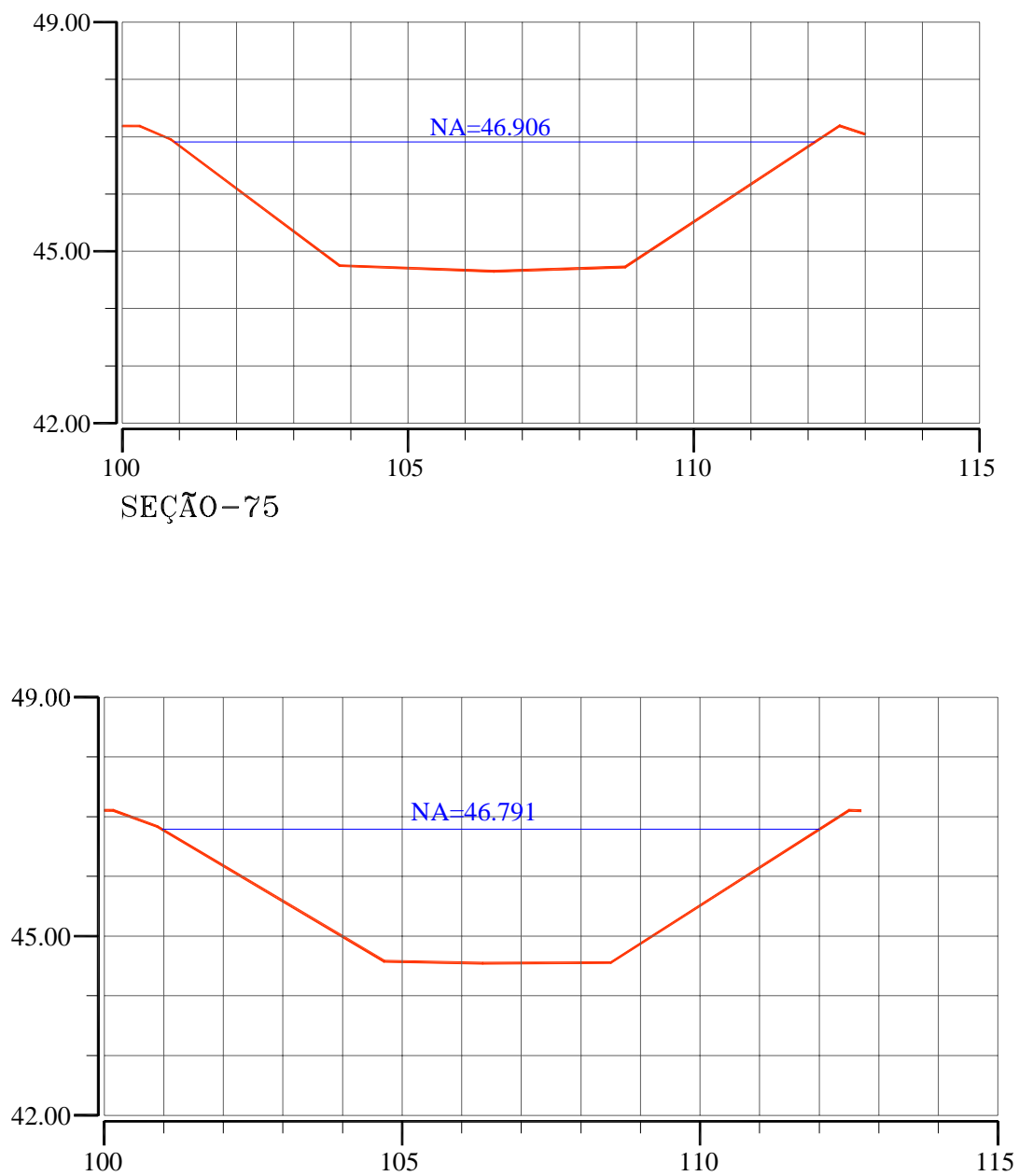

SECOEES-76,77

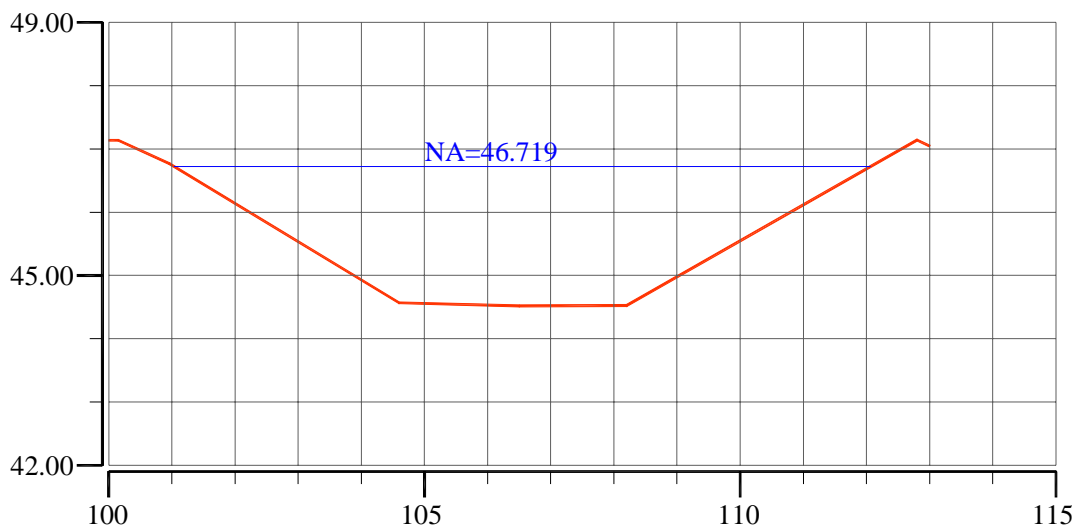

SEÇÃO-78 


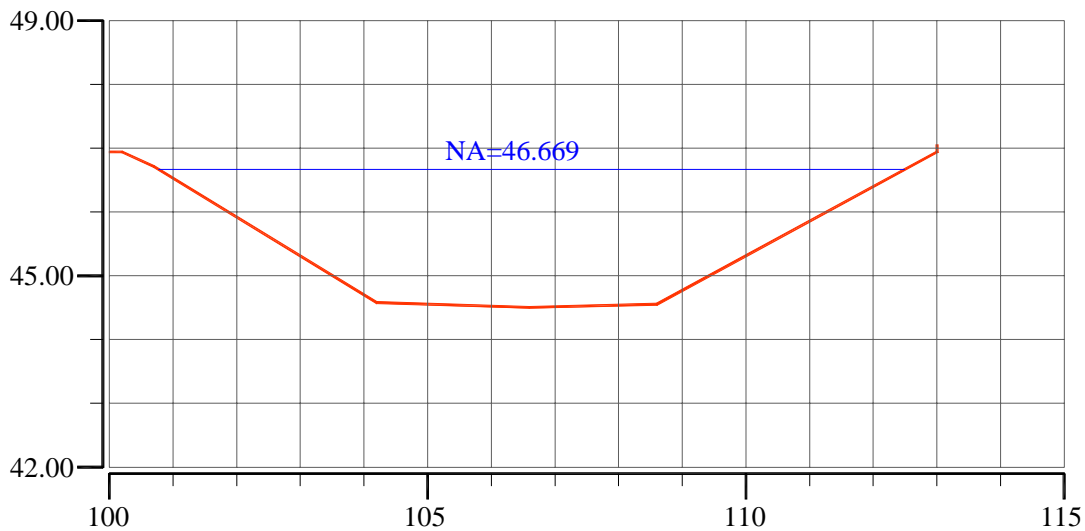

SEÇÃO-79

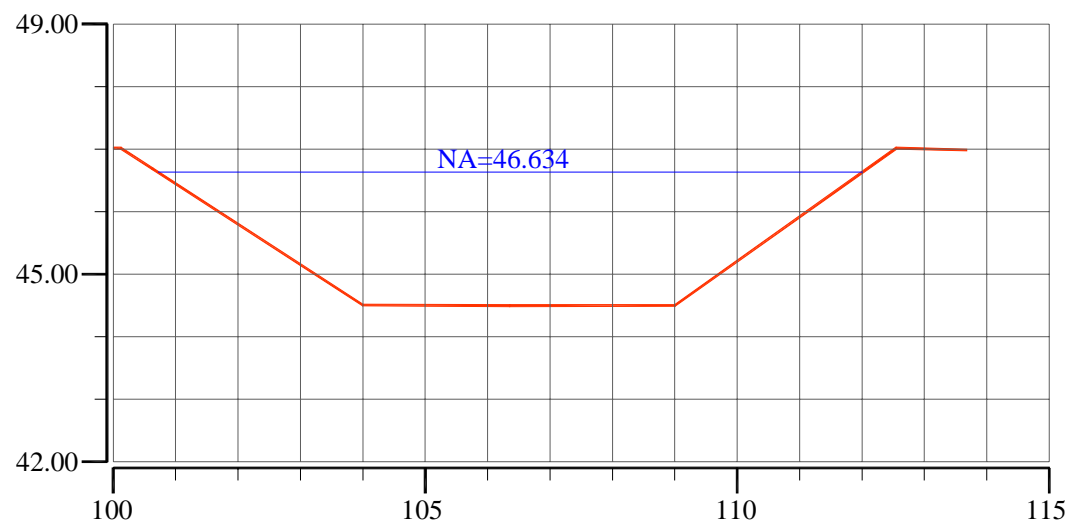

SEÇÃO-80

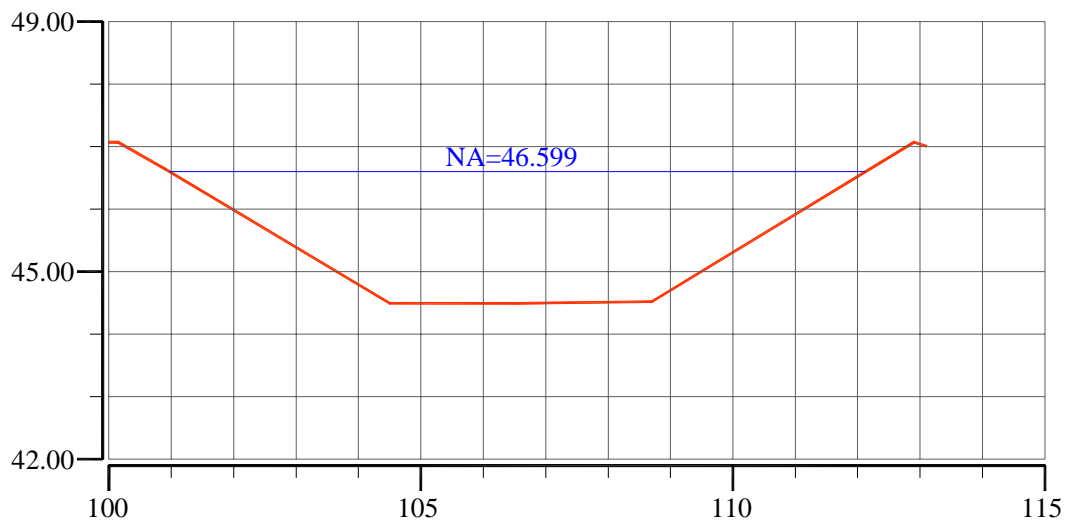

SECC̃̃O-81 


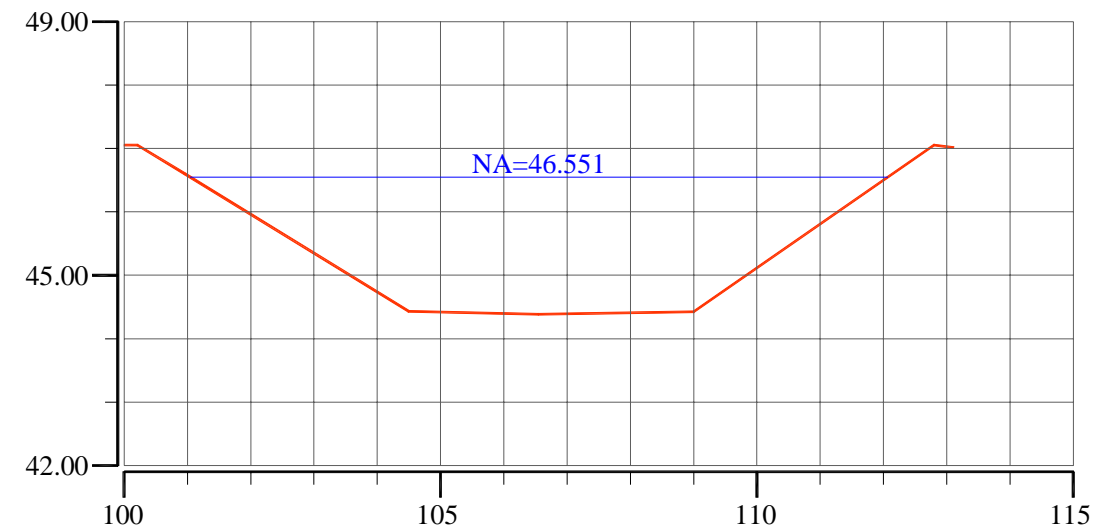

SECÃO-82

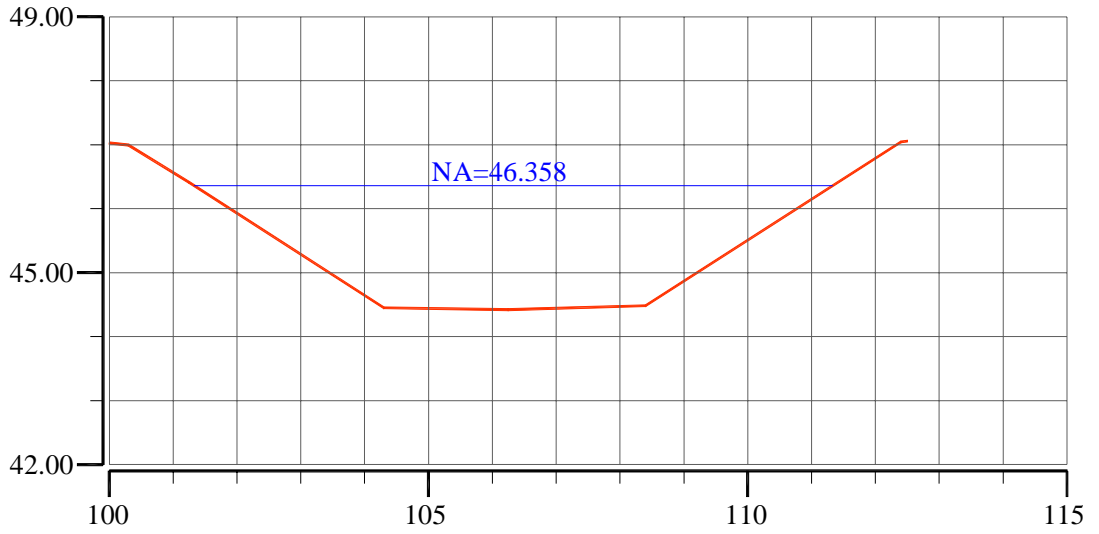

SEÇÃO-83

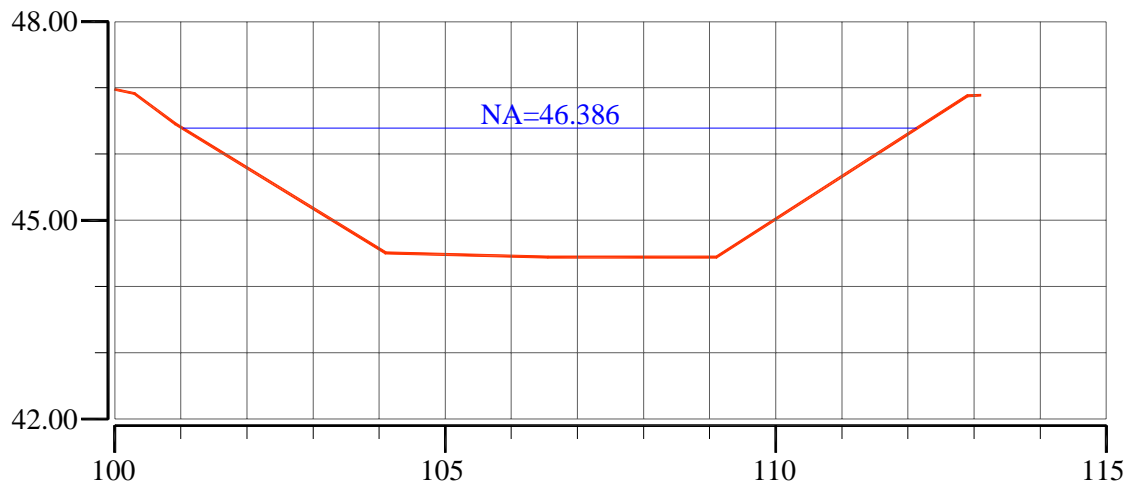

SEÇÃo-84 

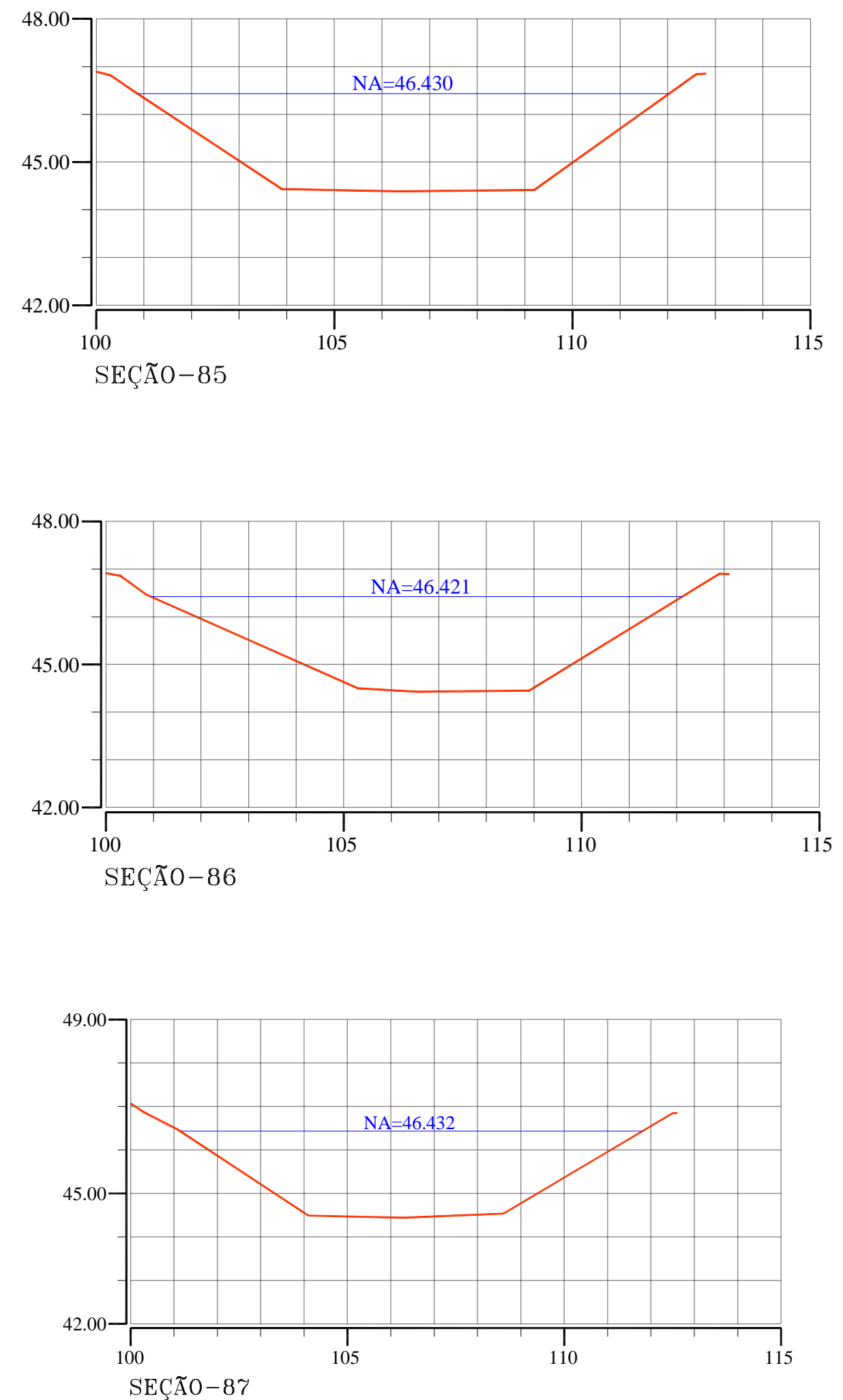


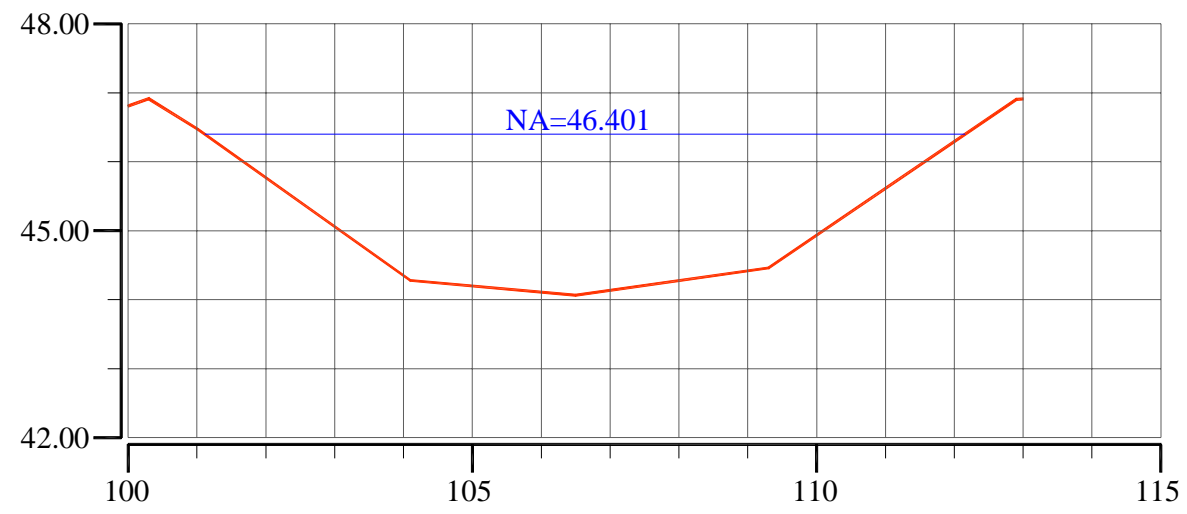

SEÇÕES-88,89

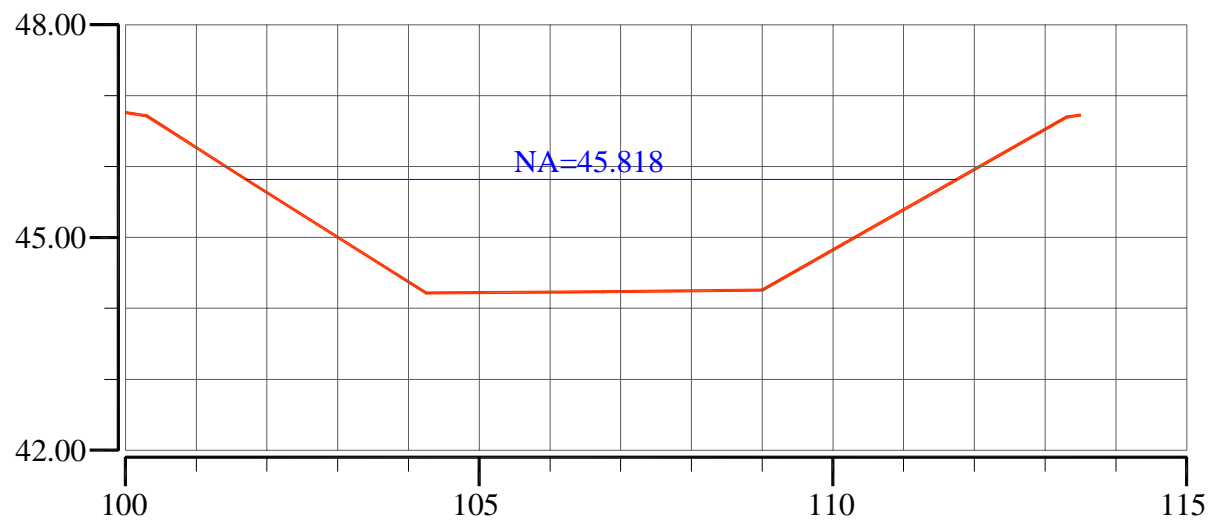

SECÕES-90,91,92,93,94,95

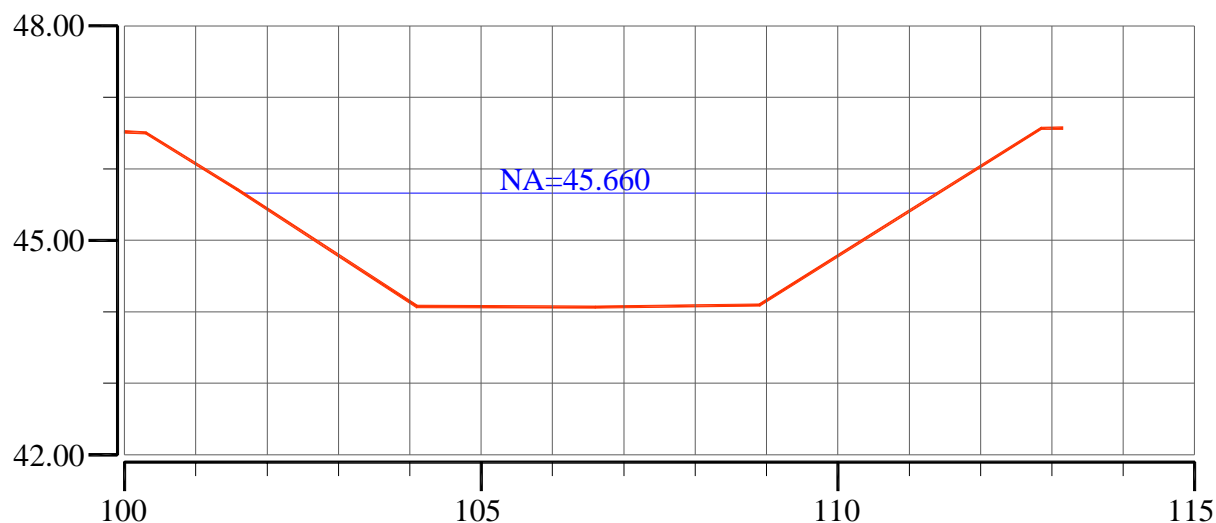

SEÇÕES-96,97,98 


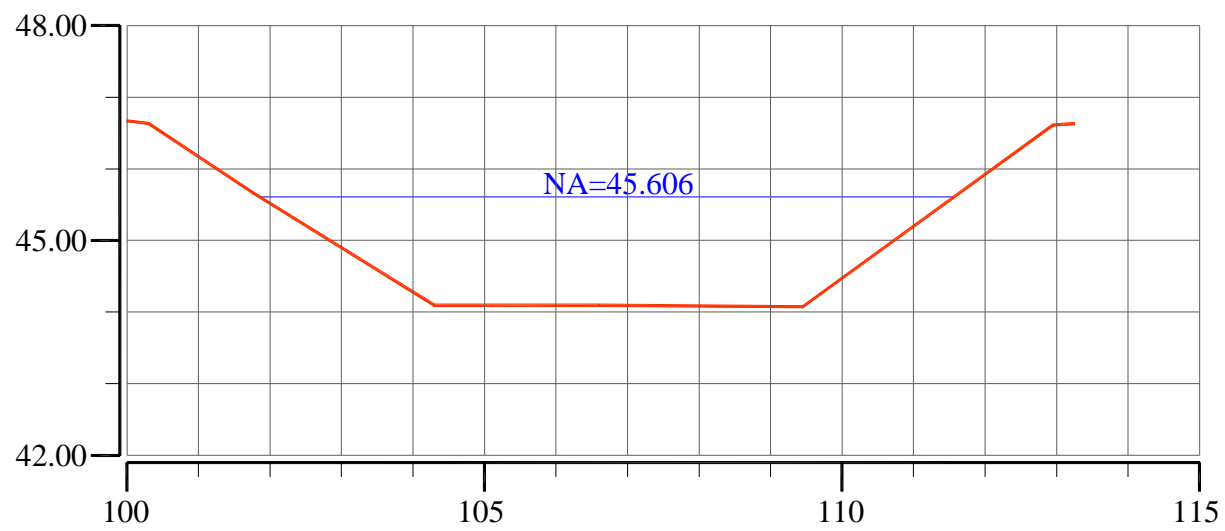

SECOCES-99,100

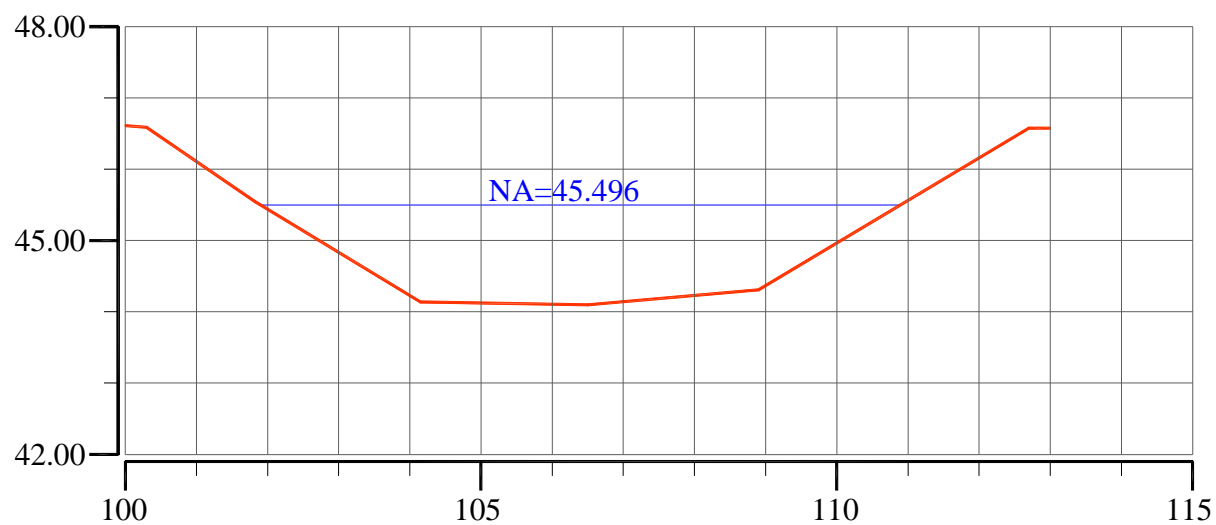

SEÇÃO-101

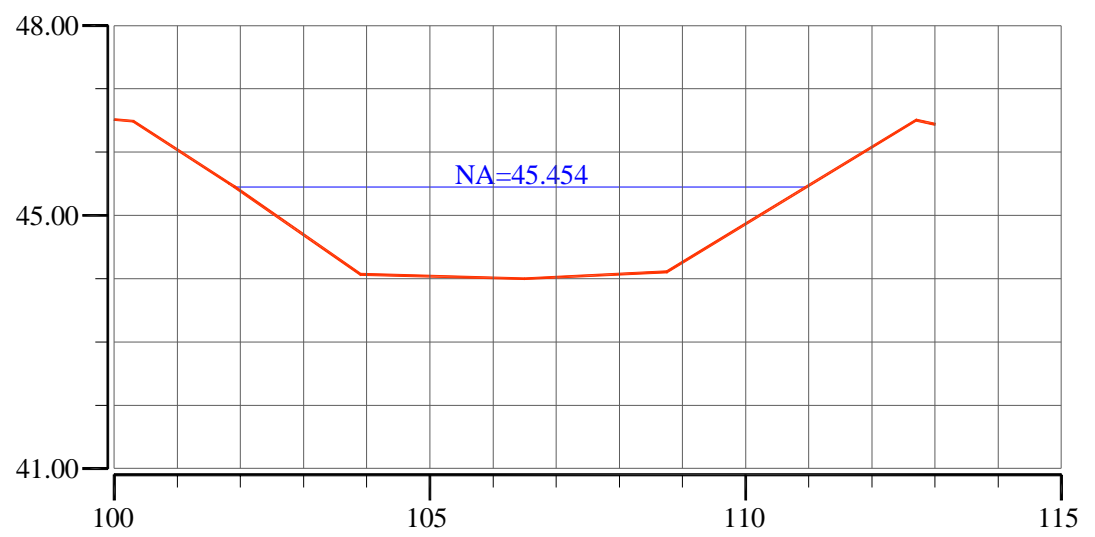

SEÇÃO-102 

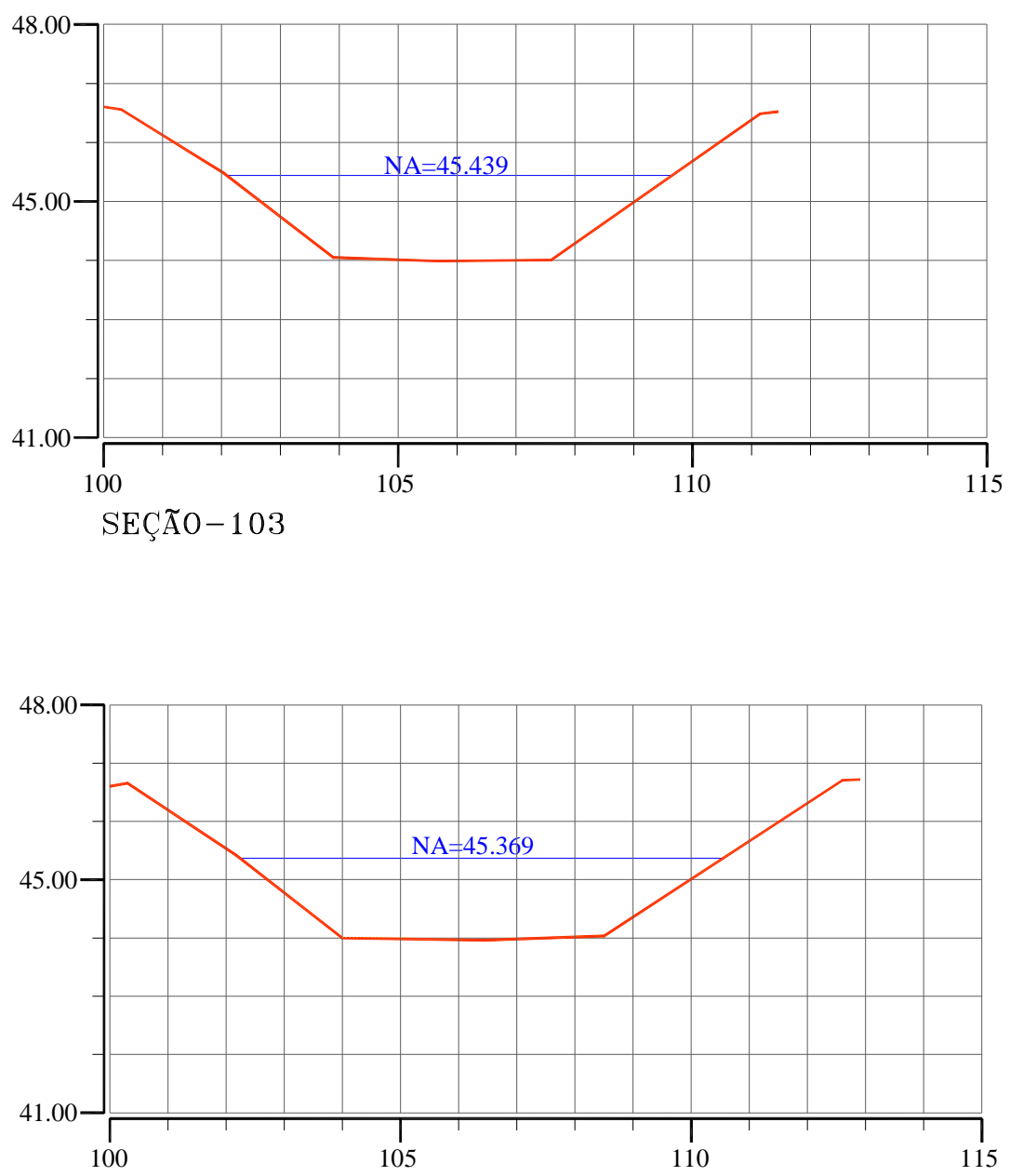

SEÇÃO-104

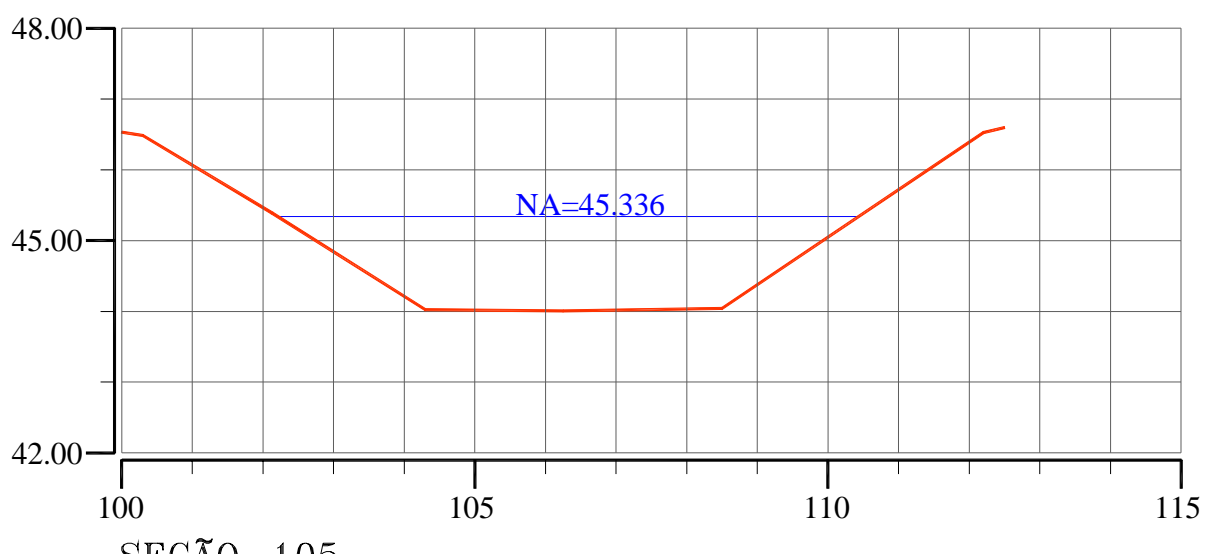

SEÇÃO-105 

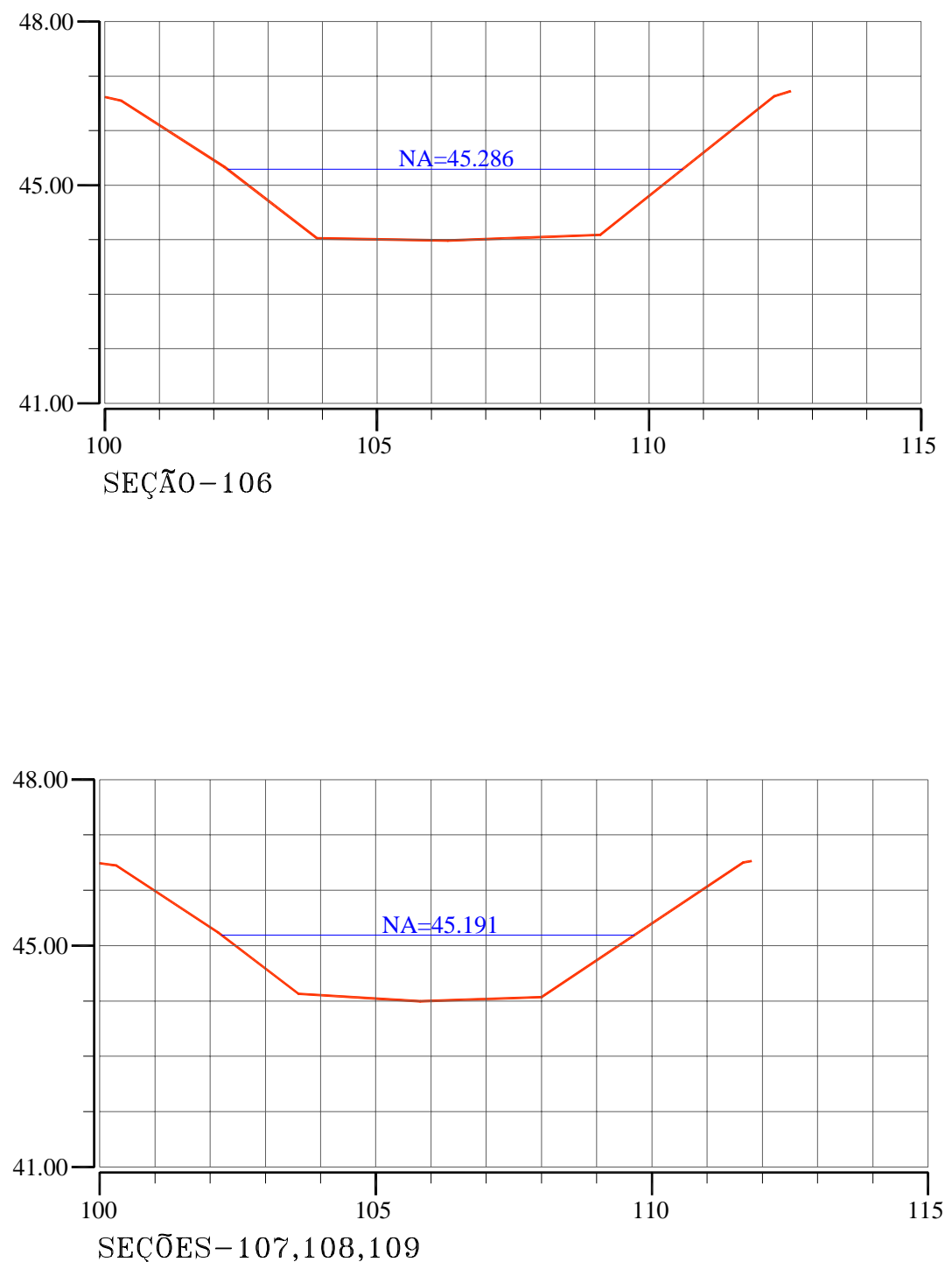
Caso 2: Canal do Trabalhador (Equações de Geometria)

SEÇÕES 01, 02, 03 e 04

$\begin{array}{cccccccc}\text { no pares } & \mathbf{y}(\mathbf{m}) & \mathbf{p}(\mathbf{m}) & \mathbf{a}(\mathbf{m} 2) & \mathbf{B}(\mathbf{m}) & & \text { tipo da equação } & \text { correlação } \\ & 0,5 & 5,87 & 2,33 & 5,61 & \mathbf{p}(\mathbf{m}) & \text { linear } & 1,0000 \\ 3 & 1,0 & 7,77 & 5,53 & 7,22 & \mathbf{a}(\mathbf{m} 2) & \text { polinomial }\left(2^{\mathrm{a}} \text { ordem }\right) & 1,0000 \\ & 1,5 & 9,66 & 9,54 & 8,84 & \mathbf{B}(\mathbf{m}) & \text { linear } & 1,0000\end{array}$
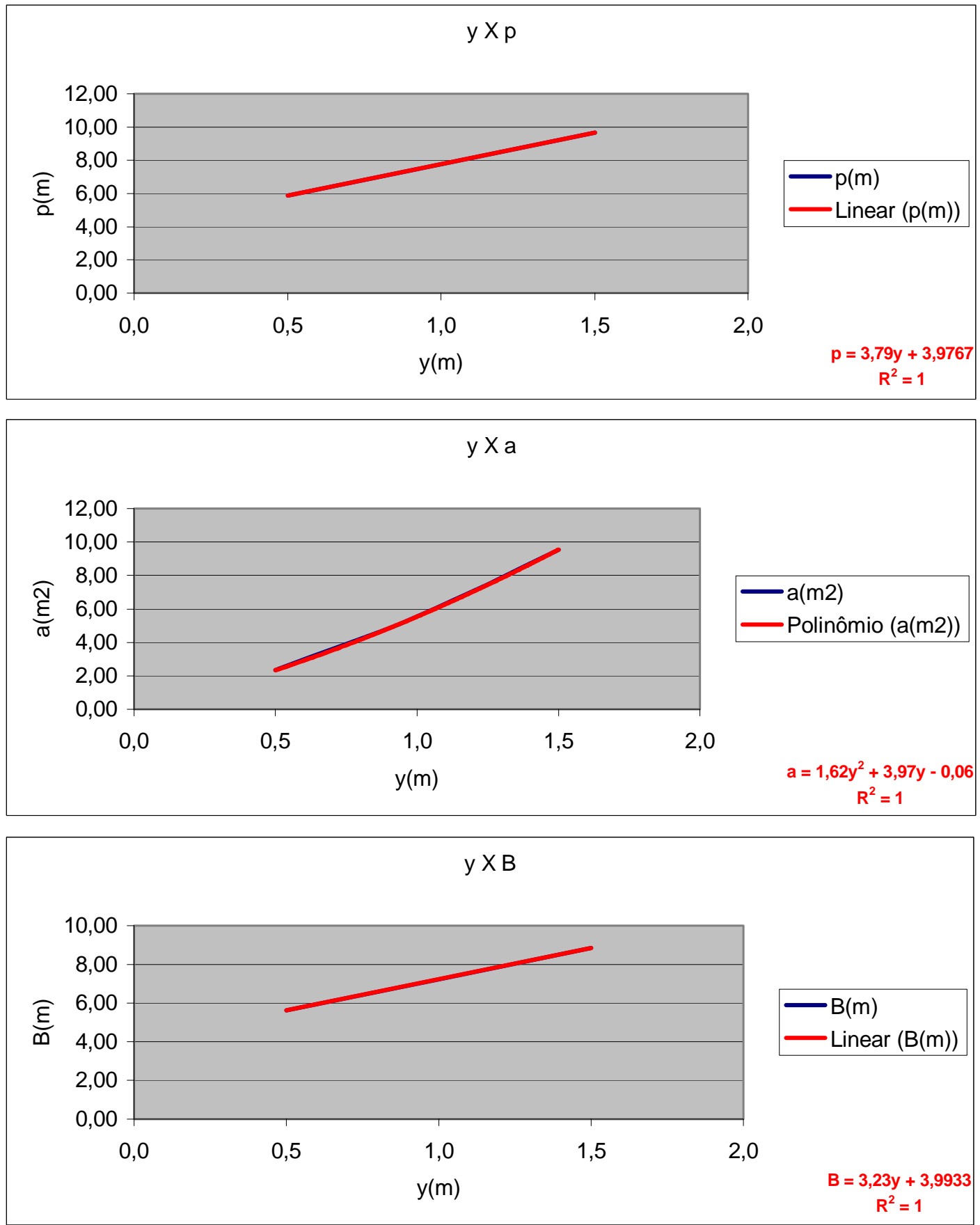
sifão macacos

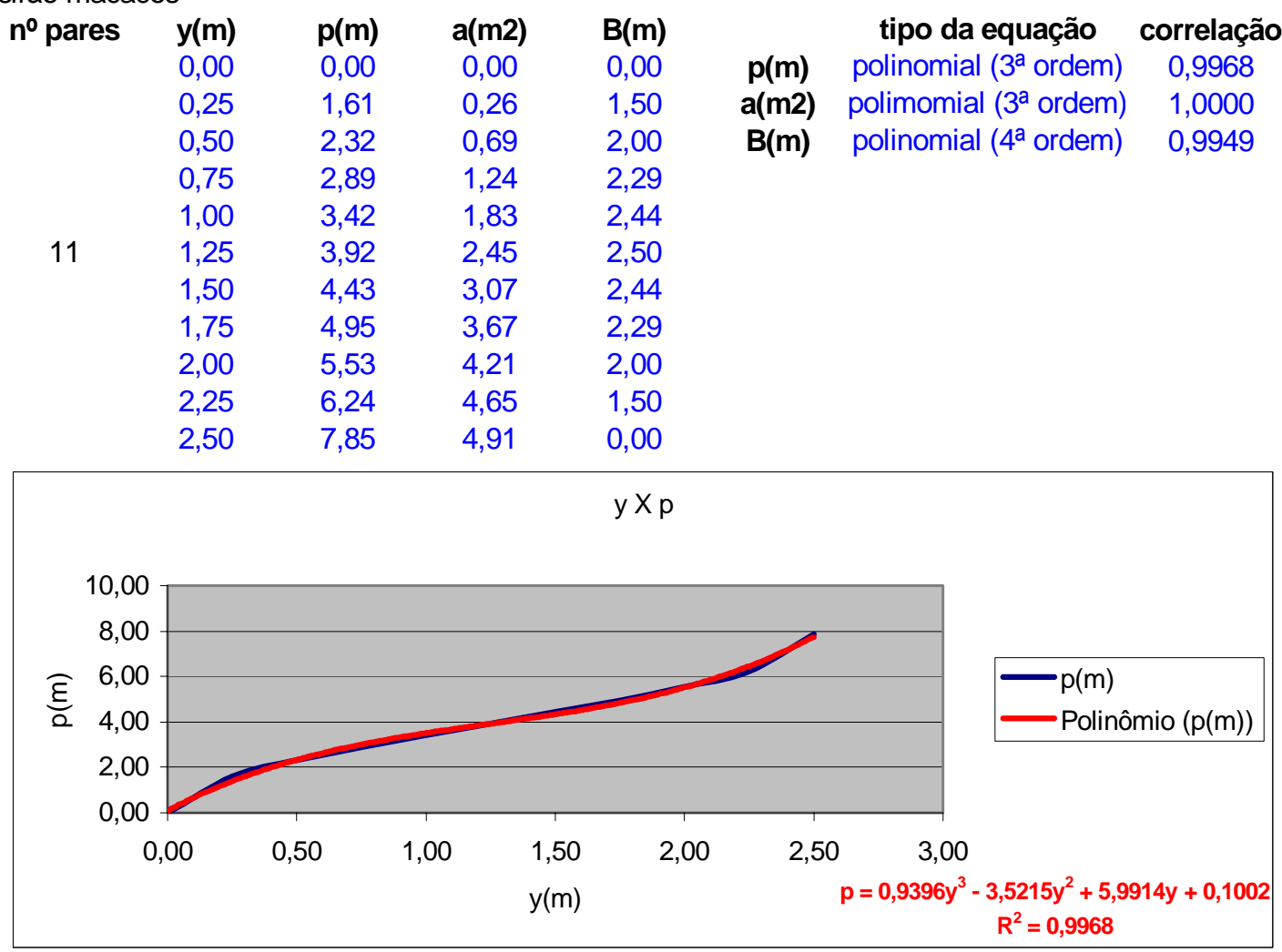
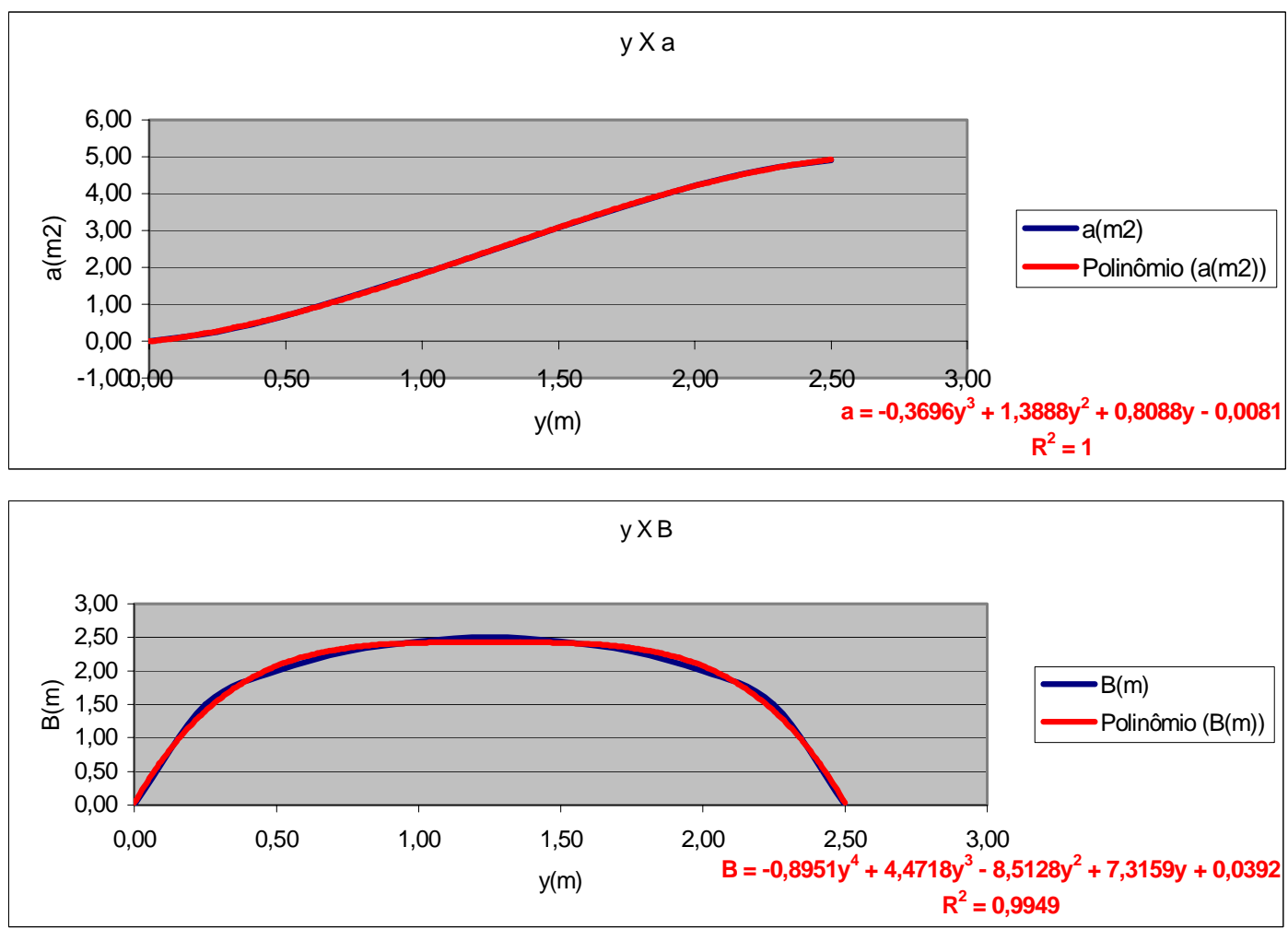
SEÇÕES 07, 08, 09 e 10

$\begin{array}{cccccccc}\text { no pares } & \mathbf{y}(\mathbf{m}) & \mathbf{p}(\mathbf{m}) & \mathbf{a}(\mathbf{m} \mathbf{2}) & \mathbf{B}(\mathbf{m}) & & \text { tipo da equação } & \text { correlação } \\ & 0,5 & 5,89 & 2,38 & 5,60 & \mathbf{p}(\mathbf{m}) & \text { linear } & 1,0000 \\ 3 & 1,0 & 7,70 & 5,55 & 7,10 & \mathbf{a}(\mathbf{m} 2) & \text { polinomial }\left(2^{a} \text { ordem) }\right. & 1,0000 \\ & 1,5 & 9,50 & 9,48 & 8,60 & \mathbf{B}(\mathbf{m}) & \text { linear } & 1,0000\end{array}$
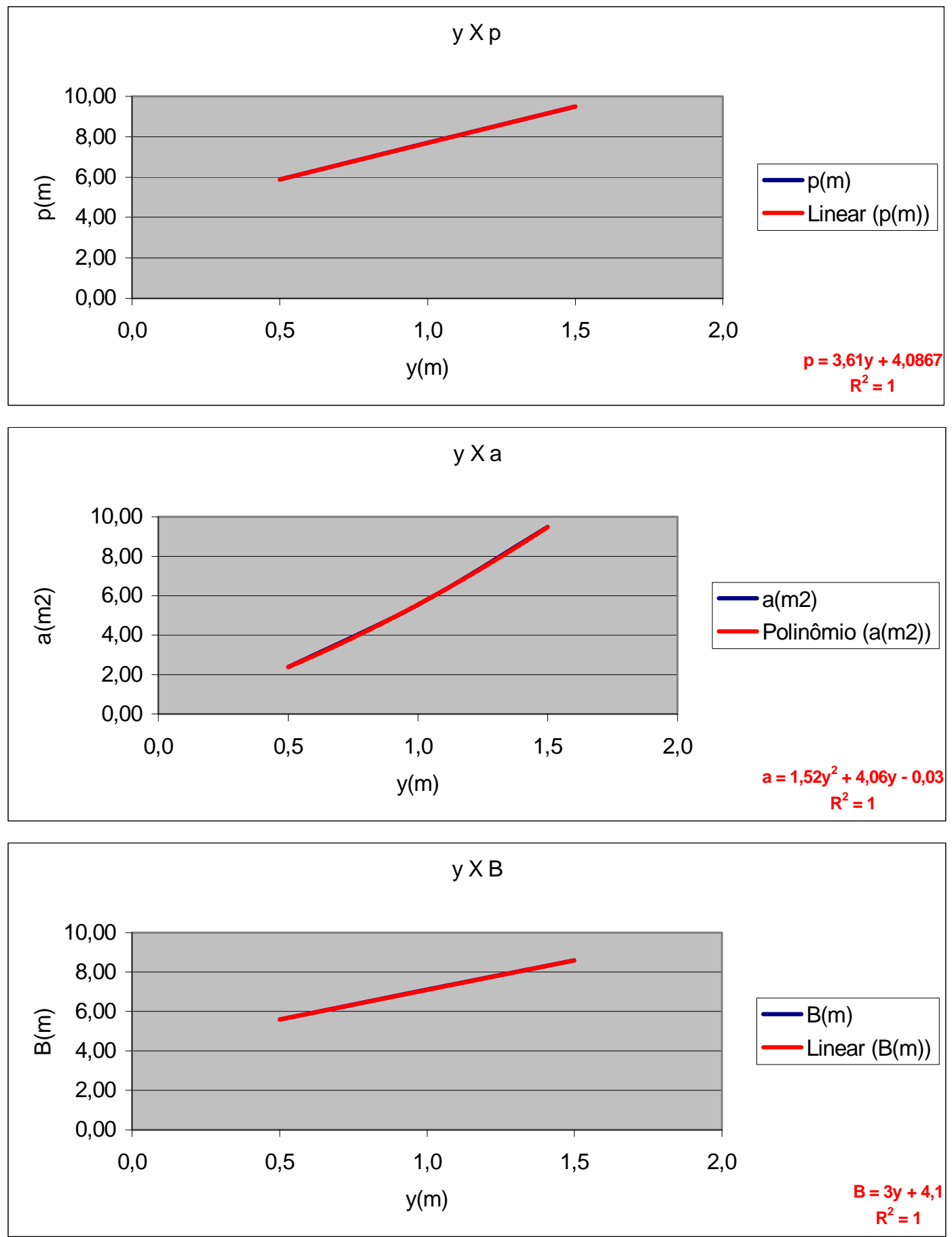


\section{SEÇÃO 11}

$\begin{array}{cccccccc}\text { no pares } & \mathbf{y}(\mathbf{m}) & \mathbf{p}(\mathbf{m}) & \mathbf{a}(\mathbf{m} 2) & \mathbf{B}(\mathbf{m}) & & \text { tipo da equação } & \text { correlação } \\ & 0,5 & 5,40 & 2,14 & 5,13 & \mathbf{p}(\mathbf{m}) & \text { linear } & 1,0000 \\ 3 & 1,0 & 7,39 & 5,14 & 6,84 & \mathbf{a}(\mathbf{m} 2) & \text { polinomial }\left(2^{\mathrm{a}} \text { ordem }\right) & 1,0000 \\ & 1,5 & 9,37 & 8,99 & 8,55 & \mathbf{B}(\mathbf{m}) & \text { linear } & 1,0000\end{array}$
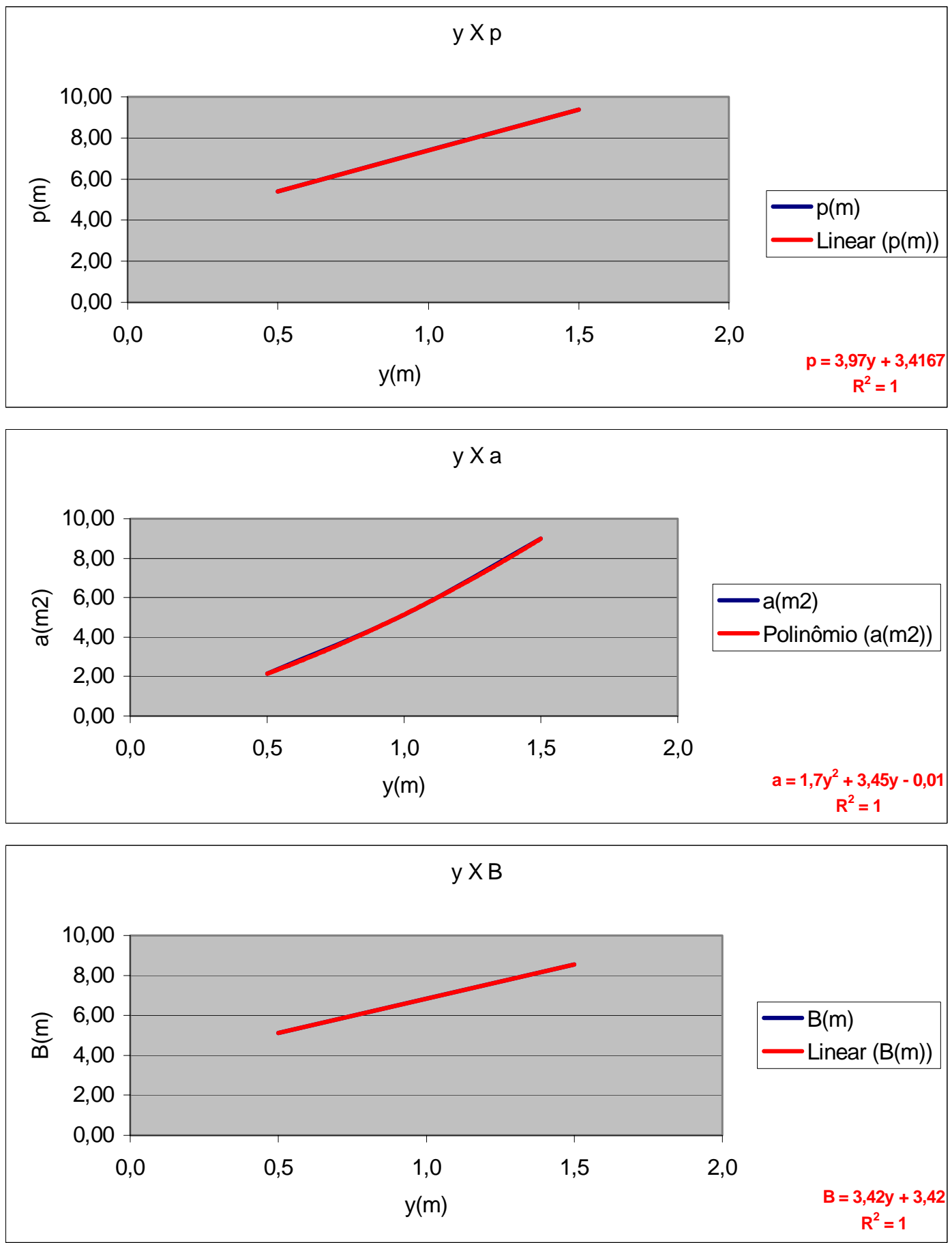
SEÇÃO 12

$\begin{array}{cccccccc}\text { no pares } & \mathbf{y}(\mathbf{m}) & \mathbf{p}(\mathbf{m}) & \mathbf{a}(\mathbf{m} 2) & \mathbf{B}(\mathbf{m}) & & \text { tipo da equação } & \text { correlação } \\ & 0,5 & 6,08 & 2,69 & 5,78 & \mathbf{p}(\mathbf{m}) & \text { linear } & 1,0000 \\ 3 & 1,0 & 7,94 & 5,98 & 7,34 & \mathbf{a}(\mathbf{m} 2) & \text { polinomial }\left(2^{\mathrm{a}} \text { ordem }\right) & 1,0000 \\ & 1,5 & 9,80 & 10,04 & 9,65 & \mathbf{B}(\mathbf{m}) & \text { polinomial }\left(2^{\mathrm{a}} \text { ordem }\right) & 1,0000\end{array}$
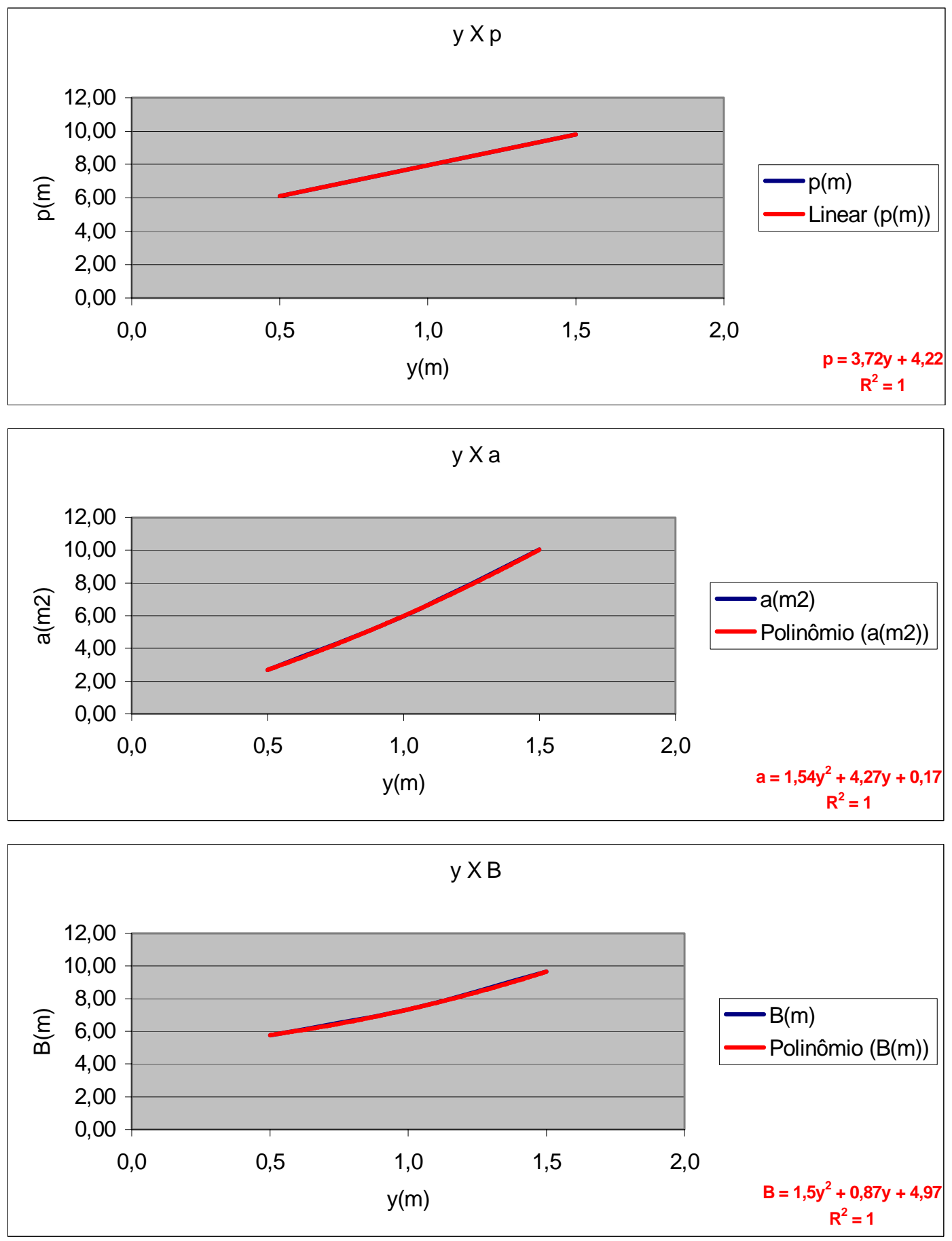
SEÇÕES 13 e 14
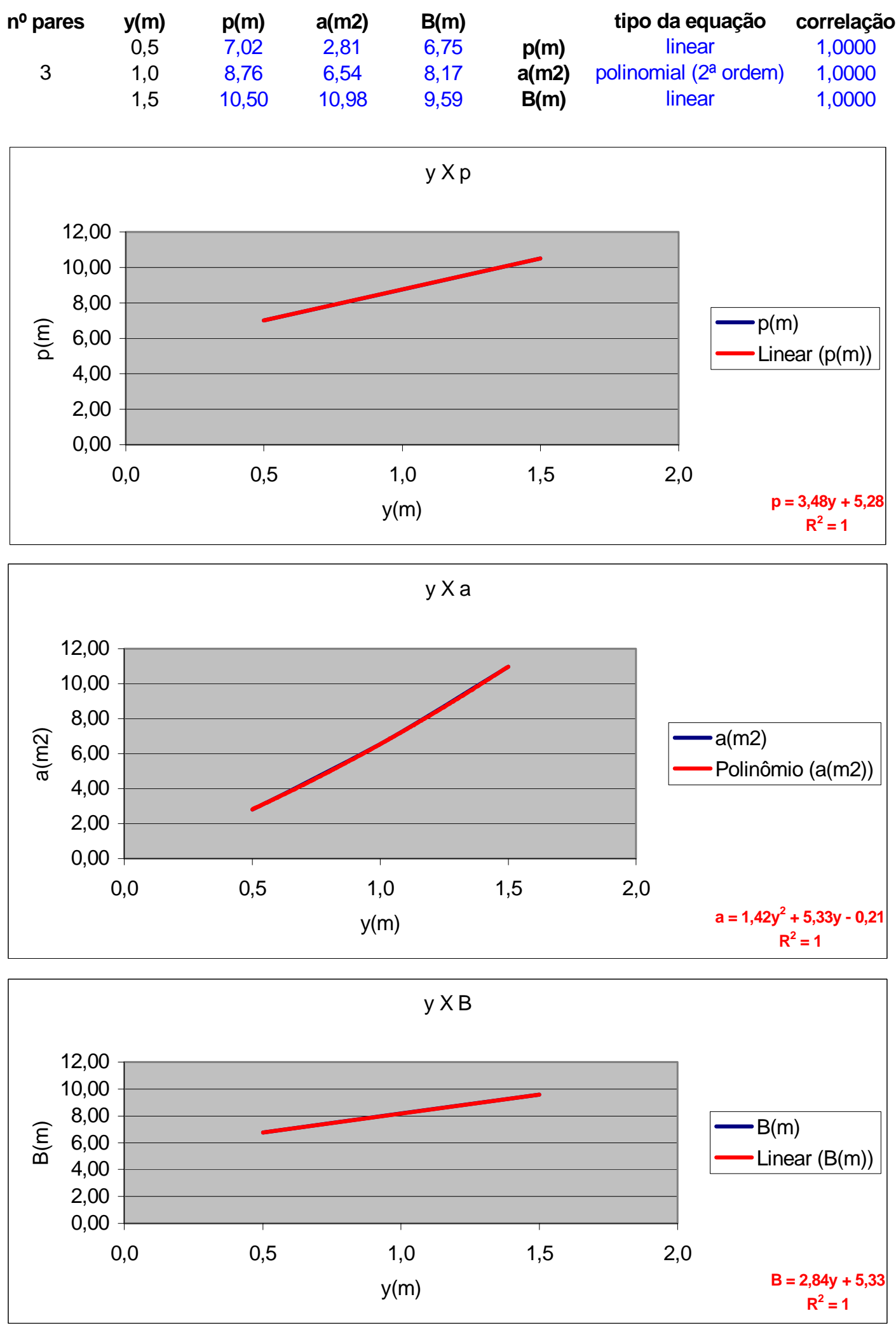


\section{SEÇÃO 15}

$\begin{array}{cccccccc}\text { no pares } & \mathbf{y}(\mathbf{m}) & \mathbf{p}(\mathbf{m}) & \mathbf{a}(\mathbf{m} \mathbf{2}) & \mathbf{B}(\mathbf{m}) & & \text { tipo da equação } & \text { correlação } \\ & 0,5 & 6,25 & 2,64 & 5,99 & \mathbf{p}(\mathbf{m}) & \text { linear } & 1,0000 \\ 3 & 1,0 & 8,21 & 6,06 & 7,66 & \mathbf{a}(\mathbf{m} 2) & \text { polinomial }\left(2^{a} \text { ordem) }\right. & 1,0000 \\ & 1,5 & 10,16 & 10,31 & 9,34 & \mathbf{B}(\mathbf{m}) & \text { linear } & 1,0000\end{array}$
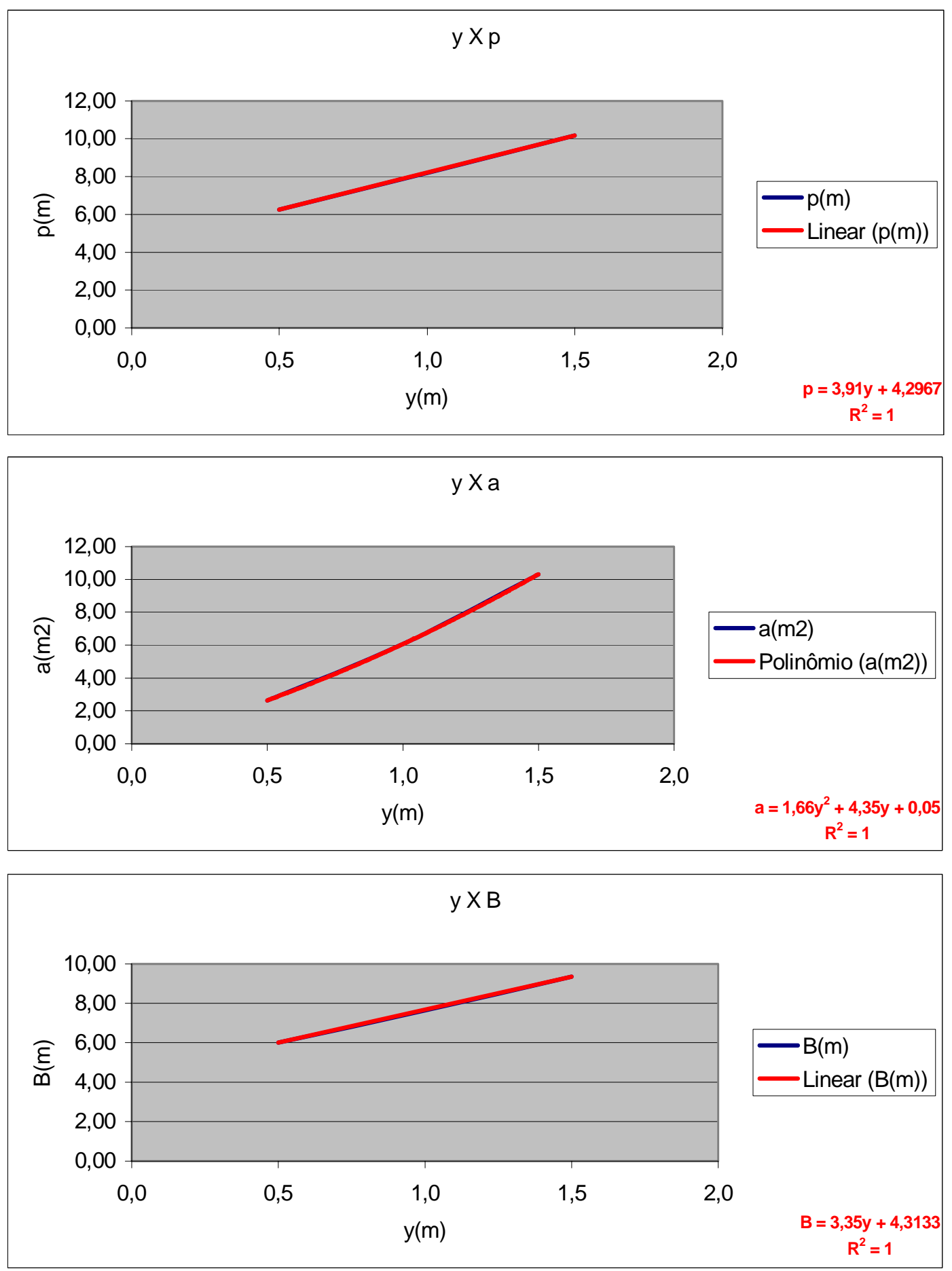


\section{SEÇÃO 16}
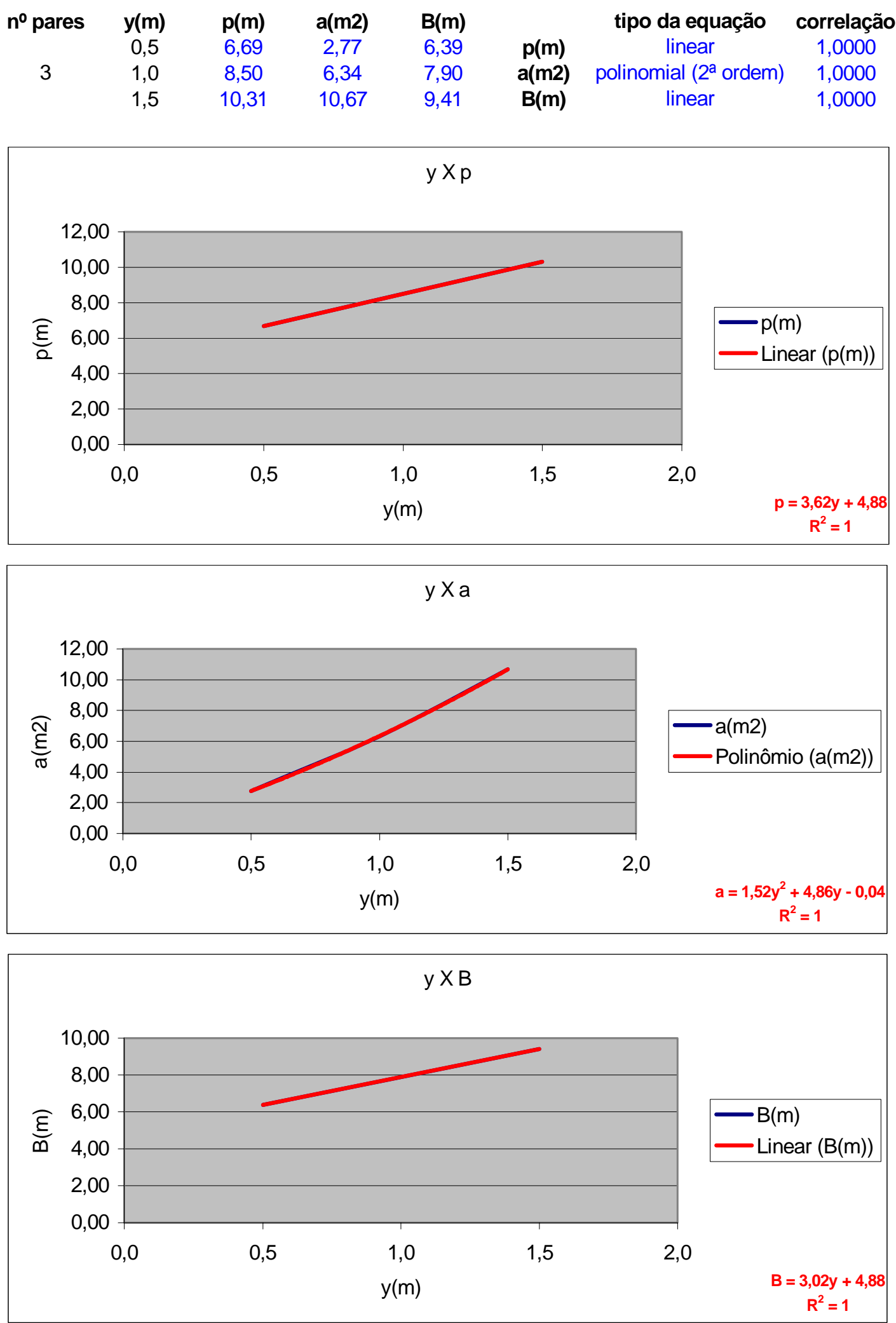


\section{SEÇÃO 17}

$\begin{array}{cccccccc}\text { no pares } & \mathbf{y}(\mathbf{m}) & \mathbf{p}(\mathbf{m}) & \mathbf{a}(\mathbf{m} 2) & \mathbf{B}(\mathbf{m}) & & \text { tipo da equação } & \text { correlação } \\ & 0,5 & 6,82 & 2,91 & 6,51 & \mathbf{p}(\mathbf{m}) & \text { linear } & 1,0000 \\ 3 & 1,0 & 8,64 & 6,55 & 8,04 & \mathbf{a}(\mathbf{m} 2) & \text { polinomial }\left(2^{\mathrm{a}} \text { ordem }\right) & 1,0000 \\ & 1,5 & 10,46 & 10,95 & 9,56 & \mathbf{B}(\mathbf{m}) & \text { linear } & 1,0000\end{array}$
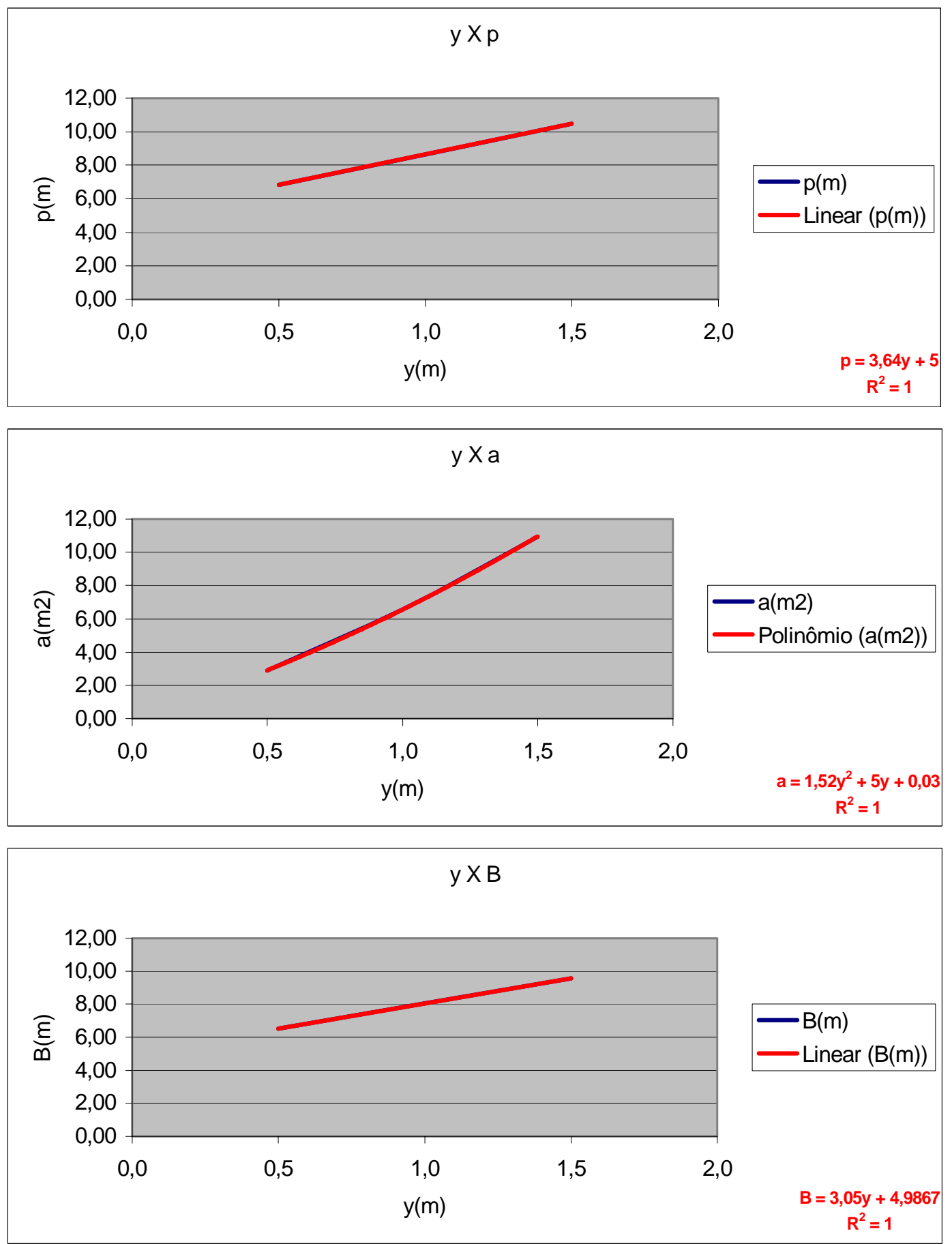


\section{SEÇÃO 18}

$\begin{array}{cccccccc}\text { no pares } & \mathbf{y}(\mathbf{m}) & \mathbf{p}(\mathbf{m}) & \mathbf{a}(\mathbf{m} 2) & \mathbf{B}(\mathbf{m}) & & \text { tipo da equação } & \text { correlação } \\ & 0,5 & 6,86 & 2,97 & 6,56 & \mathbf{p}(\mathbf{m}) & \text { linear } & 1,0000 \\ 3 & 1,0 & 8,70 & 6,63 & 8,10 & \mathbf{a}(\mathbf{m} 2) & \text { polinomial }\left(2^{\mathrm{a}} \text { ordem }\right) & 1,0000 \\ & 1,5 & 10,53 & 11,06 & 9,64 & \mathbf{B}(\mathbf{m}) & \text { linear } & 1,0000\end{array}$
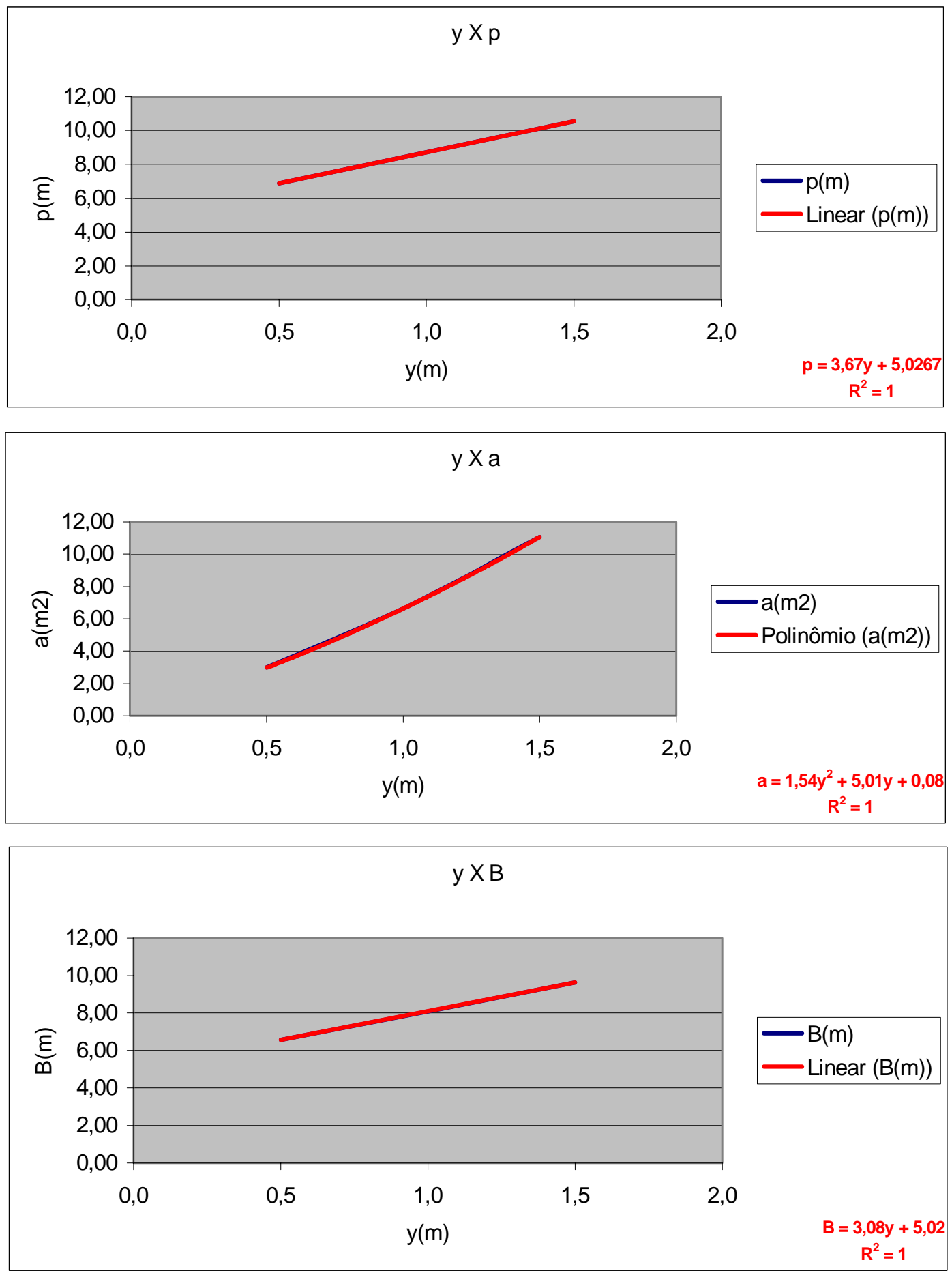


\section{SEÇÃO 19}

$\begin{array}{cccccccc}\text { no pares } & \mathbf{y}(\mathbf{m}) & \mathbf{p}(\mathbf{m}) & \mathbf{a}(\mathbf{m} \mathbf{2}) & \mathbf{B}(\mathbf{m}) & & \text { tipo da equação } & \text { correlação } \\ & 0,5 & 13,10 & 6,01 & 12,82 & \mathbf{p}(\mathbf{m}) & \text { linear } & 1,0000 \\ 3 & 1,0 & 15,12 & 12,86 & 14,58 & \mathbf{a}(\mathbf{m} 2) & \text { polinomial }\left(2^{a} \text { ordem) }\right. & 1,0000 \\ & 1,5 & 17,15 & 20,59 & 16,34 & \mathbf{B}(\mathbf{m}) & \text { linear } & 1,0000\end{array}$
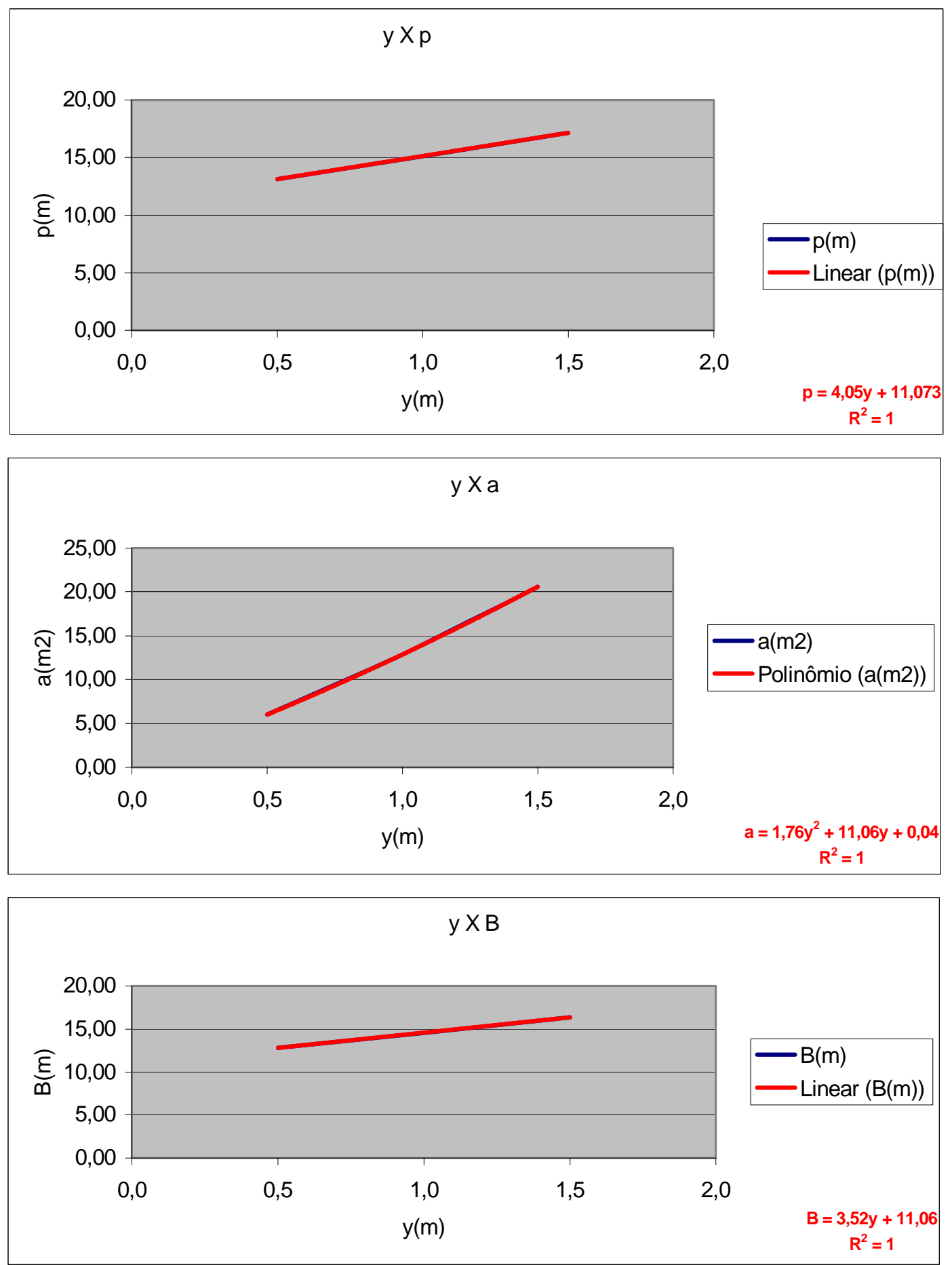


\section{SEÇÃO 20}

$\begin{array}{cccccccc}\text { no pares } & \mathbf{y}(\mathbf{m}) & \mathbf{p}(\mathbf{m}) & \mathbf{a}(\mathbf{m} 2) & \mathbf{B}(\mathbf{m}) & & \text { tipo da equação } & \text { correlação } \\ & 0,5 & 7,37 & 3,31 & 7,06 & \mathbf{p}(\mathbf{m}) & \text { linear } & 1,0000 \\ 3 & 1,0 & 9,23 & 7,23 & 8,62 & \mathbf{a}(\mathbf{m} 2) & \text { polinomial }\left(2^{\mathrm{a}} \text { ordem }\right) & 1,0000 \\ & 1,5 & 11,08 & 11,93 & 10,18 & \mathbf{B}(\mathbf{m}) & \text { linear } & 1,0000\end{array}$
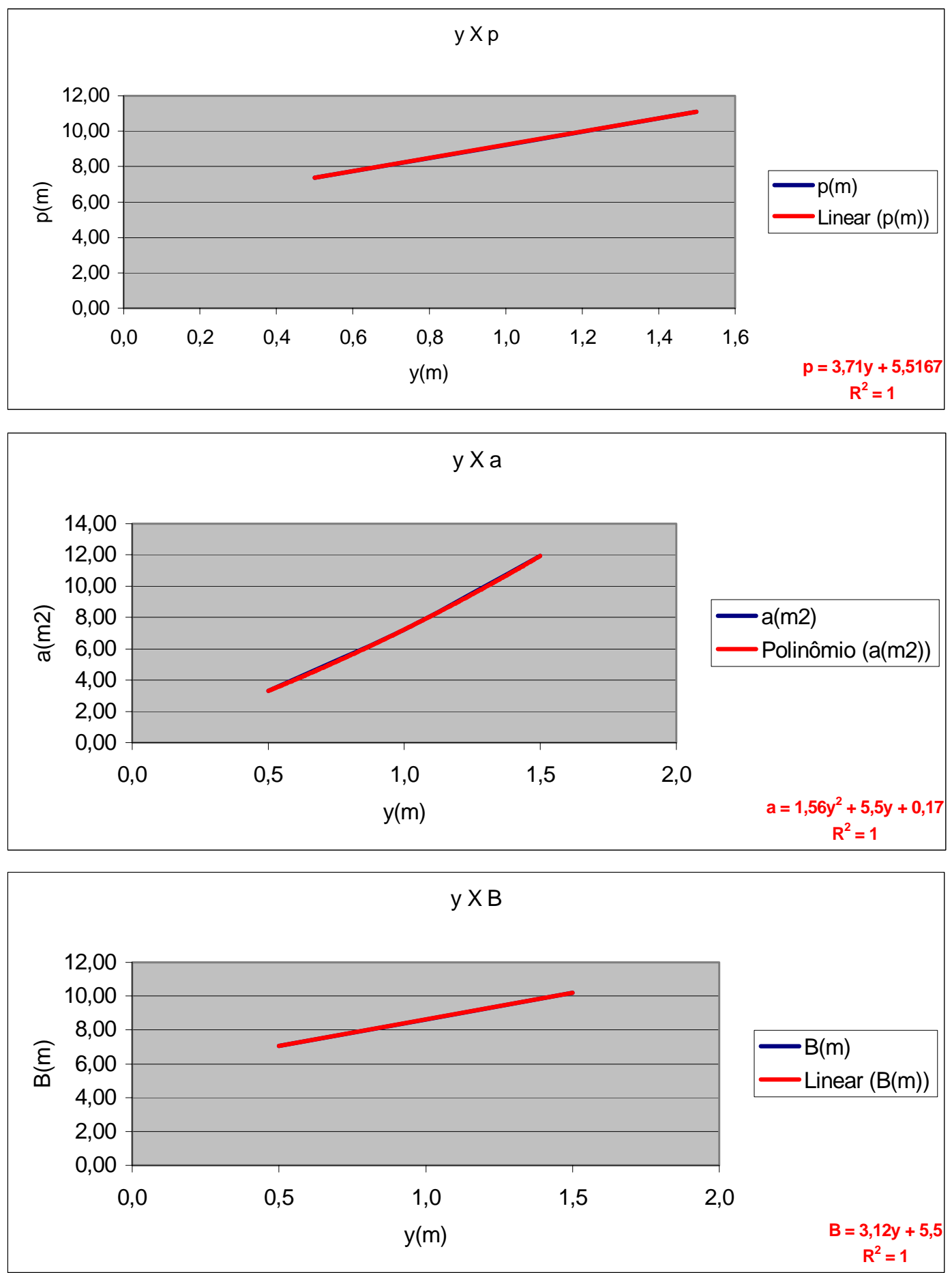


\section{SEÇÃO 21}

$\begin{array}{cccccccc}\text { no pares } & \mathbf{y}(\mathbf{m}) & \mathbf{p}(\mathbf{m}) & \mathbf{a}(\mathbf{m} 2) & \mathbf{B}(\mathbf{m}) & & \text { tipo da equação } & \text { correlação } \\ & 0,5 & 10,97 & 4,88 & 10,67 & \mathbf{p}(\mathbf{m}) & \text { linear } & 1,0000 \\ 3 & 1,0 & 12,77 & 10,59 & 12,17 & \mathbf{a}(\mathbf{m} 2) & \text { polinomial }\left(2^{\mathrm{a}} \text { ordem }\right) & 1,0000 \\ & 1,5 & 14,57 & 17,05 & 13,66 & \mathbf{B}(\mathbf{m}) & \text { linear } & 1,0000\end{array}$
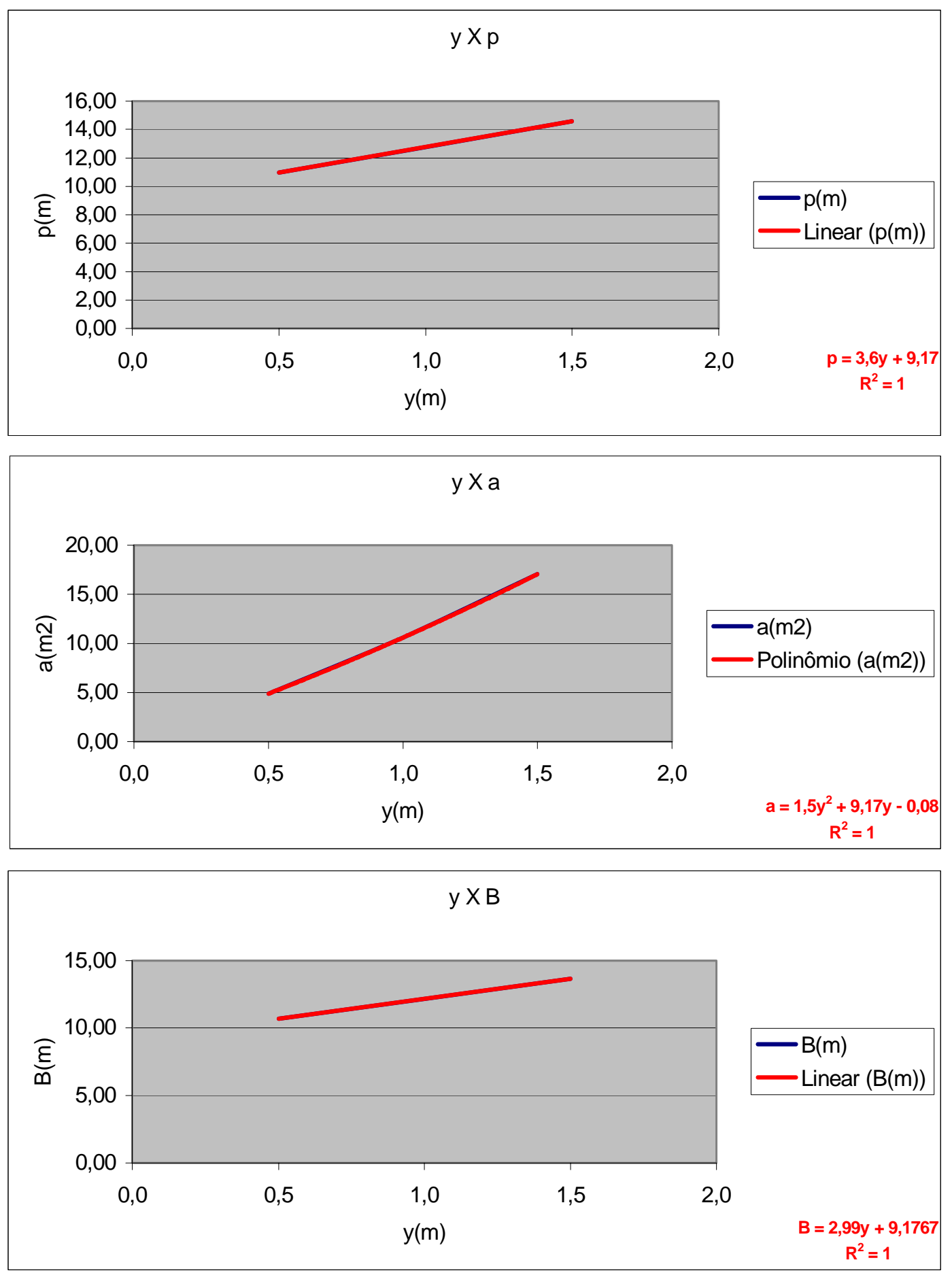


\section{SEÇÃO 22}

$\begin{array}{cccccccc}\text { no pares } & \mathbf{y}(\mathbf{m}) & \mathbf{p}(\mathbf{m}) & \mathbf{a}(\mathbf{m} \mathbf{2}) & \mathbf{B}(\mathbf{m}) & & \text { tipo da equação } & \text { correlação } \\ & 0,5 & 6,52 & 2,68 & 6,25 & \mathbf{p}(\mathbf{m}) & \text { linear } & 1,0000 \\ 3 & 1,0 & 8,49 & 6,23 & 7,95 & \mathbf{a}(\mathbf{m} 2) & \text { polinomial }\left(2^{a} \text { ordem) }\right. & 1,0000 \\ & 1,5 & 10,46 & 10,63 & 9,65 & \mathbf{B}(\mathbf{m}) & \text { linear } & 1,0000\end{array}$
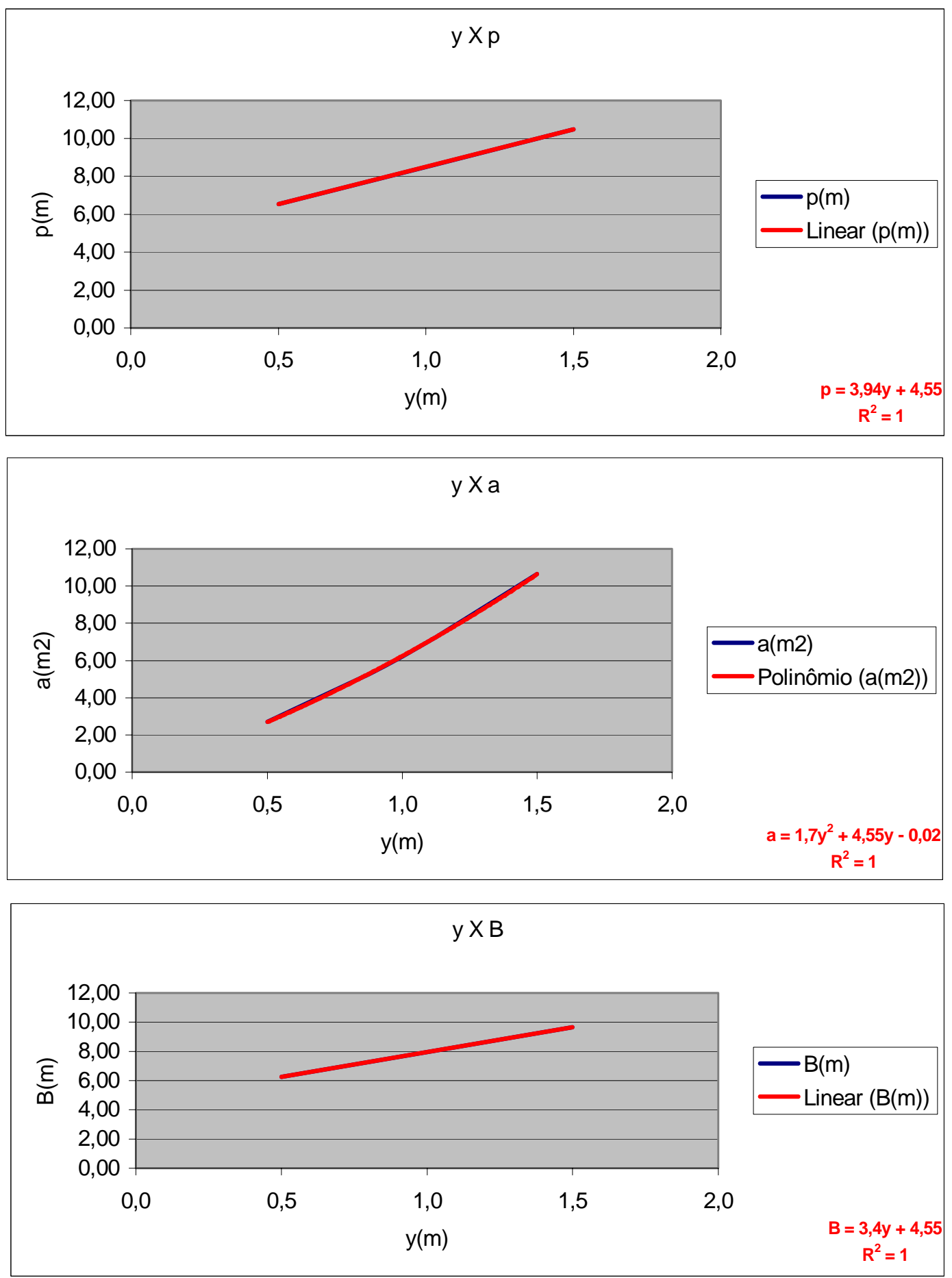


\section{SEÇÃO 23}

$\begin{array}{cccccccc}\text { no pares } & \mathbf{y}(\mathbf{m}) & \mathbf{p}(\mathbf{m}) & \mathbf{a}(\mathbf{m} 2) & \mathbf{B}(\mathbf{m}) & & \text { tipo da equação } & \text { correlação } \\ & 0,5 & 7,29 & 3,24 & 6,94 & \mathbf{p}(\mathbf{m}) & \text { linear } & 1,0000 \\ 3 & 1,0 & 9,15 & 7,09 & 8,50 & \mathbf{a}(\mathbf{m} 2) & \text { polinomial }\left(2^{\mathrm{a}} \text { ordem }\right) & 1,0000 \\ & 1,5 & 11,03 & 11,74 & 10,10 & \mathbf{B}(\mathbf{m}) & \text { linear } & 0,9999\end{array}$
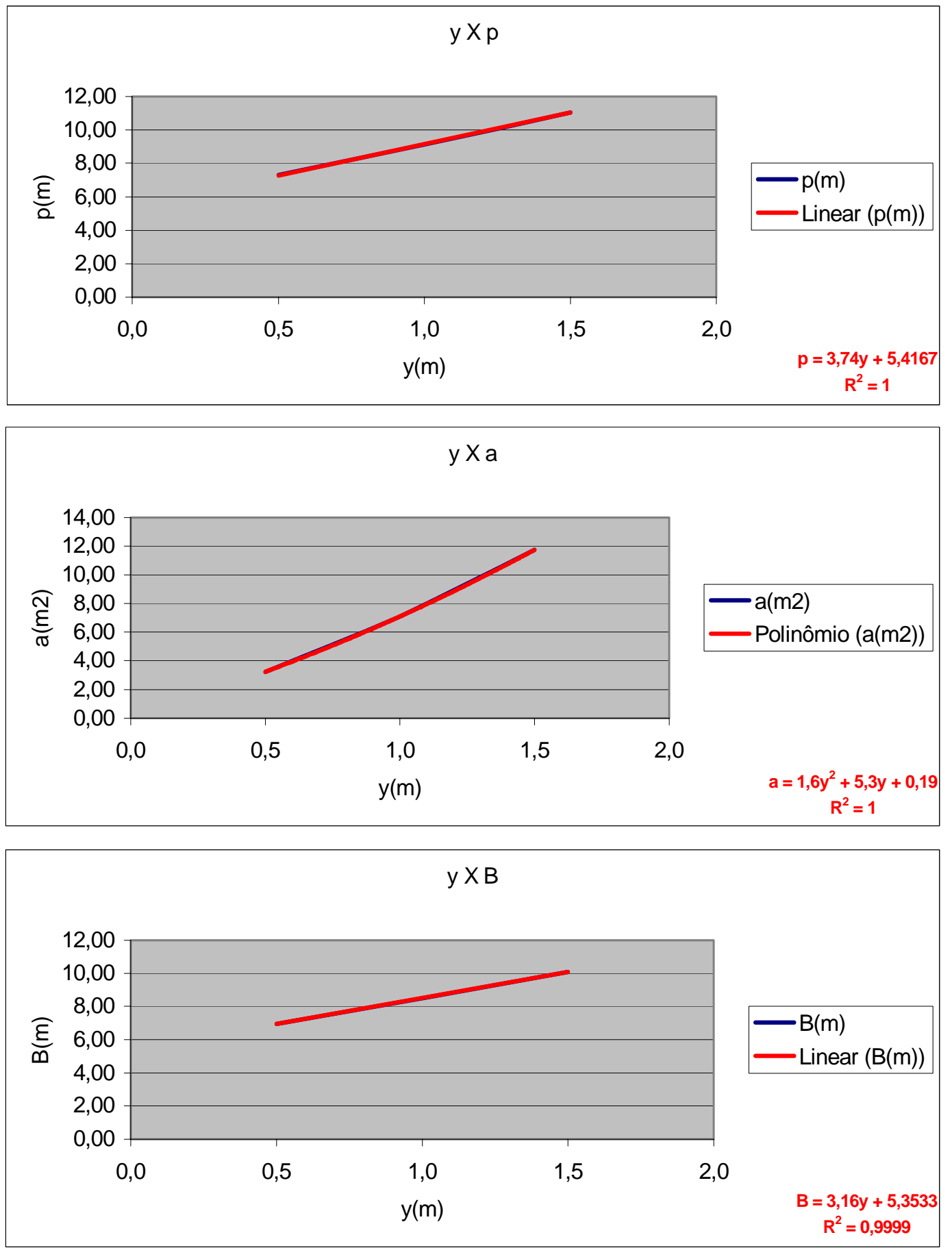


\section{SEÇÃO 24}

$\begin{array}{cccccccc}\text { no pares } & \mathbf{y}(\mathbf{m}) & \mathbf{p}(\mathbf{m}) & \mathbf{a}(\mathbf{m} 2) & \mathbf{B}(\mathbf{m}) & & \text { tipo da equação } & \text { correlação } \\ & 0,5 & 6,81 & 2,85 & 6,54 & \mathbf{p}(\mathbf{m}) & \text { linear } & 1,0000 \\ 3 & 1,0 & 8,63 & 6,50 & 8,07 & \mathbf{a}(\mathbf{m} 2) & \text { polinomial }\left(2^{a} \text { ordem) }\right. & 1,0000 \\ & 1,5 & 10,46 & 10,91 & 9,59 & \mathbf{B}(\mathbf{m}) & \text { linear } & 1,0000\end{array}$
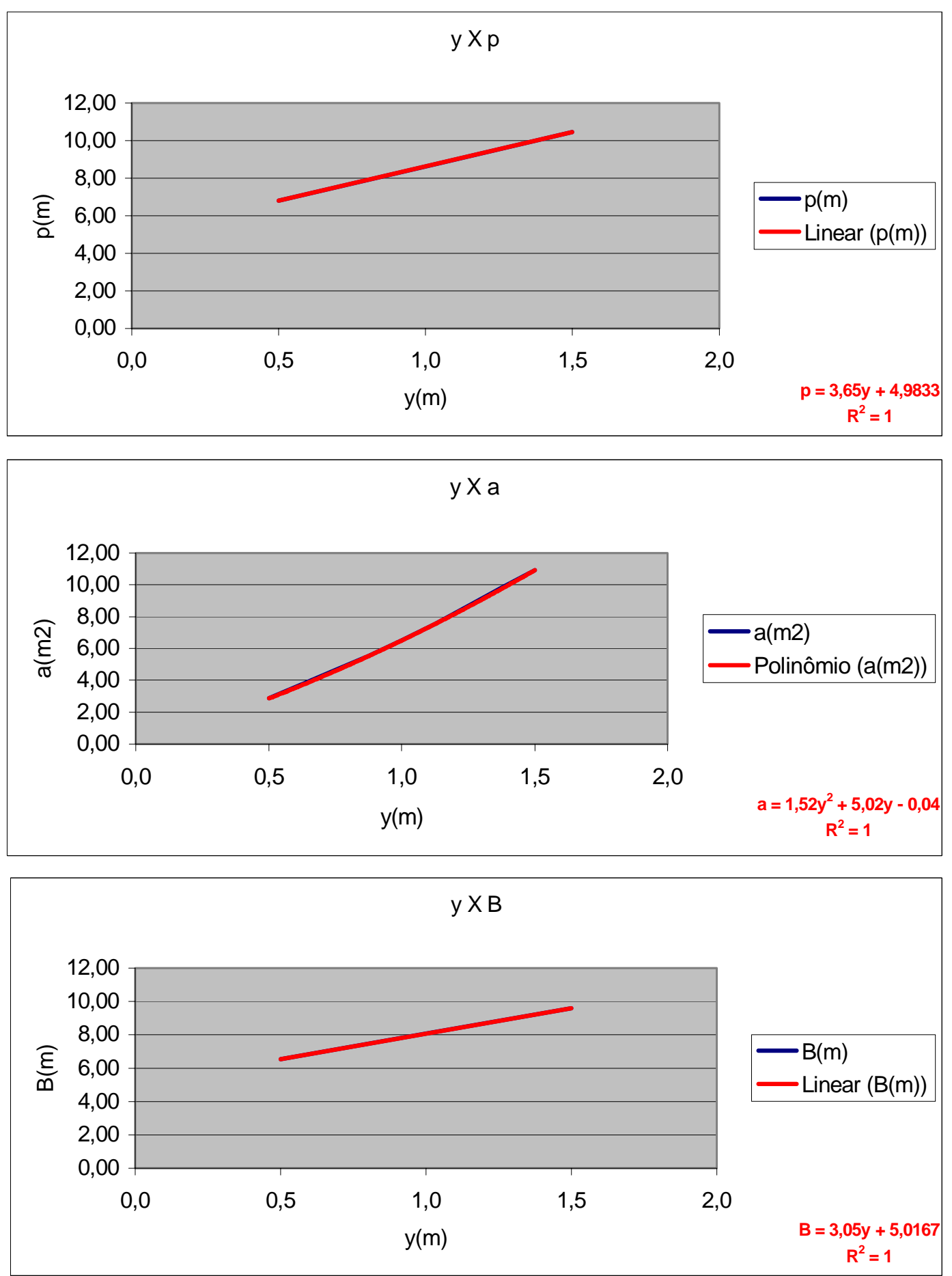
SEÇÕES 25 e 26

$\begin{array}{cccccccc}\text { no pares } & \mathbf{y}(\mathbf{m}) & \mathbf{p}(\mathbf{m}) & \mathbf{a}(\mathbf{m} 2) & \mathbf{B}(\mathbf{m}) & & \text { tipo da equação } & \text { correlação } \\ & 0,5 & 6,17 & 2,46 & 5,90 & \mathbf{p}(\mathbf{m}) & \text { linear } & 1,0000 \\ 3 & 1,0 & 8,06 & 5,81 & 7,51 & \mathbf{a}(\mathbf{m} 2) & \text { polinomial }\left(2^{a} \text { ordem) }\right. & 1,0000 \\ & 1,5 & 9,96 & 9,97 & 9,12 & \mathbf{B}(\mathbf{m}) & \text { linear } & 1,0000\end{array}$
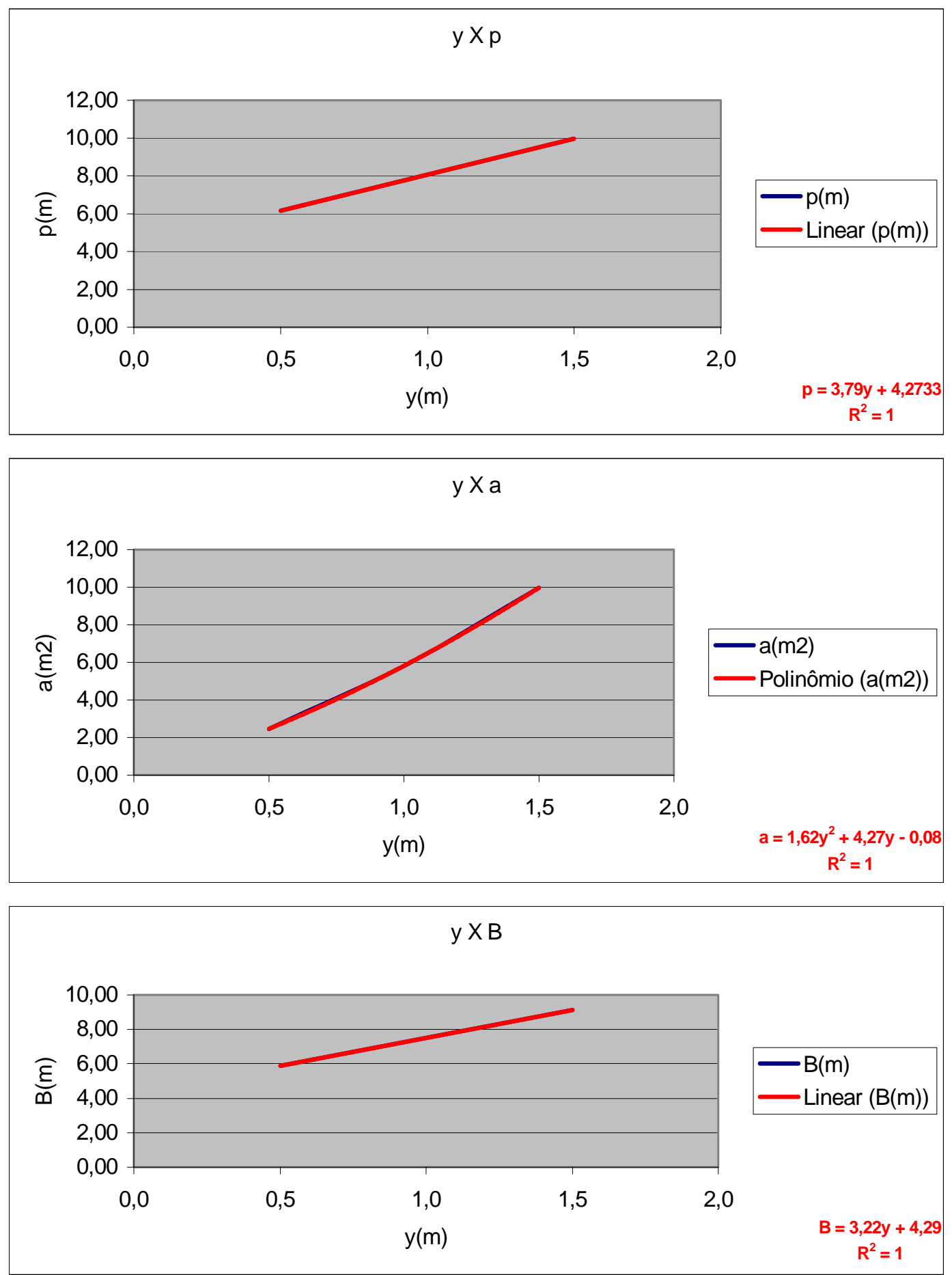
sifão umburanas

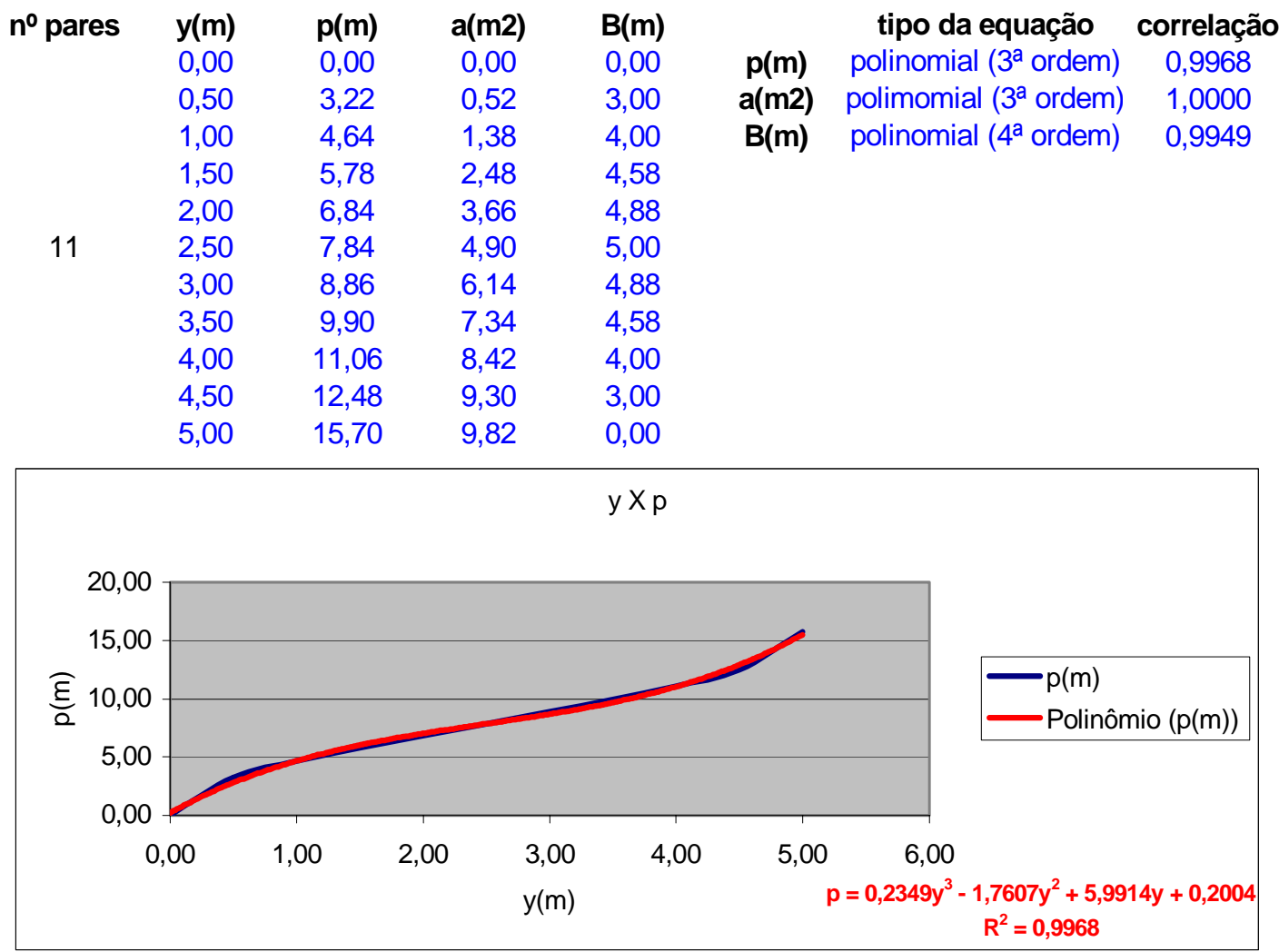
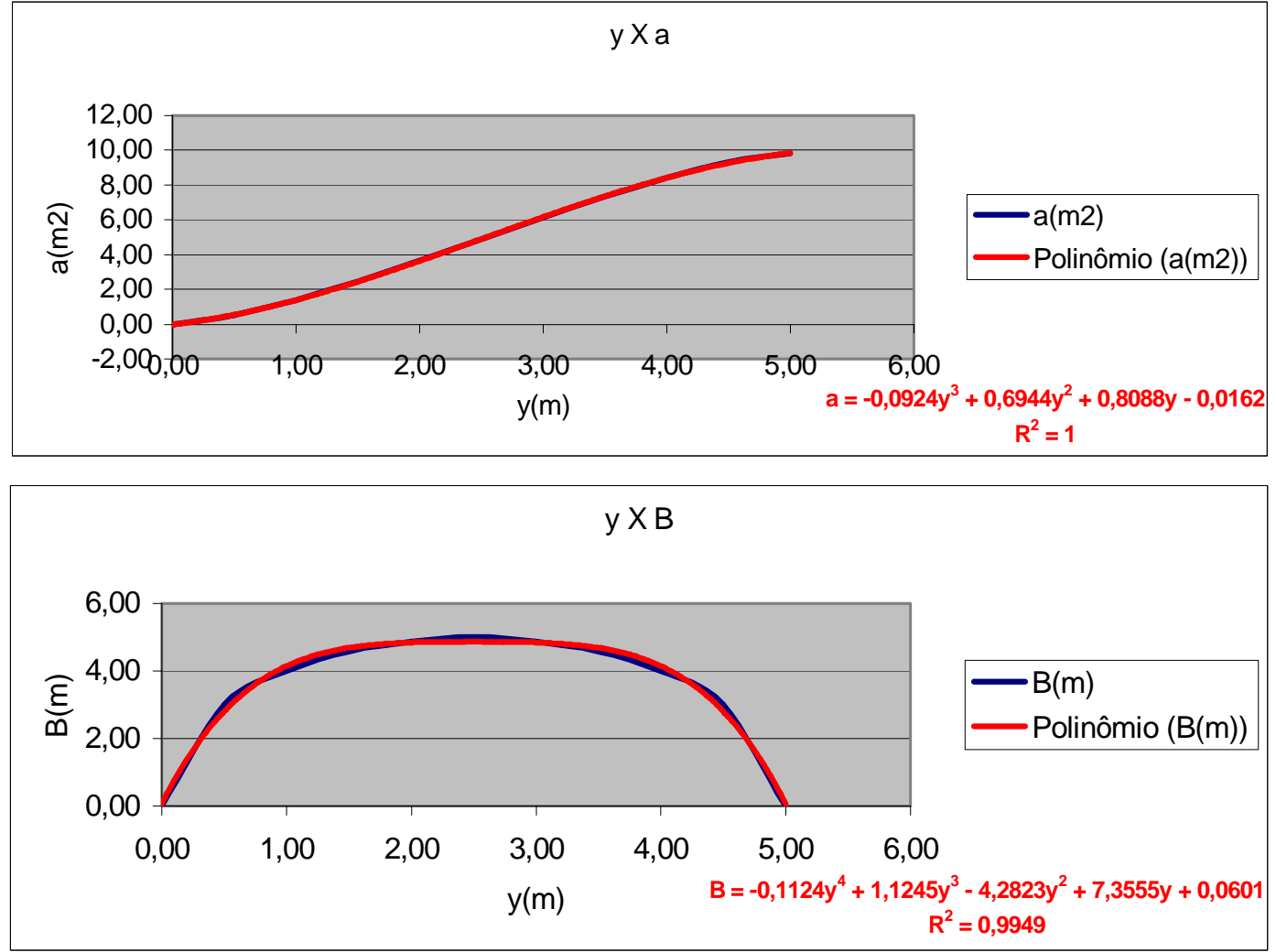


\section{SEÇÃO 32}

$\begin{array}{cccccccc}\text { no pares } & \mathbf{y}(\mathbf{m}) & \mathbf{p}(\mathbf{m}) & \mathbf{a}(\mathbf{m} \mathbf{2}) & \mathbf{B}(\mathbf{m}) & & \text { tipo da equação } & \text { correlação } \\ & 0,5 & 17,22 & 8,01 & 16,98 & \mathbf{p}(\mathbf{m}) & \text { linear } & 0,9995 \\ 3 & 1,0 & 19,40 & 16,98 & 18,92 & \mathbf{a}(\mathbf{m} 2) & \text { polinomial }\left(2^{\mathrm{a}} \text { ordem) }\right. & 1,0000 \\ & 1,5 & 21,42 & 26,90 & 20,67 & \mathbf{B}(\mathbf{m}) & \text { linear } & 0,9991\end{array}$
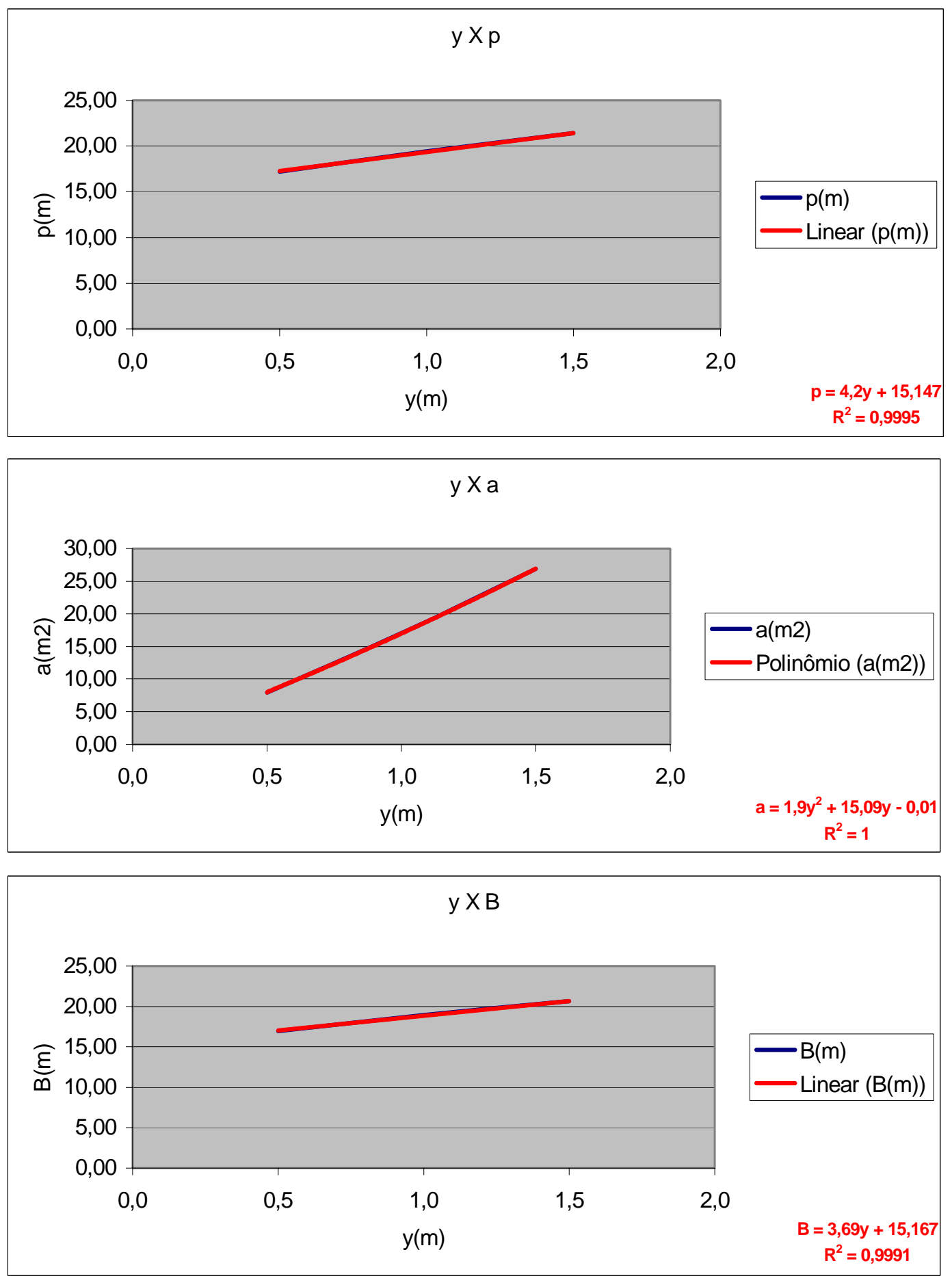


\section{SEÇÃO 33}

$\begin{array}{cccccccc}\text { no pares } & \mathbf{y}(\mathbf{m}) & \mathbf{p}(\mathbf{m}) & \mathbf{a}(\mathbf{m} 2) & \mathbf{B}(\mathbf{m}) & & \text { tipo da equação } & \text { correlação } \\ & 0,5 & 6,72 & 2,88 & 6,42 & \mathbf{p}(\mathbf{m}) & \text { linear } & 0,9999 \\ 3 & 1,0 & 8,57 & 6,48 & 7,98 & \mathbf{a}(\mathbf{m} 2) & \text { polinomial }\left(2^{\mathrm{a}} \text { ordem }\right) & 1,0000 \\ & 1,5 & 10,36 & 10,84 & 9,47 & \mathbf{B}(\mathbf{m}) & \text { linear } & 0,9998\end{array}$
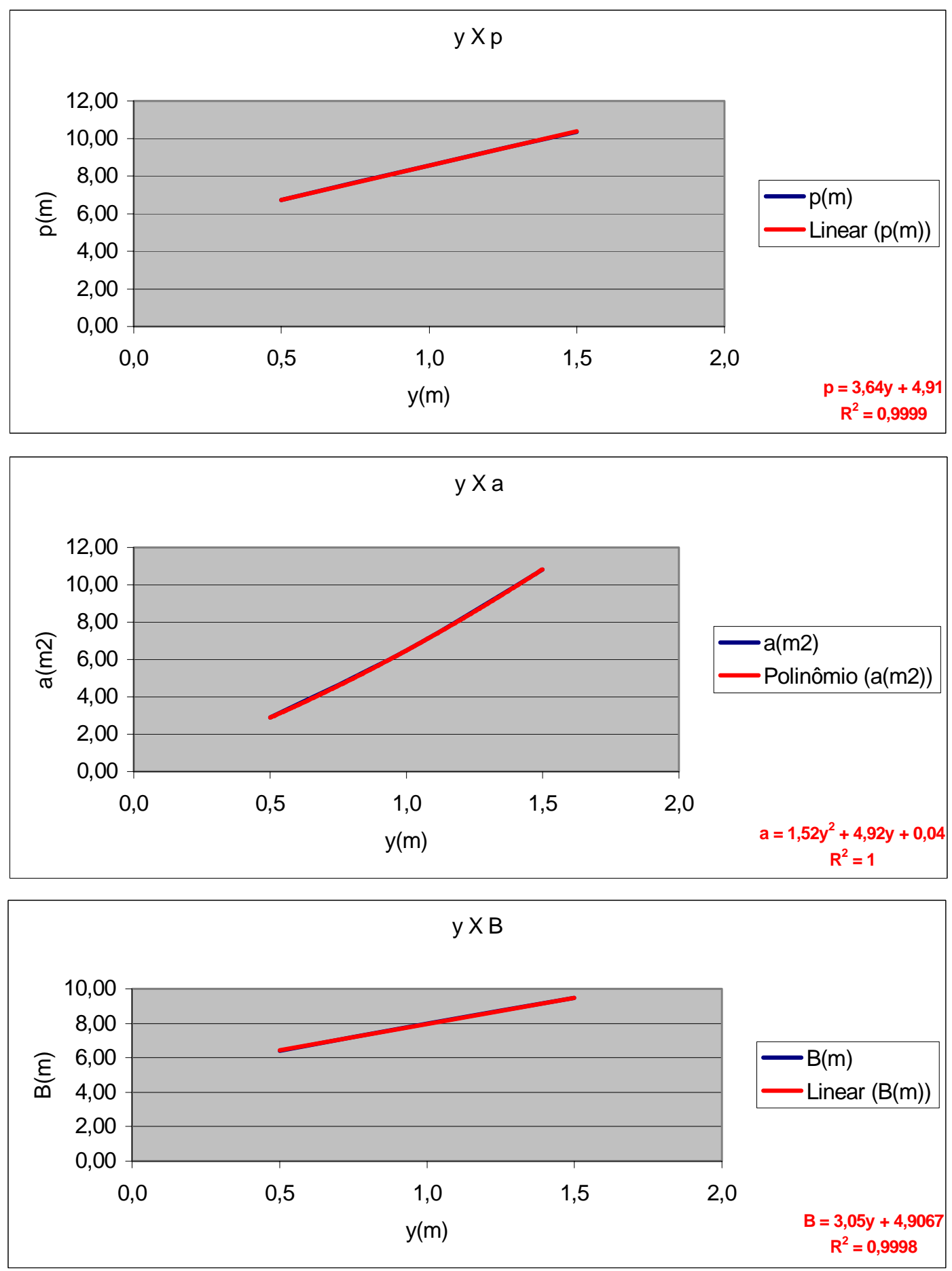
SEÇÕES 34 e 35

$\begin{array}{cccccccc}\text { no pares } & \mathbf{y}(\mathbf{m}) & \mathbf{p}(\mathbf{m}) & \mathbf{a}(\mathbf{m} \mathbf{2}) & \mathbf{B}(\mathbf{m}) & & \text { tipo da equação } & \text { correlação } \\ & 0,5 & 7,16 & 3,09 & 6,86 & \mathbf{p}(\mathbf{m}) & \text { linear } & 0,9998 \\ 3 & 1,0 & 8,96 & 6,91 & 8,35 & \mathbf{a}(\mathbf{m} 2) & \text { polinomial }\left(2^{a} \text { ordem) }\right. & 1,0000 \\ & 1,5 & 10,68 & 11,43 & 9,75 & \mathbf{B}(\mathbf{m}) & \text { linear } & 0,9997\end{array}$
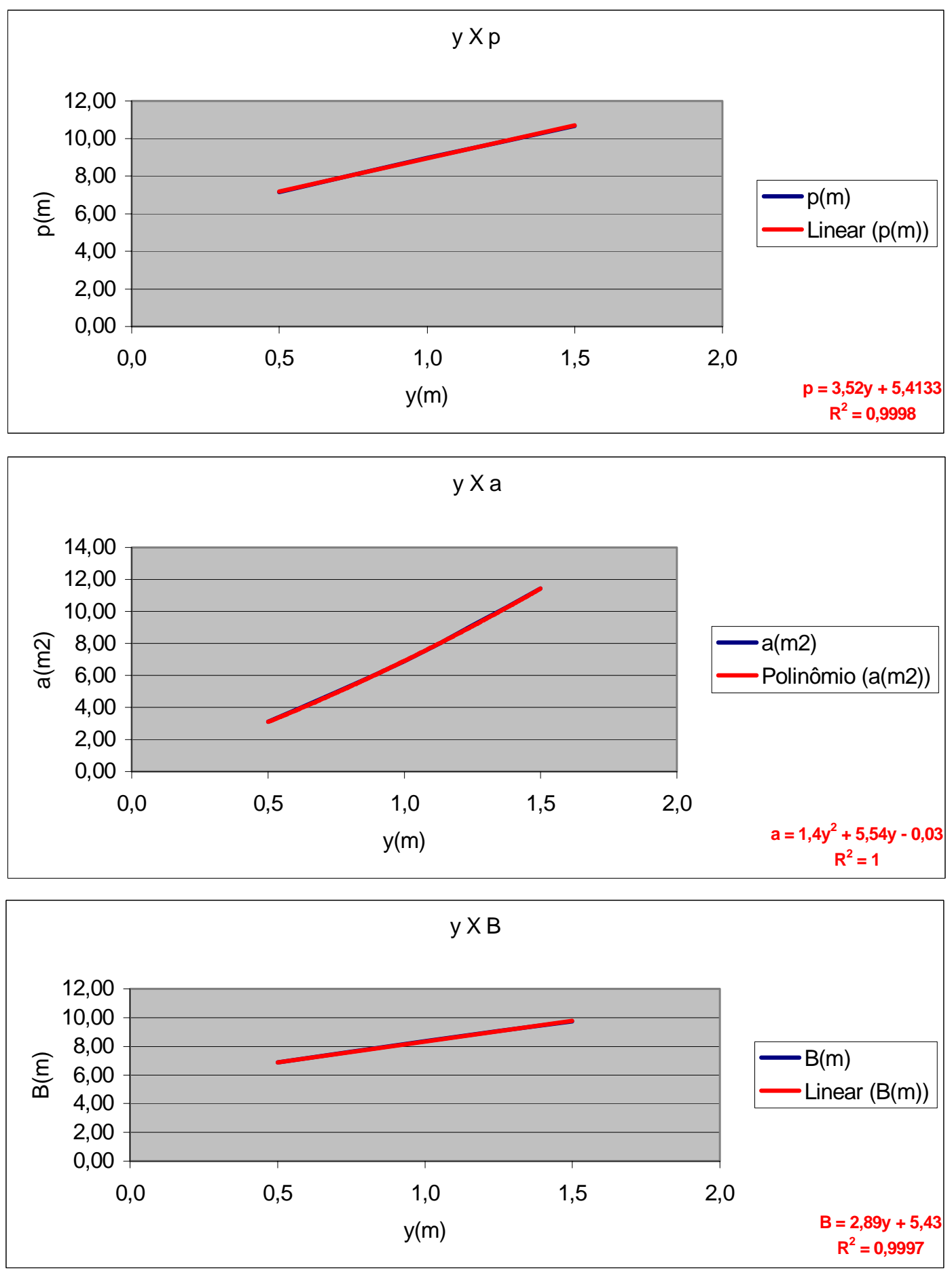
SEÇÕES 36 e 37

$\begin{array}{cccccccc}\text { no pares } & \mathbf{y}(\mathbf{m}) & \mathbf{p}(\mathbf{m}) & \mathbf{a}(\mathbf{m} 2) & \mathbf{B}(\mathbf{m}) & & \text { tipo da equação } & \text { correlação } \\ & 0,5 & 7,78 & 3,44 & 7,54 & \mathbf{p}(\mathbf{m}) & \text { linear } & 1,0000 \\ 3 & 1,0 & 9,54 & 7,58 & 8,99 & \mathbf{a}(\mathbf{m} 2) & \text { polinomial }\left(2^{\mathrm{a}} \text { ordem }\right) & 1,0000 \\ & 1,5 & 11,31 & 12,43 & 10,44 & \mathbf{B}(\mathbf{m}) & \text { linear } & 1,0000\end{array}$
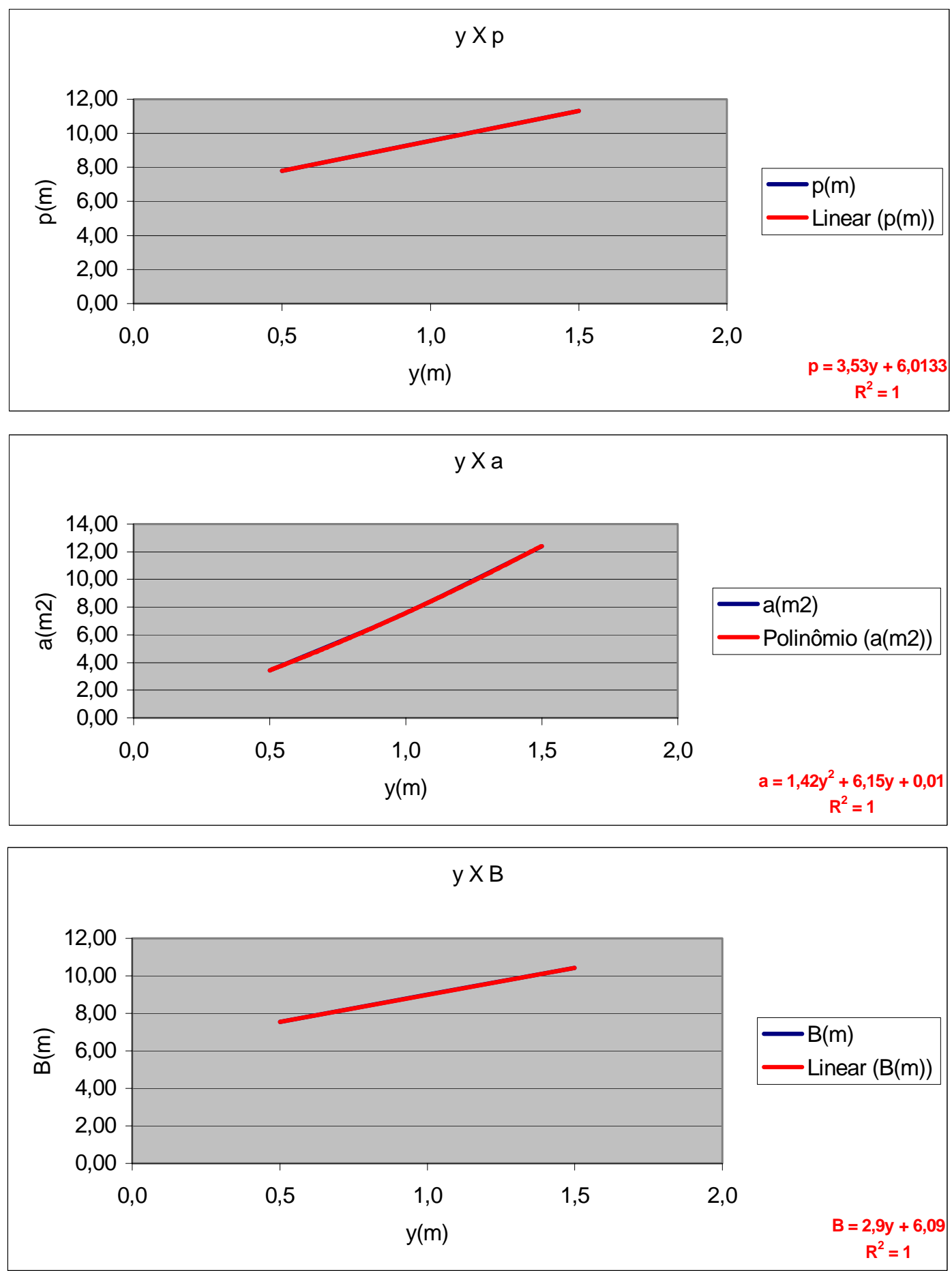
SEÇÕES 38 e 39

$\begin{array}{cccccccc}\text { no pares } & \mathbf{y}(\mathbf{m}) & \mathbf{p}(\mathbf{m}) & \mathbf{a}(\mathbf{m} 2) & \mathbf{B}(\mathbf{m}) & & \text { tipo da equação } & \text { correlação } \\ & 0,5 & 6,64 & 3,04 & 6,36 & \mathbf{p}(\mathbf{m}) & \text { linear } & 1,0000 \\ 3 & 1,0 & 8,43 & 6,59 & 7,84 & \mathbf{a}(\mathbf{m} 2) & \text { polinomial }\left(2^{a} \text { ordem }\right) & 1,0000 \\ & 1,5 & 10,20 & 10,87 & 9,28 & \mathbf{B}(\mathbf{m}) & \text { linear } & 0,9999\end{array}$
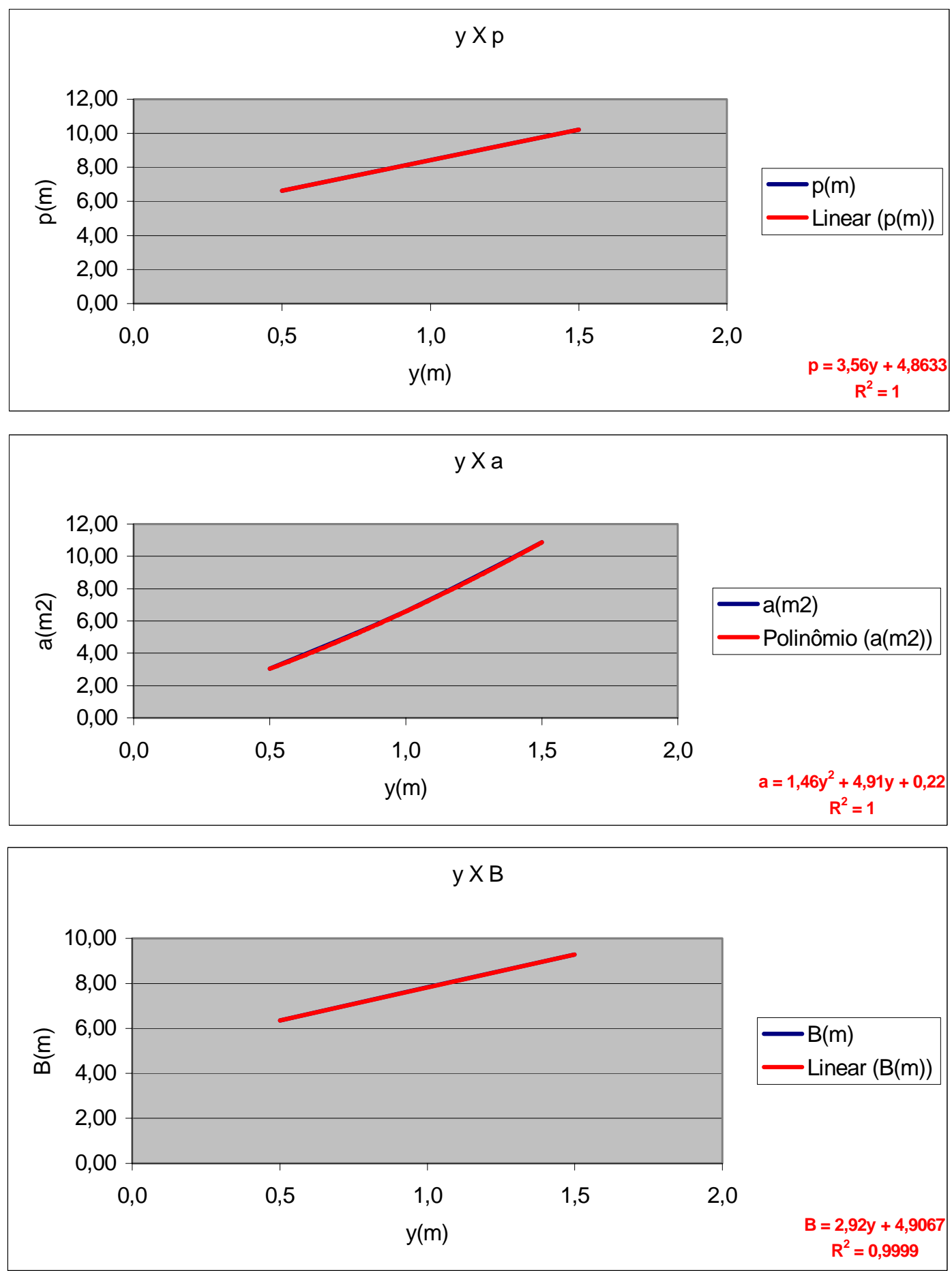
SEÇÕES 40, 41 e 42

$\begin{array}{cccccccc}\text { no pares } & \mathbf{y}(\mathbf{m}) & \mathbf{p}(\mathbf{m}) & \mathbf{a}(\mathbf{m} 2) & \mathbf{B}(\mathbf{m}) & & \text { tipo da equação } & \text { correlação } \\ & 0,5 & 8,30 & 3,68 & 8,06 & \mathbf{p}(\mathbf{m}) & \text { linear } & 1,0000 \\ 3 & 1,0 & 10,26 & 8,13 & 9,74 & \mathbf{a}(\mathbf{m} 2) & \text { polinomial }\left(2^{a} \text { ordem }\right) & 1,0000 \\ & 1,5 & 12,22 & 13,41 & 11,42 & \mathbf{B}(\mathbf{m}) & \text { linear } & 1,0000\end{array}$
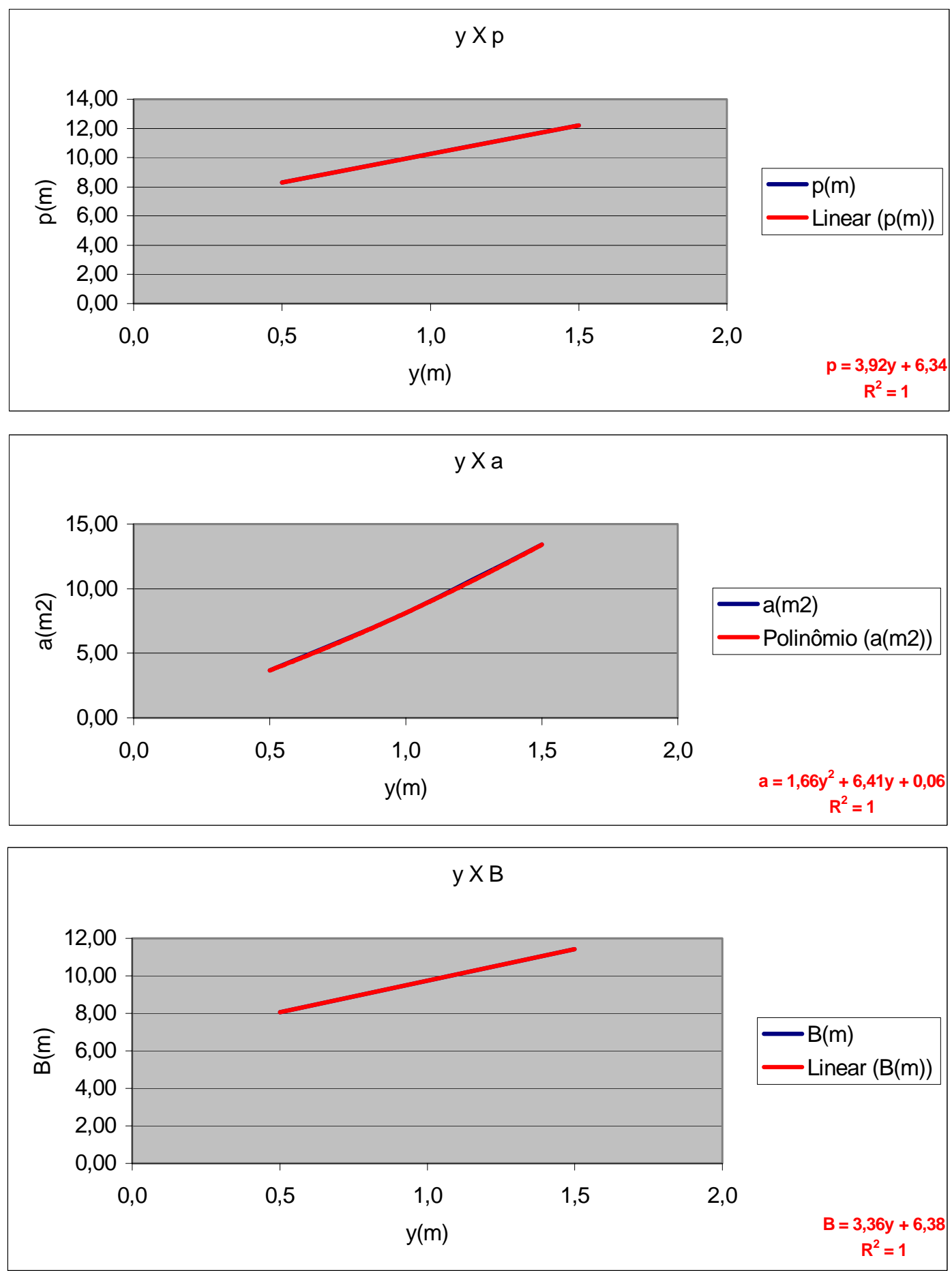


\section{SEÇÕES 43, 44 e 45}

$\begin{array}{cccccccc}\text { no pares } & \mathbf{y}(\mathbf{m}) & \mathbf{p}(\mathbf{m}) & \mathbf{a}(\mathbf{m} 2) & \mathbf{B}(\mathbf{m}) & & \text { tipo da equação } & \text { correlação } \\ & 0,5 & 6,63 & 2,88 & 6,34 & \mathbf{p}(\mathbf{m}) & \text { linear } & 1,0000 \\ 3 & 1,0 & 8,53 & 6,45 & 7,95 & \mathbf{a}(\mathbf{m} 2) & \text { polinomial }\left(2^{\mathrm{a}} \text { ordem }\right) & 1,0000 \\ & 1,5 & 10,42 & 10,83 & 9,56 & \mathbf{B}(\mathbf{m}) & \text { linear } & 1,0000\end{array}$
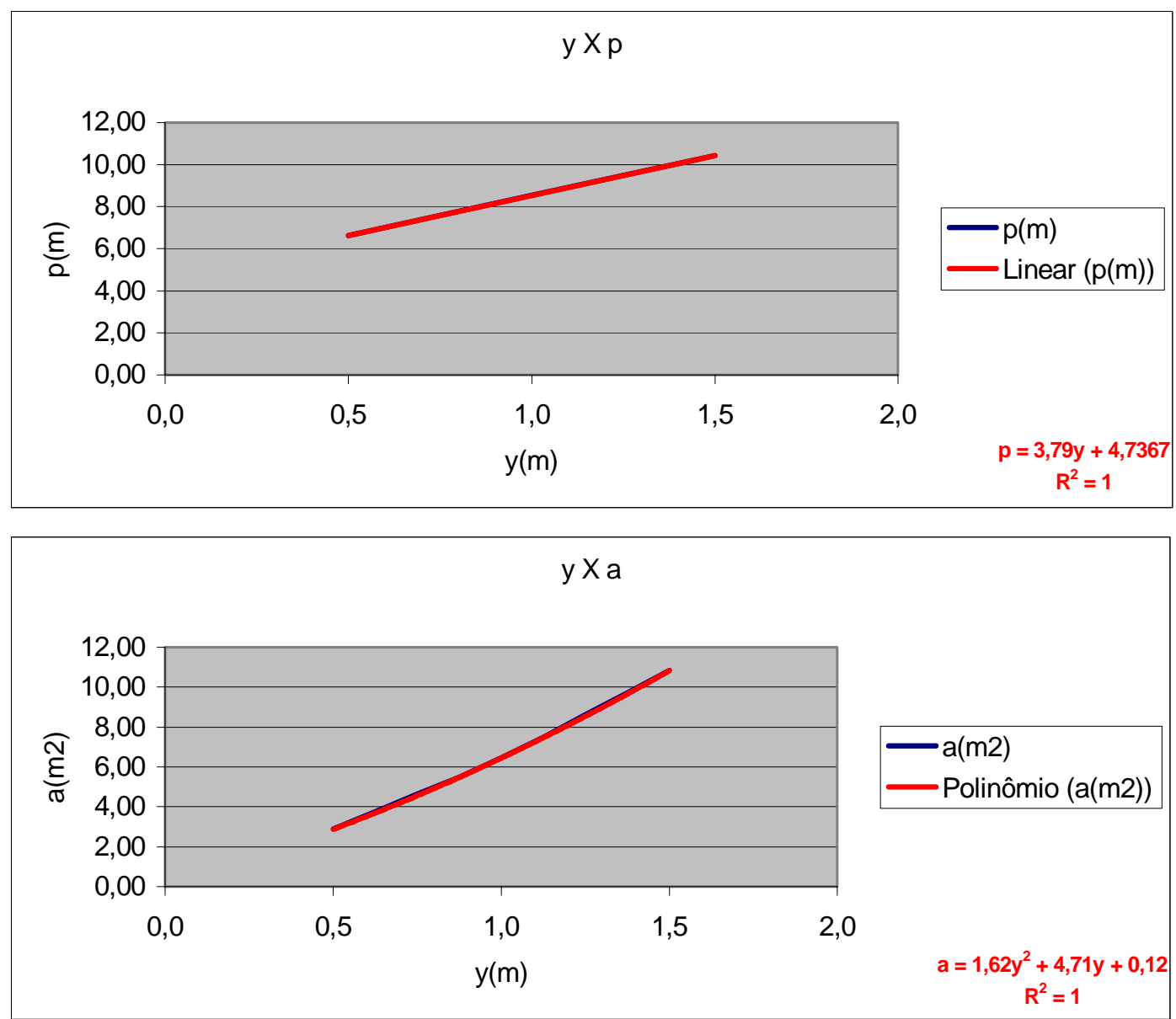

$y \times B$

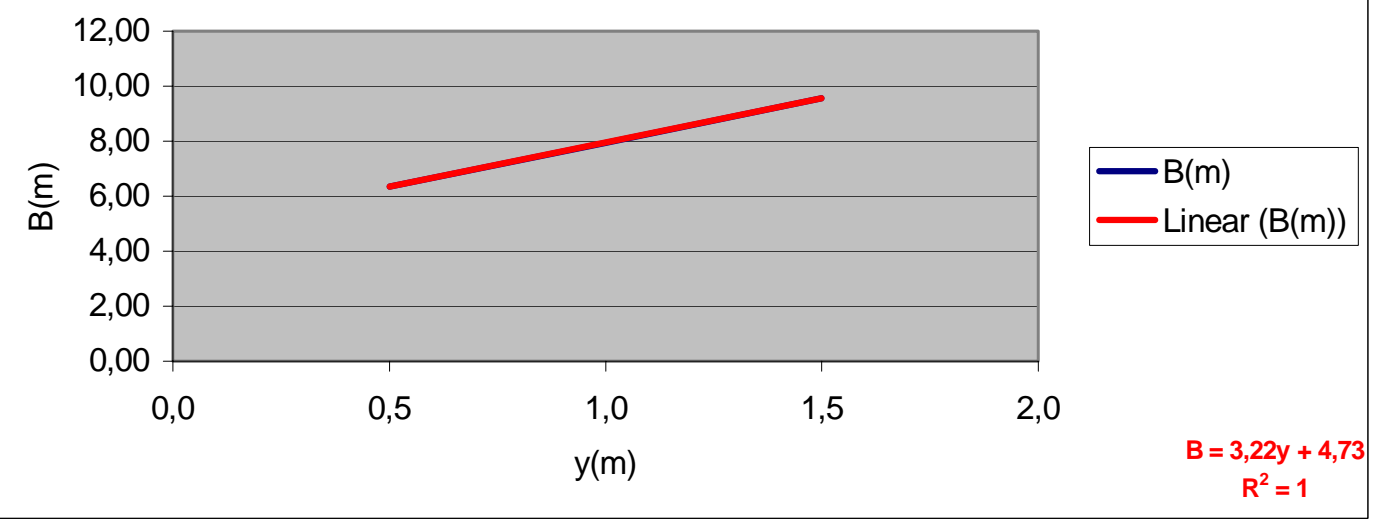


SEÇÕES 46 e 47

$\begin{array}{cccccccc}\text { no pares } & \mathbf{y}(\mathbf{m}) & \mathbf{p}(\mathbf{m}) & \mathbf{a}(\mathbf{m} 2) & \mathbf{B}(\mathbf{m}) & & \text { tipo da equação } & \text { correlação } \\ & 0,5 & 6,25 & 2,63 & 5,95 & \mathbf{p}(\mathbf{m}) & \text { linear } & 1,0000 \\ 3 & 1,0 & 8,05 & 5,98 & 7,44 & \mathbf{a}(\mathbf{m} 2) & \text { polinomial }\left(2^{a} \text { ordem }\right) & 1,0000 \\ & 1,5 & 9,85 & 10,08 & 8,94 & \mathbf{B}(\mathbf{m}) & \text { linear } & 1,0000\end{array}$
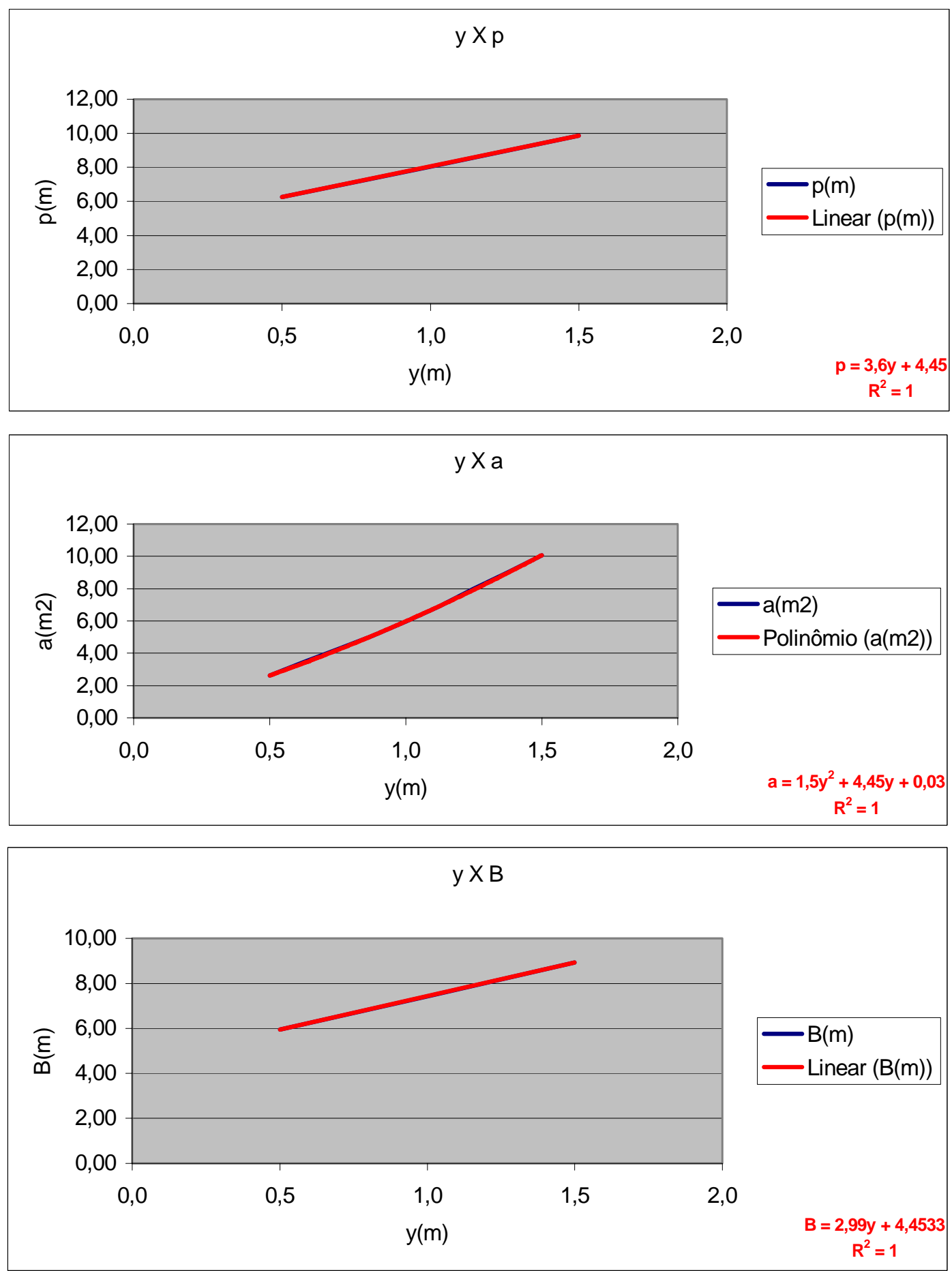


\section{SEÇÃO 48}

$\begin{array}{cccccccc}\text { no pares } & \mathbf{y}(\mathbf{m}) & \mathbf{p}(\mathbf{m}) & \mathbf{a}(\mathbf{m} \mathbf{2}) & \mathbf{B}(\mathbf{m}) & & \text { tipo da equação } & \text { correlação } \\ & 0,5 & 6,11 & 2,71 & 5,82 & \mathbf{p}(\mathbf{m}) & \text { linear } & 1,0000 \\ 3 & 1,0 & 7,99 & 6,02 & 7,42 & \mathbf{a}(\mathbf{m} 2) & \text { polinomial }\left(2^{a} \text { ordem) }\right. & 1,0000 \\ & 1,5 & 9,88 & 10,13 & 9,01 & \mathbf{B}(\mathbf{m}) & \text { linear } & 1,0000\end{array}$
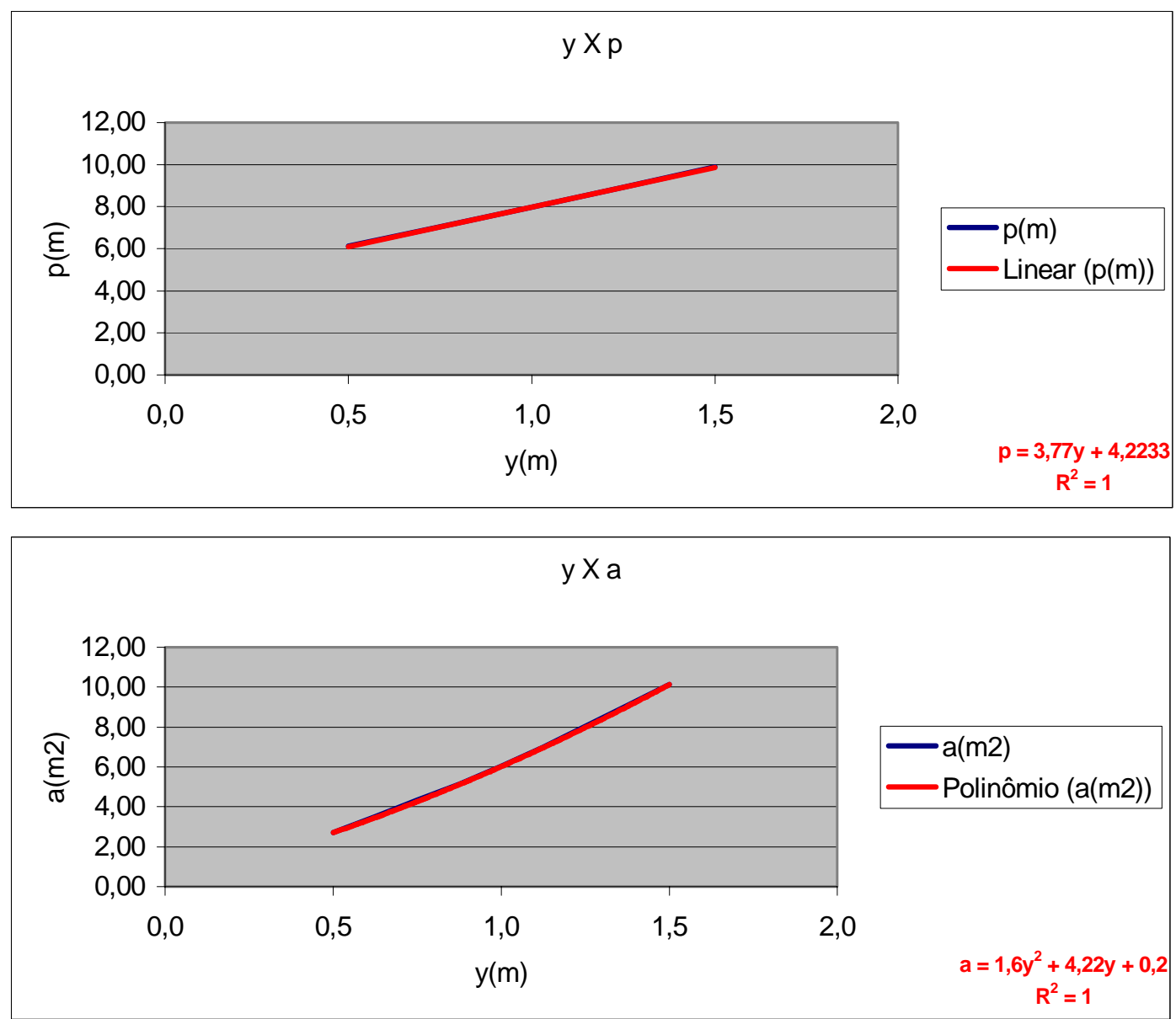

$y \times B$

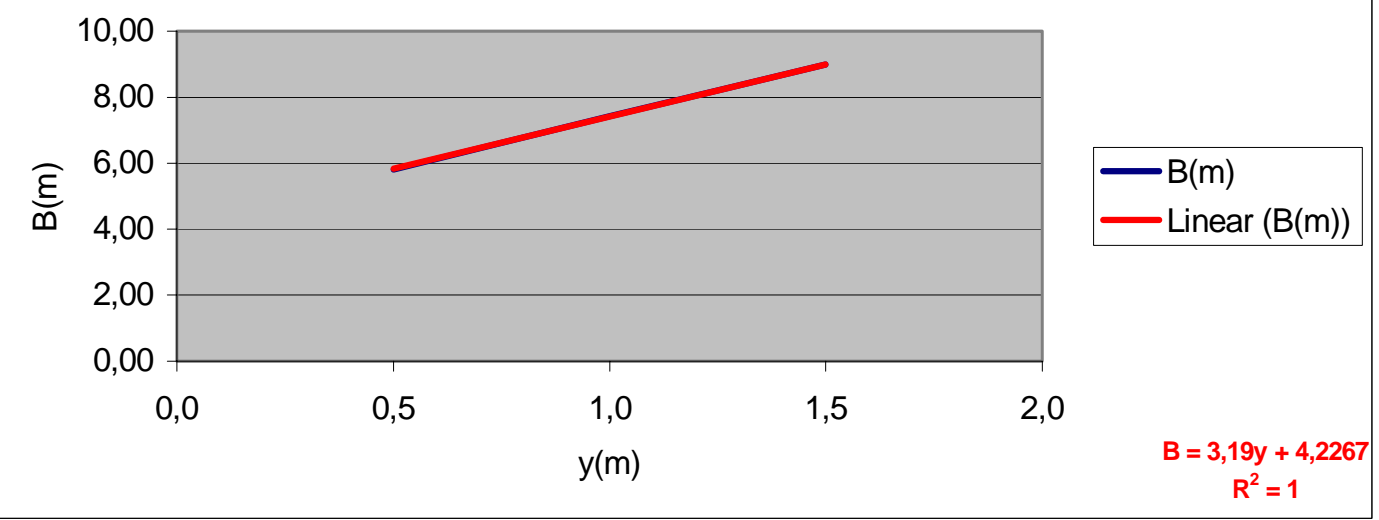




\section{SEÇÃO 49}

$\begin{array}{cccccccc}\text { no pares } & \mathbf{y}(\mathbf{m}) & \mathbf{p}(\mathbf{m}) & \mathbf{a}(\mathbf{m} 2) & \mathbf{B}(\mathbf{m}) & & \text { tipo da equação } & \text { correlação } \\ & 0,5 & 5,81 & 2,29 & 5,54 & \mathbf{p}(\mathbf{m}) & \text { linear } & 1,0000 \\ 3 & 1,0 & 7,67 & 5,45 & 7,10 & \mathbf{a}(\mathbf{m} 2) & \text { polinomial }\left(2^{\mathrm{a}} \text { ordem }\right) & 1,0000 \\ & 1,5 & 9,52 & 9,40 & 8,67 & \mathbf{B}(\mathbf{m}) & \text { linear } & 1,0000\end{array}$
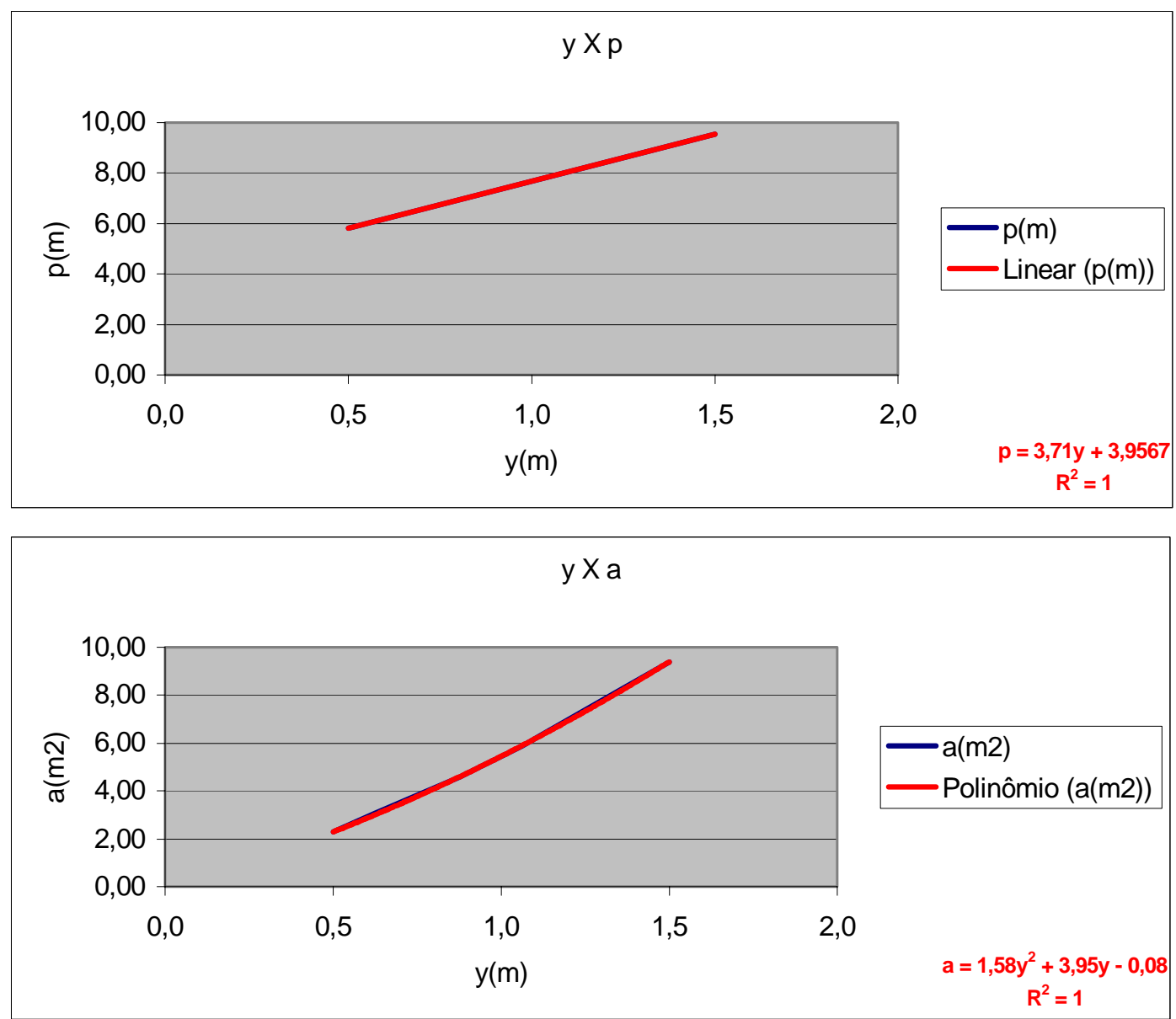

$y \times B$

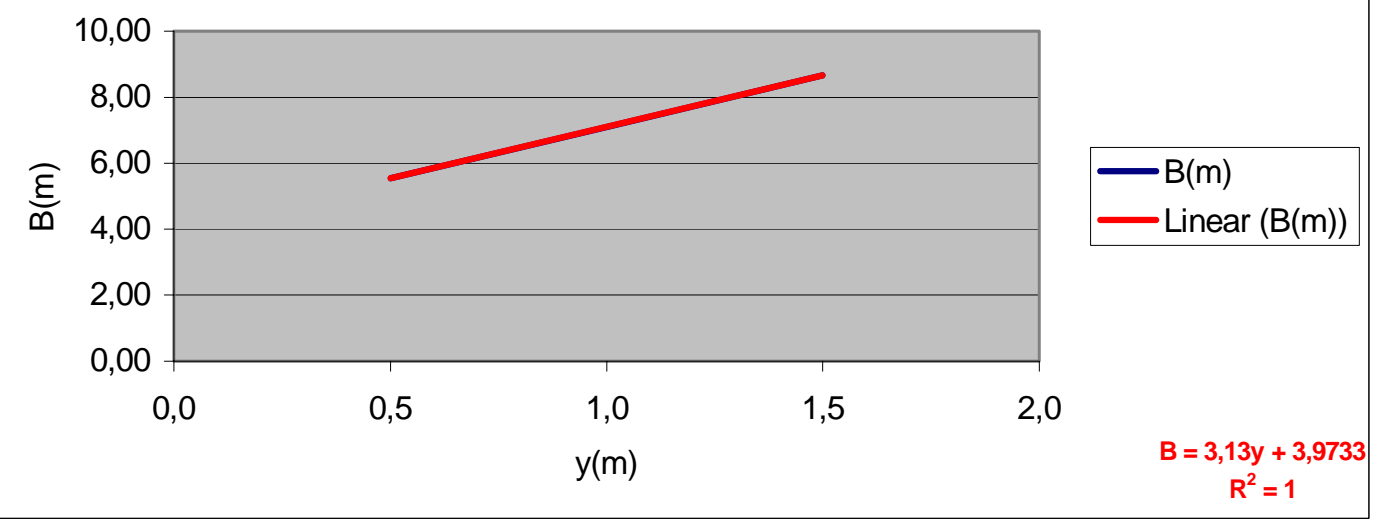




\section{SEÇÃO 50}

$\begin{array}{cccccccc}\text { no pares } & \mathbf{y}(\mathbf{m}) & \mathbf{p}(\mathbf{m}) & \mathbf{a}(\mathbf{m} 2) & \mathbf{B}(\mathbf{m}) & & \text { tipo da equação } & \text { correlação } \\ & 0,5 & 7,45 & 3,18 & 7,15 & \mathbf{p}(\mathbf{m}) & \text { linear } & 1,0000 \\ 3 & 1,0 & 9,18 & 7,10 & 8,56 & \mathbf{a}(\mathbf{m} 2) & \text { polinomial }\left(2^{\mathrm{a}} \text { ordem }\right) & 1,0000 \\ & 1,5 & 10,91 & 11,74 & 9,97 & \mathbf{B}(\mathbf{m}) & \text { linear } & 1,0000\end{array}$
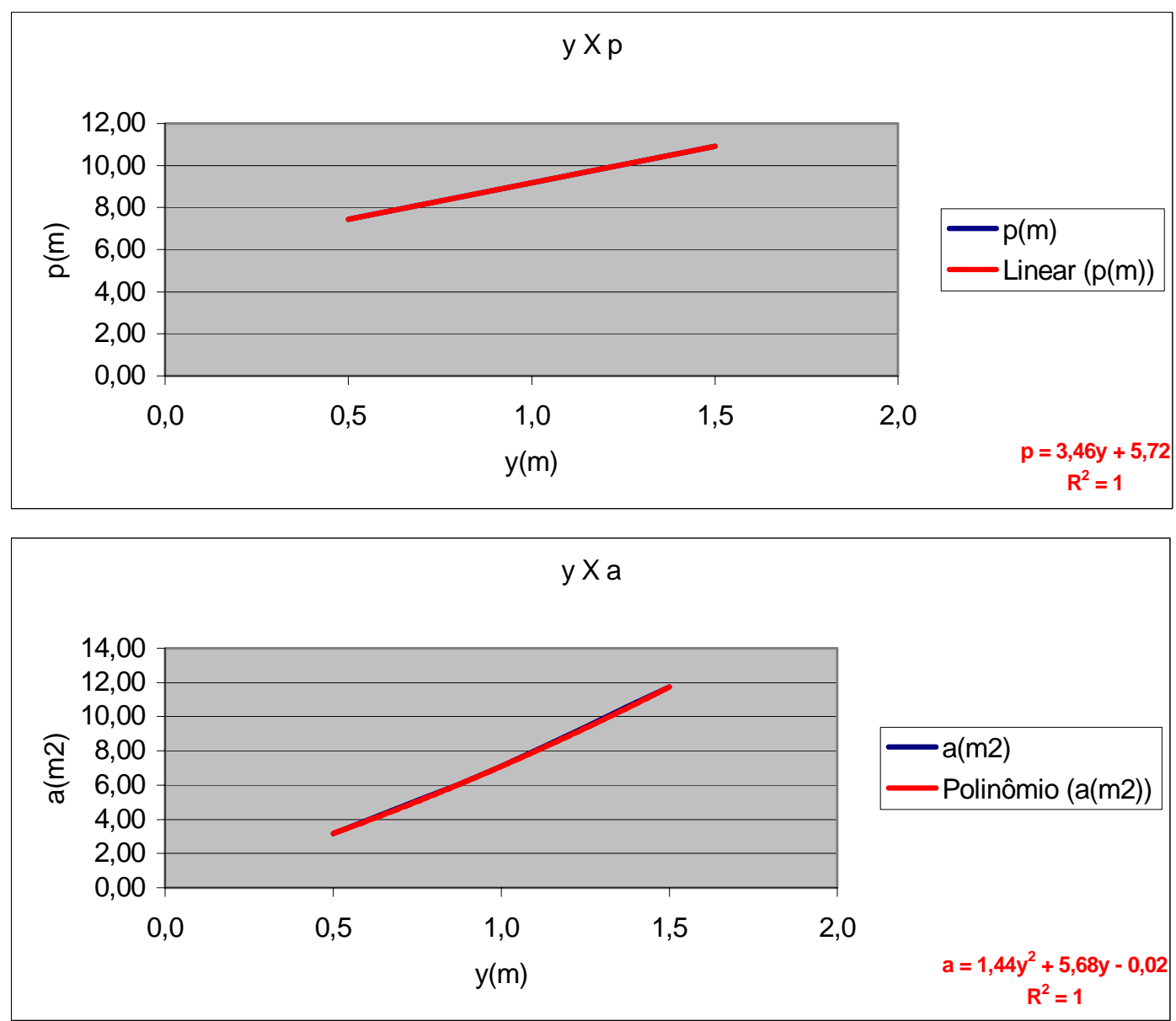

$y \times B$

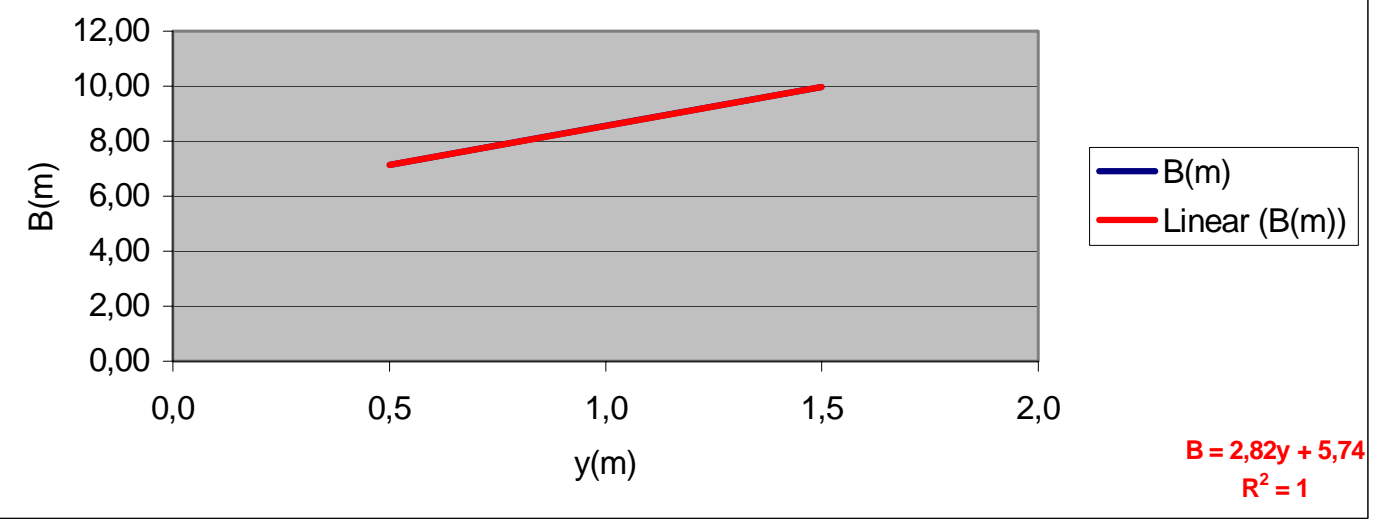




\section{SEÇÃO 51}

$\begin{array}{cccccccc}\text { no pares } & \mathbf{y}(\mathbf{m}) & \mathbf{p}(\mathbf{m}) & \mathbf{a}(\mathbf{m} \mathbf{2}) & \mathbf{B}(\mathbf{m}) & & \text { tipo da equação } & \text { correlação } \\ & 0,5 & 6,10 & 2,47 & 5,83 & \mathbf{p}(\mathbf{m}) & \text { linear } & 1,0000 \\ 3 & 1,0 & 7,87 & 5,75 & 7,29 & \mathbf{a}(\mathbf{m} 2) & \text { polinomial }\left(2^{a} \text { ordem) }\right. & 1,0000 \\ & 1,5 & 9,64 & 9,76 & 8,75 & \mathbf{B}(\mathbf{m}) & \text { linear } & 1,0000\end{array}$
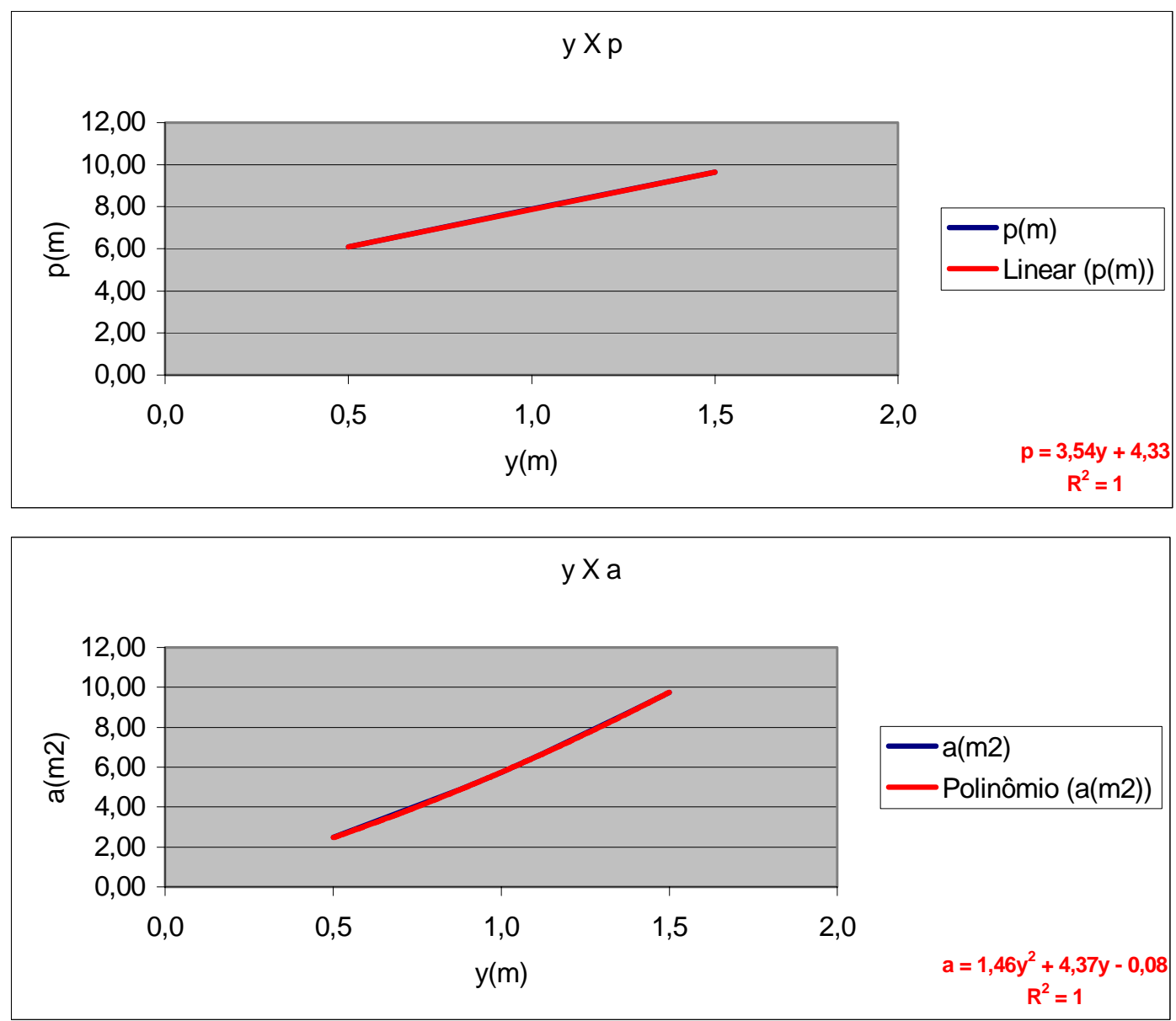

$y \times B$

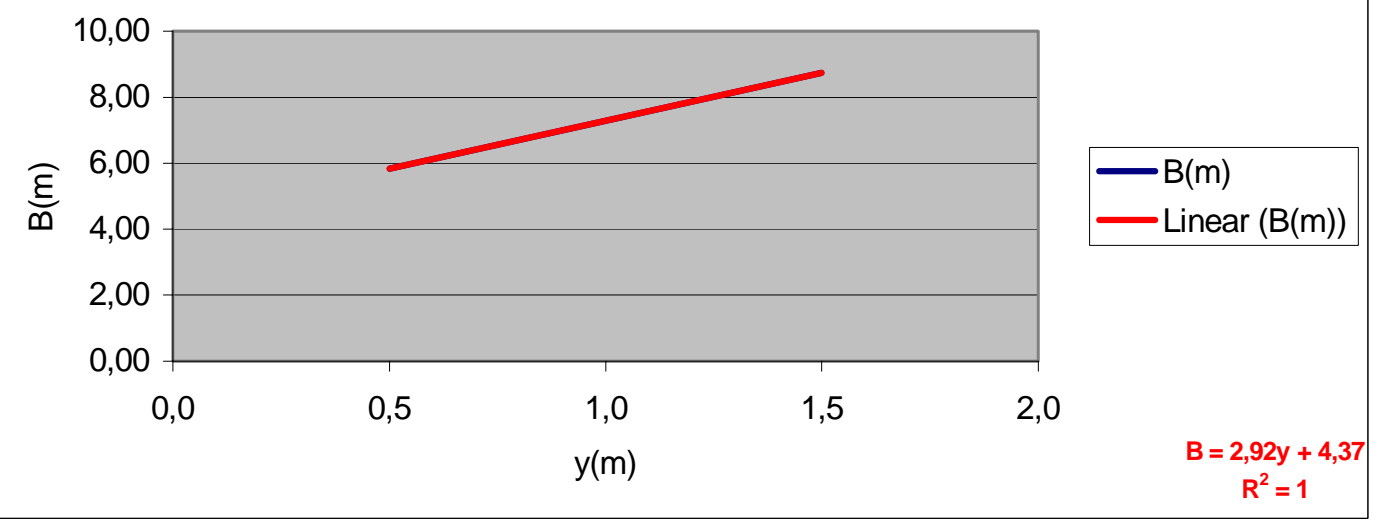




\section{SEÇÃO 52}

$\begin{array}{cccccccc}\text { no pares } & \mathbf{y}(\mathbf{m}) & \mathbf{p}(\mathbf{m}) & \mathbf{a}(\mathbf{m} 2) & \mathbf{B}(\mathbf{m}) & & \text { tipo da equação } & \text { correlação } \\ & 0,5 & 6,49 & 2,82 & 6,14 & \mathbf{p}(\mathbf{m}) & \text { linear } & 1,0000 \\ 3 & 1,0 & 8,15 & 6,21 & 7,45 & \mathbf{a}(\mathbf{m} 2) & \text { polinomial }\left(2^{a} \text { ordem) }\right. & 1,0000 \\ & 1,5 & 9,80 & 10,27 & 8,77 & \mathbf{B}(\mathbf{m}) & \text { linear } & 1,0000\end{array}$
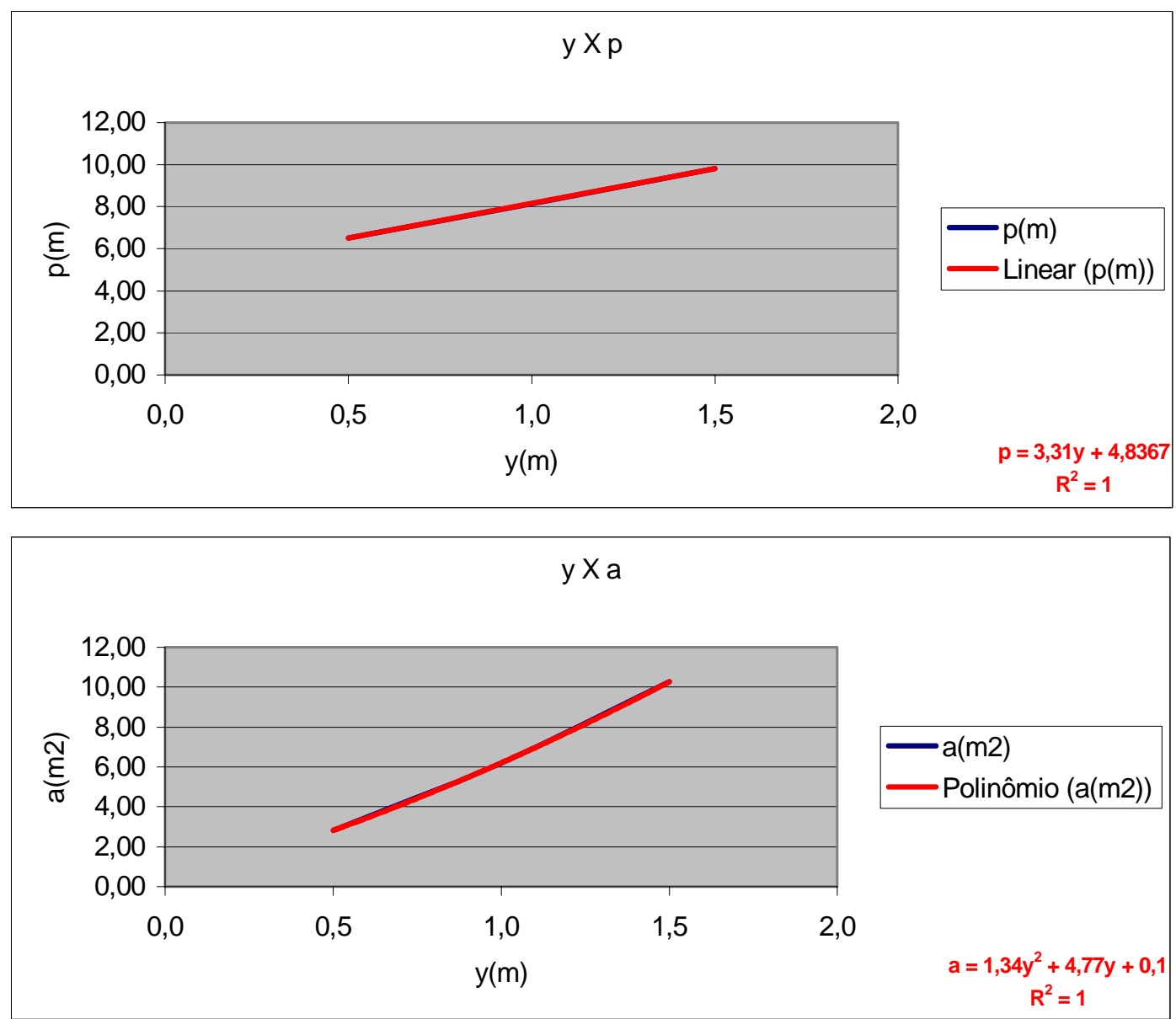

$y \times B$

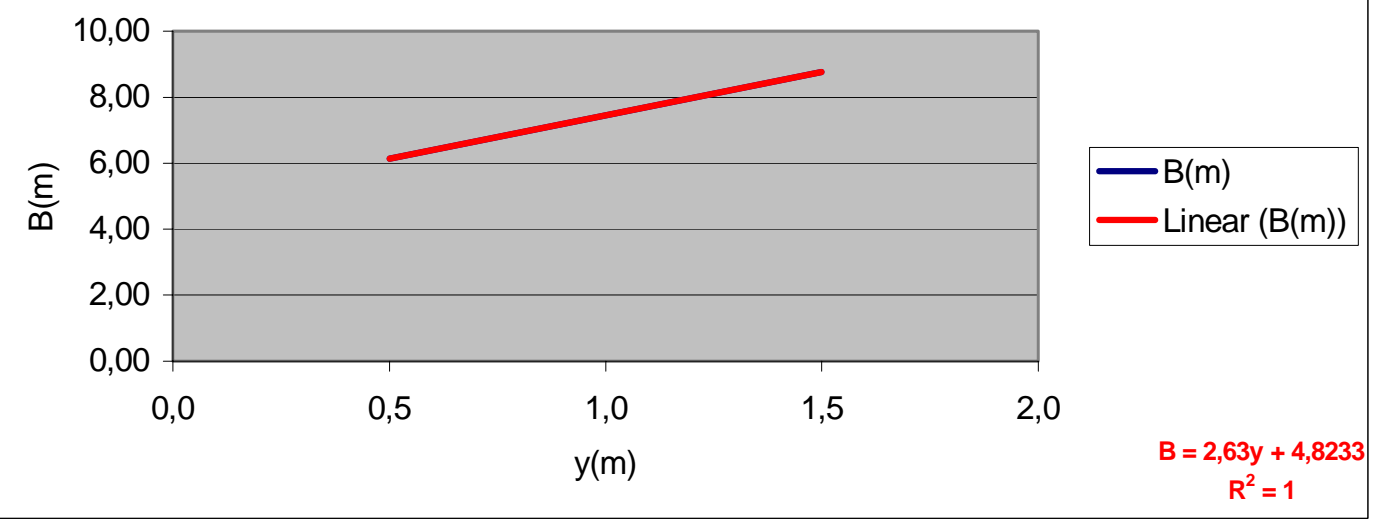




\section{SEÇÃO 53}

$\begin{array}{cccccccc}\text { no pares } & \mathbf{y}(\mathbf{m}) & \mathbf{p}(\mathbf{m}) & \mathbf{a}(\mathbf{m} 2) & \mathbf{B}(\mathbf{m}) & & \text { tipo da equação } & \text { correlação } \\ & 0,5 & 6,84 & 3,02 & 6,51 & \mathbf{p}(\mathbf{m}) & \text { linear } & 1,0000 \\ 3 & 1,0 & 8,48 & 6,60 & 7,81 & \mathbf{a}(\mathbf{m} 2) & \text { polinomial }\left(2^{a} \text { ordem) }\right. & 1,0000 \\ & 1,5 & 10,12 & 10,83 & 9,11 & \mathbf{B}(\mathbf{m}) & \text { linear } & 1,0000\end{array}$
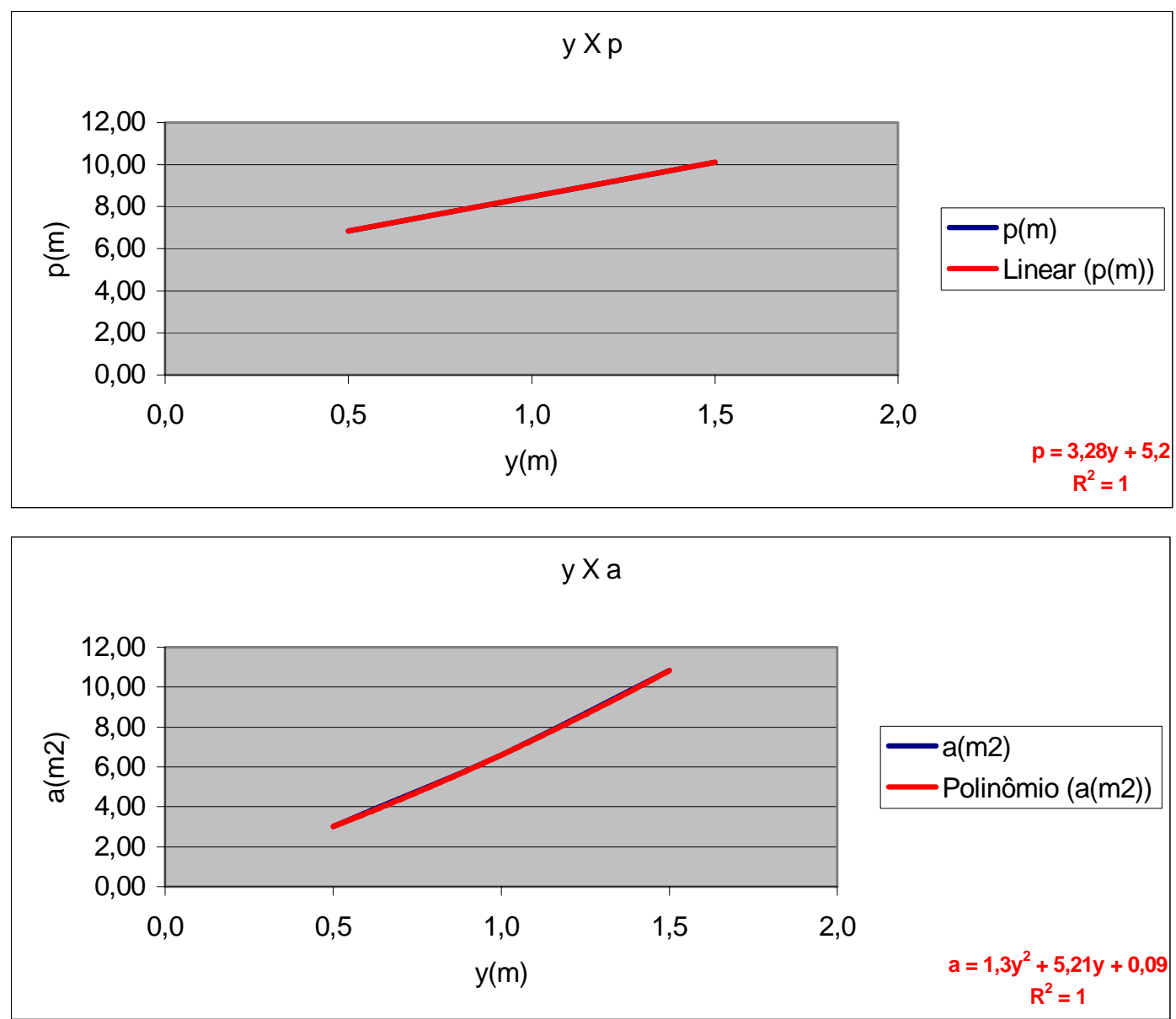

$y \times B$

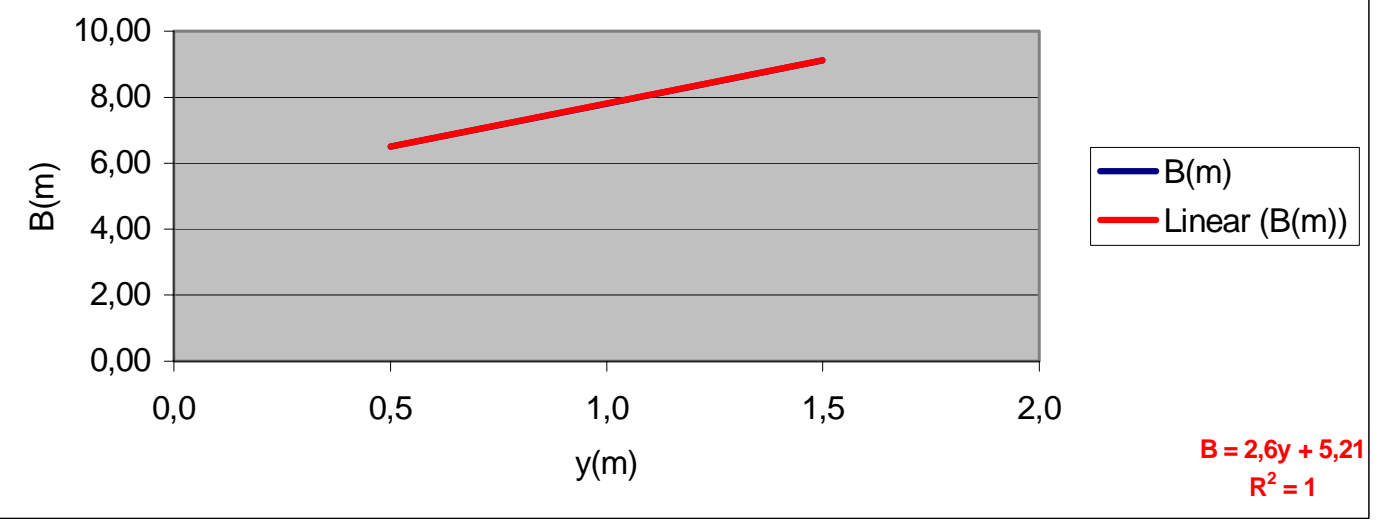




\section{SEÇÃO 54}

$\begin{array}{cccccccc}\text { no pares } & \mathbf{y}(\mathbf{m}) & \mathbf{p}(\mathbf{m}) & \mathbf{a}(\mathbf{m} 2) & \mathbf{B}(\mathbf{m}) & & \text { tipo da equação } & \text { correlação } \\ & 0,5 & 6,38 & 2,98 & 5,98 & \mathbf{p}(\mathbf{m}) & \text { linear } & 1,0000 \\ 3 & 1,0 & 7,92 & 6,26 & 7,14 & \mathbf{a}(\mathbf{m} 2) & \text { polinomial }\left(2^{a} \text { ordem) }\right. & 1,0000 \\ & 1,5 & 9,45 & 10,12 & 8,29 & \mathbf{B}(\mathbf{m}) & \text { linear } & 1,0000\end{array}$
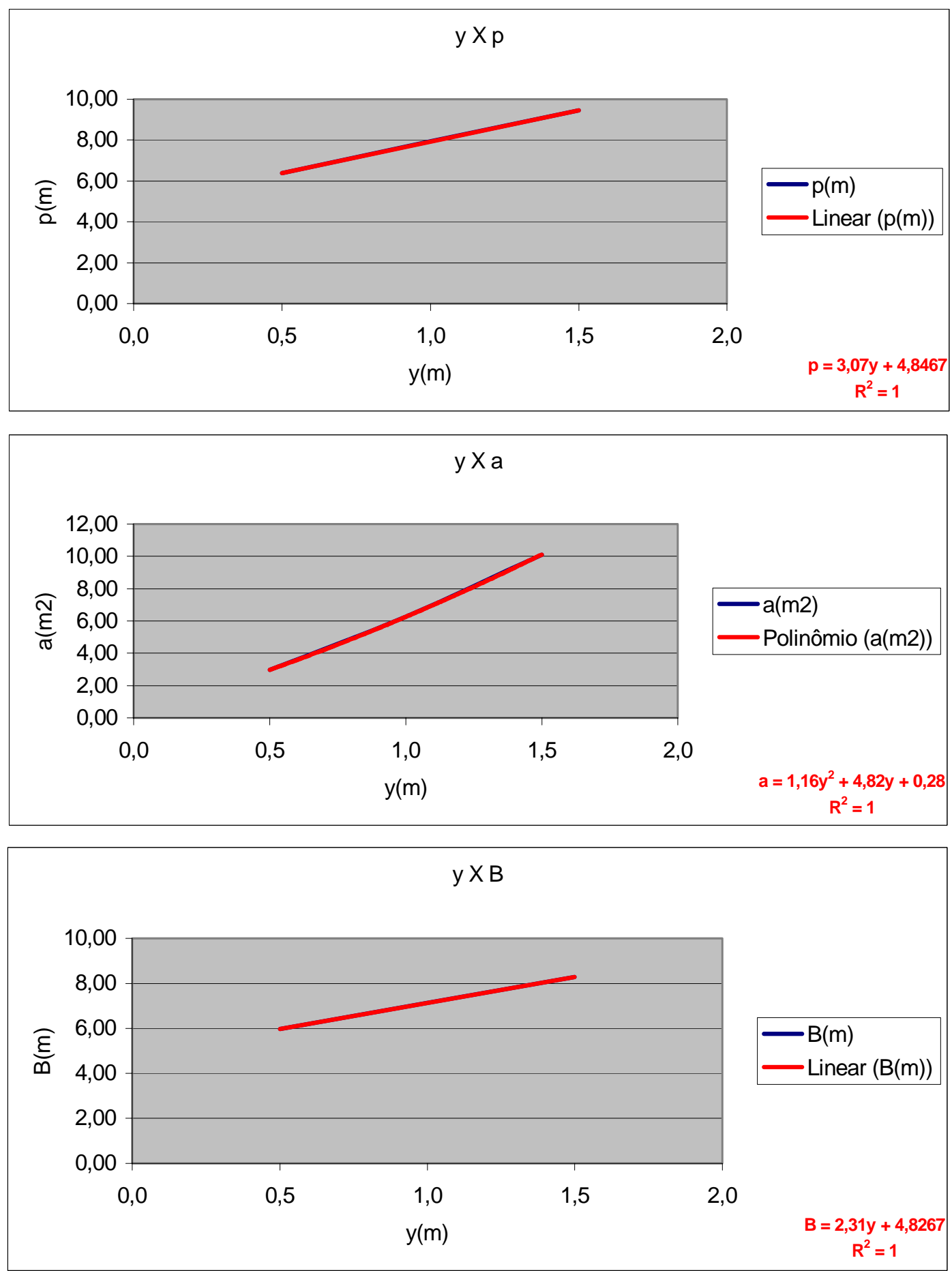


\section{SEÇÃO 55}

$\begin{array}{cccccccc}\text { no pares } & \mathbf{y}(\mathbf{m}) & \mathbf{p}(\mathbf{m}) & \mathbf{a}(\mathbf{m} \mathbf{2}) & \mathbf{B}(\mathbf{m}) & & \text { tipo da equação } & \text { correlação } \\ & 0,5 & 7,44 & 3,50 & 6,96 & \mathbf{p}(\mathbf{m}) & \text { linear } & 1,0000 \\ 3 & 1,0 & 8,82 & 7,22 & 7,91 & \mathbf{a}(\mathbf{m} 2) & \text { polinomial }\left(2^{a} \text { ordem) }\right. & 1,0000 \\ & 1,5 & 10,20 & 11,42 & 8,86 & \mathbf{B}(\mathbf{m}) & \text { linear } & 1,0000\end{array}$
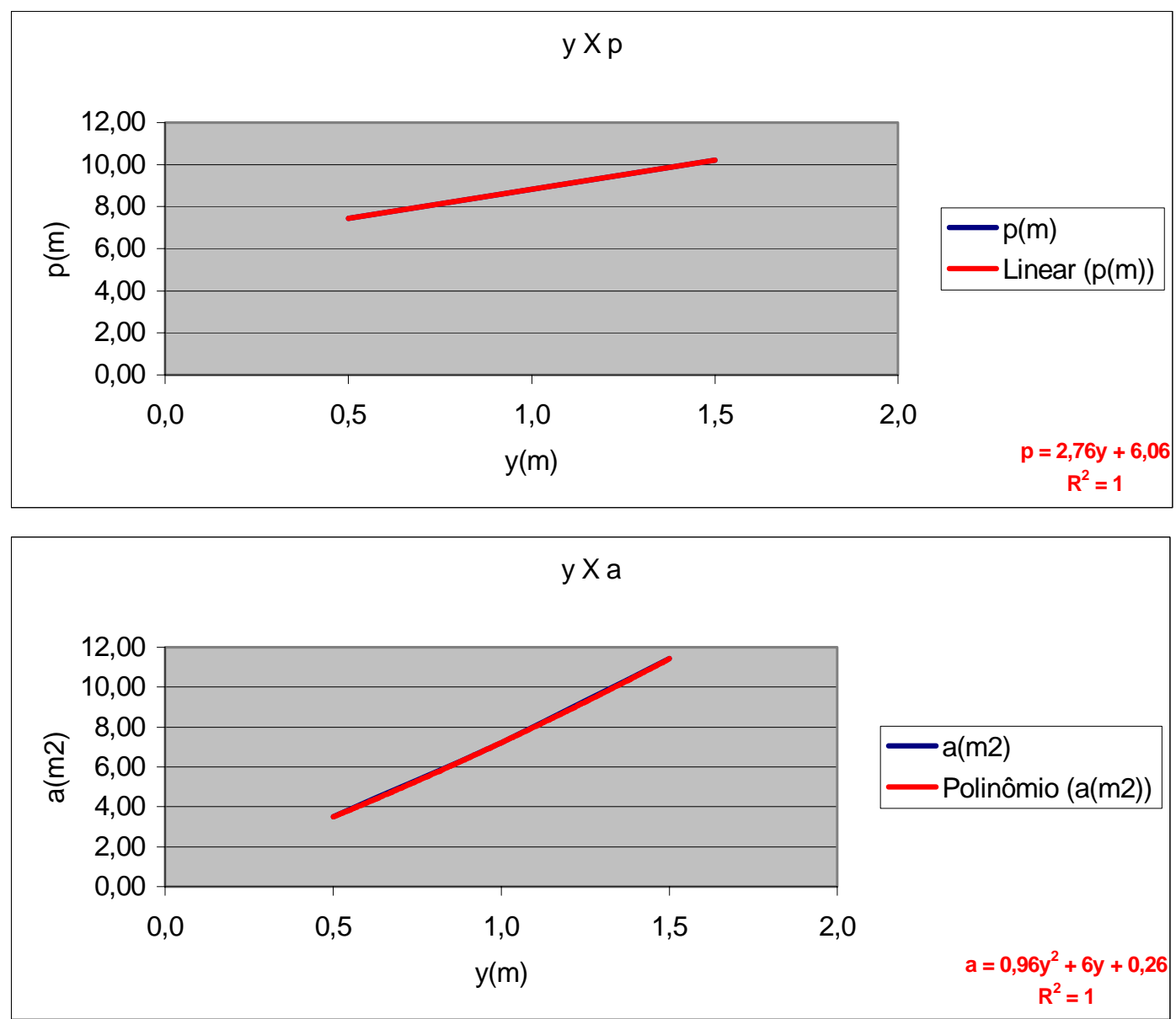

yXB

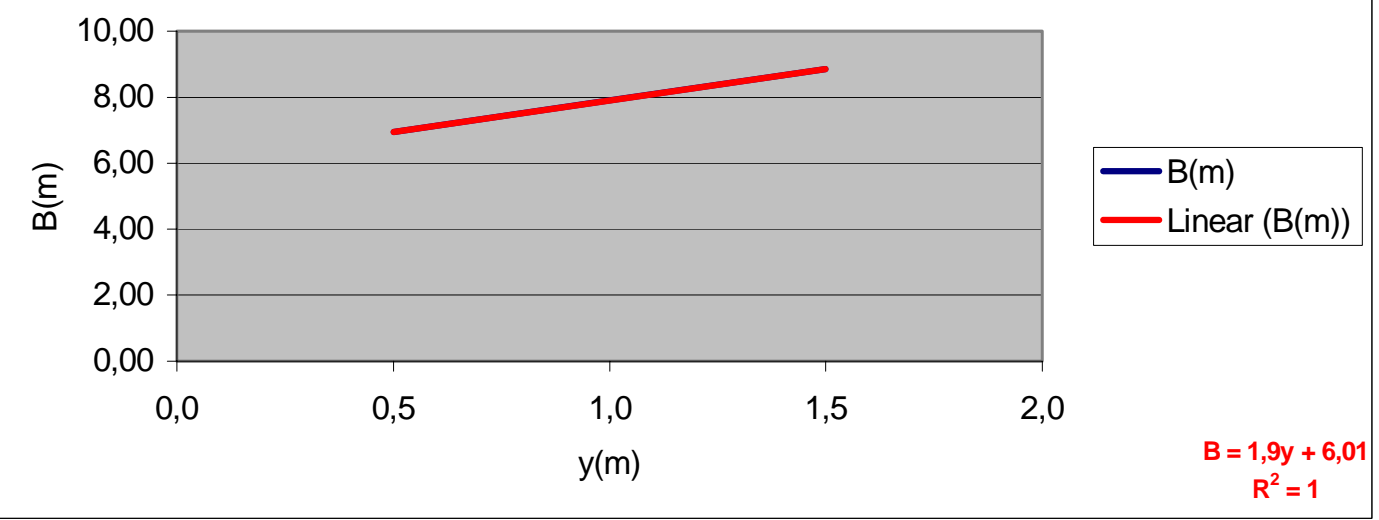




\section{SEÇÃO 56}

$\begin{array}{cccccccc}\text { no pares } & \mathbf{y}(\mathbf{m}) & \mathbf{p}(\mathbf{m}) & \mathbf{a}(\mathbf{m} 2) & \mathbf{B}(\mathbf{m}) & & \text { tipo da equação } & \text { correlação } \\ & 0,5 & 7,17 & 3,19 & 6,90 & \mathbf{p}(\mathbf{m}) & \text { linear } & 1,0000 \\ 3 & 1,0 & 9,03 & 7,04 & 8,47 & \mathbf{a}(\mathbf{m} 2) & \text { polinomial }\left(2^{\mathrm{a}} \text { ordem }\right) & 1,0000 \\ & 1,5 & 10,89 & 11,66 & 10,03 & \mathbf{B}(\mathbf{m}) & \text { linear } & 1,0000\end{array}$
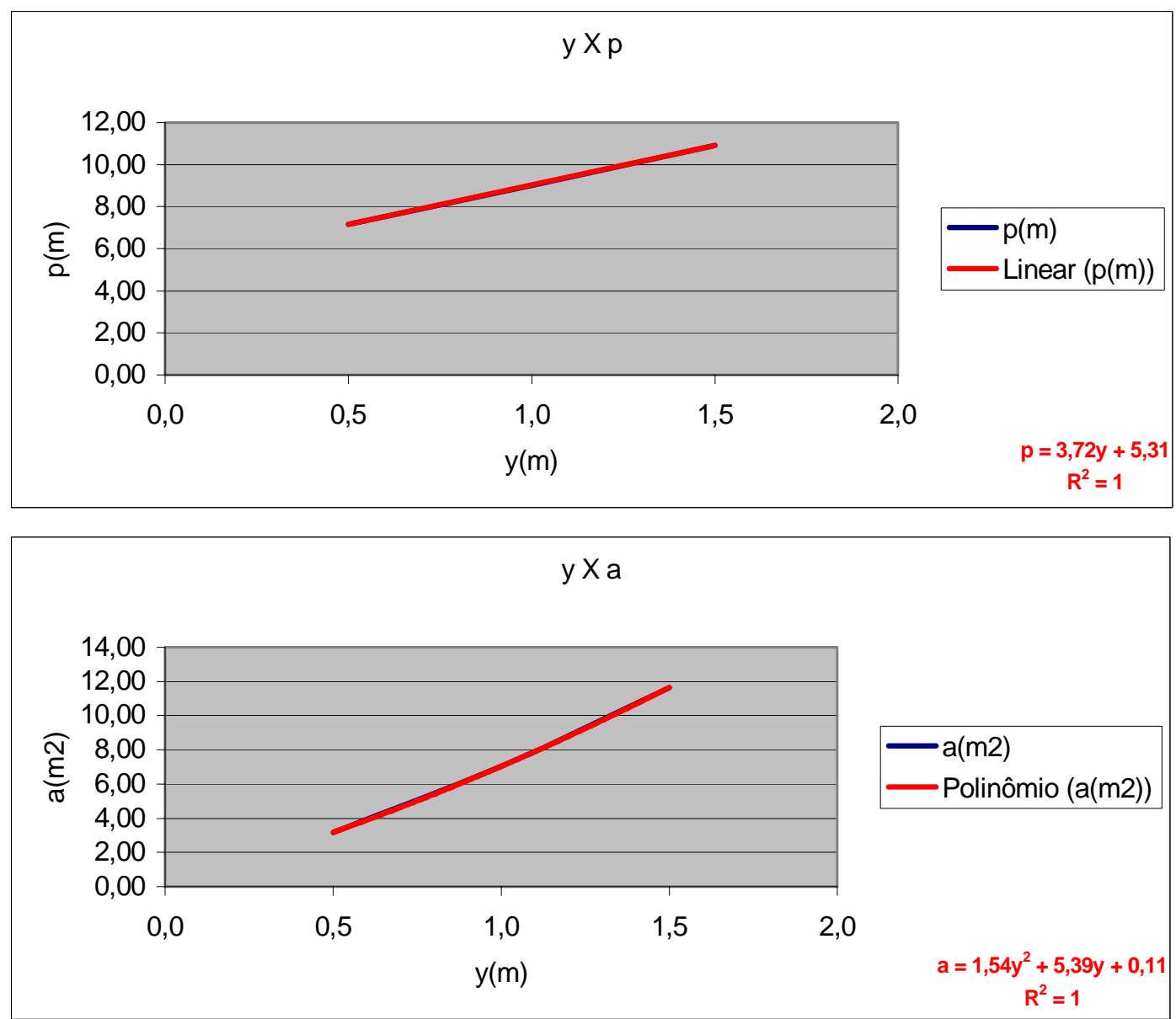

$y \times B$

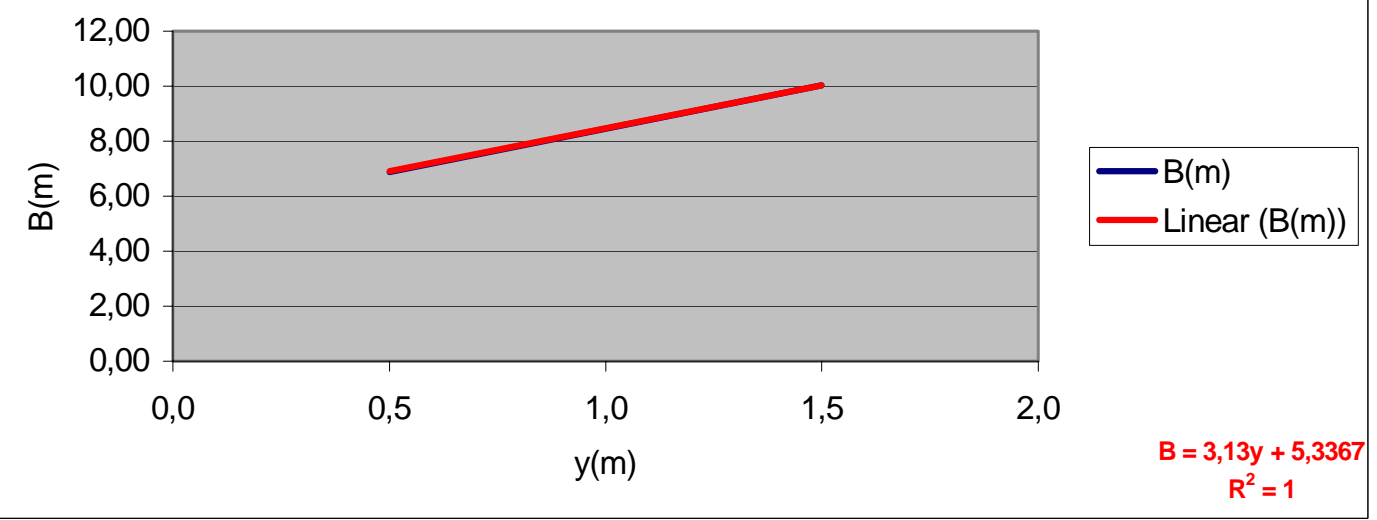




\section{SEÇÃO 57}

$\begin{array}{cccccccc}\text { no pares } & \mathbf{y}(\mathbf{m}) & \mathbf{p}(\mathbf{m}) & \mathbf{a}(\mathbf{m} 2) & \mathbf{B}(\mathbf{m}) & & \text { tipo da equação } & \text { correlação } \\ & 0,5 & 6,31 & 2,56 & 6,03 & \mathbf{p}(\mathbf{m}) & \text { linear } & 1,0000 \\ 3 & 1,0 & 8,16 & 5,96 & 7,58 & \mathbf{a}(\mathbf{m} 2) & \text { polinomial }\left(2^{\mathrm{a}} \text { ordem }\right) & 1,0000 \\ & 1,5 & 10,01 & 10,14 & 9,13 & \mathbf{B}(\mathbf{m}) & \text { linear } & 1,0000\end{array}$
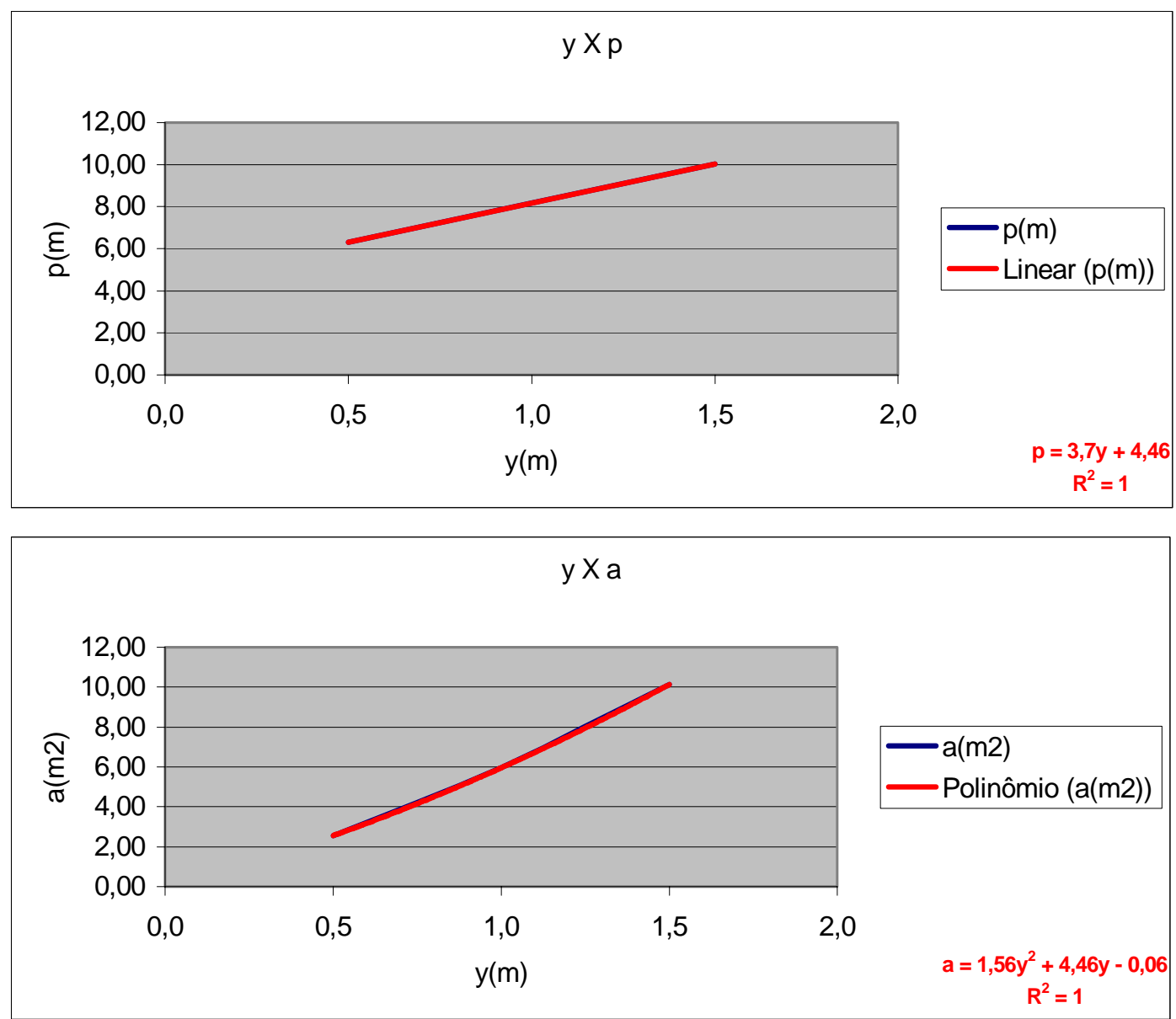

$y \times B$

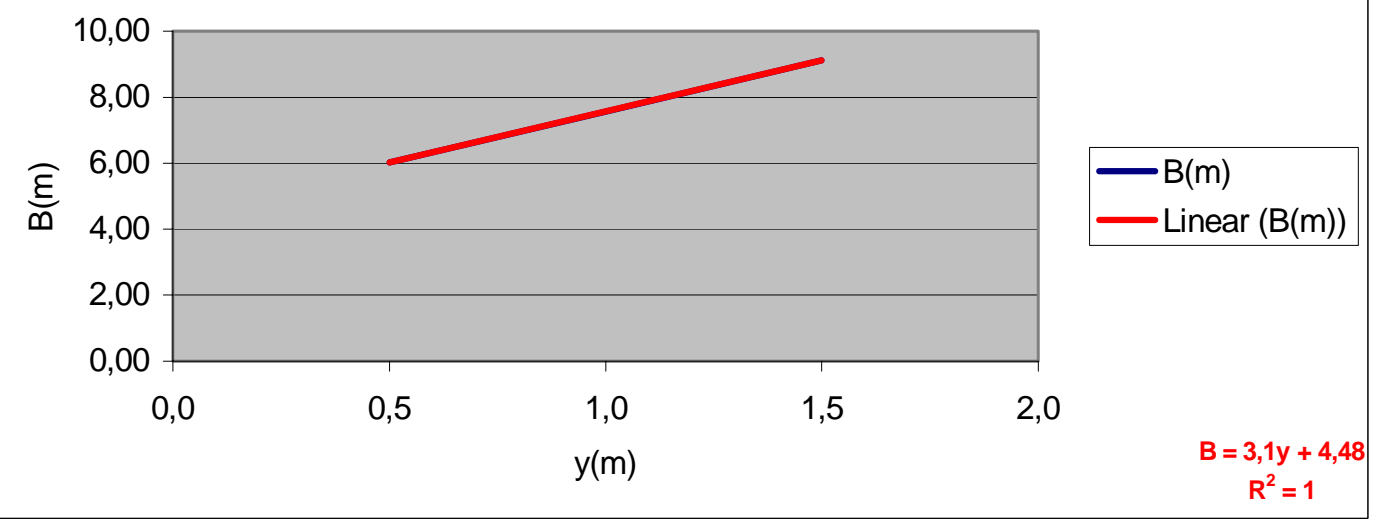




\section{SEÇÃO 58}

$\begin{array}{cccccccc}\text { no pares } & \mathbf{y}(\mathbf{m}) & \mathbf{p}(\mathbf{m}) & \mathbf{a}(\mathbf{m} \mathbf{2}) & \mathbf{B}(\mathbf{m}) & & \text { tipo da equação } & \text { correlação } \\ & 0,5 & 6,40 & 2,73 & 6,10 & \mathbf{p}(\mathbf{m}) & \text { linear } & 1,0000 \\ 3 & 1,0 & 8,16 & 6,14 & 7,55 & \mathbf{a}(\mathbf{m} 2) & \text { polinomial }\left(2^{a} \text { ordem) }\right. & 1,0000 \\ & 1,5 & 9,91 & 10,28 & 8,99 & \mathbf{B}(\mathbf{m}) & \text { linear } & 1,0000\end{array}$
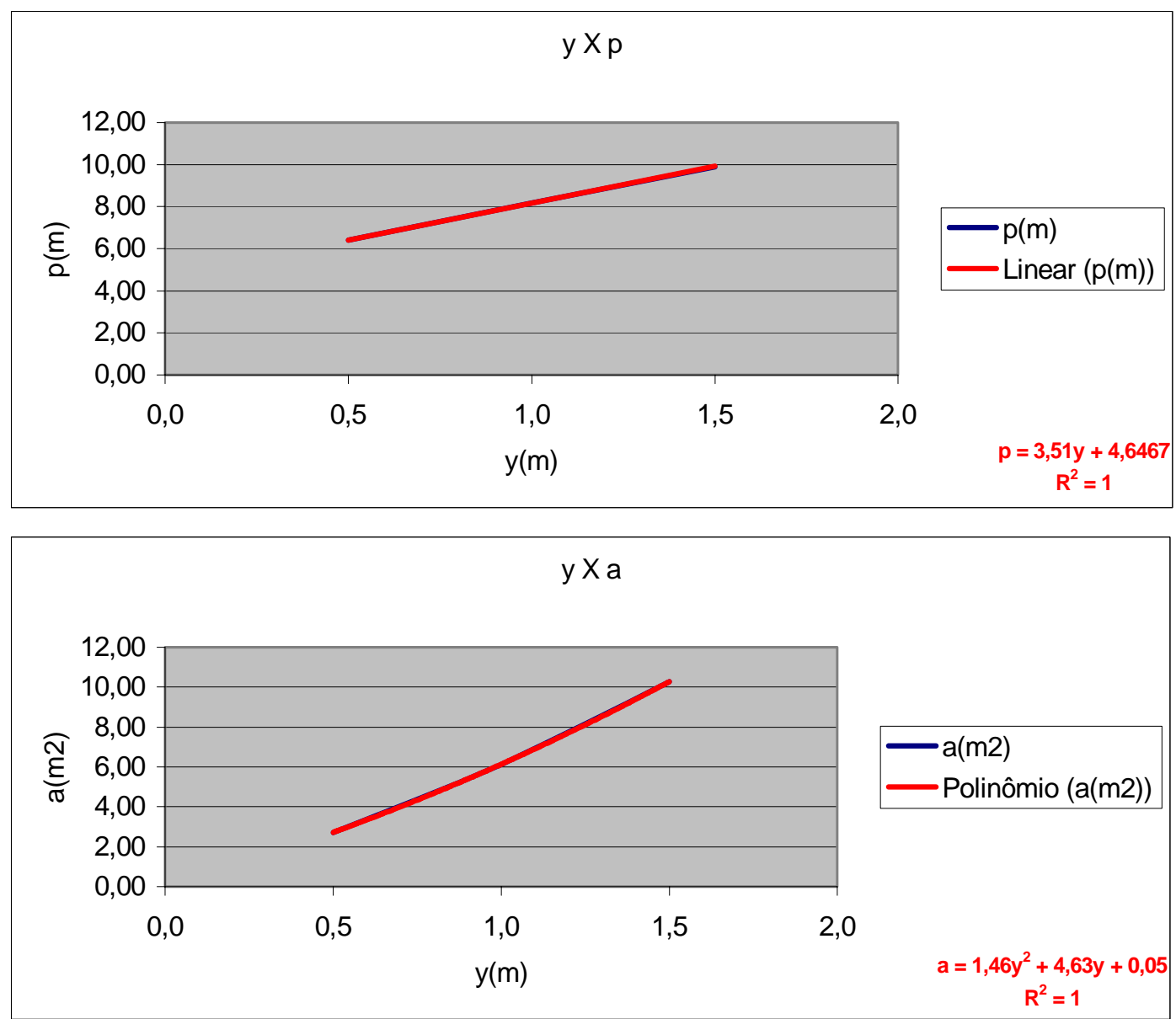

$y \times B$

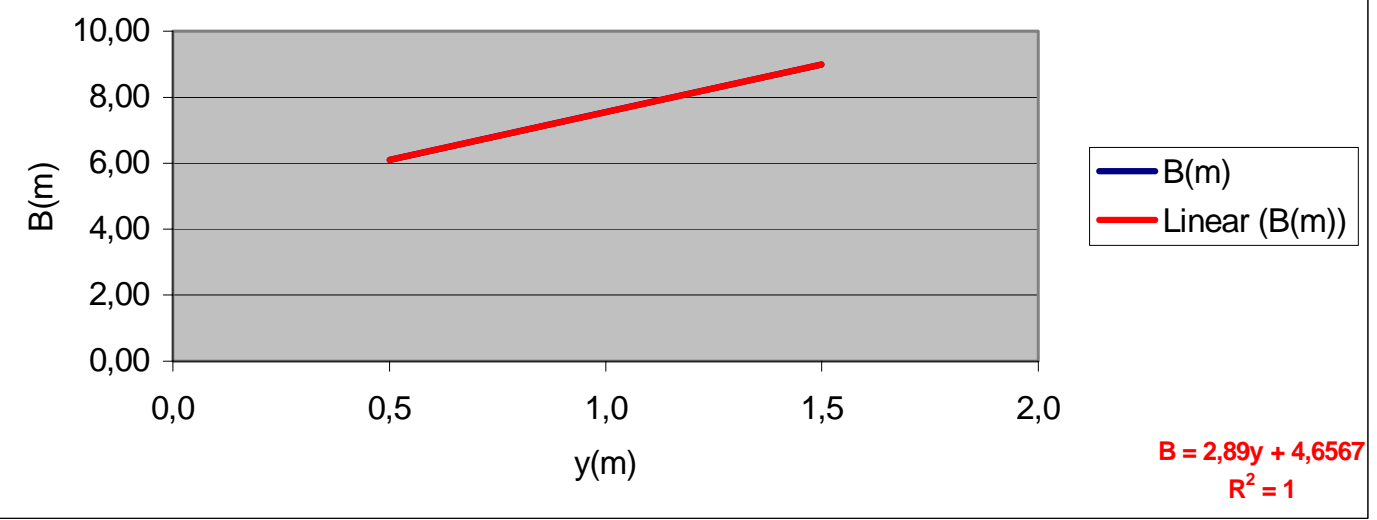




\section{SEÇÃO 59}

$\begin{array}{cccccccc}\text { no pares } & \mathbf{y}(\mathbf{m}) & \mathbf{p}(\mathbf{m}) & \mathbf{a}(\mathbf{m} 2) & \mathbf{B}(\mathbf{m}) & & \text { tipo da equação } & \text { correlação } \\ & 0,5 & 6,74 & 2,81 & 6,42 & \mathbf{p}(\mathbf{m}) & \text { linear } & 1,0000 \\ 3 & 1,0 & 8,41 & 6,36 & 7,77 & \mathbf{a}(\mathbf{m} 2) & \text { polinomial }\left(2^{a} \text { ordem) }\right. & 1,0000 \\ & 1,5 & 10,09 & 10,58 & 9,11 & \mathbf{B}(\mathbf{m}) & \text { linear } & 1,0000\end{array}$
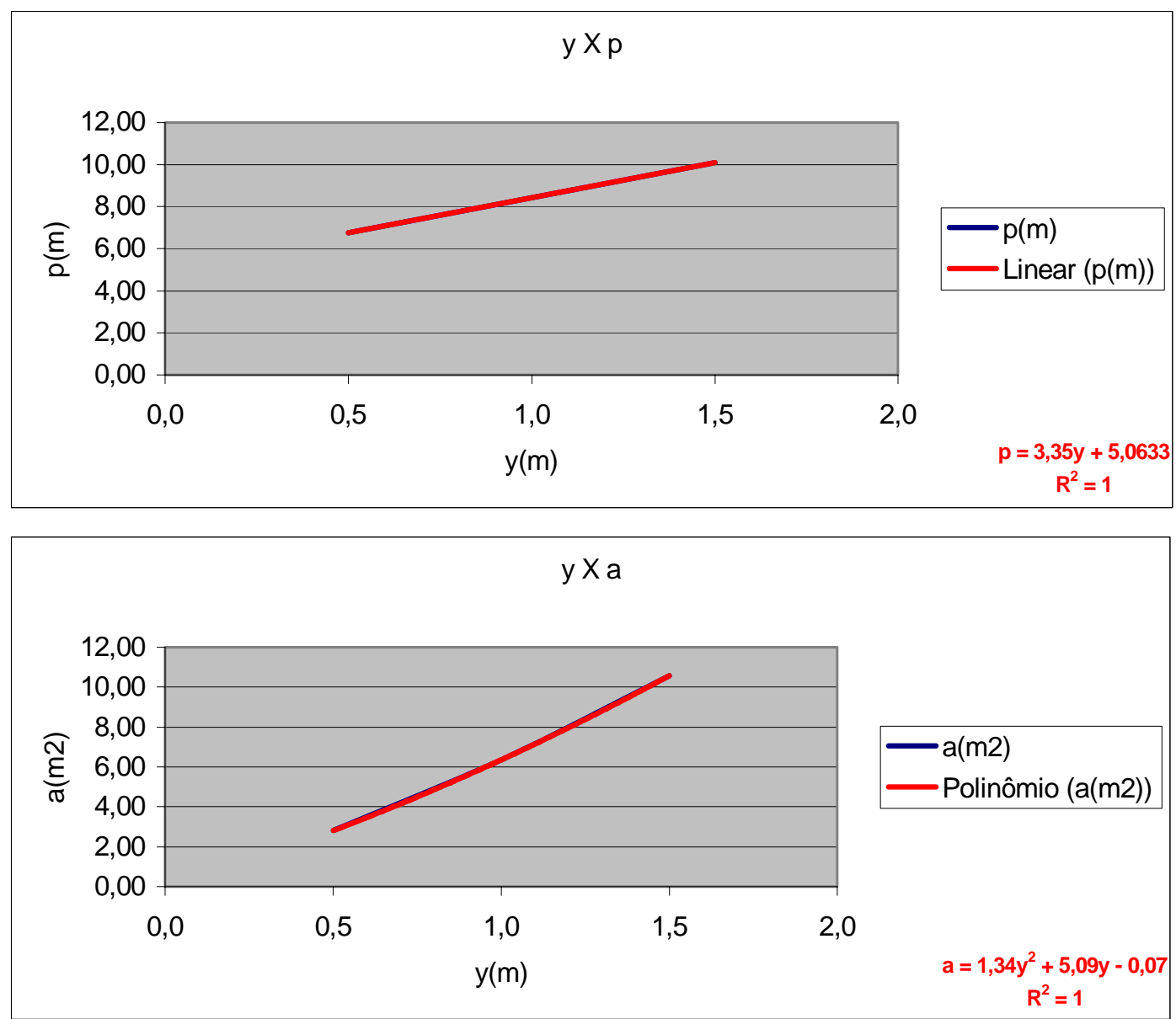

$y \times B$

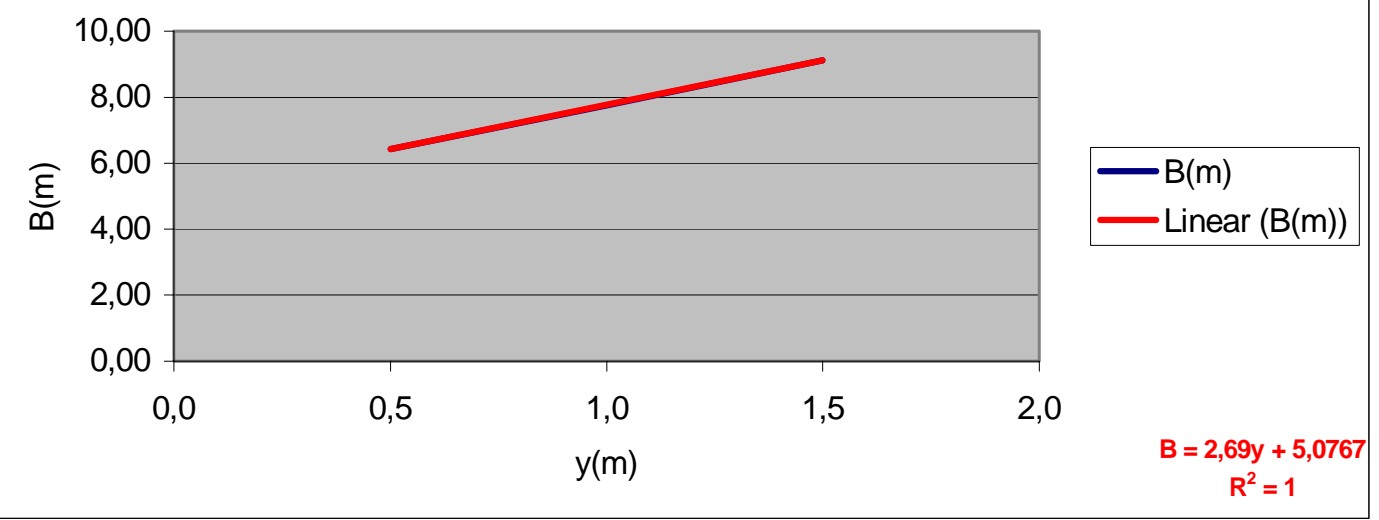




\section{SEÇÕES 60 e 61}

$\begin{array}{cccccccc}\text { no pares } & \mathbf{y}(\mathbf{m}) & \mathbf{p}(\mathbf{m}) & \mathbf{a}(\mathbf{m} 2) & \mathbf{B}(\mathbf{m}) & & \text { tipo da equação } & \text { correlação } \\ & 0,5 & 6,41 & 2,72 & 6,09 & \mathbf{p}(\mathbf{m}) & \text { linear } & 1,0000 \\ 3 & 1,0 & 8,11 & 6,10 & 7,46 & \mathbf{a}(\mathbf{m} 2) & \text { polinomial }\left(2^{a} \text { ordem) }\right. & 1,0000 \\ & 1,5 & 9,80 & 10,17 & 8,83 & \mathbf{B}(\mathbf{m}) & \text { linear } & 1,0000\end{array}$
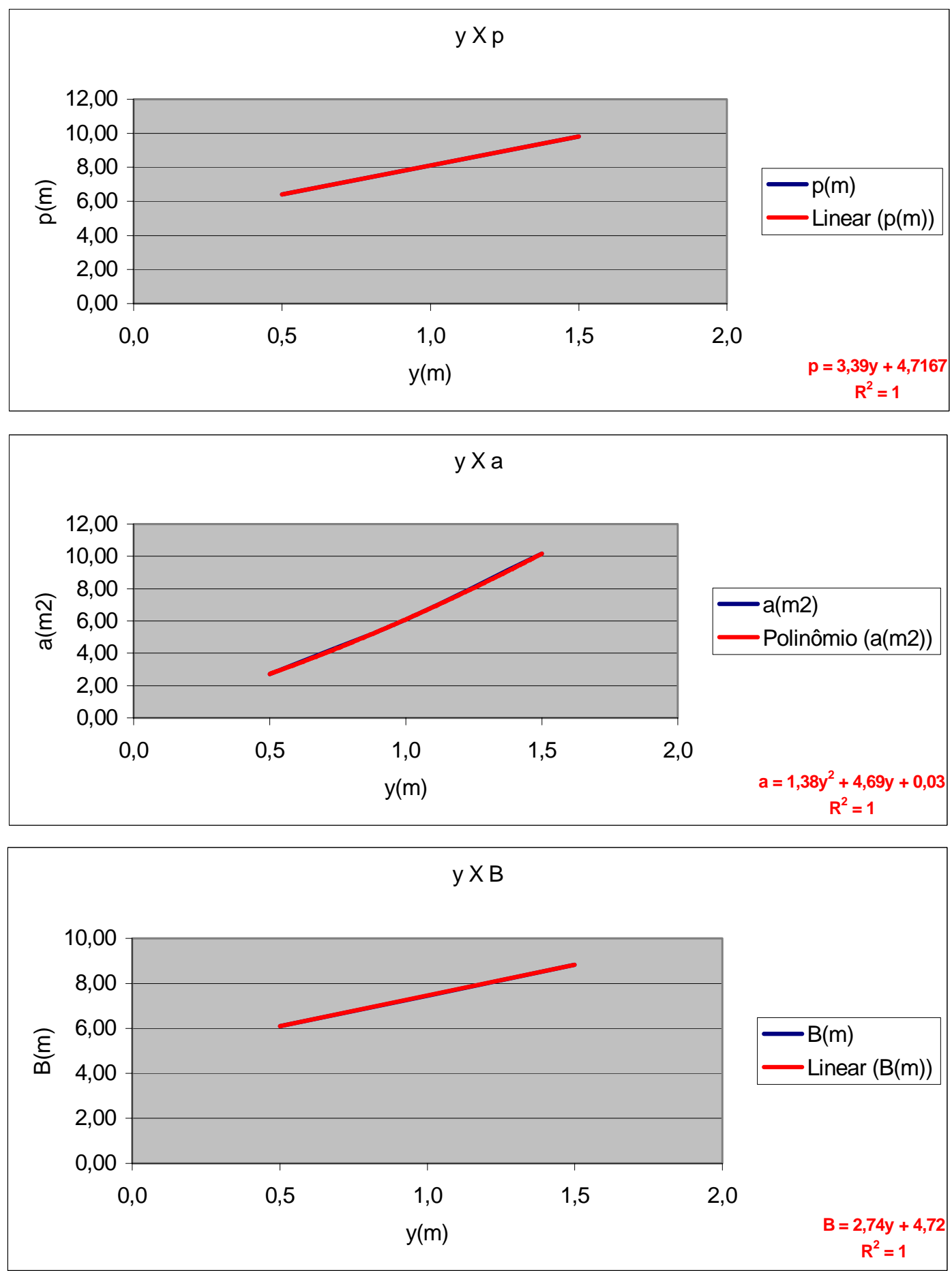


\section{SEÇÃO 62}

$\begin{array}{cccccccc}\text { no pares } & \mathbf{y}(\mathbf{m}) & \mathbf{p}(\mathbf{m}) & \mathbf{a}(\mathbf{m} 2) & \mathbf{B}(\mathbf{m}) & & \text { tipo da equação } & \text { correlação } \\ & 0,5 & 6,50 & 2,76 & 6,20 & \mathbf{p}(\mathbf{m}) & \text { linear } & 1,0000 \\ 3 & 1,0 & 8,34 & 6,25 & 7,74 & \mathbf{a}(\mathbf{m} 2) & \text { polinomial }\left(2^{\mathrm{a}} \text { ordem }\right) & 1,0000 \\ & 1,5 & 10,18 & 10,50 & 9,29 & \mathbf{B}(\mathbf{m}) & \text { linear } & 1,0000\end{array}$
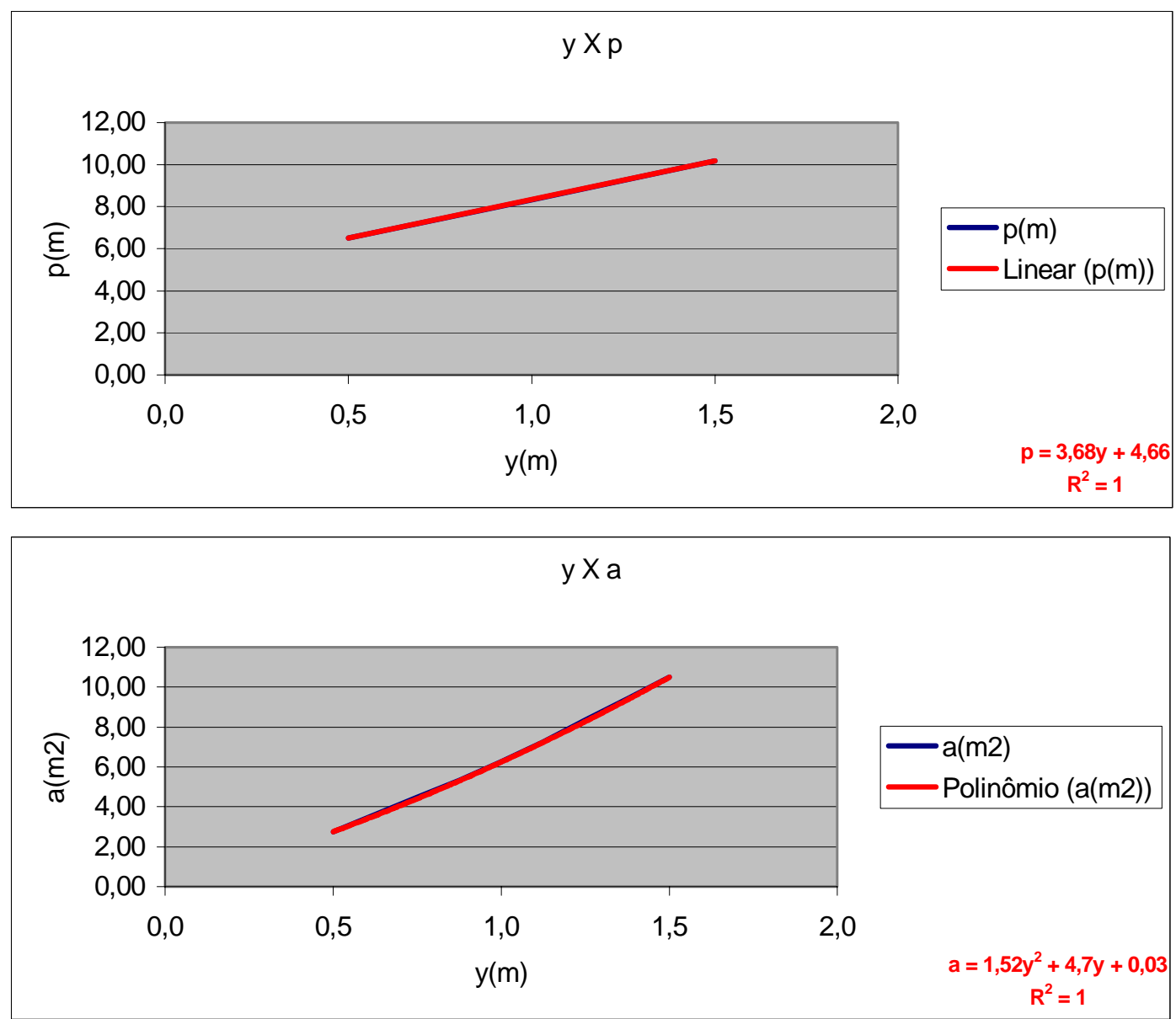

$y \times B$

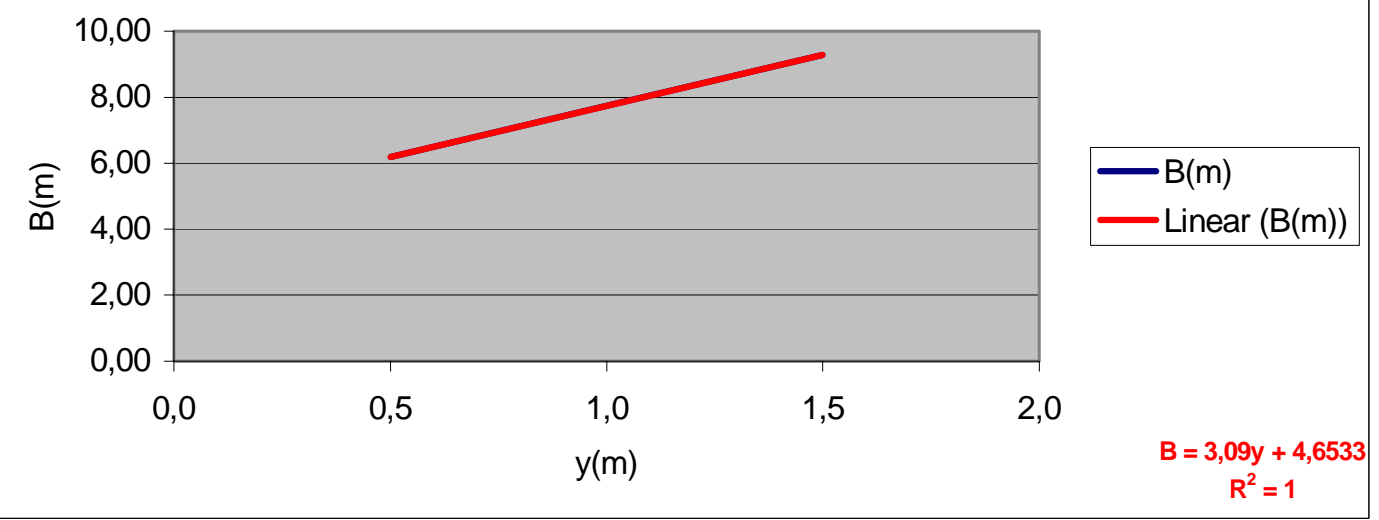




\section{SEÇÃO 63}

$\begin{array}{cccccccc}\text { no pares } & \mathbf{y}(\mathbf{m}) & \mathbf{p}(\mathbf{m}) & \mathbf{a}(\mathbf{m} 2) & \mathbf{B}(\mathbf{m}) & & \text { tipo da equação } & \text { correlação } \\ & 0,5 & 6,66 & 2,90 & 6,38 & \mathbf{p}(\mathbf{m}) & \text { linear } & 1,0000 \\ 3 & 1,0 & 8,52 & 6,48 & 7,96 & \mathbf{a}(\mathbf{m} 2) & \text { polinomial }\left(2^{\mathrm{a}} \text { ordem) }\right. & 1,0000 \\ & 1,5 & 10,35 & 10,85 & 9,49 & \mathbf{B}(\mathbf{m}) & \text { linear } & 0,9999\end{array}$
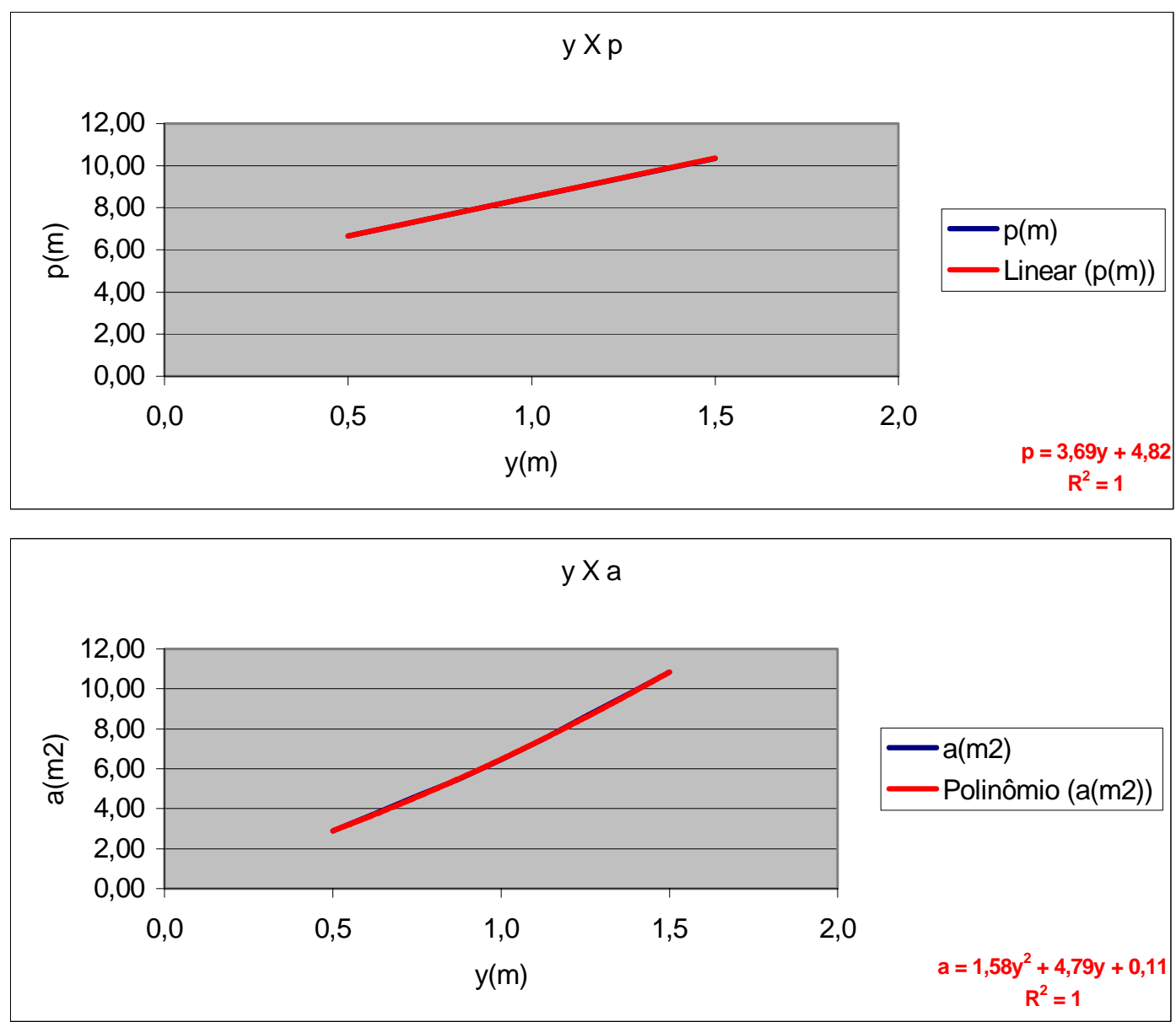

$y \times B$

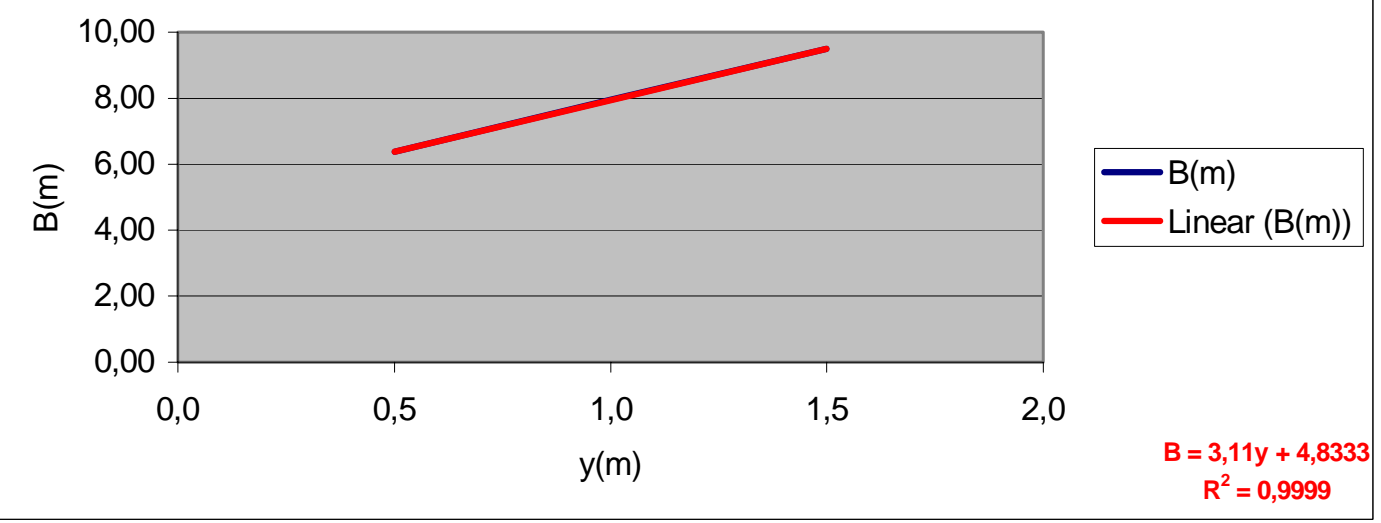




\section{SEÇÃO 64}

$\begin{array}{cccccccc}\text { no pares } & \mathbf{y}(\mathbf{m}) & \mathbf{p}(\mathbf{m}) & \mathbf{a}(\mathbf{m} 2) & \mathbf{B}(\mathbf{m}) & & \text { tipo da equação } & \text { correlação } \\ & 0,5 & 6,24 & 2,64 & 5,95 & \mathbf{p}(\mathbf{m}) & \text { linear } & 1,0000 \\ 3 & 1,0 & 8,06 & 5,99 & 7,46 & \mathbf{a}(\mathbf{m} 2) & \text { polinomial }\left(2^{\mathrm{a}} \text { ordem }\right) & 1,0000 \\ & 1,5 & 9,88 & 10,10 & 8,98 & \mathbf{B}(\mathbf{m}) & \text { linear } & 1,0000\end{array}$
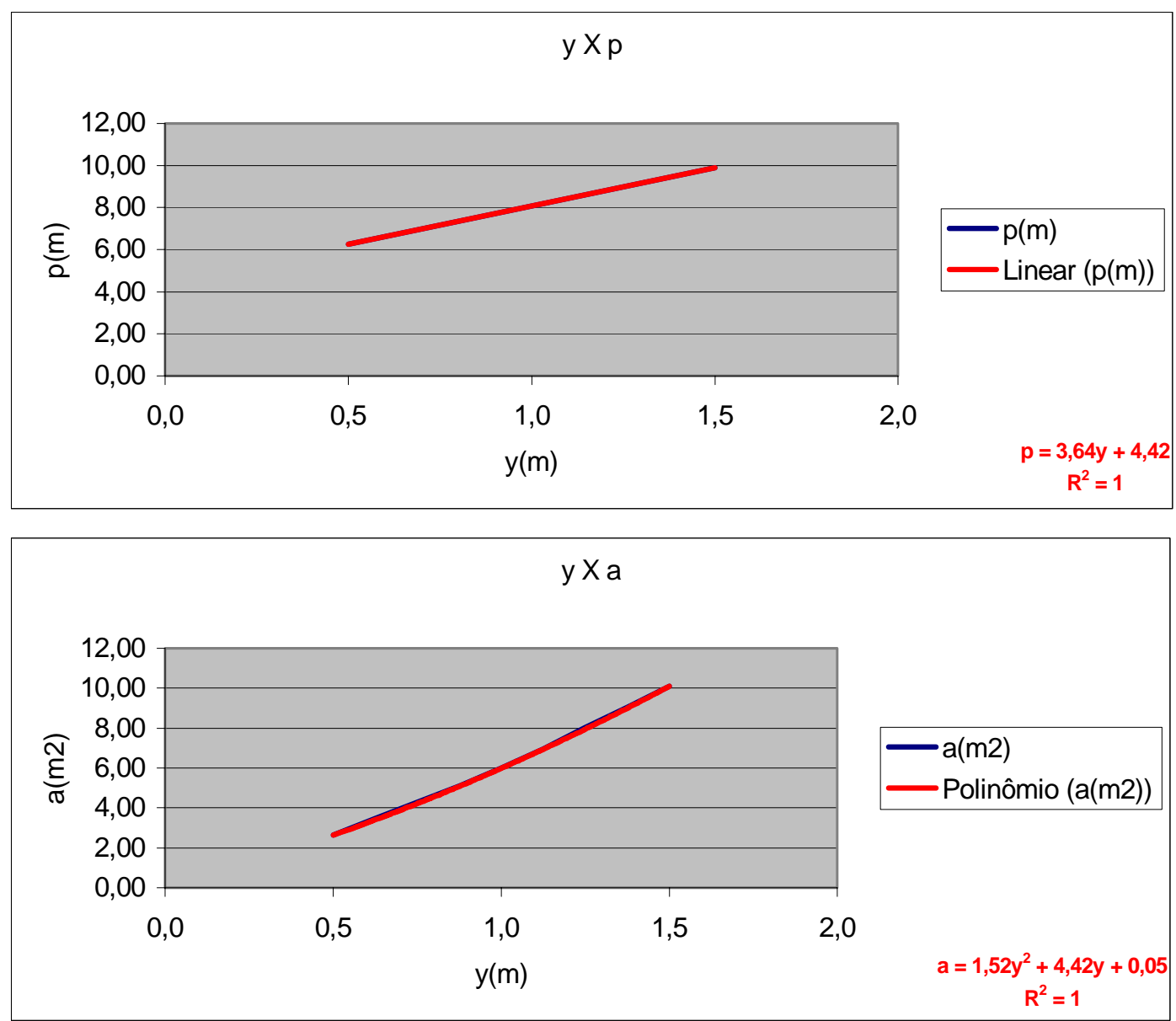

$y \times B$

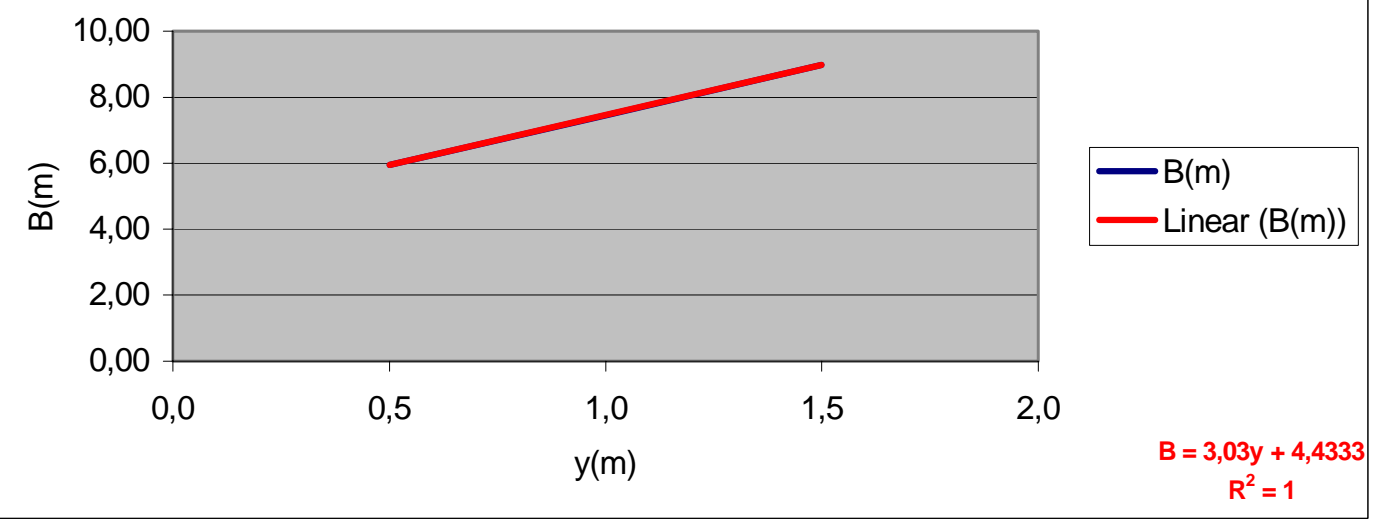




\section{SEÇÃO 65}

$\begin{array}{cccccccc}\text { no pares } & \mathbf{y}(\mathbf{m}) & \mathbf{p}(\mathbf{m}) & \mathbf{a}(\mathbf{m} \mathbf{2}) & \mathbf{B}(\mathbf{m}) & & \text { tipo da equação } & \text { correlação } \\ & 0,5 & 6,26 & 2,53 & 6,00 & \mathbf{p}(\mathbf{m}) & \text { linear } & 1,0000 \\ 3 & 1,0 & 8,19 & 5,94 & 7,65 & \mathbf{a}(\mathbf{m} 2) & \text { polinomial }\left(2^{a} \text { ordem) }\right. & 1,0000 \\ & 1,5 & 10,09 & 10,17 & 9,26 & \mathbf{B}(\mathbf{m}) & \text { linear } & 0,9999\end{array}$
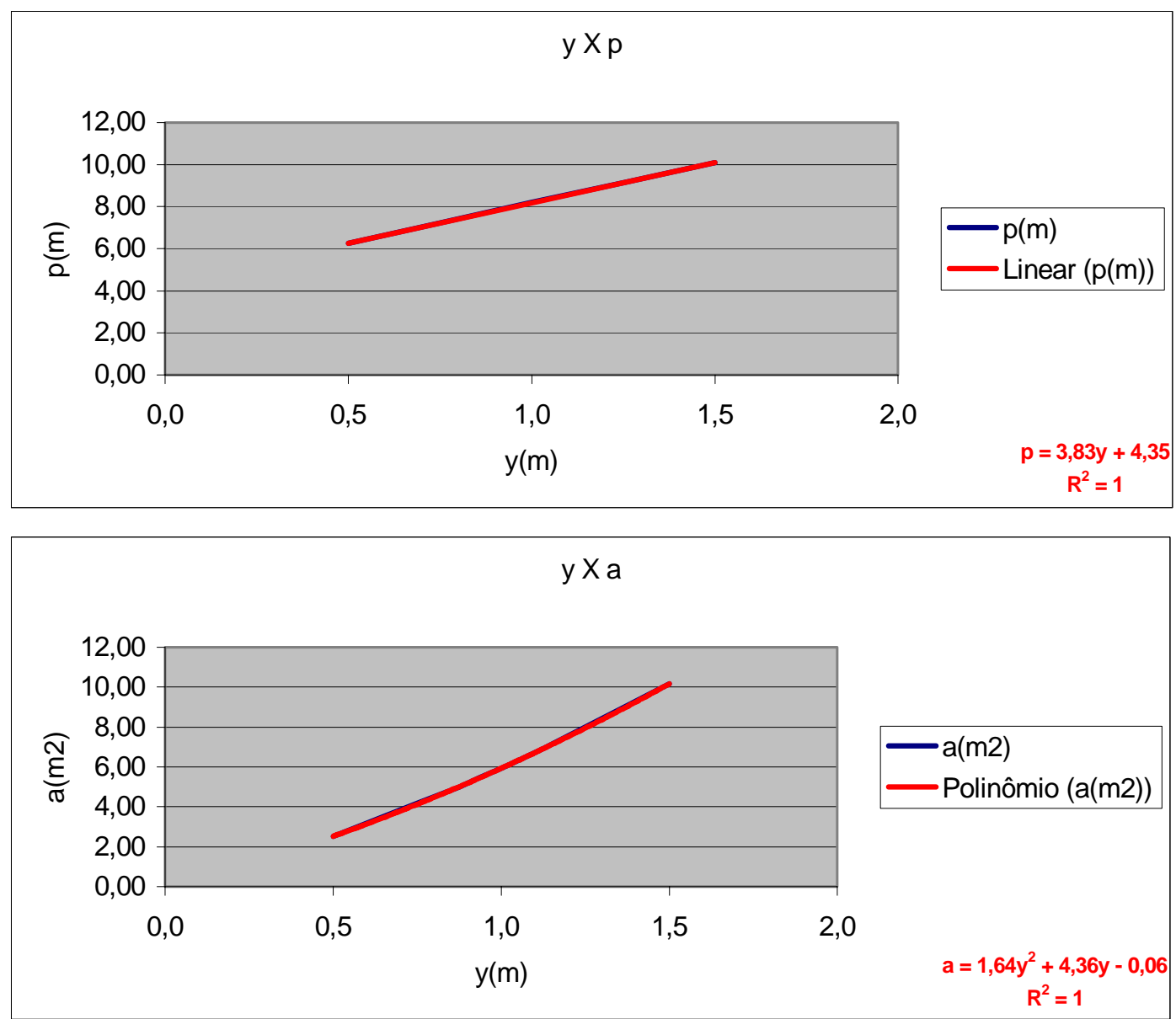

$y \times B$

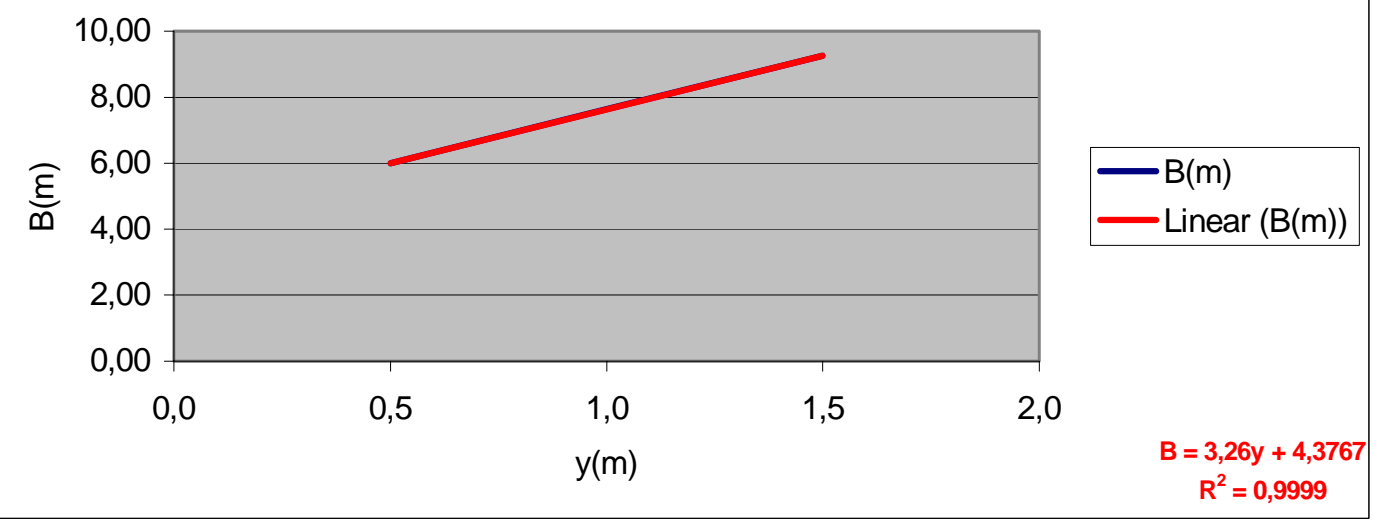




\section{SEÇÃO 66}

$\begin{array}{cccccccc}\text { no pares } & \mathbf{y}(\mathbf{m}) & \mathbf{p}(\mathbf{m}) & \mathbf{a}(\mathbf{m} 2) & \mathbf{B}(\mathbf{m}) & & \text { tipo da equação } & \text { correlação } \\ & 0,5 & 6,35 & 2,72 & 6,07 & \mathbf{p}(\mathbf{m}) & \text { linear } & 0,9999 \\ 3 & 1,0 & 8,26 & 6,16 & 7,69 & \mathbf{a}(\mathbf{m} 2) & \text { polinomial }\left(2^{\mathrm{a}} \text { ordem }\right) & 1,0000 \\ & 1,5 & 10,12 & 10,40 & 9,26 & \mathbf{B}(\mathbf{m}) & \text { linear } & 0,9999\end{array}$
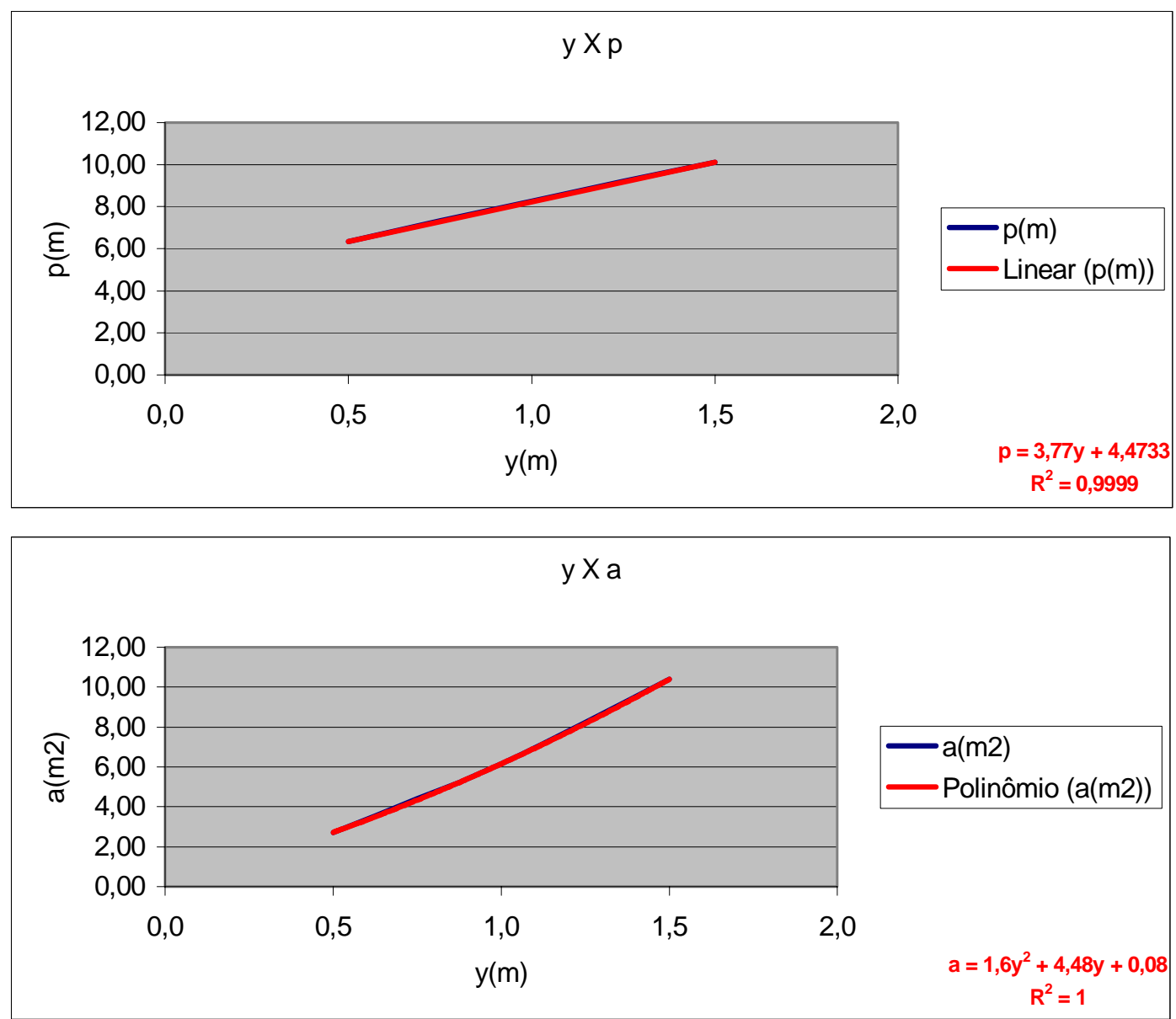

$y \times B$

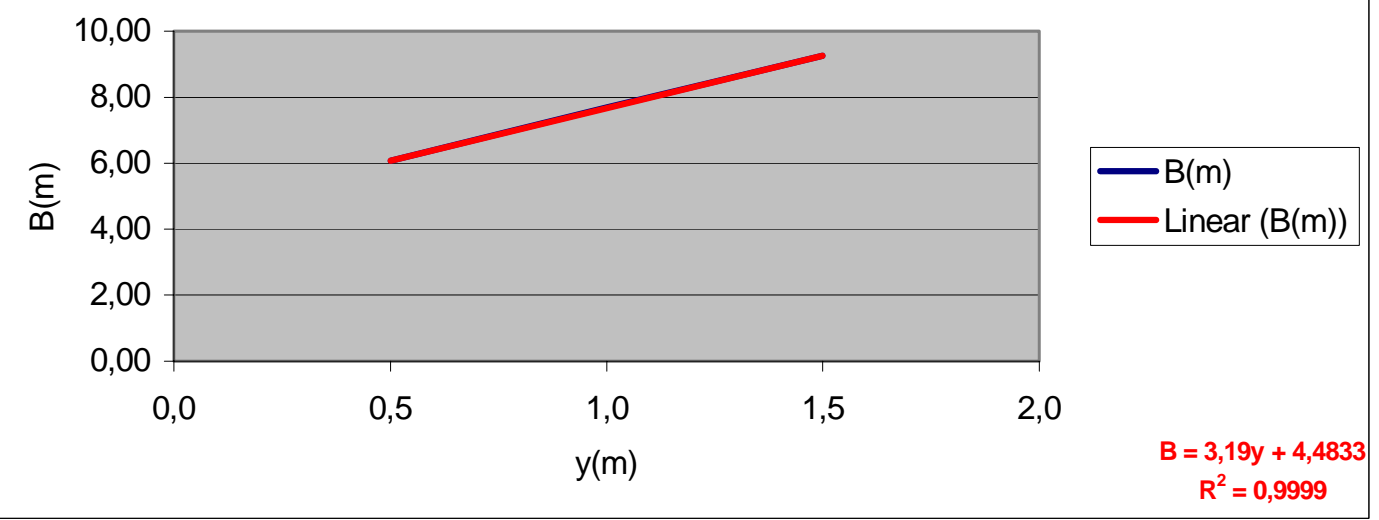




\section{SEÇÃO 67}

$\begin{array}{cccccccc}\text { no pares } & \mathbf{y}(\mathbf{m}) & \mathbf{p}(\mathbf{m}) & \mathbf{a}(\mathbf{m} 2) & \mathbf{B}(\mathbf{m}) & & \text { tipo da equação } & \text { correlação } \\ & 0,5 & 6,29 & 2,70 & 6,02 & \mathbf{p}(\mathbf{m}) & \text { linear } & 1,0000 \\ 3 & 1,0 & 8,26 & 6,13 & 7,71 & \mathbf{a}(\mathbf{m} 2) & \text { polinomial }\left(2^{\mathrm{a}} \text { ordem }\right) & 1,0000 \\ & 1,5 & 10,20 & 10,41 & 9,37 & \mathbf{B}(\mathbf{m}) & \text { linear } & 1,0000\end{array}$
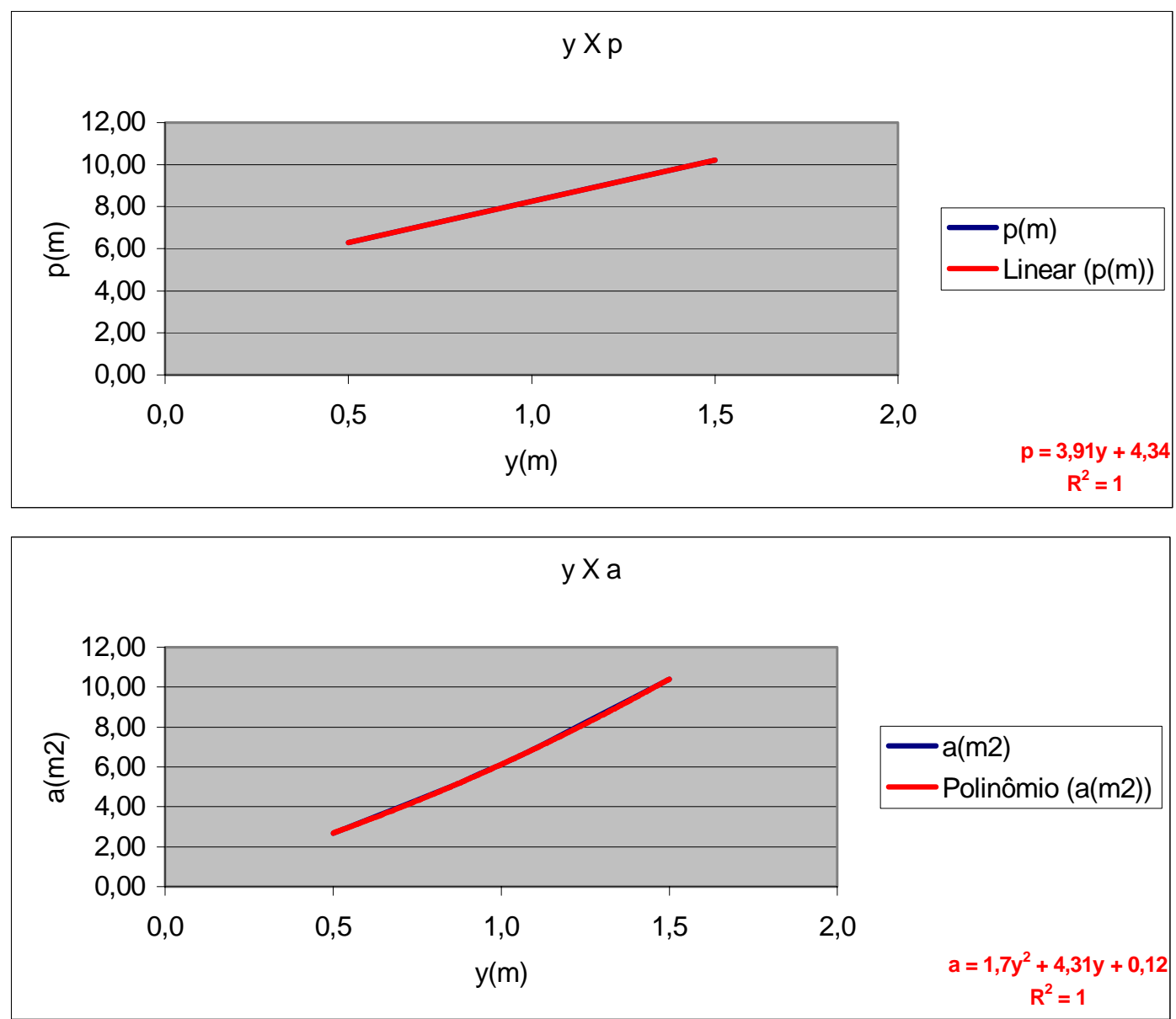

$y \times B$

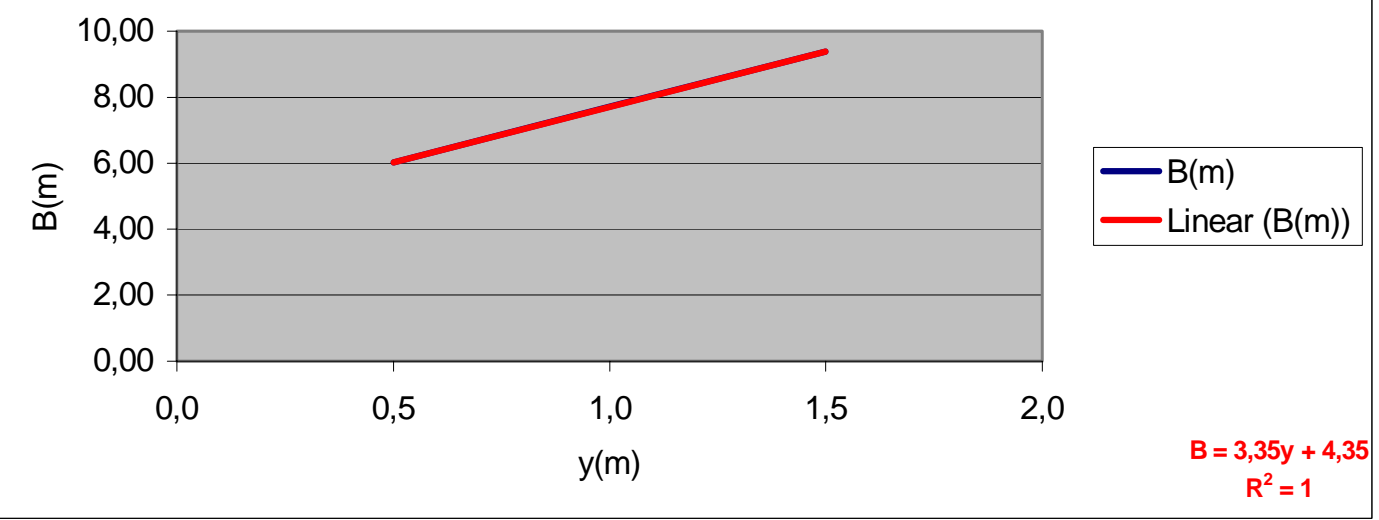




\section{SEÇÃO 68}

$\begin{array}{cccccccc}\text { no pares } & \mathbf{y}(\mathbf{m}) & \mathbf{p}(\mathbf{m}) & \mathbf{a}(\mathbf{m} 2) & \mathbf{B}(\mathbf{m}) & & \text { tipo da equação } & \text { correlação } \\ & 0,5 & 6,63 & 2,78 & 6,35 & \mathbf{p}(\mathbf{m}) & \text { linear } & 1,0000 \\ 3 & 1,0 & 8,51 & 6,36 & 7,95 & \mathbf{a}(\mathbf{m} 2) & \text { polinomial }\left(2^{\mathrm{a}} \text { ordem }\right) & 1,0000 \\ & 1,5 & 10,38 & 10,73 & 9,52 & \mathbf{B}(\mathbf{m}) & \text { linear } & 1,0000\end{array}$
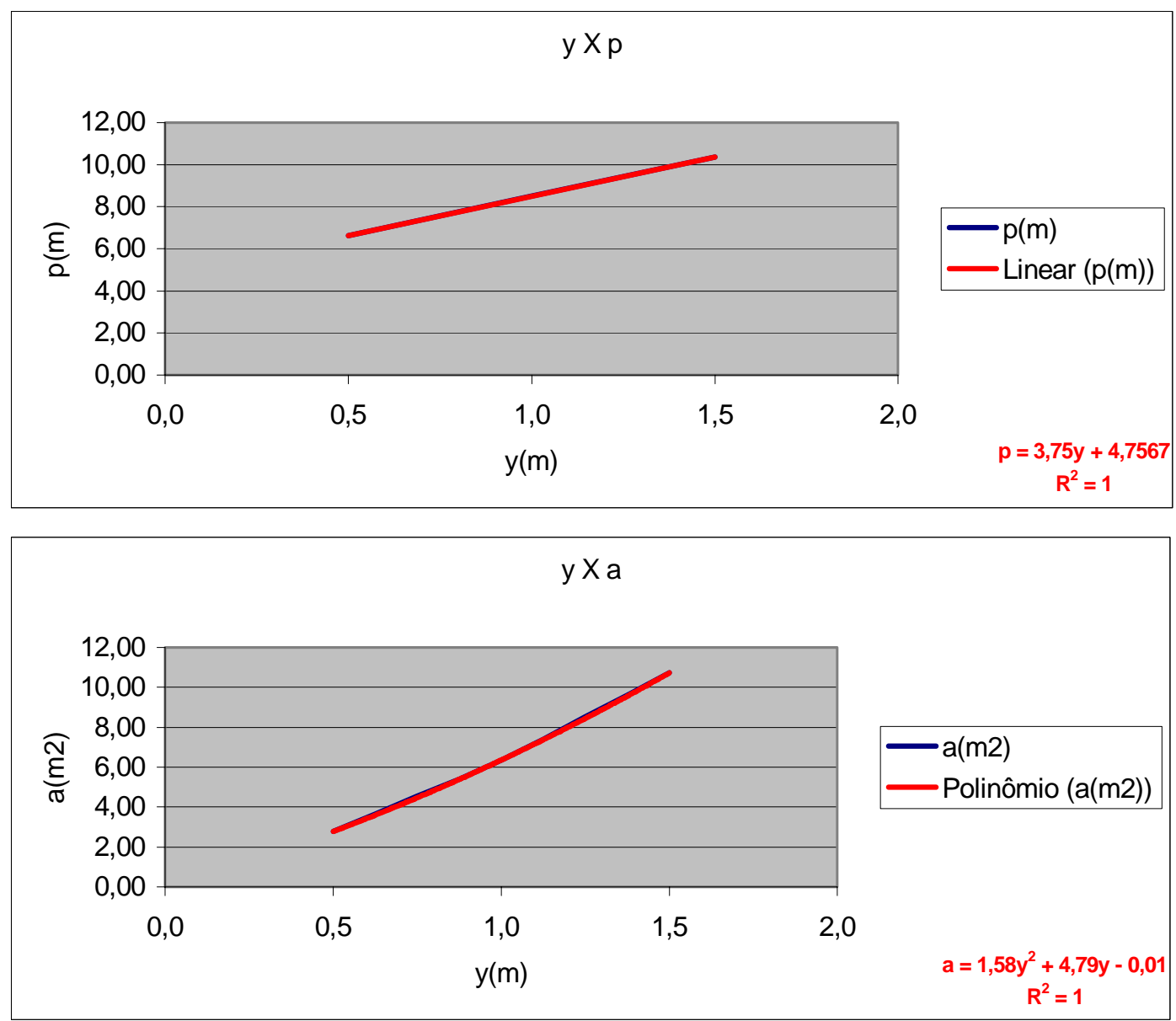

$y \times B$

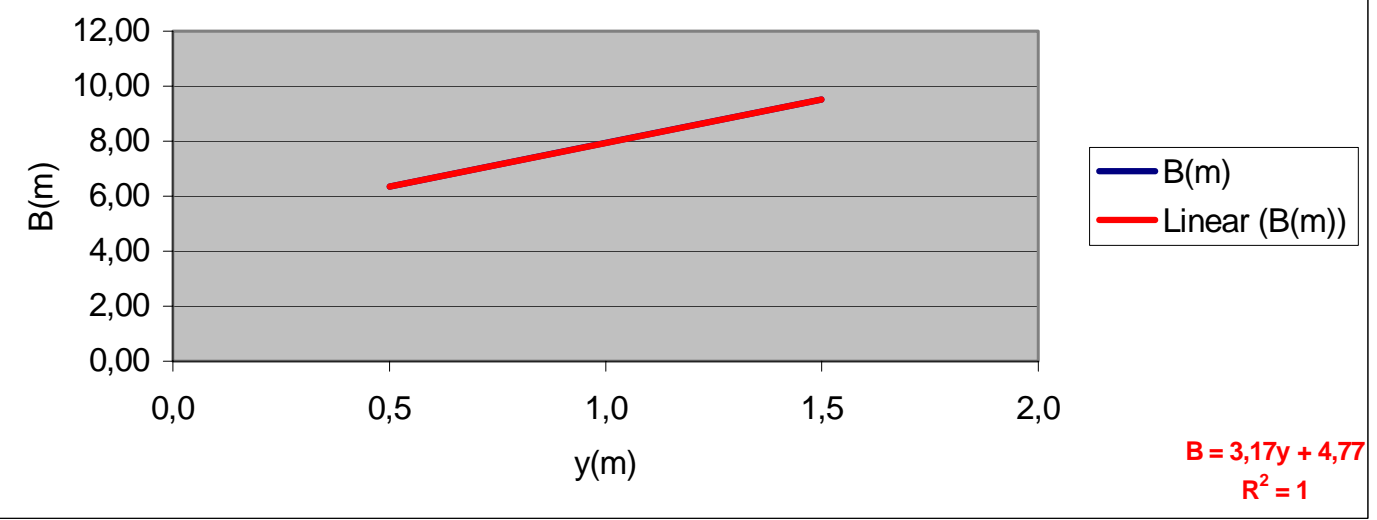




\section{SEÇÃO 69}

$\begin{array}{cccccccc}\text { no pares } & \mathbf{y}(\mathbf{m}) & \mathbf{p}(\mathbf{m}) & \mathbf{a}(\mathbf{m} 2) & \mathbf{B}(\mathbf{m}) & & \text { tipo da equação } & \text { correlação } \\ & 0,5 & 8,65 & 3,83 & 8,40 & \mathbf{p}(\mathbf{m}) & \text { linear } & 0,9994 \\ 3 & 1,0 & 10,70 & 8,48 & 10,19 & \mathbf{a}(\mathbf{m} 2) & \text { polinomial }\left(2^{a} \text { ordem }\right) & 1,0000 \\ & 1,5 & 12,58 & 13,98 & 11,78 & \mathbf{B}(\mathbf{m}) & \text { linear } & 0,9988\end{array}$
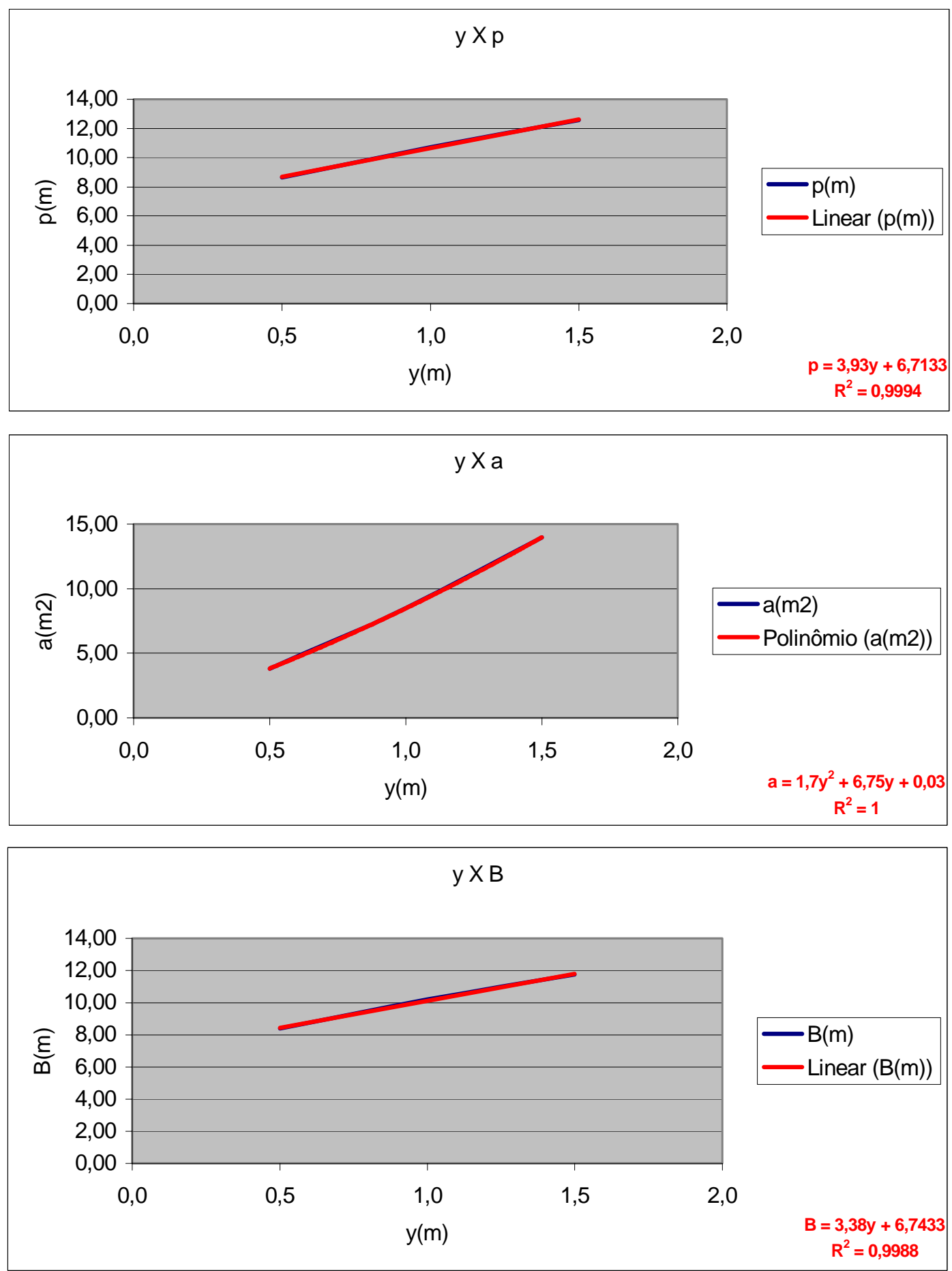


\section{SEÇÃO 70}

$\begin{array}{cccccccc}\text { no pares } & \mathbf{y}(\mathbf{m}) & \mathbf{p}(\mathbf{m}) & \mathbf{a}(\mathbf{m} 2) & \mathbf{B}(\mathbf{m}) & & \text { tipo da equação } & \text { correlação } \\ & 0,5 & 6,73 & 2,89 & 6,45 & \mathbf{p}(\mathbf{m}) & \text { linear } & 0,9995 \\ 3 & 1,0 & 8,66 & 6,53 & 8,10 & \mathbf{a}(\mathbf{m} 2) & \text { polinomial }\left(2^{a} \text { ordem) }\right. & 1,0000 \\ & 1,5 & 10,45 & 10,95 & 9,58 & \mathbf{B}(\mathbf{m}) & \text { linear } & 0,9990\end{array}$
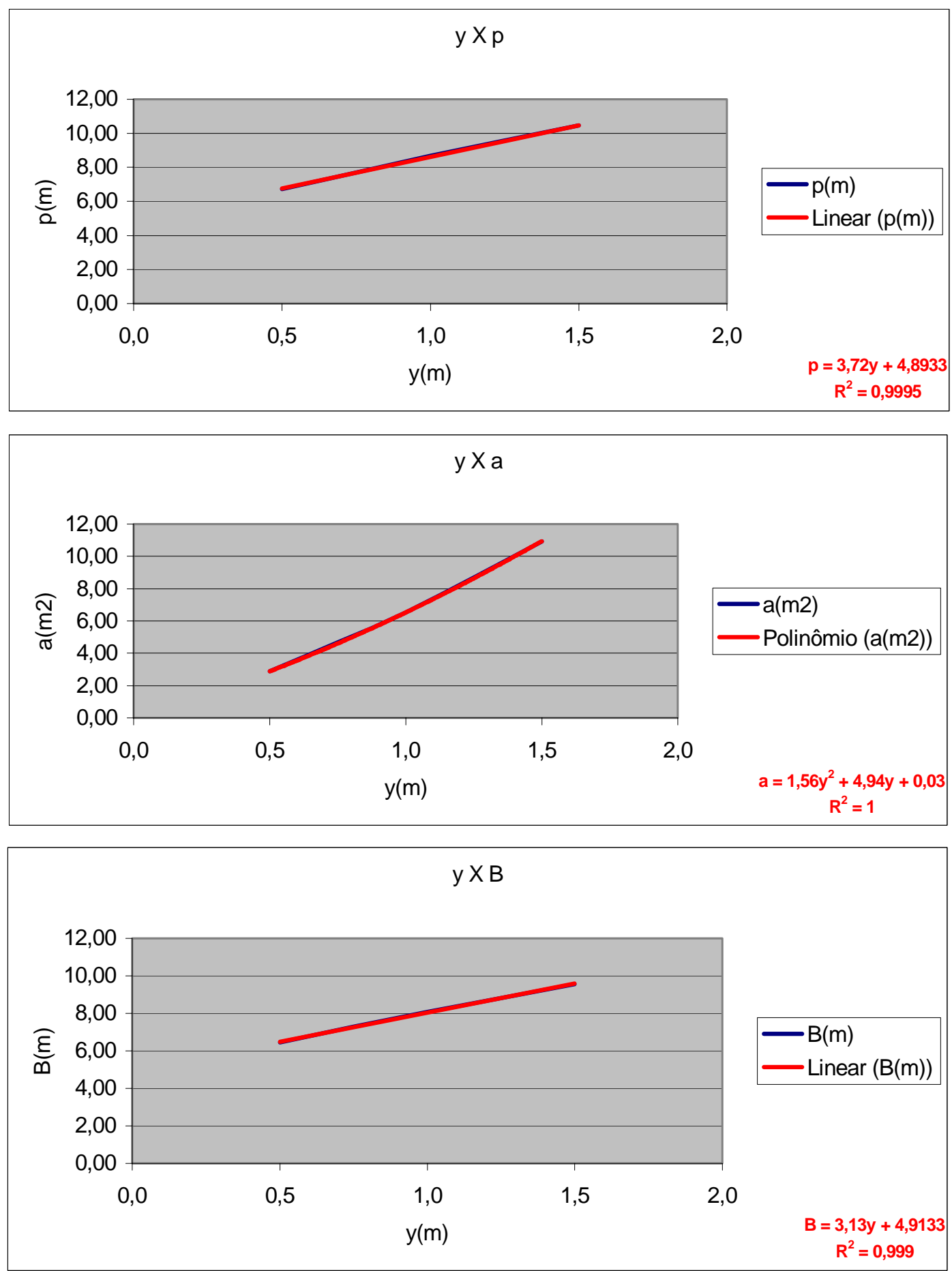


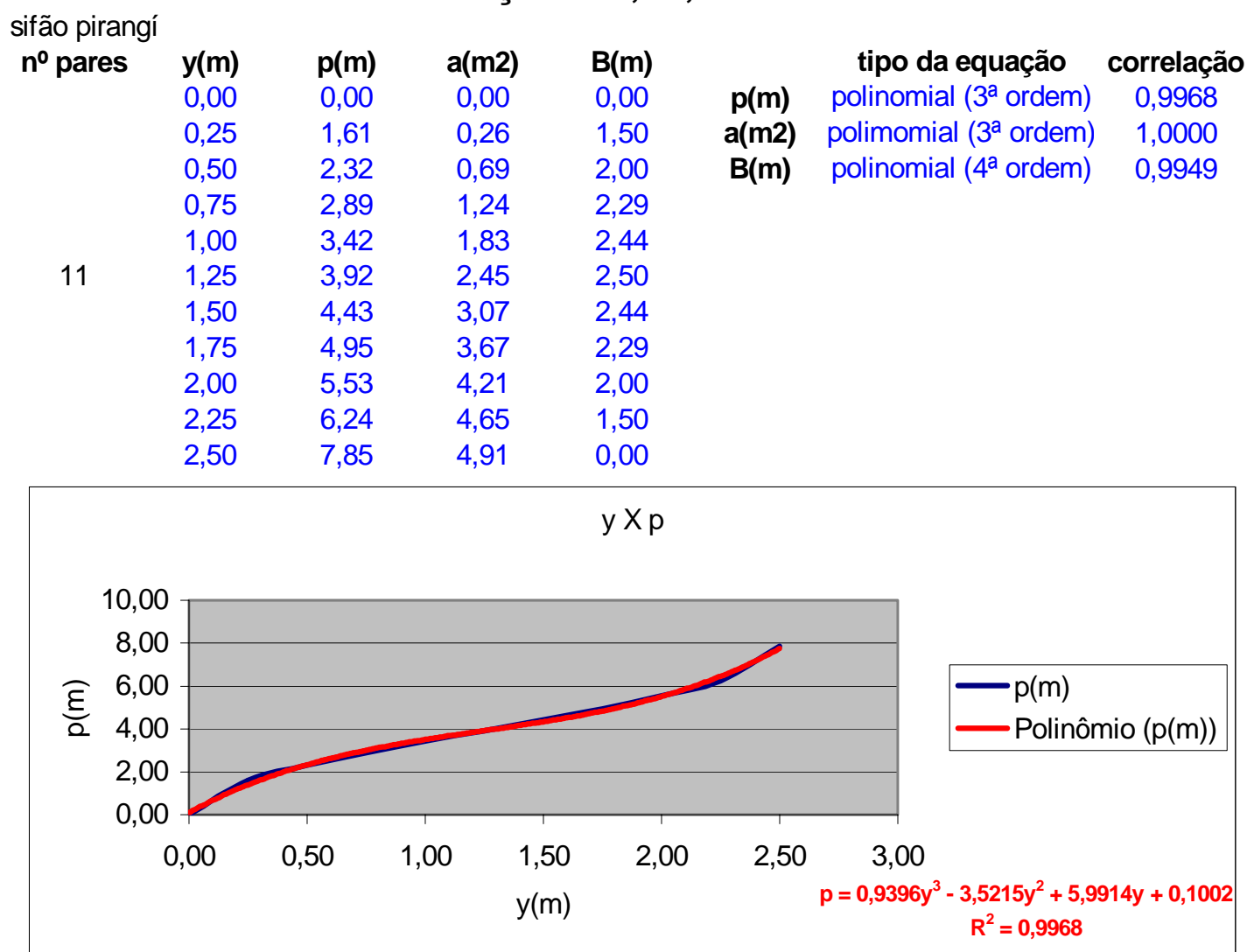
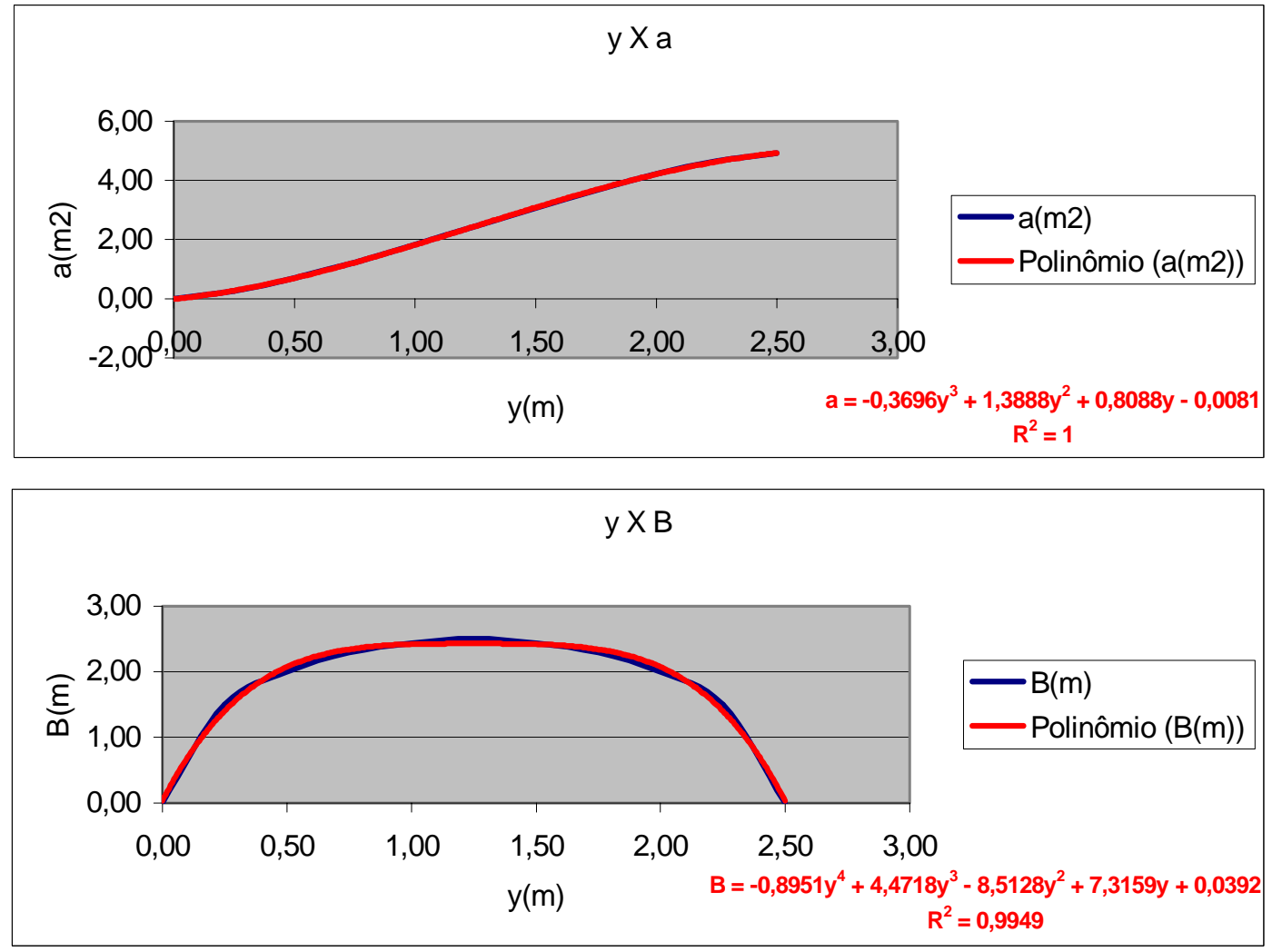


\section{SEÇÃO 75}

$\begin{array}{cccccccc}\text { no pares } & \mathbf{y}(\mathbf{m}) & \mathbf{p}(\mathbf{m}) & \mathbf{a}(\mathbf{m} 2) & \mathbf{B}(\mathbf{m}) & & \text { tipo da equação } & \text { correlação } \\ & 0,5 & 6,70 & 2,98 & 6,39 & \mathbf{p}(\mathbf{m}) & \text { linear } & 1,0000 \\ 3 & 1,0 & 8,45 & 6,53 & 7,82 & \mathbf{a}(\mathbf{m} 2) & \text { polinomial }\left(2^{\mathrm{a}} \text { ordem }\right) & 1,0000 \\ & 1,5 & 10,19 & 10,80 & 9,25 & \mathbf{B}(\mathbf{m}) & \text { linear } & 1,0000\end{array}$
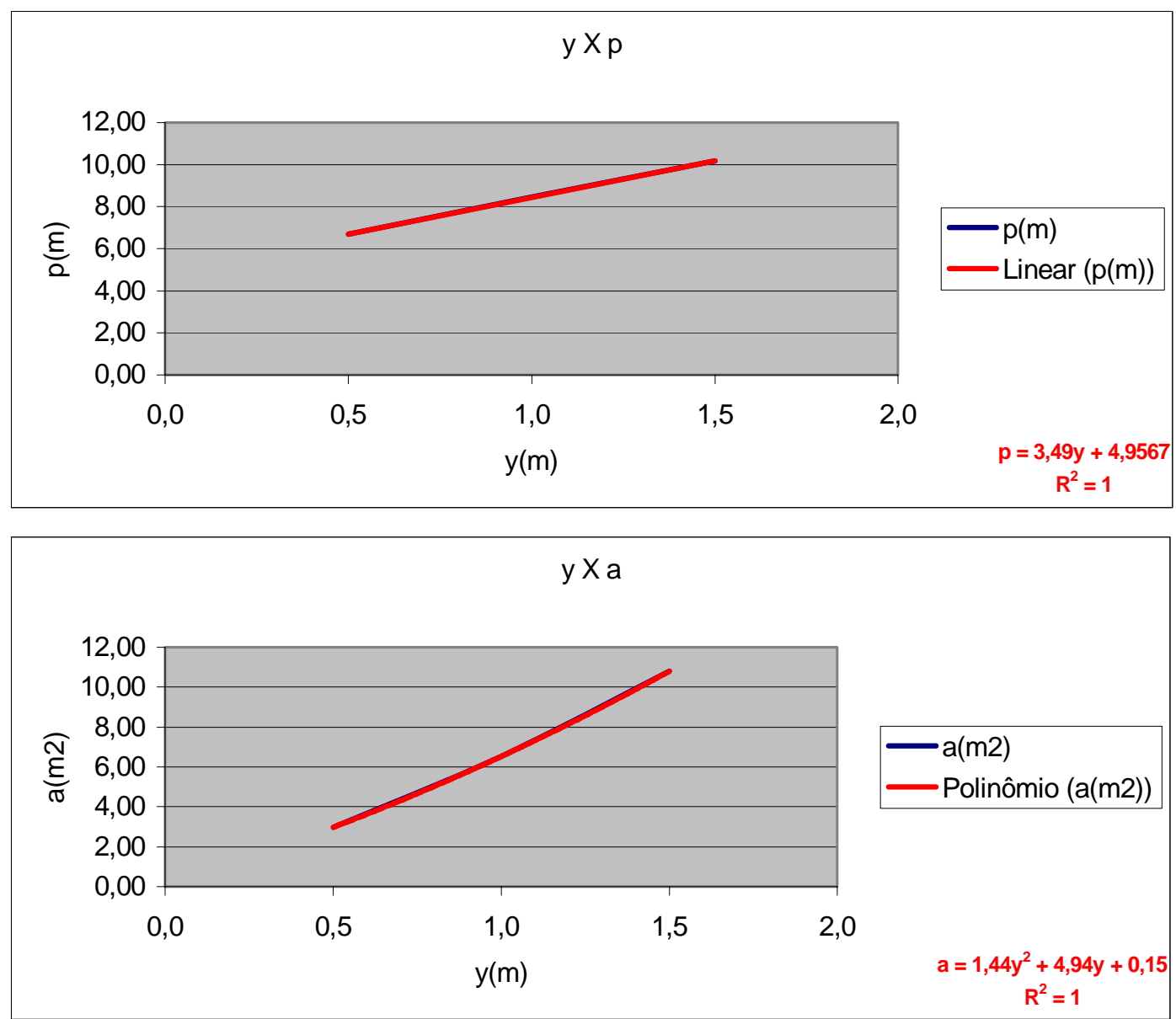

$y \times B$

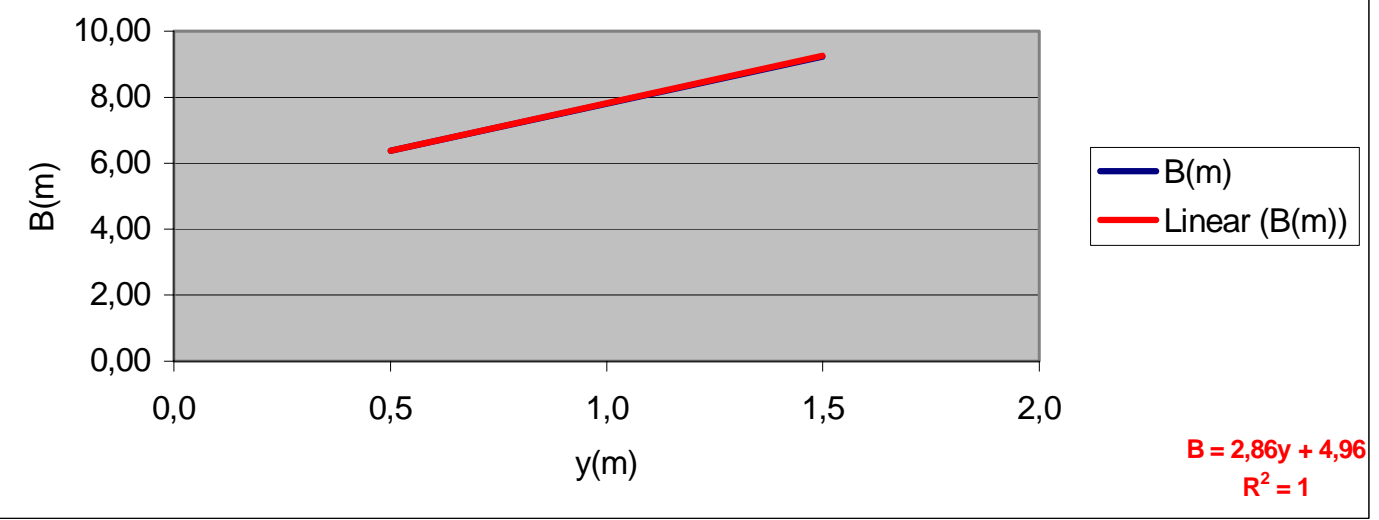


SEÇÕES 76 e 77

$\begin{array}{cccccccc}\text { no pares } & \mathbf{y}(\mathbf{m}) & \mathbf{p}(\mathbf{m}) & \mathbf{a}(\mathbf{m} \mathbf{2}) & \mathbf{B}(\mathbf{m}) & & \text { tipo da equação } & \text { correlação } \\ & 0,5 & 5,72 & 2,37 & 5,44 & \mathbf{p}(\mathbf{m}) & \text { linear } & 1,0000 \\ 3 & 1,0 & 7,63 & 5,50 & 7,07 & \mathbf{a}(\mathbf{m} 2) & \text { polinomial }\left(2^{a} \text { ordem) }\right. & 1,0000 \\ & 1,5 & 9,54 & 9,44 & 8,69 & \mathbf{B}(\mathbf{m}) & \text { linear } & 1,0000\end{array}$
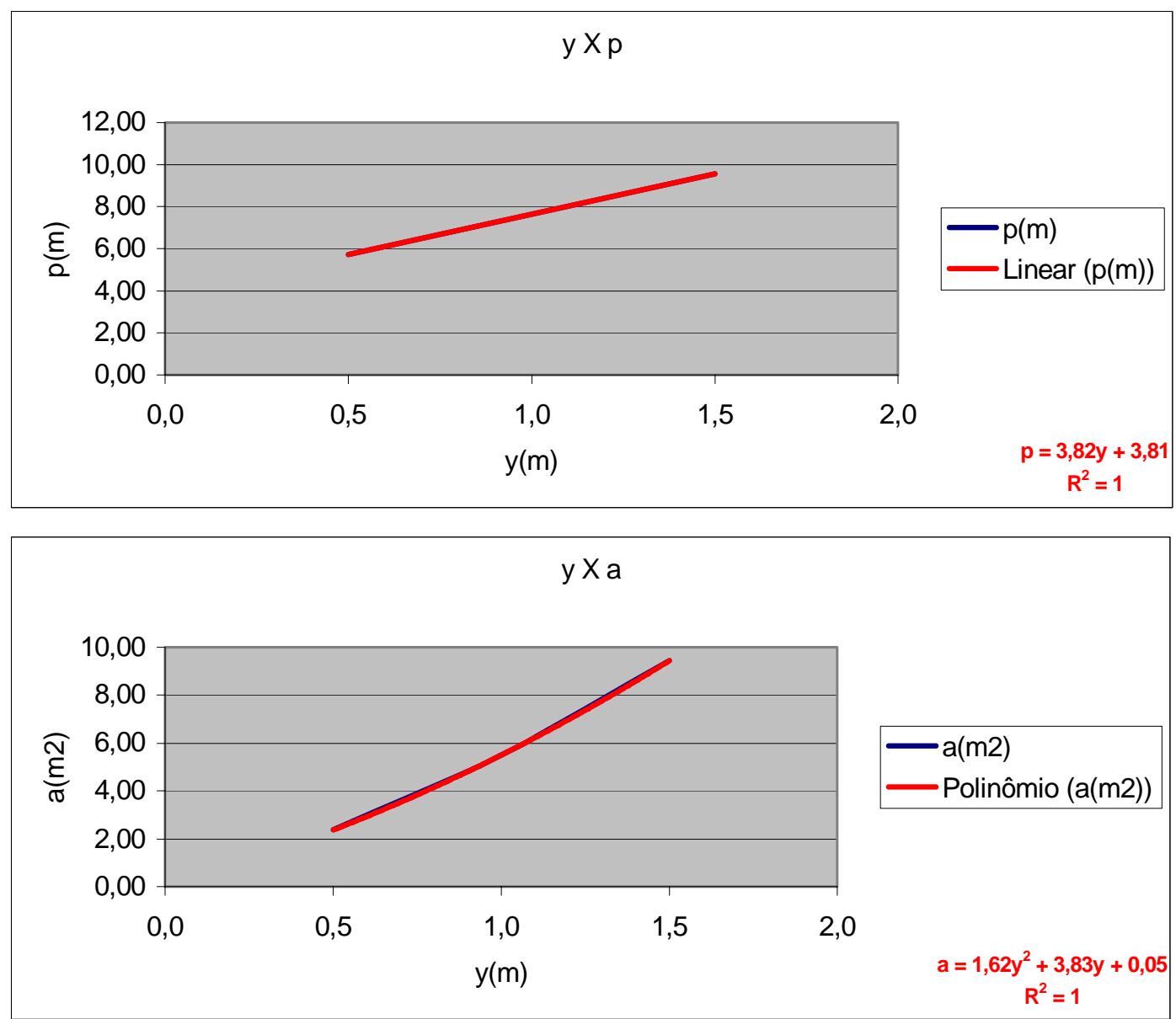

$y X B$

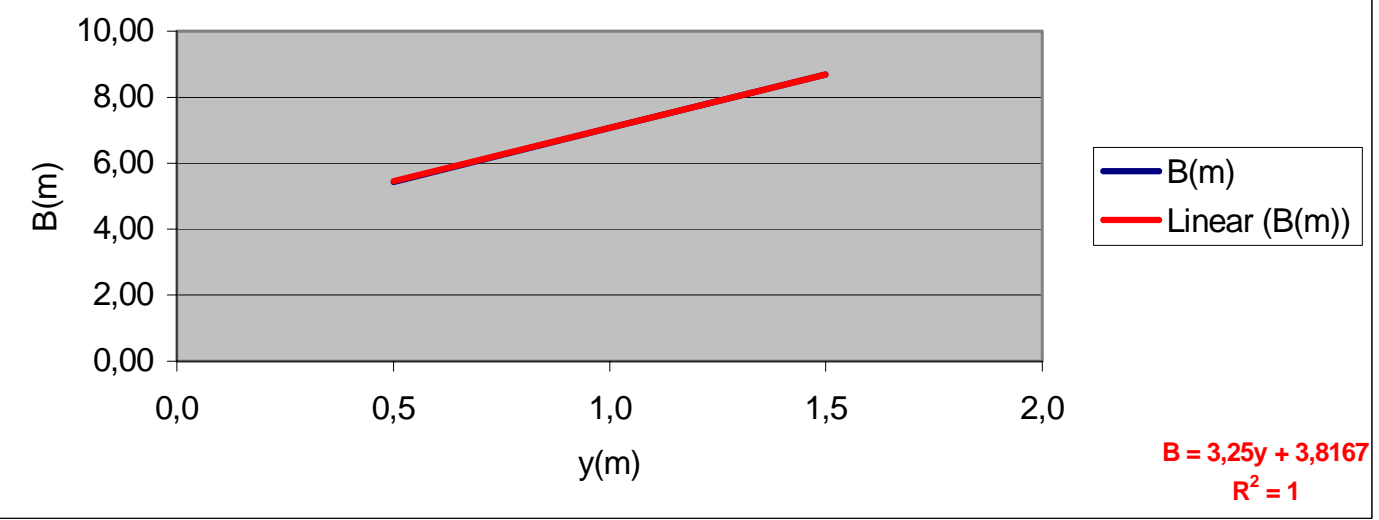




\section{SEÇÃO 78}

$\begin{array}{cccccccc}\text { no pares } & \mathbf{y}(\mathbf{m}) & \mathbf{p}(\mathbf{m}) & \mathbf{a}(\mathbf{m} 2) & \mathbf{B}(\mathbf{m}) & & \text { tipo da equação } & \text { correlação } \\ & 0,5 & 5,46 & 2,12 & 5,21 & \mathbf{p}(\mathbf{m}) & \text { linear } & 1,0000 \\ 3 & 1,0 & 7,44 & 5,15 & 6,92 & \mathbf{a}(\mathbf{m} 2) & \text { polinomial }\left(2^{\mathrm{a}} \text { ordem }\right) & 1,0000 \\ & 1,5 & 9,42 & 9,03 & 8,63 & \mathbf{B}(\mathbf{m}) & \text { linear } & 1,0000\end{array}$
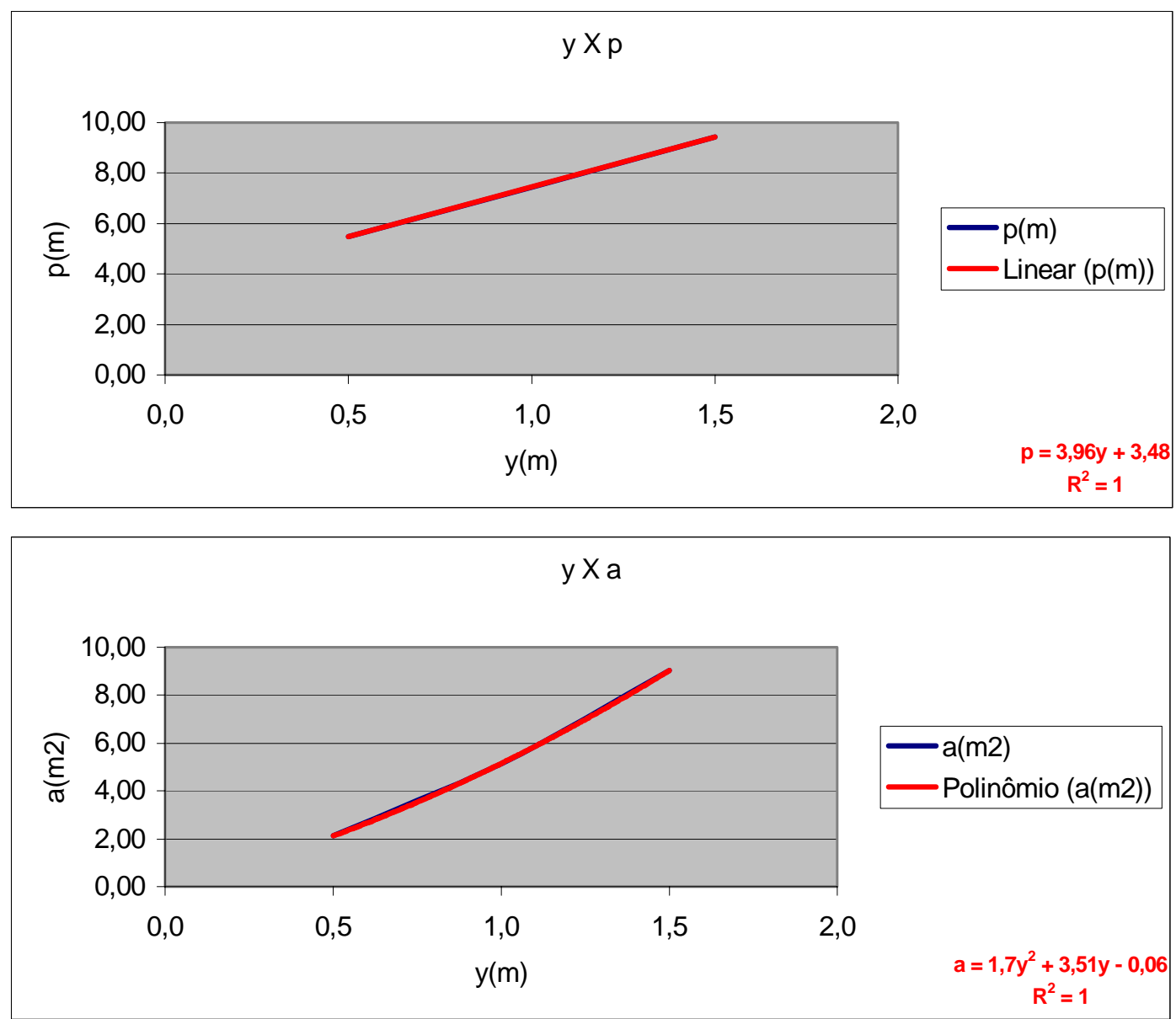

yXB

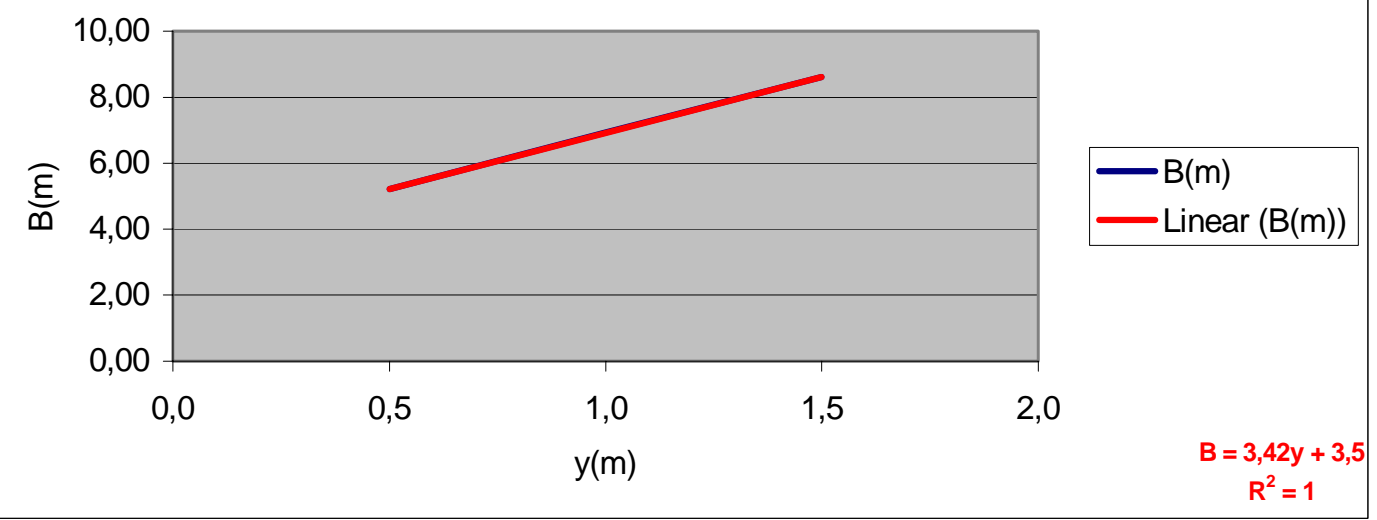




\section{SEÇÃO 79}

$\begin{array}{cccccccc}\text { no pares } & \mathbf{y}(\mathbf{m}) & \mathbf{p}(\mathbf{m}) & \mathbf{a}(\mathbf{m} \mathbf{2}) & \mathbf{B}(\mathbf{m}) & & \text { tipo da equação } & \text { correlação } \\ & 0,5 & 6,28 & 2,58 & 6,03 & \mathbf{p}(\mathbf{m}) & \text { linear } & 1,0000 \\ 3 & 1,0 & 8,29 & 6,03 & 7,77 & \mathbf{a}(\mathbf{m} 2) & \text { polinomial }\left(2^{a} \text { ordem) }\right. & 1,0000 \\ & 1,5 & 10,30 & 10,35 & 9,51 & \mathbf{B}(\mathbf{m}) & \text { linear } & 1,0000\end{array}$
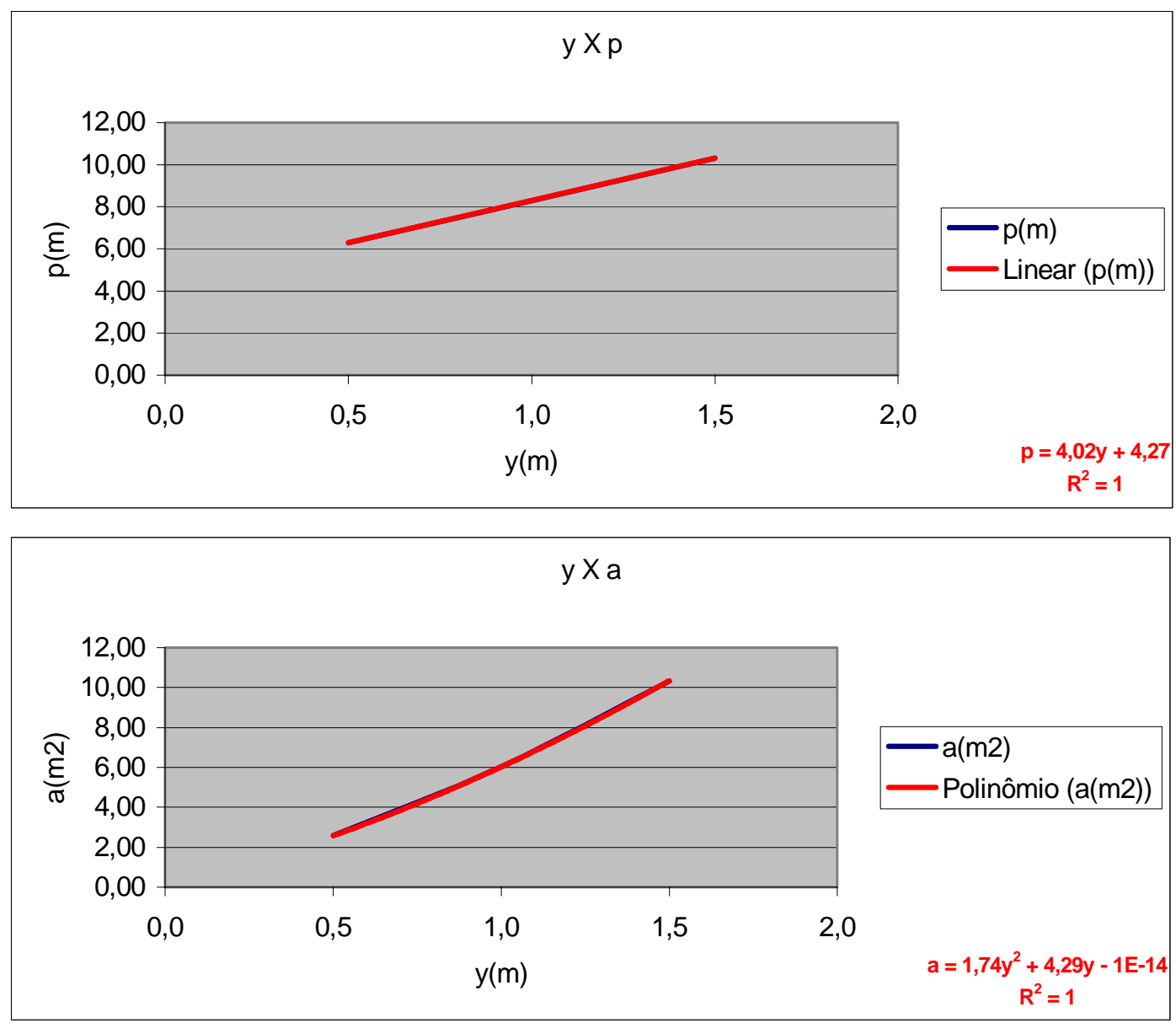

$y \times B$

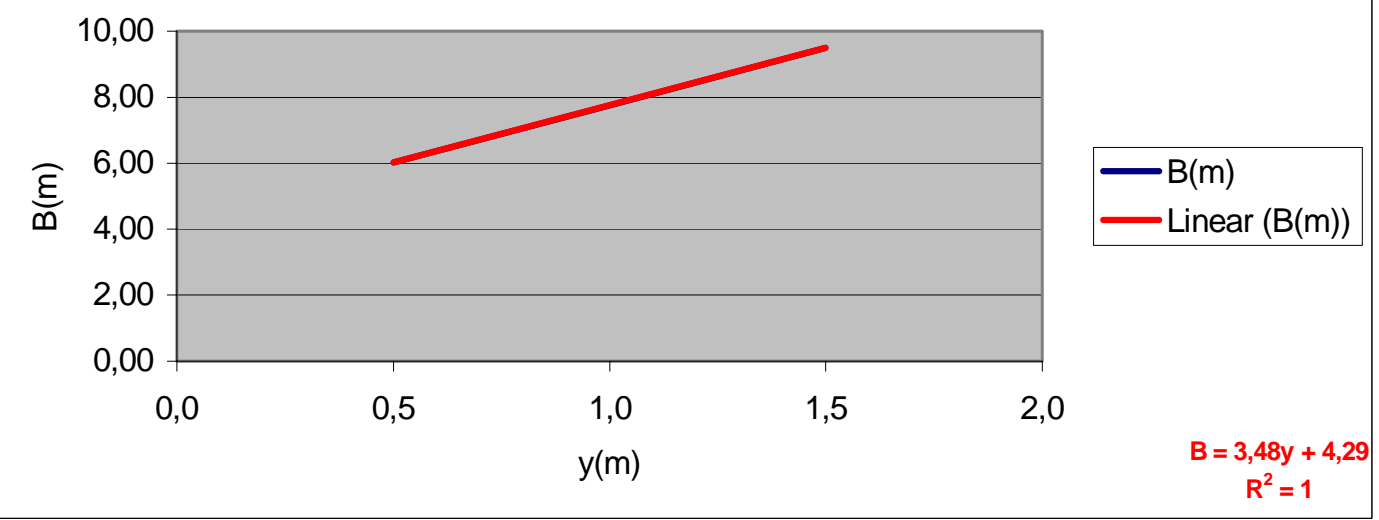




\section{SEÇÃO 80}

$\begin{array}{cccccccc}\text { no pares } & \mathbf{y}(\mathbf{m}) & \mathbf{p}(\mathbf{m}) & \mathbf{a}(\mathbf{m} 2) & \mathbf{B}(\mathbf{m}) & & \text { tipo da equação } & \text { correlação } \\ & 0,5 & 6,80 & 2,91 & 6,49 & \mathbf{p}(\mathbf{m}) & \text { linear } & 1,0000 \\ 3 & 1,0 & 8,58 & 6,53 & 7,97 & \mathbf{a}(\mathbf{m} 2) & \text { polinomial }\left(2^{\mathrm{a}} \text { ordem }\right) & 1,0000 \\ & 1,5 & 10,37 & 10,88 & 9,45 & \mathbf{B}(\mathbf{m}) & \text { linear } & 1,0000\end{array}$
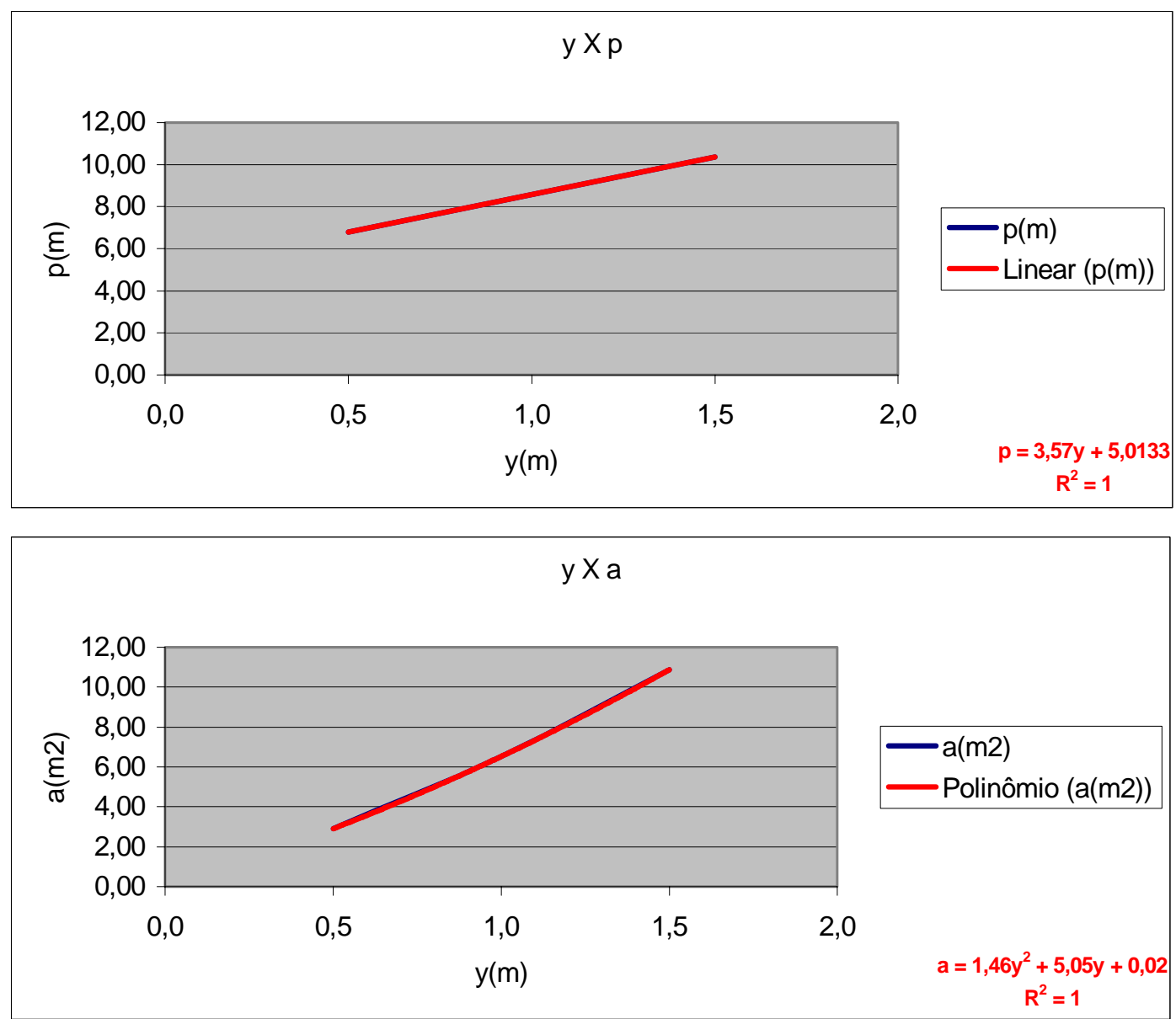

$y \times B$

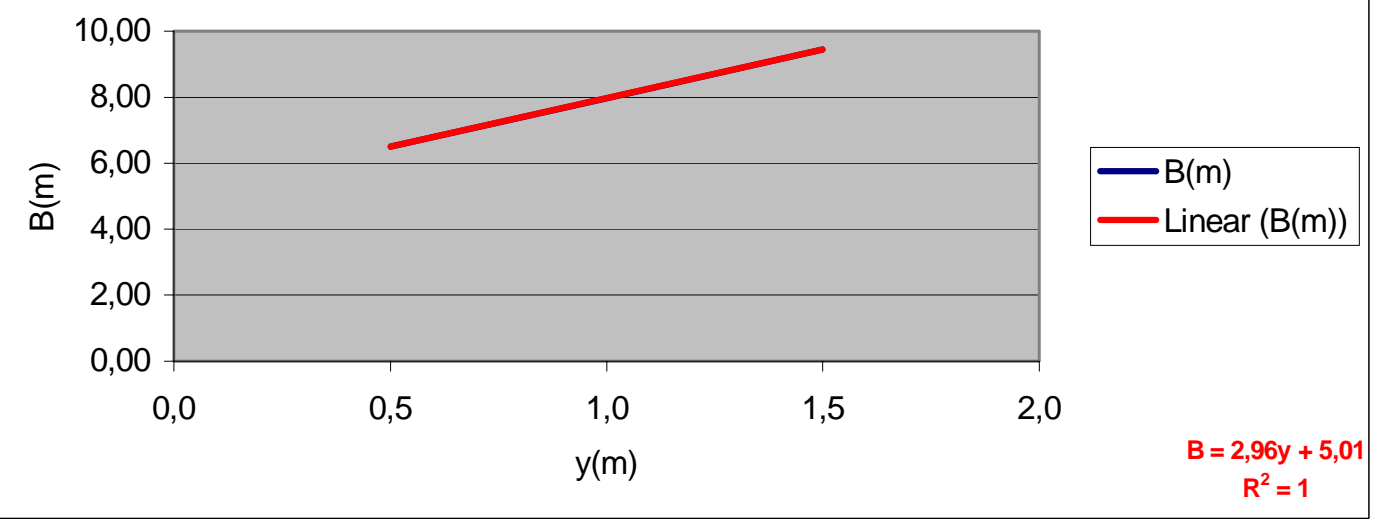




\section{SEÇÃO 81}

$\begin{array}{cccccccc}\text { no pares } & \mathbf{y}(\mathbf{m}) & \mathbf{p}(\mathbf{m}) & \mathbf{a}(\mathbf{m} 2) & \mathbf{B}(\mathbf{m}) & & \text { tipo da equação } & \text { correlação } \\ & 0,5 & 6,22 & 2,67 & 5,93 & \mathbf{p}(\mathbf{m}) & \text { linear } & 1,0000 \\ 3 & 1,0 & 8,16 & 6,06 & 7,60 & \mathbf{a}(\mathbf{m} 2) & \text { polinomial }\left(2^{\mathrm{a}} \text { ordem }\right) & 1,0000 \\ & 1,5 & 10,10 & 10,27 & 9,26 & \mathbf{B}(\mathbf{m}) & \text { linear } & 1,0000\end{array}$
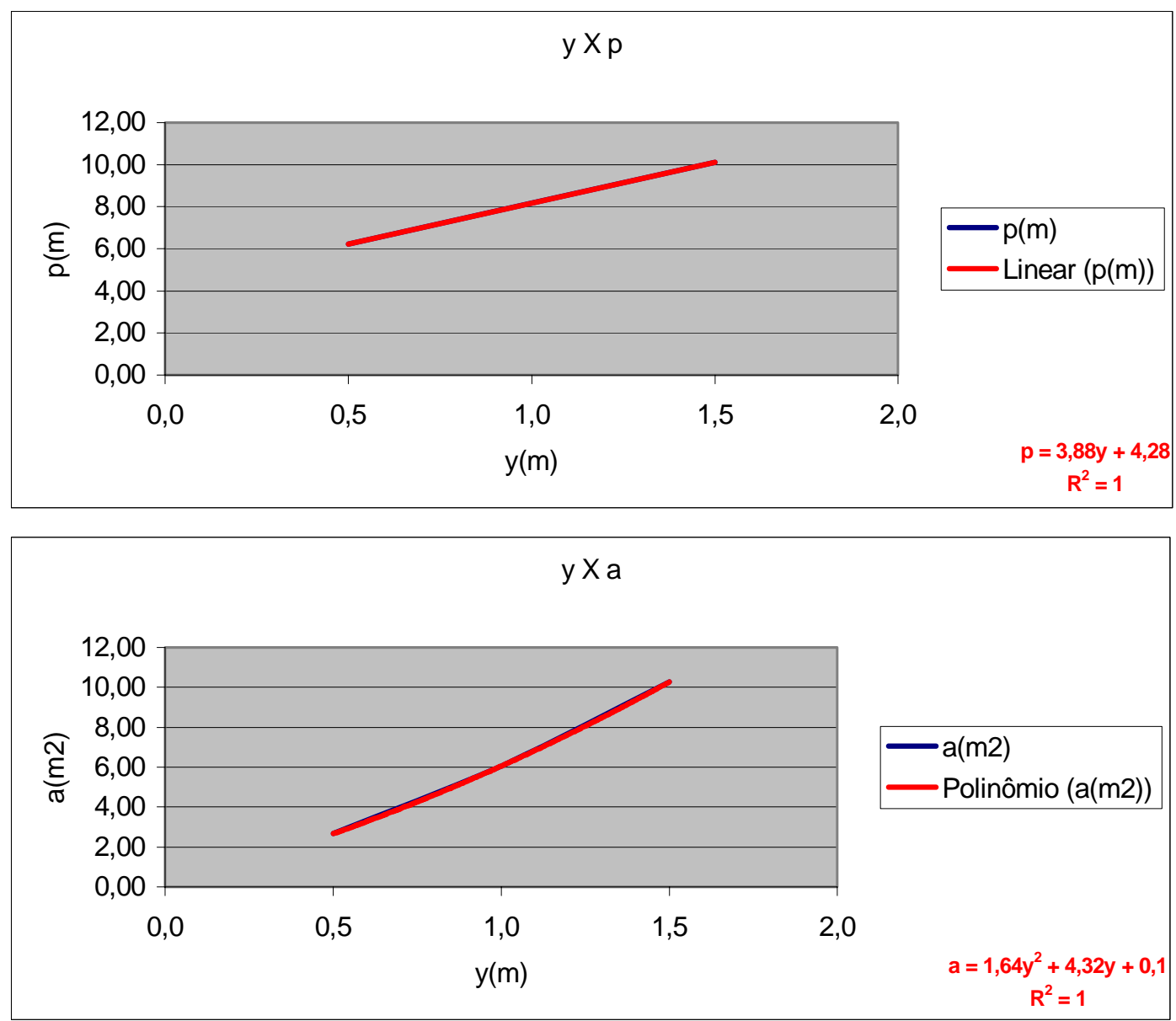

$y \times B$

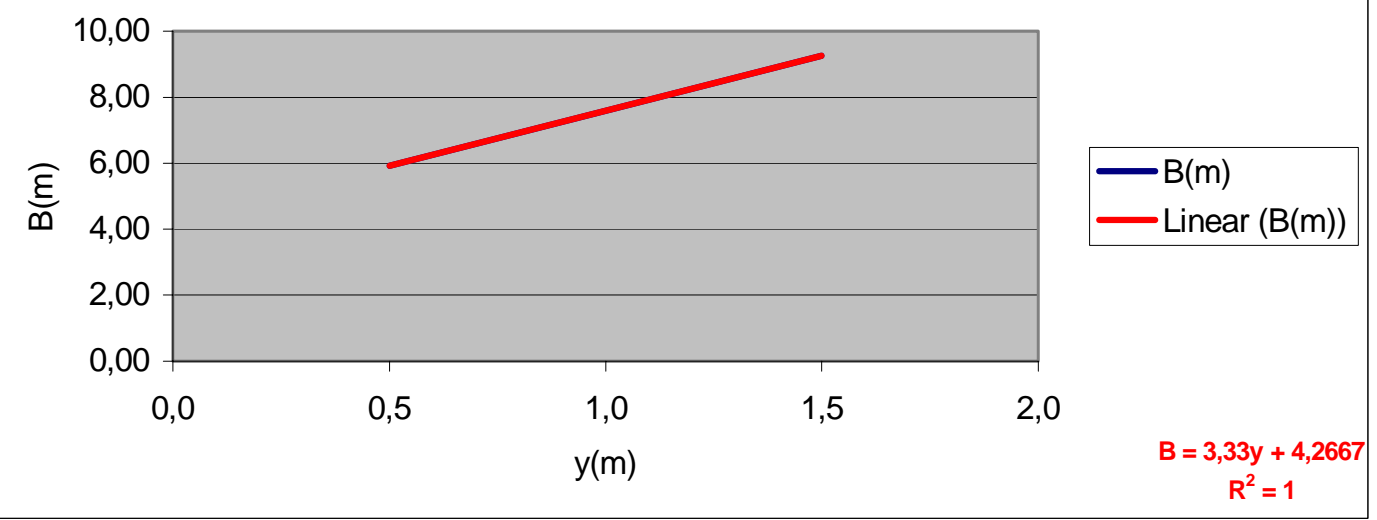




\section{SEÇÃO 82}

$\begin{array}{cccccccc}\text { no pares } & \mathbf{y}(\mathbf{m}) & \mathbf{p}(\mathbf{m}) & \mathbf{a}(\mathbf{m} 2) & \mathbf{B}(\mathbf{m}) & & \text { tipo da equação } & \text { correlação } \\ & 0,5 & 6,33 & 2,72 & 6,03 & \mathbf{p}(\mathbf{m}) & \text { linear } & 1,0000 \\ 3 & 1,0 & 8,16 & 6,12 & 7,57 & \mathbf{a}(\mathbf{m} 2) & \text { polinomial }\left(2^{\mathrm{a}} \text { ordem }\right) & 1,0000 \\ & 1,5 & 10,00 & 10,29 & 9,11 & \mathbf{B}(\mathbf{m}) & \text { linear } & 1,0000\end{array}$
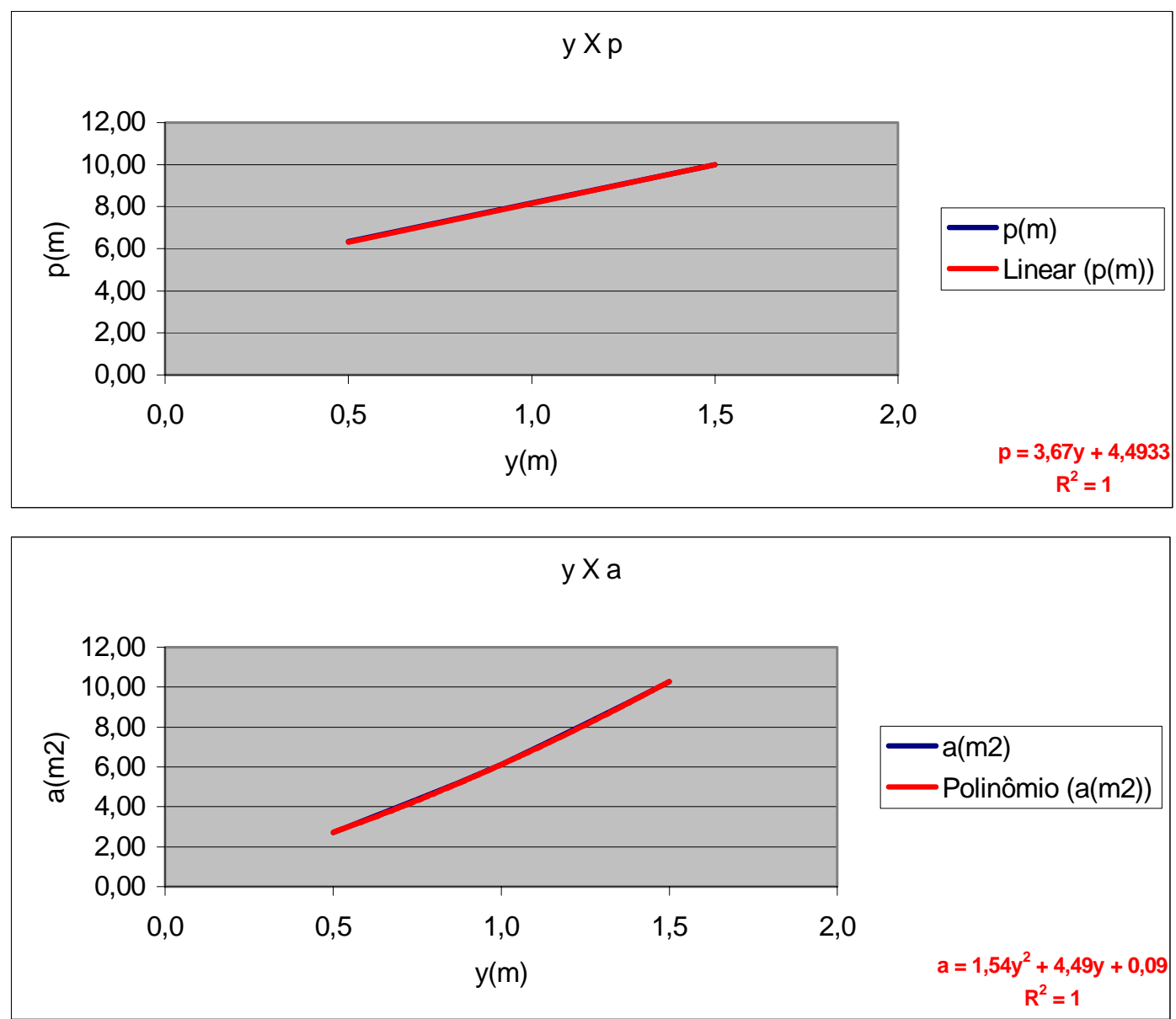

$y \times B$

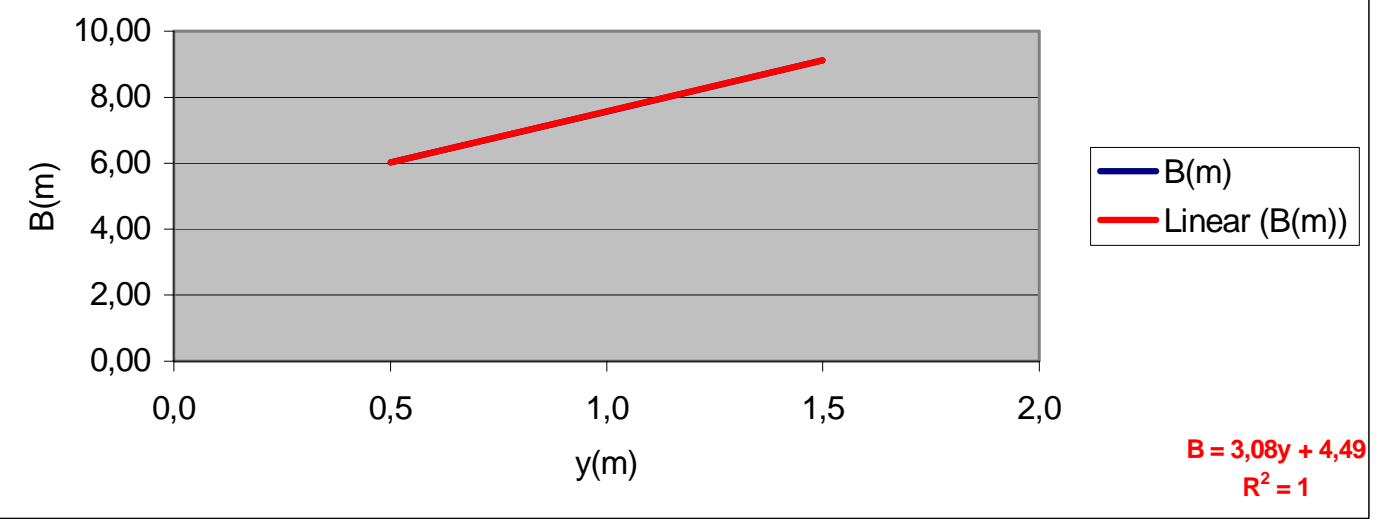




\section{SEÇÃO 83}

$\begin{array}{cccccccc}\text { no pares } & \mathbf{y}(\mathbf{m}) & \mathbf{p}(\mathbf{m}) & \mathbf{a}(\mathbf{m} \mathbf{2}) & \mathbf{B}(\mathbf{m}) & & \text { tipo da equação } & \text { correlação } \\ & 0,5 & 5,83 & 2,35 & 5,56 & \mathbf{p}(\mathbf{m}) & \text { linear } & 1,0000 \\ 3 & 1,0 & 7,69 & 5,52 & 7,12 & \mathbf{a}(\mathbf{m} 2) & \text { polinomial }\left(2^{a} \text { ordem) }\right. & 1,0000 \\ & 1,5 & 9,54 & 9,47 & 8,68 & \mathbf{B}(\mathbf{m}) & \text { linear } & 1,0000\end{array}$
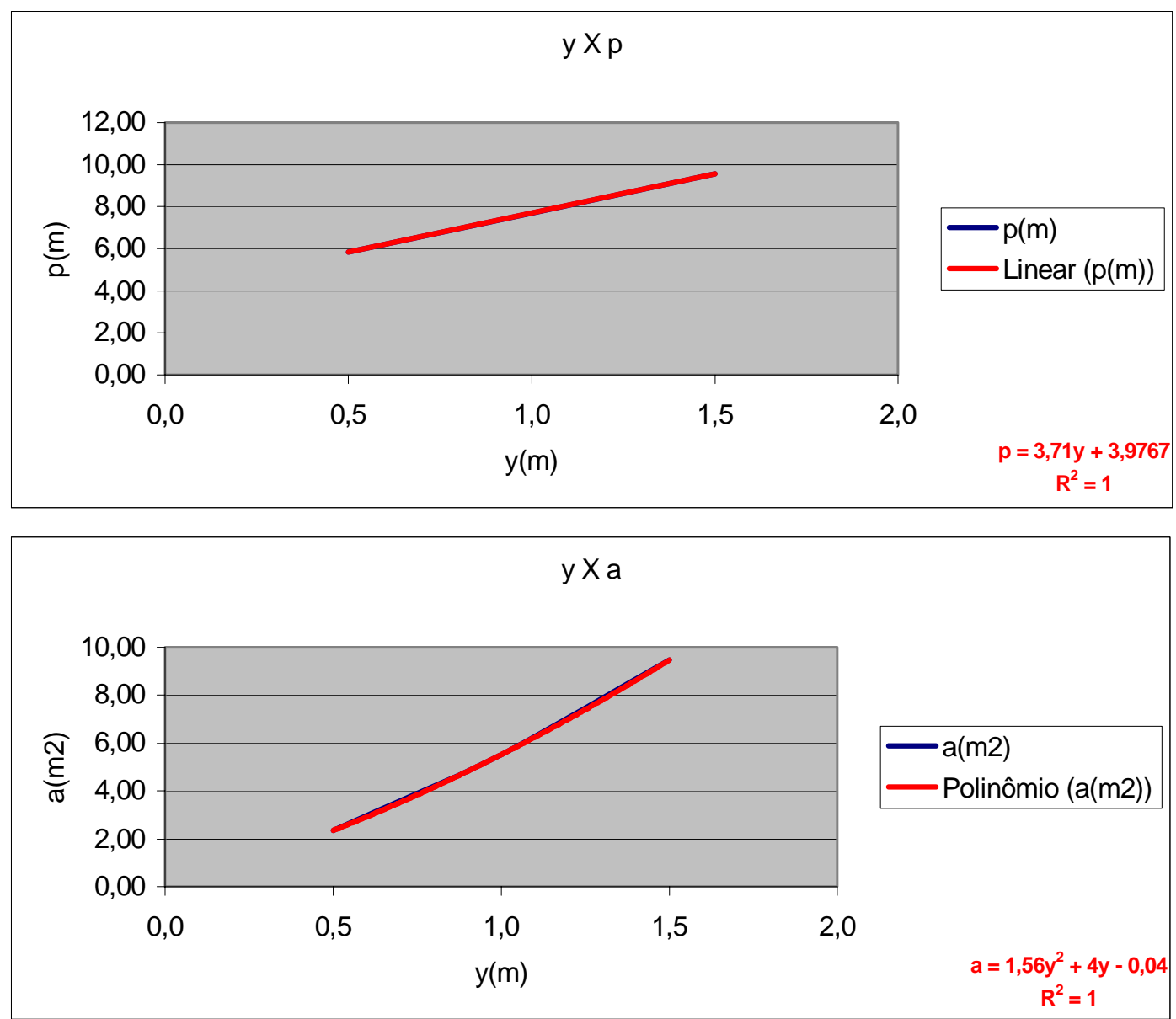

$y \times B$

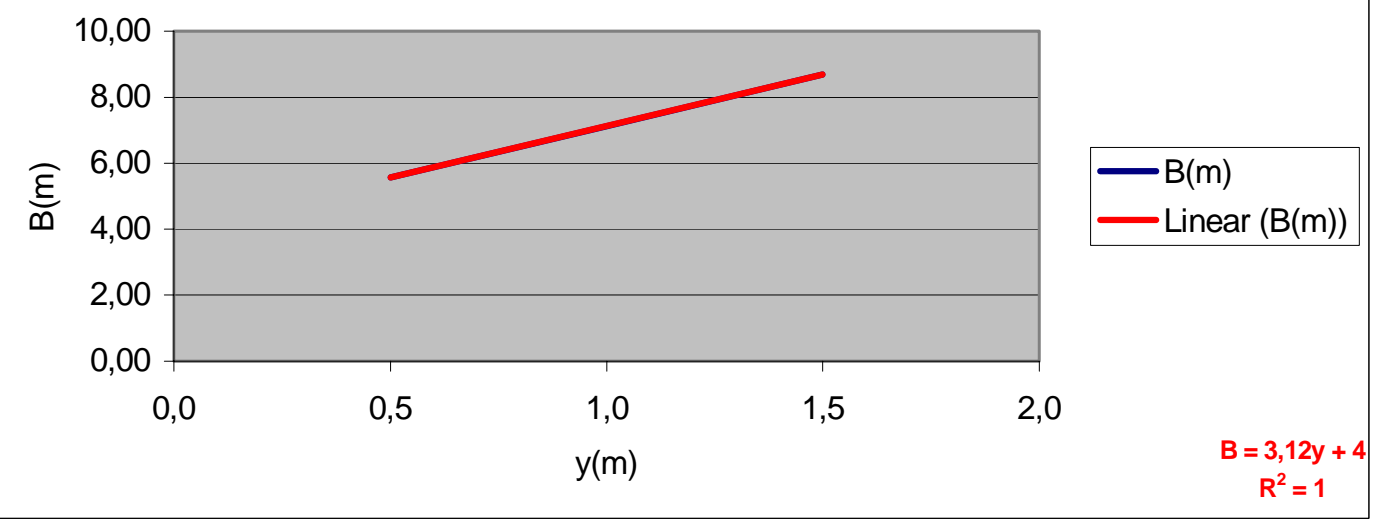


SEÇÃO 84

$\begin{array}{cccccccc}\mathbf{n} \text { o pares } & \mathbf{y}(\mathbf{m}) & \mathbf{p}(\mathbf{m}) & \mathbf{a}(\mathbf{m} 2) & \mathbf{B}(\mathbf{m}) & & \text { tipo da equação } & \text { correlação } \\ & 0,5 & 6,86 & 2,95 & 6,58 & \mathbf{p}(\mathbf{m}) & \text { linear } & 1,0000 \\ 3 & 1,0 & 8,75 & 6,64 & 8,18 & \mathbf{a}(\mathbf{m} 2) & \text { polinomial }\left(2^{\mathrm{a}} \text { ordem }\right) & 1,0000 \\ & 1,5 & 10,63 & 11,13 & 9,77 & \mathbf{B}(\mathbf{m}) & \text { linear } & 1,0000\end{array}$
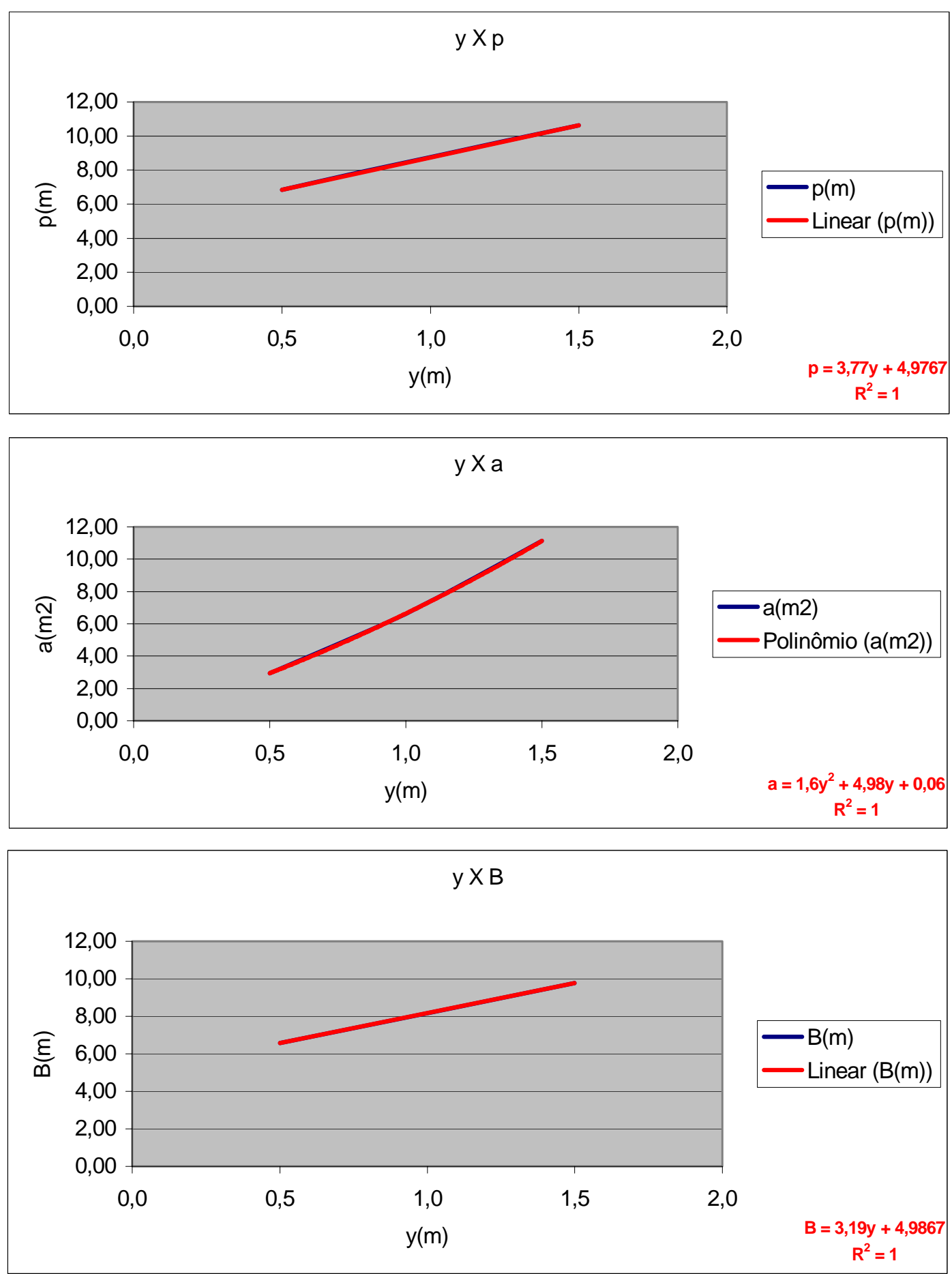


\section{SEÇÃO 85}

$\begin{array}{cccccccc}\text { no pares } & \mathbf{y}(\mathbf{m}) & \mathbf{p}(\mathbf{m}) & \mathbf{a}(\mathbf{m} 2) & \mathbf{B}(\mathbf{m}) & & \text { tipo da equação } & \text { correlação } \\ & 0,5 & 7,12 & 3,22 & 6,80 & \mathbf{p}(\mathbf{m}) & \text { linear } & 1,0000 \\ 3 & 1,0 & 8,89 & 6,99 & 8,26 & \mathbf{a}(\mathbf{m} 2) & \text { polinomial }\left(2^{\mathrm{a}} \text { ordem }\right) & 1,0000 \\ & 1,5 & 10,66 & 11,48 & 9,72 & \mathbf{B}(\mathbf{m}) & \text { linear } & 1,0000\end{array}$
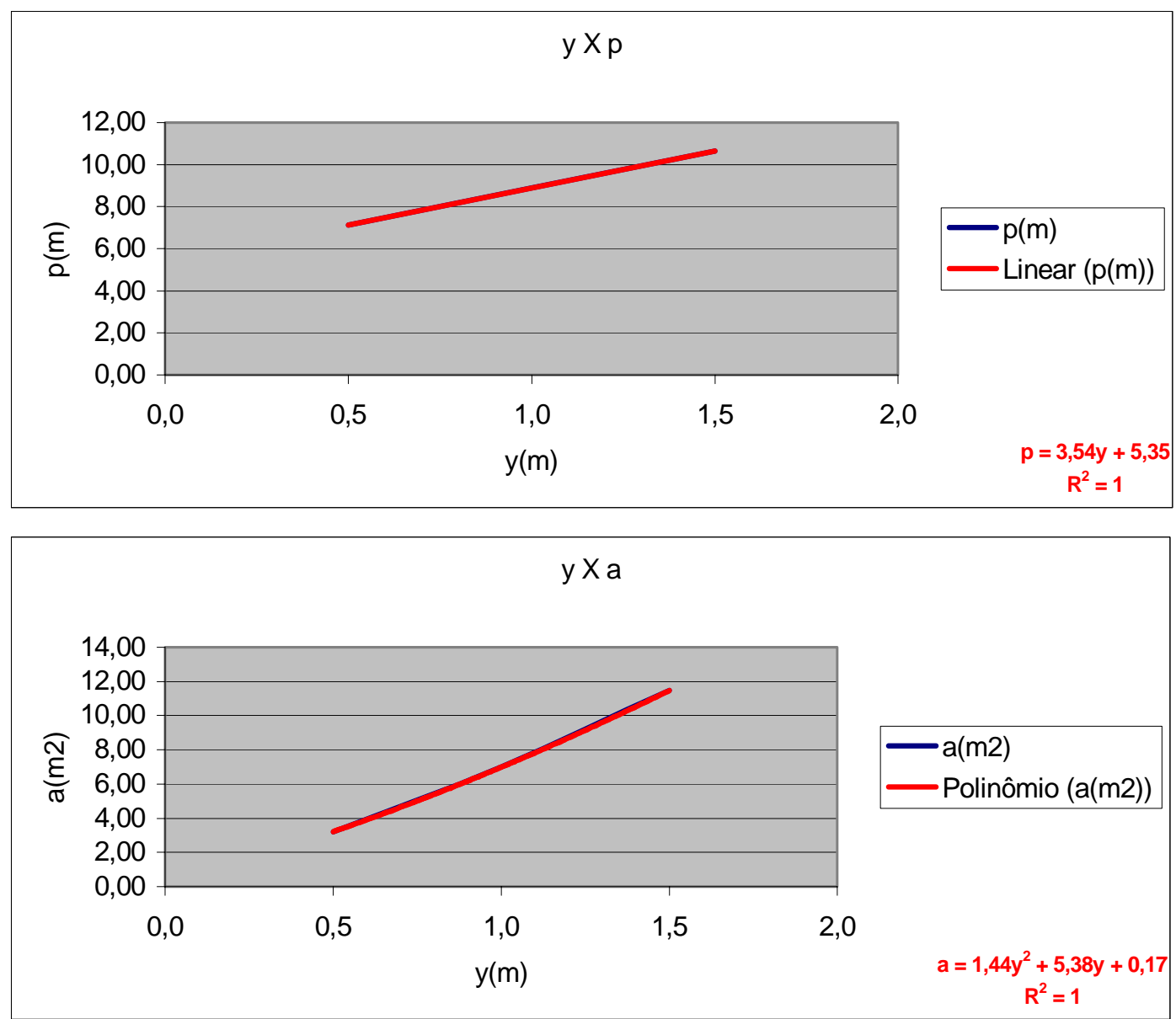

$y \times B$

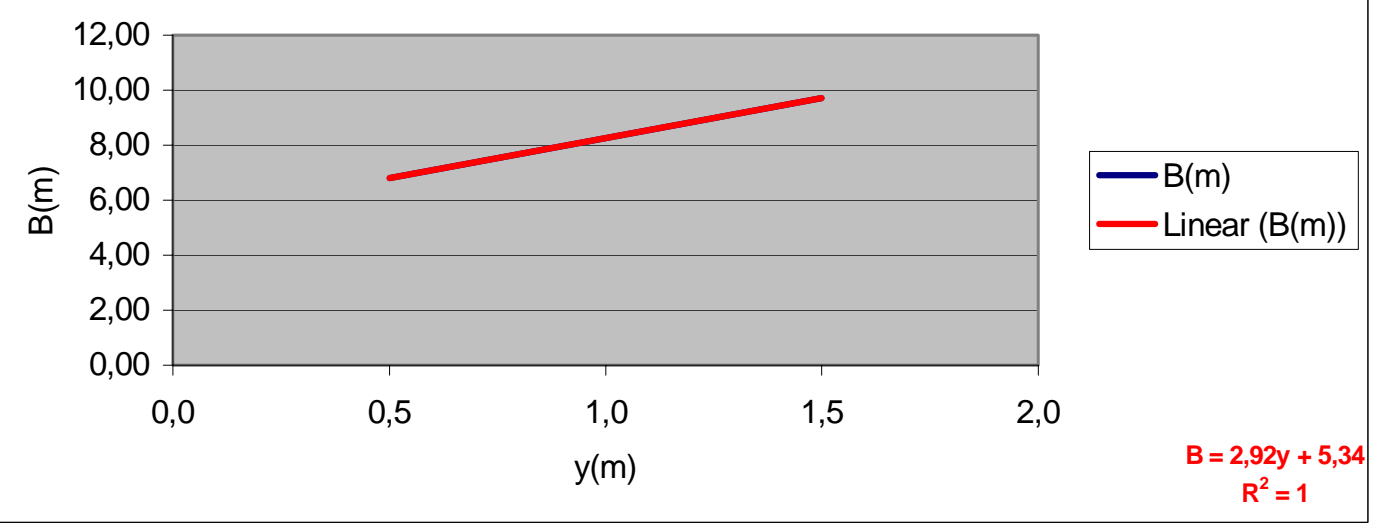




\section{SEÇÃO 86}

$\begin{array}{cccccccc}\text { no pares } & \mathbf{y}(\mathbf{m}) & \mathbf{p}(\mathbf{m}) & \mathbf{a}(\mathbf{m} \mathbf{2}) & \mathbf{B}(\mathbf{m}) & & \text { tipo da equação } & \text { correlação } \\ & 0,5 & 5,75 & 2,34 & 5,50 & \mathbf{p}(\mathbf{m}) & \text { linear } & 1,0000 \\ 3 & 1,0 & 7,95 & 5,58 & 7,45 & \mathbf{a}(\mathbf{m} 2) & \text { polinomial }\left(2^{a} \text { ordem) }\right. & 1,0000 \\ & 1,5 & 10,14 & 9,80 & 9,40 & \mathbf{B}(\mathbf{m}) & \text { linear } & 1,0000\end{array}$
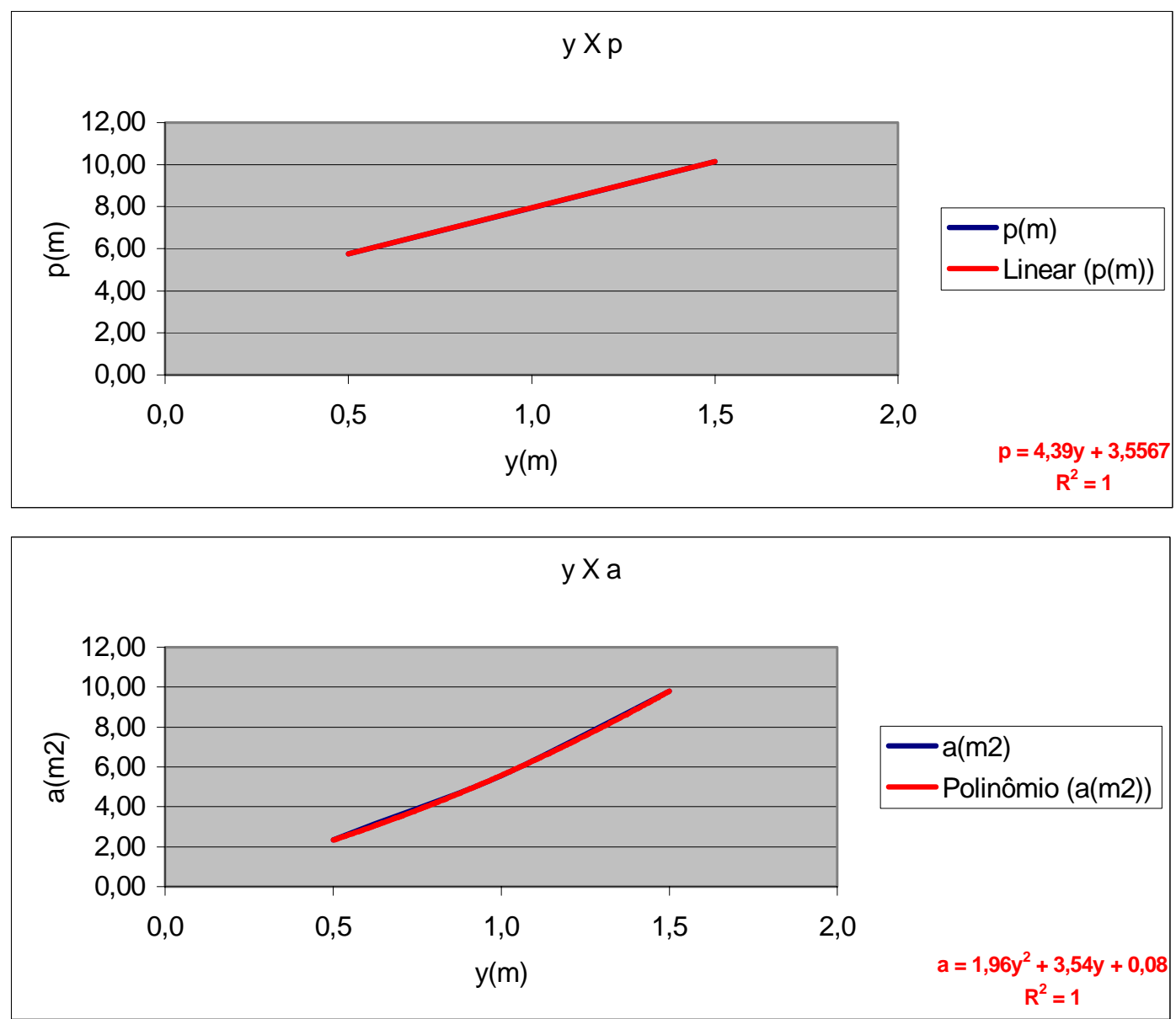

$y \times B$

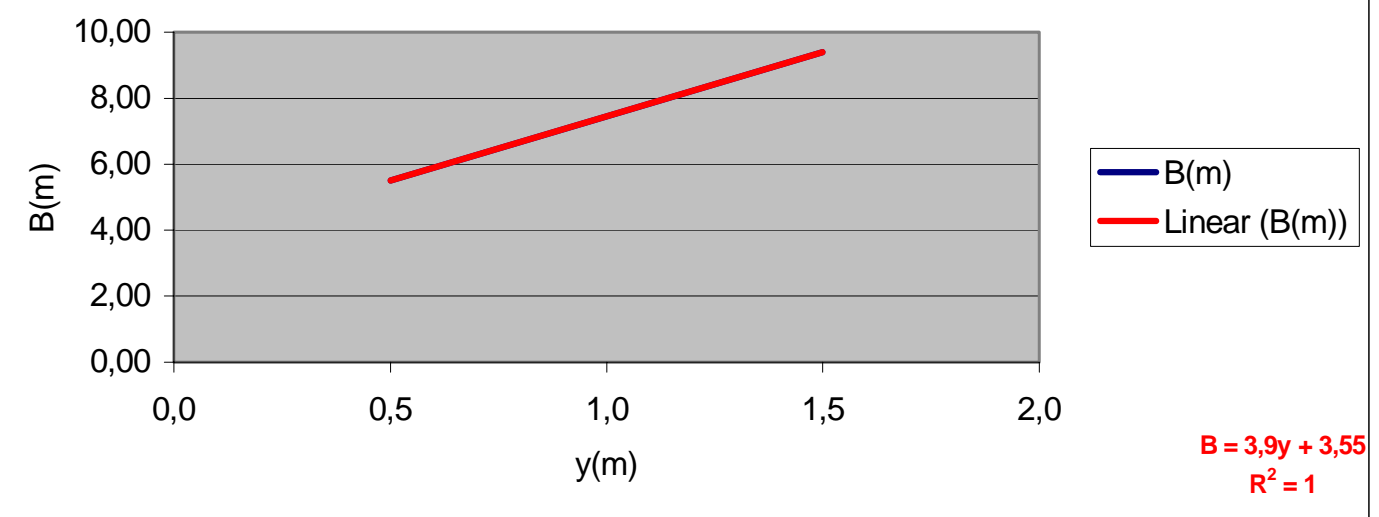


SEÇÃO 87

$\begin{array}{cccccccc}\text { no pares } & \mathbf{y}(\mathbf{m}) & \mathbf{p}(\mathbf{m}) & \mathbf{a}(\mathbf{m} 2) & \mathbf{B}(\mathbf{m}) & & \text { tipo da equação } & \text { correlação } \\ & 0,5 & 6,24 & 2,56 & 5,97 & \mathbf{p}(\mathbf{m}) & \text { linear } & 1,0000 \\ 3 & 1,0 & 8,13 & 5,95 & 7,57 & \mathbf{a}(\mathbf{m} 2) & \text { polinomial }\left(2^{a} \text { ordem }\right) & 1,0000 \\ & 1,5 & 10,02 & 10,14 & 9,18 & \mathbf{B}(\mathbf{m}) & \text { linear } & 1,0000\end{array}$
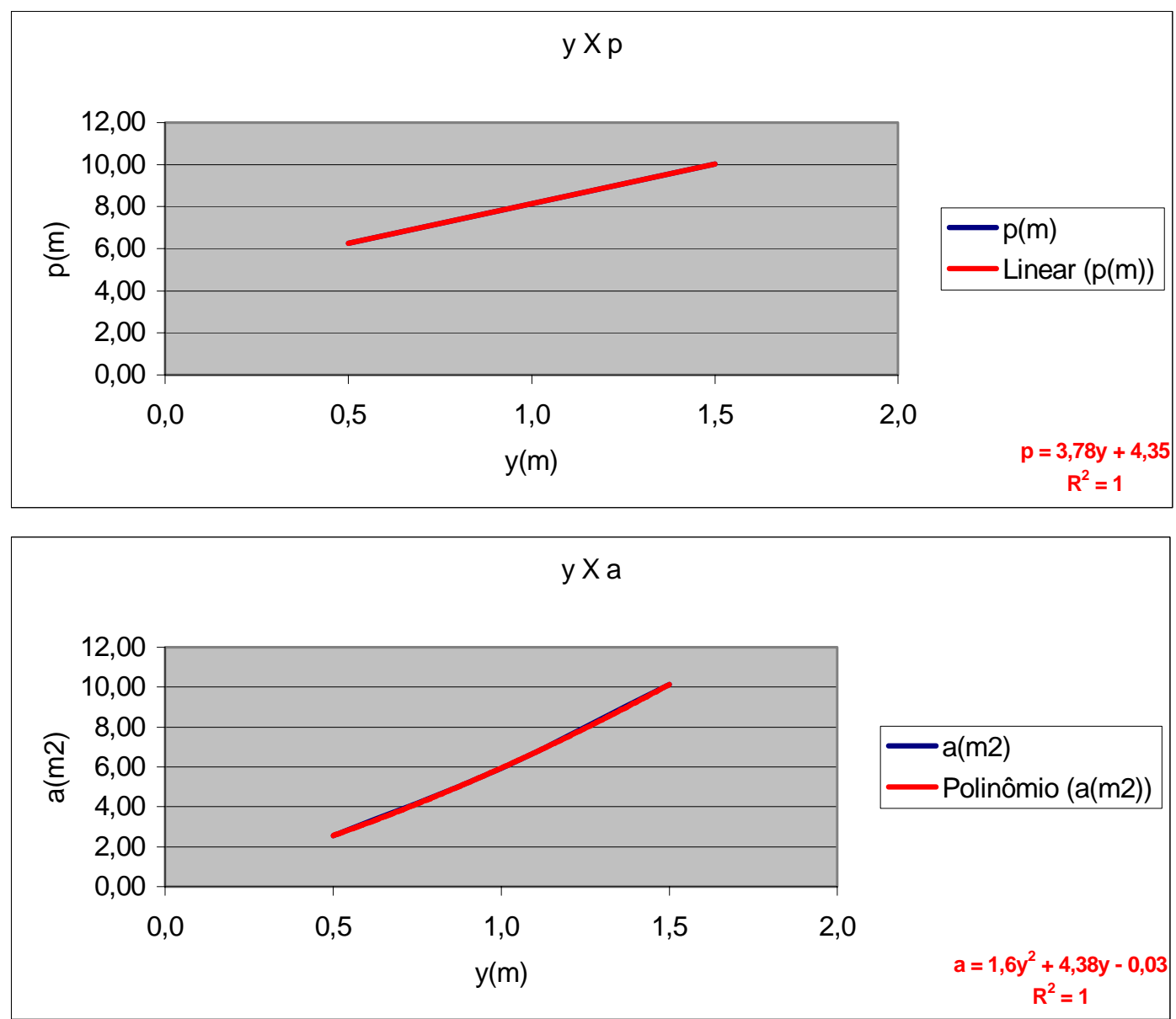

$y \times B$

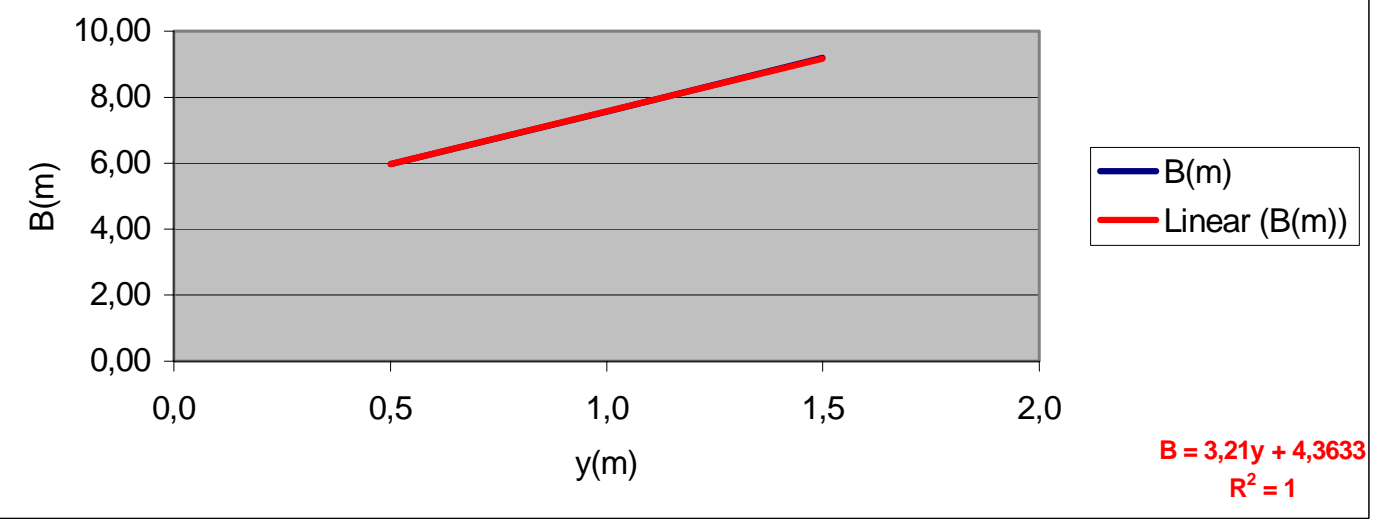


SEÇÕES 88 e 89

$\begin{array}{cccccccc}\text { no pares } & \mathbf{y}(\mathbf{m}) & \mathbf{p}(\mathbf{m}) & \mathbf{a}(\mathbf{m} \mathbf{2}) & \mathbf{B}(\mathbf{m}) & & \text { tipo da equação } & \text { correlação } \\ & 0,5 & 6,60 & 3,03 & 6,32 & \mathbf{p}(\mathbf{m}) & \text { linear } & 1,0000 \\ 3 & 1,0 & 8,35 & 6,55 & 7,76 & \mathbf{a}(\mathbf{m} 2) & \text { polinomial }\left(2^{a} \text { ordem) }\right. & 1,0000 \\ & 1,5 & 10,11 & 10,79 & 9,20 & \mathbf{B}(\mathbf{m}) & \text { linear } & 1,0000\end{array}$
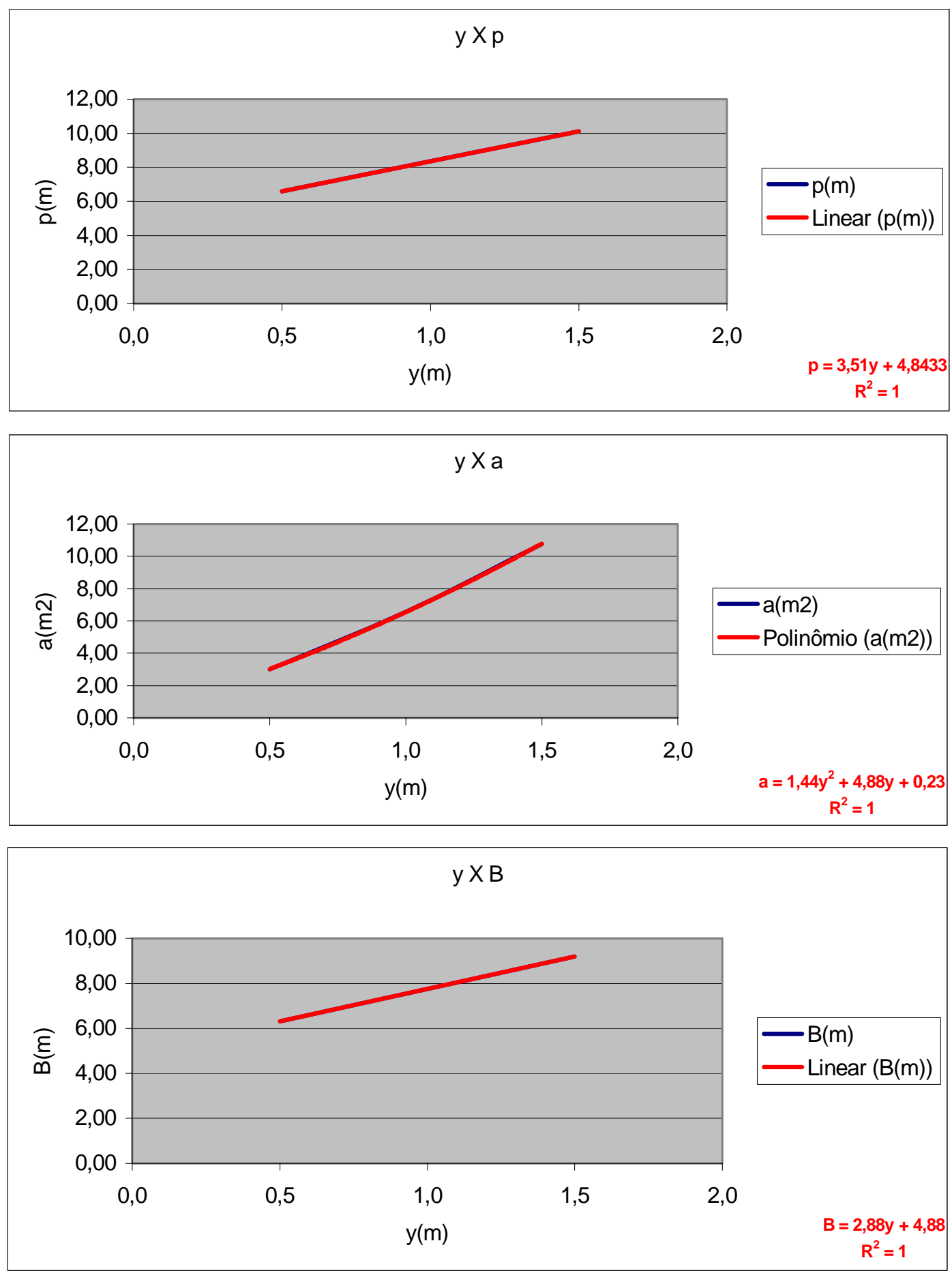


\section{SEÇÕES 90, 91, 92, 93, 94 e 95}

$\begin{array}{cccccccc}\text { no pares } & \mathbf{y}(\mathbf{m}) & \mathbf{p}(\mathbf{m}) & \mathbf{a}(\mathbf{m} 2) & \mathbf{B}(\mathbf{m}) & & \text { tipo da equação } & \text { correlação } \\ & 0,5 & 6,77 & 2,91 & 6,48 & \mathbf{p}(\mathbf{m}) & \text { linear } & 1,0000 \\ 3 & 1,0 & 8,72 & 6,57 & 8,16 & \mathbf{a}(\mathbf{m} 2) & \text { polinomial }\left(2^{\mathrm{a}} \text { ordem }\right) & 1,0000 \\ & 1,5 & 10,67 & 11,07 & 9,84 & \mathbf{B}(\mathbf{m}) & \text { linear } & 1,0000\end{array}$
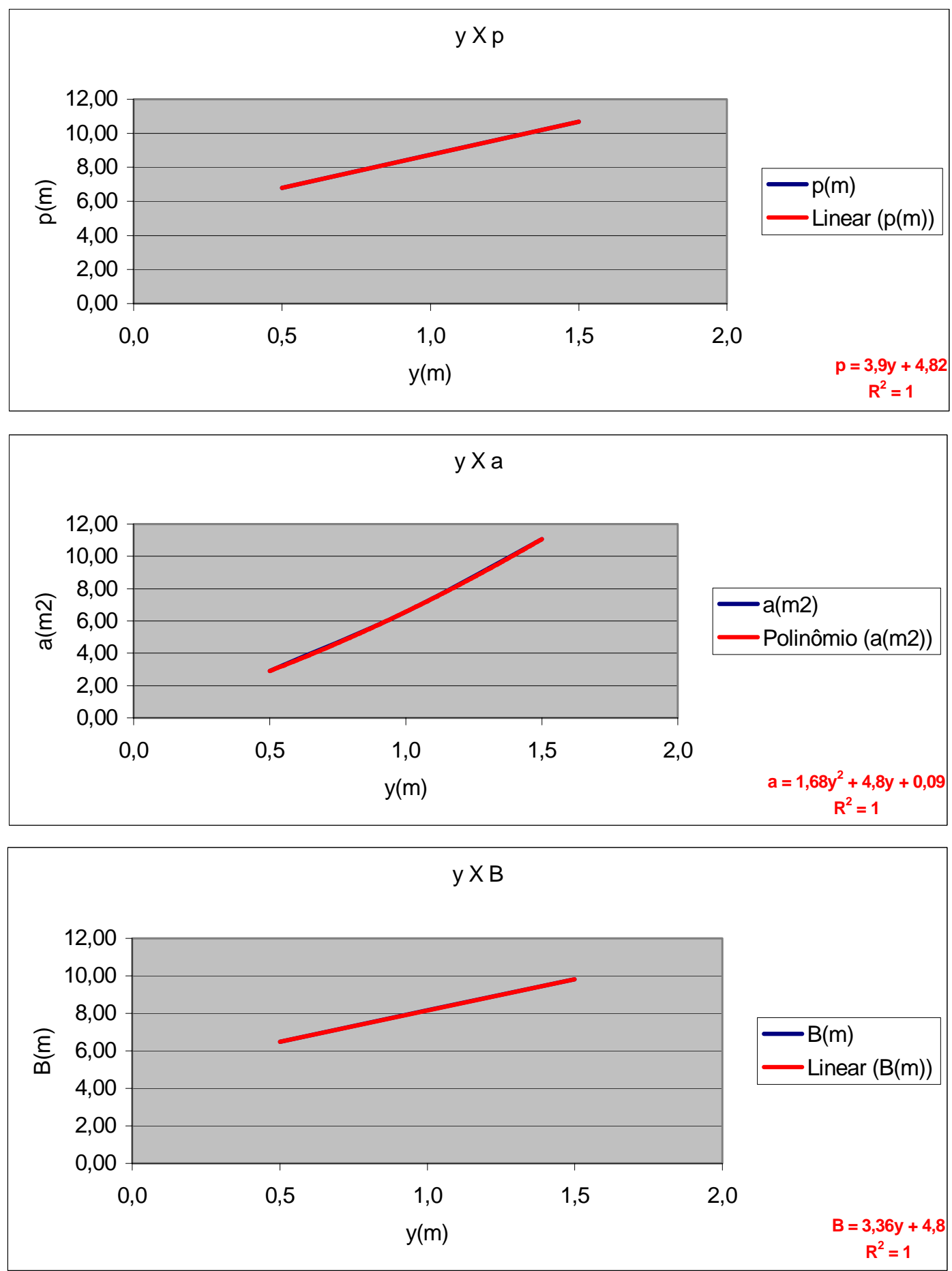


\section{SEÇÕES 96, 97 e 98}

$\begin{array}{cccccccc}\text { no pares } & \mathbf{y}(\mathbf{m}) & \mathbf{p}(\mathbf{m}) & \mathbf{a}(\mathbf{m} 2) & \mathbf{B}(\mathbf{m}) & & \text { tipo da equação } & \text { correlação } \\ & 0,5 & 6,65 & 2,82 & 6,36 & \mathbf{p}(\mathbf{m}) & \text { linear } & 1,0000 \\ 3 & 1,0 & 8,51 & 6,40 & 7,93 & \mathbf{a}(\mathbf{m} 2) & \text { polinomial }\left(2^{\mathrm{a}} \text { ordem }\right) & 1,0000 \\ & 1,5 & 10,37 & 10,76 & 9,50 & \mathbf{B}(\mathbf{m}) & \text { linear } & 1,0000\end{array}$
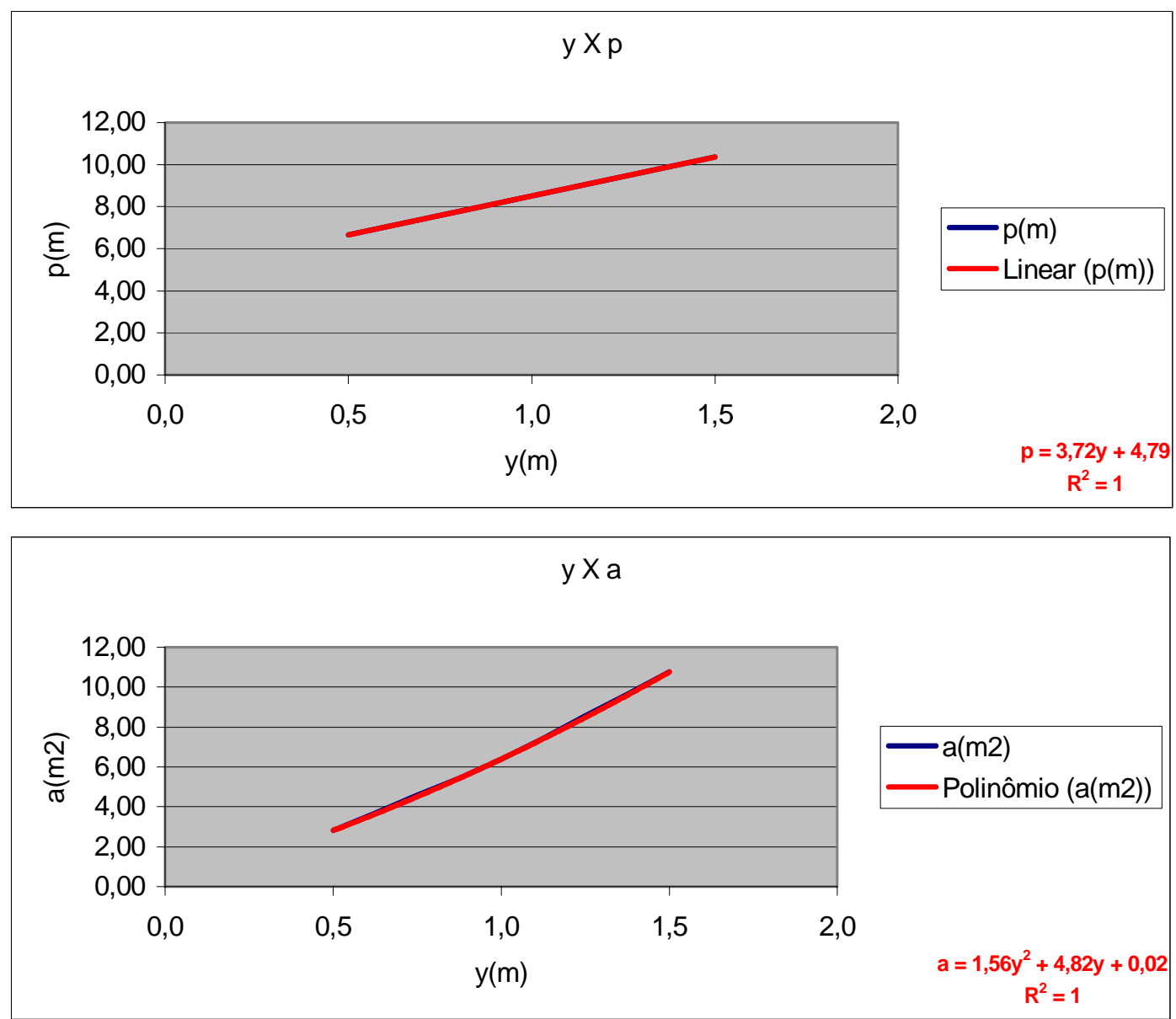

$y \times B$

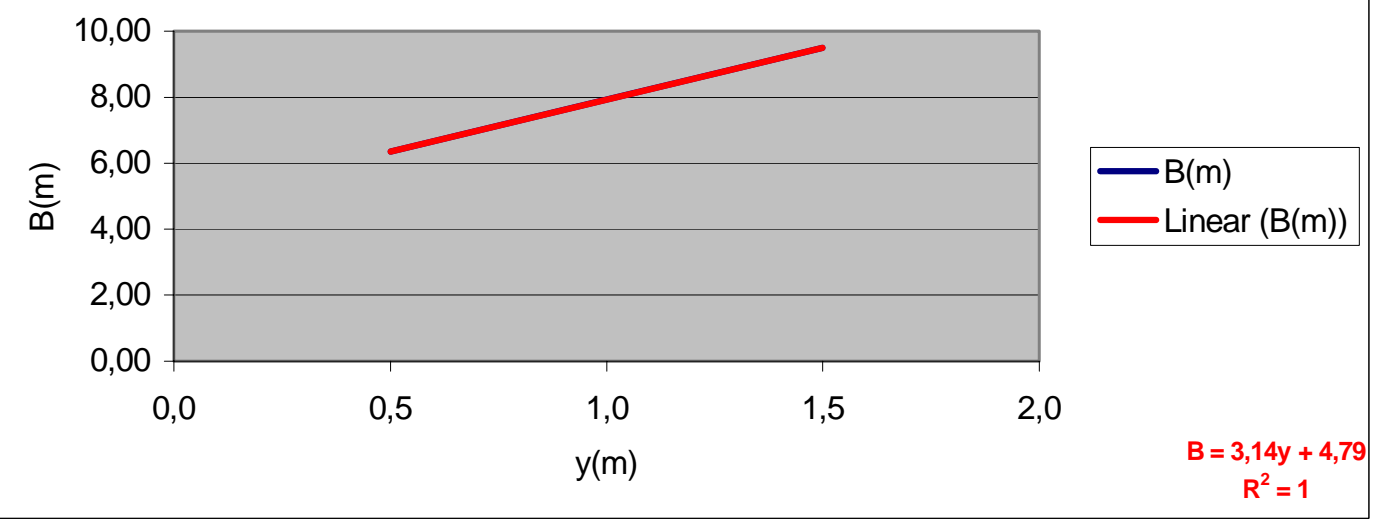




\section{SEÇÕES 99 e 100}

$\begin{array}{cccccccc}\text { no pares } & \mathbf{y}(\mathbf{m}) & \mathbf{p}(\mathbf{m}) & \mathbf{a}(\mathbf{m} 2) & \mathbf{B}(\mathbf{m}) & & \text { tipo da equação } & \text { correlação } \\ & 0,5 & 6,97 & 2,96 & 6,66 & \mathbf{p}(\mathbf{m}) & \text { linear } & 1,0000 \\ 3 & 1,0 & 8,77 & 6,67 & 8,16 & \mathbf{a}(\mathbf{m} 2) & \text { polinomial }\left(2^{a} \text { ordem) }\right. & 1,0000 \\ & 1,5 & 10,58 & 11,12 & 9,67 & \mathbf{B}(\mathbf{m}) & \text { linear } & 1,0000\end{array}$
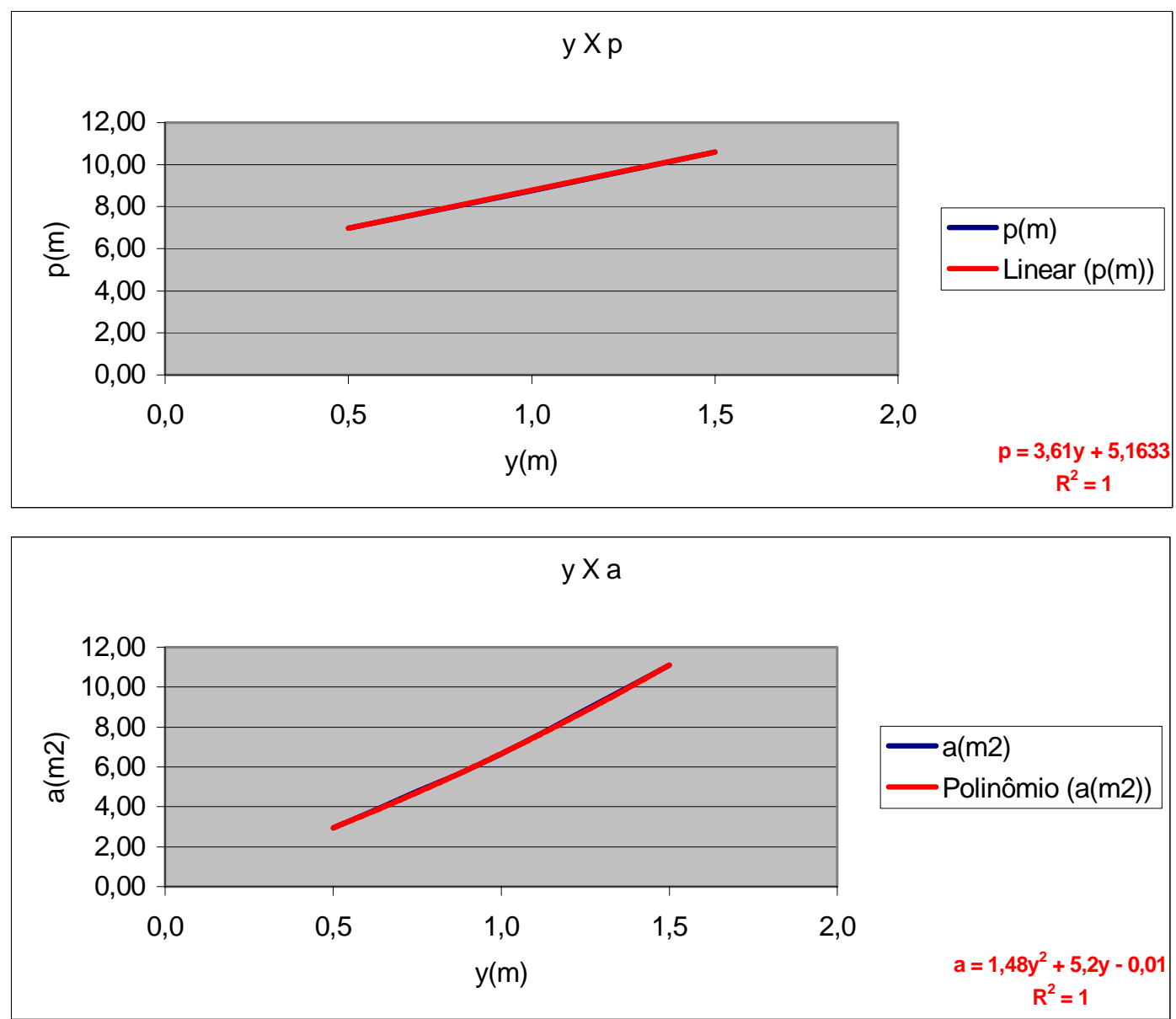

$y \times B$

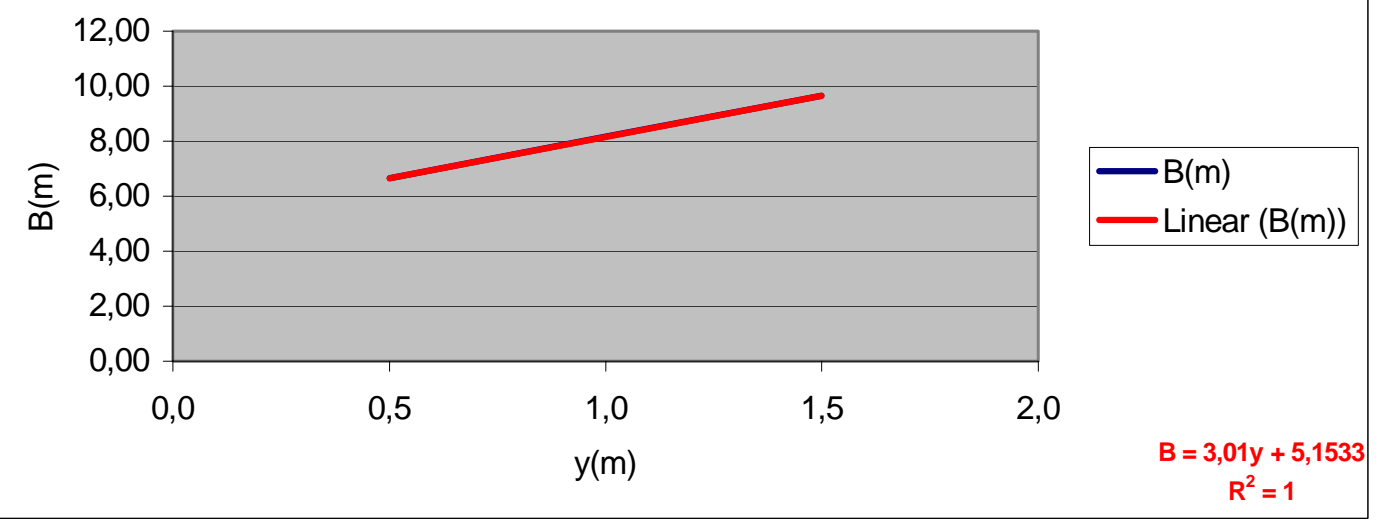




\section{SEÇÃO 101}

$\begin{array}{cccccccc}\text { no pares } & \mathbf{y}(\mathbf{m}) & \mathbf{p}(\mathbf{m}) & \mathbf{a}(\mathbf{m} 2) & \mathbf{B}(\mathbf{m}) & & \text { tipo da equação } & \text { correlação } \\ & 0,5 & 6,51 & 2,79 & 6,25 & \mathbf{p}(\mathbf{m}) & \text { linear } & 1,0000 \\ 3 & 1,0 & 8,45 & 6,33 & 7,92 & \mathbf{a}(\mathbf{m} 2) & \text { polinomial }\left(2^{\mathrm{a}} \text { ordem }\right) & 1,0000 \\ & 1,5 & 10,37 & 10,70 & 9,56 & \mathbf{B}(\mathbf{m}) & \text { linear } & 1,0000\end{array}$
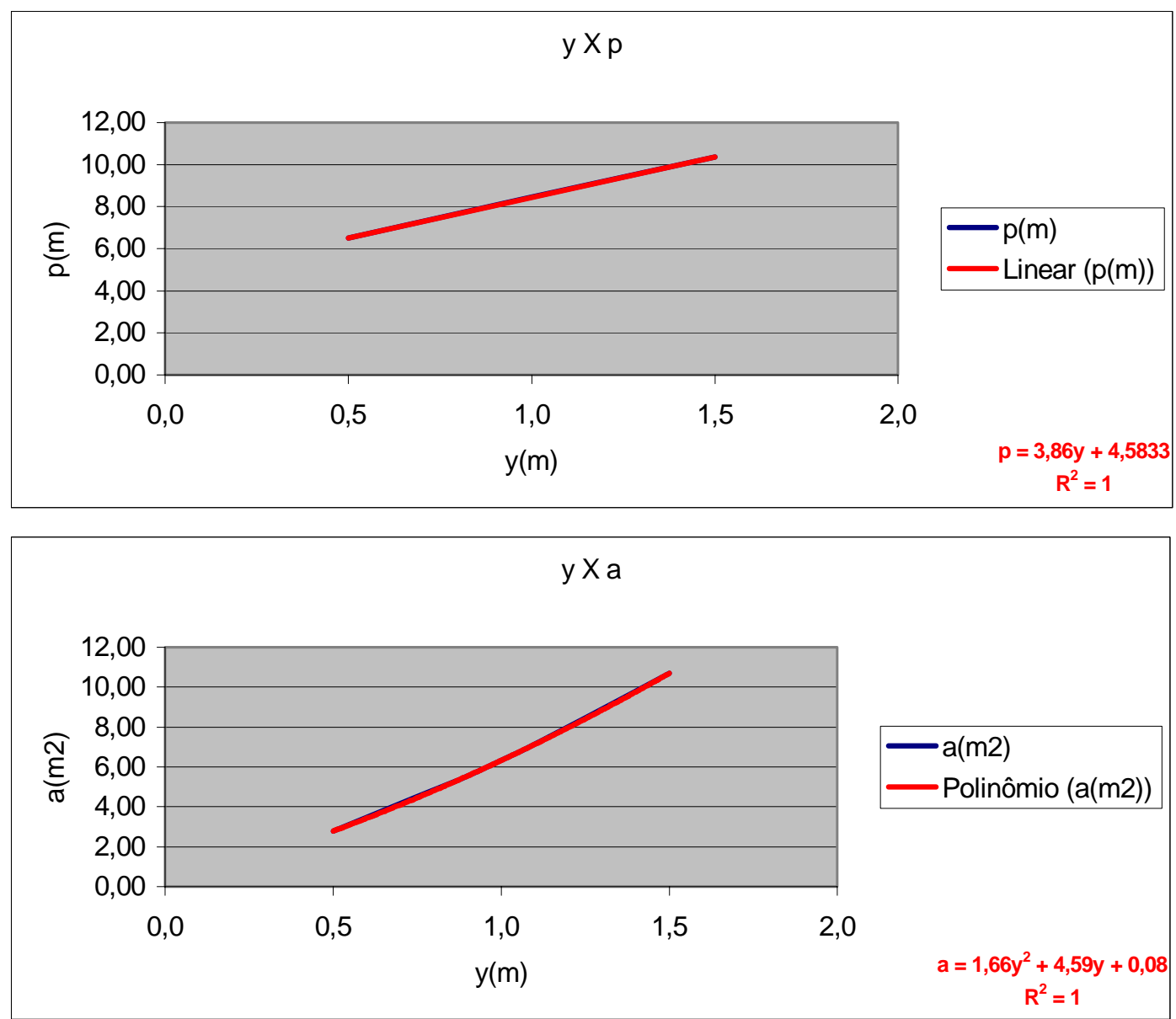

$y \times B$

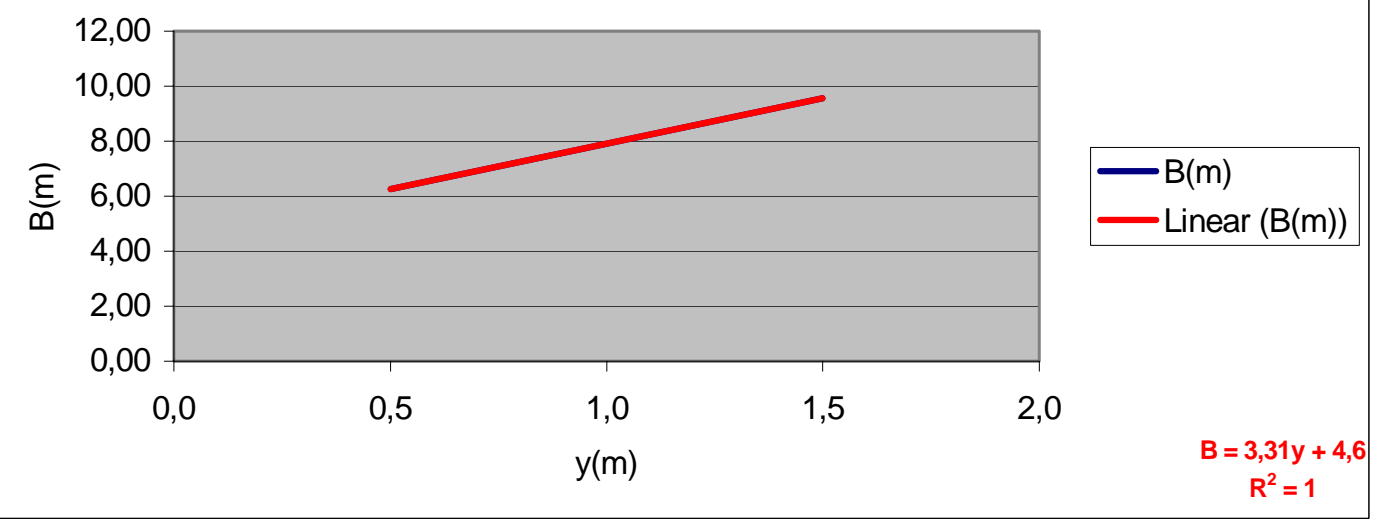




\section{SEÇÃO 102}

$\begin{array}{cccccccc}\text { no pares } & \mathbf{y}(\mathbf{m}) & \mathbf{p}(\mathbf{m}) & \mathbf{a}(\mathbf{m} 2) & \mathbf{B}(\mathbf{m}) & & \text { tipo da equação } & \text { correlação } \\ & 0,5 & 6,66 & 2,98 & 6,36 & \mathbf{p}(\mathbf{m}) & \text { linear } & 1,0000 \\ 3 & 1,0 & 8,50 & 6,54 & 7,91 & \mathbf{a}(\mathbf{m} 2) & \text { polinomial }\left(2^{a} \text { ordem }\right) & 1,0000 \\ & 1,5 & 10,35 & 10,89 & 9,47 & \mathbf{B}(\mathbf{m}) & \text { linear } & 1,0000\end{array}$
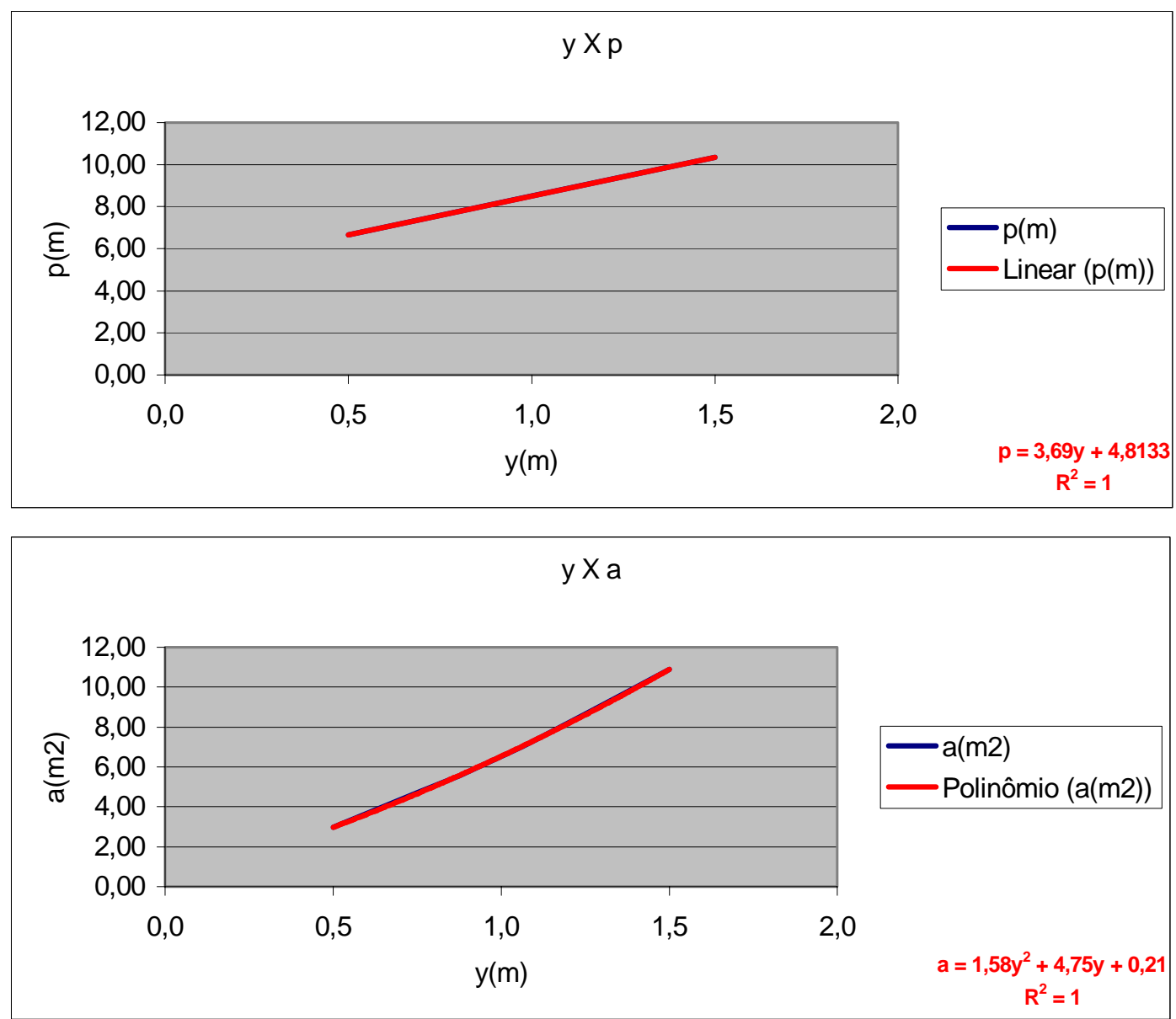

$y \times B$

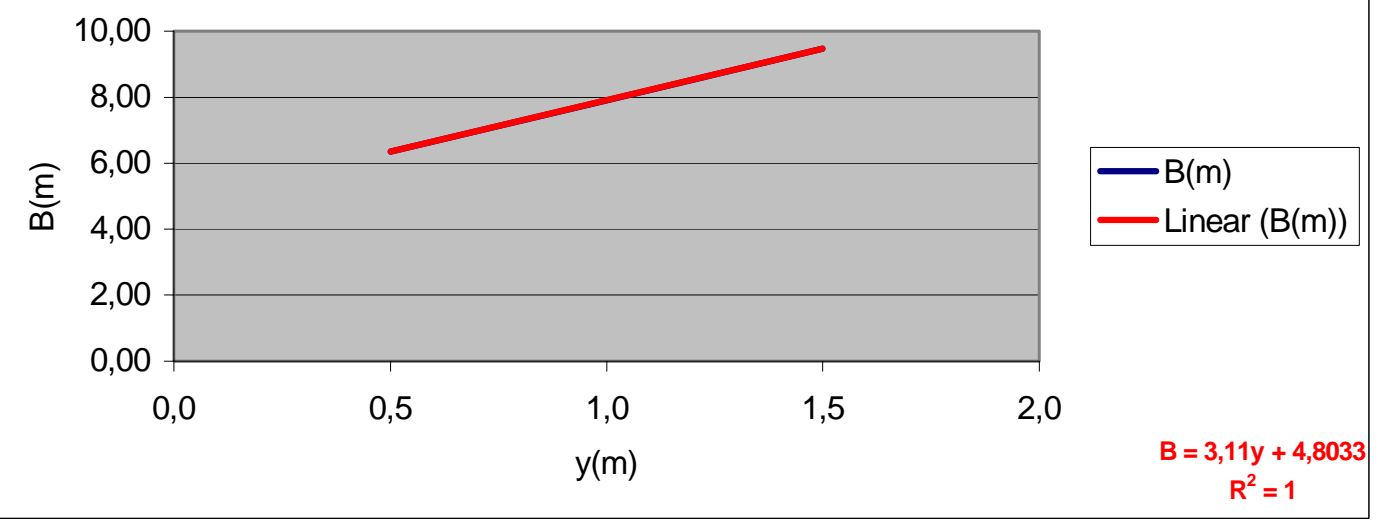




\section{SEÇÃO 103}

$\begin{array}{cccccccc}\text { no pares } & \mathbf{y}(\mathbf{m}) & \mathbf{p}(\mathbf{m}) & \mathbf{a}(\mathbf{m} \mathbf{2}) & \mathbf{B}(\mathbf{m}) & & \text { tipo da equação } & \text { correlação } \\ & 0,5 & 5,30 & 2,13 & 5,00 & \mathbf{p}(\mathbf{m}) & \text { linear } & 1,0000 \\ 3 & 1,0 & 7,00 & 4,97 & 6,36 & \mathbf{a}(\mathbf{m} 2) & \text { polinomial }\left(2^{a} \text { ordem) }\right. & 1,0000 \\ & 1,5 & 8,70 & 8,50 & 7,74 & \mathbf{B}(\mathbf{m}) & \text { linear } & 1,0000\end{array}$
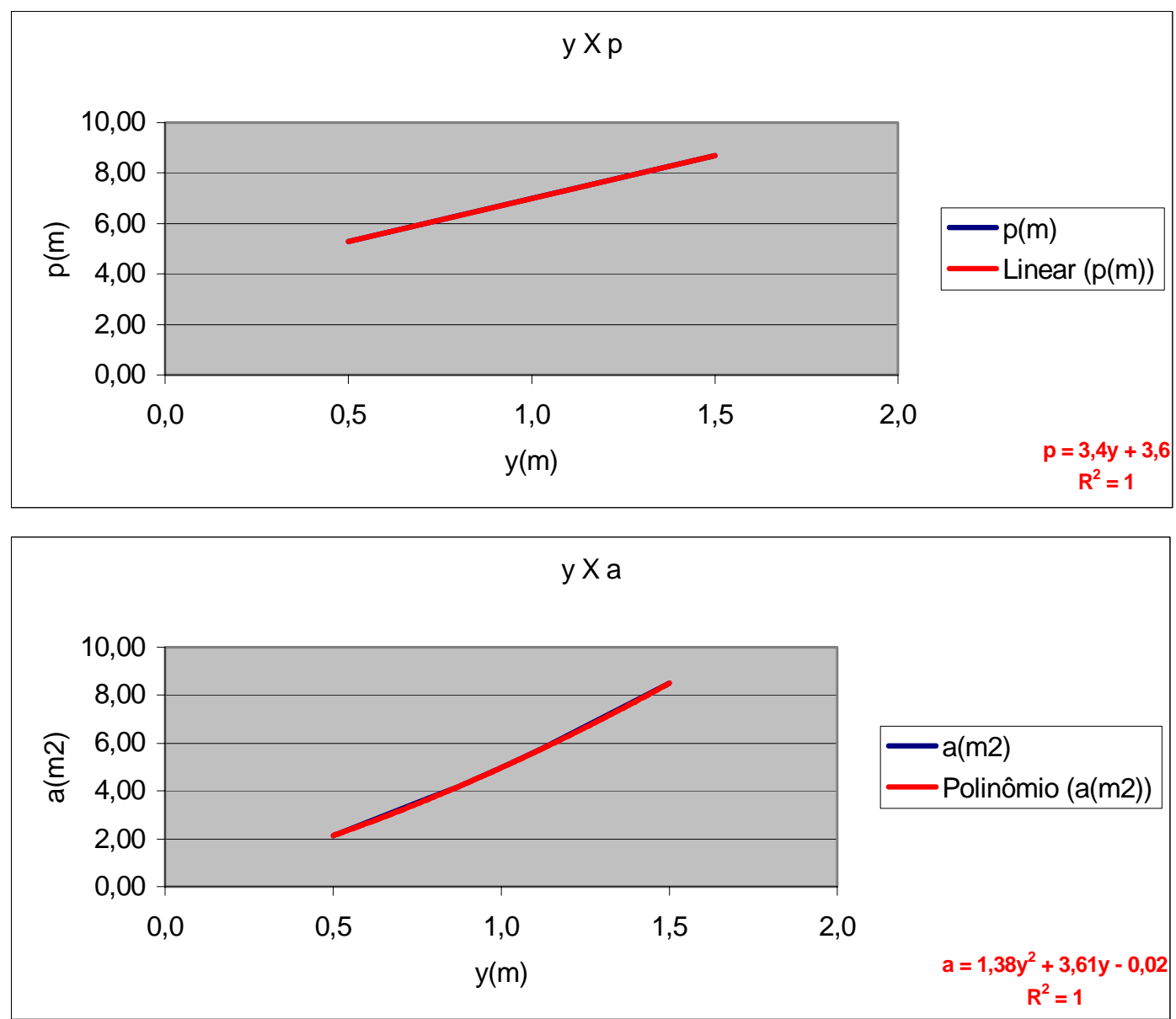

$y \times B$

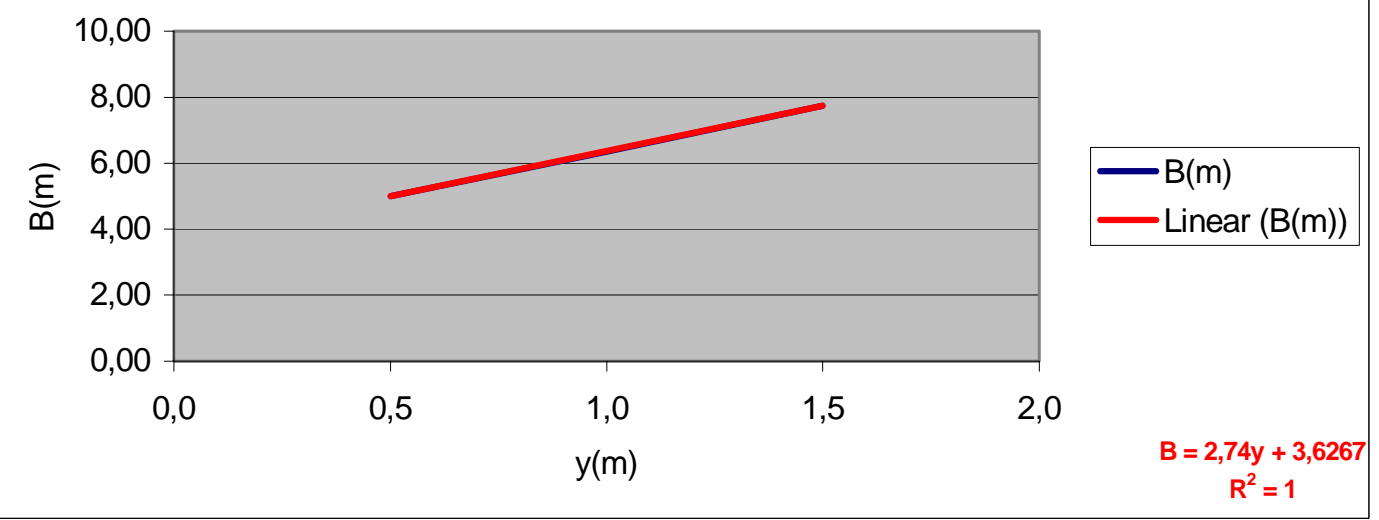




\section{SEÇÃO 104}

$\begin{array}{cccccccc}\text { no pares } & \mathbf{y}(\mathbf{m}) & \mathbf{p}(\mathbf{m}) & \mathbf{a}(\mathbf{m} \mathbf{2}) & \mathbf{B}(\mathbf{m}) & & \text { tipo da equação } & \text { correlação } \\ & 0,5 & 6,09 & 2,49 & 5,79 & \mathbf{p}(\mathbf{m}) & \text { linear } & 1,0000 \\ 3 & 1,0 & 7,82 & 5,74 & 7,20 & \mathbf{a}(\mathbf{m} 2) & \text { polinomial }\left(2^{a} \text { ordem) }\right. & 1,0000 \\ & 1,5 & 9,56 & 9,70 & 8,63 & \mathbf{B}(\mathbf{m}) & \text { linear } & 1,0000\end{array}$
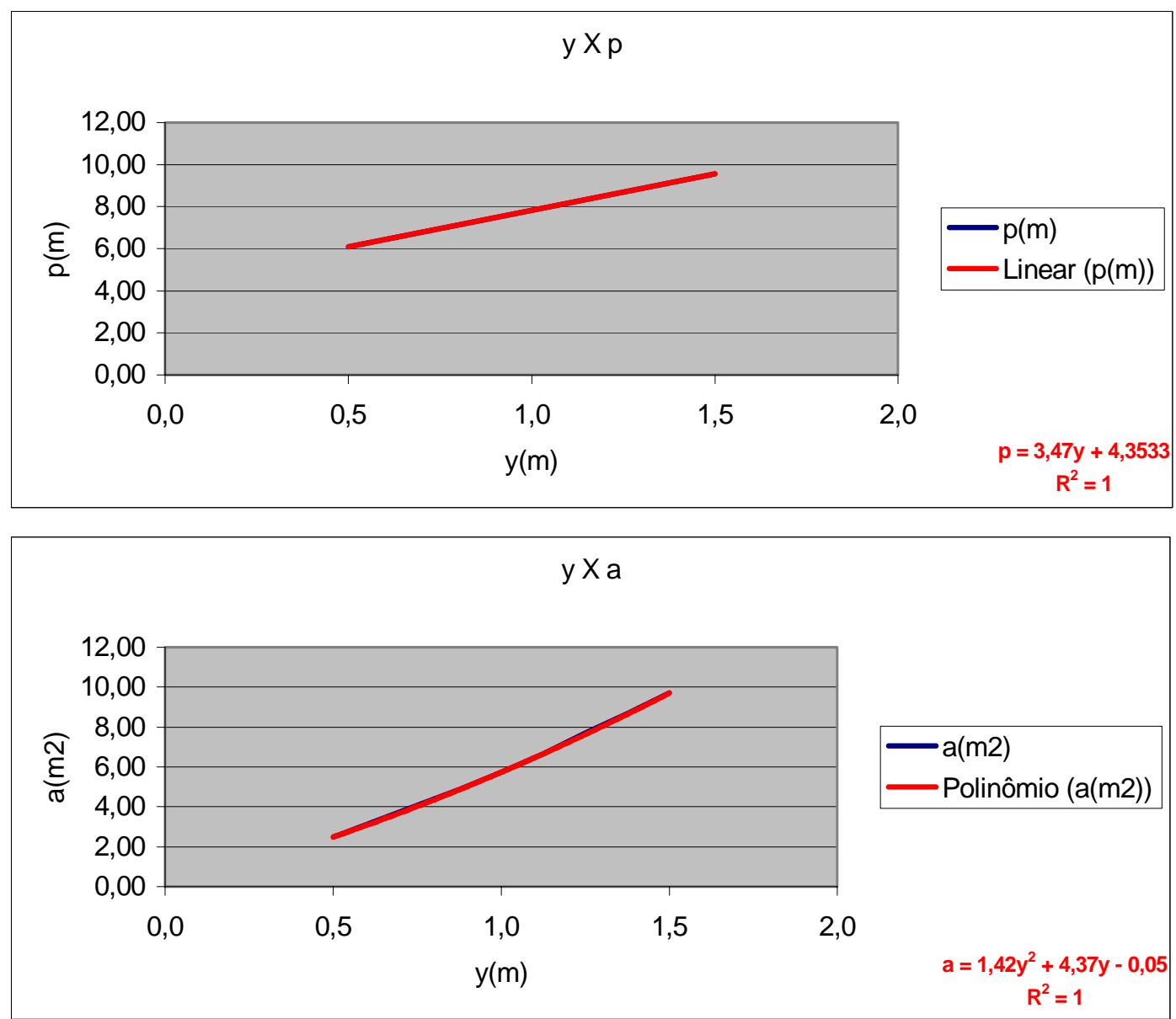

$y \times B$

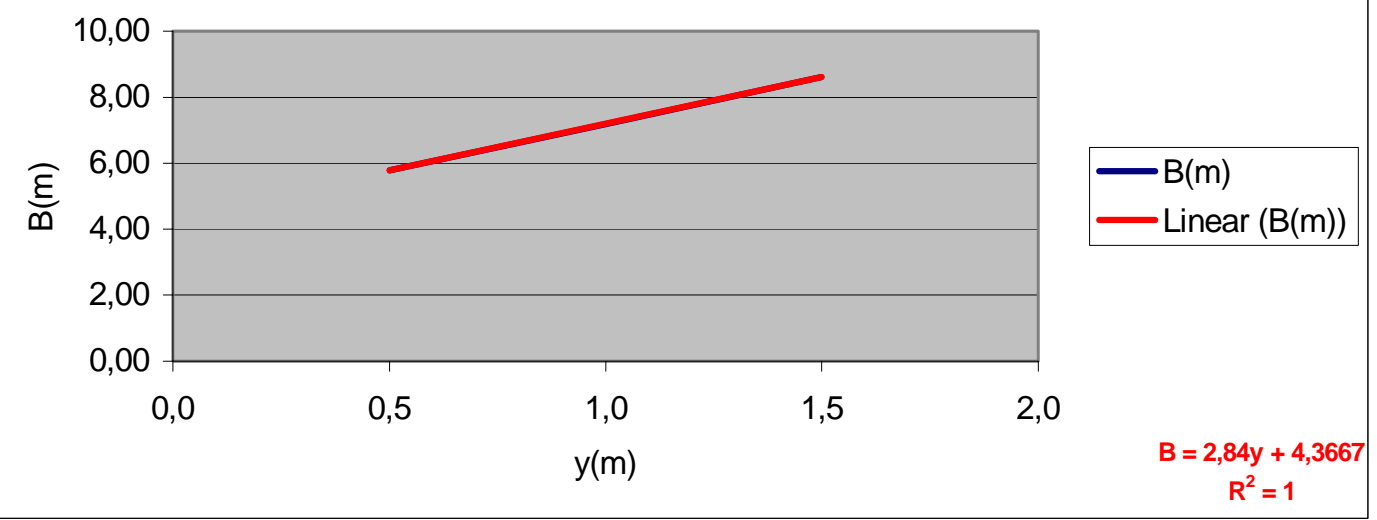




\section{SEÇÃO 105}

$\begin{array}{cccccccc}\text { no pares } & \mathbf{y}(\mathbf{m}) & \mathbf{p}(\mathbf{m}) & \mathbf{a}(\mathbf{m} 2) & \mathbf{B}(\mathbf{m}) & & \text { tipo da equação } & \text { correlação } \\ & 0,5 & 6,04 & 2,55 & 5,74 & \mathbf{p}(\mathbf{m}) & \text { linear } & 1,0000 \\ 3 & 1,0 & 7,88 & 5,81 & 7,28 & \mathbf{a}(\mathbf{m} 2) & \text { polinomial }\left(2^{\mathrm{a}} \text { ordem }\right) & 1,0000 \\ & 1,5 & 9,72 & 9,83 & 8,83 & \mathbf{B}(\mathbf{m}) & \text { linear } & 1,0000\end{array}$
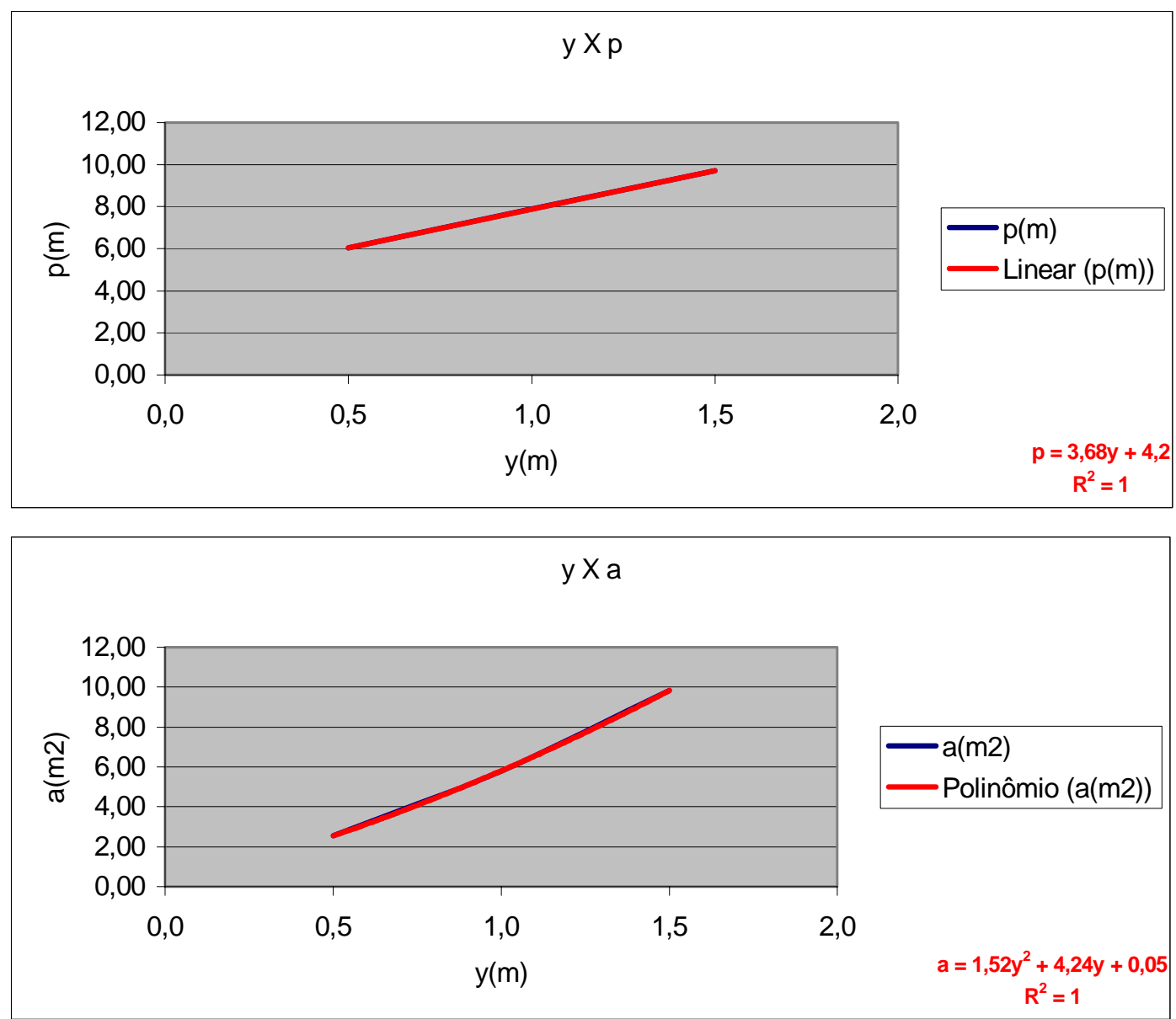

$y \times B$

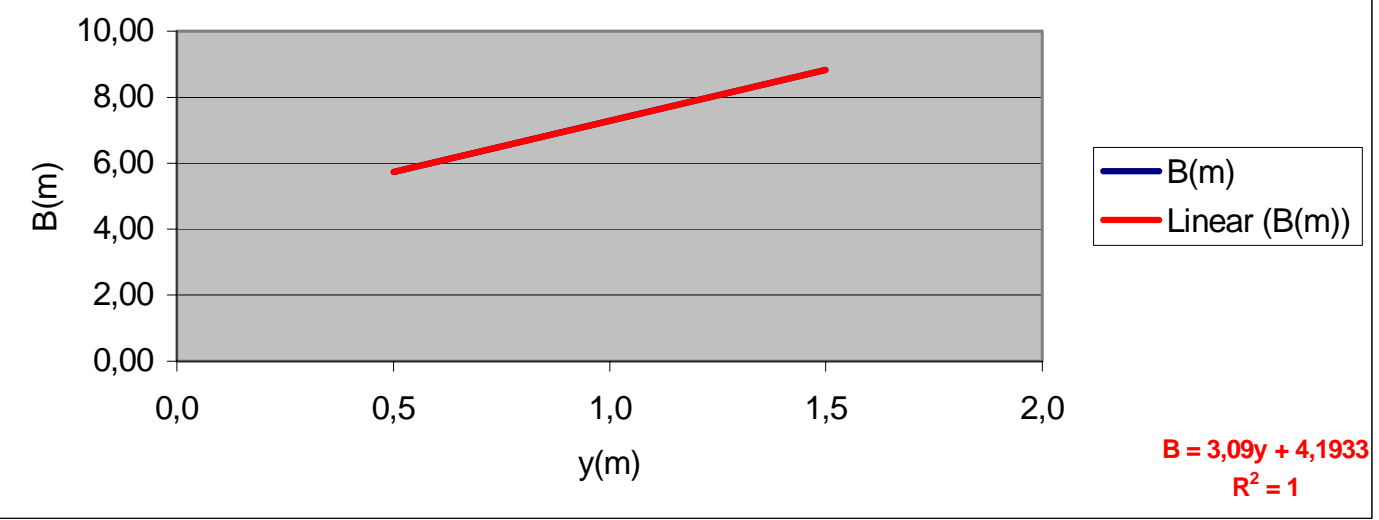


SEÇÃO 106
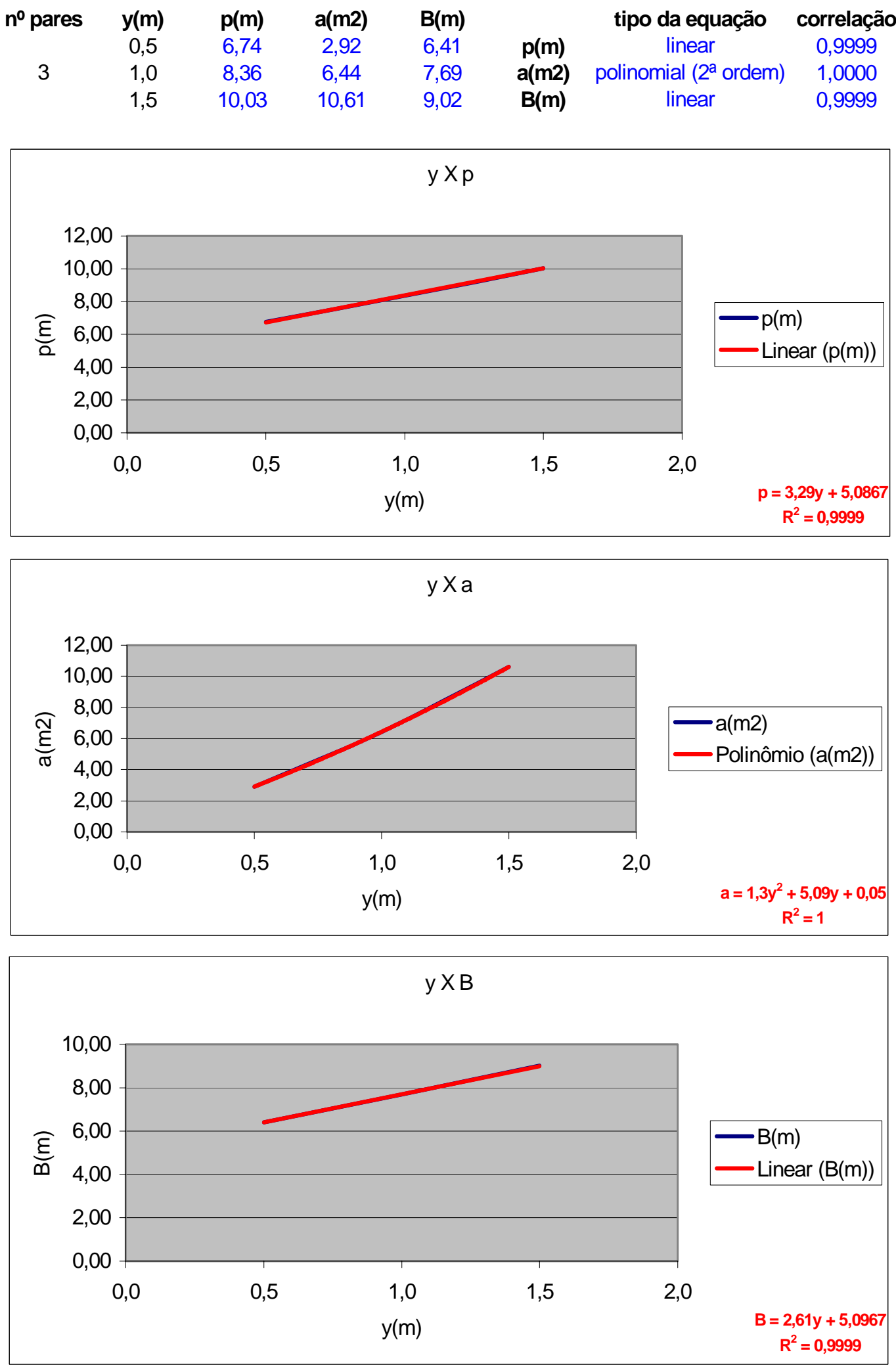
SEÇÕES 107, 108 e 109

$\begin{array}{cccccccc}\mathbf{n} \text { - pares } & \mathbf{y}(\mathbf{m}) & \mathbf{p}(\mathbf{m}) & \mathbf{a}(\mathbf{m} 2) & \mathbf{B}(\mathbf{m}) & & \text { tipo da equação } & \text { correlação } \\ & 0,5 & 6,04 & 2,62 & 5,73 & \mathbf{p}(\mathbf{m}) & \text { linear } & 0,9999 \\ 3 & 1,0 & 7,77 & 5,84 & 7,14 & \mathbf{a}(\mathbf{m} 2) & \text { polinomial }\left(2^{\mathrm{a}} \text { ordem }\right) & 1,0000 \\ & 1,5 & 9,55 & 9,77 & 8,62 & \mathbf{B}(\mathbf{m}) & \text { linear } & 0,9998\end{array}$
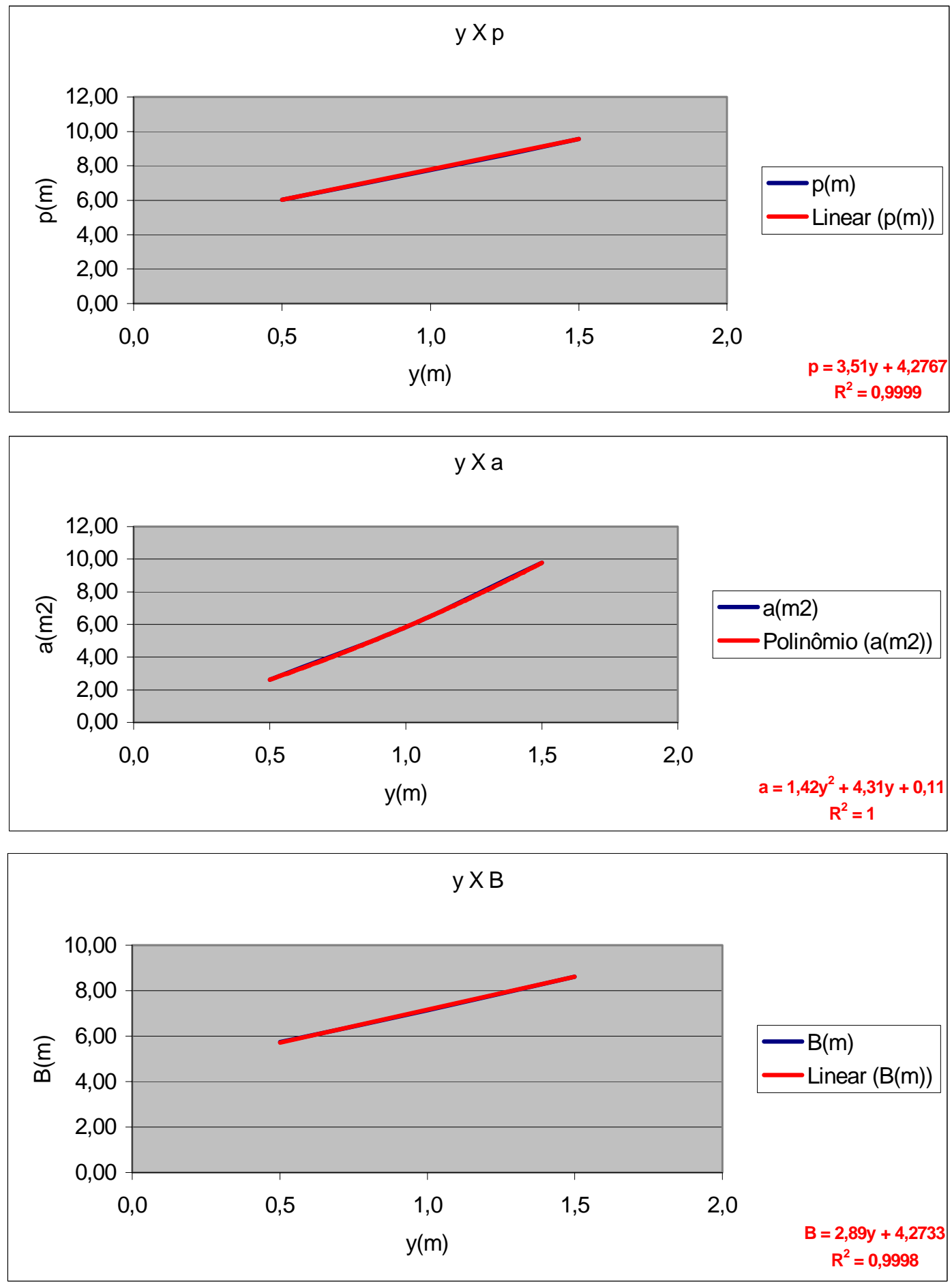